\title{
THE IMPACT OF WINDOW-TO-WALL RATIO ON ENERGY INTENSITY OF EXISTING OFFICE BUILDINGS IN ONTARIO AND QUEBEC
}

by

\author{
Viktoriya Mykytyak \\ Bachelor of Civil Engineering, Ryerson University, 2008
}

\author{
A MRP \\ presented to Ryerson University \\ in partial fulfillment of the \\ requirements for the degree of \\ Master of Building Science \\ iin the Department of \\ Architectural Science
}

Toronto, Ontario, Canada, 2015

(C) Viktoriya Mykytyak 2015 



\section{AUTHOR'S DECLARATION FOR ELECTRONIC SUBMISSION OF A MRP}

I hereby declare that I am the sole author of this MRP. This is a true copy of the thesis, including any required final revisions, as accepted by my examiners.

I authorize Ryerson University to lend this MRP to other institutions or individuals for the purpose of scholarly research.

I further authorize Ryerson University to reproduce this MRP by photocopying or by other means, in total or in part, at the request of other institutions or individuals for the purpose of scholarly research.

I understand that my dissertation may be made electronically available to the public. 

the impact of window-to-wall ratio on energy intensity of existing office buildings in ontario and quebec Master of Science 2015

\author{
Viktoriya Mykytyak \\ Building Science \\ Ryerson University
}

\begin{abstract}
Energy codes, such as SB-10, provide significant impact on the thermal performance of the building envelope. For design of new buildings, a window-to-wall ratio (WWR) of $40 \%$ is considered as a threshold in Ontario for using prescriptive solutions for thermal resistance of the enclosure. This study will demonstrate the relationship of the energy intensity of the existing office building to the WWR, through analysis of 15 office buildings located in Ontario and Quebec. Recent studies indicate that building geometry can influence the energy efficiency of the building; nevertheless, factors that impact energy intensity of existing buildings are not researched in full, and this study's aim is to minimize the knowledge gap in this field of literature. The outcome of this research shows that WWR directly influences energy intensity of the building. Energy balance calculations and energy loads distribution showed that WWR impacts on average $15 \%$ of overall energy consumption.
\end{abstract}




\section{Acknowledgements}

I would like to express my sincerest thank you to my research advisor Professor Hitesh Doshi and Professor Ramani Ramakrishnan. I am very grateful for their support, encouragement and patience. Both professors provided me with all necessary guidance, knowledge and support that I needed to complete my MRP.

Secondly, I would like to thank David Faltenhine (from Operation and Maintenance Division of SNC Lavalin) for providing all required materials and data for my MRP, as well as spending a lot of time to teach me how to use EnergyCAP software. David helped me with essential advises and directions that were fundamental to the completion of my MRP.

In addition, I would like to thank Oliver Andres (from O\&M SNC Lavalin) for providing me with access to energy audits and Energy CAP. Special thanks to John Farias and John Sousa (from Acturus Realty) for providing me with architectural drawings for case-study buildings.

I also would like to take this opportunity to thank to my faculty professors, especially Professor Miljana Horvat, Professor Mark Gorgolewski, Professor Russell Richman, Professor Zaiyi Liao, Professor Rakesh Kumar, Professor Vera Straka and Professor Greg Allen. They were extremely helpful throughout the years; their teachings, knowledge and personal guidance have been of great value to me.

Last but not least, I would like to extend my gratitude to my family and my husband Yuriy Malkov for their constant support and encouragement throughout entire process. 



\section{Contents}

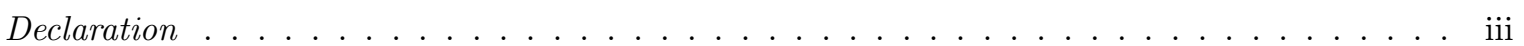

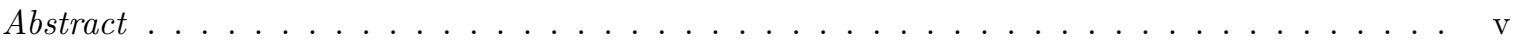

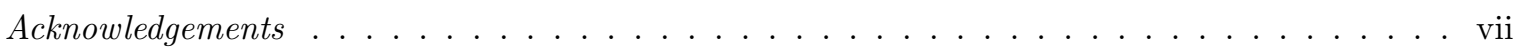

List of Tables . . . . . . . . . . . . . . . . . . . . . . . xi

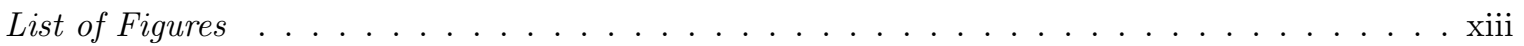

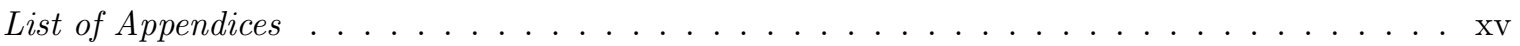

$\begin{array}{ll}\text { Introduction } & 1\end{array}$

1 Literature review $\quad 3$

1.1 Building Energy Intensity . . . . . . . . . . . . . . . . . . . . . . . . 3

1.2 Role of WWR in Building Energy Consumption . . . . . . . . . . . . . . 8

1.3 WWR Role in Typical Energy Audits . . . . . . . . . . . . . . . . . . . . . . 8

1.4 Establishing Effective WWR Based on Energy Efficiency . . . . . . . . . . . . . . . . 10

1.4.1 Fenestration Systems and Daylighting . . . . . . . . . . . . . . . 10

1.4.2 Fenestration Thermal Efficiency . . . . . . . . . . . . . . . . 11

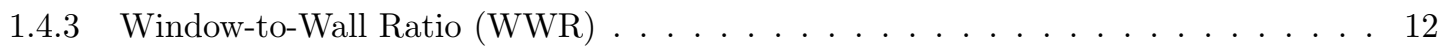

1.5 Literature Review Summary . . . . . . . . . . . . . . . . . . . . . . . . . . 14

2 Scope and Approach $\quad 15$

2.1 Research Questions . . . . . . . . . . . . . . . . . . . . . . . . . 15

3 Methodology 17

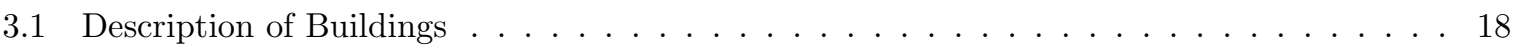

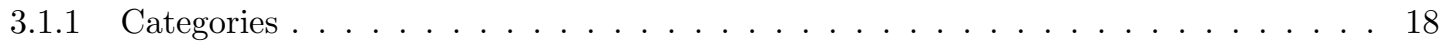

3.1.2 Energy Audits Overview . . . . . . . . . . . . . . . . . . . . . . 22

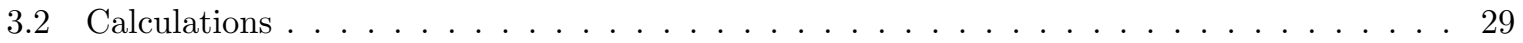

3.2 .1 Energy Intensity Calculations . . . . . . . . . . . . . . . . . . . . . . 29

$3.2 .2 \quad$ WWR Calculations . . . . . . . . . . . . . . . . . . 34

3.2.3 Building Envelope Thermal Resistance Calculations . . . . . . . . . . . . . . 35

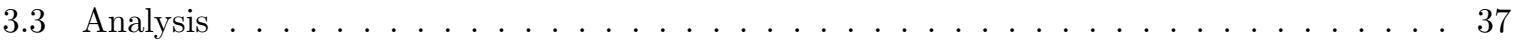


3.3 .1 Analysis of Energy Audits . . . . . . . . . . . . . . . . . 37

3.3.2 Energy Intensity Analysis, Summary of Case-Study Buildings . . . . . . . . . . 38

3.4 WWR analysis . . . . . . . . . . . . . . . . . . . . . 42

3.5 Thermal Resistance Analysis . . . . . . . . . . . . . . . . . . . . 44

3.6 Building Indicators That Impact Energy Consumption . . . . . . . . . . . . . . . . . . 44

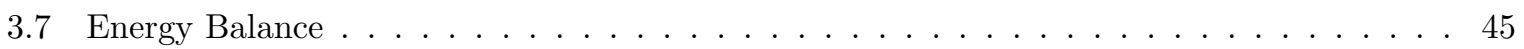

3.7 .1 Summary for Energy Balance . . . . . . . . . . . . . . . . . . . 49

3.8 Analysis Summary . . . . . . . . . . . . . . . . . . . . . 50

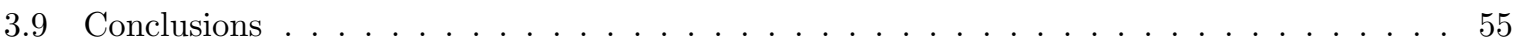

$\begin{array}{ll}\text { Bibliography } & 207\end{array}$

$\begin{array}{ll}\text { Glossary } & 211\end{array}$ 


\section{List of Tables}

1.1 Literature Review Findings Summary _ . . . . . . . . . . . . . . . . . . . . . . 14

3.1 Buildings' Shape Summary . . . . . . . . . . . . . . . . . . . . . . . . . . . . . 19

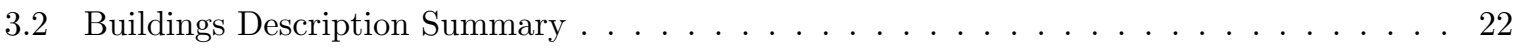

3.3 Building \#1 Utility Bills Calculations $\ldots \ldots \ldots \ldots \ldots$

3.4 WWR Summary of Case-Study Buildings . . . . . . . . . . . . . . . . . . 34

3.5 Three Case-Study Buildings Summary (Includes Thermal Resistance for Building Enve-

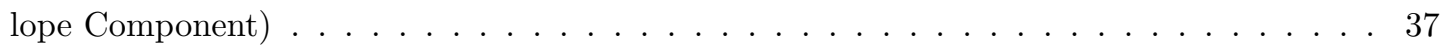

3.6 Summary of Case-Study Buildings (Energy Intensity Calculations) $\ldots \ldots \ldots$

3.7 Heating Loads Distribution (Electricity) in GJ Based on Architectural Features Indicators 48

3.8 Heating Loads Distribution (Electricity) in GJ $/ \mathrm{m}^{2} /$ year Based on Architectural Features Indicators . . . . . . . . . . . . . . . . . . . . . 48

3.9 Total Energy Loads Distribution Based on WWR Indicator (GJ) Average per Year . . . . 49

3.10 Total Energy Loads Distribution Based on WWR Indicator $\left(\mathrm{GJ} / \mathrm{m}^{2} /\right.$ year $) \ldots \ldots . . . . .49$

3.11 WWR Percentage of Total Energy Consumption . . . . . . . . . . . . . . 50 



\section{List of Figures}

1.1 Energy Intensity in GJ $/ \mathrm{m}^{2}$ for Commercial/Institutional Sector (Natural Resources Canada

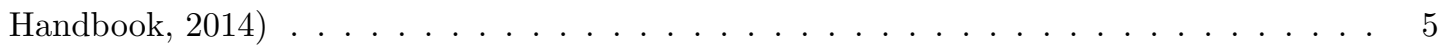

$1.2 \quad$ C\&I Energy Use by Energy Source . . . . . . . . . . . . . . . . . . . . . . . 6

1.3 C\&I Energy Use by End-Use . . . . . . . . . . . . . . . . . . . . . 7

1.4 C\&I Energy Use by Activity Type (PJ) in Canada . . . . . . . . . . . . . . . . . . 7

3.1 Methodology Framework . . . . . . . . . . . . . . . . . . . . . . . . . 18

3.2 Category 1 Various Shapes of Case-Study Buildings (Retrieved from Google Earth) _ . . 20

3.3 Category 2 Height of the Case-Study Buildings . . . . . . . . . . . . . . . . . . 21

3.4 Category 3 Year of Construction of Case-Study Buildings . . . . . . . . . . . . . . . . 21

3.5 Example Building \#1 - Yearly Electricity Consumption ～. . . . . . . . . . . . . . 31

3.6 Example Building \#1 - Yearly Gas Consumption . . . . . . . . . . . . . . . . . . 31

3.7 Example Building \#1 Yearly Energy Intensity Comparison _ . . . . . . . . . . . . . . 32

3.8 Example Building \#1 - Normalized Energy Intensity Calculations (year of the highest energy consumption vs. year with lowest consumption) $\ldots \ldots \ldots \ldots 33$

3.9 Energy Intensity vs. BOMAs Average Value . . . . . . . . . . . . . . . . . . . . . 39

3.10 Energy Intensity vs. Building Shape Category (Complex Shape) . . . . . . . . . . . . 40

3.11 Energy Intensity vs. Building Shape Category (Square Shape) . . . . . . . . . . . . . . 40

3.12 Energy Intensity vs. Building Shape Category (Rectangular Shape) . . . . . . . . . . . . 41

3.13 Energy Intensity vs. Buildings' Age Category, (Left) all years included, (Right) only more recent years included . . . . . . . . . . . . . . . . . . . 42

3.14 Energy Intensity vs. Building Height in Floors . . . . . . . . . . . . . . . . . . 42

3.15 Energy Intensity vs. WWR . . . . . . . . . . . . . . . . . . 43

3.16 Comparison of Case-Study Buildings' Year of Construction vs. WWR . . . . . . . . . 43

3.17 Comparison of Case-Study Buildings' Year of Construction vs. WWR . . . . . . . . . . 44

3.18 (Left) - Case-Study Building Energy Consumption in \%, (Right) - Average Percentage . . 45

3.19 (Left) - Heating Loads Percentage Distribution for the Typical Office Building, (Right) Pie Chart of these Values . . . . . . . . . . . . . . . . . . . . 45

3.20 (Left) - Cooling Loads Percentage Distribution for Typical Office, (Right) - Pie Chart of these Values . . . . . . . . . . . . . . . . . . . . . . . . 46 
3.21 Commercial/Institutional Energy Use by End-Use, 2007 (Percent) (NRC, 2010) . . . . . 46

3.22 Energy Balance of Case-Study Buildings, (Left) Electricity, (Right) - Gas . . . . . . . . . 47

3.23 Energy Intensity Value Frequency . . . . . . . . . . . . . . . . . . . . . . 51

3.24 Boxplot Analysis of Buildings' Shape . . . . . . . . . . . . . . . . . . . . . 51

3.25 Boxplot Analysis of Buildings' Age . . . . . . . . . . . . . . . . . . . 52

3.26 Boxplot Analysis of Buildings' Age . . . . . . . . . . . . . . . . . . 52

3.27 Boxplot Analysis of WWR to Energy Intensity . . . . . . . . . . . . . . . 53

3.28 Boxplot Analysis of WWR Energy Consumption (GJ/m²/year) to WWR . . . . . . . . . 54

3.29 Boxplot Analysis of Energy Intensity to WWR . . . . . . . . . . . . . . 54

3.30 Overall Energy Intensity vs. WWR Energy Intensity . . . . . . . . . . . . . . 55 


\section{List of Appendices}

$\begin{array}{lll}1 & \text { Appendix A } & 57\end{array}$

2 Appendix B $\quad 171$

3 Appendix C 185

4 Appendix D $r$ 



\section{Introduction}

The inspiration for this study came due to of the importance of window-to-wall ratio (WWR) that is being given during the design of new buildings. Several studies have been done for various types of buildings with a view, to quantify the impact of WWR and envelope characteristics on the total energy consumption of the building. These studies have shown that there is a significant impact on the total energy consumption because of the WWR. For instance, Dogrusoy \& Tureyen (2007) and Ross (2009) in their studies showed that WWR, has slightly overpowering results on energy use in commercial buildings than other building geometry parameters. In addition, Ferdous (2012) research outlines that WWR influences the energy intensity of existing office buildings. The current OBC requirements put a threshold of WWR of $40 \%$ up to which the thermal characteristics of the building envelope may be chosen based on prescriptive requirements. The manner in which this $40 \%$ is established is not very well understood.

All the studies that have been examined were carried out on buildings using energy modeling and typical shapes. There is hardly any information on the energy consumption in existing buildings and its relationship to the WWR. Furthermore the shapes assumed in many of these studies are much different from the architectural form that some of the existing buildings take. This study explores the possibility of using actual energy consumption data along with actual architectural forms and building envelope characteristics to examine the type of relationship that exists between the WWR and the energy consumption. This study also explores the potential for changes in envelope characteristics to contribute to reduction in energy consumption of the existing buildings. Additionally, the findings of this study that are reported here, will discuss the weight of potential benefits of WWR calculations when assessing energy consumption, by evaluating guidelines of Level 1 energy audits. 



\section{Chapter 1}

\section{Literature review}

Energy conservation and sustainability are subjects of great interest in today's society; this applies especially to the commercial and institutional sector due to very high and growing demand for energy. According to National Resources Canada (2008), commercial and institutional (C\&I) establishments accounts for two third of the housing sector. Survey specifies that $36 \%$ of commercial and institutional establishments are located in Ontario, $22 \%$ in Quebec, $18 \%$ in the Prairies, $16 \%$ in BC and $8 \%$ in Atlantic Canada. In addition, Ontario accounts for the highest amount energy consumption, approximately $30 \%$ each; Quebec stands third with $23 \%$ of overall energy consumption. Therefore C\&I sector in Ontario and Quebec requires close attention in terms of energy efficiency. Typically, efforts to reduce energy consumption in the C\&I sector are put towards research and development of energy efficient building technologies such as equipment, heating and air conditioning (HVAC), lighting and ventilation systems. It is not very common to proceed with passive technologies such as WWR ratio to achieve energy efficiency in the existing building. Despite common strategies, WWR solution has been promoted on a large scale through different mechanisms, including building codes and incentives. Supplementary standards SB-10 to the Building Code address WWR specifications and compliances to how it should be implemented. For design of new buildings a WWR of $40 \%$ is considered as a threshold in Ontario allowing for the use of prescriptive solutions for thermal resistance of the enclosure.

Following literature review was completed to identify factors that relate to the WWR and its impact on energy use/energy loads. Also to review how or whether WWR gets taken into account in energy audits of existing buildings. And to set a benchmark values for energy intensity, literature review was summarized to get an idea about the energy performance of existing buildings.

\section{$1.1 \quad$ Building Energy Intensity}

Canada's commercial and institutional establishments, cold climate and vast geography all contribute to it being a highly energy-intensive country (The Conference Board of Canada, 2013). Energy intensity is a total primary energy supply per unit of gross domestic product (GDP) (The Conference Board of 
Canada, 2013). Currently Canada ranks last for energy intensity in comparison to 17 peer countries (some of the countries are Ireland, Switzerland, Italy, U.K. and others). In 2009, Canadian primary energy supply was 0.25 tonnes of oil equivalent (toe) per US\$1,000 GDP, in comparison to the peer country average of 0.15 (toe). The positive aspect of this is that Canada has reduced its energy intensity by $39 \%$ since 1971 (The Conference Board of Canada, 2013), and slowly reducing even more; therefore, increased awareness of energy conservation and sustainability are beneficial on the large scale.

The Conference Board of Canada (2013) defines energy intensity in GDP, but in this report, calculations of energy consumption will be expressed in gigajoules [GJ], floor area will be expressed in square meters $\left[\mathrm{m}^{2}\right]$, and energy intensity will be expressed in gigajoules per square meter $\left[\mathrm{GJ} / \mathrm{m}^{2}\right]$, as per Natural Resources Canada's Office of Energy Efficiency (OEE). In addition energy intensity can be adjusted for the energy consumed in producing electricity (for fuel choices such as natural gas, oil, coal, biomass or fuel wood); energy intensity is defined as total energy consumed, divided by total floor area, for the reference year (National Resources Canada, 2008).

Every year, Natural Resources Canada's Office of Energy Efficiency (OEE) estimates Canada's energy consumption by economic sector; these studies collected energy data, and estimated energy consumption in the C\&I sector. Commercial and Institutional Building Energy Use Survey (CIBEUS) is a detailed study that was conducted on behalf of the Office of Energy Efficiency of Natural Resources Canada (NRCan). This is the first survey of its kind conducted to provide detailed information on the commercial sector. This survey gathered data on energy consumption, energy intensity and the physical and energy efficient characteristics of commercial and institutional buildings located in Canada. Survey was completed in 2000, and all the data was analyzed, summarized and published in 2002. Report (OEE, 2002) was based on data in major Canadian cities, and concluded that in year 2000, the overall energy intensity was $1.59 \mathrm{GJ} / \mathrm{m}^{2}$. In 2003 the first Consumption of Energy Survey (CES) was completed. This report focused exclusively on Canada's universities, colleges and hospitals. This survey covered all ten provinces, and showed results as energy intensity for universities to be $2.04 \mathrm{GJ} / \mathrm{m}^{2}$, for colleges to be $1.48 \mathrm{GJ} / \mathrm{m}^{2}$ and for hospitals to be $2.65 \mathrm{GJ} / \mathrm{m}^{2}$ (OEE, 2003). A year later in 2004 another survey was performed to cover much broader C\&I sector, and energy intensity results in this survey were estimated as 1.6 GJ $/ \mathrm{m}^{2}$ (OEE, 2004). Later in 2006 Statistics Canada conducted Commercial and Institutional Consumption of Energy Survey (CICES) for Natural Resources Canada, collecting 2005 data. For business and institutions, energy intensity was estimated as $1.54 \mathrm{GJ} / \mathrm{m}^{2}$ (OEE, 2005). This report gathered data on the age of establishment, also on energy sources used for space heating, space cooling and water heating. (OEE, 2005) report contains in-depth analysis of each of these variables. In 2011 similar survey estimated that in 2008 Canadian C\&I sector comprised of almost 470,000 establishments occupying 705 million square meters of floor area. (OEE, 2011) also estimated energy intensity for Canadian C\&I sector as $1.23 \mathrm{GJ} / \mathrm{m}^{2}$, in addition, the report provides values for Ontario only as $1.02 \mathrm{GJ} / \mathrm{m}^{2}$ in comparison to higher values in Quebec and Prairie. The most recent survey report that is available to the public was published in 2013 based on survey data in 2009. Report claims that in 2009 there were 482,000 C\&I buildings; it is 12,000 more than just a year ago, and these establishments are occupying about 766 million $\mathrm{m}^{2}$ of floor space (OEE, 2013). Report estimates that in 2009 the overall energy intensity of C\&I buildings in Canada was $1.10 \mathrm{GJ} / \mathrm{m}^{2}$, this value is lower than in previous study, and considerably lower 
than in all previous surveys. $27 \%$ of all C\&I buildings in Canada were at least 50 years old, but buildings built in the 1970s had the highest proportions of both floor space and energy use. Report claims that Survey of Commercial and Institutional Energy Use (SCIEU) 2009 estimated that $46 \%$ of the C\&I buildings were renovated between 2005 and 2009. The most common type of building renovations was lighting, and it's around $26 \%$. Only $4.6 \%$ of C\&I buildings underwent additions or reductions, and $23 \%$ underwent windows and insulation refurbishment (OEE, 2013).

To review the fluctuating energy intensity value, an evaluation of all survey results prepared by OEE and Natural Resources Canada was done. The summary of data from reports was compiled in Figure 1.1 to determine if the fluctuations in energy intensity value over the years were decreasing or increasing. Specifically, the last survey performed in 2009 reports claims a considerable decrease in energy intensity value in C\&I Canadian sector. In addition, every year, the Office of Energy Efficiency publishes the Energy Use Data Handbook that provides a statistical overview of Canada's sectorial energy use as well as GHG emissions. This handbook (Natural Resources Canada Handbook, 2014) summarizes and compares energy intensity data estimated in every survey. Among the other sectors, this handbook provides data on energy consumption of C\&I sector per year starting from 1990 (Fig. 1.1). Energy intensity in 1990 was estimated as $1.68 \mathrm{GJ} / \mathrm{m}^{2}$, and the most recent value of energy intensity is provided for 2012 equals to $1.43 \mathrm{GJ} / \mathrm{m}^{2}$. Handbook tables demonstrate $14.9 \%$ decrease in energy consumption from 1990, and almost 19\% decrease from 2000, 2002 and 2003.

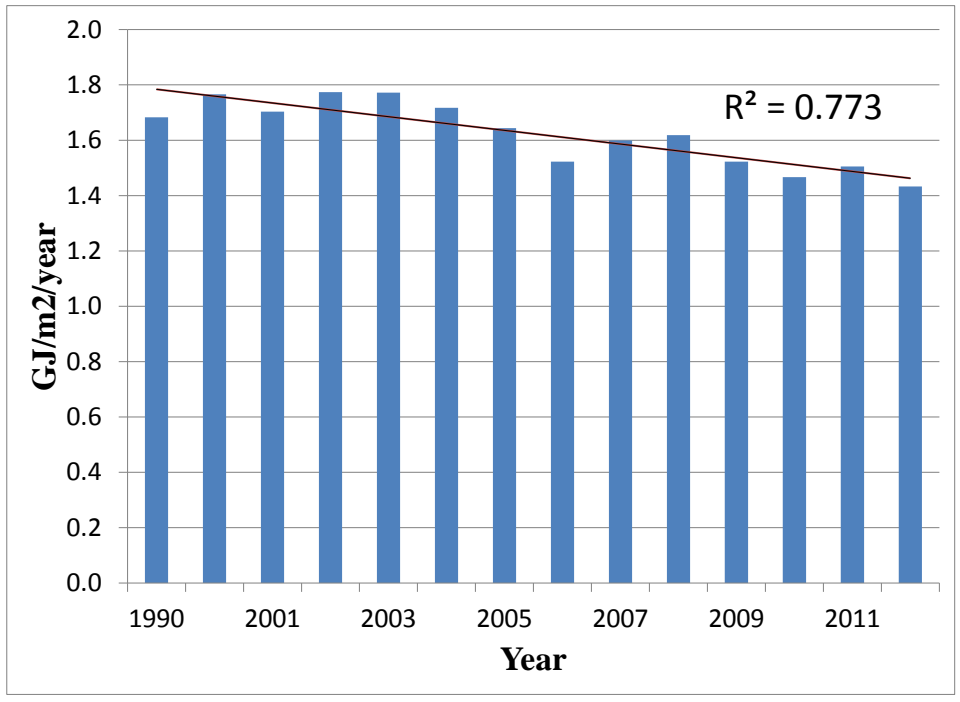

Figure 1.1: Energy Intensity in GJ $/ \mathrm{m}^{2}$ for Commercial/Institutional Sector (Natural Resources Canada Handbook, 2014)

To establish benchmark value for energy intensity of commercial and institutional buildings, in ad- 


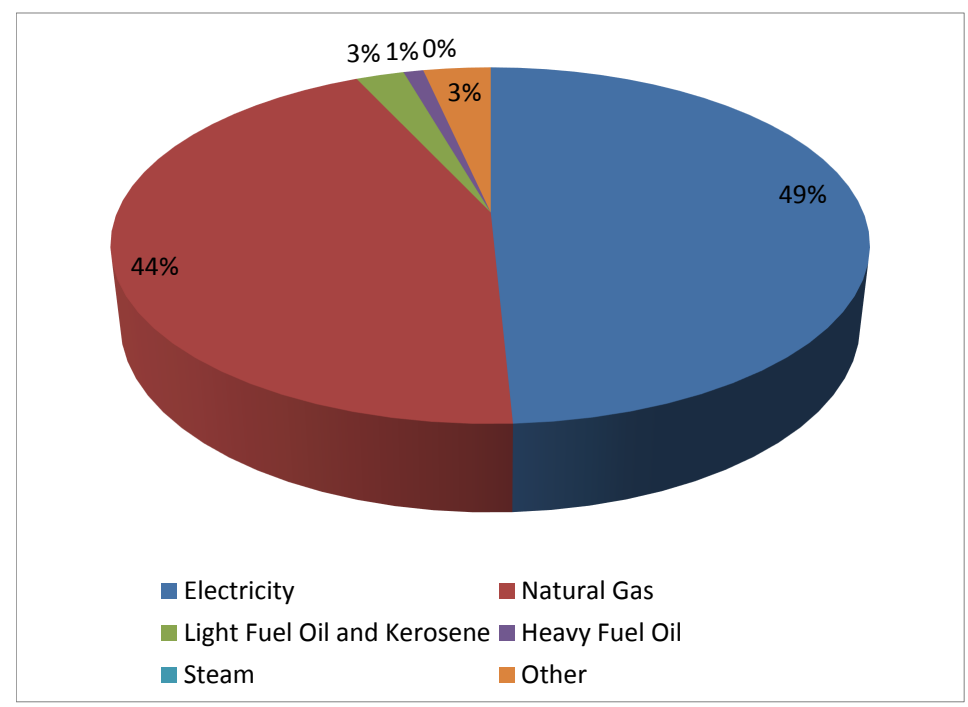

Figure 1.2: C\&I Energy Use by Energy Source

dition to previous literature, BOMA BEST Energy and Environment Report (BBEER) were reviewed. BBEER is Canada's leading assessment and certification program that provides benchmark data and performance success case studies. 3,562 buildings have achieved BOMA BESt certification and/or recertification across Canada since 2005 (BOMA, 2014). Report shows that average energy use intensity for certified Office Buildings is $27.1 \mathrm{ekWh} / \mathrm{ft}^{2} / \mathrm{yr}$ (or $1.05 \mathrm{GJ} / \mathrm{m}^{2} /$ year).

Based on percentages of energy consumption by Ontario and Quebec, as well as percentages of institutional and commercial buildings located in these two provinces, this information was combined with Natural Resources of Canada Handbook data for 2012; the following can be summarized. In Canada, total C\&I energy use for 2012 was equal to 1069.2 (PJ) with the following breakdown for energy use by energy source (Figure 1.2), energy use by end-use (Figure 1.3) and energy use by activity type (Figure $1.4)$, with total energy intensity of $1.43\left(\mathrm{GJ} / \mathrm{m}^{2} /\right.$ year) based on total floor space 741 (million $\mathrm{m}^{2}$ ).

Summary: from the above data, it can be concluded that Canadian offices account for $34.9 \%$ of overall energy consumption, with total floor area of 305.15 (million $\mathrm{m}^{2}$ ), and energy intensity of 1.22 $\left(\mathrm{GJ} / \mathrm{m}^{2} /\right.$ year). Approximately $22 \%$ of these offices are located in Ontario and $18 \%$ in Quebec. It was noticed that Quebec accounts for $23 \%$ of total energy consumption, and Ontario, not too much higher, is accounted for 30\%. Based on total C\&I energy of 1,069.2 (PJ) Quebec infrastructure and commercial sector consumes significantly less energy of 44.26 (PJ) than Ontario 70.56 (PJ). Energy intensity is directly dependent on the total floor area of the building, and building envelope characteristics do not influence these calculations. Buildings total energy consumption indicators, based on building orientation, size and facade components, can provide a breakdown on how does actual energy data relates 


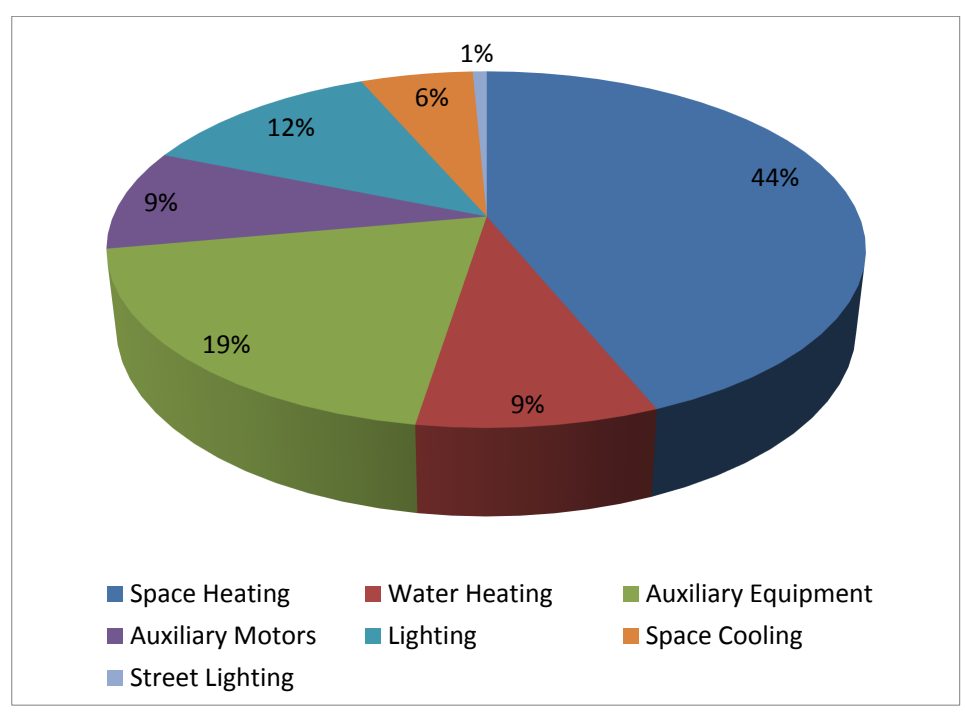

Figure 1.3: C\&I Energy Use by End-Use

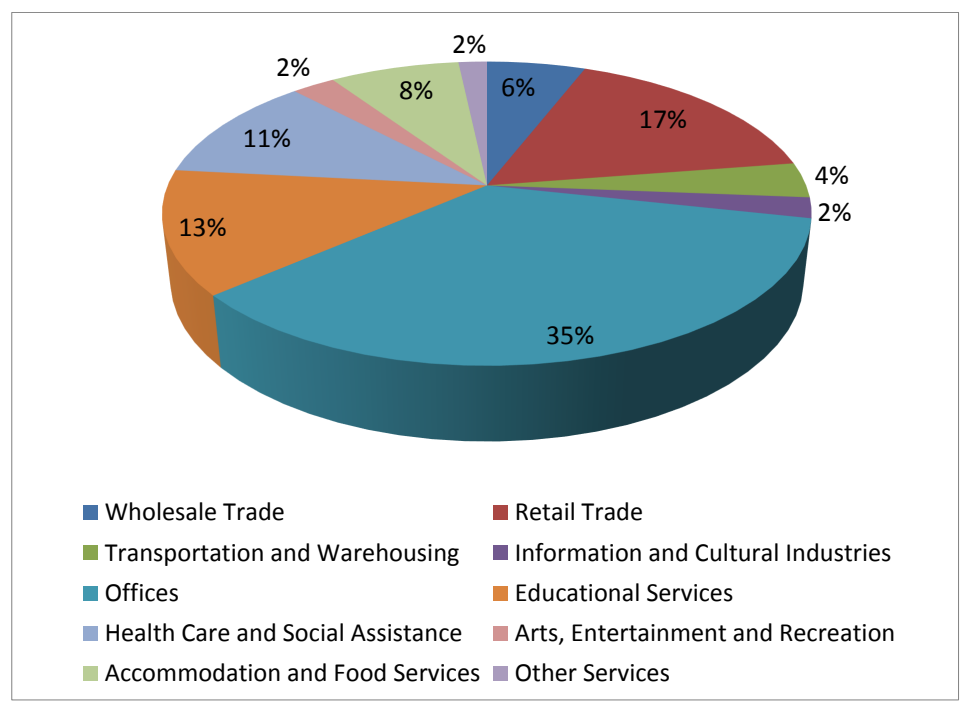

Figure 1.4: C\&I Energy Use by Activity Type (PJ) in Canada 
to building envelope characteristics.

\subsection{Role of WWR in Building Energy Consumption}

In order to analyze the relationship between WWR and the energy intensity of the building, a number of papers were reviewed with regards to factors influencing the building's energy intensity. (Harvey, 2013) in his research identifies essential principles of low-energy design, and lists important steps in the design of low-energy buildings, these are: building orientation (this includes also surface area-to-volume ratio and thermal mass), high performance building envelope, passive systems (heating, cooling, ventilation and daylighting), individual energy devises (to ensure that energy devises can be controlled individually based on necessity of users), and proper commissioning of the building. Also (Harvey, 2013) distinguishes between energy loads and energy use. The term load refers to the amount of heat that has to be added or removed from the building to maintain the desired indoor temperature. Energy loads directly depend on the following factors: climate, the form and orientation of the building, external shading, characteristics of the building envelope (including insulation, fenestration properties, WWR and air tightness) and desired indoor comfort (temperatures during the heating and cooling seasons). Additional factors are also internal heat from equipment, lighting and human occupancy. (Harvey, 2013) explains that energy uses are given by the heating and cooling load divided by the efficiency of the building's systems and equipment. Therefore the main difference between energy loads and energy use is that energy loads are established at the design stage and can be predicted by simulation and estimations, but energy uses are variable unit and directly depends on current efficiency of the building, which can only be determined by analyzing energy bills. To summarize: modifying the building's design or influencing energy uses (stirring them towards energy efficiency) is the only way to minimize energy loads.

Summary: upon review of the (Harvey, 2013) research, it can be concluded that WWR is inversely directed to low-energy building designs, as well as energy consumption of these buildings. WWR has an important role to play in reducing energy intensity of the commercial building sector, and help to maximize the return on investment in energy-efficient technologies. Building energy intensity can be minimized by bringing into focus, the percentages of efficient building envelope window to wall; thus generating savings that could partly balance additional costs for pricey high-efficiency equipment and high-performance envelope. Harvey (2013) in his report provides that the average total energy use in commercial buildings in the United States and Canada is $266 \mathrm{kWh} / \mathrm{m}^{2} /$ year (or $0.97 \mathrm{GJ} / \mathrm{m}^{2} /$ yeah), whereas the average energy use of the same if complying with the ASHRAE 90.1-2004 standard would be $157 \mathrm{kWh} / \mathrm{m}^{2} /$ year (or $0.57 \mathrm{GJ} / \mathrm{m}^{2} /$ year), this could provide savings of $41 \%$.

\subsection{WWR Role in Typical Energy Audits}

Mainly energy audits are conducted to analyze the energy consumption of the building and to make a preliminary list of energy efficiency measures. Typically, the report produces following actions: reduce wastage at the source, use of high-efficiency products, optimize use of facilities to ensure best possible 
comfort for occupants and of course minimize energy consumption. Energy audits very rarely include any discussion on building envelope assemblies; they don't analyze current thermal resistance of building envelope and only propose immediate actions to building envelope if significant damage is evident.

Energy auditing of a building can range from a short walk-through of the facility to a detailed analysis with computer simulations. (Krarti, 2010) in his book presents simplified analysis methods to evaluate energy conservation opportunities in commercial buildings, and these methods are based on wellestablished engineering methods. Book is also used as reference for practitioners as well as textbook for students. Generally, four types of energy audits can be distinguished: walk-through audit (during which immediate and inexpensive actions can be concluded), utility cost analysis (detailed analysis of energy bills are performed to identify the patterns of energy use, peak demand, weather effects and potential energy savings; this audit should be performed in combination with walk-through audit), standard energy audit (during which comprehensive energy analysis of the energy systems are conducted; in addition to walk-through audit and utility cost analysis, the standard energy audit includes the development of a baseline for the building's energy use, energy savings and cost-effective measures), and detailed energy audit (subsequently, during this audit, instruments are used to measure energy; to evaluate possible energy retrofits for the building, computer simulations are used). Energy modeling is performed during the standard energy audit; these include: baseline energy modeling, degree-day methods and linear regression models, as well as payback analysis.

To evaluate if building envelope characteristics are analyzed during energy audit and to what extent building envelope retrofits are considered, general procedure of detailed energy audit was reviewed in more details. Building envelope is considered as one of energy conservation measures (ECMs), and is recommended to be evaluated during walk-through survey, wherein the auditor should determine the actual characteristics of the building envelope, and all necessary repairs. (Krarti, 2010) specifies that energy audit of the envelope is especially important for residential buildings, and it's believed that for commercial and institutional buildings improvements to the building envelope are often not cost-effective due to the fact that modifications to the building envelope are often too expensive. Nevertheless, it is highly recommended to perform audit for envelope components systematically not only to determine the potential for energy savings but also to ensure the integrity of its overall condition. Main concerns are always thermal bridging and moisture condensation, and no concerns in regards to WWR are mentioned during energy conservation measures (ECMs).

Summary: it can be concluded that although building envelope is an important item during energy audit, it is very rarely considered during an actual audit of the existing building. Because WWR is typically part of building envelope evaluation, therefore WWR is not considered during energy audit either. 


\subsection{Establishing Effective WWR Based on Energy Efficiency}

\subsubsection{Fenestration Systems and Daylighting}

In the building concept, fenestration systems are typically the main source of sunlight, therefore directly related to daylighting potentials of the building. ASHRAE defines fenestration systems as assemblies and components of windows and openings located on building envelope (ASHRAE Handbook Fundamentals, 2005). While fenestration can be extremely beneficial by providing daylight access, natural ventilation and visual communication between the interior and exterior, if glazed areas are not properly designed it can negatively impact energy consumption of the building. The following three papers were reviewed to outline significance of fenestration systems and its impact on building's energy efficiency.

First literature (ASHRAE Handbook Fundamentals, 2012) is a manual that provides current engineering procedures and practices, and it was reviewed to summarize key points of daylighting. (Ko, 2009) is a dissertation paper that provides research on fenestration and daylighting, and summarizes this information into guidelines; this paper was reviewed to conclude if energy conservation through daylight can overpower energy loss due to lowering thermal resistance of the building envelope. (Public Works and Government Services Canada, 2002)'s report is a daylighting guide for Canadian commercial buildings and it provides a 10-step guide for daylighting design process; this guideline was reviewed for fenestration design concept and WWR calculations.

Fenestration system in the building is typically a component with the lower thermal resistance, therefore fenestration properties such as configuration of fenestration openings, window area, U-factor solar heat gain coefficient (SHGC) and visible transmittance (VT) have to be considered to achieve energy efficient buildings. According to Ko (2009), the size of the fenestration plays an important role in saving energy.

ASHRAE Handbook explains key points of daylighting, these points are: daylighting is the illumination of a building's interiors by sunlight; daylight affects visual performance, lighting capacity, health, human performance and energy efficiency; daylight can provide significant energy conservation of the building and reduce electric lighting if utilized properly (ASHRAE Handbook Fundamentals, 2005). Though daylight provides above-mentioned benefits, on the other hand, it could create an issue in the energy efficient design parameters related to energy conservation due to lowering thermal performance of the building envelope. If fenestration area is oversized, this can directly contribute to increasing the building's energy consumption. Therefore proper fenestration design should be integrated with other building parameters to achieve energy efficient building.

In the report prepared by Public works and Government Services Canada (2002) the same conclusion is made that daylight can adversely impact thermal resistance of the building due to bigger window sizes, resulting in higher energy consumption. The report provides a 10-step daylighting design process; selecting optimal window placement, room size, window area and space configuration can provide adequate and uniform daylight for rooms around the building perimeter. The report also provides an equation for WWR calculations, where the net glazing area (windows area minus mullions and framing) is divided by gross exterior wall area (width of the bay by floor-to-floor height). In addition, the report provides 
alternative procedures on how required WWR can be calculated for a standard room with specific properties. Calculations provide typical WWR value as 0.3 (fraction), from where required net glazing area can be calculated by multiplying the WWR by the wall area.

Summary: daylight can significantly reduce energy consumption utilized for artificial indoor lighting; based on a number of researches, energy savings of $15 \%$ to $45 \%$ can be achieved by a daylighting scheme, depending on shape and climate zone of the building (Ko, 2009). Although daylighting benefits can be significant, oversizing fenestration area can negatively impact thermal resistance of the building envelope as well as contribute to overheating and glare. Therefore two main components: fenestration design and WWR will be reviewed further.

\subsubsection{Fenestration Thermal Efficiency}

One can easily assume that the disadvantage of beneficial daylighting is a lower thermal resistance of a building, solution being to increase thermal resistance of the fenestration part of the building envelope. Consequently, a fenestration part of building envelope can be over-insulated to accommodate lost thermal efficiency; the high costs of these, however, may result in them not being very feasible. To examine the relationship between windows and building energy consumption, and explore existing opportunities for improving energy use in existing buildings, additional literature was reviewed.

In Tzempelikos (2005) report, benefits of advanced glazing products are discussed. Recently these products have replaced traditional double-glazed windows and have low-emissivity glazing (low-e) that includes a special coating on one of the surfaces, this coating dramatically reduces the longwave radiation and minimizes heat losses (Tzempelikos, 2005). The report explains how various types of advanced glazing allow the dynamic use of building envelope, and how they help to maintain interior thermal needs, and at the same time respond to outdoor climate. In addition, author sufficiently reviews different types of advanced glazing such as electrochromic, thermochromic, translucent, photochromic and gasochromic glazing. Through analysis of different research literature, the Tzempelikos claims that by selecting proper fenestration, annual energy consumption can be reduced drastically (from $11 \%$ to $18 \%$ ) in comparison to conventional double-glazed windows. The report provides detailed guidelines for selecting WWR, as well as recommendations for choosing shading device properties and control in conjunction with electric lighting operation. Guidelines include option from selecting WWR from theoretical graph, or by calculations through formulas. With supporting calculations, the author demonstrates that daylight availability ratio and thermal loads always increase as WWR increases for all orientations. WWR is directly influencing energy demand of the building; nevertheless energy demand for both heating and cooling can be considerably reduced if windows would have higher thermal resistance (Tzempelikos, 2005).

Summary: by improving building envelope characteristic, energy use of existing building can be also improved, therefore WWR is a very important factor that impacts energy use compared to other components of building envelope, due to its very low thermal resistance. 


\subsubsection{Window-to-Wall Ratio (WWR)}

Further literature was reviewed to investigate to what extent WWR impacts energy consumption compared to other parameters such as building orientation and shading; and what is preferred occupants' optimal size of the windows. In (Dogrusoy \& Tureyen, 2007) field study, occupants' visual satisfaction was achieved when window area occupies $44-100 \%$ of the wall area. Occupants in the (Ludlow, 1976) study preferred the window area of 50-80\% for visual satisfaction, which was significantly lower than that of the (Dogrusoy \& Tureyen, 2007). This percentage is higher, and could be due to study being completed much earlier than Dogrusoy \& Tureyen field study. Occupants are more aware the importance of thermal efficiency. Another study which took place in Canadian office concluded by (Boubekri, Hull, \& Boyer, 1991) found that the optimal size of the window was between $15 \%$ and $25 \%$ of the total wall area, and $40 \%$ was found to be a maximum acceptable limit. This study was based on relaxation study, and study suggests that sunlight penetration can promote relaxed feelings and overall satisfaction.

Thesis research completed by (Ross, 2009) demonstrates the impact of architects on environmental loads imposed by building through building form, orientation and enclosure design, including WWR design. The report summarises best practice design approaches, and highlights that facade design strategy with WWR between $20 \%$ and $40 \%$ are most functional. Through simulations and calculations, research also suggests list of operations that lead to lower energy intensity of the building; research emphasizes that by modifying WWR within the previously mentioned percentage range, would lead to more energy efficiency. WWR has stronger impact on the energy intensity than building form, orientation, window orientation and shading (Ross, 2009). In addition, the more WWR was reduced, the bigger affect it had on energy intensity of the building, and therefore energy intensity was lowered. The report identifies that $5 \%$ reduction in energy-use-intensity occurred with each $20 \%$ decrease in the WWR

(Ferdous, 2012) in her report investigated the potential of building geometry to minimize energy consumption in office buildings. Five different geometries were modeled as commercial occupancies in the context of Toronto, Ontario, and examined with various design parameters: WWR and external static shading devices. The modeling was performed with WWR of $30 \%, 50 \%, 70 \%$ and $80 \%$ for all five building geometries; total height, floor to ceiling height for each floor and gross floor area were kept the same of all buildings. To investigate driving force affecting the thermal conditions of a building climate analysis were performed, as well as space heating, cooling and interior lighting energy loads. Results showed that the consumption for space heating almost doubled for each plan type (with inclusion of the shading devices) when WWR was increased from $30 \%$ to $80 \%$. The consumption for space cooling energy had also gradually increased when WWR increases (with no shading), but only varied a little when the shading was in place. Lighting energy was significantly impacted by WWR, as the WWR increased the energy demand for lighting reduced. To summarize the research, author claims that as WWR increased gradually from $30 \%$ to $80 \%$, the total annual energy consumption for every modeled archetype also increased, and effect was more significant than the building shape (Ferdous, 2012). Below

are results summary charts to represent the impact of WWR on energy intensity from Ferdous' report. The increase in total energy use ranged from $10.9 \%$ to $16.3 \%$ as WWR increased. 
When WWR increased from 30\% to 80\%, results for individual energy factors in Ferdous' report are following (for Square shape building, no shading): heating energy increased by $45.9 \%$ (from $222 \mathrm{MWh}$ to $410 \mathrm{MWh}$ ); cooling energy increased by $18.14 \%$ (from $76.62 \mathrm{MWh}$ to $93.6 \mathrm{MWh}$ ), however cooling energy was found to be dependent on interior lighting energy. From above WWR has significant impact on occupants' visual and mood satisfaction, but even more significant, it had an effect on total energy demand of the building.

However papers above conducted on site or simulation studies to calculate required WWR there are already established standards that provide acceptable WWR percentage. In Europe, energy performance standards for buildings are guided by the European Commission's Energy Performance in Buildings Directive. In US, each state develops their individual building codes, and many directives vary by state. As an example, in California, the California Energy Commission (which sets building standards) and the California Public Utility Commission (which regulates utilities) are both pursuing decrease of energy intensity. However, each state has different standards; there are two bodies providing a baseline for building energy codes, these are: International Energy Conservation Code (IECC) and the American Society of Heating, Refrigeration and Air conditioning Engineers, (ASHRAE) Standard 90.1 Energy Standard for Buildings except Low Rise Buildings (Ryan, 2012). In Canada, codes and standards for energy efficiency and window-to-wall specifications are Supplementary Standard SB-10 to the Building Code (energy efficiency for housing). In addition ASHRAE standards also act as a baseline for energy efficiency in Canada.

Specific standards recommendations concerning the fenestration of the facade also differ from country to country (Motuziene \& Juodis, 2010). For instance, ASHRAE (2004) recommends WWR to be from $20 \%$ to $40 \%$; some of the European countries such as Norwegian standards for building energy performance NS 3031:2007 recommends that the glazing area must not exceed 20\% of the heated wall area; however in Canada the recommended fenestration area is calculated due to the dimensions of the room, and the calculations usually give WWR a value close to $30 \%$ (PWC, 2002).

SB-10 under its prescriptive requirements, states for minimum performance requirements in the code, specifies that for non-residential occupancy buildings, the gross area of fenestration to the gross area of peripheral wall measured from grade to the top of the most upper ceiling shall be less than $40 \%$. If the glazed area exceeds prescriptive requirements, this area shall comply with additional (higher R-value) prescriptive approach. As it has been discussed previously in this report in fenestration systems and daylighting section, a glazed area is directly related to both heating and cooling loads in the buildings. Thermal performance of glazing units significantly contribute to heat loss through the building envelope, therefore impact heating loads and overall energy demand of the building. In addition, a glazed area can cause unwanted heat gains that contribute to increased cooling loads. SB-10 also specifies maximum solar heat gain coefficient (SHGC), to oversee unmanaged heat gains. The main objectives for introducing limit percentage for $\mathrm{W}$ in SB-10 prescriptive requirements are to minimize heat loss in winter and heat gain in summer.

Summary: based on literature review above, WWR plays an important role for occupant's satisfaction and energy efficiency of the building. WWR is summarized in the Table 1.1 below. 
Table 1.1: Literature Review Findings Summary

\begin{tabular}{|c|c|c|}
\hline Literature Review & WWR $\%$ & Impact \\
\hline Dogrusoy \& Tureyen, 2007 & $44 \%-100 \%$ & Occupants visuals (based on field study) \\
\hline Ludlow, 1976 & $50 \%-80 \%$ & $\begin{array}{l}\text { Occupants Satisfaction (based on design tools used by } \\
\text { author) }\end{array}$ \\
\hline Boubekri, Hull, \& Boyer, 1991 & $15 \%-25 \%$ & $\begin{array}{l}\text { Occupants Satisfaction (based on study in the office } \\
\text { room of a typical size and how it influenced workers' } \\
\text { mood) }\end{array}$ \\
\hline Ross, 2009 & $20 \%-40 \%$ & $\begin{array}{l}5 \% \text { reduction in energy-use-intensity occurred with } \\
\text { each } 20 \% \text { WWR (based on designed series of proto- } \\
\text { types of office building) }\end{array}$ \\
\hline Ferdous, 2012 & $30 \%-40 \%$ & $\begin{array}{l}45.9 \% \text { increase in heating energy consumption from } \\
30 \% \text { to } 80 \% \text { (based on modelling of five building } \\
\text { shapes) }\end{array}$ \\
\hline Ferdous, 2012 & $30 \%-40 \%$ & $\begin{array}{l}18.14 \% \text { increase in cooling energy consumption from } \\
30 \% \text { to } 80 \% \text { (based on modelling of five building } \\
\text { shapes) }\end{array}$ \\
\hline PWC, 2002 & $30 \%$ & Based on energy efficiency calculations \\
\hline ASHRAE, 2004 & $20 \%-40 \%$ & Based on energy efficiency analysis \\
\hline SB-10 & below $40 \%$ & Based on energy efficiency analysis \\
\hline
\end{tabular}

\subsection{Literature Review Summary}

From the above reviewed information it can be concluded that for most part WWR is not taken into account in audits of existing buildings perhaps because this has not been addressed previously. But, by looking at the collected information, it is evident that WWR has impact on energy use and energy load of the building. Therefore, by introducing parameters of WWR analysis into energy audits could at least alert owners about the possibilities of envelope improvements. BOMA average energy value of $1.05 \mathrm{GJ} / \mathrm{m}^{2} /$ year will be used as benchmark guide value in case-study building analysis. As well as, WWR of $40 \%$ will be used as maximum value of existing buildings analysis, as per Ontario prescriptive solutions for thermal resistance of the enclosure. 


\section{Chapter 2}

\section{Scope and Approach}

The approach of this study is to determine and quantify to what extent WWR influences energy usage of office buildings selected for this research. This will be achieved by reviewing and evaluating utility bills and calculations of energy consumption of each building; data was provided by SNC Lavalin, Operational and Maintenance department. For this study to be successful it was required to draw upon the energy consumption data for existing buildings. Pursuing the inspiration of this idea through the workplace it was determined that energy data of existing commercial buildings could be obtained. Initial exploration of this data determined that it was complete in terms of energy usage by fuel type and month for several years of occupancy. The availability of this data encouraged further pursuit of this topic.

Research will analyze actual energy data of existing buildings, and conclusions will be made on how this data relates to a building envelope characteristics. Thorough calculations and analysis research will evaluate the significance of WWR in comparison to other energy consumption indicators such as number of stories, building orientation and window and opaque thermal performance based on heating and cooling loads.

\subsection{Research Questions}

Research Questions:

- How does energy intensity of existing case-study office buildings compare with averages for similar buildings and those that would be resulting from application of current standards?

- In determining potential for energy savings in existing case-study buildings what is the impact of envelope upgrades on energy consumption?

- How does the energy intensity of existing case-study buildings using square meter of gross area measure vary with the WWR of that building?

- Should analysis of WWR be introduced into energy audit (Level One) report? 



\section{Chapter 3}

\section{Methodology}

To carry out the research, 15 case-study buildings were reviewed and analyzed with respect to the research questions. Microsoft Excel was used for most of the calculations, and served the best for the intended purpose of this research. Assumptions were made and adjusted based on common practices. Analysis and comparisons are based on the calculation results.

Methodology section is separated into three main subsections: description of buildings, calculations and analysis. This section briefly outlines the methodology adopted in current research, however more detailed explanation of methodology process is shown in the Figure 3.1 below.

In addition, detailed calculations and explanations on some of the topics are included in appendices at the end of the paper. 


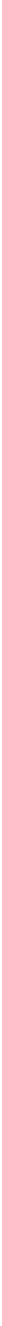

Figure 3.1: Methodology Framework

\subsection{Description of Buildings}

\subsubsection{Categories}

Fifteen office buildings were selected for this study, eleven of case-study buildings are located in Ontario and four located in Quebec province of Canada. These fifteen buildings were selected because they represent typical buildings within a portfolio of office buildings managed by SNC Lavalin. All case-study buildings are different in shape, height and age. Buildings were categorized in the following manner:

Category 1 Shape:

Case-study buildings were divided into four different categories shown in the Figure 3.2

Photo of each building's shape was taken from Google Earth web source. As shown above most of the buildings have a complex irregular shape, however when buildings were selected they represented 
typical office buildings in Ontario/Quebec provinces. Table 3.1 summarizes repetition of each shape category. Shape names were chosen in the following manner: if building footprint has very distinctive square or rectangular shape they would be called accordingly; but if building footprint has more than four distinguishable corners they would fall under complex category; however to make it simpler, they still would be related to the square or rectangular shape.

Table 3.1: Buildings' Shape Summary

\begin{tabular}{lc}
\hline \hline Shape & Quantity \\
\hline Square & 3 \\
Rectangular & 4 \\
Complex - Square & 2 \\
Complex - Rectangular & 6 \\
\hline
\end{tabular}

Three of the square buildings that are located in Ottawa have very similar shape and are located at the same office site, but the height of each building varies. Four rectangular buildings also vary in height, two of them are 2 floors only, one is 4 floors in height and fourth building is a high rise. Most of the complex shape buildings also have complex flooring height, meaning they have an irregular number of floors in different parts of the building. It was noted that although case-study building were chosen for being typical office structures, but more than half of them have a complex and a nonstandard shape of the footprint. Only 3 buildings have a square shape, and 4 rectangular; the rest have non-typical complex shapes. In (Ferdous, 2012), the report author analyzes five distinguishing types of building shapes: square, rectangular horizontal, rectangular vertical, cross and h-type. Based on casestudy buildings selected for this study, only seven building can fall under these categories of geometric descriptions, and the rest would require more complex simulations.

\section{Category 2 Height:}

Fifteen case-study buildings were divided into three categories based on their height, the Figure 3.3 shows all buildings and the above number represents how many floors each building has.

Buildings were grouped into three categories with regards to height: low-rise buildings from 1 to 3 floors, mid-rise from 4 to 5 floors, and high-rise from 6 and up. 15 buildings spread out; five evenly in each category.

\section{Category 3 Age:}

Most of the buildings were constructed between 1975 and 1990; only one building was constructed in 1873 and one was constructed after 1990, in 1993. None of the buildings is under Ontario or Quebec Heritage Properties act. Figure 3.4 shows all 15 building based on the year of construction. 


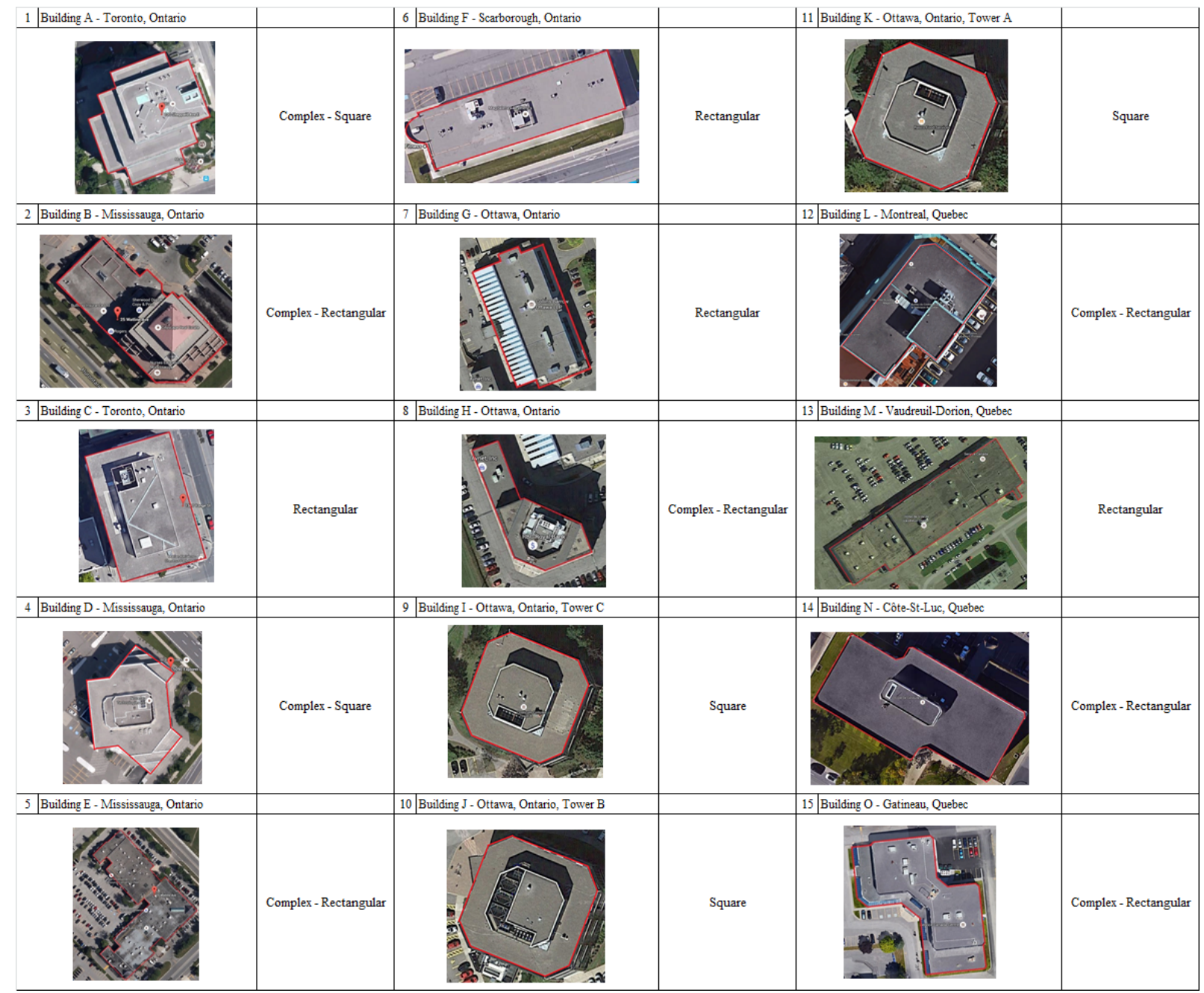

Figure 3.2: Category 1 Various Shapes of Case-Study Buildings (Retrieved from Google Earth) 


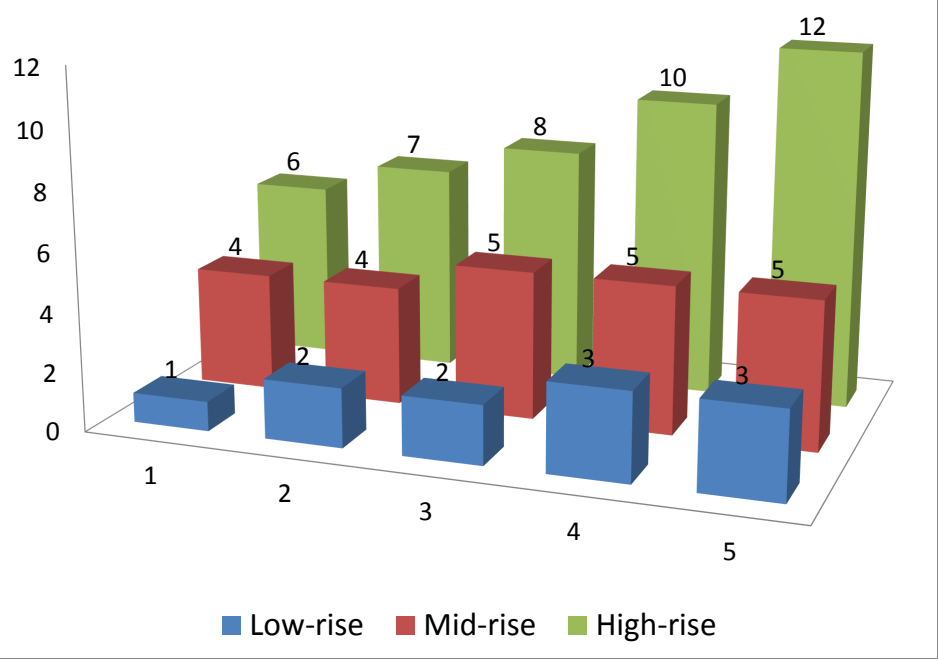

Figure 3.3: Category 2 Height of the Case-Study Buildings

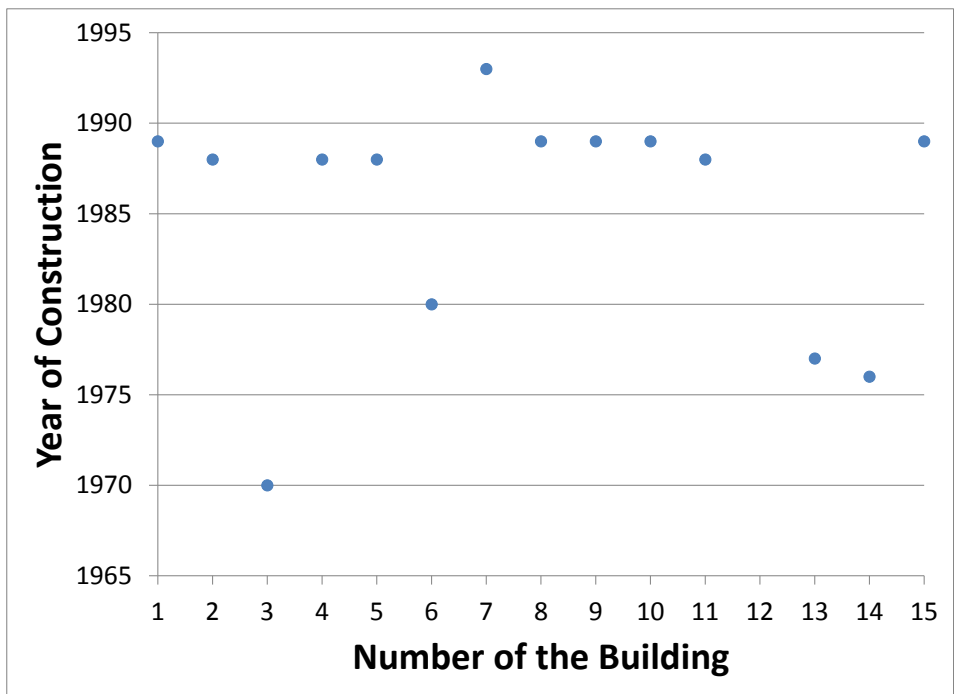

Figure 3.4: Category 3 Year of Construction of Case-Study Buildings 


\subsubsection{Energy Audits Overview}

Table 3 summarized information for all fifteen buildings: building shape, height and year of construction; in addition, the gross floor area for each building is included as well as the buildings locations.

Table 3.2: Buildings Description Summary

\begin{tabular}{|c|c|c|c|c|}
\hline \# Location & Building Shape & $\begin{array}{c}\text { Building } \\
\text { Height }\end{array}$ & $\begin{array}{c}\text { Building } \\
\text { Construction } \\
\text { Year } \\
\end{array}$ & $\begin{array}{c}\text { Gross } \\
\text { floor area } \\
\mathrm{m}^{2} \\
\end{array}$ \\
\hline 1 Building - Toronto, Ontario & Square & 12 & 1989 & 25,424 \\
\hline 2 Building - Mississauga, Ontario & Complex Shape & 6 & 1988 & 8,225 \\
\hline 3 Building - Toronto, Ontario & Rectangular & 8 & 1970 & 9,240 \\
\hline 4 Building - Mississauga, Ontario & Complex Shape & 10 & 1988 & 15,712 \\
\hline 5 Building - Mississauga, Ontario & Complex Shape & 1 & 1988 & 6,332 \\
\hline 6 Building - Scarborough, Ontario & Rectangular & 2 & 1980 & 2,130 \\
\hline 7 Building - Ottawa, Ontario & Rectangular & 4 & 1993 & 8,180 \\
\hline 8 Building - Ottawa, Ontario & Complex Shape & 5 & 1989 & 5,020 \\
\hline 9 Building - Ottawa, Ontario, Tower C & Square & 3 & 1989 & 4,854 \\
\hline 10 Building - Ottawa, Ontario, Tower B & Square & 5 & 1989 & 8,270 \\
\hline 11 Building - Ottawa, Ontario, Tower A & Square & 4 & 1988 & 6,162 \\
\hline 12 Building - Montreal, Quebec & Complex Shape & 7 & 1873 & 3,518 \\
\hline 13 Building - Vaudreuil-Dorion, Quebec & Rectangular & 2 & 1977 & 8,022 \\
\hline 14 Building - Cote-St-Luc, Quebec & Rectangular & 5 & 1976 & 7,943 \\
\hline 15 Building - Bellehumeur, Gatineau, Quebec & Complex Shape & 3 & 1989 & 5,518 \\
\hline
\end{tabular}

Building \#1 is located at Toronto, Ontario.

Overview: the 12-story building is mainly office space with underground parking (three levels with 304 parking stalls); a penthouse is on the mechanical level, and the main level includes a few stores and a cafe. Total gross area is $25,424 \mathrm{~m}^{2}$. Building was constructed in 1989. Typical office hours are Monday to Friday from $7 \mathrm{am}$ to $6 \mathrm{pm}$, and Saturdays from $9 \mathrm{am}$ to $6 \mathrm{pm}$. The building is typically closed down on Sundays.

Energy audit 1 was completed in June, 2013 by SNC Lavalin O\&M department. During this audit, assessment of the energy savings potential for the facility was completed, and a site walk-through was conducted that included interviews with site personnel. The following information was summarized based on the building audit. Energy consumption of the building is moderately high in comparison to similar office buildings in same region. The primary HVAC system of the building consists of gas fired boilers, serving the perimeter radiation units for building heating, and the MUA (make-up air) unit for heating the ventilation air. AHU (air-handling unit) is located on each floor for air distribution. Cooling of the building is provided by cooling towers, and they are designed in a way to be shut off during the winter months when cooling is not required. Lighting in the building has been upgraded in cafe service 
area and office areas to lower voltage. Cafe area lighting was proposed to be upgraded from 20 MR16-30 walls each pot-lights, to LED MR17-7 wall each, however these changes were not implemented yet. Office area lighting is primary 32 watt T 82 lamp fixtures. There is no humidifier equipment in the building.

Building \#2 is located at Mississauga, Ontario.

Overview: A 6 story building that is mainly office space with underground parking as well as a penthouse mechanical level. The building's first floor includes various retail stores. Total gross area of the building is $8,225 \mathrm{~m}^{2}$, and it was constructed in 1988. Typical office hours are Monday to Friday from $7 \mathrm{am}$ to $7 \mathrm{pm}$. The building is typically closed down on Saturdays and Sundays.

Energy audit 1 was conducted on May, 2013 by SNC Lavalin O\&M department. During energy audit an assessment of energy savings of facility was completed. In addition, a site walk-through was performed as well as interviews with site personnel. From the energy audit, the following information was summarized. Energy consumption of the building is moderately high in comparison to similar office buildings in the same region. The primary HVAC system is provided by water cooled heat-pumps. Two packaged rooftops units serve the common areas of the building and the main level. However tenants of the retail area receive their own electric bills, these were included in calculations to represent overall usage. The gas fired MUA (make-up air) unit provides ventilation air to the building. Domestic hot water is provided by a gas-fired atmospheric heater with re-circulation pumps. There is no humidifier equipment in the building.

Building \#3 is located at Toronto, Ontario.

Overview: 8-story building with two levels of underground parking and a penthouse mechanical room. The building was built in 1970 and serves mainly as an office facility. Typical office hours are Monday to Friday from $7 \mathrm{am}$ to $7 \mathrm{pm}$, and Saturdays from $9 \mathrm{am}$ to $6 \mathrm{pm}$. The building is usually closed on Sundays. The total gross area of the building is $9,240 \mathrm{~m}^{2}$.

Energy audit 1 was completed in September, 2013 by SNC Lavalin O\&M department. Audit was conducted to achieve measures to reduce energy consumption. During this audit assessment of the energy savings potential of the facility was completed, and a site walk-through was conducted that included interviews with site personnel. From energy audit following information for Building \#3 was summarized. Energy consumption of the building is moderately high in comparison to similar office buildings in same region. The HVAC is provided by high-pressure air handler serving the perimeter induction units. Heating and cooling for the air handlers and perimeter induction units are provided by gas fired atmospheric hot water boilers and centrifugal chiller. A single return fan is controlled by the ambient static pressure return air. There is no humidifier equipment in the building.

Building \#4 is located at Mississauga, Ontario.

Overview: a 10-story building is mainly an office building with an approximate number of 500 occupants. The building was constructed in 1988 and has a total gross area of $15,712 \mathrm{~m}^{2}$. Building has an indoor parking lot and mechanical penthouse. Typical working hours are from Monday to Friday from $6 \mathrm{am}$ to $7 \mathrm{pm}$, and Saturday from $6 \mathrm{am}$ to $7 \mathrm{pm}$, on Sundays, the building is closed. 
Energy audit 1 was completed in June, 2013 by SNC Lavalin O\&M department. During this audit, an assessment of the energy savings potential of the facility was completed, and a site walk-through was conducted that included interviews with site personnel. This site audit allowed for the initial selection of energy conservation measures. From energy audit following information was summarized. Energy consumption of the building is average in comparison to similar office buildings in same region. Water source heat-pumps provide HVAC for the building with gas fired boilers and a cooling tower. A gas fired MUA (make-up air) unit brings outside air and deliver ventilated air back. There is a humidifier in the building. Building also has Building Automation System to control heat pumps and other major equipment.

Building \#5 is located at Mississauga, Ontario.

Overview: single story strip building containing 18 retail and office tenants. Building has floor gross area of $6,332 \mathrm{~m}^{2}$, and has outdoor parking lot around the exterior and at the back of the building. Building was constructed in 1988. Typical building operating hours are from Monday to Friday from $6 \mathrm{am}$ to 11:30pm, on Saturdays from 7am to $6 \mathrm{pm}$, and on Sundays the building is closed.

Energy audit 1 was completed in July, 2013 by SNC Lavalin O\&M department. During this audit assessment of the energy savings potential of the facility was completed, and a site walk-through was conducted that included interviews with site personnel. From energy audit following information was summarized. Energy consumption of the building is very low in comparison to similar building in this region. This could be attributed to the fact that some of the tenants pay for electricity independently, which is not captured by energy bills. Therefore $25 \%$ will be added to energy index value to approximate missing data. The HVAC is provided by 40 roof top units. The RTUs are electric cooling and natural gas heating and many are still original equipment since 1988. Building also has Building Automation System (BAS) and controls scheduling of equipment. Energy audit for this building suggests completing refurbishment for a roof as signs of deterioration are showing; however this was not done yet.

Building \#6 is located at Scarborough, Ontario.

Overview: the building is a combination of office space and retail space, with 2,130 $\mathrm{m}^{2}$ of gross floor area. The building was constructed in 1980. Already two first level energy audits were performed for this building, but no upgrades were completed yet. Typical building operating hours are from Monday to Friday from 6am to 7pm, on Saturdays from 7am to 6pm, and on Sundays the building is closed. However each office operates on a different schedule and as result has different hours of work.

Energy audit 1 was completed in March, 2014 by SNC Lavalin O\&M department; a previous energy audit was conducted in April 2011 however no upgrades were implemented to the building. During March 2014, audit assessment of the energy savings potential of the facility was completed, and a site walk-through was conducted that included interviews with site personnel. From energy audit, the following information was summarized. Energy consumption of the building is relatively low in comparison to similar building in this region. But this is could be due to the fact that some tenants receive individual bills and although it was a priority to track all bills for this building, but some bills could be paid separately. Therefore for further calculations and comparison energy index will be increased by 
$10 \%$ to approximate missing information. By applying this assumption this would bring the overall level of energy consumption to more realistic value. Heating and cooling for second floor of the building is provided by packaged rooftop units (electric cooling and gas heating) with VAV system. Building also uses electric fan-coil heaters (this used at the entrance), and individual split A/C systems with electric heaters in the air-handling unit. The fresh air to the building is provided by louvers. All tenants are individually metered for energy consumption, therefore pay for it separately.

Building \#7 is located at Ottawa, Ontario.

Overview: 4 story building is mostly an office building with typical building operating hours from Monday to Friday from 8 am to 5pm, on Saturdays and Sundays, the building is closed (except rooftop units). Building was constructed in 1993, with total floor area of $8,180 \mathrm{~m}^{2}$.

Energy audit 1 was completed in December, 2008 by SNC Lavalin O\&M department. During this audit information was collected on site and preliminary calculations included description for each measure of energy savings. From energy audit, the following information was summarized. Energy consumption of the building is slightly higher in comparison to similar building in this region. Increased energy consumption is due to the rooftop units operating $24 / 7$, but because the building has a big atrium energy, consumption balances due to the wasted floor space. Domestic hot water is heated by electric water heaters located through the building. Building does not have Building Automation System; all controls on HVAC equipment are mechanical or pneumatic. Building has variable air volume (VAV) rooftop units that provide conditioned ventilation air to the 3rd and 4th floors of the building, similar smaller units provide conditioned air to the atrium. Air-handling units (AHU) provide air to the suites on the rest of the floors. Atrium is heated by three gas-fired rooftop units.

Building \#8 is located at Ottawa, Ontario.

Overview: A 5-story building, mostly an office building with total floor area of 5,020 $\mathrm{m}^{2}$, and heated underground garage. Building was constructed in 1989. Typical building operating hours are from Monday to Friday from $7 \mathrm{am}$ to 7pm, on Saturdays from 7am to 5pm, and on Sundays, the building is closed. Garage operates $24 / 7$.

Energy audit 1 was completed in November, 2008 by SNC Lavalin O\&M department. During this audit discussions with client for background information was completed, in addition site visit and discussions with building operators was conducted, all this information was analyzed with backup of utility bills and analysis of potential retrofit measures were prepared. From energy audit, the following information was summarized. Energy consumption of the building is very high in comparison to similar building in this region. Building has high energy consumption due to following factors: first is the rooftop equipment that operated 24/7, also heated underground parking (maintained to $15 \mathrm{C}$ during winter), and in addition make-up air (MUA) units appears to be oversized. Domestic hot water for the building is provided by electric water heater in the basement electrical room. Building does not have Building Automation System, and all controls on HVAC equipment are mechanical or pneumatic. Climatemaster rooftop units provide conditioned ventilation air to the building, and it operates 24/7. Building also has electric humidifier, but it is not operating. Rooftop also holds packaged heat/cool 
unit, and various split $\mathrm{A} / \mathrm{C}$ condensing units.

Building \#9 is located at Ottawa, Ontario, Tower C.

Overview: A 3-story building is an office building contracted in 1989, with total floor area of 4,854 $\mathrm{m}^{2}$. Building has exterior parking for 165 spaces, there is no interior parking. Typical building operating hours are from Monday to Friday from 7 am to $7 \mathrm{pm}$, and its typically closed on Saturdays and Sundays.

Energy audit 1 was completed in June, 2010 by SNC Lavalin O\&M department. During this audit assessment of the energy savings potential of the facility was completed, and a site walk-through was conducted that included interviews with site personnel. From energy audit, the following information was summarized. Energy consumption of the building is average in comparison to similar building in this region. Heating in the building is provided by electricity. Domestic hot water also is provided by electricity and is sourced by water tanks. Energy audit that was performed for this building suggests upgrading windows glazing, given the age of the building the glazing is not up to current efficiency level, and heat penetration through building envelope into the building is higher.

Building \#10 is located at Ottawa, Ontario, Tower B.

Overview: a 5-story building is an office building constructed in 1989 with total floor area of $8,270 \mathrm{~m}^{2}$. Total building occupancy is 732 with current occupancy of approximate 600 people. Typical building operating hours are from Monday to Friday from 6am to 6pm; however some tenants remain in the building until 8pm.

Energy audit 1 was completed in December, 2010 by SNC Lavalin O\&M department. During this audit assessment of the energy savings potential of the facility was completed, and a site walk-through was conducted that included interviews with site personnel. During site visit some of the areas were not accessible due to security concerns, but nevertheless site audit allowed for the initial selection of energy conservation measures. From energy audit following information was summarized. Energy consumption of the building is very high in comparison to similar building in this region, and in comparison to BOMA energy efficient building value of $1.05 \mathrm{GJ} / \mathrm{m}^{2} /$ year however it is much lower than average National Resources Canada value of $1.43 \mathrm{GJ} / \mathrm{m}^{2} /$ year. High energy consumption is due to the data center which is located in the basement and ground floor of the building. Generally data center requires higher amount of equipment and consumed more energy. Therefore to provide more accurate assumptions, data center is factored out of analysis as $25 \%$ of the buildings overall energy usage (based on the area of data center). The electricity used by the tenants of data center is related to cooling equipment. The facility is equipped with an electrical meter by the utility to maintain night and holiday schedules. In addition, the building has Building Automation System (BAS) to monitor and control key systems of the building. Building heating is served by electricity, and there is no natural gas in the building. The main entrance vestibule of the building is heated by an electric forced fan heater. The building air side system consists of two air handlers, and building cooling is supplied by roof-mounted air cooled chiller.

Building \#11 is located at Ottawa, Ontario, Tower A.

Overview: A 4-story building was built in 1988 with total floor area of $6,162 \mathrm{~m}^{2}$. Typical building 
operating hours are from Monday to Friday from 6am to 6pm; however, some tenants remain in the building until 8pm. The building is closed on Saturdays and Sundays.

Energy audit 1 was completed in July, 2011 by SNC Lavalin O\&M department. During this audit assessment of the energy savings potential of the facility was completed, and a site walk-through was conducted that included interviews with site personnel. From energy audit, the following information was summarized. Energy consumption of the building is average in comparison to similar building in this region. Similarly as Building B, Building A heating is served by electricity, and there is no natural gas in the building. Energy audits completed for B and A Buildings recommend switching to natural gas, as natural gas is available on site (servicing Building C) and can be utilized for other two buildings. HVAC system in the building is air cooler chiller and circulating pump. Energy audit also suggests upgrading window glazing, due to the similar reasons as in Building C.

Building \#12 is located at Montreal, Quebec.

Overview: A 7-floor office building was constructed in 1873 and has undergone a few upgrades in 1987 and 1988. Occupancy of the building is around 150 people, and typical building operating hours are from Monday to Friday from 7am to 6pm, closed on Saturdays and Sundays.

Energy audit 1 was completed in March, 2015 by SNC Lavalin O\&M department. During this audit assessment of the energy savings potential of the facility was completed, and a site walk-through was conducted that included interviews with site personnel. From energy audit, the following information was summarized. Energy consumption of the building is relatively low in comparison to similar building in this region. Building does not have Building Automation System (BAS) however there is a remote monitoring. In 2011 new make-up air unit was installed on the roof to supply fresh air. A variable speed-cooling tower operates year-round and serves the heat pump units on each floor. The cooling tower operates with pan heater to deal with cooling loads that occur in the winter months. Constant speed pumps in the penthouse level serve condenser water from the cooling tower to a heat exchanger. Domestic hot water is supplied with electric hot water tanks. Each floor has heat pump air handlers. Building has no insulation and constructed on multiple courses of stone and brick. Windows are double glazed, but are in fair to poor condition.

Building \#13 is located at Vaudreuil-Dorion, Quebec.

Overview: A one story building with partial second floor at the main entrance. Building was constructed in 1977 with total floor area of $8,022 \mathrm{~m}^{2}$. At the beginning, the building was intended to be a shopping center, however currently, the ground floor is occupied by offices and a billiard hall/restaurant partially, and the second floor is occupied by offices. Typical building operating hours are from Monday to Friday from 7 am to $5 \mathrm{pm}$, with the billiard hall and restaurant, having late hours past midnight. Billiard hall and restaurant is also open on Saturdays and Sundays. Approximate occupancy is 120 people.

Energy audit 1 was completed in March, 2015 by SNC Lavalin O\&M department. During this audit assessment of the energy savings potential of the facility was completed, and a site walk-through was conducted that included interviews with operations personnel. From energy audit, the following 
information was summarized. Energy consumption of the building is average in comparison to similar building in this region. The building is not equipped with a building automation system, many systems run continuously as there is no means of scheduling. The heating and cooling system is composed of packaged rooftop units installed on the rooftop of the building. Supplementary heating in the form of several electric baseboard heaters is also used. Domestic hot water is supplied to the building by multiple electric boilers.

Building \#14 is located at Cte-St-Luc, Quebec.

Overview: A 5 floor office building was constructed in 1976 with a total floor area of 7,943 $\mathrm{m}^{2}$. Building consists primary of offices with typical building operating hours are from Monday to Friday from $7 \mathrm{am}$ to $8 \mathrm{pm}$. But the building also has Montreal Police space on the ground floor, which operates 24 hours a day. The approximate occupancy of the building is 300 people. Building has heated underground parking lot.

Energy audit 1 was completed in March, 2015 by SNC Lavalin O\&M department. During this audit assessment of the energy savings potential of the facility was completed, and a site walk-through was conducted that included interviews with site personnel. From energy audit, the following information was summarized. Energy consumption of the building is relatively high in comparison to similar building in this region, and in comparison to BOMA energy efficient building value of $1.05 \mathrm{GJ} / \mathrm{m}^{2} / \mathrm{yr}$ however it is lower than average National Resources Canada value of $1.43 \mathrm{GJ} / \mathrm{m}^{2} /$ year. Energy audit completed for this building specifies that building is not energy efficient. The building is not equipped with a building automation system; all controls are manual and standalone, therefore scheduling is not controlled. The heating and cooling system is composed of through-the-wall heat pumps installed on the building facades. All units are controlled locally on the unit. In addition there are three heat pumps on the roof. The cooling system is equipped with an indoor cooling tower. Also, there are unit heaters throughout the building, particularly in the underground parking lot. These heaters operate continuously in the winter period. Fresh air in the building is supplied from the penthouse, and this equipment also operates continuously. The buildings domestic hot water is supplied through electric water heaters.

Building \#15 is located at Gatineau, Quebec.

Overview: A 3-floor building was constructed in 1989 with total floor area of 5,518 $\mathrm{m}^{2}$. Building is a typical office with approximate occupancy of 200 people. Typical building operating hours are from Monday to Friday from 7am to 6pm, and closed on Saturdays and Sundays.

Energy audit 1 was completed in October, 2014 by SNC Lavalin O\&M department. During this audit assessment of the energy savings potential of the facility was completed, and a site walk-through was conducted that included interviews with site personnel. From energy audit, the following information was summarized. Energy consumption of the building is high in comparison to similar building in this region. HVAC requirements are met by rooftop units, with electric baseboard heaters installed around the perimeter of the floors to compensate for any heat loss. Central chiller supplies air conditioning, but it only serves ground and top two floors. The rest of the building is equipped with air handling units. Electric water heater provides domestic hot water. Building has an electrical humidifier. 


\subsection{Calculations}

\subsubsection{Energy Intensity Calculations}

To determine energy intensity of each case-study building, meta-analysis data set will combine energy-use data from utility bills and audits Level 1 measures, from two sources namely: EnergyCAP and CAMS (SNC Lavalin O\&M databases).

Utility bills information (electricity and natural gas consumption) for the range of years was obtained through energy tracking service, which monitors billing data using the EnergyCAP software application. This data was considered in the analysis to obtain an overall picture of the buildings monthly and annual energy consumption. EnergyCAP software provides the following information: actual data (summary, commodity of electric, natural gas, and water; monthly consumption, greenhouse gas emissions. For each category, data is split up into: total cost, energy cost percentage, daily average cost. Savings: summary, commodity, monthly (water, natural gas). For each commodity: monthly energy bills and demand.

For each case-study building utility invoices were analyzed, following procedure was utilized and all results and summary can be found in Appendix A. Utility bill analysis (general overview of the buildings various energy consumption levels), utility analysis summary (general overview of various consumption data for the particular facility), trending report for high energy consumption year and low energy consumption year (this is an equivalent $\mathrm{kWh}$ per square meter graph of the various types of energy used in the facility normalized by number of days in the month. Equation per month is as follows: $\mathrm{kWh}$ per month/building area $\mathrm{m} 2 / \#$ days per month. By dividing the $\mathrm{GJ} / \mathrm{m} 2$ values by the number of days in a given month, energy consumption is normalized). Comparison of energy intensity for high energy consumption year and low energy consumption year, average energy intensity is plotted to be compared to the BOMA benchmark value. Linear Regression for total energy consumption per degree days (here mathematical equation that defines the linear line is given on the graph itself. The relationship between energy consumed and weather (degree days) was plotted. The higher the degree days, the higher the energy consumption should be. The dots on the graph represent actual energy (electricity and natural gas) consumption. This is measured by the value $\mathrm{R} 2$ and the closer $\mathrm{R} 2$ is to 1.0 the better the trending. For buildings with negative trending, there may be an opportunity for improvements, if the dot is above the line; this indicates an occasion where high consumption may not have been warranted. During utility bills evaluations, attention was paid to understanding utility rate structure that applies to the facility, also to notice any additional utility monthly charges and disregard any inconsistent data.

Calculations of energy index for Building \#1 are shown below as an example; calculations for the rest of the case-study buildings can be found in Appendix A.

Energy CAP database was utilized to collect energy consumption information for the building. Energy consumption was provided by utility bills for electricity and gas. For Building \#1 utility bills were provided from December 2006 to March 2015. To complete most accurate analysis, utility bills for 2007 to 2014 were only analyzed because 2006 and 2015 has incomplete data. Following calculations were done based on utility bills: sum of electrical total cost per year, sum of gas total cost per year, sum of electrical consumption per year and sum of gas consumption per year. By having total floor area 
for the entire building of $25,424 \mathrm{~m}^{2}$, energy index in $\mathrm{GJ} / \mathrm{m}^{2} /$ year was calculated. From calculations it was noticed that 2008 provides inconsistent values in comparison with the rest of years, therefore for calculations of average yearly energy index 2008 year was excluded.

By summarizing utility bills data following calculations were made:

Table 3.3: Building \#1 Utility Bills Calculations

\begin{tabular}{|c|c|c|c|c|c|c|}
\hline \multicolumn{7}{|c|}{ Building A - Toronto, Ontario } \\
\hline Units & & $\mathrm{kWh}$ & & $\mathrm{m}^{3}$ & Total GJ/year & $25,424.00$ \\
\hline Row Labels & $\begin{array}{c}\text { Sum of } \\
\text { Electricity } \\
\text { Total } \\
\text { Cost / } \\
\text { Year } \\
\end{array}$ & $\begin{array}{l}\text { Sum of Electricity } \\
\text { Consumption / Year }\end{array}$ & $\begin{array}{c}\text { Sum of } \\
\text { Gas Total } \\
\text { Cost / } \\
\text { Year }\end{array}$ & $\begin{array}{c}\text { Sum of } \\
\text { Gas Con- } \\
\text { sumption } \\
\text { / Year }\end{array}$ & $\begin{array}{c}\text { Total } \\
\text { (Electric- } \\
\text { ity }+ \\
\text { Gas })\end{array}$ & $\mathrm{GJ} / \mathrm{m}^{2} / \mathrm{yr}$ \\
\hline Year 2006 & $\$ 41,516.27$ & $421,367.05$ & & & & \\
\hline Year 2007 & $\$ 570,890.60$ & $5,091,354.15$ & $\$ 131,724.54$ & $268,388.00$ & $28,312.91$ & 1.11 \\
\hline Year 2008 & $\$ 569,094.68$ & $4,972,063.86$ & $\$ 107,359.18$ & $174,537.00$ & $24,392.21$ & 0.96 \\
\hline Year 2009 & $\$ 579,662.09$ & $5,244,523.90$ & $\$ 119,726.55$ & $248,527.00$ & $28,125.49$ & 1.11 \\
\hline Year 2010 & $\$ 604,472.94$ & $5,301,976.03$ & $\$ 127,649.39$ & $257,151.00$ & $28,653.13$ & 1.13 \\
\hline Year 2011 & $\$ 652,951.71$ & $5,468,612.54$ & $\$ 95,527.36$ & $209,070.00$ & $27,464.41$ & 1.08 \\
\hline Year 2012 & $\$ 702,682.00$ & $5,475,785.13$ & $\$ 54,017.26$ & $225,168.00$ & $28,089.08$ & 1.10 \\
\hline Year 2013 & $\$ 769,177.23$ & $5,426,172.96$ & $\$ 69,769.34$ & $294,926.00$ & $30,505.47$ & 1.20 \\
\hline Year 2014 & $\$ 795,137.19$ & $5,486,980.86$ & $\$ 80,626.79$ & $292,762.00$ & $30,643.88$ & 1.21 \\
\hline Year 2015 & $\$ 189,033.38$ & $1,326,773.63$ & $\$ 79,274.42$ & $229,157.00$ & & \\
\hline Average & $\$ \$ \$ 667,853.39$ & $5,356,486.51$ & (\$97,005.89 & $256,570.29$ & & 1.13 \\
\hline
\end{tabular}

As it was specified in energy audit, energy consumption of the Building \#1 is moderately high in comparison to similar office buildings in same region; and therefore average energy index which equals to $1.13 \mathrm{GJ} / \mathrm{m}^{2} / \mathrm{yr}$ is also high in comparison to benchmark values of BOMA energy efficient building value of $1.05 \mathrm{GJ} / \mathrm{m}^{2} / \mathrm{yr}$ or National Resources Canada value of $1.43 \mathrm{GJ} / \mathrm{m}^{2} / \mathrm{yr}$.

Two charts below (Figure 3.5 and 3.6) show electricity and gas consumption per year. Electricity consumption chart demonstrates prominent increase in energy usage, 2012 and 2014 shows the highest values. However gas consumption chart does not increase in such an obvious pattern, but the highest gas consumption values are also in more recent years 2013 and 2014. 


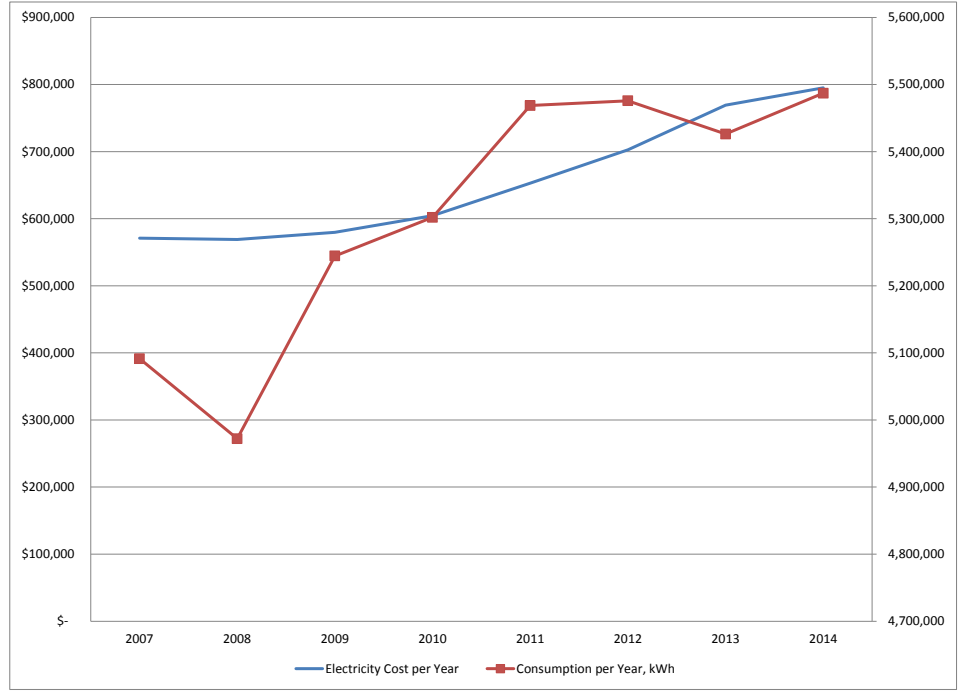

Figure 3.5: Example Building \#1 - Yearly Electricity Consumption

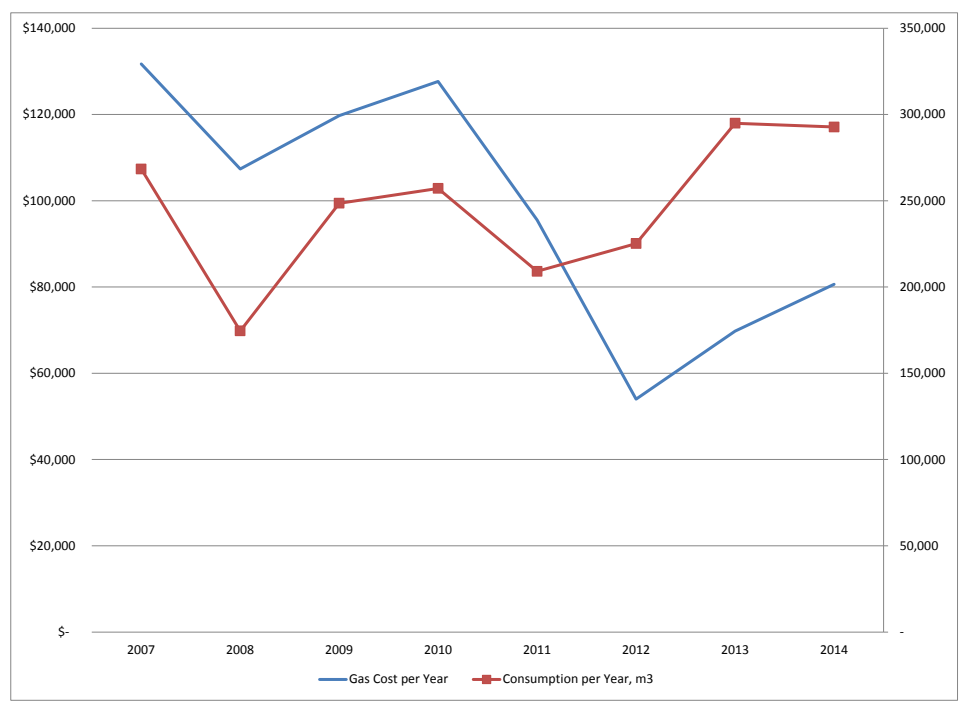

Figure 3.6: Example Building \#1 - Yearly Gas Consumption 
Yearly energy intensity (index) was also plotted to demonstrate increase or decrease over the range of years for which data is available. The chart below (Figure 3.7) shows that energy index value is gradually increasing and currently around $1.21 \mathrm{GJ} / \mathrm{m}^{2} / \mathrm{yr}$. The lowest energy index was in 2011 and highest in 2013. These two years data will be used for further calculations and comparisons.

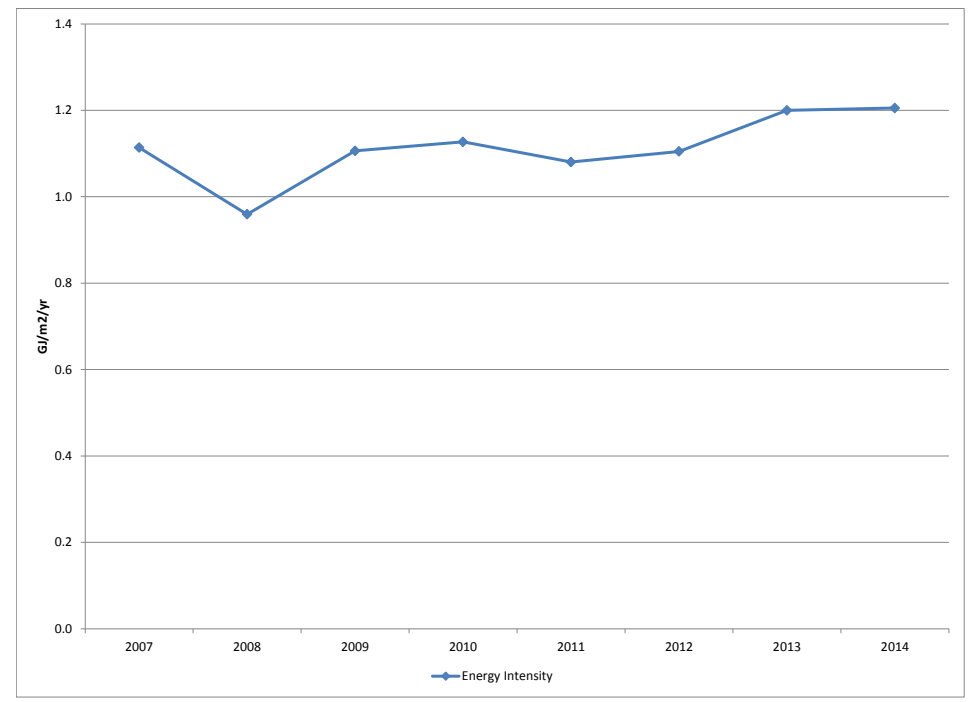

Figure 3.7: Example Building \#1 Yearly Energy Intensity Comparison

Because weather varies from day to day and year to year, normalization measures provide the best solution to represent how weather impacts energy consumption of the building. Energy used for heating and cooling is directly dependant on how cold or hot it was during a specific year or season. Weather normalization was applied on year with the lowest energy usage, so it could be compared to the year with highest energy usage. Comparing normalized data showed actual energy consumption not dependant on weather during such periods. Data for heating and cooling degree days was taken from weatherstats.ca webpage. By using total degree days (HDD plus CDD) normalized total energy consumption was calculated for Building \#1. Based on plotted results, shown below in the chart (Figure 3.8), it can be concluded that energy consumption for 2013 is higher than for 2011. This proves that regardless of weather conditions, 2013 has higher energy consumptions than in 2011. Implementing trend-line equations, the average equation was calculated:

$$
\gamma=3.1724 x+1340.45
$$

From the above equation, normalized average energy index was calculated as $1.14 \mathrm{GJ} / \mathrm{m}^{2} / \mathrm{yr}$; this value is slightly higher than average for 2007 to 2014 years range. Calculated value will be used for further 
case-study buildings comparison. Figure 3.8 shows linear progression for normalized data with equations.

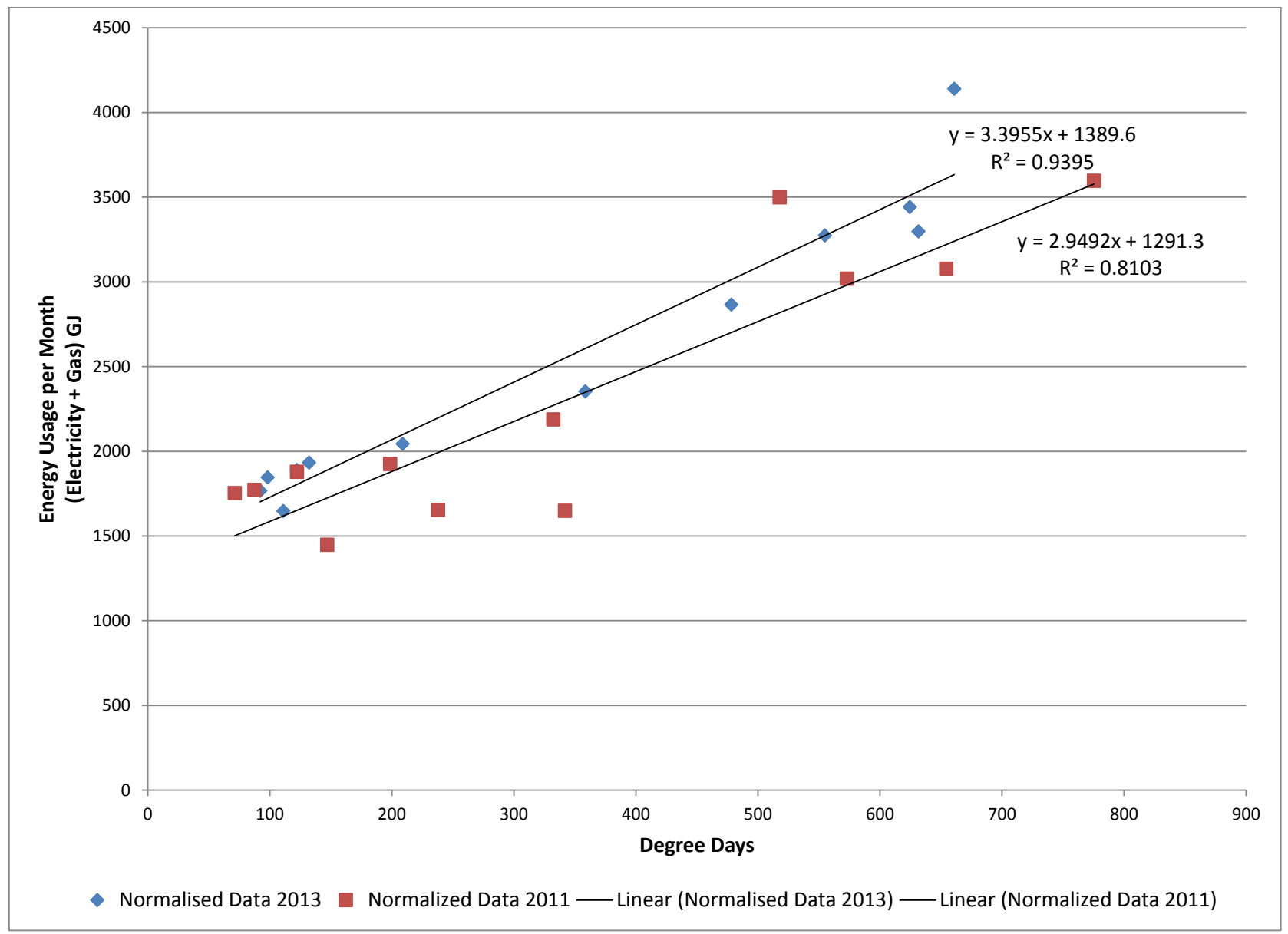

Figure 3.8: Example Building \#1 - Normalized Energy Intensity Calculations (year of the highest energy consumption vs. year with lowest consumption)

Additional analysis of energy bills for Building \#1 can be found in Appendix A. Tables and charts include summarized utility bills actual data used for calculations for 2013 and 2011 years, and calculations of energy index. Also two charts showing how electricity and gas consumption corresponds to heating and cooling periods (for highest and lowest energy consumption years), as well as additional an chart that shows monthly energy intensity for plotted comparison between highest energy consumption year, lowest, average and benchmark (BOMA) energy intensity. 
As previously mentioned, a similar procedure was applied to calculate energy intensity for the rest of 14 case-study buildings, and details of calculation can be found in Appendix A.

\subsubsection{WWR Calculations}

To calculate WWR for each case-study building, architectural drawings were utilized; architectural drawings were available only for four case-study buildings: \#1, \#2, \#3 and \#4. From elevations as well as cross-sections details drawings WWR was calculated for each building. For the rest of the building, where architectural drawings were not available, either a site visit was conducted or assumptions were made from photographs and Google Earth 3D images. WWR was calculated based on the equation provided in (Public works and Government Services Canada, 2002) guide. Complete calculations for each building can be found in Appendix B.

Table 3.4: WWR Summary of Case-Study Buildings

\begin{tabular}{|c|c|c|c|c|c|}
\hline & Address & $\begin{array}{c}\text { Images from Google } \\
\text { Earth }\end{array}$ & Shape & WWR & Notes: \\
\hline 1 & Toronto, Ontario & & Complex Shape & $44 \%$ & $\begin{array}{l}\text { Drawings } \\
\text { Provided }\end{array}$ \\
\hline 2 & Mississauga, Ontario & & Complex Shape & $27 \%$ & $\begin{array}{l}\text { Drawings } \\
\text { Provided }\end{array}$ \\
\hline 3 & Toronto, Ontario & 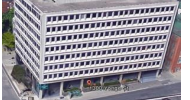 & Rectangular & $39 \%$ & $\begin{array}{c}\text { Drawings } \\
\text { Provided }\end{array}$ \\
\hline 4 & Mississauga, Ontario & & Complex Shape & $42 \%$ & $\begin{array}{l}\text { Drawings } \\
\text { Provided }\end{array}$ \\
\hline 5 & Mississauga, Ontario & & Complex Shape & $40 \%$ & $\begin{array}{c}\text { Site Visit has } \\
\text { been Completed }\end{array}$ \\
\hline 6 & Toronto, Ontario & & Rectangular & $40 \%$ & $\begin{array}{c}\text { Site Visit has } \\
\text { been Completed }\end{array}$ \\
\hline 7 & Ottawa, Ontario & & Rectangular & $32 \%$ & $\begin{array}{c}\text { Based on } \\
\text { Google Images }\end{array}$ \\
\hline 8 & Ottawa, Ontario & & Complex Shape & $43 \%$ & $\begin{array}{c}\text { Based on } \\
\text { Google Images }\end{array}$ \\
\hline
\end{tabular}




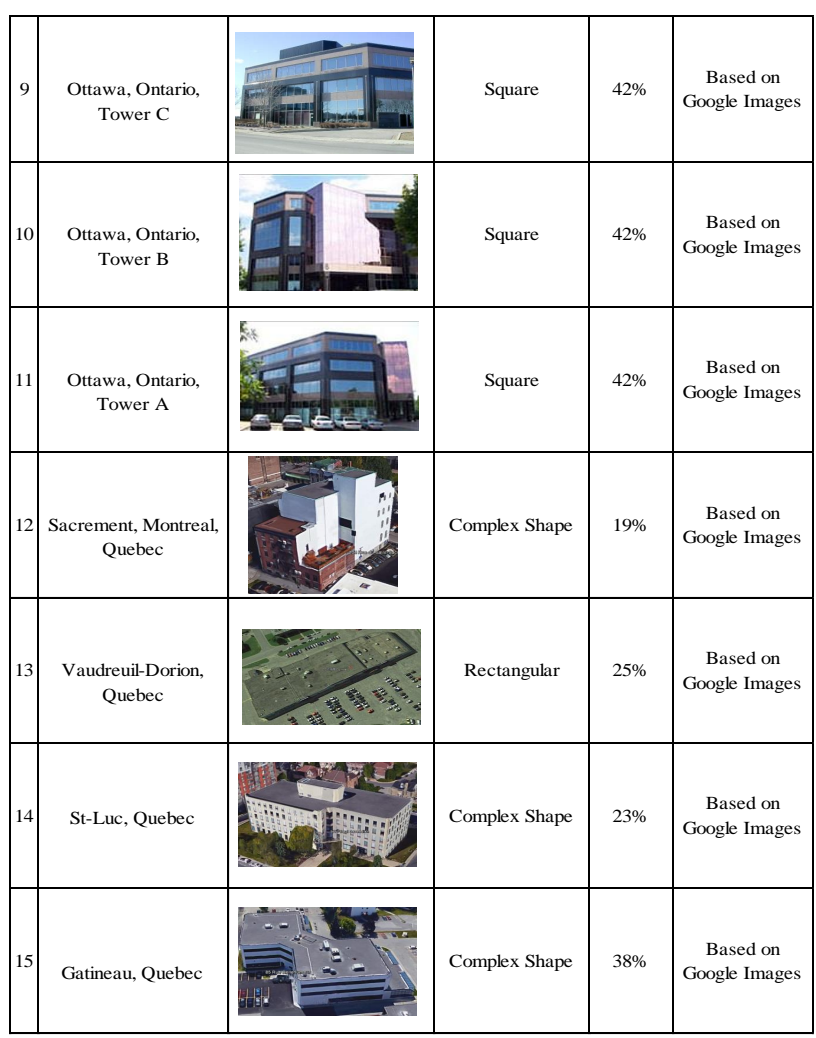

For visualizing purposes images from Google Earth were retrieved and shown in the window-to-wall summary table above (Table 3.4). Summary table contains the following information: building number, building location/name and WWR for each case study building. All images show South orientation of each case-study building.

\subsubsection{Building Envelope Thermal Resistance Calculations}

Architectural drawings as well as information provided in energy audits reports were used to analyze building envelopes of case-study buildings:

- Building Envelope for Building \#1 consists of typical cavity wall with architectural concrete block, concrete block on the inside and insulation in between. Windows are mostly double glazed curtain wall assemblies. Built-up roof with precast concrete pavers, insulation, roofing membrane and structural slab sloped to drain.

- Building Envelope for Building \#2 consists of a typical cavity wall with brick from the outside, concrete block and stud framing with R-8 batt insulation. Double glazed windows have thermally broken aluminum window frames. Built-up roof consists of stone ballast on fabrene sheet, rigid insulation, single ply membrane and sloped concrete. 
- Building Envelope for Building \#3 consists of typical wall system such as tinted gray glazing in precast concrete panels. At the first level, windows are clear glass in aluminum frames. Typical roof system is built-up roofing with rigid insulation, vapor barrier and concrete slab.

- Building Envelope for Building \#4 consists of double cable type clear anodized aluminum frame set into curtain wall framing, also insulated prefinished metal siding with frameless butt glazing. Typical roof consists of precast concrete pavers on precast waterproofing membrane and sloped concrete.

- Building Envelope for Building \#9, \#10 and \#11 consists of granite and double glazed curtain wall, and built-up roof. Insulation values could not be ascertained on site without destructive testing; therefore assumptions for thermal resistance will be made. Windows are heavily tinted.

Architectural drawings were only available for four buildings, but one set of drawings (for building \#4) was incomplete; therefore, building envelope components were not specified. Also, energy audits only provided brief building envelope description for buildings \#9, \#10 and \#11, and calculations of thermal resistance were not possible. Due to such restrictions, thermal resistance was only calculated for buildings $\# 1, \# 2$ and $\# 3$.

For thermal resistance calculations, assumptions for building envelope assembly components were based on ANSI/ASHRAE/IES Standard 90.1-2010 (CHAPTER 26), Table 4 Typical Thermal Properties of Common Building and Insulating Materials. However architectural drawings provided typical walls and roof construction components, but because construction specifications were not available, numerous assumptions had to be made. Assumptions are listed in spreadsheets used for calculations, and can be found in Appendix C.

Existing building RSI-values are compared to "Minimum thermal values requirements of building envelopes as per SB-10", Climate Zone 6, TABLE SB5.5-6, (Supersedes Table 5.5-6 in ANSI/ASHRAE/IESNA Standard 90.1). Based on this, calculation tables (can be found in Appendix C) specify whether higher greater thermal resistance of building component is required or determines if it satisfies the minimum requirements.

Summary table below shows thermal resistance of three main building envelope components: wall, roof and windows. All these components are area dependent, therefore effective thermal resistance for overall building envelope for each building was calculated. Following formula (as per SB-10 guidelines) was utilized to calculate effective thermal resistance:

$$
R_{o}=3 R_{i} A_{i} / A_{o}=\left(R_{1} A_{1}+R_{2} A_{2}+\ldots+R_{n} A_{n}\right) / A_{o}
$$

By analyzing this data it can be concluded that buildings with higher WWR have lower effective thermal resistance due to bigger fenestration area in comparison to more thermally resistant opaque area. Table 6 provides summary of calculated thermal resistance. 
Table 3.5: Three Case-Study Buildings Summary (Includes Thermal Resistance for Building Envelope Component)

\begin{tabular}{lcccc}
\hline \hline \multicolumn{6}{c}{ Thermal Resistance $\left(K * m^{2} / W\right)$} \\
\hline$\# \quad$ Address & Wall & Roof & Window & Effective \\
\hline 1 Building A - Toronto, Ontario & 1.62 & 0.47 & 0.15 & 0.98 \\
2 Building B - Mississauga, Ontario & 2.12 & 0.13 & 0.15 & 1.59 \\
3 Building C - Toronto, Ontario & 0.34 & 1.59 & 0.15 & 0.27
\end{tabular}

\subsection{Analysis}

\subsubsection{Analysis of Energy Audits}

To complete energy audits, SNC Lavalin follows the standard format of reporting, and after reviewing 15 energy audit reports (Phase One) it was concluded that all reports follow similar outline: overview and general information of the building, general findings that included analysis from the utility bills, energy index calculations and load factor analysis, also the initial selection of Energy Conservation Measures (ECM), and at the end energy conservation measures. The conservation measures section includes existing conditions and proposed solutions for various building systems and equipment, such as lighting fixtures replacement, upgrade of thermostat control, retrofit of heating / cooling equipment and others. Some of the audit reports also proposed to conduct further calculations as a solution; such calculations were: to perform heat loss calculations to estimate correct size of heating/cooling equipment, perform retro-commissioning audit on building automation system to identify energy and efficiency opportunities, conduct HVAC capital study that will include analysis and moving forward plan, upgrade lighting schedule, development of replacement plan by providing analysis and ranking the order of which units will be upgraded, and others. As a result, each report provides executive conservation measure summary where high level cost estimate for all upgrades is listed. Reports also provide the next step section, where anticipated implementations are discussed and high level plan of actions is provided.

After analyzing all 15 energy audit (Phase One) reports, it was observed that building envelope was only briefly discussed in four reports. Building \#3 report proposes to replace single pane outdated windows with new, double pane, thermally broken, solar reflective windows. Building \#5 report proposes to upgrade the existing roof due to ponding and signs of deterioration. Building \#9 and \#11 reports propose to upgrade existing windows by adding supplemental window glazing/shading to help reduce the heat penetration during the cooling season. From this, it can be concluded that building envelope upgrade is not typically considered as a part of the potential energy and cost savings measure during phase one energy audits analysis. However most of the reports claim that energy audit is based on an established process to identify measures for reducing energy consumption (perform renovations to eliminate thermal bridges), measures for improving occupant comfort, and measures for reducing greenhouse emissions, but very small percentage of them discussing building envelope concerns. It is explained in one of energy 
audit reports, that to eliminate thermal bridges in the building would require a full building retrofit; accurately calculating the savings for such a major project is beyond the scope of such report.

\subsubsection{Energy Intensity Analysis, Summary of Case-Study Buildings}

Below is the summary of all 15 case-study buildings. Table 3.6 provides the year range for which energy bills were available, electricity consumption and cost, gas consumption and cost, and energy intensity result for each building. All case-study buildings are office facilities with typical office hours and in most cases with typical occupancy (except \#2 and \#6 with retail space, \#13 with billiard hall/restaurant space, and \#14 with space dedicated for Montreal Police). Based on these and other differences, buildings have inconsistent energy consumption.

Table 3.6: Summary of Case-Study Buildings (Energy Intensity Calculations)

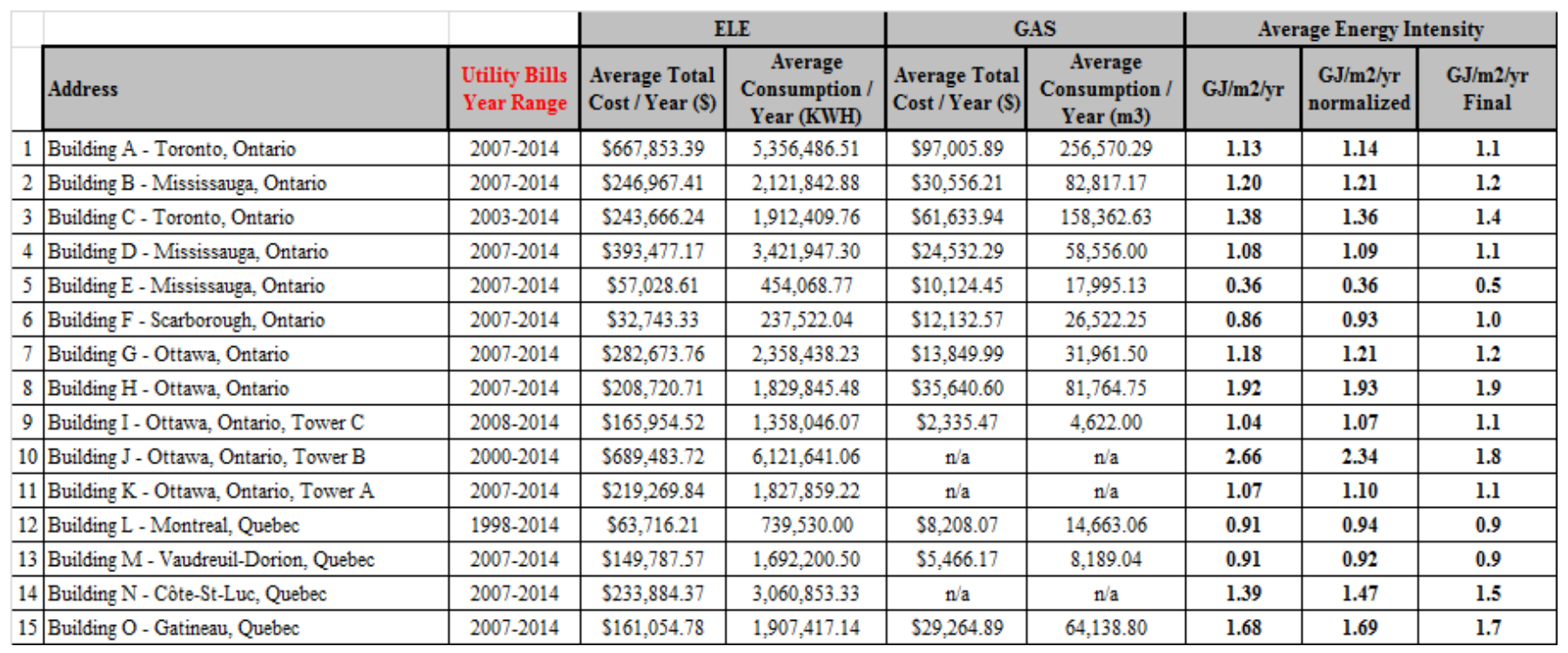

As it was specified previously, energy intensity benchmark value is used from BOMA report, where average energy use intensity for certified Office Buildings, is $27.1 \mathrm{ekWh} / \mathrm{ft}^{2} / \mathrm{yr}$ (or $1.05 \mathrm{GJ} / \mathrm{m}^{2} / \mathrm{yr}$ ). The chart below (Figure 3.9) demonstrates the comparison of energy intensity of each case-study building to BOMAs average value. 


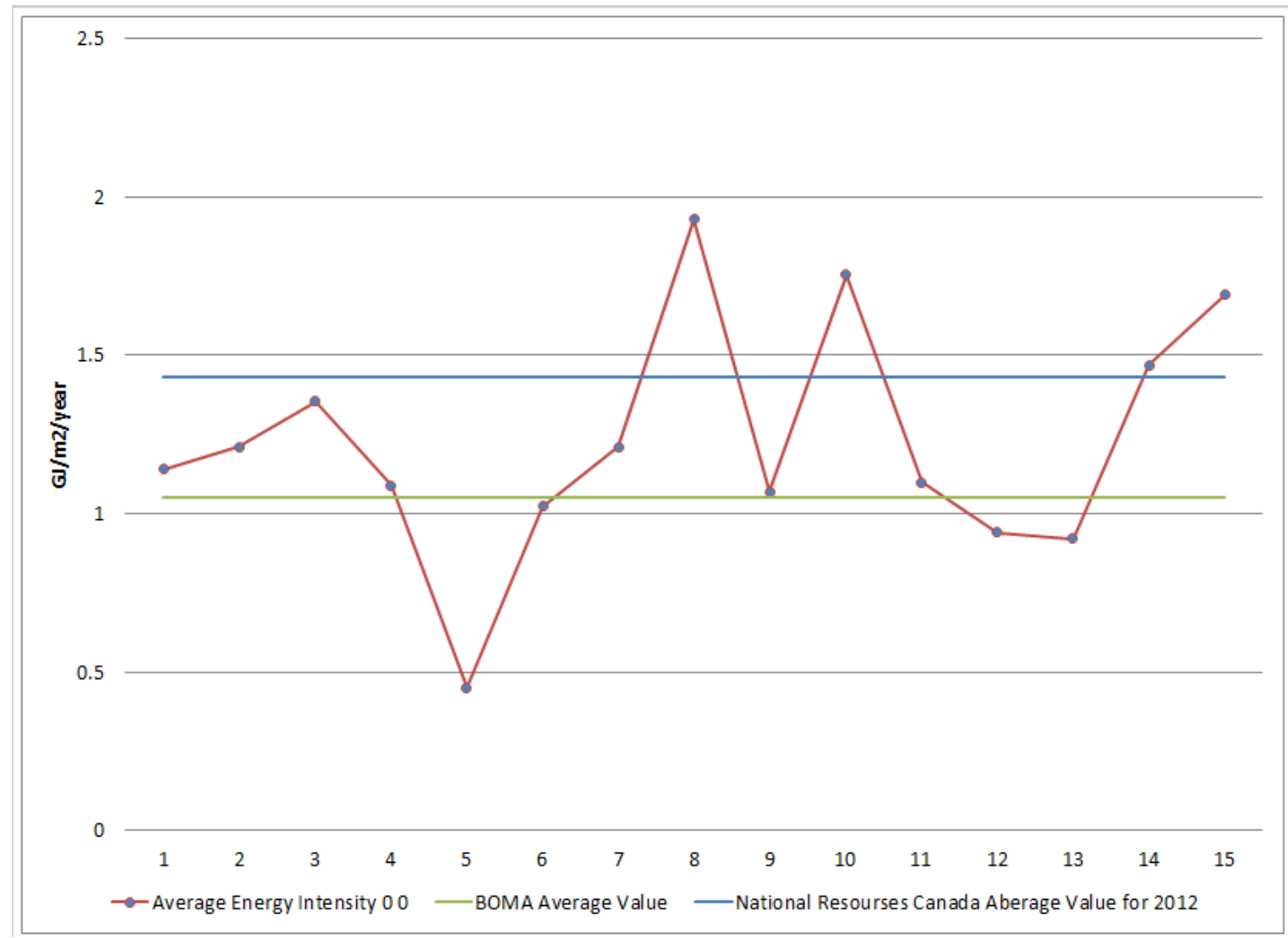

Figure 3.9: Energy Intensity vs. BOMAs Average Value

Two buildings \#8 and \#10 show significantly higher value from the benchmark value and building \#5 shows very low value in comparison to the rest of the buildings. More than half of the case-study buildings have energy index value around benchmark BOMA value; this demonstrates that buildings are performing at levels as per BOMA benchmark.

As it was mentioned before, buildings are divided into four main shape categories, however in charts below (Figure 3.10) combined complex shapes into one category. 


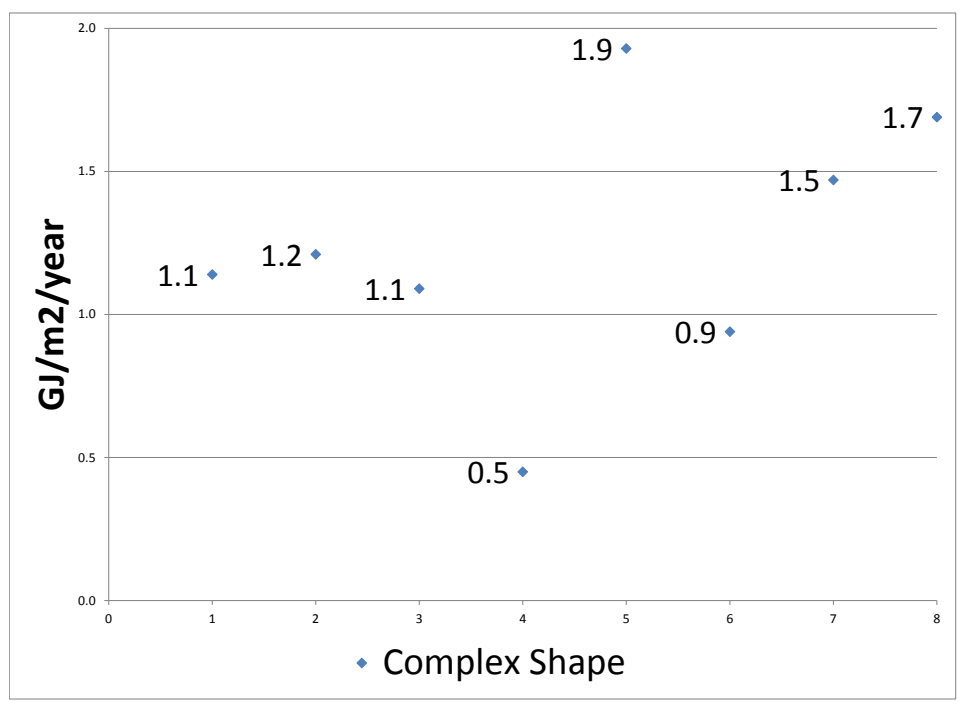

Figure 3.10: Energy Intensity vs. Building Shape Category (Complex Shape)

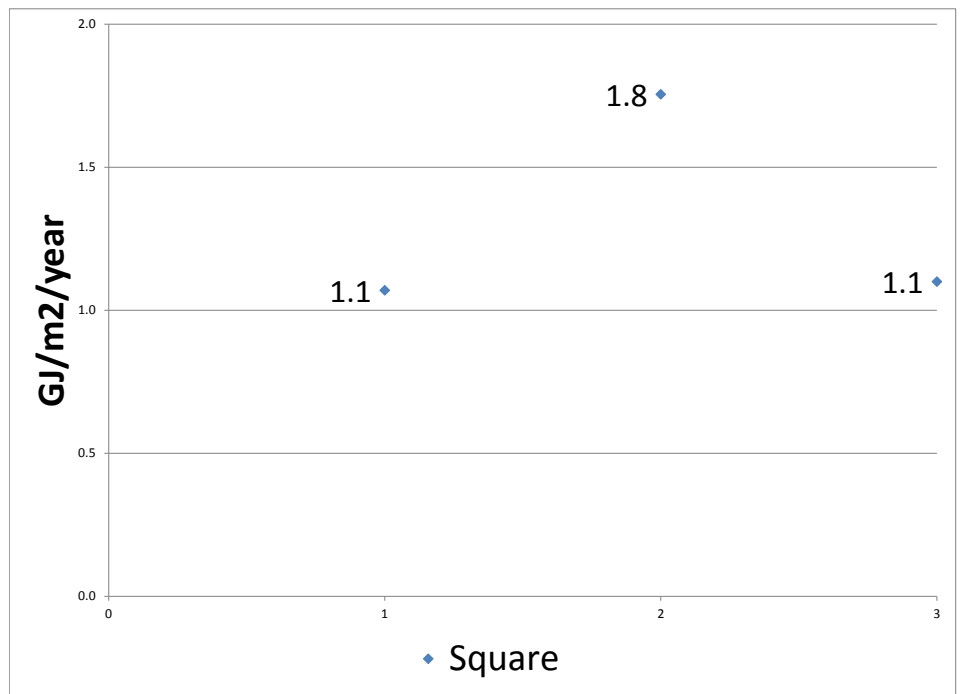

Figure 3.11: Energy Intensity vs. Building Shape Category (Square Shape) 


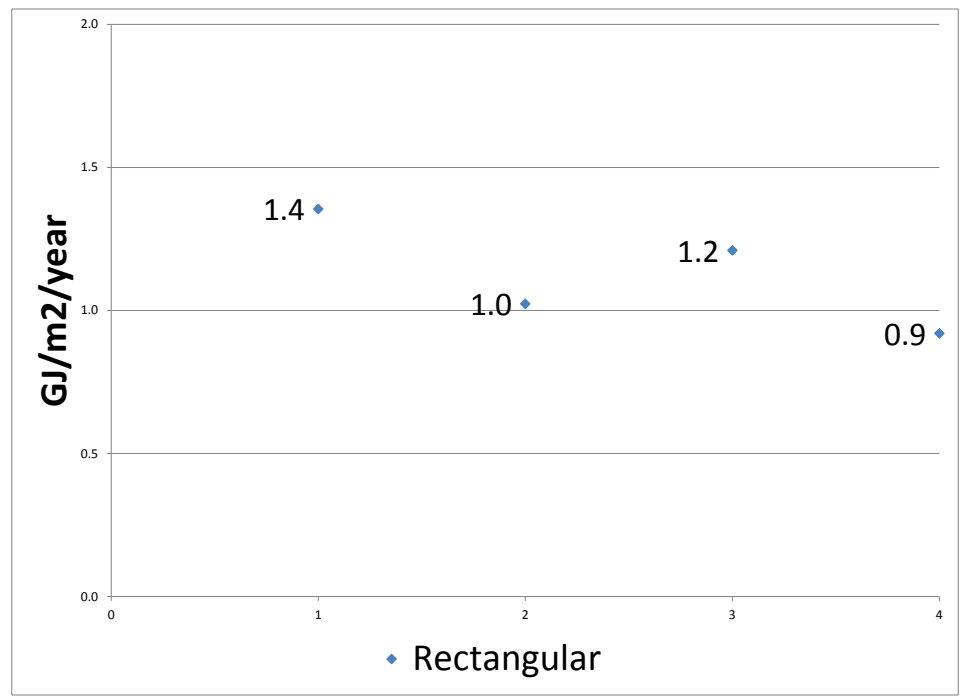

Figure 3.12: Energy Intensity vs. Building Shape Category (Rectangular Shape)

By grouping building based on their building shape, analysis didnt show much of the consistency. Buildings in all categories have energy intensity values higher than BOMA benchmark energy intensity value; however square shape category, which only contains three buildings, has only energy intensity higher than BOMA value and not lower.

Following analysis were conducted to conclude how age of the building influence energy intensity results, and linear progression was plotted (Figure 3.13).

Most of the buildings were constructed between 1970 and 1993; only one building was constructed in 1873. Surprisingly Building \#12, which was built in 19th century, has relatively low energy consumption in comparison to the newer buildings. Figure below (Left) includes all buildings, and demonstrates increasing pattern of trendline direction. Additional figure (that excludes Building \#12 that was constructed in 1873), shows very steady pattern however there is also an increase into positive direction. Two buildings with the highest energy consumption were both constructed in the same year 1989. This summarizes that selected case-studies do not imply that older building have higher energy consumption in comparison to newer constructed buildings. Most of the buildings selected for this research are midrise buildings, however to divide these building into categories all building were grouped into low-rise (1 to 3 floors), mid-rise ( 4 to 5 floors), and high-rise ( 6 to 12). Each category has 5 buildings. Figure 3.14 shows that linear trendline has increasing pattern in regards to energy consumption of these buildings reflected as energy intensity index. Low-rise buildings show the lowest energy consumption, and mid-rise having the highest. Additionally Figure 3.14 shows how energy intensity correlates with height of each building. From chart can be concluded that, based on case-study buildings, mid-rise building with height 

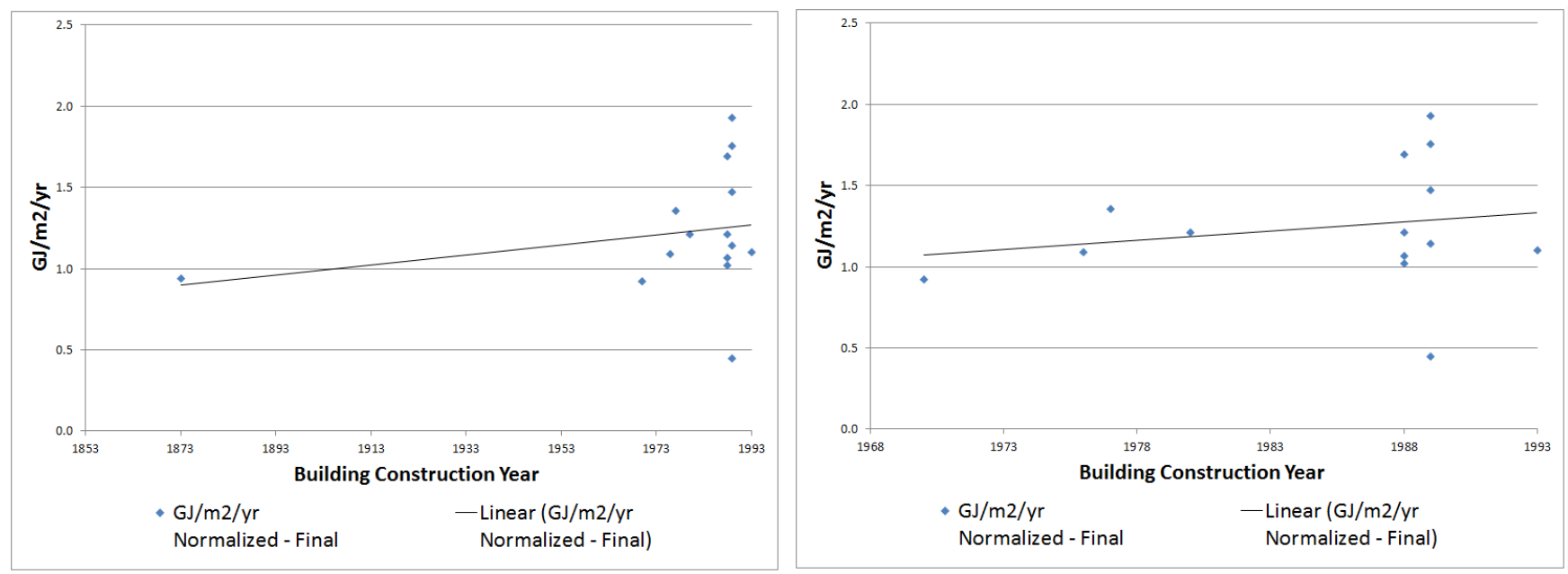

Figure 3.13: Energy Intensity vs. Buildings' Age Category, (Left) all years included, (Right) only more recent years included

4-5 floors have higher energy consumption.

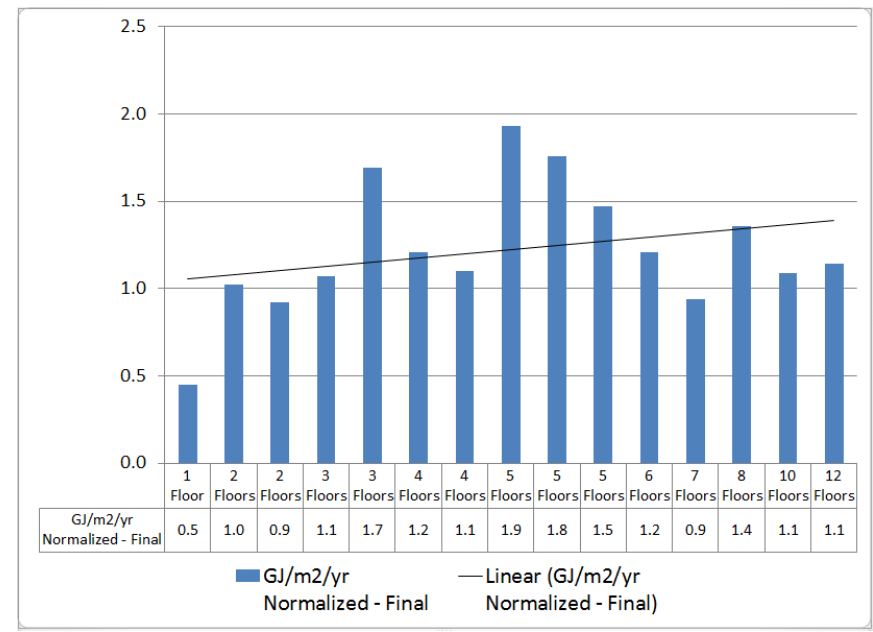

Figure 3.14: Energy Intensity vs. Building Height in Floors

\subsection{WWR analysis}

Figure 3.15 outlines the relationship between energy intensity and the WWR of 15 case-study buildings. All buildings WWR range between $20 \%$ to $45 \%$; only one building has a WWR lower than $20 \%$, as well as none of the building have WWR higher than $45 \%$. Trendline was plotted to identify which direction the chart is approaching: upwards or downwards. 


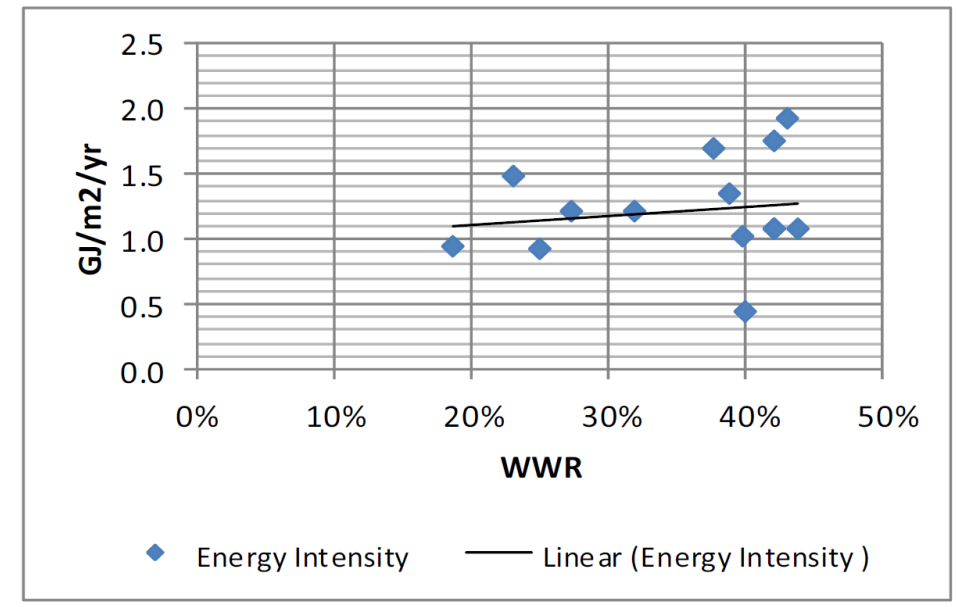

Figure 3.15: Energy Intensity vs. WWR

In addition, WWR was plotted against age of the buildings (Figure 3.16), to see if newer buildings have higher fenestration areas. From the chart below, it is shown that newer building do have higher WWR, and building \#12 which was constructed in 1873 has the lowest fenestration area therefore WWR. It has to be noted that energy consumption data for all buildings was analyzed to exclude any inconsistency, as well as normalized to calculate the most accurate average energy index that does not depend on weather conditions for a specific year.

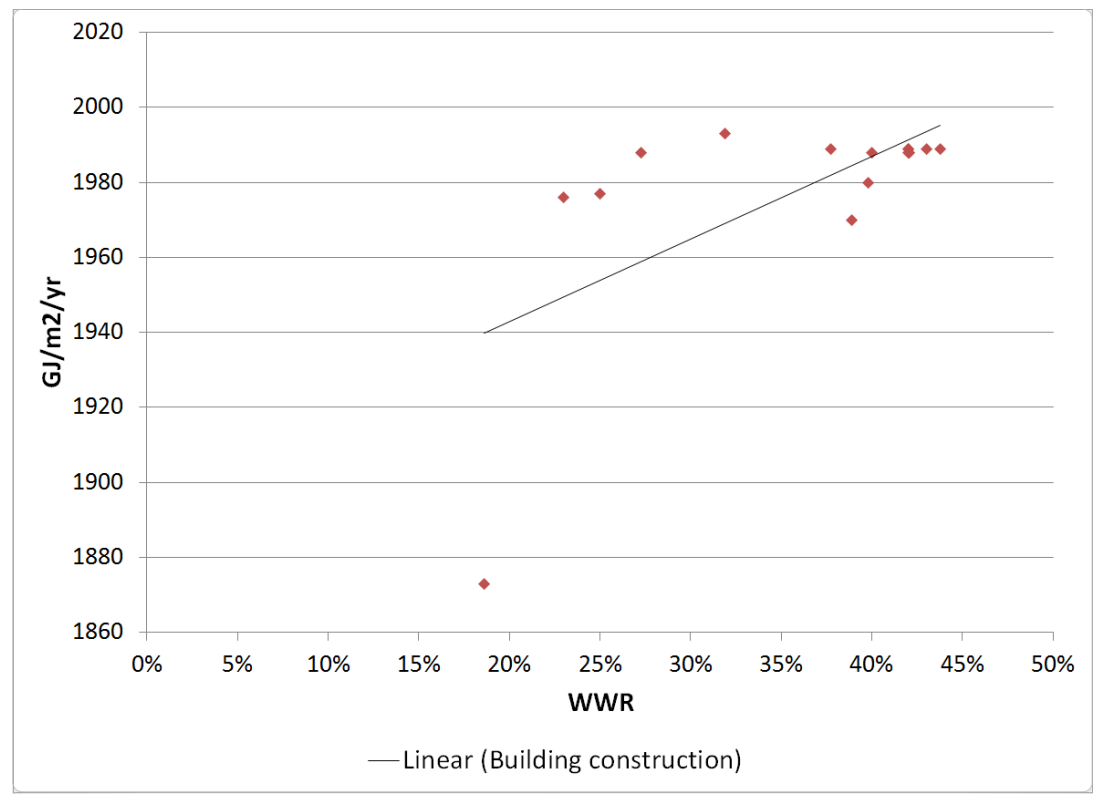

Figure 3.16: Comparison of Case-Study Buildings' Year of Construction vs. WWR 


\subsection{Thermal Resistance Analysis}

Due to limited access to architectural drawings as well as incomplete information, thermal resistance analysis can be only completed for three buildings: \#1, \#2 and \#3. Figure 21 below demonstrates the relationship between effective thermal resistance, WWR and energy intensity.

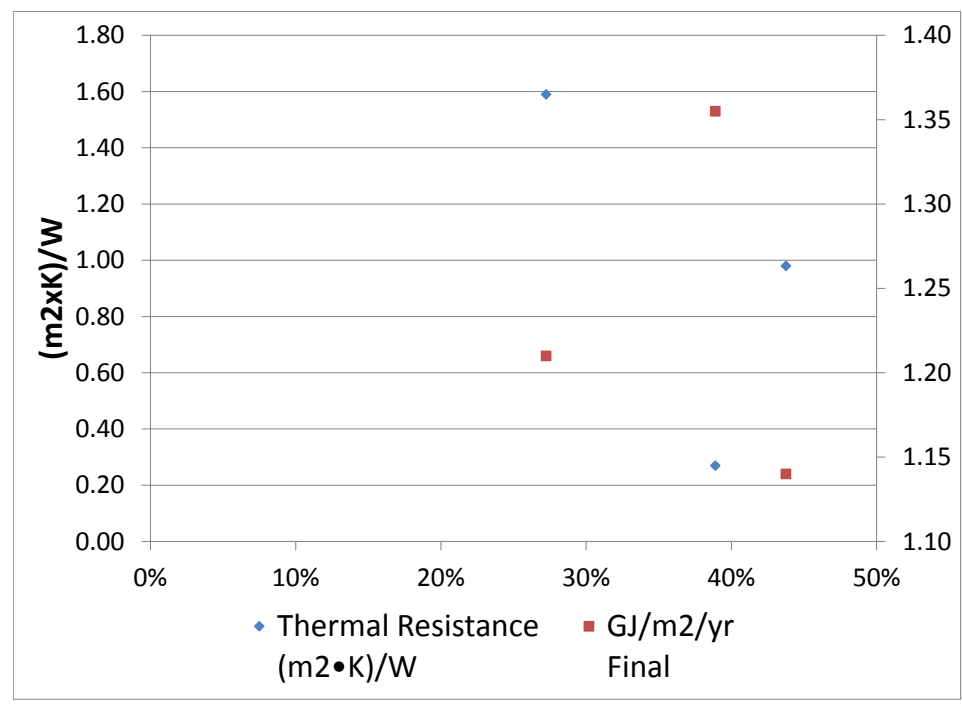

Figure 3.17: Comparison of Case-Study Buildings' Year of Construction vs. WWR

Two buildings, Building \#1 and \#2 show proportional relationship between thermal resistance and energy intensity; the higher the thermal resistance, the lower energy intensity the building has. Building \#3 has very low thermal resistance, and as expected very high energy intensity index and therefore energy consumption. However data was only available for three buildings, but nevertheless results demonstrated an expected outcome. In regards to WWR, results are not very consistent; the building with the highest WWR has $0.98\left(\mathrm{~K}^{*} \mathrm{~m}^{2}\right) / \mathrm{W}$ effective thermal resistance, which fall at the middle between three buildings. Another two buildings show expected results; the higher the WWR, the lower effective thermal resistance the building has.

\subsection{Building Indicators That Impact Energy Consumption}

For case-study buildings, major energy consumption breakdown lies between electricity and natural gas consumption. Figure 3.18 show the summary of the percentage breakdown in energy consumption for each facility for the average yearly energy consumption. For comparison purposes, the natural gas and electricity have been converted to common unit of energy (GJ). 


\begin{tabular}{|c|c|c|c|c|c|c|}
\hline & Address & $\begin{array}{c}\text { Total } \\
\text { Consumption }\end{array}$ & $\begin{array}{c}\text { Electricity } \\
\text { Consumption }\end{array}$ & $\begin{array}{c}\text { Gas } \\
\text { Consumption }\end{array}$ & $\begin{array}{c}\text { Electricity } \\
\%\end{array}$ & Gas $\%$ \\
\hline 1 & Building A - Toronto, Ontario & $28,827.77$ & $19,283.35$ & $9,544.41$ & $67 \%$ & $33 \%$ \\
\hline 2 & Building B - Mississauga, Ontario & $10,719.43$ & $7,638.63$ & $3,080.80$ & $71 \%$ & $29 \%$ \\
\hline 3 & Building C - Toronto, Ontario & $12,775.76$ & $6,884.68$ & $5,891.09$ & $54 \%$ & $46 \%$ \\
\hline 4 & Building D - Mississauga, Ontario & $14,497.29$ & $12,319.01$ & $2,178.28$ & $85 \%$ & $15 \%$ \\
\hline 5 & Building E - Mississauga, Ontario & $2,304.07$ & $1,634.65$ & 669.42 & $71 \%$ & $29 \%$ \\
\hline 6 & Building F - Scarborough, Ontario & $1,841.71$ & 855.08 & 986.63 & $46 \%$ & $54 \%$ \\
\hline 7 & Building G - Ottawa, Ontario & $9,679.35$ & $8,490.38$ & $1,188.97$ & $88 \%$ & $12 \%$ \\
\hline 8 & Building H - Ottawa, Ontario & $9,629.09$ & $6,587.44$ & $3,041.65$ & $68 \%$ & $32 \%$ \\
\hline 9 & Building I - Ottawa, Ontario, Tower C & $5,060.90$ & $4,888.97$ & 171.94 & $97 \%$ & $3 \%$ \\
\hline 10 & Building J - Ottawa, Ontario, Tower B & $22,037.91$ & $22,037.91$ & & $100 \%$ & \\
\hline 11 & Building K - Ottawa, Ontario, Tower A & $6,580.29$ & $6,580.29$ & & $100 \%$ & \\
\hline 12 & Building L - Montreal, Quebec & $3,207.77$ & $2,662.31$ & 545.47 & $83 \%$ & $17 \%$ \\
\hline 13 & Building M - Vaudreuil-Dorion, Quebec & $6,396.55$ & $6,091.92$ & 304.63 & $95 \%$ & $5 \%$ \\
\hline 14 & Building N - Côte-St-Luc, Quebec & $11,019.07$ & $11,019.07$ & & $100 \%$ & \\
\hline 15 & Building O - Gatineau, Quebec & $9,252.67$ & $6,866.70$ & $2,385.96$ & $74 \%$ & $26 \%$ \\
\hline & Total Average (excluding zero values) & & & & $75 \%$ & $25 \%$ \\
\hline
\end{tabular}

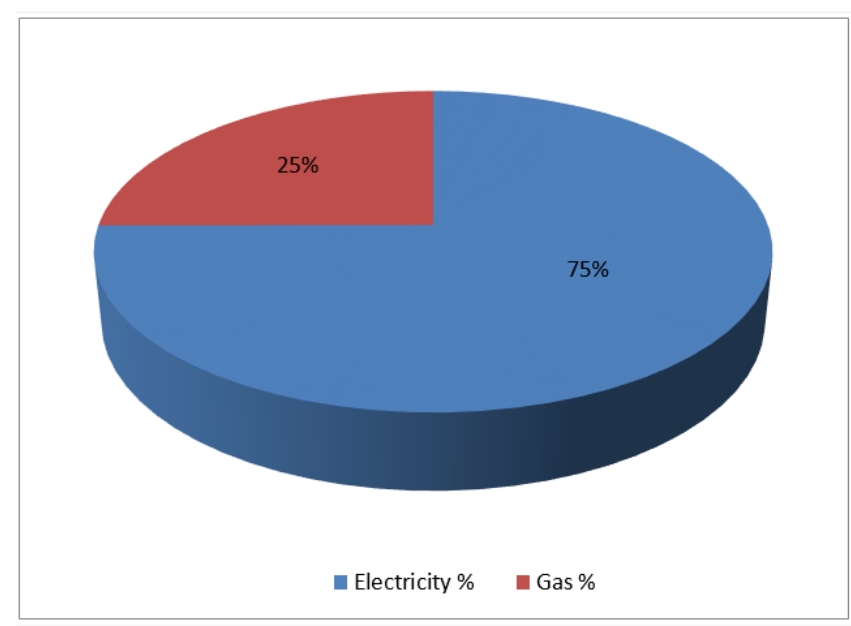

Figure 3.18: (Left) - Case-Study Building Energy Consumption in \%, (Right) - Average Percentage

\subsection{Energy Balance}

In order to identify where energy is used in the buildings, energy balance was completed for the facility. The energy balance identifies the electricity and natural gas consumption by individual systems; it also analyses if that consumption is weather dependant. Energy balance approach demonstrates the overall relative impact of the architectural features on the heating and cooling loads of the building. The larger percentage represents those elements that have a greater impact on heating and cooling loads therefore more attention should be given to these architectural features. Typically energy balance values are estimated based on ammeter readings, equipment schedules and software modelling. Figures 3.19 and 3.20 , show energy balance for the typical office building.

\begin{tabular}{|c|c|}
\hline \multicolumn{2}{|l|}{ Heating Loads } \\
\hline Number of Stories & $25 \%$ \\
\hline Building Orientation & $10 \%$ \\
\hline Window to Wall ratio & $15 \%$ \\
\hline Window Thermal Performance & $15 \%$ \\
\hline Opaque Wall Thermal Performance & $30 \%$ \\
\hline Other & $5 \%$ \\
\hline
\end{tabular}

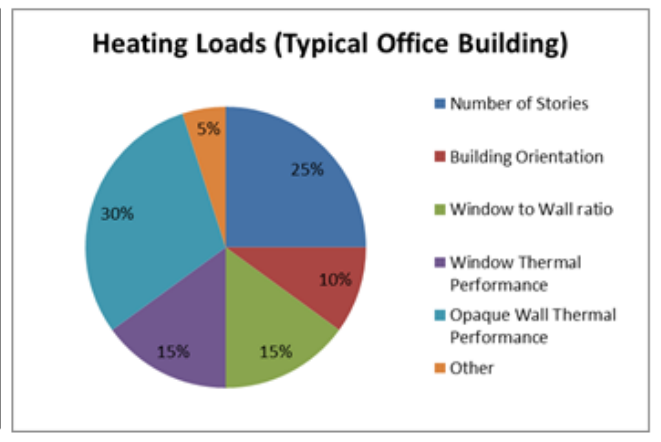

Figure 3.19: (Left) - Heating Loads Percentage Distribution for the Typical Office Building, (Right) Pie Chart of these Values 


\begin{tabular}{|c|c|}
\hline \multicolumn{2}{|l|}{ Cooling Loads } \\
\hline Number of Stories & $5 \%$ \\
\hline Building Orientation & $5 \%$ \\
\hline Window to Wall ratio & $35 \%$ \\
\hline Window Thermal Performance & $35 \%$ \\
\hline Opaque Wall Thermal Performance & $5 \%$ \\
\hline Other & $15 \%$ \\
\hline
\end{tabular}

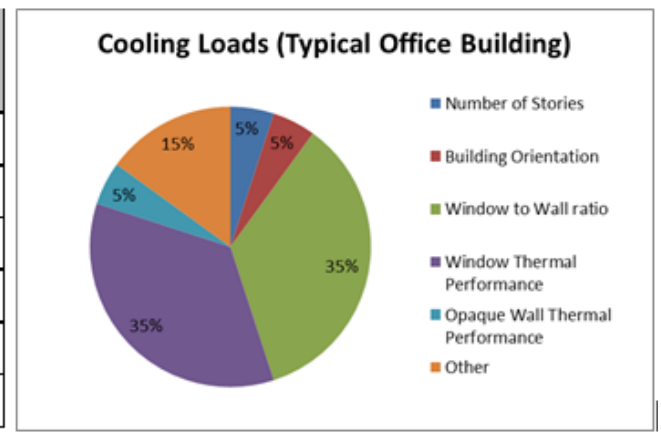

Figure 3.20: (Left) - Cooling Loads Percentage Distribution for Typical Office, (Right) - Pie Chart of these Values

These values were calculated based on case-study energy audits reports as well as Canada Mortgage and Housing Corporation (CMHC), 2014. Research study prepared by Canada Mortgage and Housing Corporation (CMHC), (2014) provides percentages of the overall relative impact of the architectural features on the heating loads and cooling loads for MURBs. Values were slightly adjusted to suit typical office buildings; assumptions were made based on case-study energy audits. The Other category includes all other parameters that might influence a typical office building. Figures 3.19 and 3.20 summarises percentage distribution for heating and cooling. Percentage distribution example can be found in Appendix D.

The pie chart below (Figure 3.21) demonstrates average percentages of energy use by end-use for commercial/institutional buildings as per National Resources Canada (NRC), 2010.

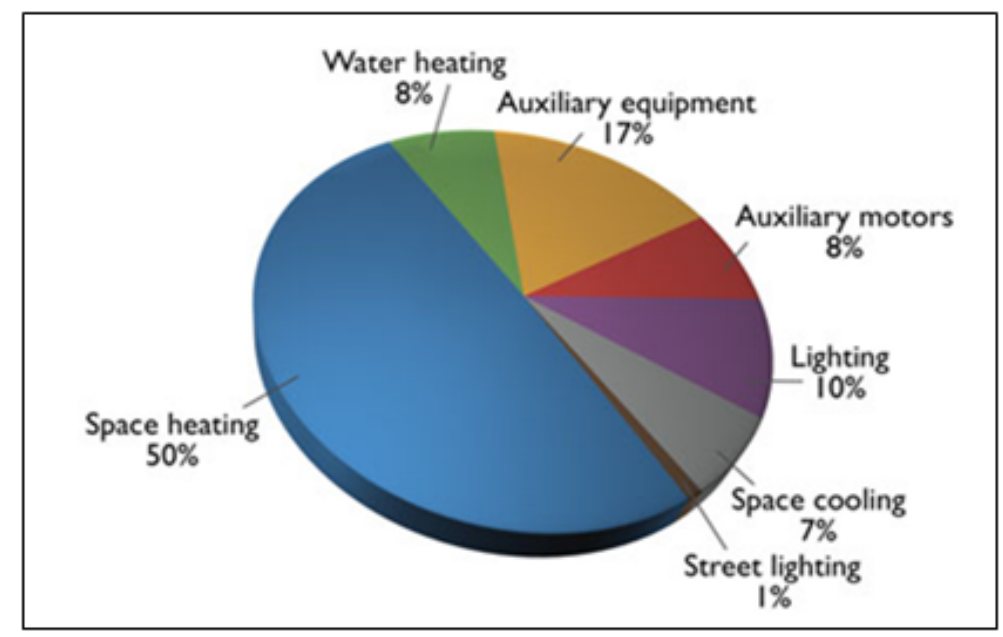

Figure 3.21: Commercial/Institutional Energy Use by End-Use, 2007 (Percent) (NRC, 2010)

Percentage distribution from Figure 3.21 were analysed against energy audit reports for building 
\#7 (301 Moodie Drive, Ottawa, Ontario), and \#8 (303 Moodie Drive, Ottawa, Ontario), and energy balance breakdown was calculated (shown in Figure 3.22).

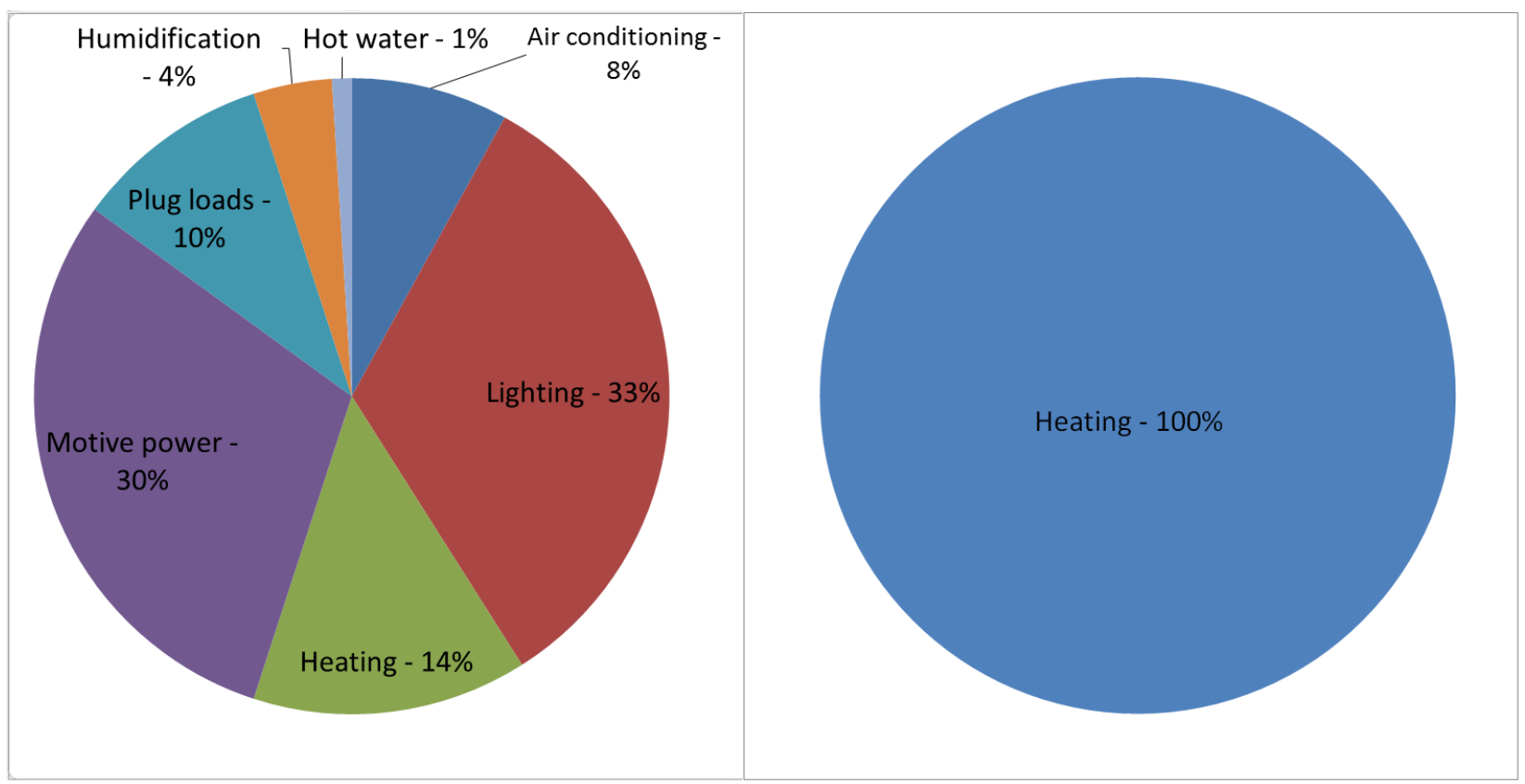

Figure 3.22: Energy Balance of Case-Study Buildings, (Left) Electricity, (Right) - Gas

Buildings total energy consumption indicators include the following: heating (includes the heating load for external areas and the heating load attributed to fresh air), air conditioning (includes cooling and de-humidification of fresh air and the air conditioning load for internal and external areas), lighting (corresponds to the proportion of consumption attributable to light fixtures), motive power (represents consumption associated with pumps, fan motors and elevator motors), plug loads (represents all the loads not included in the other items and electricity consumption of all office equipment including workstations, printers and photocopying machines), humidification (represents consumption associated with the humidification of fresh air), and hot water (corresponds to the heating load required to produce domestic hot water).

Heating, cooling and lighting consume significant percentage of electricity and gas usage of the typical office building. Based on a previously reviewed literature, the exact percentage was not provided on how architectural features of the building impact lighting energy consumption. Therefore, an assumption was made based on calculations provided in Ross (2009) report as WWR accounts for $40 \%$ of lighting loads. The following analyses were completed to conclude the total energy consumption impacted by WWR for each case study building. This was achieved by applying energy balance for electricity and gas consumption as well as heating, cooling and lighting loads energy distribution per architectural features, for each case-study building. 
Table 3.7: Heating Loads Distribution (Electricity) in GJ Based on Architectural Features Indicators

\begin{tabular}{|c|c|c|c|c|c|c|c|c|}
\hline & Heating Loads Percentage Distribution & & $25 \%$ & $10 \%$ & $15 \%$ & $15 \%$ & $30 \%$ & $5 \%$ \\
\hline & & & GJ & & & & & \\
\hline & Address & $\begin{array}{c}\text { Heating Loads } \\
\text { Electricity } \\
\text { Balance } \\
\end{array}$ & $\begin{array}{c}\text { Number of } \\
\text { Stories }\end{array}$ & $\begin{array}{l}\text { Building } \\
\text { Orientation }\end{array}$ & $\begin{array}{l}\text { Window to } \\
\text { Wall ratio }\end{array}$ & $\begin{array}{c}\text { Window } \\
\text { Thermal } \\
\text { Performance }\end{array}$ & \begin{tabular}{|c|} 
Opaque Wall \\
Thermal \\
Performance \\
\end{tabular} & Other \\
\hline 1 & Building A - Toronto, Ontario & $14 \%$ & $187,477.0$ & $74,990.8$ & $112,486.2$ & $112,486.2$ & $224,972.4$ & $37,495.4$ \\
\hline 2 & Building B - Mississauga, Ontario & $14 \%$ & $74,264.5$ & $29,705.8$ & $44,558.7$ & $44,558.7$ & $89,117.4$ & $14,852.9$ \\
\hline 3 & Building C - Toronto, Ontario & $14 \%$ & $66,934.3$ & $26,773.7$ & $40,160.6$ & $40,160.6$ & $80,321.2$ & $13,386.9$ \\
\hline 4 & Building D - Mississauga, Ontario & $14 \%$ & $119,768.2$ & $47,907.3$ & $71,860.9$ & $71,860.9$ & $143,721.8$ & $23,953.6$ \\
\hline 5 & Building E - Mississauga, Ontario & $14 \%$ & $15,892.4$ & $6,357.0$ & $9,535.4$ & $9,535.4$ & $19,070.9$ & $3,178.5$ \\
\hline 6 & Building F - Scarborough, Ontario & $14 \%$ & $8,313.3$ & $3,325.3$ & $4,988.0$ & $4,988.0$ & $9,975.9$ & $1,662.7$ \\
\hline 7 & Building G - Ottawa, Ontario & $14 \%$ & $82,545.3$ & $33,018.1$ & $49,527.2$ & $49,527.2$ & $99,054.4$ & $16,509.1$ \\
\hline 8 & Building H - Ottawa, Ontario & $14 \%$ & $64,044.6$ & $25,617.8$ & $38,426.8$ & $38,426.8$ & $76,853.5$ & $12,808.9$ \\
\hline 9 & Building I - Ottawa, Ontario, Tower C & $14 \%$ & $47,531.6$ & $19,012.6$ & $28,519.0$ & $28,519.0$ & $57,037.9$ & $9,506.3$ \\
\hline 10 & Building J - Ottawa, Ontario, Tower B & $14 \%$ & $214,257.4$ & $85,703.0$ & $128,554.5$ & $128,554.5$ & $257,108.9$ & $42,851.5$ \\
\hline 11 & Building K - Ottawa, Ontario, Tower A & $14 \%$ & $63,975.1$ & $25,590.0$ & $38,385.0$ & $38,385.0$ & $76,770.1$ & $12,795.0$ \\
\hline 12 & Building L - Montreal, Quebec & $14 \%$ & $25,883.6$ & $10,353.4$ & $15,530.1$ & $15,530.1$ & $31,060.3$ & $5,176.7$ \\
\hline 13 & Building M - Vaudreuil-Dorion, Quebec & $14 \%$ & $59,227.0$ & $23,690.8$ & $35,536.2$ & $35,536.2$ & $71,072.4$ & $11,845.4$ \\
\hline 14 & Building N - Côte-St-Luc, Quebec & $14 \%$ & $107,129.9$ & $42,851.9$ & $64,277.9$ & $64,277.9$ & $128,555.8$ & $21,426.0$ \\
\hline 15 & Building O - Gatineau, Quebec & $14 \%$ & $66,759.6$ & $26,703.8$ & $40,055.8$ & $40,055.8$ & $80,111.5$ & $13,351.9$ \\
\hline
\end{tabular}

Calculations above (Table 3.7 ) are based on electricity consumption in (GJ). To be able to compare values between all buildings, data was introduced as energy intensity (divided by total floor area of each building); calculated values are shown in the table below. WWR impacts $15 \%$ of overall electricity consumption of the heating loads. Table 3.8 contains the same data but is introduced through energy index value $\left(\mathrm{GJ} / \mathrm{m}^{2} /\right.$ year$)$.

Table 3.8: Heating Loads Distribution (Electricity) in GJ $/ \mathrm{m}^{2} /$ year Based on Architectural Features Indicators

\begin{tabular}{|c|c|c|c|c|c|c|c|c|}
\hline \multirow{2}{*}{\multicolumn{2}{|c|}{ Heating Loads Percentage Distribution }} & & $25 \%$ & $10 \%$ & \multirow[t]{2}{*}{$15 \%$} & \multirow[t]{2}{*}{$15 \%$} & \multirow[t]{2}{*}{$30 \%$} & \multirow[t]{2}{*}{$5 \%$} \\
\hline & & \multicolumn{3}{|c|}{ GJ/m2/yeah } & & & & \\
\hline & Address & \begin{tabular}{|c} 
Heating Loads \\
Electricity \\
Balance \\
\end{tabular} & $\begin{array}{c}\text { Number of } \\
\text { Stories }\end{array}$ & $\begin{array}{c}\text { Building } \\
\text { Orientation }\end{array}$ & $\begin{array}{l}\text { Window to } \\
\text { Wall ratio }\end{array}$ & $\begin{array}{c}\text { Window } \\
\text { Thermal } \\
\text { Performance }\end{array}$ & $\begin{array}{c}\text { Opaque Wall } \\
\text { Thermal } \\
\text { Performance }\end{array}$ & Other \\
\hline 1 & Building A - Toronto, Ontario & $14 \%$ & 0.027 & 0.011 & 0.016 & 0.016 & 0.032 & 0.005 \\
\hline 2 & Building B - Mississauga, Ontario & $14 \%$ & 0.033 & 0.013 & 0.020 & 0.020 & 0.039 & 0.007 \\
\hline 3 & Building C - Toronto, Ontario & $14 \%$ & 0.026 & 0.010 & 0.016 & 0.016 & 0.031 & 0.005 \\
\hline 4 & Building D - Mississauga, Ontario & $14 \%$ & 0.027 & 0.011 & 0.016 & 0.016 & 0.033 & 0.005 \\
\hline 5 & Building E - Mississauga, Ontario & $14 \%$ & 0.009 & 0.004 & 0.005 & 0.005 & 0.011 & 0.002 \\
\hline 6 & Building F - Scarborough, Ontario & $14 \%$ & 0.014 & 0.006 & 0.008 & 0.008 & 0.017 & 0.003 \\
\hline 7 & Building G - Ottawa, Ontario & $14 \%$ & 0.036 & 0.015 & 0.022 & 0.022 & 0.044 & 0.007 \\
\hline 8 & Building H - Ottawa, Ontario & $14 \%$ & 0.046 & 0.018 & 0.028 & 0.028 & 0.055 & 0.009 \\
\hline 9 & Building I - Ottawa, Ontario, Tower C & $14 \%$ & 0.035 & 0.014 & 0.021 & 0.021 & 0.042 & 0.007 \\
\hline 10 & Building J - Ottawa, Ontario, Tower B & $14 \%$ & 0.093 & 0.037 & 0.056 & 0.056 & 0.112 & 0.019 \\
\hline 11 & Building K - Ottawa, Ontario, Tower A & $14 \%$ & 0.037 & 0.015 & 0.022 & 0.022 & 0.045 & 0.007 \\
\hline 12 & Building L - Montreal, Quebec & $14 \%$ & 0.026 & 0.011 & 0.016 & 0.016 & 0.032 & 0.005 \\
\hline 13 & Building M - Vaudreuil-Dorion, Quebec & $14 \%$ & 0.027 & 0.011 & 0.016 & 0.016 & 0.032 & 0.005 \\
\hline 14 & Building N - Côte-St-Luc, Quebec & $14 \%$ & 0.049 & 0.019 & 0.029 & 0.029 & 0.058 & 0.010 \\
\hline 15 & Building O - Gatineau, Quebec & $14 \%$ & 0.044 & 0.017 & 0.026 & 0.026 & 0.052 & 0.009 \\
\hline
\end{tabular}

Similar calculations were completed for electricity consumption for cooling loads, gas consumption 
for heating and electricity consumption for lighting loads based on architectural features indicators for each case-study building. Calculations are summarized into tables and can be found in Appendix D.

\subsubsection{Summary for Energy Balance}

Table 3.9 and 3.10 summarizes energy consumption impacted by WWR, based on loads percentage, distribution and energy balance in GJ/year and GJ $/ \mathrm{m}^{2} /$ year.

Table 3.9: Total Energy Loads Distribution Based on WWR Indicator (GJ) Average per Year

\begin{tabular}{|c|c|c|c|c|c|c|c|c|c|c|}
\hline \multicolumn{2}{|r|}{ Loads Percentage Distribution } & & $15 \%$ & & $35 \%$ & & $15 \%$ & & $40 \%$ & \\
\hline 2 & Building B - Mississauga, Ontario & $14 \%$ & $44,558.7$ & $8 \%$ & $103,970.3$ & $100 \%$ & $12,422.6$ & $33 \%$ & $280,083.3$ & $441,034.8$ \\
\hline 3 & Building C - Toronto, Ontario & $14 \%$ & $40,160.6$ & $8 \%$ & $93,708.1$ & $100 \%$ & $23,754.4$ & $33 \%$ & $252,438.1$ & $410,061.2$ \\
\hline 4 & Building D - Mississauga, Ontario & $14 \%$ & $71,860.9$ & $8 \%$ & $167,675.4$ & $100 \%$ & $8,783.4$ & $33 \%$ & $451,697.0$ & $700,016.8$ \\
\hline 7 & Building G - Ottawa, Ontario & $14 \%$ & $49,527.2$ & $8 \%$ & $115,563.5$ & $100 \%$ & $4,794.2$ & $33 \%$ & $311,313.8$ & $481,198.7$ \\
\hline 8 & Building H - Ottawa, Ontario & $14 \%$ & $38,426.8$ & $8 \%$ & $89,662.4$ & $100 \%$ & $12,264.7$ & $33 \%$ & $241,539.6$ & $381,893.5$ \\
\hline 9 & Building I - Ottawa, Ontario, Tower C & $14 \%$ & $28,519.0$ & $8 \%$ & $66,544.3$ & $100 \%$ & 693.3 & $33 \%$ & $179,262.1$ & $275,018.6$ \\
\hline 10 & Building J - Ottawa, Ontario, Tower B & $14 \%$ & $128,554.5$ & $8 \%$ & $299,960.4$ & $100 \%$ & & $33 \%$ & $808,056.6$ & $1,236,571.5$ \\
\hline 11 & Building K - Ottawa, Ontario, Tower A & $14 \%$ & $38,385.0$ & $8 \%$ & $89,565.1$ & $100 \%$ & & $33 \%$ & $241,277.4$ & $369,227.6$ \\
\hline 12 & Building L - Montreal, Quebec & $14 \%$ & $15,530.1$ & $8 \%$ & $36,237.0$ & $100 \%$ & $2,199.5$ & $33 \%$ & $97,618.0$ & $151,584.5$ \\
\hline
\end{tabular}

Table 3.10: Total Energy Loads Distribution Based on WWR Indicator (GJ $/ \mathrm{m}^{2} /$ year)

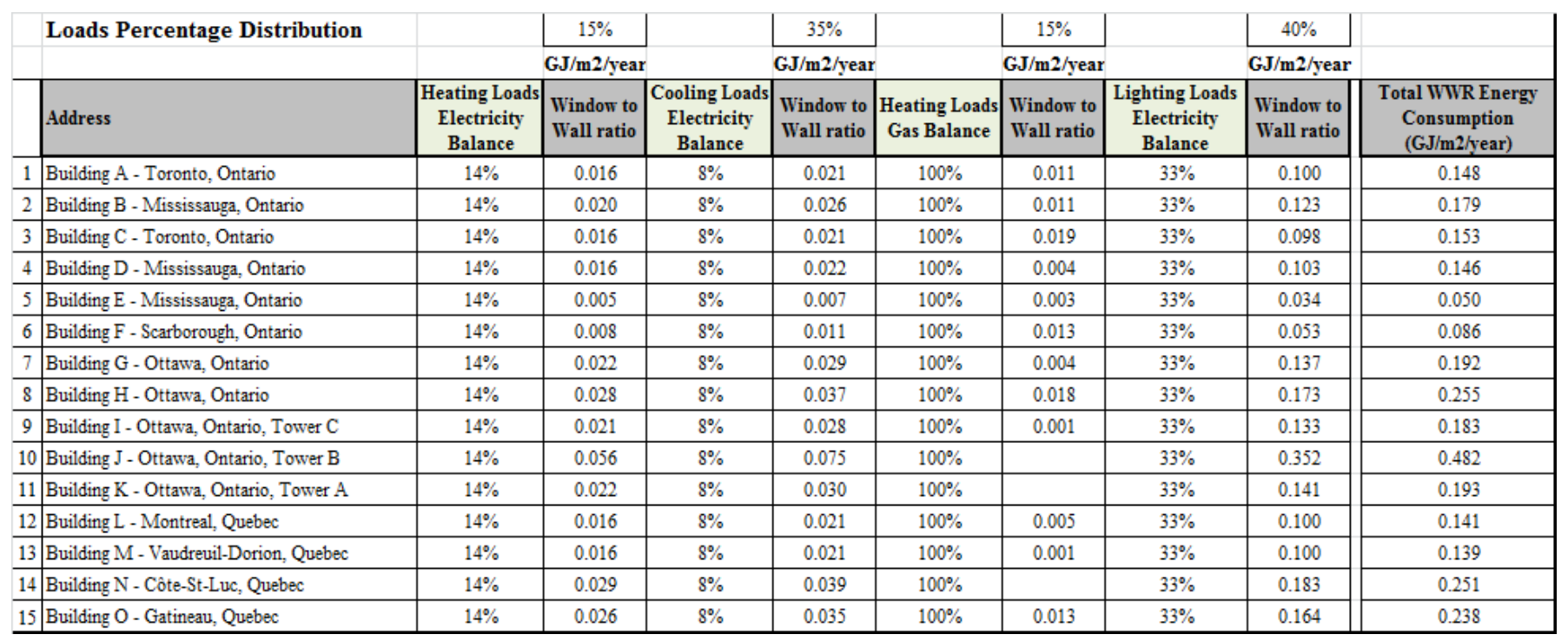


Table 3.11: WWR Percentage of Total Energy Consumption

\begin{tabular}{c|l|c|} 
& Address & $\begin{array}{c}\text { WWR \% of Total } \\
\text { Energy Consumption } \\
\text { (Normalized) }\end{array}$ \\
\hline 1 & Building A - Toronto, Ontario & $13 \%$ \\
\hline 2 & Building B - Mississauga, Ontario & $15 \%$ \\
\hline 3 & Building C - Toronto, Ontario & $11 \%$ \\
\hline 4 & Building D - Mississauga, Ontario & $13 \%$ \\
\hline 5 & Building E - Mississauga, Ontario & $11 \%$ \\
\hline 6 & Building F - Scarborough, Ontario & $8 \%$ \\
\hline 7 & Building G - Ottawa, Ontario & $16 \%$ \\
\hline 8 & Building H - Ottawa, Ontario & $13 \%$ \\
\hline 9 & Building I - Ottawa, Ontario, Tower C & $17 \%$ \\
\hline 10 & Building J - Ottawa, Ontario, Tower B & $27 \%$ \\
\hline 11 & Building K - Ottawa, Ontario, Tower A & $18 \%$ \\
\hline 12 & Building L - Montreal, Quebec & $15 \%$ \\
\hline 13 & Building M - Vaudreuil-Dorion, Quebec & $15 \%$ \\
\hline 14 & Building N - Cóte-St-Luc, Quebec & $17 \%$ \\
\hline 15 & Building O - Gatineau, Quebec & $14 \%$ \\
\hline
\end{tabular}

Table 3.11 summarizes the percentage that WWR consumes from overall building energy consumption, based on heating, cooling and lighting energy balance. The same loads percentage distribution was applied for all buildings, but based on normalized energy intensity value, electricity and gas consumption percentages vary; some buildings do not use natural gas for building operations and this also influenced calculations. As per these results, WWR impacts significant percentage of energy consumption for these case-study buildings.

\subsection{Analysis Summary}

WWR is directly related to energy intensity of existing building, however set of data calculated from fifteen case-study buildings showed very inconsistent analysis. To summarize all data in relationship to energy intensity, box plot analysis were performed. Typically box plot analysis demonstrates statistical analysis of the set of data, but in this case due to sample size bias it act more as the summary and not statistical analysis. This type of analysis was chosen as a very clear approach to demonstrate patterns of response for each category. Here the overall size of the box plot (how much it stretches on the y-axis) shows how spread out the data is. If the box itself is very short, then most of the data is huddled close together. Data in different boxes can be compared by looking at how tall or short the boxes are, and also their position relative to one another. If the boxes are roughly centered, then there is little or no difference in average or median between the data sets. If there is a shift between the boxes, then there likely is a statistically significant difference in average or median for the data sets. From tables below 
it can be concluded that all of the box plots compared are relatively similar. This implies that there is little significant difference between the data groups.

Figure 3.23 demonstrates frequency of energy intensity value, for here is can be concluded that most of the buildings have energy intensity around $1-1.25 \mathrm{GJ} / \mathrm{m}^{2} /$ year, meaning that they are relatively energy efficient building in relationship to BOMA benchmark.

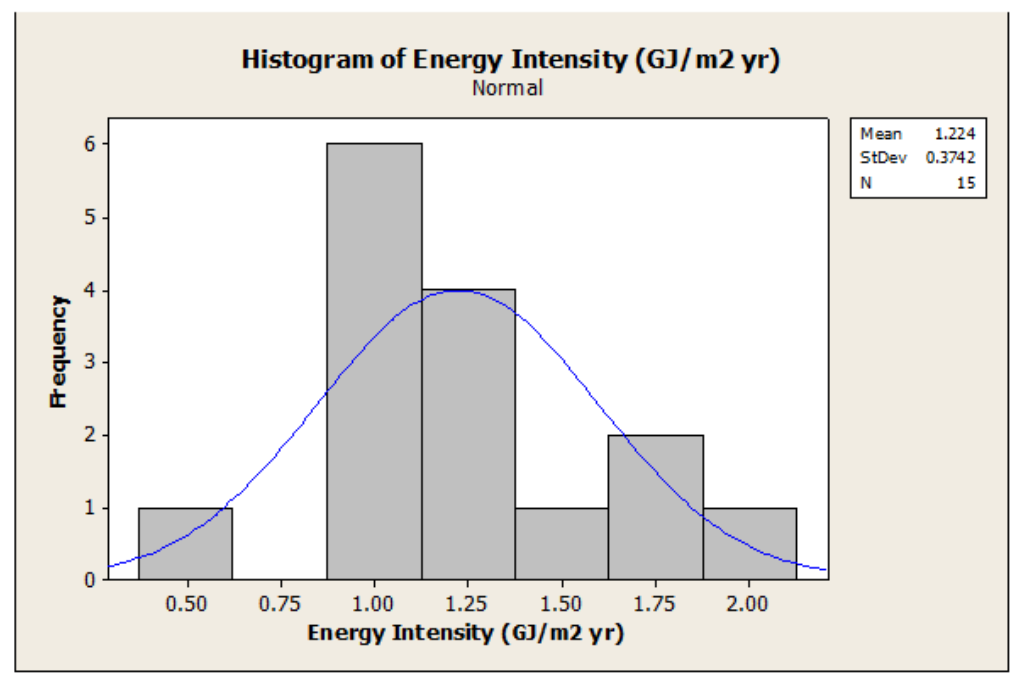

Figure 3.23: Energy Intensity Value Frequency

Figures $3.24,3.25$ and 3.26 provide boxplot analysis of all three buildings categories (shape, height and age)

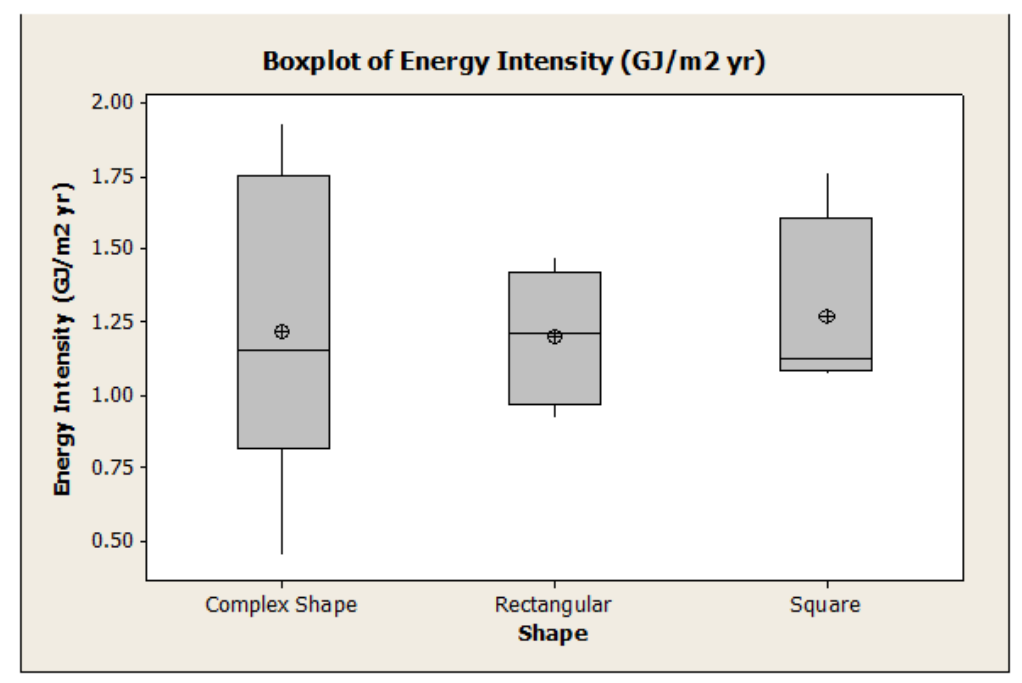

Figure 3.24: Boxplot Analysis of Buildings' Shape 


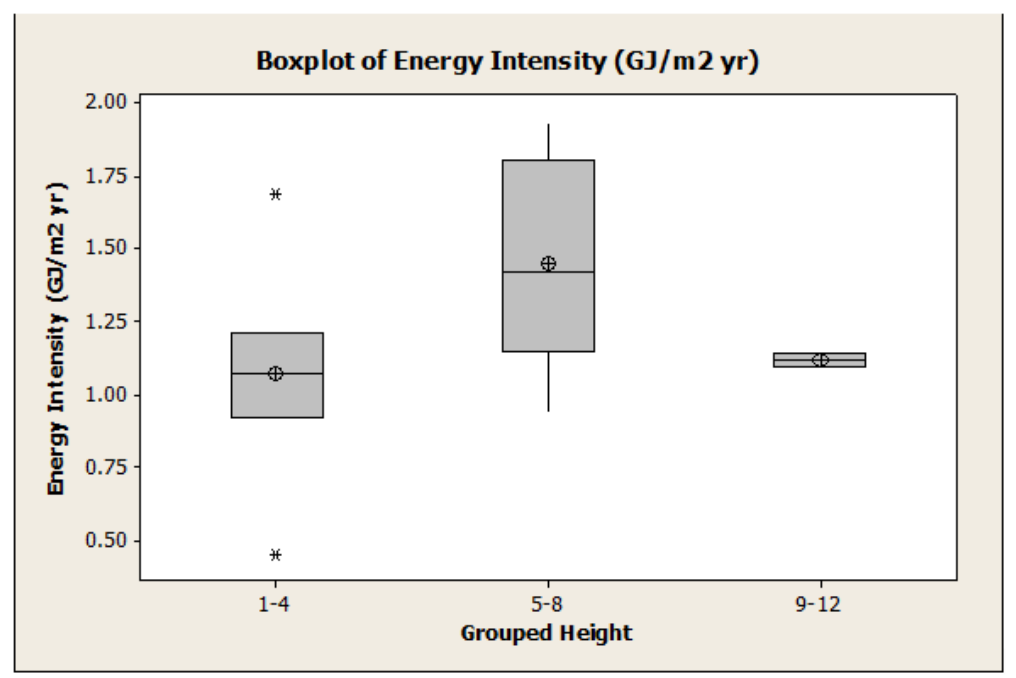

Figure 3.25: Boxplot Analysis of Buildings' Age

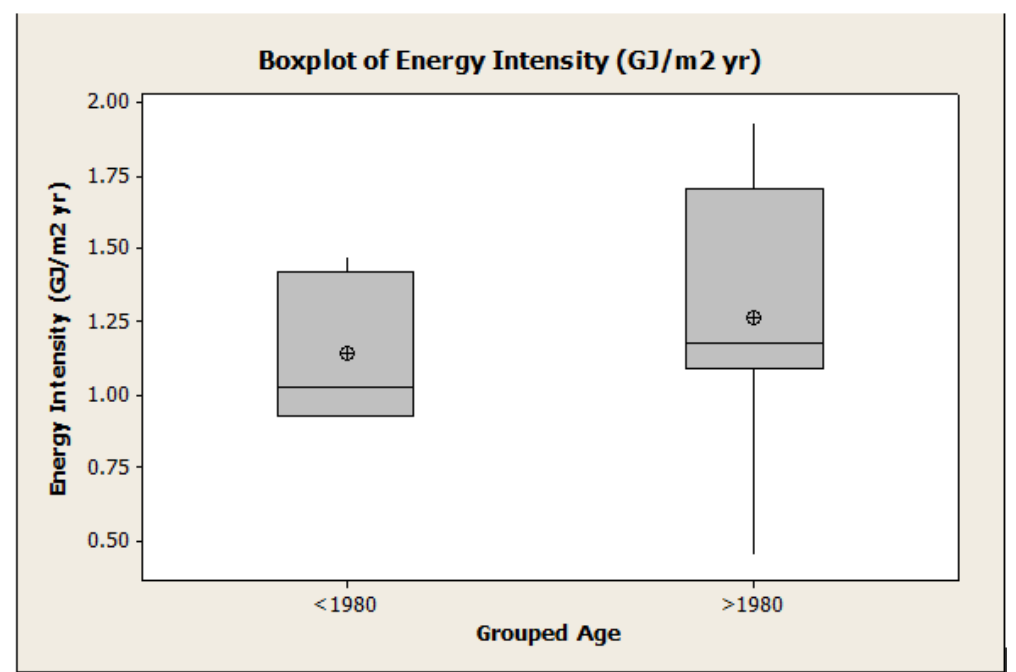

Figure 3.26: Boxplot Analysis of Buildings' Age

Case-study buildings with more complex shape and mid-rise buildings have very wide range of energy intensity data. 


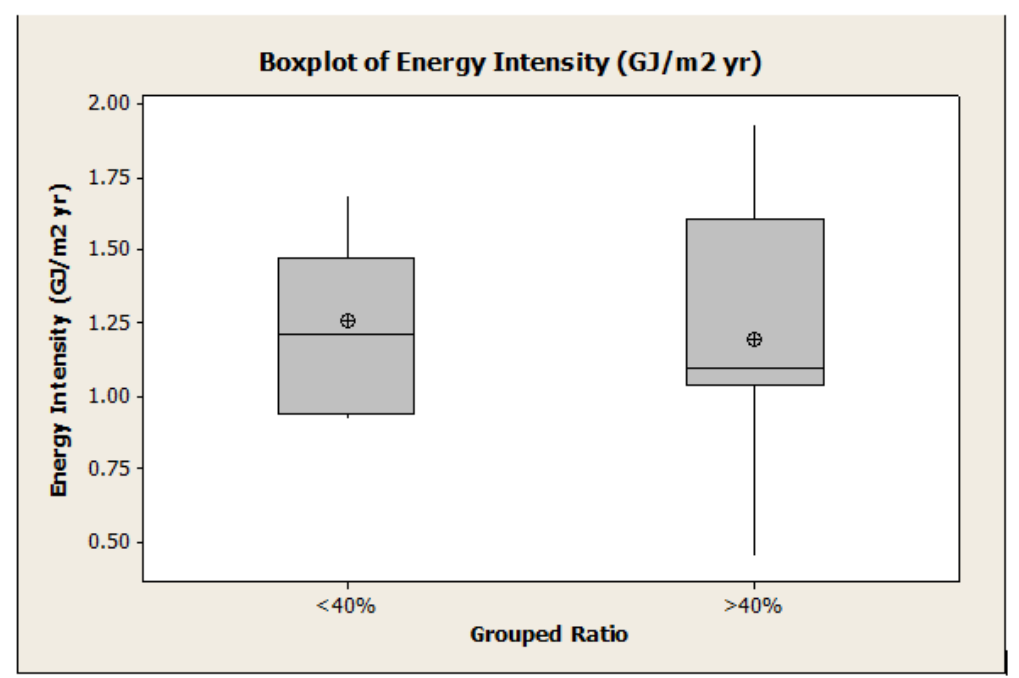

Figure 3.27: Boxplot Analysis of WWR to Energy Intensity

In addition boxplot analyses were completed to compare window-to-wall energy consumption to WWR. Essentially, Figure 31 is showing that the WWR doesn't have direct impact on the energy intensity (EI). The boxes (which are actually 2 quartiles) are almost the same size and line up almost perfectly well. This means that the middle $50 \%$ of each data set are very similar. The horizontal line inside the box is the median, or the middle value of the entire data set for each group, here they are very close to being lined up, which means the medians are very similar. The little crosshair sign at the middle is an average value; again these are lined up pretty well, so the average of each group is almost the same. Lastly, the vertical lines extending above and below the boxes each represent $25 \%$ of the data points (the lowest and highest quartile). The fact that the top lines are roughly the same size means that they upper $25 \%$ of each data set look very similar. Data $i 40 \%$ has a much longer lower quartile line, this means that there is one value that reaches all the way down to 0.50 , while the first box has a min value closer to 0.9 (there's only a little stub of a line on the first box). From boxplot analysis of energy intensity versus WWR can be concluded that regardless how inconsistent and spread-out data is, buildings with WWR of more than $40 \%$ did not show higher results in terms of energy intensity.

Following two steps, energy consumption related to WWR was analyzed in comparison to overall building energy consumption. Here data from energy balance calculations was utilized. 


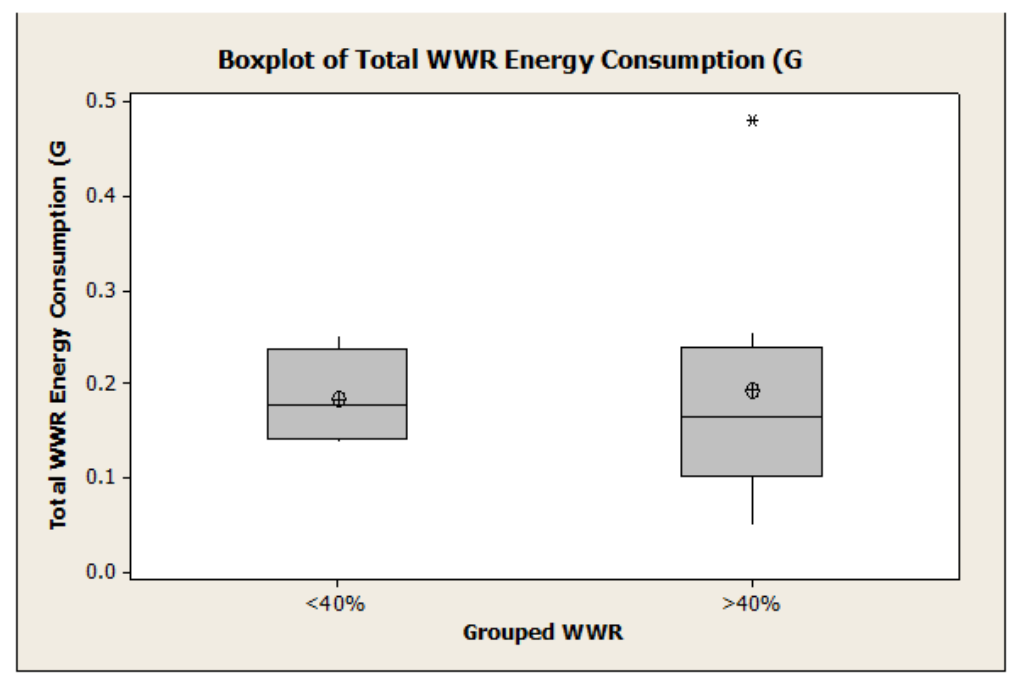

Figure 3.28: Boxplot Analysis of WWR Energy Consumption (GJ $/ \mathrm{m}^{2} /$ year) to WWR

As seen above in Figure 3.28, there is no significant difference when comparing WWR Consumption to WWR\%. Note that the boxes are roughly centered and are approximately equally sized. However, there is a little more variation in energy intensity when the WWR\% is greater than $40 \%$.

Also energy intensity was analysed in regards to WWR As seen below in Figure 3.29 , there is also no significant difference when comparing WWR Consumption to WWF:\%. The same trend of more variation in the data is seen with a W/WR 40\%, but the boxes are still centered and the same size.

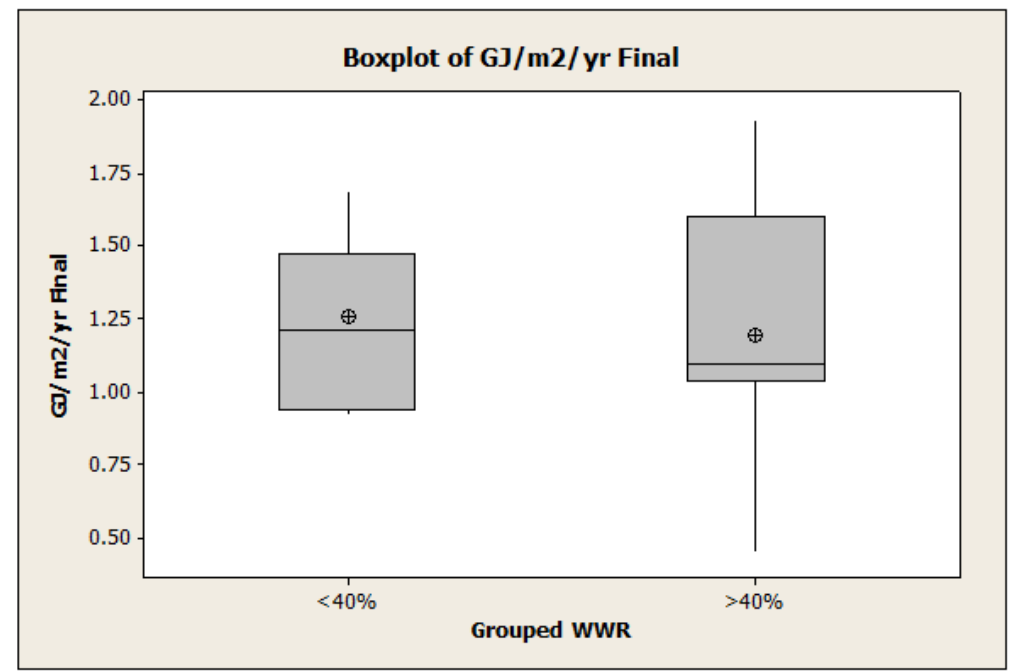

Figure 3.29: Boxplot Analysis of Energy Intensity to WWR

Lastly comparison analysis of overall buildings energy intensity to WWR energy consumption, which 
was calculated through energy balance, was performed. As shown in Figure 3.30, there is a slight positive correlation between the Overall Energy Intensity and the WWR Energy Consumption, as noted by the $\mathrm{R} 2$ value of 0.61 . This means that $61 \%$ of the variation in the data (the distance above and below the line) can be explained by normal variation. This implies that there may be other external parameters that may be affecting the data, either by themselves, or in conjunction with one another. The bubbles size shows the relative value of the WWR\%. There isn't a discernible pattern to the distribution of bubble size along the trend line. This further emphasizes the above analysis that shows WWR\% has very little correlation with either the Energy Intensity or the WWR Energy Consumption.

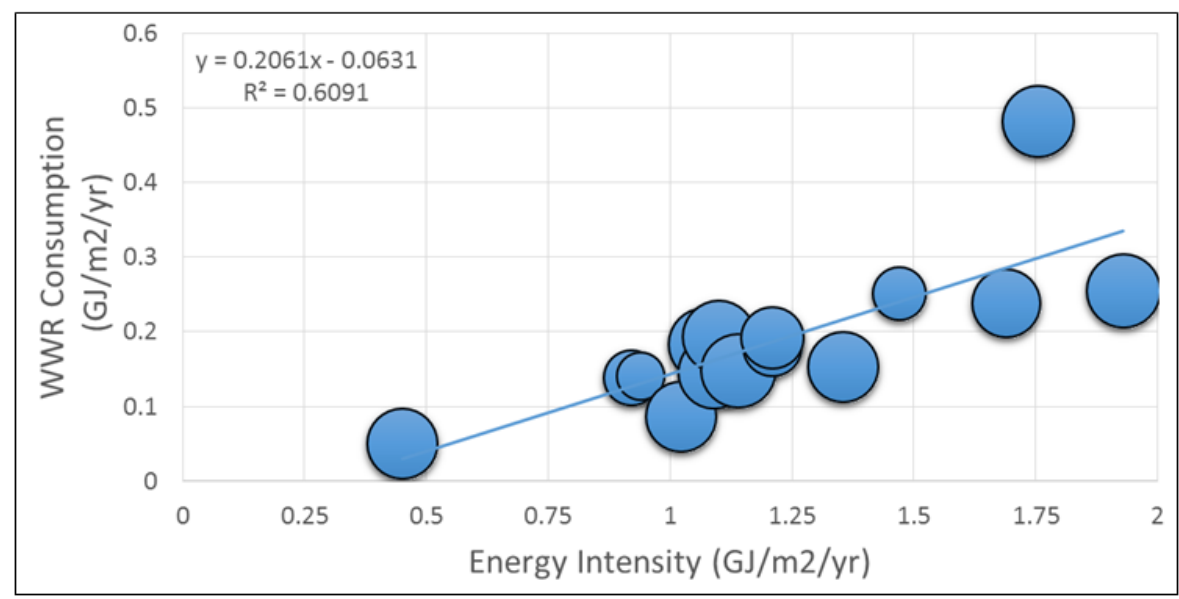

Figure 3.30: Overall Energy Intensity vs. WWR Energy Intensity

\subsection{Conclusions}

WWR is directly related to energy intensity of existing building, fifteen case-study buildings were analysed to calculate how energy intensity of existing case-study office buildings compare with averages for similar buildings, and those that would be resulting from the application of current standards. As for the energy intensity benchmark value BOMA average energy use intensity for certified Office Buildings $\left(1.05 \mathrm{GJ} / \mathrm{m}^{2} / \mathrm{yr}\right)$ was selected, and for minimum WWR benchmark SB-10 for building envelope prescriptive requirement (below 40\%). Calculations for case-study buildings showed that the building shape didnt directly influence energy intensity, however analysis based on the age of the building showed that the newer buildings are more energy efficient, and analysis on buildings height concluded that taller case study buildings have higher energy intensity, therefore energy consumption. Energy balance exercise was completed to analyse the impact of five architectural features such as number of stories, building orientation, WWR, building thermal performance and opaque wall thermal performance on energy consumption, based on energy distribution. This helped to determine the potential for energy savings in existing case-study buildings through envelope upgrades. Calculations showed that based on energy balance and energy loads distribution (as per architectural features indicators), WWR impacts 
on average $15 \%$ of overall energy consumption. By evaluation, using the energy audit (Level One) report, it is believed that it would be extremely beneficial to introduce the analysis of WWR into energy audit procedure.

However prescriptive requirements of SB-10, which is based on $40 \% \mathrm{WWR}$, are aiming for energy efficient design, but the possibility is that building's energy consumption could be even increased. If the shape of the building is complex, it is not feasible to fit it under the same standards. Energy intensity of the buildings cannot be directly related to its WWR; although $15 \%$ of energy consumption could be linked to percentage of fenestration area in relationship to wall area. 
Appendix 1

Appendix A 


\section{Building \#1 - Utility Bills Analysis}

\section{Actual data used for calculations (year with highest energy consumption):}

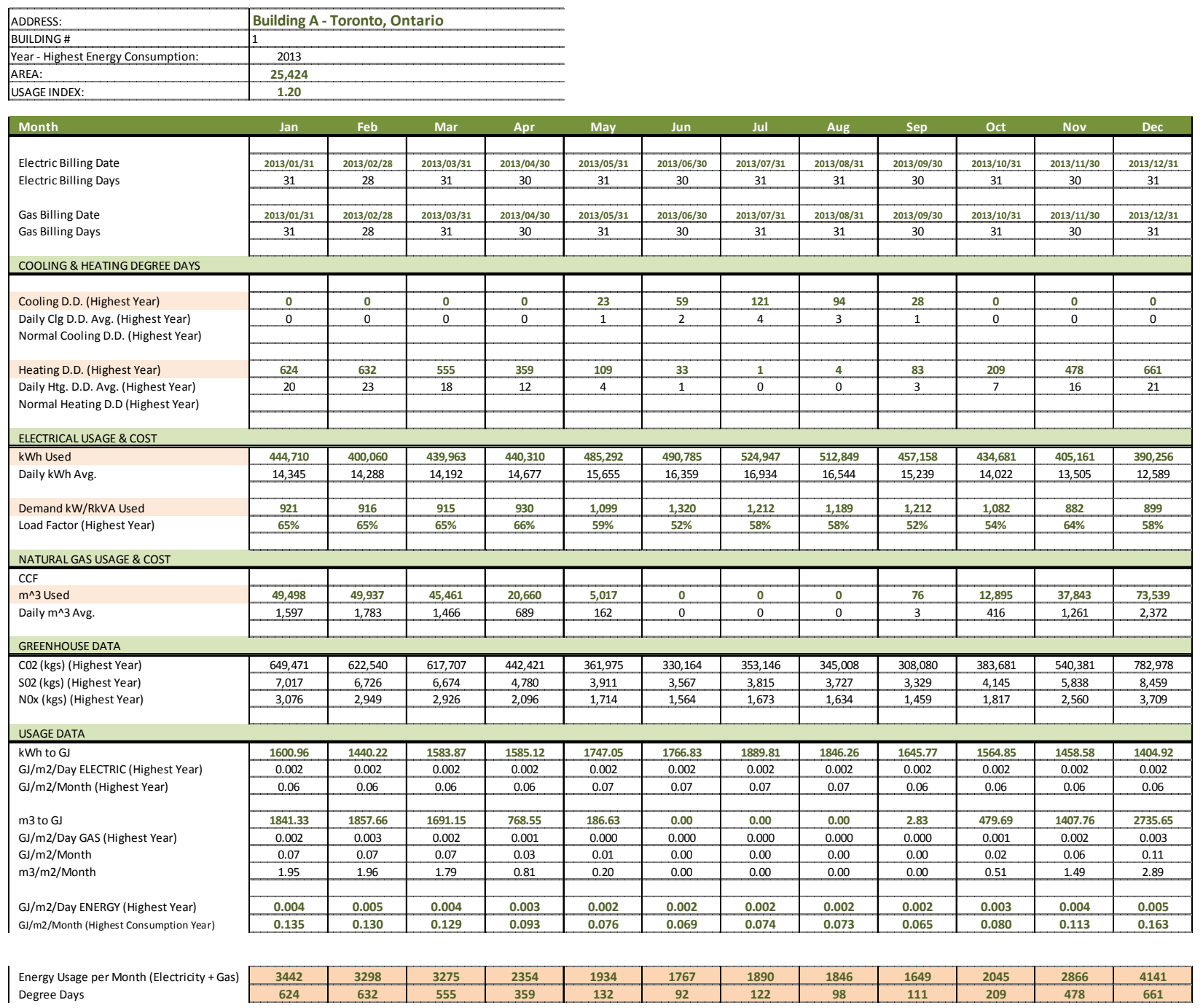




\section{Actual data used for calculations (year with lowest energy consumption):}

\begin{tabular}{|c|c|c|c|c|c|c|c|c|c|c|c|c|}
\hline ADDRESS: & \multicolumn{4}{|c|}{ Building A - Toronto, Ontario } & & & & & & & & \\
\hline BUILDING \# & \multicolumn{4}{|c|}{1} & & & & & & & & \\
\hline Year - Lowest Energy Consumption: & \multicolumn{4}{|l|}{2011} & & & & & & & & \\
\hline AREA: & \multicolumn{4}{|l|}{25,424} & & & & & & & & \\
\hline USAGE INDEX: & 1.08 & AVERAGE: & 1.14006 & 1.13999 & & & & & & & & \\
\hline Month & Jan & Feb & Mar & Apr & May & Jun & Jul & Aug & Sep & Oct & Nov & Dec \\
\hline \multirow{2}{*}{$\begin{array}{l}\text { Electric Billing Date } \\
\text { Electric Billing Days }\end{array}$} & $2011 / 01 / 31$ & $2011 / 02 / 28$ & $2011 / 03 / 31$ & $2011 / 04 / 30$ & $2011 / 05 / 31$ & $2011 / 06 / 30$ & $2011 / 07 / 31$ & $2011 / 08 / 31$ & $2011 / 09 / 30$ & $2011 / 10 / 31$ & $2011 / 11 / 30$ & $2011 / 12 / 31$ \\
\hline & 31 & 28 & 31 & 30 & 31 & 30 & 31 & 31 & 30 & 31 & 30 & 31 \\
\hline \multirow{2}{*}{$\begin{array}{l}\text { Gas Billing Date } \\
\text { Gas Billing Days }\end{array}$} & $2011 / 02 / 01$ & $2011 / 03 / 02$ & $2011 / 04 / 05$ & $2011 / 05 / 03$ & $2011 / 06 / 03$ & $2011 / 07 / 03$ & $2011 / 08 / 02$ & $2011 / 09 / 02$ & $2011 / 10 / 02$ & $2011 / 11 / 02$ & $2011 / 12 / 02$ & $2012 / 01 / 03$ \\
\hline & 31 & 29 & 34 & 28 & 31 & 30 & 30 & 31 & 30 & 31 & 30 & 32 \\
\hline \multicolumn{13}{|l|}{ COOLING \& HEATING DEGREE DAYS } \\
\hline & & & & & & & & & & & & \\
\hline \multirow{4}{*}{$\begin{array}{l}\text { Cooling D.D. (Lowest Year) } \\
\text { Daily Clg D.D. Avg. (Lowest Year) } \\
\text { Normal Cooling D.D. (Lowest Year) }\end{array}$} & 0 & 0 & 0 & 0 & 13 & 52 & 199 & 122 & 39 & 2 & 0 & 0 \\
\hline & 0 & 0 & 0 & 0 & 0 & 2 & 6 & 4 & 1 & 0 & 0 & 0 \\
\hline & & & & & & & & & & & & \\
\hline & & & & & & & & & & & & \\
\hline \multirow{4}{*}{$\begin{array}{l}\text { Heating D.D. (Lowest Year) } \\
\text { Daily Htg. D.D. Avg. (Lowest Year) } \\
\text { Normal Heating D.D (Lowest Year) }\end{array}$} & 775 & 654 & 573 & 332 & 134 & 19 & 0 & 0 & 48 & 235 & 342 & 518 \\
\hline & 25 & 23 & 17 & 12 & 4 & 1 & 0 & 0 & 2 & 8 & 11 & 16 \\
\hline & & & & & & & & & & & & \\
\hline & & & & & & & & & & & & \\
\hline \multicolumn{13}{|l|}{ ELECTRICAL USAGE \& COST } \\
\hline \multirow{3}{*}{$\begin{array}{l}\text { kWh Used } \\
\text { Daily kWh Avg. }\end{array}$} & 419,798 & 394,149 & 443,891 & 405,758 & 402,198 & 487,192 & 534,864 & 522,070 & 492,117 & 439,272 & 456,542 & 470,760 \\
\hline & 13,542 & 13,591 & 13,056 & 14,491 & 12,974 & 16,240 & 17,829 & 16,841 & 16,404 & 14,170 & 15,218 & 14,711 \\
\hline & & & & & & & & & & & & \\
\hline \multirow{3}{*}{$\begin{array}{l}\text { Demand kW/RkVA Used } \\
\text { Load Factor (Lowest Year) }\end{array}$} & 943 & 976 & 960 & 1,053 & 1,211 & 1,279 & 1,371 & 1,227 & 1,166 & 1,135 & 1,126 & 1,000 \\
\hline & $60 \%$ & $60 \%$ & $62 \%$ & $54 \%$ & $45 \%$ & $53 \%$ & $52 \%$ & $57 \%$ & $59 \%$ & $52 \%$ & $56 \%$ & $63 \%$ \\
\hline & \multicolumn{12}{|c|}{ NATURAL GAS USAGE \& COST } \\
\hline \multicolumn{13}{|l|}{ CCF } \\
\hline $\mathrm{m}^{\wedge} 3$ Used & 56,050 & 44,600 & 38,217 & 19,569 & 0 & 0 & 0 & 0 & 0 & 1,972 & 164 & 48,498 \\
\hline Daily $\mathrm{m}^{\wedge} 3$ Avg. & 1,808 & 1,538 & 1,124 & 699 & 0 & 0 & 0 & 0 & 0 & 64 & 5 & 1,516 \\
\hline & & & & & & & & & & & & \\
\hline GREENHOUSE DATA & & & & & & & & & & & & \\
\hline C02 (kgs) (Lowest Year) & 679,081 & 580,793 & 569,083 & 411,456 & 270,570 & 327,748 & 359,818 & 351,211 & 331,061 & 309,466 & 308,289 & 659,918 \\
\hline S02 (kgs) (Lowest Year) & 7,337 & 6,275 & 6,148 & 4,445 & 2,923 & 3,541 & 3,887 & 3,794 & 3,577 & 3,343 & 3,331 & 7,130 \\
\hline NOx (kgs) (Lowest Year) & 3,216 & 2,751 & 2,695 & 1,949 & 1,282 & 1,552 & 1,704 & 1,664 & 1,568 & 1,466 & 1,460 & 3,126 \\
\hline & & & & & & & & & & & & \\
\hline USAGE DATA & & & & & & & & & & & & \\
\hline kWh to GJ & 1511.27 & 1418.94 & 1598.01 & 1460.73 & 1447.91 & 1753.89 & 1925.51 & 1879.45 & 1771.62 & 1581.38 & 1643.55 & 1694.74 \\
\hline GJ/m2/Day ELECTRIC (Lowest Year) & 0.002 & 0.002 & 0.002 & 0.002 & 0.002 & 0.002 & 0.002 & 0.002 & 0.002 & 0.002 & 0.002 & 0.002 \\
\hline GJ/m2/Month (Lowest Year) & 0.06 & 0.06 & 0.06 & 0.06 & 0.06 & 0.07 & 0.08 & 0.07 & 0.07 & 0.06 & 0.06 & 0.07 \\
\hline & & & & & & & & & & & & \\
\hline $\mathrm{m} 3$ to $\mathrm{GJ}$ & 2085.06 & 1659.12 & 1421.67 & 727.97 & 0.00 & 0.00 & 0.00 & 0.00 & 0.00 & 73.36 & 6.10 & 1804.13 \\
\hline GJ/m2/Day GAS (Lowest Year) & 0.003 & 0.002 & 0.002 & 0.001 & 0.000 & 0.000 & 0.000 & 0.000 & 0.000 & 0.000 & 0.000 & 0.002 \\
\hline $\mathrm{GJ} / \mathrm{m} 2 /$ Month & 0.08 & 0.07 & 0.06 & 0.03 & 0.00 & 0.00 & 0.00 & 0.00 & 0.00 & 0.00 & 0.00 & 0.07 \\
\hline $\mathrm{m} 3 / \mathrm{m} 2 /$ Month & 2.20 & 1.75 & 1.50 & 0.77 & 0.00 & 0.00 & 0.00 & 0.00 & 0.00 & 0.08 & 0.01 & 1.91 \\
\hline GJ/m2/Day ENERGY (Lowest Year) & 0.005 & 0.004 & 0.004 & 0.003 & 0.002 & 0.002 & 0.002 & 0.002 & 0.002 & 0.002 & 0.002 & 0.004 \\
\hline $\mathrm{GJ} / \mathrm{m} 2 /$ Month (Lowest Consumption Year) & 0.141 & 0.121 & 0.119 & 0.086 & 0.057 & 0.069 & 0.076 & 0.074 & 0.070 & 0.065 & 0.065 & 0.138 \\
\hline Average Highest Year to Lowest Year & 0.138 & 0.125 & 0.124 & 0.089 & 0.067 & 0.069 & 0.075 & 0.073 & 0.067 & 0.073 & 0.089 & 0.150 \\
\hline BOMA Mean Value per Month & 0.111 & 0.111 & 0.111 & 0.111 & 0.111 & 0.111 & 0.111 & 0.111 & 0.111 & 0.111 & 0.111 & 0.111 \\
\hline Energy Usage per Month (Electricity + Gas) & 3596 & 3078 & 3020 & 2189 & 1448 & 1754 & 1926 & 1879 & 1772 & 1655 & 1650 & 3499 \\
\hline Degree Days & 775 & 654 & 573 & 332 & 147 & 71 & 199 & 122 & 87 & 238 & 342 & 518 \\
\hline Normalized Data (Average Degree Days) & 700 & 643 & 564 & 345 & 140 & 82 & 160 & 110 & 99 & 223 & 410 & 589 \\
\hline Normalized Data (Av Energy Consumption) & 3561 & 3380 & 3129 & 2436 & 1783 & 1599 & 1849 & 1690 & 1655 & 2049 & 2641 & 3210 \\
\hline Normalized Data (Av Energy Index / month) & 0.140 & 0.133 & 0.123 & 0.096 & 0.070 & 0.063 & 0.073 & 0.066 & 0.065 & 0.081 & 0.104 & 0.126 \\
\hline
\end{tabular}


Analysis on how electricity and gas consumption corresponds to heating and cooling periods (for highest energy consumption year):

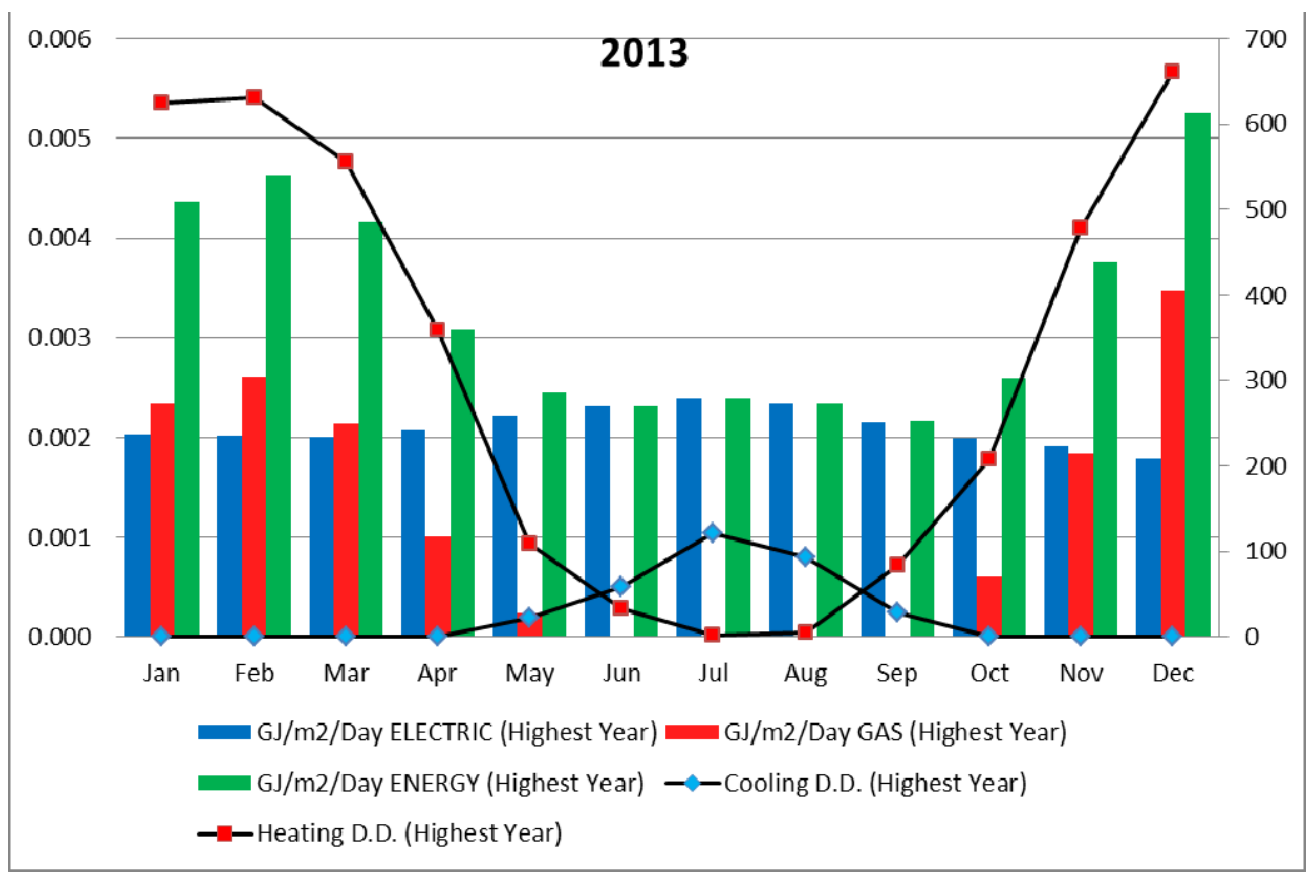

Analysis on how electricity and gas consumption corresponds to heating and cooling periods (for lowest energy consumption year):

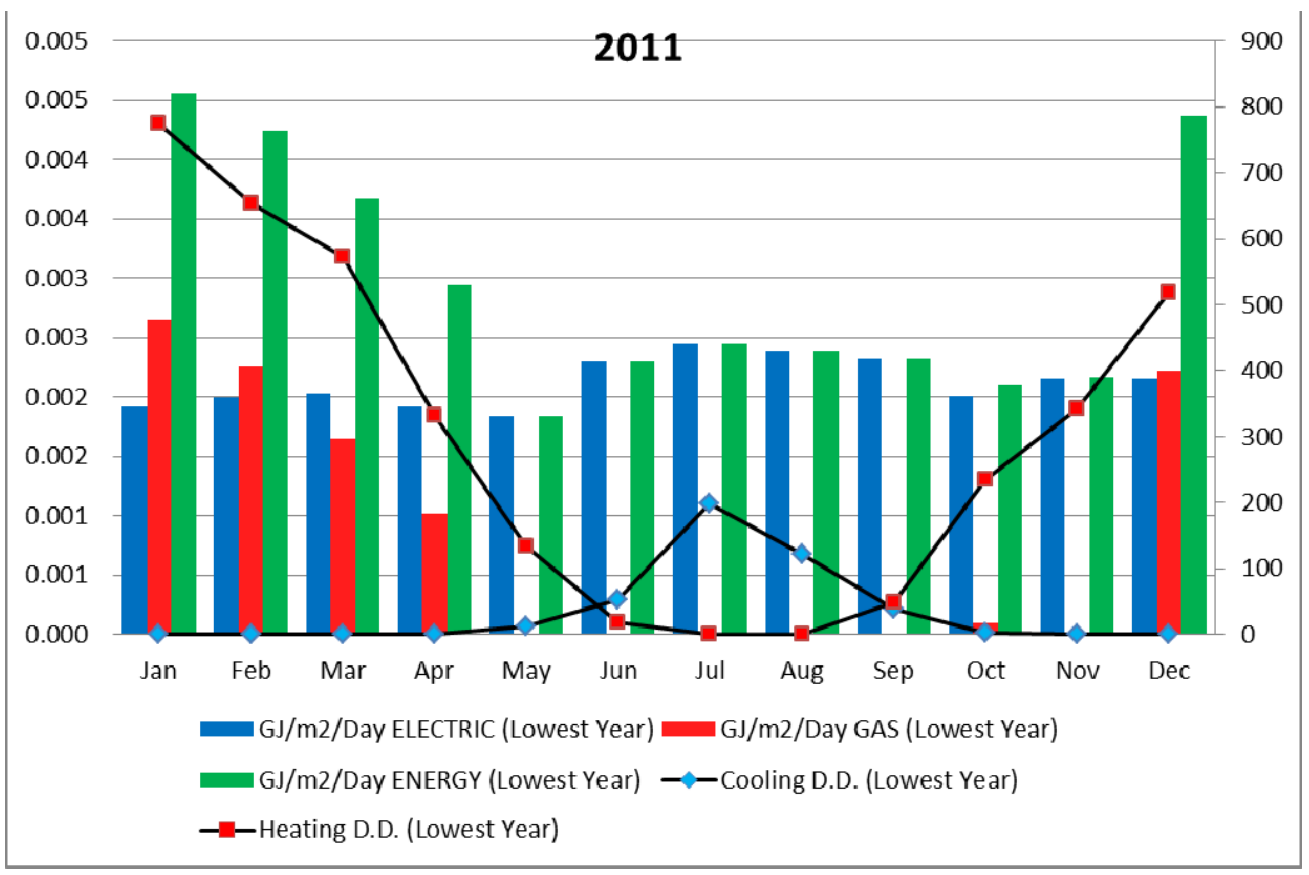


Monthly energy index comparison between highest energy consumption year, lowest, average and benchmark (BOMA) energy intensity:

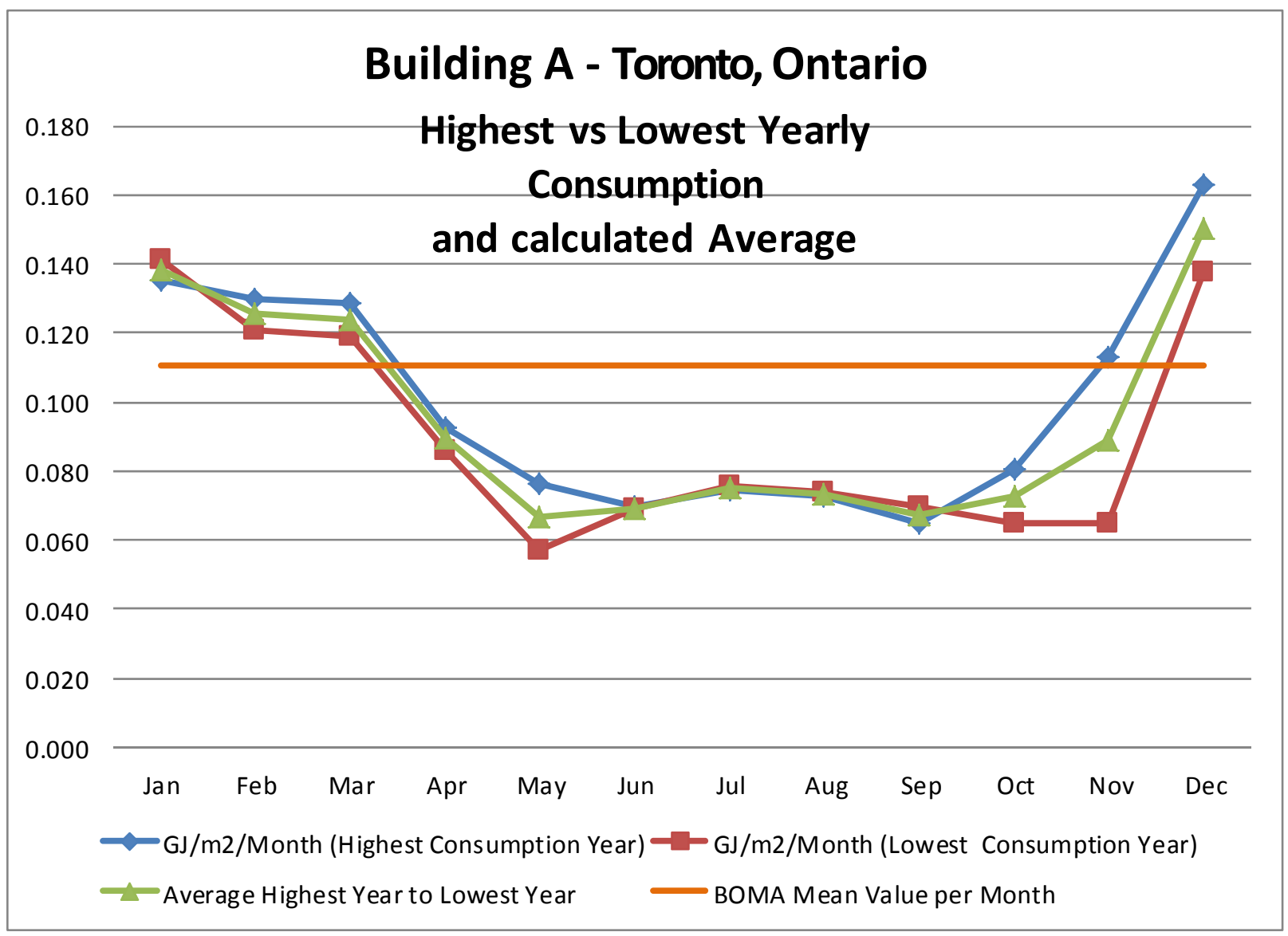


Building \#2 - Utility Bills Analysis

\section{Calculations for Energy Index for Building \#2}

Similar procedure as was utilized for Building \#1 was done for Building \#2. Energy CAP database was utilized to collect energy consumption information for the building. Energy consumption was provided by utility bills for electricity and gas. For Building \#2 utility bills were provided from December 2006 to March 2015. Summarized yearly data showed relatively consistent values except gas consumption for 2014 year, this is could have been due to additional equipment installation after energy audit proposal. Therefore 2014 total energy consumption was not included in average energy index calculations. By having total floor area of 8,225 $\mathrm{m}^{2}$ energy index was calculated in $\mathrm{GJ} / \mathrm{m}^{2} / \mathrm{yr}$.

Utility bills analysis showed following:

\begin{tabular}{|c|c|c|c|c|c|c|c|c|}
\hline \multicolumn{6}{|c|}{ Building B - Mississauga, Ontario } & \multirow[b]{2}{*}{$\mathrm{m}^{3}$-ngas } & \multirow[b]{2}{*}{ Total GJ/yr } & \multirow[b]{2}{*}{$8,225.00$} \\
\hline & & & kWh & & & & & \\
\hline Row Labels & \multicolumn{2}{|c|}{$\begin{array}{c}\text { Sum of Ele Total } \\
\text { Cost / Year }\end{array}$} & $\begin{array}{c}\text { Sum of Ele } \\
\begin{array}{c}\text { Consumption / } \\
\text { Year }\end{array}\end{array}$ & \multicolumn{2}{|c|}{$\begin{array}{c}\text { Sum of Gas Total } \\
\text { Cost / Year }\end{array}$} & $\begin{array}{c}\text { Sum of Gas } \\
\text { Consumption } \\
\text { / Year }\end{array}$ & Total & $\mathrm{GJ} / \mathrm{m} 2 / \mathrm{yr}$ \\
\hline Year 2006 & $\$$ & $20,177.03$ & $190,800.00$ & $\$$ & $2,536.39$ & $4,853.00$ & & \\
\hline Year 2007 & $\$$ & $220,341.47$ & $1,992,960.00$ & $\$$ & $27,691.10$ & $54,442.00$ & $9,199.90$ & 1.12 \\
\hline Year 2008 & $\$$ & $202,864.43$ & $2,147,040.00$ & $\$$ & $26,571.55$ & $52,367.00$ & $9,677.40$ & 1.18 \\
\hline Year 2009 & $\$$ & $198,438.54$ & $1,992,960.00$ & $\$$ & $23,774.25$ & $47,032.00$ & $8,924.25$ & 1.09 \\
\hline Year 2010 & $\$$ & $230,118.15$ & $2,039,760.00$ & $\$$ & $40,845.86$ & $81,291.00$ & $10,367.16$ & 1.26 \\
\hline Year 2011 & $\$$ & $246,250.71$ & $2,095,217.28$ & $\$$ & $44,531.43$ & $92,998.00$ & $11,002.31$ & 1.34 \\
\hline Year 2012 & $\$$ & $248,670.86$ & $2,033,280.00$ & $\$$ & $15,918.09$ & $62,255.00$ & $9,635.69$ & 1.17 \\
\hline Year 2013 & $\$$ & $292,958.48$ & $2,157,840.00$ & $\$$ & $16,921.91$ & $64,682.00$ & $10,174.39$ & 1.24 \\
\hline Year 2014 & $\$$ & $336,096.60$ & $2,412,000.00$ & $\$$ & $48,195.47$ & $141,235.00$ & $13,937.14$ & 1.69 \\
\hline Year 2015 & $\$$ & $86,020.69$ & $606,240.00$ & $\$$ & $24,990.54$ & $70,886.00$ & & \\
\hline Average & $\$$ & $246,967.41$ & $2,121,842.88$ & $\$$ & $30,556.21$ & $82,817.17$ & & 1.20 \\
\hline
\end{tabular}

Similarly to energy audit conclusion that energy consumption of the building is moderately high in comparison to similar office buildings in same region; energy index value showed high results as well in comparison to BOMA energy efficient building value of $1.05 \mathrm{GJ} / \mathrm{m}^{2} / \mathrm{yr}$ or but lower than average National Resources Canada value of $1.43 \mathrm{GJ} / \mathrm{m}^{2} / \mathrm{yr}$.

Two charts below show electricity and gas consumption per year for Building \#2. Electricity consumption chart demonstrates steady but not very prominent increase in energy usage; however 2014 shows the highest value. But because 2014 will not be used for further calculations due to inconsistency, therefore 2013 considered as 
the highest value. Gas consumption chart show values that vary a lot from year to year, there is prominent decrease in gas consumption in 2012 and 2013, but because 2014 data is very inconsistent it's not reasonable to conclude that gas consumption of the Building \#2 decreasing and more efficient. Another assumption can be made that 2014 gas utility bills data actually contains partial gas consumption from 2012 and 2013, but from utility bills information this cannot be confirmed.
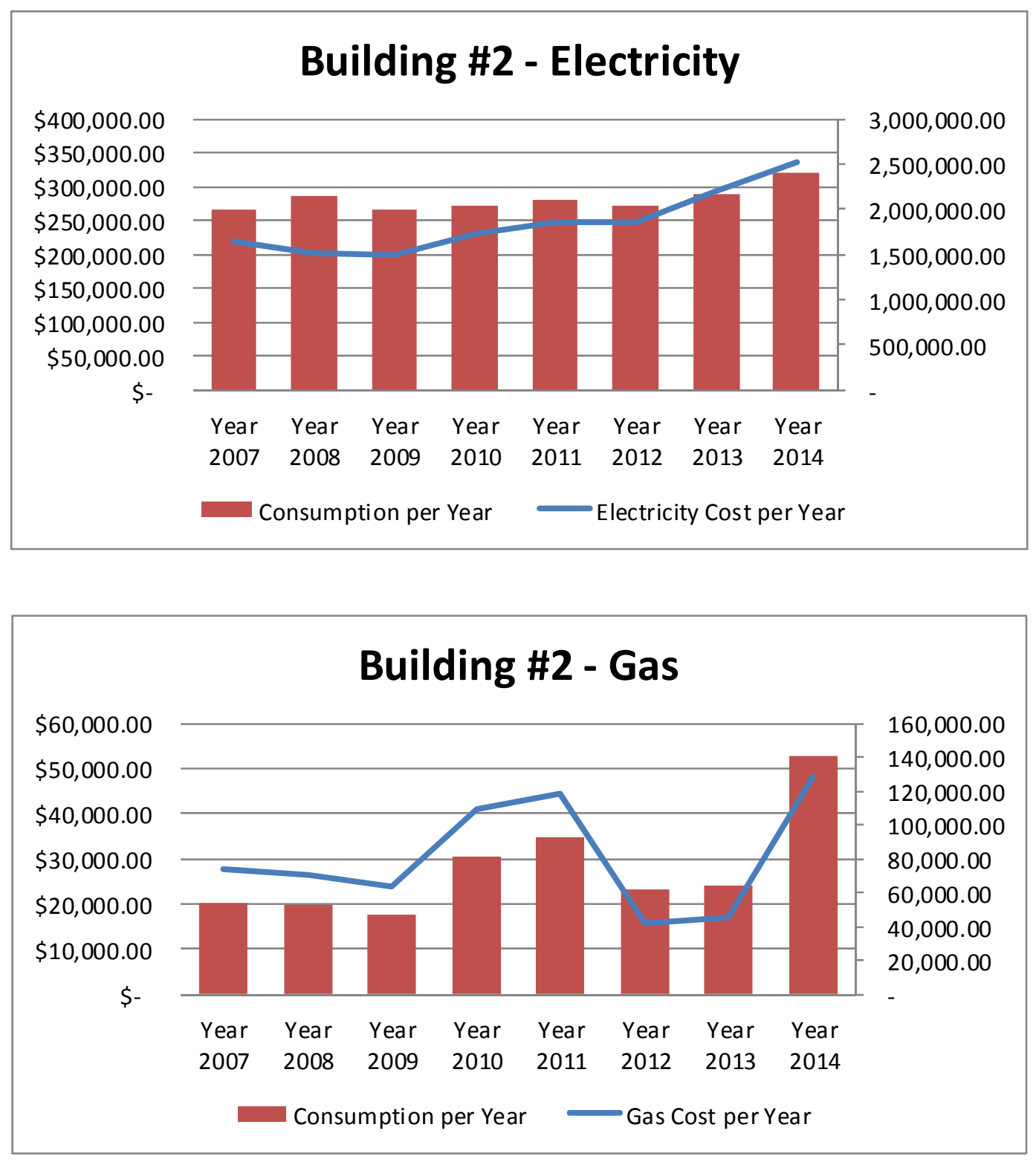
Yearly energy intensity (index) was also plotted to demonstrate increase or decrease over the range of years for which data is available. Chart below shows that energy index value is fluctuating. The lowest energy index was in 2009 and highest in 2011. These two years' data will be used for further calculations and comparisons.

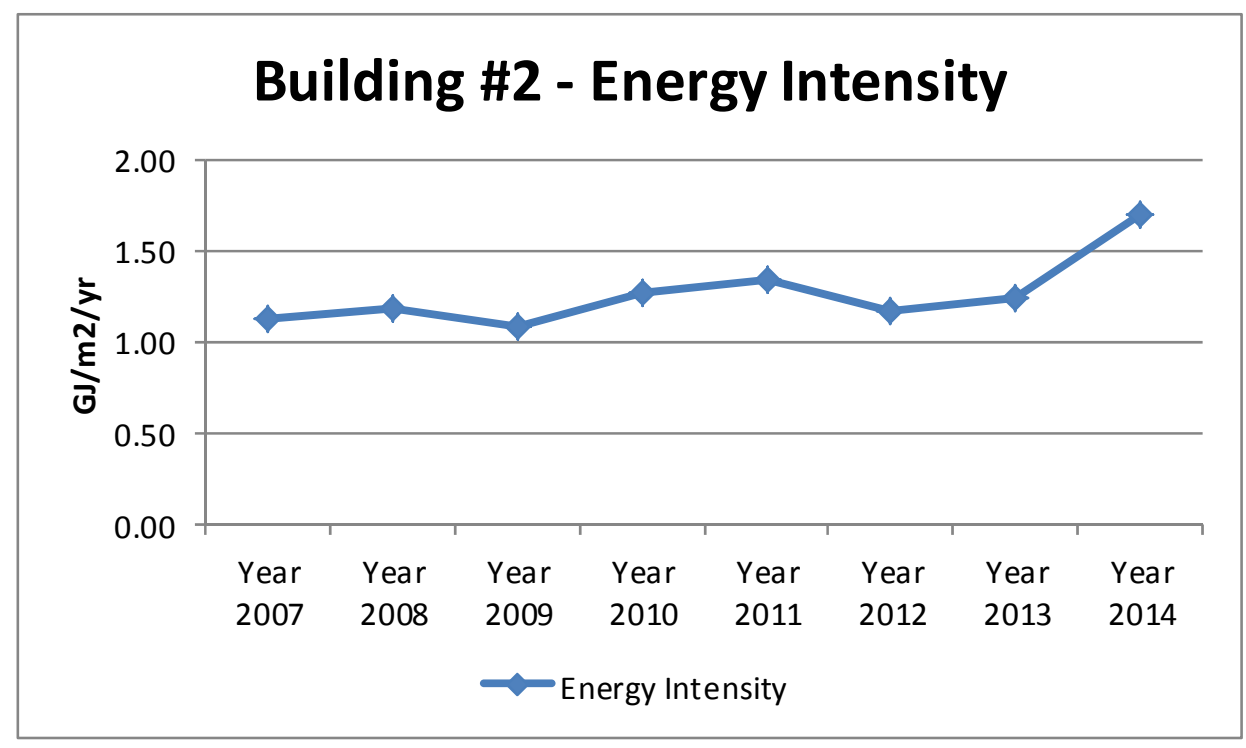

Normalized total energy consumption was calculated for Building \#2 for 2011 and 2009 as they represent highest and lowest energy consumption respectively. Based on plotted results, shown below in the chart, it can be concluded that energy consumption for 2011 is higher than for 2009. This proves that regardless of weather conditions 2011 has higher energy consumptions than in 2009. Implementing trendline equations, average equation was calculated:

\section{$\gamma=1.2214 x+4.8,575$}

From above equation normalized average energy index was calculated as $1.21 \mathrm{GJ} / \mathrm{m}^{2} / \mathrm{yr}$, this value is slightly higher than average for 2007 to 2014 years range. Calculated value will be used for further case-study buildings comparison. 


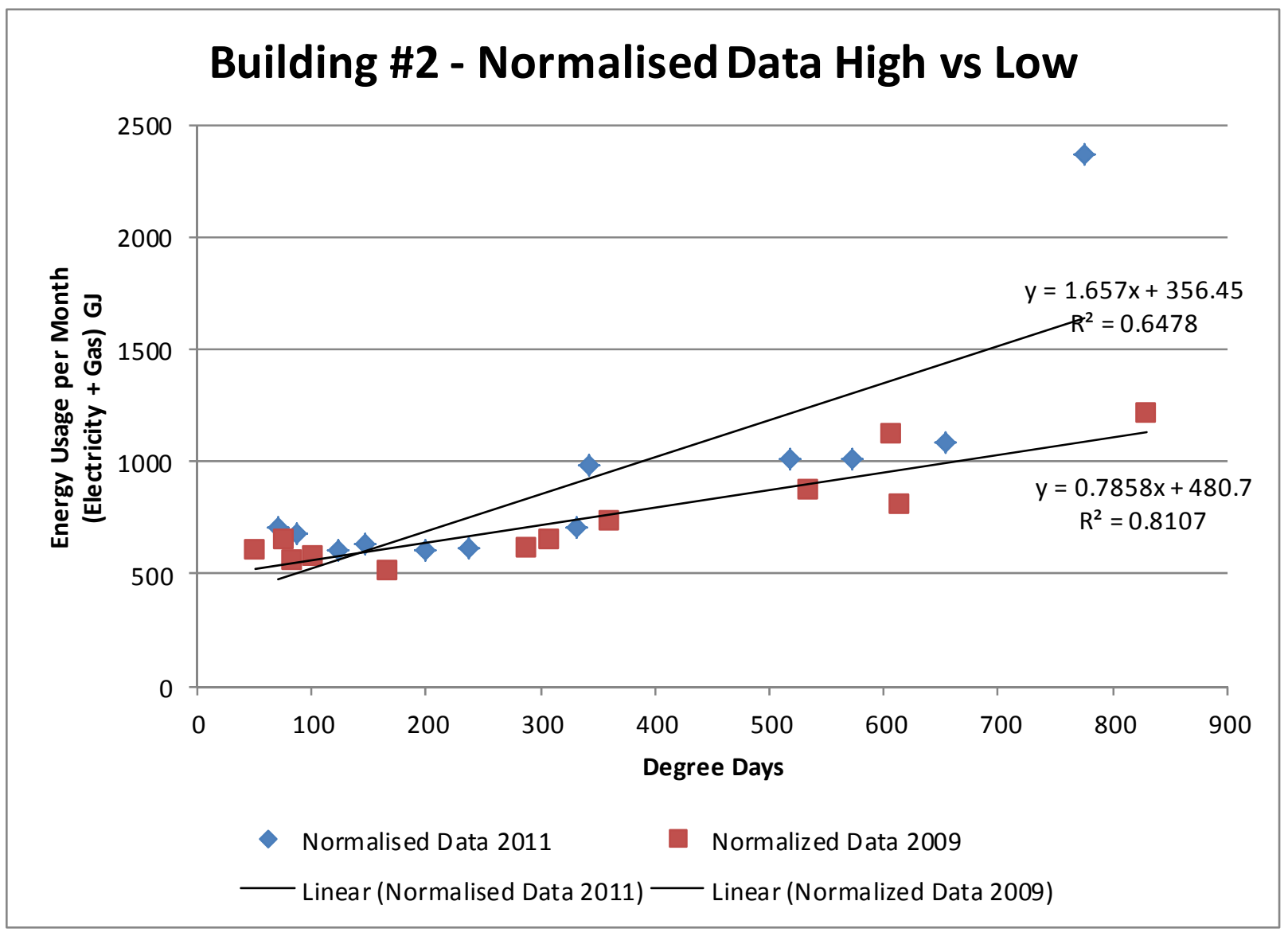


Actual data used for calculations (year with highest energy consumption):

\begin{tabular}{|c|c|c|c|c|c|c|c|c|c|c|c|c|}
\hline ADDRESS: & \multicolumn{4}{|c|}{ Building B - Mississauga, Ontario } & & & & & & & & \\
\hline BUILDING\# & \multicolumn{4}{|c|}{2} & & & & & & & & \\
\hline Year - Highest Energy Consumption: & \multicolumn{4}{|l|}{2011} & & & & & & & & \\
\hline AREA: & \multicolumn{4}{|l|}{8,225} & & & & & & & & \\
\hline USAGE INDEX: & \multicolumn{4}{|l|}{1.34} & & & & & & & & \\
\hline Month & Jan & Feb & Mar & Apr & May & Jun & Jul & Aug & Sep & Oct & Nov & Dec \\
\hline \multirow{2}{*}{$\begin{array}{l}\text { Electric Billing Date } \\
\text { Electric Billing Days }\end{array}$} & $2011 / 02 / 03$ & $2011 / 03 / 03$ & $2011 / 04 / 01$ & $2011 / 05 / 03$ & $2011 / 06 / 02$ & $2011 / 07 / 06$ & $2011 / 08 / 04$ & $2011 / 09 / 01$ & $2011 / 10 / 04$ & $2011 / 11 / 02$ & $2011 / 12 / 02$ & $2012 / 01 / 03$ \\
\hline & 31 & 28 & 29 & 32 & 30 & 34 & 29 & 28 & 33 & 29 & 30 & 32 \\
\hline \multirow{2}{*}{$\begin{array}{l}\text { Gas Billing Date } \\
\text { Gas Billing Days }\end{array}$} & $2011 / 02 / 04$ & 2011/03/03 & 2011/04/04 & $2011 / 05 / 04$ & 2011/06/06 & 2011/07/06 & 2011/08/05 & $2011 / 09 / 06$ & $2011 / 10 / 04$ & $2011 / 11 / 02$ & $2011 / 12 / 05$ & $2012 / 01 / 03$ \\
\hline & 31 & 27 & 32 & 30 & 33 & 30 & 30 & 32 & 28 & 29 & 33 & 29 \\
\hline \multicolumn{13}{|l|}{ COOLING \& HEATING DEGREE DAYS } \\
\hline & & & & & & & & & & & & \\
\hline \multirow{4}{*}{$\begin{array}{l}\text { Cooling D.D. (Highest Year) } \\
\text { Daily Clg D.D. Avg. (Highest Year) } \\
\text { Normal Cooling D.D. (Highest Year) }\end{array}$} & 0 & 0 & 0 & 0 & 13 & 52 & 199 & 122 & 39 & 2 & 0 & 0 \\
\hline & 0 & 0 & 0 & 0 & 0 & 2 & 7 & 4 & 1 & 0 & 0 & 0 \\
\hline & & & & & & & & & & & & \\
\hline & & & & & & & & & & & & \\
\hline \multirow{4}{*}{$\begin{array}{l}\text { Heating D.D. (Highest Year) } \\
\text { Daily Htg. D.D. Avg. (Highest Year) } \\
\text { Normal Heating D.D (Highest Year) }\end{array}$} & 775 & 654 & 573 & 332 & 134 & 19 & 0 & 0 & 48 & 235 & 342 & 518 \\
\hline & 25 & 24 & 18 & 11 & 4 & 1 & 0 & 0 & 2 & 8 & 10 & 18 \\
\hline & & & & & & & & & & & & \\
\hline & & & & & & & & & & & & \\
\hline \multicolumn{13}{|l|}{ ELECTRICAL USAGE \& COST } \\
\hline \multirow{2}{*}{$\begin{array}{l}\text { kWh Used } \\
\text { Daily kWh Avg. }\end{array}$} & 216,000 & 184,320 & 163,440 & 163,440 & 154,405 & 193,193 & 169,324 & 152,168 & 177,529 & 151,422 & 173,799 & 196,177 \\
\hline & 6,968 & 6,827 & 5,108 & 5,448 & 4,679 & 6,440 & 5,644 & 4,755 & 6,340 & 5,221 & 5,267 & 6,765 \\
\hline & & & & & & & & & & & & \\
\hline Demand kW/RkVA Used & 396 & 401 & 335 & 335 & 330 & 338 & 354 & 354 & 354 & 315 & 401 & 412 \\
\hline \multirow[t]{2}{*}{ Load Factor (Highest Year) } & $73 \%$ & $68 \%$ & $70 \%$ & $64 \%$ & $65 \%$ & $70 \%$ & $69 \%$ & $64 \%$ & $63 \%$ & $69 \%$ & $60 \%$ & $62 \%$ \\
\hline & & & & & & & & & & & & \\
\hline \multicolumn{13}{|l|}{ NATURAL GAS USAGE \& COST } \\
\hline \multicolumn{13}{|l|}{ CCF } \\
\hline $\mathrm{m}^{\wedge} 3$ Used & 42,616 & 11,280 & 11,273 & 3,215 & 2,157 & 182 & 0 & 1,510 & 1,027 & 1,870 & 9,699 & 8,169 \\
\hline \multirow{2}{*}{ Daily $\mathrm{m}^{\wedge} 3$ Avg. } & 1,375 & 418 & 352 & 107 & 65 & 6 & 0 & 47 & 37 & 64 & 294 & 282 \\
\hline & & & & & & & & & & & & \\
\hline GREENHOUSE DATA & & & & & & & & & & & & \\
\hline C02 (kgs) (Highest Year) & 446,906 & 203,827 & 189,731 & 132,703 & 119,138 & 131,254 & 113,909 & 113,054 & 126,697 & 115,100 & 185,560 & 189,786 \\
\hline S02 (kgs) (Highest Year) & 4,828 & 2,202 & 2,050 & 1,434 & 1,287 & 1,418 & 1,231 & 1,221 & 1,369 & 1,244 & 2,005 & 2,050 \\
\hline NOx (kgs) (Highest Year) & 2,117 & 965 & 899 & 629 & 564 & 622 & 540 & 535 & 600 & 545 & 879 & 899 \\
\hline & & & & & & & & & & & & \\
\hline USAGE DATA & & & & & & & & & & & & \\
\hline kWh to GJ & 777.60 & 663.55 & 588.38 & 588.38 & 555.86 & 695.50 & 609.57 & 547.80 & 639.10 & 545.12 & 625.68 & 706.24 \\
\hline GJ/m2/Day ELECTRIC (Highest Year) & 0.003 & 0.003 & 0.002 & 0.002 & 0.002 & 0.002 & 0.003 & 0.002 & 0.002 & 0.002 & 0.003 & 0.003 \\
\hline GJ/m2/Month (Highest Year) & 0.09 & 0.08 & 0.07 & 0.07 & 0.07 & 0.08 & 0.07 & 0.07 & 0.08 & 0.07 & 0.08 & 0.09 \\
\hline $\mathrm{m} 3$ to $\mathrm{GJ}$ & 1585.32 & 419.62 & 419.36 & 119.60 & 80.24 & 6.77 & 0.00 & 56.17 & 38.20 & 69.56 & 360.80 & 303.89 \\
\hline GJ/m2/Day GAS (Highest Year) & 0.006 & 0.002 & 0.002 & 0.000 & 0.000 & 0.000 & 0.000 & 0.000 & 0.000 & 0.000 & 0.001 & 0.001 \\
\hline $\mathrm{GJ} / \mathrm{m} 2 /$ Month & 0.19 & 0.05 & 0.05 & 0.01 & 0.01 & 0.00 & 0.00 & 0.01 & 0.00 & 0.01 & 0.04 & 0.04 \\
\hline $\mathrm{m} 3 / \mathrm{m} 2 /$ Month & 5.18 & 1.37 & 1.37 & 0.39 & 0.26 & 0.02 & 0.00 & 0.18 & 0.12 & 0.23 & 1.18 & 0.99 \\
\hline GJ/m2/Day ENERGY (Highest Year) & 0.009 & 0.005 & 0.004 & 0.003 & 0.003 & 0.003 & 0.003 & 0.003 & 0.003 & 0.003 & 0.004 & 0.004 \\
\hline $\mathrm{GJ} / \mathrm{m} 2 /$ Month (Highest Consumption Year) & 0.287 & 0.132 & 0.123 & 0.086 & 0.077 & 0.085 & 0.074 & 0.073 & 0.082 & 0.075 & 0.120 & 0.123 \\
\hline Energy Usage per Month (Electricity + Gas) & 2363 & 1083 & 1008 & 708 & 636 & 702 & 610 & 604 & 677 & 615 & 986 & 1010 \\
\hline Degree Days & 775 & 654 & 573 & 332 & 147 & 71 & 199 & 122 & 87 & 238 & 342 & 518 \\
\hline
\end{tabular}




\section{Actual data used for calculations (year with lowest energy consumption):}

\begin{tabular}{|c|c|c|c|c|c|c|c|c|c|c|c|c|}
\hline ADDRESS: & \multicolumn{4}{|c|}{ Building B - Mississauga, Ontario } & & & \multirow[b]{6}{*}{ Jul } & & & & & \\
\hline BUILDING\# & \multicolumn{4}{|c|}{2} & \multirow[b]{5}{*}{ May } & \multirow[b]{5}{*}{ Jun } & & \multirow[b]{5}{*}{ Aug } & \multirow[b]{5}{*}{ Sep } & \multirow[b]{5}{*}{ Oct } & \multirow[b]{5}{*}{ Nov } & \multirow[b]{5}{*}{ Dec } \\
\hline Year - Lowest Energy Consumption: & \multicolumn{4}{|l|}{2009} & & & & & & & & \\
\hline AREA: & \multicolumn{4}{|l|}{8,225} & & & & & & & & \\
\hline USAGE INDEX: & 1.09 & AVERAGE: & 1.21134 & 1.21130 & & & & & & & & \\
\hline Month & Jan & Feb & Mar & Apr & & & & & & & & \\
\hline \multirow{2}{*}{$\begin{array}{l}\text { Electric Billing Date } \\
\text { Electric Billing Days }\end{array}$} & $2009 / 02 / 04$ & $2009 / 03 / 05$ & $2009 / 04 / 03$ & $2009 / 05 / 06$ & $2009 / 06 / 02$ & $2009 / 07 / 06$ & $2009 / 08 / 05$ & $2009 / 09 / 04$ & $2009 / 10 / 07$ & $2009 / 11 / 02$ & $2009 / 12 / 01$ & $2010 / 01 / 04$ \\
\hline & 31 & 29 & 29 & 33 & 27 & 34 & 30 & 30 & 33 & 26 & 29 & 34 \\
\hline \multirow{2}{*}{$\begin{array}{l}\text { Gas Billing Date } \\
\text { Gas Billing Days }\end{array}$} & $2009 / 02 / 05$ & 2009/03/06 & 2009/04/07 & 2009/05/07 & 2009/06/08 & 2009/07/06 & $2009 / 08 / 10$ & $2009 / 09 / 04$ & 2009/10/07 & $2009 / 11 / 04$ & $2009 / 12 / 04$ & $2010 / 01 / 04$ \\
\hline & 31 & 29 & 32 & 30 & 32 & 28 & 35 & 25 & 33 & 28 & 30 & 31 \\
\hline \multicolumn{13}{|l|}{ COOLING \& HEATING DEGREE DAYS } \\
\hline & & & & & & & & & & & & \\
\hline Cooling D.D. (Lowest Year) & 0 & 0 & 0 & 1 & 7 & 34 & 44 & 91 & 21 & 0 & 0 & 0 \\
\hline \multirow{2}{*}{$\begin{array}{l}\text { Daily Clg D.D. Avg. (Lowest Year) } \\
\text { Normal Cooling D.D. (Lowest Year) }\end{array}$} & 0 & 0 & 0 & 0 & 0 & 1 & 1 & 3 & 1 & 0 & 0 & 0 \\
\hline & & & & & & & & & & & & \\
\hline Heating D.D. (Lowest Year) & 830 & 606 & 534 & 306 & 159 & 49 & 6 & 10 & 55 & 288 & 361 & 614 \\
\hline Daily Htg. D.D. Avg. (Lowest Year) & 27 & 21 & 17 & 10 & 5 & 2 & 0 & 0 & 2 & 10 & 12 & 20 \\
\hline Normal Heating D.D (Lowest Year) & & & & & & & & & & & & \\
\hline & & & & & & & & & & & & \\
\hline ELECTRICAL USAGE \& COST & & & & & & & & & & & & \\
\hline kWh Used & 224,640 & 186,480 & 167,040 & 151,200 & 131,760 & 154,080 & 168,480 & 159,120 & 167,760 & 118,080 & 140,400 & 223,920 \\
\hline Daily kWh Avg. & 7,246 & 6,430 & 5,220 & 5,040 & 4,118 & 5,503 & 4,814 & 6,365 & 5,084 & 4,217 & 4,680 & 7,223 \\
\hline Demand kW/RkVA Used & 867 & 909 & 914 & 1,051 & 1,028 & 1,306 & 1,263 & 1,171 & 1,110 & 1,081 & 941 & 902 \\
\hline Load Factor (Lowest Year) & $35 \%$ & $29 \%$ & $26 \%$ & $\begin{array}{l}1,101 \\
18 \%\end{array}$ & $20 \%$ & $1,14 \%$ & $\begin{array}{l}1,205 \\
19 \%\end{array}$ & $\begin{array}{l}1,1 / 7 \\
19 \%\end{array}$ & $1,19 \%$ & $\begin{array}{l}1,001 \\
18 \%\end{array}$ & $21 \%$ & $30 \%$ \\
\hline & & & & & & & & & & & & \\
\hline NATURAL GAS USAGE \& COST & & & & & & & & & & & & \\
\hline CCF & & & & & & & & & & & & \\
\hline $\mathrm{m}^{\wedge} 3$ Used & 10,970 & 12,224 & 7,213 & 2,934 & 942 & 0 & 0 & 111 & 1,339 & 5,119 & 6,180 & 0 \\
\hline Daily $\mathrm{m}^{\wedge} 3$ Avg. & 354 & 422 & 225 & 98 & 29 & 0 & 0 & 4 & 41 & 183 & 206 & 0 \\
\hline & & & & & & & & & & & & \\
\hline GREENHOUSE DATA & & & & & & & & & & & & \\
\hline C02 (kgs) (Lowest Year) & 228,757 & 211,961 & 163,419 & 122,481 & 95,305 & 103,654 & 113,341 & 107,830 & 122,333 & 115,663 & 138,187 & 150,637 \\
\hline S02 (kgs) (Lowest Year) & 2,472 & 2,290 & 1,766 & 1,323 & 1,030 & 1,120 & 1,225 & 1,165 & 1,322 & 1,250 & 1,493 & 1,627 \\
\hline NOx (kgs) (Lowest Year) & 1,084 & 1,004 & 774 & 580 & 451 & 491 & 537 & 511 & 579 & 548 & 655 & 713 \\
\hline USAGE DATA & & & & & & & & & & & & \\
\hline kWh to GJ & 808.70 & 671.33 & 601.34 & 544.32 & 4774.34 & 5554.69 & 606.53 & 572.83 & 603.94 & 425.09 & 505.44 & 806.11 \\
\hline GJ/m2/Day ELECTRIC (Lowest Year) & 0.003 & 0.003 & 0.003 & 0.002 & 0.002 & 0.002 & 0.002 & 0.002 & 0.002 & 0.002 & 0.002 & 0.003 \\
\hline GJ/m2/Month (Lowest Year) & 0.10 & 0.08 & 0.07 & 0.07 & 0.06 & 0.07 & 0.07 & 0.07 & 0.07 & 0.05 & 0.06 & 0.10 \\
\hline m3 to GJ & 408.08 & 454.73 & 268.32 & 109.14 & 35.04 & 0.00 & 0.00 & 4.13 & 49.81 & 190.43 & 229.90 & 0.00 \\
\hline GJ/m2/Day GAS (Lowest Year) & 0.002 & 0.002 & 0.001 & 0.000 & 0.000 & 0.000 & 0.000 & 0.000 & 0.000 & 0.001 & 0.001 & 0.000 \\
\hline $\mathrm{GJ} / \mathrm{m} 2 /$ Month & 0.05 & 0.06 & 0.03 & 0.01 & 0.00 & 0.00 & 0.00 & 0.00 & 0.01 & 0.02 & 0.03 & 0.00 \\
\hline $\mathrm{m} 3 / \mathrm{m} 2 /$ Month & 1.33 & 1.49 & 0.88 & 0.36 & 0.11 & 0.00 & 0.00 & 0.01 & 0.16 & 0.62 & 0.75 & 0.00 \\
\hline GJ/m2/Day ENERGY (Lowest Year) & 0.005 & 0.005 & 0.004 & 0.002 & 0.002 & 0.002 & 0.002 & 0.002 & 0.002 & 0.003 & 0.003 & 0.003 \\
\hline $\mathrm{GJ} / \mathrm{m} 2 /$ Month (Lowest Consumption Year) & 0.148 & 0.137 & 0.106 & 0.079 & 0.062 & 0.067 & 0.074 & 0.070 & 0.079 & 0.075 & 0.089 & 0.098 \\
\hline Average Highest Year to Lowest Year & 0.218 & 0.134 & 0.114 & 0.083 & 0.070 & 0.076 & 0.074 & 0.072 & 0.081 & 0.075 & 0.105 & 0.110 \\
\hline BOMA Mean Value per Month & 0.111 & 0.111 & 0.111 & 0.111 & 0.111 & 0.111 & 0.111 & 0.111 & 0.111 & 0.111 & 0.111 & 0.111 \\
\hline Energy Usage per Month (Electricity + Gas) & 1217 & 1126 & 870 & 653 & 509 & 555 & 607 & 577 & 654 & 616 & 735 & 806 \\
\hline Degree Days & 830 & 606 & 534 & 307 & 166 & 84 & 50 & 101 & 76 & 288 & 361 & 614 \\
\hline Normalized Data (Average Degree Days) & 727 & 619 & 544 & 333 & 149 & 88 & 86 & 100 & 94 & 248 & 420 & 637 \\
\hline Normalized Data (Av Energy Consumption) & 1307 & 1175 & 1083 & 825 & 601 & 526 & 524 & 540 & 533 & 722 & 931 & 1197 \\
\hline Normalized Data (Av Energy Index / month) & 0.159 & 0.143 & 0.132 & 0.100 & 0.073 & 0.064 & 0.064 & 0.066 & 0.065 & 0.088 & 0.113 & 0.146 \\
\hline
\end{tabular}


Analysis on how electricity and gas consumption corresponds to heating and cooling periods (for highest energy consumption year):

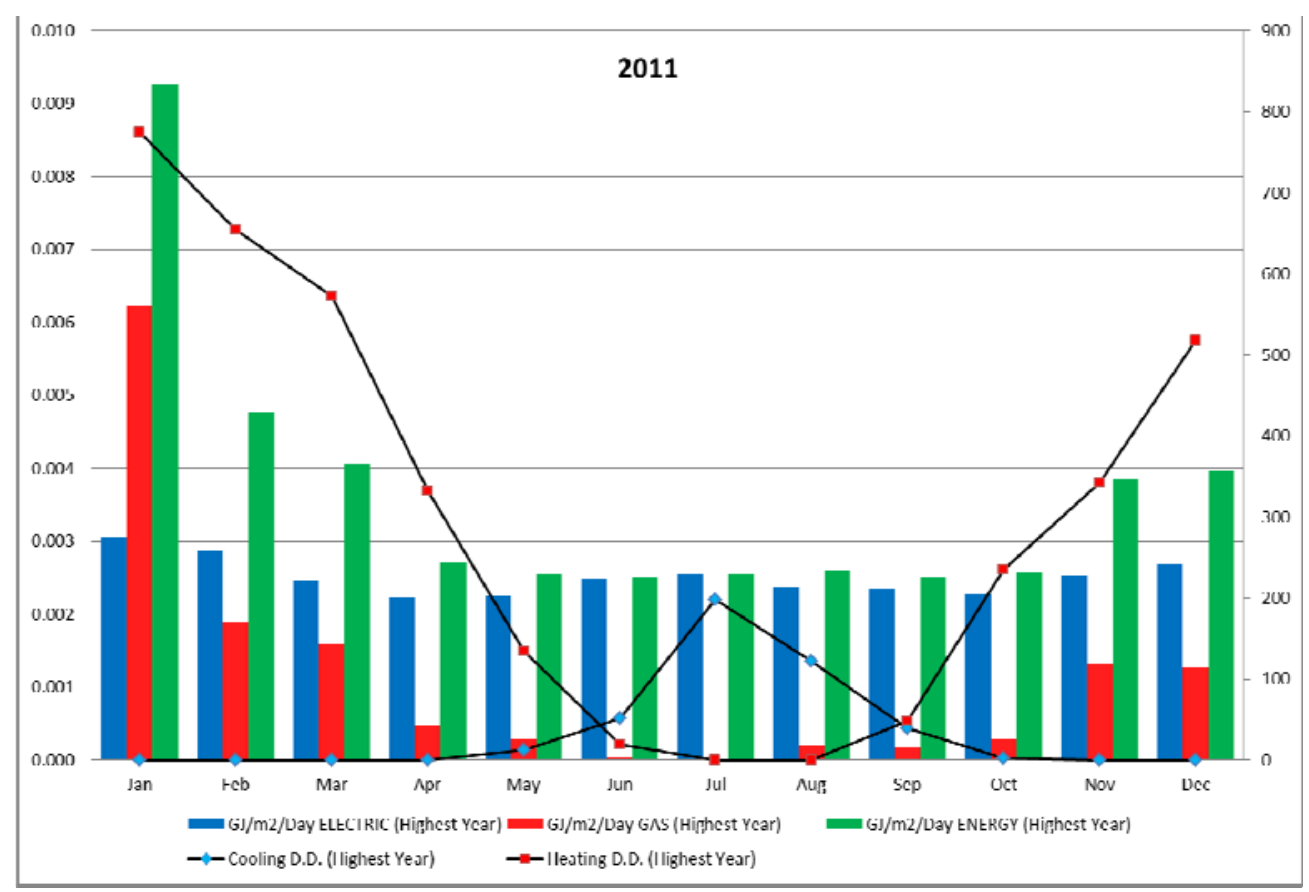

Analysis on how electricity and gas consumption corresponds to heating and cooling periods (for lowest energy consumption year):

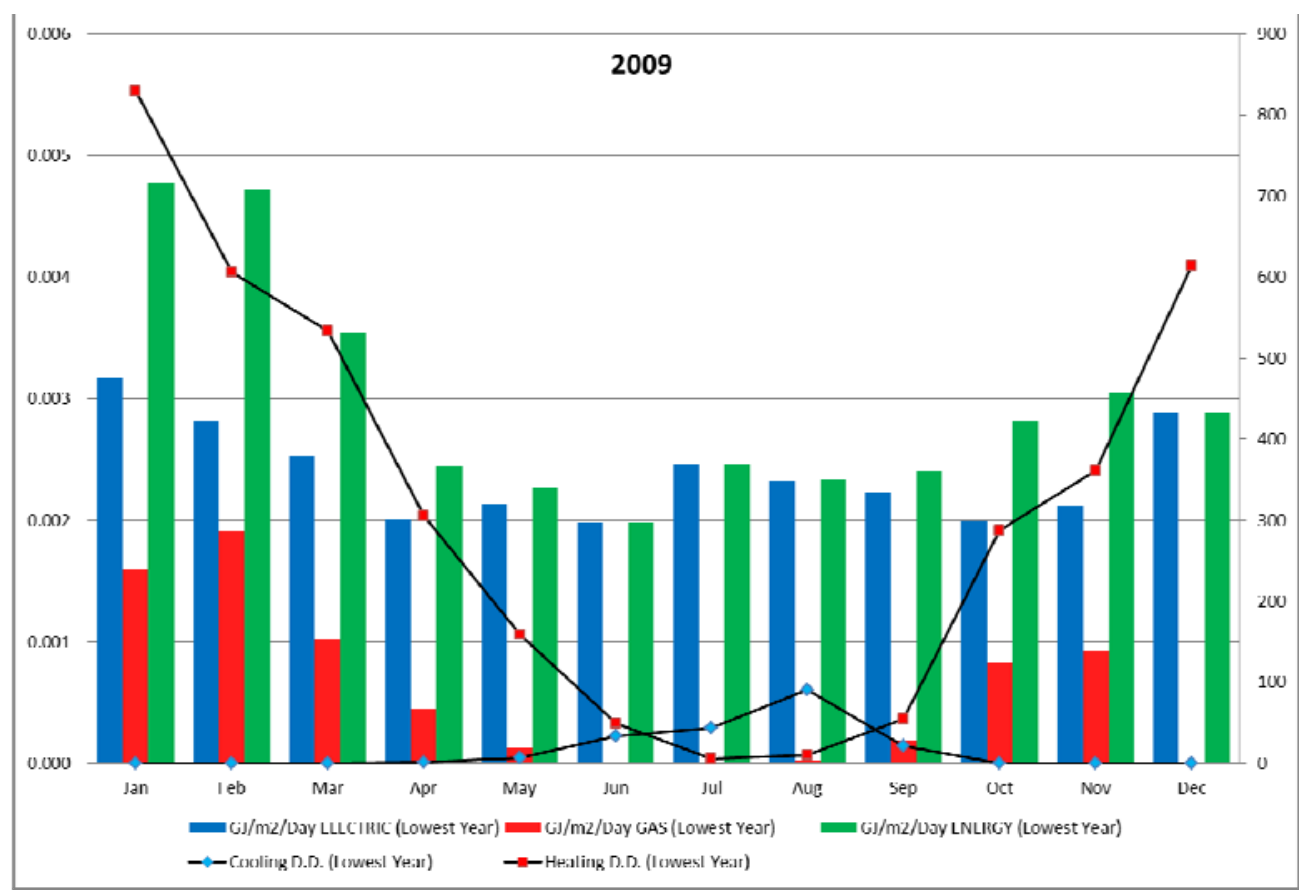


Monthly energy index comparison between highest energy consumption year, lowest, average and benchmark (BOMA) energy intensity:

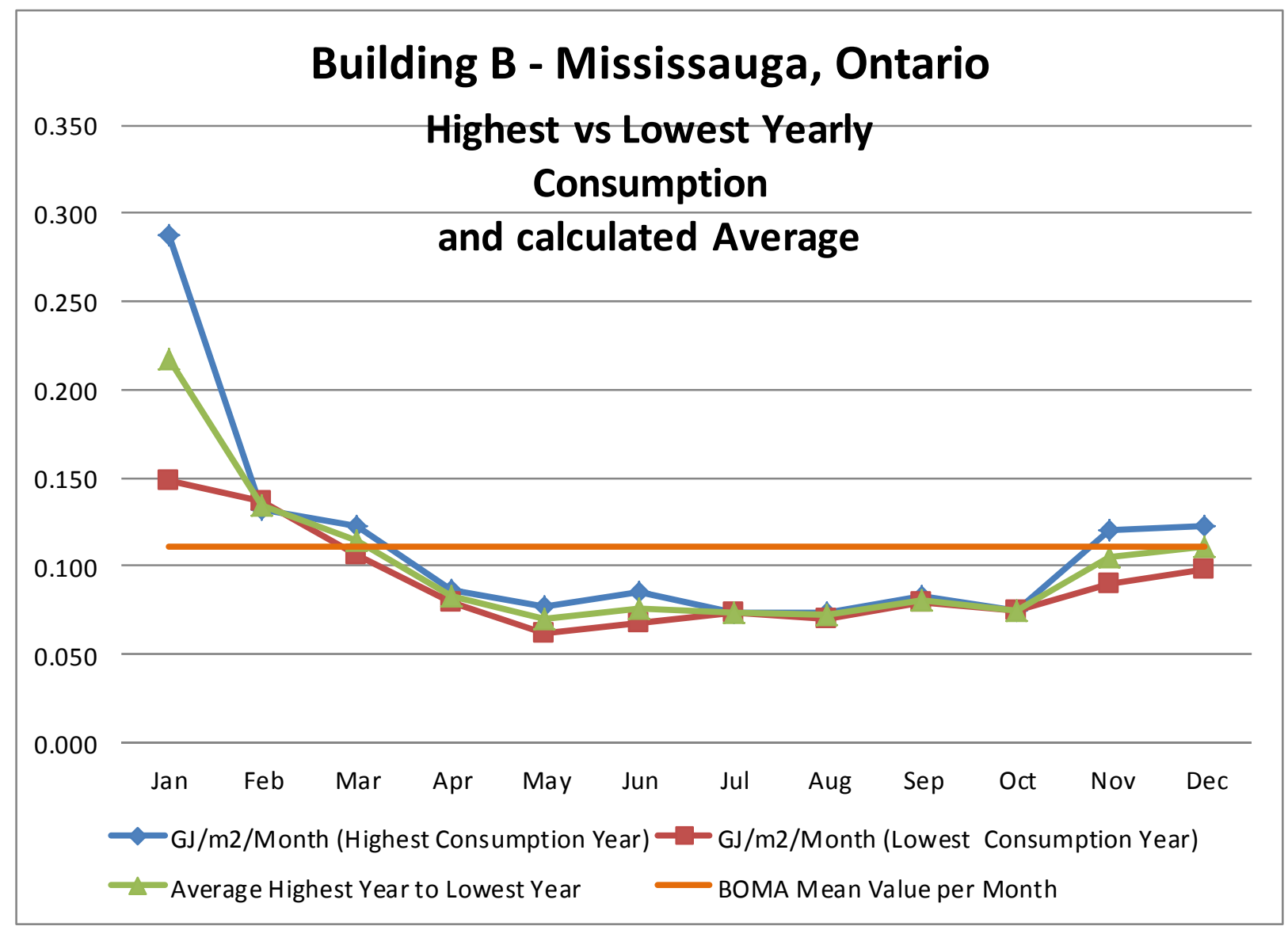


Building \#3 - Utility Bills Analysis

\section{Calculations of Energy Index for Building \#3}

Energy CAP database was utilized to collect energy consumption information for the building. Energy consumption was provided by utility bills for electricity and gas. For Building \#3 utility bills were provided from December 2006 to March 2015. To complete most accurate analysis utility bills for 2007 to 2014 were only analyzed because 2006 and 2015 has incomplete data. By having total floor area of 9,240 $\mathrm{m}^{2}$ energy intensity was calculated. From calculations it was noticed that electricity and gas utility bills provided relatively consistent data, therefore all years' data from 2007 to 2014 were included in calculations.

Utility bills analysis showed following:

\begin{tabular}{|c|c|c|c|c|c|c|c|c|}
\hline \multicolumn{9}{|c|}{ Building C - Toronto, Ontario } \\
\hline \multirow[b]{2}{*}{ Row Labels } & \multirow{2}{*}{\multicolumn{2}{|c|}{$\begin{array}{c}\text { Sum of Ele Total } \\
\text { Cost / Year }\end{array}$}} & \multirow{3}{*}{$\begin{array}{c}\text { kWh } \\
\begin{array}{c}\text { Sum of Ele } \\
\text { Consumption / } \\
\text { Year }\end{array} \\
118,800.00 \\
\end{array}$} & & & $m^{3}$-ngas & Total GJ/yr & $9,240.00$ \\
\hline & & & & \multicolumn{2}{|c|}{$\begin{array}{c}\text { Sum of Gas Total } \\
\text { Cost / Year }\end{array}$} & \multirow{2}{*}{$\begin{array}{c}\begin{array}{c}\text { Sum of Gas } \\
\text { Consumption / } \\
\text { Year }\end{array} \\
16,423.00\end{array}$} & \multirow[t]{2}{*}{ Total } & \multirow[t]{2}{*}{$\mathrm{GJ} / \mathrm{m} 2 / \mathrm{yr}$} \\
\hline Year 2006 & $\$$ & $14,358.63$ & & $\$$ & $8,151.68$ & & & \\
\hline Year 2007 & $\$$ & $262,384.36$ & $2,160,600.00$ & $\$$ & $70,497.72$ & $145,115.00$ & $13,176.44$ & 1.43 \\
\hline Year 2008 & $\$$ & $250,075.96$ & $2,056,800.00$ & $\$$ & $71,866.39$ & $145,774.00$ & $12,827.27$ & 1.39 \\
\hline Year 2009 & $\$$ & $227,687.84$ & $1,939,800.00$ & $\$$ & $53,508.79$ & $108,747.00$ & $11,028.67$ & 1.19 \\
\hline Year 2010 & $\$$ & $216,924.34$ & $1,924,200.00$ & $\$$ & $69,973.69$ & $141,814.00$ & $12,202.60$ & 1.32 \\
\hline Year 2011 & $\$$ & $205,533.78$ & $1,682,878.08$ & $\$$ & $89,164.96$ & $214,286.00$ & $14,029.80$ & 1.52 \\
\hline Year 2012 & $\$$ & $284,302.26$ & $2,166,600.00$ & $\$$ & $41,423.33$ & $148,280.00$ & $13,315.78$ & 1.44 \\
\hline Year 2013 & $\$$ & $254,088.22$ & $1,717,800.00$ & $\$$ & $37,043.42$ & $150,897.00$ & $11,797.45$ & 1.28 \\
\hline Year 2014 & $\$$ & $248,333.15$ & $1,650,600.00$ & $\$$ & $59,593.20$ & $211,988.00$ & $13,828.11$ & 1.50 \\
\hline Year 2015 & $\$$ & $58,395.57$ & $399,000.00$ & $\$$ & $40,053.85$ & $114,724.00$ & & \\
\hline Average & $\$$ & $243,666.24$ & $1,912,409.76$ & $\$$ & $61,633.94$ & $158,362.63$ & & 1.38 \\
\hline
\end{tabular}

As it was specified in energy audit, energy consumption of the Building \#3 is moderately high in comparison to similar office buildings in same region; and therefore average energy index which equals to $1.38 \mathrm{GJ} / \mathrm{m}^{2} / \mathrm{yr}$ is also high in comparison to benchmark values of BOMA energy efficient building value of $1.05 \mathrm{GJ} / \mathrm{m}^{2} / \mathrm{yr}$ and around average value of National Resources Canada value of $01.43 \mathrm{GJ} / \mathrm{m}^{2} / \mathrm{yr}$.

Two charts below show electricity and gas consumption per year. Electricity consumption chart demonstrates prominent decrease in consumption from 2007 to 2011, and although 2012 shows higher value, overall electricity consumption is decreasing. Gas consumption chart doesn't show such results, 2011 shows slightly inconsistent gas consumption result, but fluctuation of consumption is prominent through entire yearly range. 

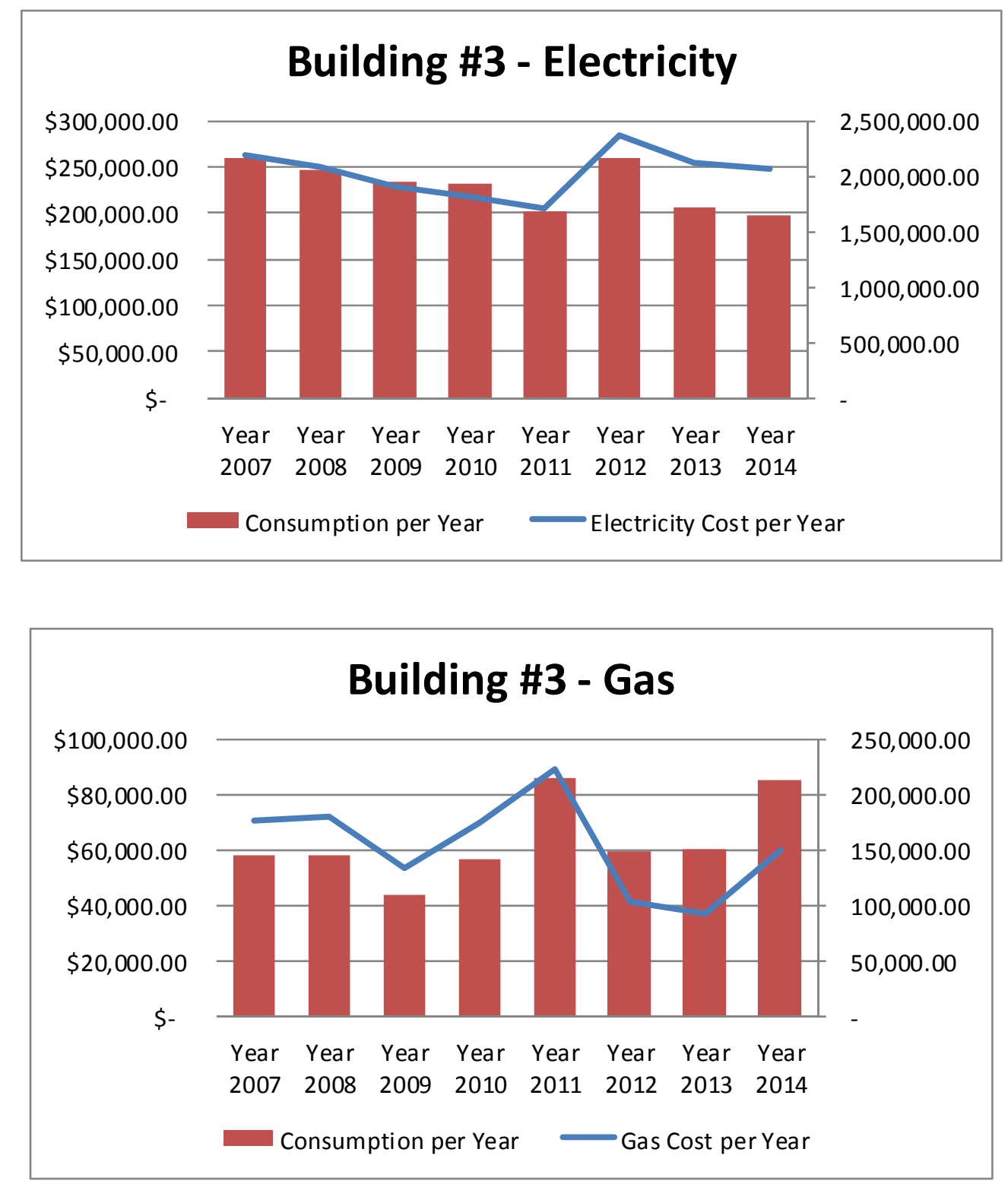

Yearly energy intensity (index) was also plotted to demonstrate increase or decrease over the range of years for which data is available. Chart below shows that energy index value fluctuating over years it's calculated, and 2011 and 2014 show very similar results. The lowest energy index was in 2009 and highest in 2011 . These two years' data will be used for further calculations and comparisons. 


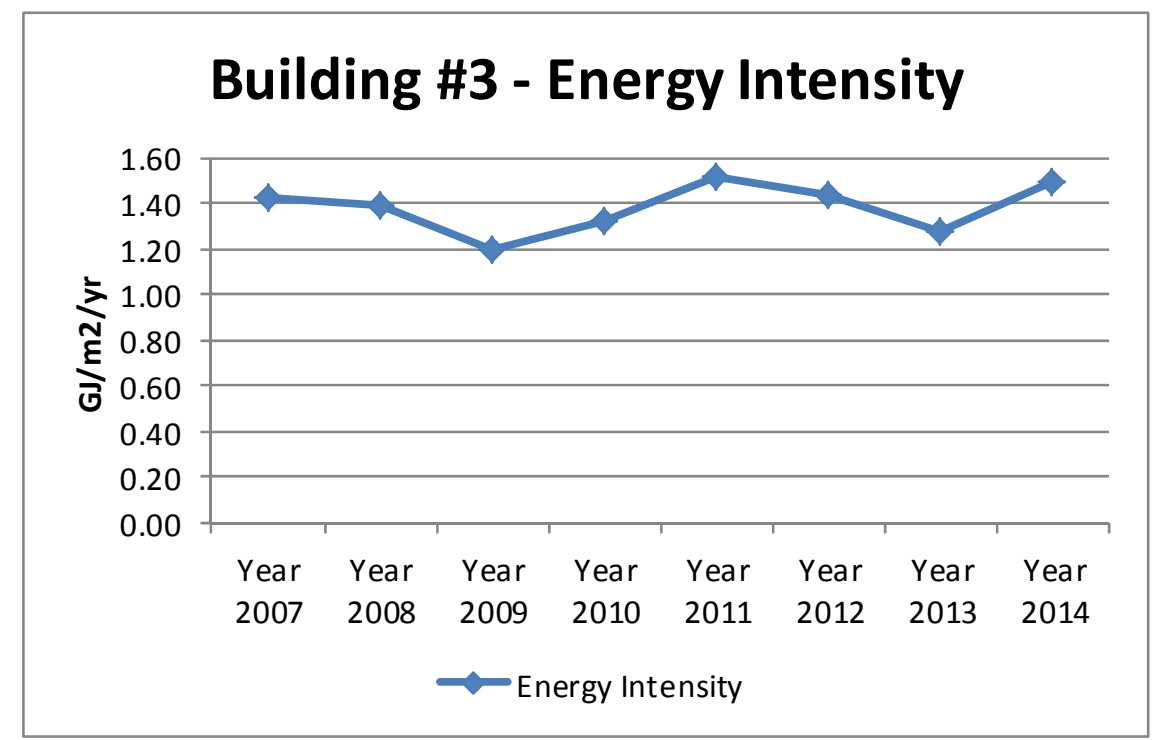

Normalized total energy consumption was calculated for Building \#3. Based on plotted results, shown below in the chart, it can be concluded that energy consumption for 2011 at some point is intersecting with 2009, but nevertheless shows higher results. Regardless of weather conditions 2011 has higher energy consumptions than in 2009. Implementing trendline equations, average equation was calculated:

\section{$\gamma=1.8184 x+430.26$}

From above equation normalized average energy index was calculated as $1.36 \mathrm{GJ} / \mathrm{m}^{2} / \mathrm{yr}$, this value is slightly higher than average for 2007 to 2014 years range. Calculated value will be used for further case-study buildings comparison. 


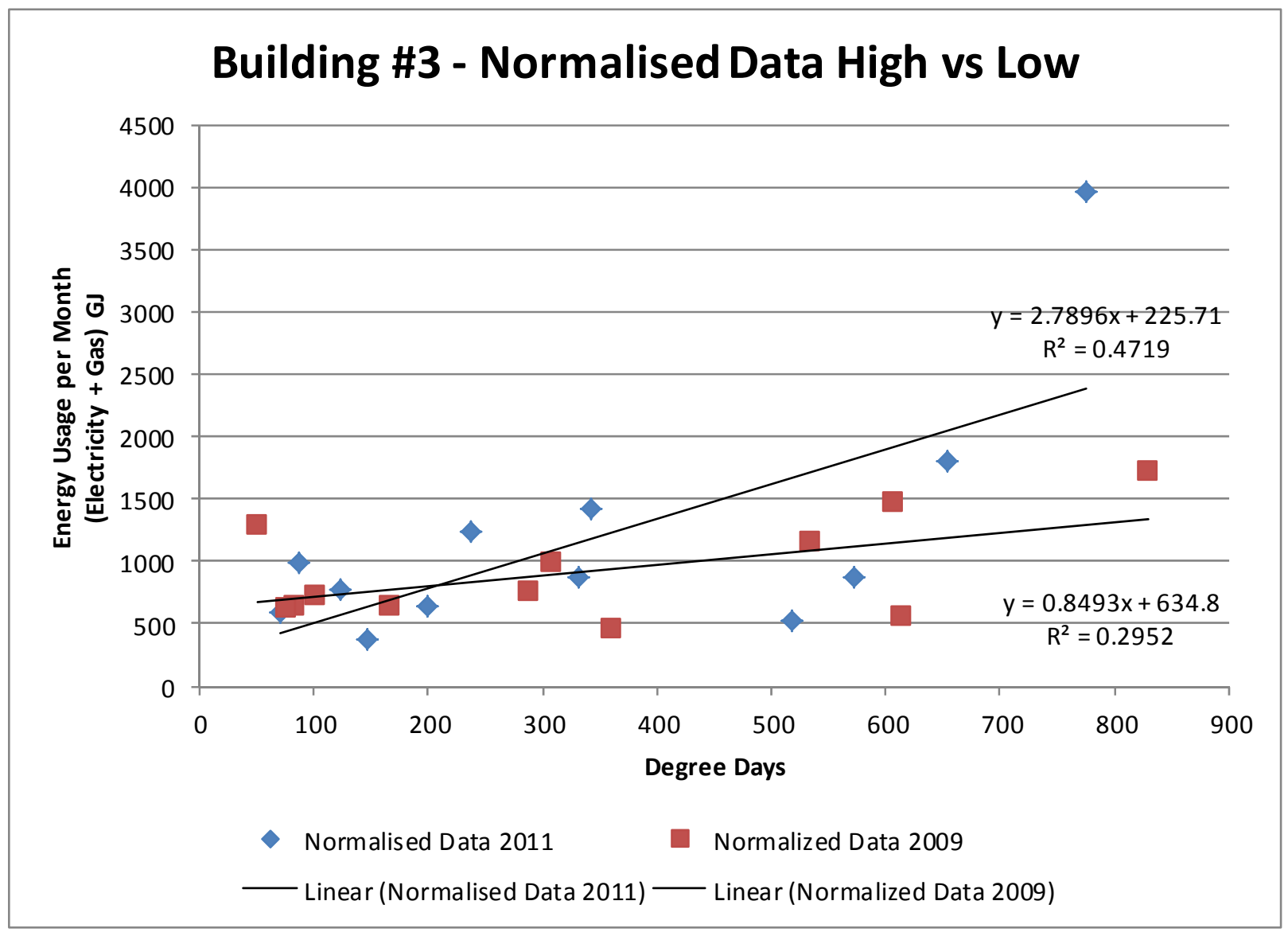


Actual data used for calculations (year with highest energy consumption):

\begin{tabular}{|c|c|c|c|c|c|c|c|c|c|c|c|c|}
\hline ADDRESS: & \multicolumn{4}{|c|}{ Building C - Toronto, Ontario } & & & & & & & & \\
\hline BUILDING \# & \multicolumn{4}{|c|}{3} & & & & & & & & \\
\hline Year - Highest Energy Consumption: & \multicolumn{4}{|l|}{2011} & & & & & & & & \\
\hline AREA: & \multicolumn{4}{|l|}{9,240} & & & & & & & & \\
\hline USAGE INDEX: & \multicolumn{4}{|l|}{1.52} & & & & & & & & \\
\hline Month & Jan & Feb & Mar & Apr & May & Jun & Jul & Aug & Sep & Oct & Nov & Dec \\
\hline \multirow{2}{*}{$\begin{array}{l}\text { Electric Billing Date } \\
\text { Electric Billing Days }\end{array}$} & $2011 / 01 / 26$ & $2011 / 03 / 01$ & $2011 / 03 / 29$ & $2011 / 05 / 02$ & $2011 / 06 / 01$ & $2011 / 06 / 30$ & $2011 / 08 / 03$ & $2011 / 08 / 31$ & $2011 / 09 / 30$ & $2011 / 11 / 01$ & $2011 / 11 / 30$ & $2012 / 01 / 03$ \\
\hline & 31 & 34 & 28 & 34 & 30 & 29 & 34 & 28 & 30 & 32 & 29 & 34 \\
\hline \multirow{2}{*}{$\begin{array}{l}\text { Gas Billing Date } \\
\text { Gas Billing Days }\end{array}$} & $2011 / 02 / 24$ & $2011 / 03 / 23$ & $2011 / 04 / 25$ & $2011 / 05 / 26$ & $2011 / 07 / 23$ & $2011 / 08 / 25$ & $2011 / 09 / 24$ & $2011 / 10 / 25$ & $2011 / 11 / 23$ & $2011 / 12 / 22$ & $2012 / 01 / 23$ & $2012 / 12 / 21$ \\
\hline & 31 & 27 & 33 & 31 & 58 & 33 & 30 & 31 & 29 & 29 & 32 & 333 \\
\hline \multicolumn{13}{|l|}{ COOLING \& HEATING DEGREE DAYS } \\
\hline \multirow{5}{*}{$\begin{array}{l}\text { Cooling D.D. (Highest Year) } \\
\text { Daily Clg D.D. Avg. (Highest Year) } \\
\text { Normal Cooling D.D. (Highest Year) }\end{array}$} & & & & & & & & & & & & \\
\hline & 0 & 0 & 0 & 0 & 13 & 52 & 199 & 122 & 39 & 2 & 0 & $\mathbf{0}$ \\
\hline & 0 & 0 & 0 & 0 & 0 & 2 & 6 & 4 & 1 & 0 & 0 & 0 \\
\hline & & & & & & & & & & & & \\
\hline & & & & & & & & & & & & \\
\hline \multirow{4}{*}{$\begin{array}{l}\text { Heating D.D. (Highest Year) } \\
\text { Daily Htg. D.D. Avg. (Highest Year) } \\
\text { Normal Heating D.D (Highest Year) }\end{array}$} & 775 & 654 & 573 & 332 & 134 & 19 & 0 & 0 & 48 & 235 & 342 & 518 \\
\hline & 25 & 24 & 17 & 11 & 2 & 1 & 0 & 0 & 2 & 8 & 11 & 2 \\
\hline & & & & & & & & & & & & \\
\hline \multirow{2}{*}{\multicolumn{13}{|c|}{ ELECTRICAL USAGE \& COST }} \\
\hline & & & & & & & & & & & & \\
\hline \multirow{2}{*}{$\begin{array}{l}\text { kWh Used } \\
\text { Daily kWh Avg. }\end{array}$} & 119,532 & 188,013 & 63,501 & 175,562 & 90,894 & 159,375 & 173,694 & 167,469 & 142,566 & 126,380 & 129,492 & 146,400 \\
\hline & 3,856 & 6,963 & 1,924 & 5,663 & 1,567 & 4,830 & 5,790 & 5,402 & 4,916 & 4,358 & 4,047 & 440 \\
\hline \multirow{3}{*}{$\begin{array}{l}\text { Demand kW/RkVA Used } \\
\text { Load Factor (Highest Year) }\end{array}$} & 273 & 413 & 272 & 356 & 401 & 422 & 451 & 470 & 440 & 470 & 287 & 287 \\
\hline & $59 \%$ & $56 \%$ & $35 \%$ & $60 \%$ & $31 \%$ & $54 \%$ & $43 \%$ & $53 \%$ & $45 \%$ & $35 \%$ & $65 \%$ & $63 \%$ \\
\hline & & & & & & & & & & & & \\
\hline \multicolumn{13}{|l|}{ NATURAL GAS USAGE \& COST } \\
\hline \multicolumn{13}{|l|}{ CCF } \\
\hline $\mathrm{m}^{\wedge} 3$ Used & 94,962 & 30,109 & 17,216 & 6,358 & 1,191 & 435 & 278 & 4,429 & 12,722 & 20,919 & 25,667 & 0 \\
\hline \multirow{2}{*}{ Daily $\mathrm{m}^{\wedge} 3$ Avg. } & 3,063 & 1,115 & 522 & 205 & 21 & 13 & 9 & 143 & 439 & 721 & 802 & 0 \\
\hline & & & & & & & & & & & & \\
\hline \multicolumn{13}{|l|}{ GREENHOUSE DATA } \\
\hline \multirow{4}{*}{$\begin{array}{l}\text { C02 (kgs) (Highest Year) } \\
\text { S02 (kgs) (Highest Year) } \\
\text { NOx (kgs) (Highest Year) }\end{array}$} & 752,467 & 339,566 & 164,558 & 163,101 & 69,576 & 110,295 & 118,816 & 144,005 & 185,943 & 233,065 & 268,761 & 98,487 \\
\hline & 8,130 & 3,669 & 1,778 & 1,762 & 752 & 1,192 & 1,284 & 1,556 & 2,009 & 2,518 & 2,904 & 1,064 \\
\hline & 3,564 & 1,608 & 779 & 773 & 330 & 522 & 563 & 682 & 881 & 1,104 & 1,273 & 466 \\
\hline & & & & & & & & & & & & \\
\hline kWh to GJ & 4330.31 & 2676.85 & 2228.60 & 2632.02 & 327.22 & 573.75 & 625.30 & 602.89 & 513.24 & $\overline{4454.97}$ & 466.17 & $\overline{527.04}$ \\
\hline GJ/m2/Day ELECTRIC (Highest Year) & 0.002 & 0.002 & 0.001 & 0.002 & 0.001 & 0.002 & 0.002 & 0.002 & 0.002 & 0.002 & 0.002 & 0.002 \\
\hline GJ/m2/Month (Highest Year) & 0.05 & 0.07 & 0.02 & 0.07 & 0.04 & 0.06 & 0.07 & 0.07 & 0.06 & 0.05 & 0.05 & 0.06 \\
\hline m3 to GJ & 3532.59 & 1120.05 & 640.44 & 236.52 & 44.31 & 16.18 & 10.34 & 164.76 & 473.26 & 778.19 & 954.81 & 0.00 \\
\hline GJ/m2/Day GAS (Highest Year) & 0.012 & 0.004 & 0.002 & 0.001 & 0.000 & 0.000 & 0.000 & 0.001 & 0.002 & 0.003 & 0.003 & 0.000 \\
\hline $\mathrm{GJ} / \mathrm{m} 2 /$ Month & 0.38 & 0.12 & 0.07 & 0.03 & 0.00 & 0.00 & 0.00 & 0.02 & 0.05 & 0.08 & 0.10 & 0.00 \\
\hline $\mathrm{m} 3 / \mathrm{m} 2 /$ Month & 10.28 & 3.26 & 1.86 & 0.69 & 0.13 & 0.05 & 0.03 & 0.48 & 1.38 & 2.26 & 2.78 & 0.00 \\
\hline GJ/m2/Day ENERGY (Highest Year) & 0.014 & 0.007 & 0.003 & 0.003 & 0.001 & 0.002 & 0.002 & 0.003 & 0.004 & 0.004 & 0.005 & 0.002 \\
\hline $\mathrm{GJ} / \mathrm{m} 2 /$ Month (Highest Consumption Year) & 0.429 & 0.194 & 0.094 & 0.094 & 0.040 & 0.064 & 0.069 & 0.083 & 0.107 & 0.133 & 0.154 & 0.057 \\
\hline Energy Usage per Month (Electricity + Gas) & 3963 & 1797 & 869 & 869 & 372 & 590 & 636 & 768 & 986 & 1233 & 1421 & 527 \\
\hline Degree Days & 775 & 654 & 573 & 332 & 147 & 71 & 199 & 122 & 87 & 238 & 342 & 518 \\
\hline
\end{tabular}




\section{Actual data used for calculations (year with lowest energy consumption):}

\begin{tabular}{|c|c|c|c|c|c|c|c|c|c|c|c|c|}
\hline ADDRESS: & \multicolumn{4}{|c|}{ Building C - Toronto, Ontario } & & & & & & & & \\
\hline BUILDING \# & \multicolumn{4}{|c|}{3} & & & & & & & & \\
\hline Year - Lowest Energy Consumption: & \multicolumn{4}{|l|}{2009} & & & & & & & & \\
\hline AREA: & \multicolumn{4}{|l|}{9,240} & & & & & & & & \\
\hline USAGE INDEX: & 1.19 & AVERAGE: & 1.3560 & 1.35520 & & & & & & & & \\
\hline Month & $\operatorname{Jan}$ & Feb & Mar & Apr & May & Jun & Jul & Aug & Sep & Oct & Nov & Dec \\
\hline \multirow{4}{*}{$\begin{array}{l}\text { Electric Billing Date } \\
\text { Electric Billing Days }\end{array}$} & $2009 / 01 / 30$ & $2009 / 03 / 03$ & $2009 / 03 / 30$ & $2009 / 04 / 30$ & $2009 / 06 / 01$ & $2009 / 07 / 02$ & $2009 / 08 / 04$ & $2009 / 09 / 02$ & $2009 / 10 / 02$ & $2009 / 11 / 03$ & $2009 / 12 / 02$ & $2010 / 01 / 04$ \\
\hline & 31 & 32 & 27 & 31 & 32 & 31 & 33 & 29 & 30 & 32 & 29 & 33 \\
\hline & $2009 / 01 / 27$ & $2009 / 02 / 26$ & $2009 / 03 / 27$ & $2009 / 04 / 28$ & $2009 / 05 / 28$ & $2009 / 06 / 26$ & $2009 / 07 / 27$ & $2009 / 08 / 28$ & $2009 / 09 / 28$ & $2009 / 10 / 28$ & $2009 / 12 / 04$ & $2010 / 01 / 04$ \\
\hline & 31 & 30 & 29 & 32 & 30 & 29 & 31 & 32 & 31 & 30 & 37 & 31 \\
\hline \multicolumn{13}{|l|}{ COOLING \& HEATING DEGREE DAYS } \\
\hline & & & & & & & & & & & & \\
\hline \multirow{4}{*}{$\begin{array}{l}\text { Cooling D.D. (Lowest Year) } \\
\text { Daily Clg D.D. Avg. (Lowest Year) } \\
\text { Normal Cooling D.D. (Lowest Year) }\end{array}$} & 0 & 0 & 0 & 1 & 7 & 34 & 44 & 91 & 21 & 0 & 0 & 0 \\
\hline & 0 & 0 & 0 & 0 & 0 & 1 & 1 & 3 & 1 & 0 & 0 & 0 \\
\hline & & & & & & & & & & & & \\
\hline & & & & & & & & & & & & \\
\hline \multirow{4}{*}{$\begin{array}{l}\text { Heating D.D. (Lowest Year) } \\
\text { Daily Htg. D.D. Avg. (Lowest Year) } \\
\text { Normal Heating D.D (Lowest Year) }\end{array}$} & 830 & 606 & 534 & 306 & 159 & 49 & 6 & 10 & 55 & 288 & 361 & 614 \\
\hline & 27 & 20 & 18 & 10 & 5 & 2 & 0 & 0 & 2 & 10 & 10 & 20 \\
\hline & & & & & & & & & & & & \\
\hline & & & & & & & & & & & & \\
\hline \multicolumn{13}{|l|}{ ELECTRICAL USAGE \& COST } \\
\hline \multirow{3}{*}{$\begin{array}{l}\text { kWh Used } \\
\text { Daily kWh Avg. }\end{array}$} & 157,200 & 159,600 & 130,200 & 150,600 & 148,800 & 172,800 & 208,800 & 196,800 & 163,800 & 169,200 & 128,400 & 153,600 \\
\hline & 5,071 & 5,320 & 4,490 & 4,706 & 4,960 & 5,959 & 6,735 & 6,150 & 5,284 & 5,640 & 3,470 & 4,955 \\
\hline & & & & & & & & & & & & \\
\hline Demand kW/RkVA Used & 316 & 320 & 314 & 316 & 499 & 467 & 438 & 493 & 371 & 419 & 475 & 319 \\
\hline Load Factor (Lowest Year) & $67 \%$ & $65 \%$ & $64 \%$ & $64 \%$ & $39 \%$ & $50 \%$ & $60 \%$ & $57 \%$ & $61 \%$ & $53 \%$ & $39 \%$ & $61 \%$ \\
\hline \multicolumn{13}{|l|}{ NATURAL GAS USAGE $\&$ COST } \\
\hline \multicolumn{13}{|l|}{ CCF } \\
\hline$m^{\wedge} 3$ Used & 31,223 & 23,981 & 18,580 & 11,989 & 2,714 & 585 & 14,252 & 381 & 918 & 4,124 & 0 & 0 \\
\hline \multirow{2}{*}{ Daily $\mathrm{m}^{\wedge} 3$ Avg. } & 1,007 & 799 & 641 & 375 & 90 & 20 & 460 & 12 & 30 & 137 & 0 & 0 \\
\hline & & & & & & & & & & & & \\
\hline \multicolumn{13}{|l|}{ GREENHOUSE DATA } \\
\hline & 326,721 & 277,083 & 219,081 & 186,160 & 119,309 & 120,387 & 241,328 & 135,089 & 116,689 & 143,011 & 86,378 & 103,331 \\
\hline S02 (kgs) (Lowest Year) & 3,530 & 2,994 & 2,367 & 2,011 & 1,289 & 1,301 & 2,607 & 1,460 & 1,261 & 1,545 & 933 & 1,116 \\
\hline NOx (kgs) (Lowest Year) & 1,548 & 1,312 & 1,038 & 882 & 565 & 570 & 1,143 & 640 & 553 & 677 & 409 & 489 \\
\hline & & & & & & & & & & & & \\
\hline USAGE DATA & & & & & & & & & & & & \\
\hline kWh to GJ & 565.92 & 574.56 & 468.72 & 542.16 & 535.68 & 6222.08 & 751.68 & 708.48 & 589.68 & 609.12 & 462.24 & 552.96 \\
\hline GJ/m2/Day ELECTRIC (Lowest Year) & 0.002 & 0.002 & 0.002 & 0.002 & 0.002 & 0.002 & 0.002 & 0.003 & 0.002 & 0.002 & 0.002 & 0.002 \\
\hline GJ/m2/Month (Lowest Year) & 0.06 & 0.06 & 0.05 & 0.06 & 0.06 & 0.07 & 0.08 & 0.08 & 0.06 & 0.07 & 0.05 & 0.06 \\
\hline$m 3$ to G1 & 116150 & 89209 & 691.18 & 445.99 & 100.96 & 2176 & 530.17 & 14.17 & 34.15 & 153.41 & 0.00 & 0,00 \\
\hline $\mathrm{GJ} / \mathrm{m} 2 /$ Day GAS (Lowest Year) & 0.004 & 0.003 & 0.003 & 0.002 & 0.000 & 0.000 & 0.002 & 0.000 & 0.000 & 0.001 & 0.000 & 0.000 \\
\hline $\mathrm{GJ} / \mathrm{m} 2 /$ Month & 0.13 & 0.10 & 0.07 & 0.05 & 0.01 & 0.00 & 0.06 & 0.00 & 0.00 & 0.02 & 0.00 & 0.00 \\
\hline $\mathrm{m} 3 / \mathrm{m} 2 /$ Month & 3.38 & 2.60 & 2.01 & 1.30 & 0.29 & 0.06 & 1.54 & 0.04 & 0.10 & 0.45 & 0.00 & 0.00 \\
\hline GJ/m2/Day ENERGY (Lowest Year) & 0.006 & 0.005 & 0.004 & 0.003 & 0.002 & 0.002 & 0.004 & 0.003 & 0.002 & 0.003 & 0.002 & 0.002 \\
\hline $\mathrm{GJ} / \mathrm{m} 2 /$ Month (Lowest Consumption Year) & 0.187 & 0.159 & 0.126 & 0.107 & 0.069 & 0.070 & 0.139 & 0.078 & 0.068 & 0.083 & 0.050 & 0.060 \\
\hline Average Highest Year to Lowest Year & 0.308 & 0.177 & 0.110 & 0.100 & 0.055 & 0.067 & 0.104 & 0.081 & 0.087 & 0.108 & 0.102 & 0.058 \\
\hline BOMA Mean Value per Month & 0.111 & 0.111 & 0.111 & 0.111 & 0.111 & 0.111 & 0.111 & 0.111 & 0.111 & 0.111 & 0.111 & 0.111 \\
\hline Energy Usage per Month (Electricity + Ga & 1727 & 1467 & 1160 & 988 & 637 & 644 & 1282 & 723 & 624 & 763 & 462 & 553 \\
\hline Degree Days & 830 & 606 & 534 & 307 & 166 & 84 & 50 & 101 & 76 & 288 & 361 & 614 \\
\hline Normalized Data (Average Degree Days) & 727 & 619 & 544 & 333 & 149 & 88 & 86 & 100 & 94 & 248 & 420 & 637 \\
\hline Normalized Data (Av Energy Consumptio & 1754 & 1556 & 1421 & 1036 & 701 & 590 & 587 & 611 & 601 & 882 & 1194 & 1590 \\
\hline Normalized Data (Av Energy Index / mon & 0.190 & 0.168 & 0.154 & 0.112 & 0.076 & 0.064 & 0.063 & 0.066 & 0.065 & 0.095 & 0.129 & 0.172 \\
\hline
\end{tabular}


Analysis on how electricity and gas consumption corresponds to heating and cooling periods (for highest energy consumption year):

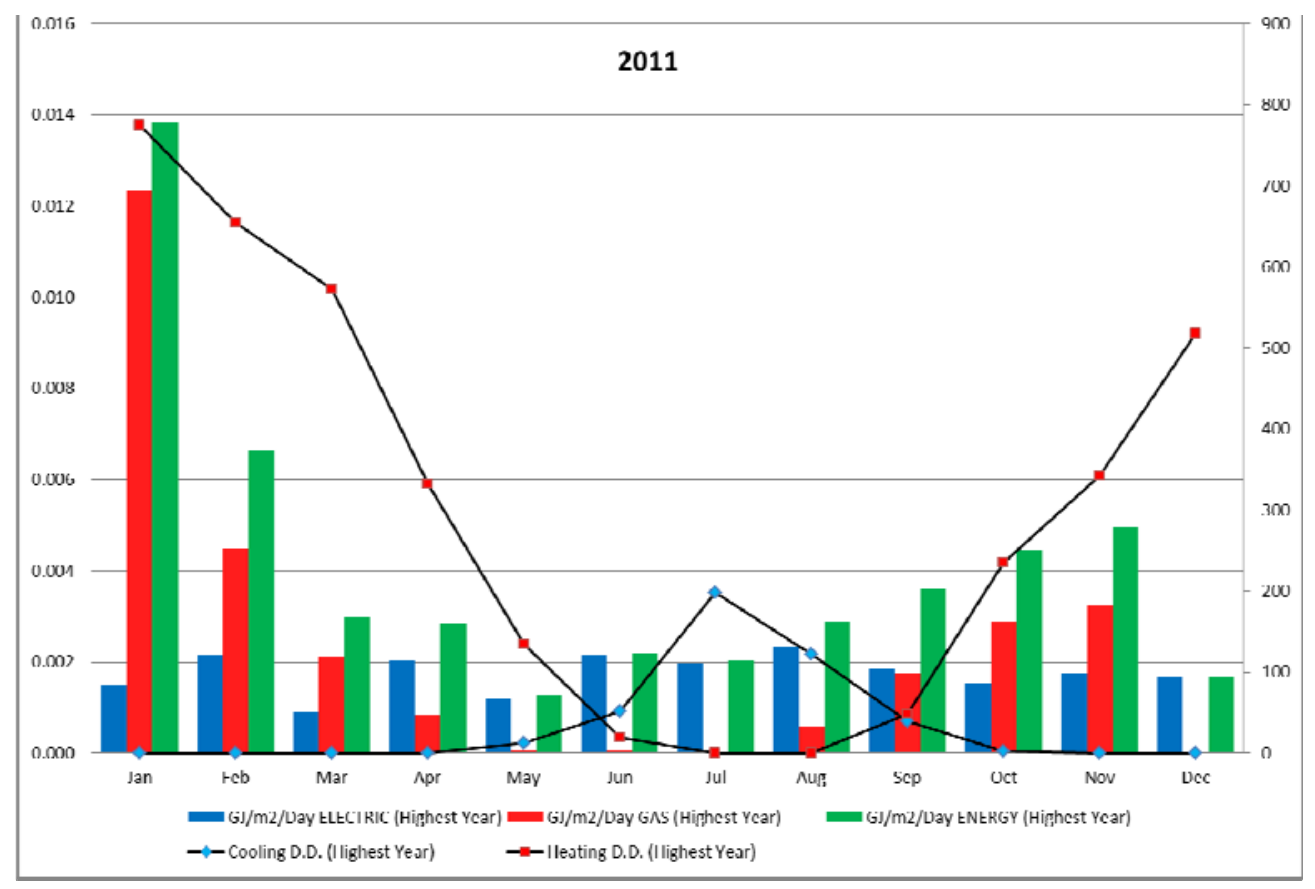

Analysis on how electricity and gas consumption corresponds to heating and cooling periods (for lowest energy consumption year):

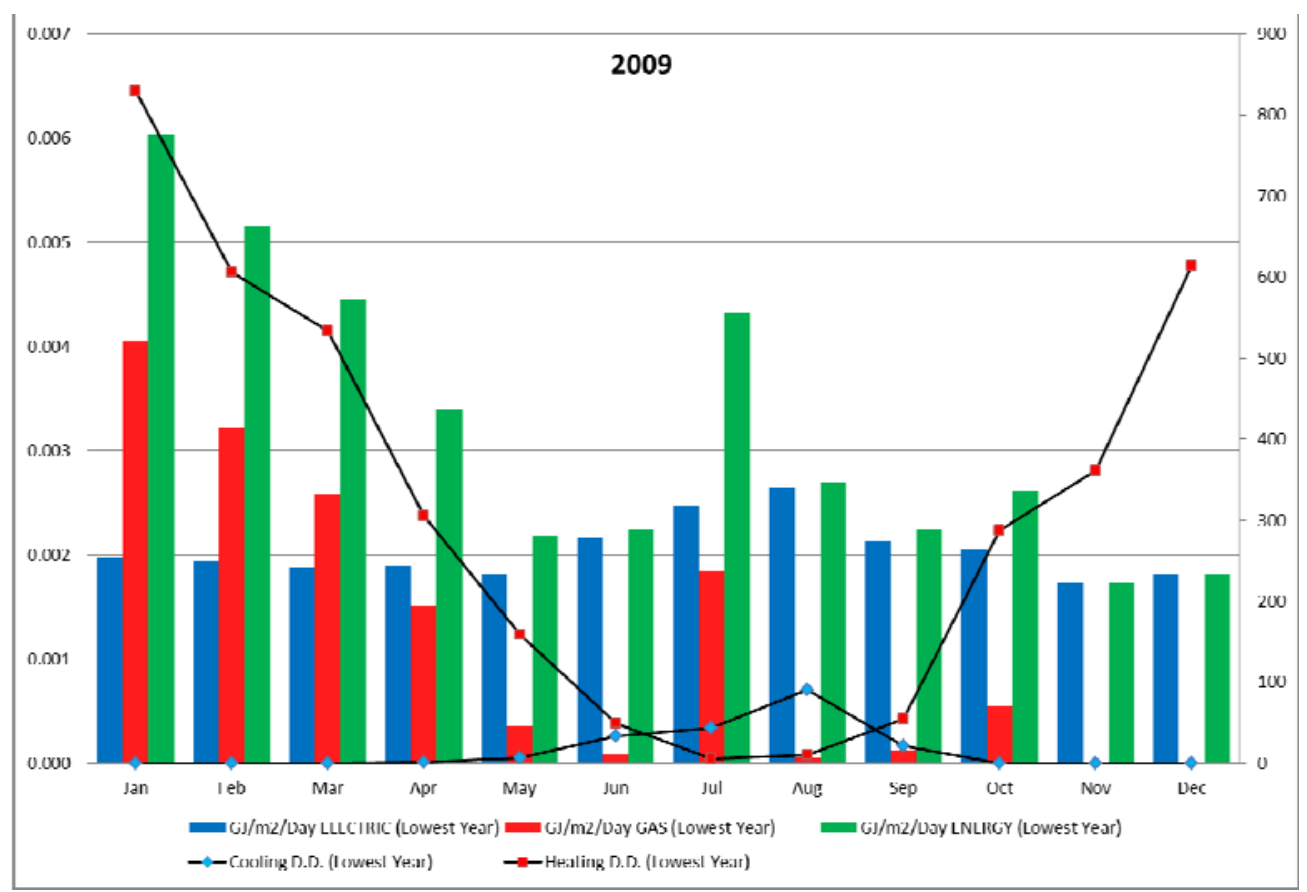


Monthly energy index comparison between highest energy consumption year, lowest, average and benchmark (BOMA) energy intensity:

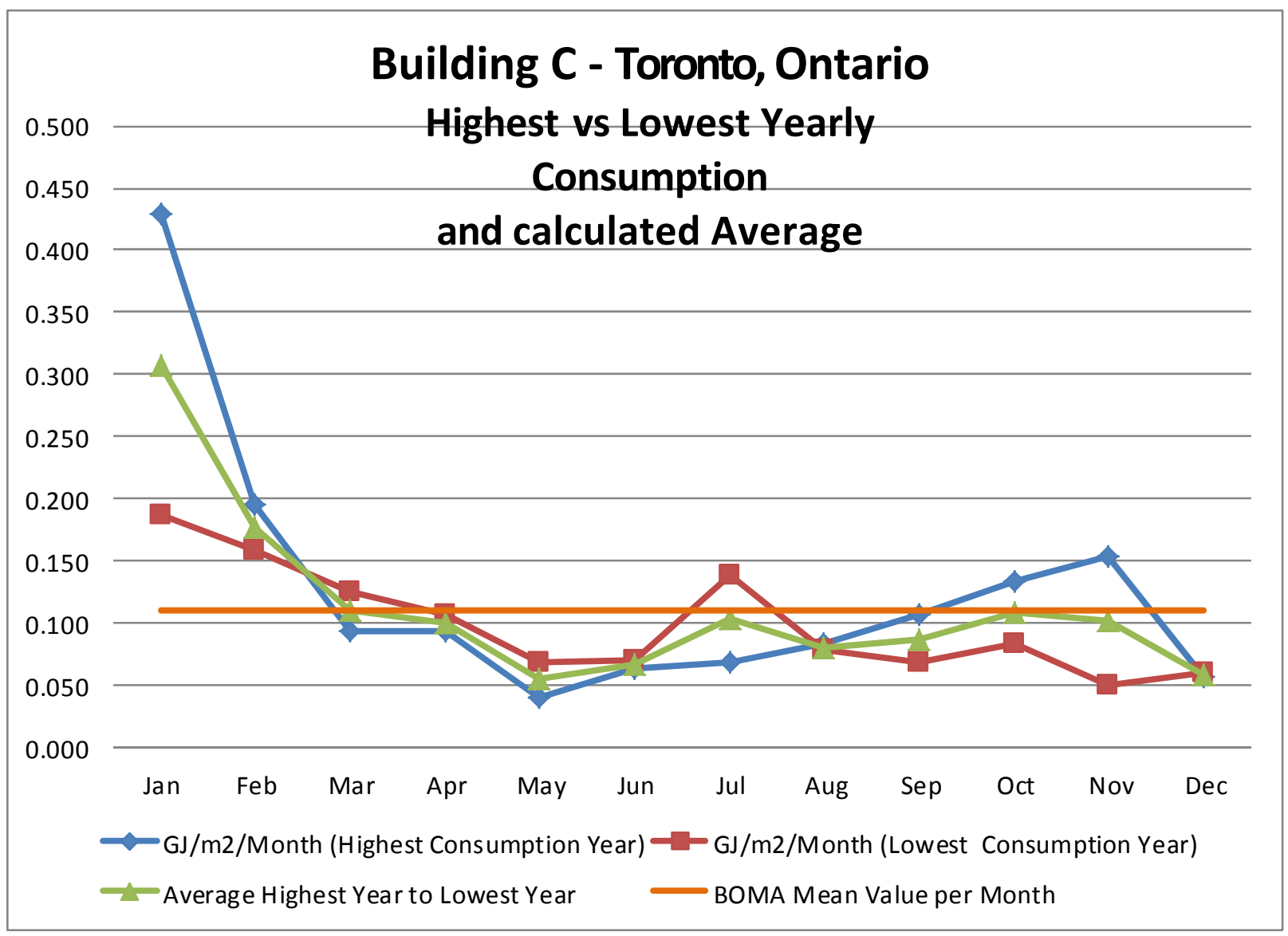


Building \#4 - Utility Bills Analysis

\section{Calculations of Energy Index for Building \#4}

Energy CAP database was utilized to collect energy consumption information for the building. Energy consumption was provided by utility bills for electricity and gas. For Building \#4 utility bills were provided from December 2006 to March 2015. To complete most accurate analysis utility bills for 2007 to 2014 were only analyzed because 2006 and 2015 has incomplete data. By having total floor area for entire building of 15,712 $\mathrm{m}^{2}$, energy index in $\mathrm{GJ} / \mathrm{m}^{2} /$ year was calculated. From calculations it was noticed that gas consumption in 2012 is lower than other years, but this year was included in calculations.

Utility bills analysis showed following:

\begin{tabular}{|c|c|c|c|c|c|c|c|c|}
\hline \multicolumn{9}{|c|}{ Building D - Mississauga, Ontario } \\
\hline & & & kWh & & & $m^{3}$-ngas & Total GJ/yr & $15,712.00$ \\
\hline Row Labels & \multicolumn{2}{|c|}{$\begin{array}{c}\text { Sum of Ele Total } \\
\text { Cost / Year }\end{array}$} & $\begin{array}{c}\text { Sum of Ele } \\
\begin{array}{c}\text { Consumption / } \\
\text { Year }\end{array} \\
\end{array}$ & \multicolumn{2}{|c|}{$\begin{array}{c}\text { Sum of Gas Total } \\
\text { Cost / Year }\end{array}$} & $\begin{array}{c}\text { Sum of Gas } \\
\text { Consumption } \\
\text { / Year }\end{array}$ & Total & $\mathrm{GJ} / \mathrm{m} 2 / \mathrm{yr}$ \\
\hline Year 2006 & $\$$ & $37,785.45$ & $334,800.00$ & & & & & \\
\hline Year 2007 & $\$$ & $410,537.45$ & $3,680,400.00$ & $\$$ & $37,382.66$ & $74,712.00$ & $16,028.73$ & 1.02 \\
\hline Year 2008 & $\$$ & $382,770.41$ & $4,057,200.00$ & $\$$ & $36,450.36$ & $73,660.00$ & $17,346.07$ & 1.10 \\
\hline Year 2009 & $\$$ & $443,793.78$ & $4,525,401.60$ & $\$$ & $34,358.18$ & $60,446.00$ & $18,540.04$ & 1.18 \\
\hline Year 2010 & $\$$ & $428,198.70$ & $3,995,644.20$ & $\$$ & $21,306.10$ & $40,093.00$ & $15,875.78$ & 1.01 \\
\hline Year 2011 & $\$$ & $526,856.96$ & $4,521,619.20$ & $\$$ & $19,058.84$ & $41,305.00$ & $17,814.38$ & 1.13 \\
\hline Year 2012 & $\$$ & $505,052.00$ & $4,231,608.00$ & $\$$ & $7,665.44$ & $27,266.00$ & $16,248.08$ & 1.03 \\
\hline Year 2013 & $\$$ & $529,230.33$ & $4,026,000.00$ & $\$$ & $17,580.83$ & $67,617.00$ & $17,008.95$ & 1.08 \\
\hline Year 2014 & $\$$ & $535,652.84$ & $3,918,000.00$ & $\$$ & $24,764.77$ & $78,886.00$ & $17,039.36$ & 1.08 \\
\hline Year 2015 & $\$$ & $134,893.74$ & $928,800.00$ & $\$$ & $22,223.44$ & $63,019.00$ & & \\
\hline Average & $\$$ & $393,477.17$ & $3,421,947.30$ & $\$$ & $24,532.29$ & $58,556.00$ & & 1.08 \\
\hline
\end{tabular}

As it was specified in energy audit, energy consumption of the Building \#4 is average in comparison to similar office buildings in same region; and therefore average energy index which equals to $1.08 \mathrm{GJ} / \mathrm{m}^{2} / \mathrm{yr}$ is also average in comparison to benchmark values of BOMA energy efficient building value of $1.05 \mathrm{GJ} / \mathrm{m}^{2} / \mathrm{yr}$, however value is much lower than average National Resources Canada value of $1.43 \mathrm{GJ} / \mathrm{m} 2 /$ year.

Two charts below show electricity and gas consumption per year. Electricity consumption chart fluctuating throughout years but doesn't show any significant improvement or degradation. On the other hand gas consumption show very low value in 2012 , this could be due to the fact that some of the gas utility bills were 
carried into 2013, however by analyzing billing information it was not possible to come to such conclusion certainly.
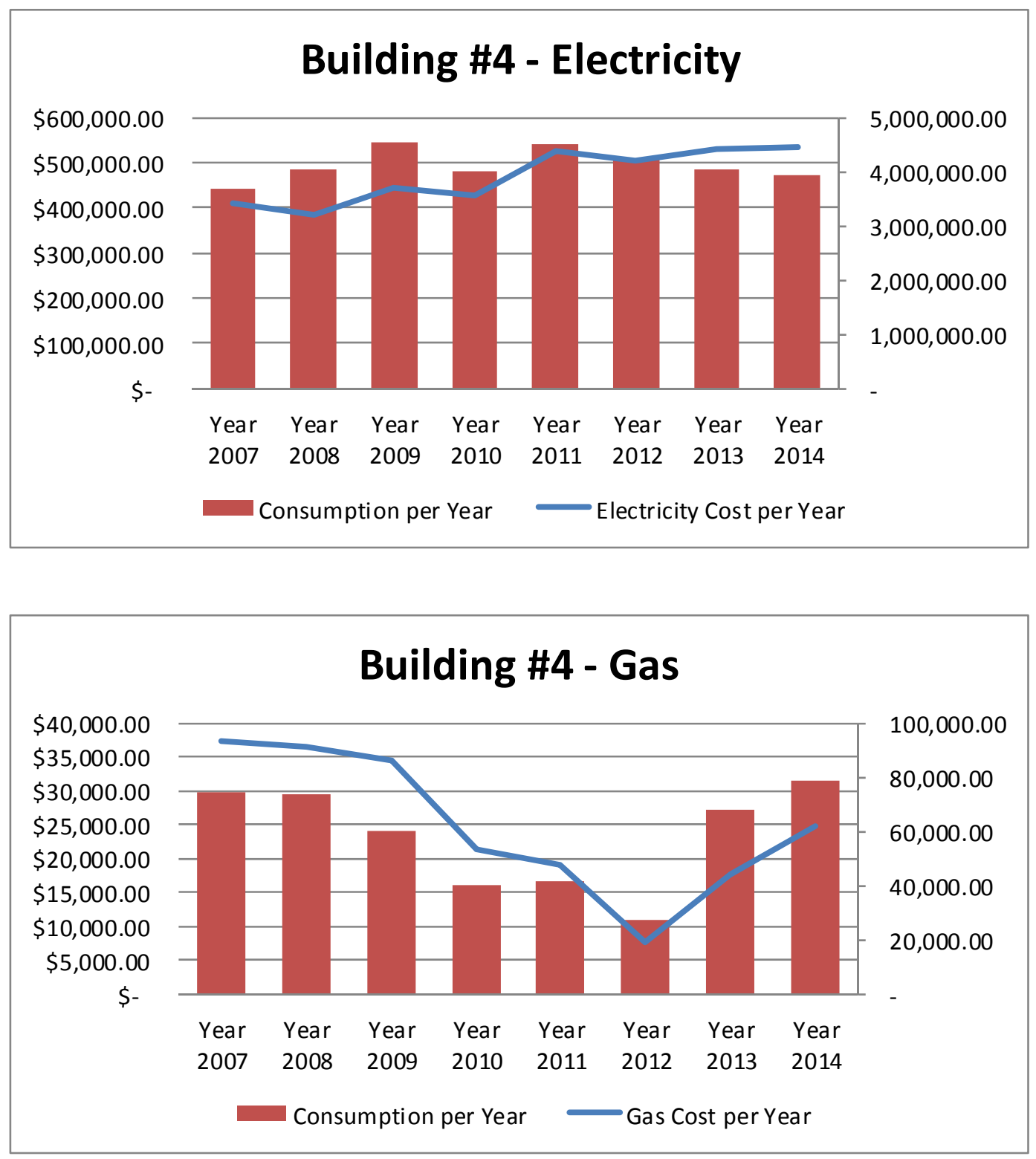

Yearly energy intensity (index) was also plotted to demonstrate increase or decrease over the range of years for which data is available. Chart below shows that energy index value is fluctuation through given year range, and in recent years is even lower than in 2010 or 2007. The lowest energy index was in 2010 and highest in 2009. These two years' data will be used for further calculations and comparisons. 


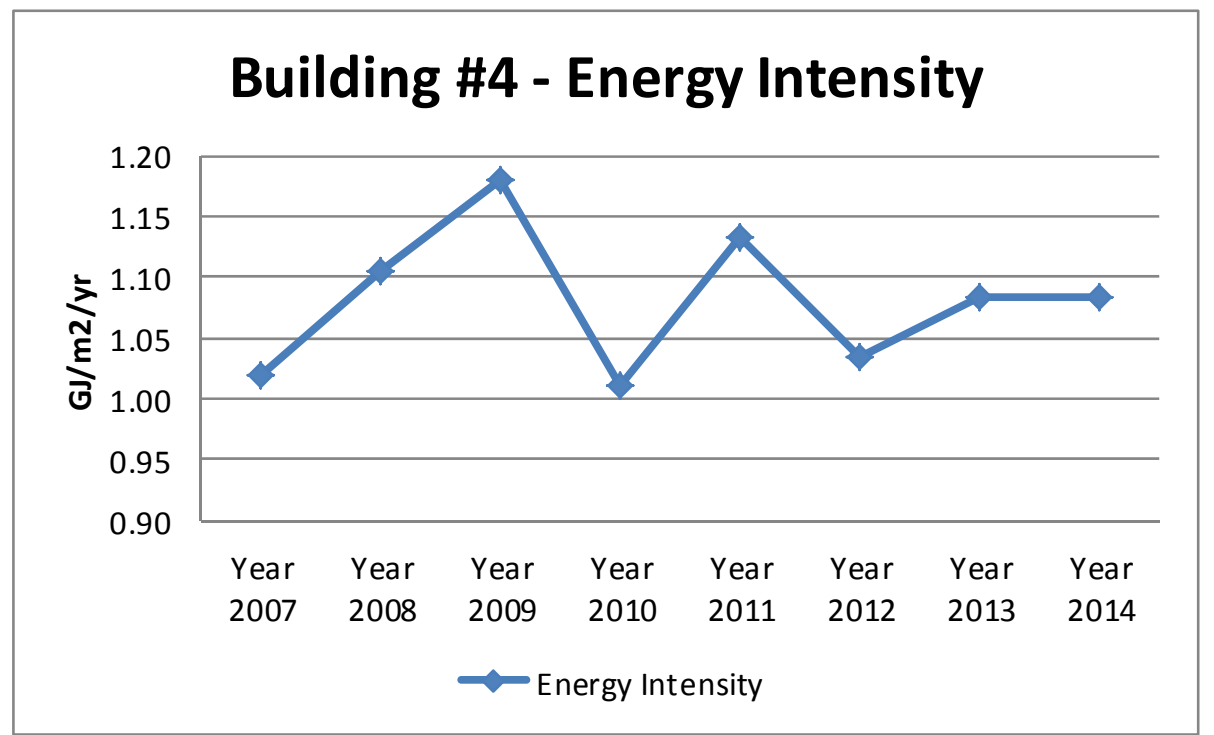

Normalized total energy consumption was calculated for Building \#4. Based on plotted results, shown below in the chart, it can be concluded that energy consumption for 2009 is higher than for 2010. This proves that regardless of weather conditions 2009 has higher energy consumptions than in 2010. Implementing trendline equations, average equation was calculated:

\section{$\gamma=0.8284 x+1161,65$}

From above equation normalized average energy index was calculated as $1.09 \mathrm{GJ} / \mathrm{m}^{2} / \mathrm{yr}$, this value is slightly higher than average for 2007 to 2014 years range. Calculated value will be used for further case-study buildings comparison. 


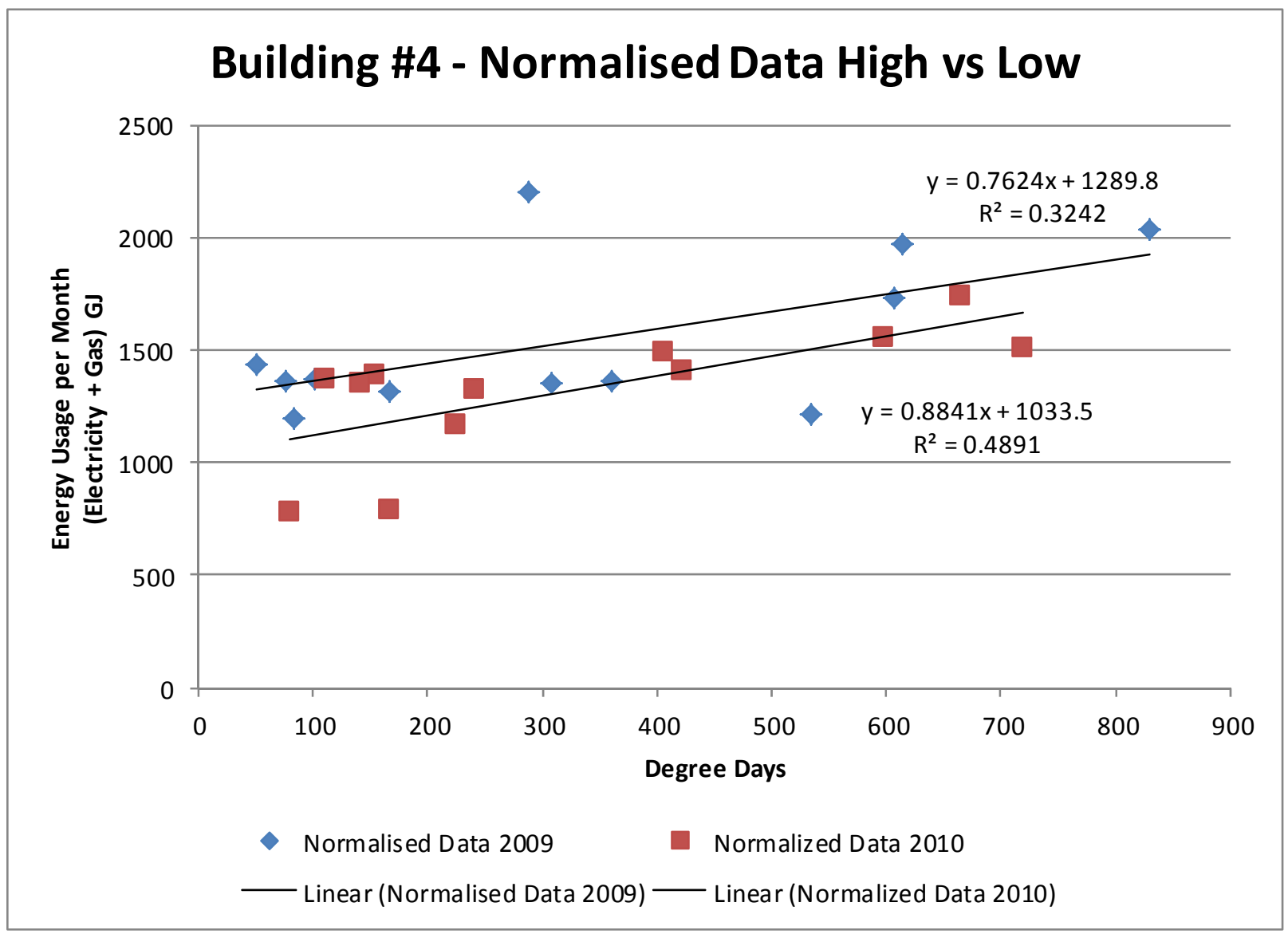


Actual data used for calculations (year with highest energy consumption):

\begin{tabular}{|c|c|c|c|c|c|c|c|c|c|c|c|c|}
\hline ADDRESS: & \multicolumn{4}{|c|}{ Building D -Mississauga, Ontario } & & & & & & & & \\
\hline BUILDING \# & \multicolumn{4}{|c|}{4} & & & & & & & & \\
\hline Year - Highest Energy Consumption: & \multicolumn{4}{|l|}{2009} & & & & & & & & \\
\hline AREA: & \multicolumn{4}{|l|}{15,712} & & & & & & & & \\
\hline USAGE INDEX: & \multicolumn{4}{|l|}{1.18} & & & & & & & & \\
\hline Month & Jan & Feb & Mar & Apr & May & Jun & Jul & Aug & Sep & Oct & Nov & Dec \\
\hline \multirow{2}{*}{$\begin{array}{l}\text { Electric Billing Date } \\
\text { Electric Billing Days }\end{array}$} & $2009 / 01 / 21$ & $2009 / 02 / 20$ & $2009 / 03 / 18$ & $2009 / 04 / 21$ & $2009 / 05 / 21$ & $2009 / 06 / 19$ & $2009 / 07 / 21$ & $2009 / 08 / 21$ & $2009 / 09 / 23$ & $2009 / 11 / 18$ & $2009 / 12 / 15$ & $2010 / 01 / 20$ \\
\hline & 31 & 30 & 26 & 34 & 30 & 29 & 32 & 31 & 33 & 56 & 27 & 36 \\
\hline \multirow{2}{*}{$\begin{array}{l}\text { Gas Billing Date } \\
\text { Gas Billing Days }\end{array}$} & $2009 / 01 / 21$ & $2009 / 02 / 20$ & $2009 / 03 / 18$ & 2009/04/21 & $2009 / 05 / 21$ & 2009/06/19 & $2009 / 07 / 21$ & 2009/08/21 & $2009 / 09 / 23$ & $2009 / 11 / 18$ & $2009 / 12 / 15$ & $2010 / 01 / 20$ \\
\hline & 31 & 30 & 26 & 34 & 30 & 29 & 32 & 31 & 33 & 56 & 27 & 36 \\
\hline \multicolumn{13}{|l|}{ COOLING \& HEATING DEGREE DAYS } \\
\hline & & & & & & & & & & & & \\
\hline \multirow{4}{*}{$\begin{array}{l}\text { Cooling D.D. (Highest Year) } \\
\text { Daily Clg D.D. Avg. (Highest Year) } \\
\text { Normal Cooling D.D. (Highest Year) }\end{array}$} & 0 & 0 & 0 & 1 & 7 & 34 & 44 & 91 & 21 & 0 & 0 & 0 \\
\hline & 0 & 0 & 0 & 0 & 0 & 1 & 1 & 3 & 1 & 0 & 0 & 0 \\
\hline & & & & & & & & & & & & \\
\hline & & & & & & & & & & & & \\
\hline \multirow{4}{*}{$\begin{array}{l}\text { Heating D.D. (Highest Year) } \\
\text { Daily Htg. D.D. Avg. (Highest Year) } \\
\text { Normal Heating D.D (Highest Year) }\end{array}$} & 830 & 606 & 534 & 306 & 159 & 49 & 6 & 10 & 55 & 288 & 361 & 614 \\
\hline & 27 & 20 & 21 & 9 & 5 & 2 & 0 & 0 & 2 & 5 & 13 & 17 \\
\hline & & & & & & & & & & & & \\
\hline & & & & & & & & & & & & \\
\hline \multicolumn{13}{|l|}{ ELECTRICAL USAGE \& COST } \\
\hline \multirow{2}{*}{$\begin{array}{l}\text { kWh Used } \\
\text { Daily kWh Avg. }\end{array}$} & 326,400 & 343,200 & 300,000 & 373,200 & 366,000 & 331,200 & 398,400 & 380,400 & 379,200 & 612,000 & 295,200 & 420,202 \\
\hline & 10,529 & 11,440 & 11,538 & 10,976 & 12,200 & 11,421 & 12,450 & 12,271 & 11,491 & 10,929 & 10,933 & 11,672 \\
\hline \multirow[b]{2}{*}{ Demand kW/RkVA Used } & & & & & & & & & & & & \\
\hline & 631 & 640 & 629 & 674 & 684 & 796 & 782 & 743 & 748 & 659 & 702 & 657 \\
\hline \multirow[t]{2}{*}{ Load Factor (Highest Year) } & $70 \%$ & $74 \%$ & $76 \%$ & $68 \%$ & $74 \%$ & $60 \%$ & $66 \%$ & $69 \%$ & $64 \%$ & $69 \%$ & $65 \%$ & $74 \%$ \\
\hline & & & & & & & & & & & & \\
\hline \multicolumn{13}{|l|}{ NATURAL GAS USAGE \& COST } \\
\hline \multicolumn{13}{|l|}{ CCF } \\
\hline$m^{\wedge} 3$ Used & 23,010 & 13,427 & 3,589 & 151 & 6 & 0 & 0 & 0 & 0 & 0 & 8,022 & 12,241 \\
\hline \multirow[t]{2}{*}{ Daily $\mathrm{m}^{\wedge} 3$ Avg. } & 742 & 448 & 138 & 4 & 0 & 0 & 0 & 0 & 0 & 0 & 297 & 340 \\
\hline & & & & & & & & & & & & \\
\hline GREENHOUSE DATA & & & & & & & & & & & & \\
\hline C02 (kgs) (Highest Year) & 382,422 & 325,904 & 227,218 & 252,130 & 246,261 & 222,807 & 268,015 & 255,905 & 255,098 & 411,709 & 255,362 & 369,312 \\
\hline S02 (kgs) (Highest Year) & 4,132 & 3,521 & 2,455 & 2,724 & 2,661 & 2,407 & 2,896 & 2,765 & 2,756 & 4,448 & 2,759 & 3,990 \\
\hline NOx (kgs) (Highest Year) & 1,811 & 1,544 & 1,076 & 1,194 & 1,166 & 1,055 & 1,269 & 1,212 & 1,208 & 1,950 & 1,210 & 1,749 \\
\hline & & & & & & & & & & & & \\
\hline USAGE DATA & & & & & & & & & & & & \\
\hline kWh to GJ & 1175.04 & 1235.52 & 1080.00 & 1343.52 & 1317.60 & 1192.32 & 1434.24 & 1369.44 & 1365.12 & 2203.20 & 1062.72 & 1512.73 \\
\hline GJ/m2/Day ELECTRIC (Highest Year) & 0.002 & 0.003 & 0.003 & 0.003 & 0.003 & 0.003 & 0.003 & 0.003 & 0.003 & 0.003 & 0.003 & 0.003 \\
\hline GJ/m2/Month (Highest Year) & 0.07 & 0.08 & 0.07 & 0.09 & 0.08 & 0.08 & 0.09 & 0.09 & 0.09 & 0.14 & 0.07 & 0.10 \\
\hline 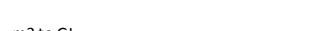 & & & & & & & & & & & & \\
\hline $\begin{array}{l}\mathrm{m} 3 \text { to GJ } \\
\mathrm{GJ} / \mathrm{m} 2 / \text { Day GAS (Highest Year) }\end{array}$ & $\begin{array}{r}855.97 \\
0.002\end{array}$ & $\begin{array}{c}499.48 \\
0.001\end{array}$ & $\frac{133.51}{0.000}$ & $\begin{array}{c}5.62 \\
0.000\end{array}$ & $\begin{array}{l}0.22 \\
0.000\end{array}$ & $\begin{array}{l}0.00 \\
0.000\end{array}$ & $\begin{array}{l}0.00 \\
0.000\end{array}$ & $\begin{array}{l}0.00 \\
0.000\end{array}$ & $\begin{array}{l}0.00 \\
0.000\end{array}$ & $\begin{array}{l}0.00 \\
0.000\end{array}$ & $\begin{array}{c}298.42 \\
0.001\end{array}$ & $\begin{array}{l}455.37 \\
0.001\end{array}$ \\
\hline $\mathrm{GJ} / \mathrm{m} 2 /$ Month & $\begin{array}{ll}0.002 \\
0.05\end{array}$ & $\begin{array}{ll}0.001 \\
0.03\end{array}$ & 0.01 & 0.00 & 0.00 & 0.00 & 0.00 & 0.00 & 0.00 & 0.00 & 0.02 & 0.03 \\
\hline $\mathrm{m} 3 / \mathrm{m} 2 /$ Month & 1.46 & 0.85 & 0.23 & 0.01 & 0.00 & 0.00 & 0.00 & 0.00 & 0.00 & 0.00 & 0.51 & 0.78 \\
\hline GJ/m2/Day ENERGY (Highest Year) & 0.004 & 0.004 & 0.003 & 0.003 & 0.003 & 0.003 & 0.003 & 0.003 & 0.003 & 0.003 & 0.003 & 0.003 \\
\hline $\mathrm{GJ} / \mathrm{m} 2 /$ Month (Highest Consumption Year) & 0.129 & 0.110 & 0.077 & 0.086 & 0.084 & 0.076 & 0.091 & 0.087 & 0.087 & 0.140 & 0.087 & 0.125 \\
\hline Energy Usage per Month (Electricity + Gas) & 2031 & 1735 & 1214 & 1349 & 1318 & 1192 & 1434 & 1369 & 1365 & 2203 & 1361 & 1968 \\
\hline Degree Days & 830 & 606 & 534 & 307 & 166 & 84 & 50 & 101 & 76 & 288 & 361 & 614 \\
\hline
\end{tabular}




\section{Actual data used for calculations (year with lowest energy consumption):}

\begin{tabular}{|c|c|c|c|c|c|c|c|c|c|c|c|c|}
\hline ADDRESS: & \multicolumn{4}{|c|}{ Building D -Mississauga, Ontario } & \multirow[b]{6}{*}{ May } & \multirow[b]{6}{*}{ Jun } & \multirow[b]{6}{*}{ Jul } & \multirow[b]{6}{*}{ Aug } & \multirow[b]{6}{*}{ Sep } & \multirow[b]{6}{*}{ Oct } & \multirow[b]{6}{*}{ Nov } & \multirow[b]{6}{*}{ Dec } \\
\hline BUILDING \# & \multicolumn{4}{|c|}{4} & & & & & & & & \\
\hline Year - Lowest Energy Consumption: & \multicolumn{4}{|l|}{2010} & & & & & & & & \\
\hline AREA: & \multicolumn{4}{|l|}{15,712} & & & & & & & & \\
\hline USAGE INDEX: & 1.01 & AVERAGE: & 1.0952 & 1.09685 & & & & & & & & \\
\hline Month & $\operatorname{Jan}$ & Feb & Mar & Apr & & & & & & & & \\
\hline \multirow{4}{*}{$\begin{array}{l}\text { Electric Billing Date } \\
\text { Electric Billing Days }\end{array}$} & $2010 / 02 / 09$ & $2010 / 03 / 10$ & $2010 / 04 / 13$ & $2010 / 05 / 13$ & $2010 / 06 / 10$ & $2010 / 07 / 13$ & $2010 / 08 / 13$ & $2010 / 09 / 13$ & $2010 / 10 / 13$ & $2010 / 11 / 09$ & $2010 / 12 / 08$ & $2011 / 01 / 05$ \\
\hline & 31 & 29 & 34 & 30 & 28 & 33 & 31 & 31 & 30 & 27 & 29 & 28 \\
\hline & $2010 / 02 / 09$ & $2010 / 03 / 10$ & $2010 / 04 / 13$ & $2010 / 05 / 13$ & $2010 / 06 / 10$ & $2010 / 07 / 13$ & 2010/08/13 & $2010 / 09 / 13$ & $2010 / 10 / 13$ & $2010 / 11 / 09$ & $2010 / 12 / 08$ & $2011 / 01 / 05$ \\
\hline & 31 & 29 & 34 & 30 & 28 & 33 & 31 & 31 & 30 & 27 & 29 & 28 \\
\hline \multicolumn{13}{|l|}{ COOLING \& HEATING DEGREE DAYS } \\
\hline Cooling D D Rumect Yearl & & & & & & & & & & & & \\
\hline Cooling D.D. (Lowest Year) & 0 & 0 & 0 & 0 & 46 & 59 & 165 & 139 & 32 & 0 & 0 & 0 \\
\hline \multirow{2}{*}{$\begin{array}{l}\text { Daily Clg D.D. Avg. (Lowest Year) } \\
\text { Normal Cooling D.D. (Lowest Year) }\end{array}$} & 0 & 0 & 0 & 0 & 2 & 2 & 5 & 4 & 1 & 0 & 0 & 0 \\
\hline & & & & & & & & & $x^{2}$ & & 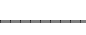 & \\
\hline Heating D.D. (Lowest Year) & 720 & 598 & 423 & 225 & 108 & 22 & 2 & 2 & 78 & 242 & 405 & 665 \\
\hline \multirow{3}{*}{$\begin{array}{l}\text { Daily Htg. D.D. Avg. (Lowest Year) } \\
\text { Normal Heating D.D (Lowest Year) }\end{array}$} & 23 & 21 & 12 & 8 & 4 & 1 & 0 & 0 & 3 & 9 & 14 & 24 \\
\hline & & & & & & & & & & & & \\
\hline & & & & & & & & & & & & \\
\hline ELECTRICAL USAGE \& COST & & & & & & & & & & & & \\
\hline kWh Used & 341,880 & 329,448 & 370,474 & 319,502 & 385,392 & 216,317 & 216,317 & 374,203 & 381,662 & 364,257 & 318,259 & 377,933 \\
\hline Daily kWh Avg. & 11,028 & 11,360 & 10,896 & 10,650 & 13,764 & 6,555 & 6,978 & 12,071 & 12,722 & 13,491 & 10,974 & 13,498 \\
\hline Demand kbu/Rkya used & 658 & 664 & 618 & 654 & 689 & 706 & 683 & 712 & 690 & 617 & & \\
\hline $\begin{array}{l}\text { Demand kW/RkVA Used } \\
\text { Load Factor (Lowest Year) }\end{array}$ & $\begin{array}{l}658 \\
70 \%\end{array}$ & 664 & 618 & 654 & 688 & 746 & 683 & 712 & 690 & 617 & 664 & 606 \\
\hline & & & & & & & $40 \%$ & $11 \%$ & $\pi \%$ & $5+1 \%$ & & (50 \\
\hline NATURAL GAS USAGE \& COST & & & & & & & & & & & & \\
\hline CCF & & & & & & & & & & & & \\
\hline $\mathrm{m}^{\wedge} 3$ Used & 7,434 & 9,857 & 2,043 & 439 & 15 & 0 & 184 & 26 & 3 & 437 & 9,378 & 10,277 \\
\hline Daily $\mathrm{m}^{\wedge} 3$ Avg. & 240 & 340 & 60 & 15 & 1 & 0 & 6 & 1 & 0 & 16 & 323 & 367 \\
\hline & & & & & & & & & & & & \\
\hline GREENHOUSE DATA & & & & & & & & & & & & \\
\hline C02 (kgs) (Lowest Year) & 282,603 & 291,388 & 263,686 & 218,045 & 259,370 & 145,522 & 146,824 & 251,921 & 256,776 & 248,138 & 280,471 & 326,977 \\
\hline S02 (kgs) (Lowest Year) & 3,053 & 3,148 & 2,849 & 2,356 & 2,802 & 1,572 & 1,586 & 2,722 & 2,774 & 2,681 & 3,030 & 3,533 \\
\hline NOx (kgs) (Lowest Year) & 1,339 & 1,380 & 1,249 & 1,033 & 1,229 & 689 & 695 & 1,193 & 1,216 & 1,175 & 1,328 & 1,549 \\
\hline & & & & & & & & & & & & \\
\hline USAGE DATA & & & & & & & & & & & & \\
\hline kWh to GJ & 1230.77 & $\begin{array}{ll}1186.01 \\
\end{array}$ & 1333.70 & 1150.21 & 1387.41 & 778.74 & 778.74 & 1347.13 & 1373.98 & 1311.33 & 1145.73 & 1360.56 \\
\hline GJ/m2/Day ELECTRIC (Lowest Year) & 0.003 & 0.003 & 0.002 & 0.002 & 0.003 & 0.002 & 0.002 & 0.003 & 0.003 & 0.003 & 0.003 & 0.003 \\
\hline GJ/m2/Month (Lowest Year) & 0.08 & 0.08 & 0.08 & 0.07 & 0.09 & 0.05 & 0.05 & 0.09 & 0.09 & 0.08 & 0.07 & 0.09 \\
\hline $\mathrm{m} 3$ to $\mathrm{GJ}$ & 276.54 & 366.68 & 76.00 & 16.33 & 0.56 & 0.00 & 6.84 & 0.97 & 0.11 & 16.26 & 348.86 & 382.30 \\
\hline GJ/m2/Day GAS (Lowest Year) & 0.001 & 0.001 & 0.000 & 0.000 & 0.000 & 0.000 & 0.000 & 0.000 & 0.000 & 0.000 & 0.001 & 0.001 \\
\hline $\mathrm{GJ} / \mathrm{m} 2 /$ Month & 0.02 & 0.02 & 0.00 & 0.00 & 0.00 & 0.00 & 0.00 & 0.00 & 0.00 & 0.00 & 0.02 & 0.02 \\
\hline $\mathrm{m} 3 / \mathrm{m} 2 /$ Month & 0.47 & 0.63 & 0.13 & 0.03 & 0.00 & 0.00 & 0.01 & 0.00 & 0.00 & 0.03 & 0.60 & 0.65 \\
\hline GJ/m2/Day ENERGY (Lowest Year) & 0.003 & 0.003 & 0.003 & 0.002 & 0.003 & 0.002 & 0.002 & 0.003 & 0.003 & 0.003 & 0.003 & 0.004 \\
\hline $\mathrm{GJ} / \mathrm{m} 2 /$ Month (Lowest Consumption Year) & 0.096 & 0.099 & 0.090 & 0.074 & 0.088 & 0.050 & 0.050 & 0.086 & 0.087 & 0.084 & 0.095 & 0.111 \\
\hline Average Highest Year to Lowest Year & 0.113 & 0.105 & 0.083 & 0.080 & 0.086 & 0.063 & 0.071 & 0.086 & 0.087 & 0.112 & 0.091 & 0.118 \\
\hline BOMA Mean Value per Month & 0.111 & 0.111 & 0.111 & 0.111 & 0.111 & 0.111 & 0.111 & 0.111 & 0.111 & 0.111 & 0.111 & 0.111 \\
\hline Energy Usage per Month (Electricity + Ga & 1507 & 1553 & 1410 & 1167 & 1388 & 779 & 786 & 1348 & 1374 & 1328 & 1495 & 1743 \\
\hline Degree Days & 720 & 598 & 423 & 225 & 154 & 80 & 167 & 141 & 110 & 242 & 405 & 665 \\
\hline Normalized Data (Average Degree Days) & 672 & 615 & 489 & 292 & 143 & 86 & 144 & 120 & 110 & 225 & 442 & 663 \\
\hline Normalized Data (Av Energy Consumptio & 1715 & 1668 & 1564 & 1402 & 1279 & 1233 & 1281 & 1260 & 1252 & 1347 & 1525 & 1707 \\
\hline Normalized Data (Av Energy Index / mon & 0.109 & 0.106 & 0.100 & 0.089 & 0.081 & 0.078 & 0.081 & 0.080 & 0.080 & 0.086 & 0.097 & 0.109 \\
\hline
\end{tabular}


Analysis on how electricity and gas consumption corresponds to heating and cooling periods (for highest energy consumption year):

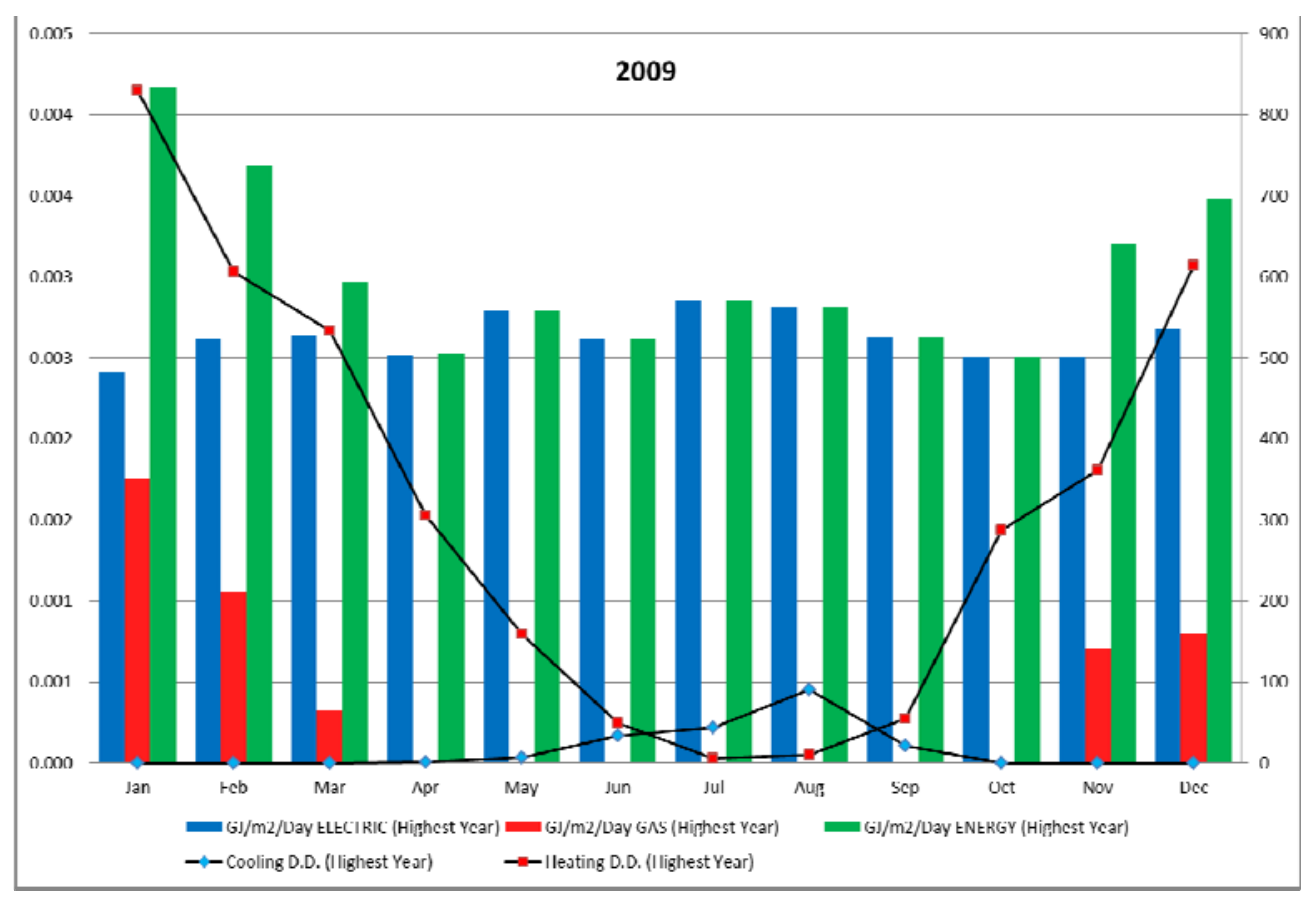

Analysis on how electricity and gas consumption corresponds to heating and cooling periods (for lowest energy consumption year):

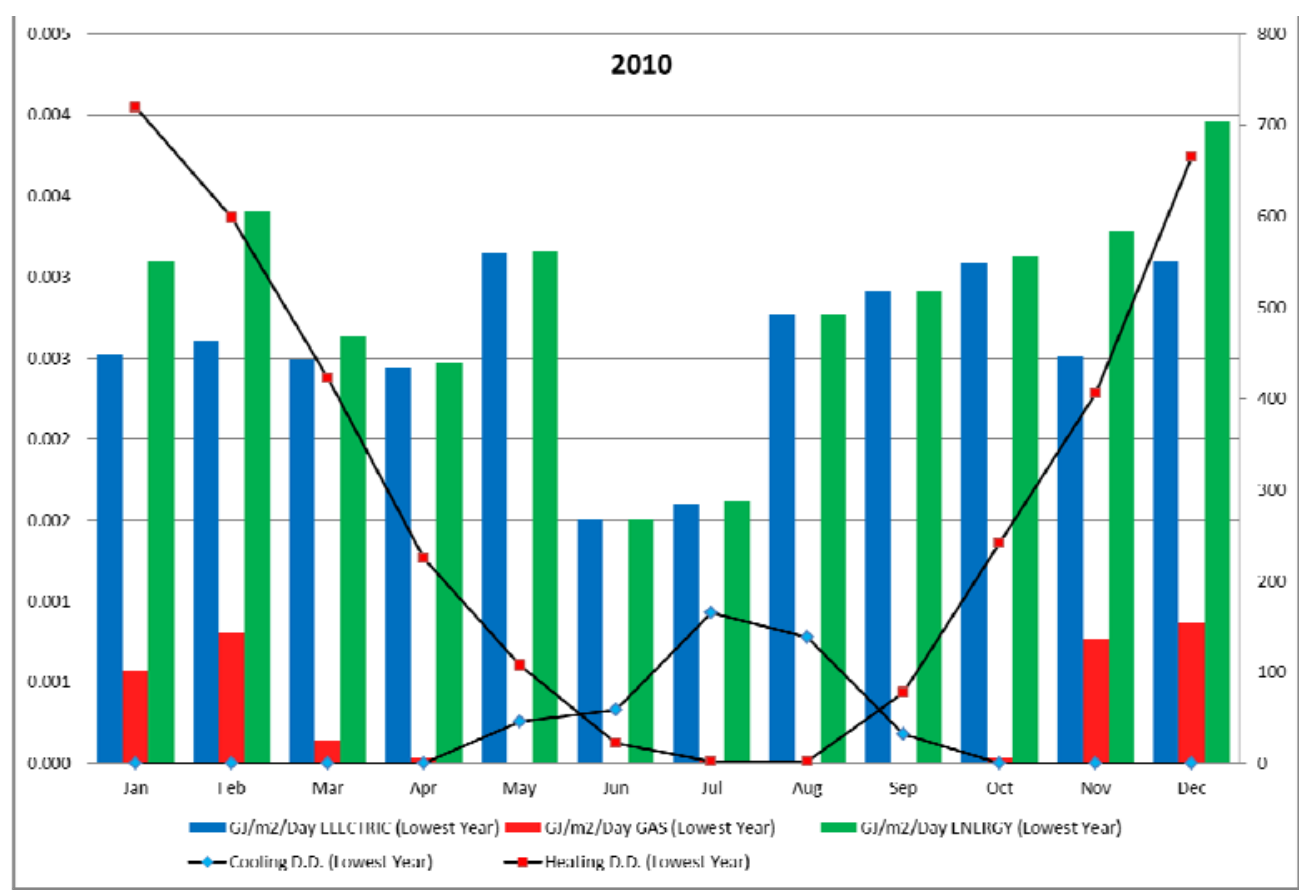


Monthly energy index comparison between highest energy consumption year, lowest, average and benchmark (BOMA) energy intensity:

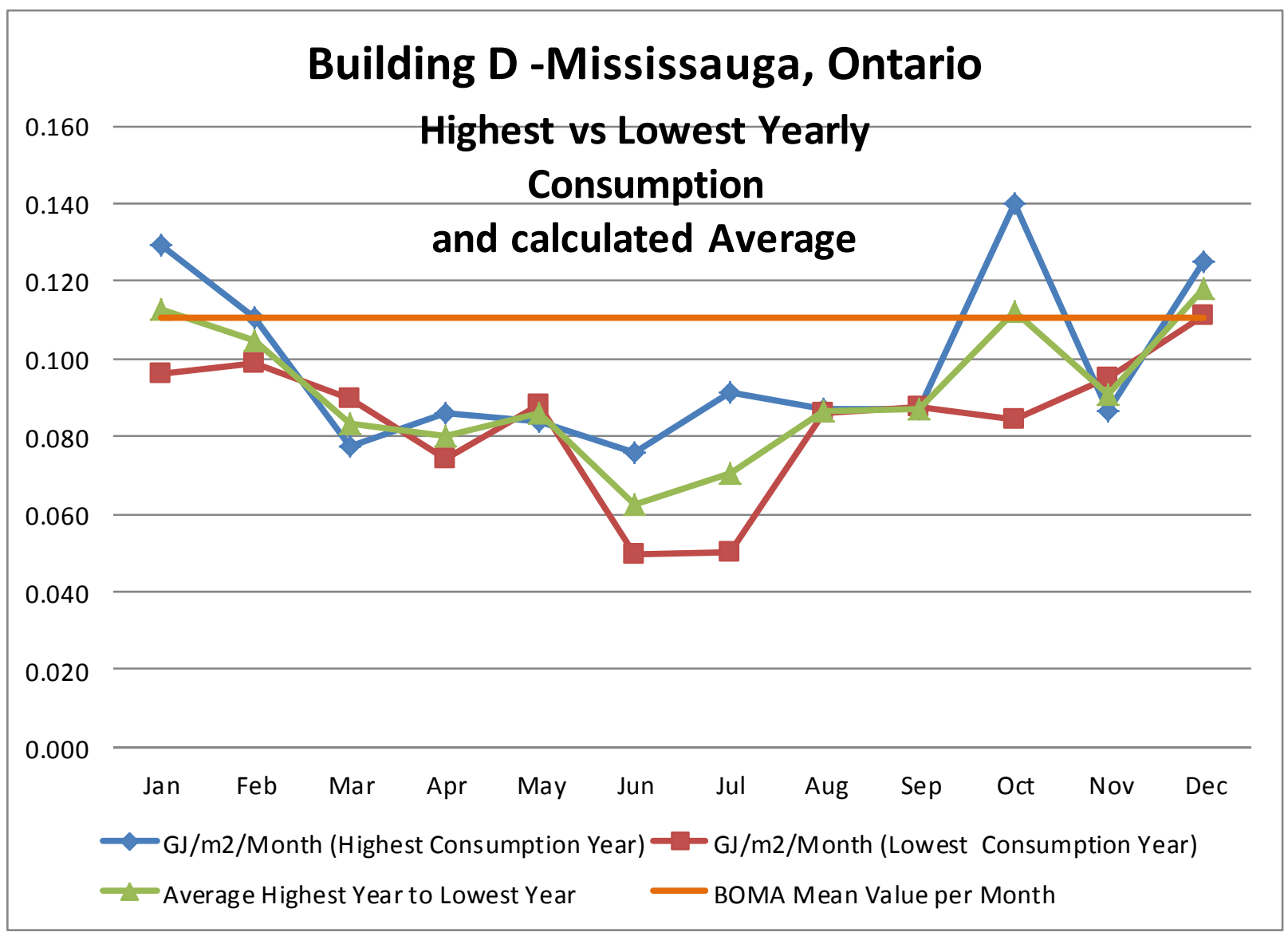


Building \#5 - Utility Bills Analysis

\section{Calculations of Energy Index for Building \#5}

Energy CAP database was utilized to collect energy consumption information for the building. Energy consumption was provided by utility bills for electricity and gas. For Building \#5 utility bills were provided from December 2006 to March 2015. To complete most accurate analysis utility bills for 2007 to 2014 were only analyzed because 2006 and 2015 has incomplete data. By having total floor area for entire building of 6,332 $\mathrm{m}^{2}$, energy index in $\mathrm{GJ} / \mathrm{m}^{2} /$ year was calculated. Calculations didn't show very significant inconsistency; therefore all years' data was included for calculations.

Utility bills analysis showed following:

\begin{tabular}{|c|c|c|c|c|c|c|c|c|}
\hline \multicolumn{6}{|c|}{ Building E - Mississauga, Ontario } & \multirow[b]{2}{*}{$\mathrm{m}^{3}$-ngas } & \multirow[b]{2}{*}{ Total GJ/yr } & \multirow[b]{2}{*}{$6,332.00$} \\
\hline & & & kWh & & & & & \\
\hline Row Labels & \multicolumn{2}{|c|}{$\begin{array}{c}\text { Sum of Ele Total } \\
\text { Cost / Year }\end{array}$} & $\begin{array}{c}\text { Sum of Ele } \\
\text { Consumption } \\
\text { / Year }\end{array}$ & \multicolumn{2}{|c|}{$\begin{array}{c}\text { Sum of Gas Total } \\
\text { Cost / Year }\end{array}$} & $\begin{array}{c}\text { Sum of Gas } \\
\text { Consumption } \\
\text { / Year }\end{array}$ & Total & $\mathrm{GJ} / \mathrm{m} 2 / \mathrm{yr}$ \\
\hline Year 2006 & $\$$ & $5,353.49$ & $48,476.00$ & & & & & \\
\hline Year 2007 & $\$$ & $52,977.78$ & $442,250.00$ & $\$$ & $11,279.06$ & $19,789.00$ & $2,328.25$ & 0.37 \\
\hline Year 2008 & $\$$ & $48,956.14$ & $479,483.00$ & $\$$ & $11,506.41$ & $19,377.00$ & $2,446.96$ & 0.39 \\
\hline Year 2009 & $\$$ & $50,152.04$ & $447,142.00$ & $\$$ & $12,667.30$ & $20,483.00$ & $2,371.68$ & 0.37 \\
\hline Year 2010 & $\$$ & $56,722.71$ & $463,824.00$ & $\$$ & $9,042.09$ & $12,824.00$ & $2,146.82$ & 0.34 \\
\hline Year 2011 & $\$$ & $57,419.84$ & $465,251.37$ & $\$$ & $11,742.19$ & $19,125.00$ & $2,386.35$ & 0.38 \\
\hline Year 2012 & $\$$ & $56,389.25$ & $433,337.78$ & $\$$ & $6,694.88$ & $13,250.00$ & $2,052.92$ & 0.32 \\
\hline Year 2013 & $\$$ & $65,225.17$ & $447,643.00$ & $\$$ & $7,931.53$ & $17,992.00$ & $2,280.82$ & 0.36 \\
\hline Year 2014 & $\$$ & $68,385.92$ & $453,619.00$ & $\$$ & $10,132.16$ & $21,121.00$ & $2,418.73$ & 0.38 \\
\hline Year 2015 & $\$$ & $18,855.43$ & $125,819.00$ & $\$$ & $5,575.48$ & $12,854.00$ & & \\
\hline Average & $\$$ & $57,028.61$ & $454,068.77$ & $\$$ & $10,124.45$ & $17,995.13$ & & 0.36 \\
\hline
\end{tabular}

As it was specified in energy audit, energy consumption of the Building \#5 is very low in comparison to similar office buildings in same region; and therefore average energy index which equals to $0.36 \mathrm{GJ} / \mathrm{m}^{2} / \mathrm{yr}$ is also very low in comparison to benchmark values of BOMA energy efficient building value of $1.05 \mathrm{GJ} / \mathrm{m}^{2} / \mathrm{yr}$, however value is much lower than average National Resources Canada value of $1.43 \mathrm{GJ} / \mathrm{m} 2 /$ year.

Two charts below show electricity and gas consumption per year. Electricity consumption chart doesn't demonstrate prominent increase or decrease in energy usage. Electricity utility bills data show 2008 having much higher consumption than other years. Gas utility bills data evenly fluctuating throughout range of years without prominent increase or decrease trend; but 2014 is approaching the highest value. 

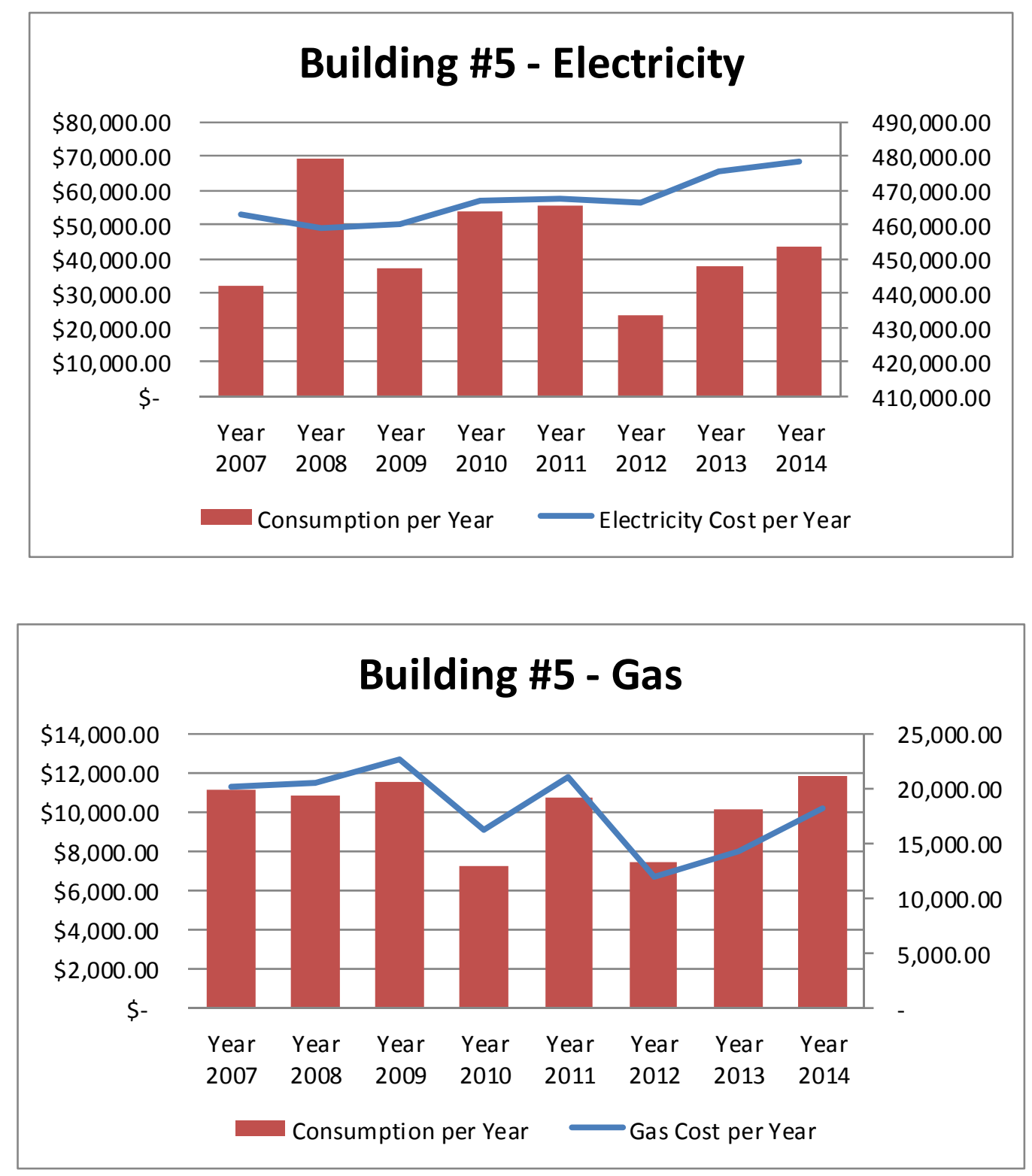

Yearly energy intensity (index) was also plotted to demonstrate increase or decrease over the range of years for which data is available. Chart below shows that energy index value is fluctuating through yearly range given. The lowest energy index was in 2012 and highest in 2008. These two years' data will be used for further calculations and comparisons. 


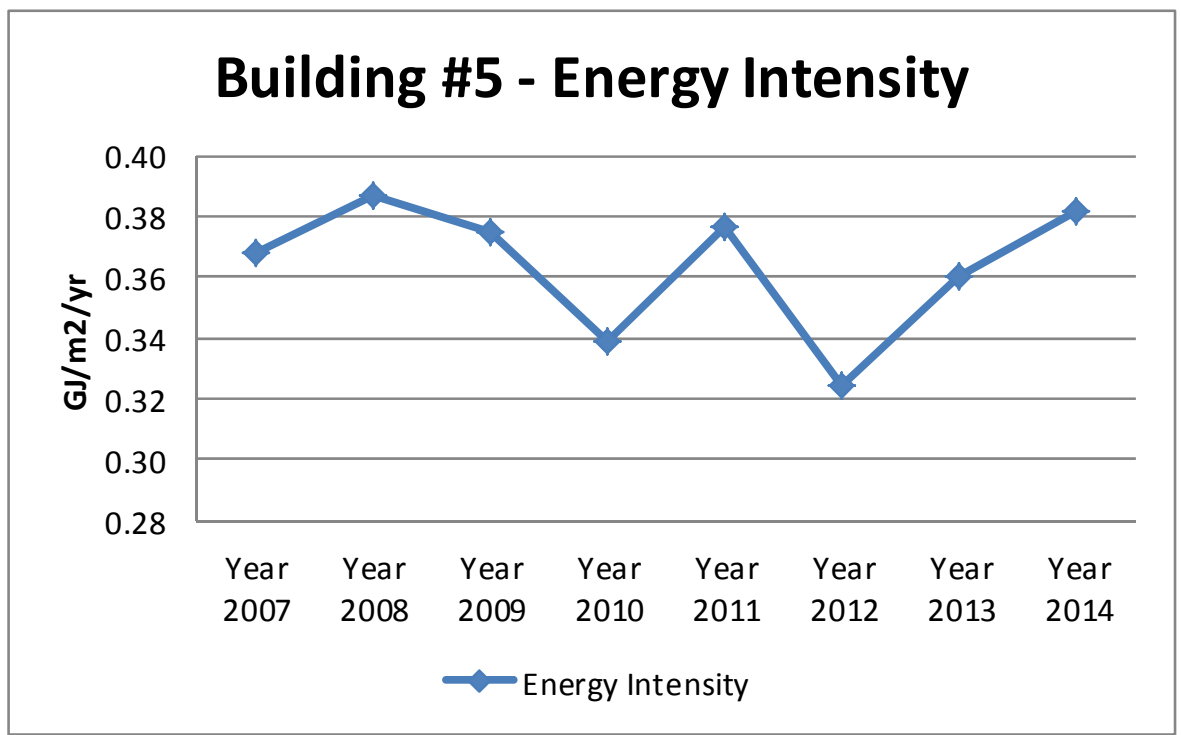

Normalized total energy consumption was calculated for Building \#5. Based on plotted results, shown below in the chart, it can be concluded that normalized energy consumption for 2008 and 2012 approaching similar alignment therefore have very close values. This proves that weather conditions could impact energy consumptions for these two years. Implementing trendline equations, average equation was calculated:

\section{$\gamma=0.3211 x+84.279$}

From above equation normalized average energy index was calculated as $0.36 \mathrm{GJ} / \mathrm{m}^{2} / \mathrm{yr}$, this value is the same as average for 2007 to 2014 years range. As it was mentioned before energy consumption will be increased by $20 \%$ to provide more accurate evaluations. Therefore new energy intensity index $0.45 \mathrm{GJ} / \mathrm{m}^{2} / \mathrm{yr}$; this value will be used for further case-study buildings comparison. 


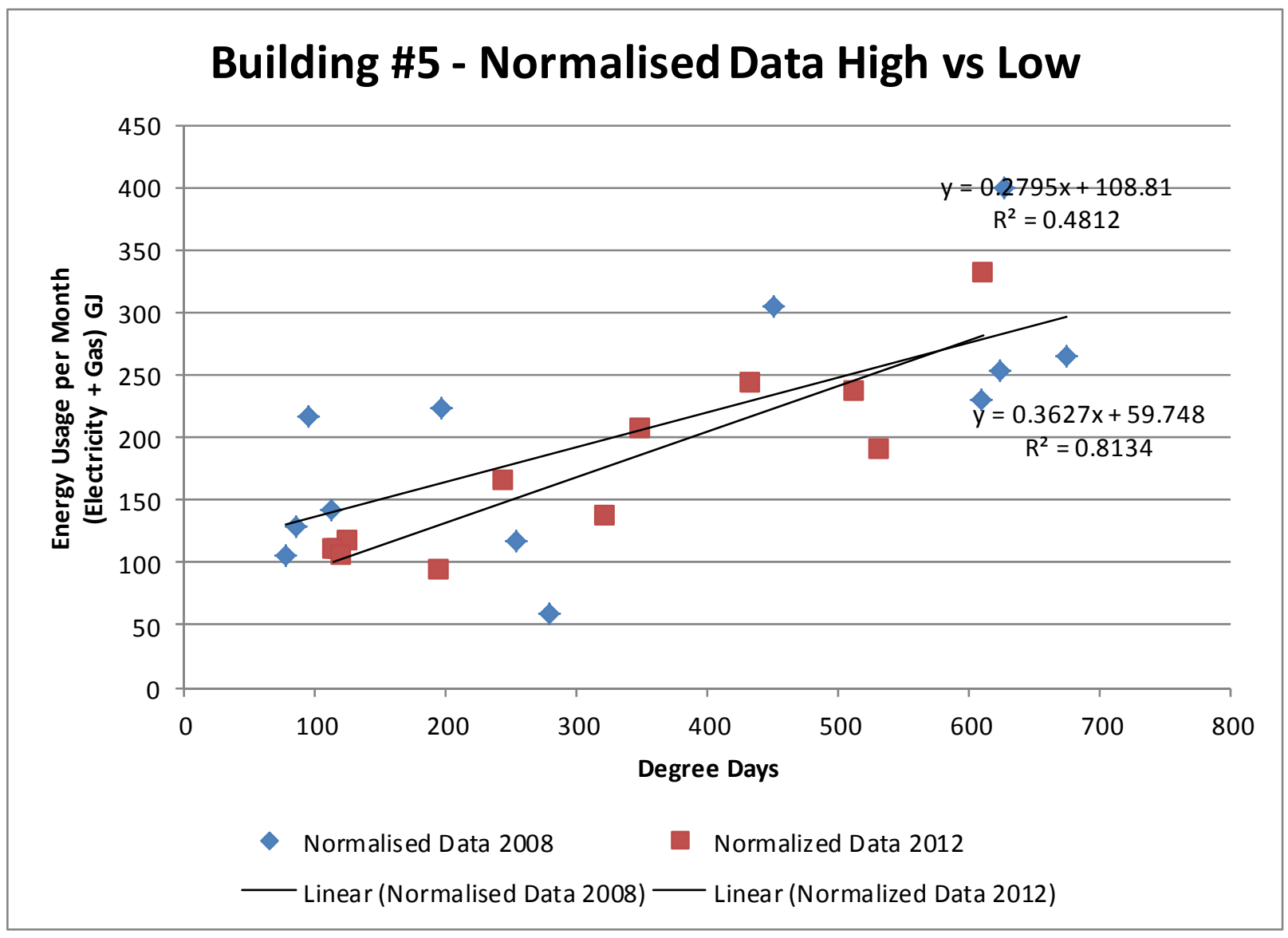


Actual data used for calculations (year with highest energy consumption):

\begin{tabular}{|c|c|c|c|c|c|c|c|c|c|c|c|c|}
\hline ADDRESS: & \multicolumn{4}{|c|}{ Building E - Mississauga, Ontario } & & & & & & & & \\
\hline BUILDING \# & \multicolumn{4}{|c|}{5} & & & & & & & & \\
\hline Year - Highest Energy Consumption: & \multicolumn{4}{|l|}{2008} & & & & & & & & \\
\hline AREA: & \multicolumn{4}{|l|}{6,332} & & & & & & & & \\
\hline USAGE INDEX: & \multicolumn{4}{|l|}{0.39} & & & & & & & & \\
\hline Month & Jan & Feb & Mar & Apr & May & Jun & Jul & Aug & Sep & Oct & Nov & Dec \\
\hline \multirow{4}{*}{$\begin{array}{l}\text { Electric Billing Date } \\
\text { Electric Billing Days }\end{array}$} & $2008 / 02 / 06$ & $2008 / 03 / 07$ & $2008 / 04 / 07$ & $2008 / 05 / 06$ & $2008 / 06 / 05$ & $2008 / 07 / 04$ & $2008 / 08 / 06$ & $2008 / 09 / 04$ & $2008 / 10 / 06$ & $2008 / 11 / 04$ & $2008 / 12 / 04$ & $2009 / 01 / 06$ \\
\hline & 31 & 30 & 31 & 29 & 30 & 29 & 33 & 29 & 32 & 29 & 30 & 33 \\
\hline & $2008 / 02 / 06$ & $2008 / 03 / 07$ & $2008 / 04 / 07$ & 2008/05/06 & $2008 / 06 / 05$ & $2008 / 07 / 04$ & $2008 / 08 / 06$ & $2008 / 09 / 04$ & 2008/10/06 & $2008 / 11 / 04$ & $2008 / 12 / 04$ & $2009 / 01 / 06$ \\
\hline & 31 & 30 & 31 & 29 & 30 & 29 & 33 & 29 & 32 & 29 & 30 & 33 \\
\hline \multicolumn{13}{|l|}{ COOLING \& HEATING DEGREE DAYS } \\
\hline \multirow{5}{*}{$\begin{array}{l}\text { Cooling D.D. (Highest Year) } \\
\text { Daily Clg D.D. Avg. (Highest Year) } \\
\text { Normal Cooling D.D. (Highest Year) }\end{array}$} & & & & & & & & & & & & \\
\hline & 0 & 0 & 0 & 0 & 3 & 72 & 111 & 64 & 27 & 0 & 0 & $\mathbf{0}$ \\
\hline & 0 & 0 & 0 & 0 & 0 & 2 & 3 & 2 & 1 & 0 & 0 & 0 \\
\hline & & & & & & & & & & & & \\
\hline & & & & & & & & & & & & \\
\hline \multirow{4}{*}{$\begin{array}{l}\text { Heating D.D. (Highest Year) } \\
\text { Daily Htg. D.D. Avg. (Highest Year) } \\
\text { Normal Heating D.D (Highest Year) }\end{array}$} & 624 & 675 & 610 & 254 & 194 & 23 & 1 & 13 & 59 & 279 & 452 & 627 \\
\hline & 20 & 22 & 20 & 9 & 6 & 1 & 0 & 0 & 2 & 10 & 15 & 19 \\
\hline & & & & & & & & & & & & \\
\hline & & & & & & & & & & & & \\
\hline \multicolumn{13}{|l|}{ ELECTRICAL USAGE \& COST } \\
\hline \multirow{3}{*}{$\begin{array}{l}\text { kWh Used } \\
\text { Daily kWh Avg. }\end{array}$} & 53,760 & 52,920 & 46,610 & 18,000 & 40,080 & 29,080 & 30,710 & 27,540 & 34,130 & 14,790 & 55,251 & 76,612 \\
\hline & 1,734 & 1,764 & 1,504 & 621 & 1,336 & 1,003 & 931 & 950 & 1,067 & 510 & 1,842 & 2,322 \\
\hline & & & & & & & & & & & & \\
\hline \multirow{3}{*}{$\begin{array}{l}\text { Demand kW/RkVA Used } \\
\text { Load Factor (Highest Year) }\end{array}$} & 103 & 103 & 97 & 54 & 93 & 126 & 88 & 88 & 85 & 38 & 103 & 101 \\
\hline & $70 \%$ & $71 \%$ & $65 \%$ & $48 \%$ & $60 \%$ & $33 \%$ & $44 \%$ & $45 \%$ & $52 \%$ & $56 \%$ & $75 \%$ & $96 \%$ \\
\hline & \multicolumn{12}{|c|}{ NATURAL GAS USAGE \& COST } \\
\hline \multicolumn{13}{|l|}{ CCCF } \\
\hline $\mathrm{m}^{\wedge} 3$ Used & 1,606 & 2,011 & 1,660 & 1,408 & 2,142 & 3,025 & 834 & 176 & 143 & 179 & 2,862 & 3,331 \\
\hline \multirow{2}{*}{ Daily $\mathrm{m}^{\wedge} 3$ Avg. } & 52 & 67 & 54 & 49 & 71 & 104 & 25 & 6 & 4 & 6 & 95 & 101 \\
\hline & & & & & & & & & & & & \\
\hline \multicolumn{13}{|l|}{ GREENHOUSE DATA } \\
\hline \multirow{4}{*}{$\begin{array}{l}\text { C02 (kgs) (Highest Year) } \\
\text { S02 (kgs) (Highest Year) } \\
\text { NOx (kgs) (Highest Year) }\end{array}$} & 47,532 & 49,833 & 43,104 & 22,074 & 42,122 & 40,971 & 26,562 & 19,772 & 23,972 & 11,216 & 57,423 & 75,113 \\
\hline & 514 & 538 & 466 & 238 & 455 & 443 & 287 & 214 & 259 & 121 & 620 & 812 \\
\hline & 225 & 236 & 204 & 105 & 200 & 194 & 126 & 94 & 114 & 53 & 272 & 356 \\
\hline & \multicolumn{12}{|c|}{ USAGE DATA } \\
\hline kWh to GJ & $\overline{193.54}$ & 190.51 & 167.80 & 64.80 & 144.29 & $\overline{104.69}$ & 1110.56 & 99.14 & $\overline{122.87}$ & 53.24 & 198.90 & 275.80 \\
\hline GJ/m2/Day ELECTRIC (Highest Year) & 0.001 & 0.001 & 0.001 & 0.000 & 0.001 & 0.001 & 0.001 & 0.001 & 0.001 & 0.000 & 0.001 & 0.001 \\
\hline $\mathrm{GJ} / \mathrm{m} 2 /$ Month (Highest Year) & 0.03 & 0.03 & 0.03 & 0.01 & 0.02 & 0.02 & 0.02 & 0.02 & 0.02 & 0.01 & 0.03 & 0.04 \\
\hline 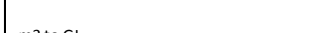 & & & & & & & & & & & & \\
\hline $\mathrm{m} 3$ to $\mathrm{GJ}$ & 59.74 & 74.81 & 61.75 & 52.38 & 79.68 & 112.53 & 31.02 & 6.55 & 5.32 & 6.66 & 106.47 & 123.91 \\
\hline GJ/m2/Day GAS (Highest Year) & 0.000 & 0.000 & 0.000 & 0.000 & 0.000 & 0.001 & 0.000 & 0.000 & 0.000 & 0.000 & 0.001 & 0.001 \\
\hline $\mathrm{GJ} / \mathrm{m} 2 /$ Month & 0.01 & 0.01 & 0.01 & 0.01 & 0.01 & 0.02 & 0.00 & 0.00 & 0.00 & 0.00 & 0.02 & 0.02 \\
\hline $\mathrm{m} 3 / \mathrm{m} 2 /$ Month & 0.25 & 0.32 & 0.26 & 0.22 & 0.34 & 0.48 & 0.13 & 0.03 & 0.02 & 0.03 & 0.45 & 0.53 \\
\hline GJ/m2/Day ENERGY (Highest Year) & 0.001 & 0.001 & 0.001 & 0.001 & 0.001 & 0.001 & 0.001 & 0.001 & 0.001 & 0.000 & 0.002 & 0.002 \\
\hline $\mathrm{GJ} / \mathrm{m} 2 /$ Month (Highest Consumption Year) & 0.040 & 0.042 & 0.036 & 0.019 & 0.035 & 0.034 & 0.022 & 0.017 & 0.020 & 0.009 & 0.048 & 0.063 \\
\hline Energy Usage per Month (Electricity + Gas) & 253 & 265 & 230 & 117 & 224 & 217 & 142 & 106 & 128 & 60 & 305 & 400 \\
\hline Degree Days & 624 & 675 & 610 & 254 & 196 & 94 & 112 & 77 & 86 & 279 & 452 & 627 \\
\hline
\end{tabular}




\section{Actual data used for calculations (year with lowest energy consumption):}

\begin{tabular}{|c|c|c|c|c|c|c|c|c|c|c|c|c|}
\hline ADDRESS: & \multicolumn{4}{|c|}{ Building E - Mississauga, Ontario } & & & & & & & & \\
\hline BUILDING \# & \multicolumn{4}{|c|}{\begin{tabular}{|l|}
5 \\
\end{tabular}} & & & & & & & & \\
\hline Year - Lowest Energy Consumption: & \multicolumn{4}{|l|}{2012} & & & & & & & & \\
\hline AREA: & \multicolumn{4}{|l|}{6,332} & & & & & & & & \\
\hline USAGE INDEX: & 0.32 & AVERAGE: & 0.355 & 0.35623 & & & & & & & & \\
\hline Month & Jan & Feb & Mar & Apr & May & Jun & Jul & Aug & Sep & Oct & Nov & Dec \\
\hline Electric Billing Date & $2012 / 02 / 03$ & $2012 / 03 / 02$ & $2012 / 04 / 04$ & $2012 / 05 / 04$ & $2012 / 06 / 06$ & $2012 / 07 / 05$ & $2012 / 08 / 07$ & $2012 / 09 / 04$ & $2012 / 10 / 04$ & $2012 / 11 / 02$ & $2012 / 12 / 04$ & $2013 / 01 / 04$ \\
\hline Electric Billing Days & 31 & 28 & 33 & 30 & 33 & 29 & 33 & 28 & 30 & 29 & 32 & 31 \\
\hline Gas Billing Date & $2012 / 02 / 03$ & $2012 / 03 / 02$ & $2012 / 04 / 04$ & 2012/05/04 & $2012 / 06 / 06$ & $2012 / 07 / 05$ & $2012 / 08 / 07$ & $2012 / 09 / 04$ & $2012 / 10 / 04$ & $2012 / 11 / 02$ & $2012 / 12 / 04$ & 2013/01/04 \\
\hline Gas Billing Days & 31 & 28 & 33 & 30 & 33 & 29 & 33 & 28 & 30 & 29 & 32 & 31 \\
\hline \multicolumn{13}{|l|}{ COOLING \& HEATING DEGREE DAYS } \\
\hline Cooling D.D. (Lowest Year) & 0 & & & & & & & & & & & \\
\hline Cooling D.D. (Lowest Year) & 0 & 0 & 0 & 0 & 37 & 102 & 195 & 112 & 36 & 1 & 0 & 0 \\
\hline Daily Clg D.D. Avg. (Lowest Year) & 0 & 0 & 0 & 0 & 1 & 4 & 6 & 4 & 1 & 0 & 0 & 0 \\
\hline Normal Cooling D.D. (Lowest Year) & & & & & & & & & & & & \\
\hline Heating D.D. (Lowest Year) & 611 & 532 & 349 & 322 & 81 & 23 & 0 & 2 & 85 & 243 & 434 & 513 \\
\hline Daily Htg. D.D. Avg. (Lowest Year) & 20 & 19 & 11 & 11 & 2 & 1 & 0 & 0 & 3 & 8 & 14 & 17 \\
\hline Normal Heating D.D (Lowest Year) & & & & & & & & & & & & \\
\hline & & & & & & & & & & & & \\
\hline ELECTRICAL USAGE \& COST & & & & & & & & & & & & \\
\hline kWh Used & 47,164 & 44,236 & 38,941 & 31,064 & 27,357 & 31,033 & 25,812 & 30,144 & 28,601 & 34,782 & 44,577 & 49,627 \\
\hline Daily kWh Avg. & 1,521 & 1,580 & 1,180 & 1,035 & 829 & 1,070 & 782 & 1,077 & 953 & 1,199 & 1,393 & 1,601 \\
\hline Demand kW/RkVA Used & 63 & 61 & 59 & 52 & 47 & 48 & 50 & 49 & 55 & 57 & 61 & 61 \\
\hline Load Factor (Lowest Year) & $101 \%$ & $108 \%$ & $83 \%$ & $84 \%$ & $73 \%$ & $93 \%$ & $65 \%$ & $92 \%$ & $72 \%$ & $88 \%$ & $95 \%$ & $109 \%$ \\
\hline & & & & & & & & & & & & \\
\hline NATURAL GAS USAGE \& COST & & & & & & & & & & & & \\
\hline CCF & & & & & & & & & & & & \\
\hline $\mathrm{m}^{\wedge} 3$ Used & 4,333 & 854 & 1,786 & 690 & 330 & 148 & 26 & 51 & 72 & 1,100 & 2,220 & 1,578 \\
\hline Daily $\mathrm{m}^{\wedge} 3$ Avg. & 140 & 31 & 54 & 23 & 10 & 5 & 1 & 2 & 2 & 38 & 69 & 51 \\
\hline & & & & & & & & & & & & \\
\hline GREENHOUSE DATA & & & & & & & & & & & & \\
\hline C02 (kgs) (Lowest Year) & 62,394 & 35,803 & 38,836 & 25,781 & 20,739 & 21,924 & 17,548 & 20,640 & 19,750 & 31,184 & 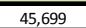 & 44,553 \\
\hline S02 (kgs) (Lowest Year) & 674 & 387 & 420 & 279 & 224 & 237 & 190 & 223 & 213 & 337 & 494 & 481 \\
\hline NOx (kgs) (Lowest Year) & 296 & 170 & 184 & 122 & 98 & 104 & 83 & 98 & 94 & 148 & 216 & 211 \\
\hline & & & & & & & & & & & & \\
\hline USAGE DATA & & & & & & & & & & & & \\
\hline kWh to GJ & 169.79 & 159.25 & 140.19 & 111.83 & 98.48 & 111.72 & 92.92 & 108.52 & 102.96 & 125.22 & 160.48 & 178.66 \\
\hline GJ/m2/Day ELECTRIC (Lowest Year) & 0.001 & 0.001 & 0.001 & 0.001 & 0.000 & 0.001 & 0.000 & 0.001 & 0.001 & 0.001 & 0.001 & 0.001 \\
\hline $\mathrm{GJ} / \mathrm{m} 2 /$ Month (Lowest Year) & 0.03 & 0.03 & 0.02 & 0.02 & 0.02 & 0.02 & 0.01 & 0.02 & 0.02 & 0.02 & 0.03 & 0.03 \\
\hline m3 to GJ & 161.19 & 31.77 & 66.44 & 25.67 & 12.28 & 5.51 & 0.97 & 1.90 & 2.68 & 40.92 & 82.58 & 58.70 \\
\hline GJ/m2/Day GAS (Lowest Year) & 0.001 & 0.000 & 0.000 & 0.000 & 0.000 & 0.000 & 0.000 & 0.000 & 0.000 & 0.000 & 0.000 & 0.000 \\
\hline $\mathrm{GJ} / \mathrm{m} 2 /$ Month & 0.03 & 0.01 & 0.01 & 0.00 & 0.00 & 0.00 & 0.00 & 0.00 & 0.00 & 0.01 & 0.01 & 0.01 \\
\hline $\mathrm{m} 3 / \mathrm{m} 2 /$ Month & 0.68 & 0.13 & 0.28 & 0.11 & 0.05 & 0.02 & 0.00 & 0.01 & 0.01 & 0.17 & 0.35 & 0.25 \\
\hline GJ/m2/Day ENERGY (Lowest Year) & 0.002 & 0.001 & 0.001 & 0.001 & 0.001 & 0.001 & 0.000 & 0.001 & 0.001 & 0.001 & 0.001 & 0.001 \\
\hline $\mathrm{GJ} / \mathrm{m} 2 /$ Month (Lowest Consumption Year) & 0.052 & 0.030 & 0.033 & 0.022 & 0.017 & 0.019 & 0.015 & 0.017 & 0.017 & 0.026 & 0.038 & 0.037 \\
\hline Average Highest Year to Lowest Year & 0.046 & 0.036 & 0.034 & 0.020 & 0.026 & 0.026 & 0.019 & 0.017 & 0.018 & 0.018 & 0.043 & 0.050 \\
\hline BOMA Mean Value per Month & 0.111 & 0.111 & 0.111 & 0.111 & 0.111 & 0.111 & 0.111 & 0.111 & 0.111 & 0.111 & 0.111 & 0.111 \\
\hline Energy Usage per Month (Electricity + Ga & 331 & 191 & 207 & 137 & 111 & 117 & 94 & 110 & 106 & 166 & 243 & 237 \\
\hline Degree Days & 611 & 532 & 350 & 322 & 117 & 125 & 195 & 114 & 121 & 244 & 434 & 513 \\
\hline Normalized Data (Average Degree Days) & 618 & 582 & 452 & 340 & 125 & 108 & 159 & 106 & 116 & 226 & 456 & 587 \\
\hline Normalized Data (Av Energy Consumptio & 283 & 271 & 229 & 194 & 124 & 119 & 135 & 118 & 121 & 157 & 231 & 273 \\
\hline Normalized Data (Av Energy Index / mon & 0.045 & 0.043 & 0.036 & 0.031 & 0.020 & 0.019 & 0.021 & 0.019 & 0.019 & 0.025 & 0.036 & 0.043 \\
\hline
\end{tabular}


Analysis on how electricity and gas consumption corresponds to heating and cooling periods (for highest energy consumption year):

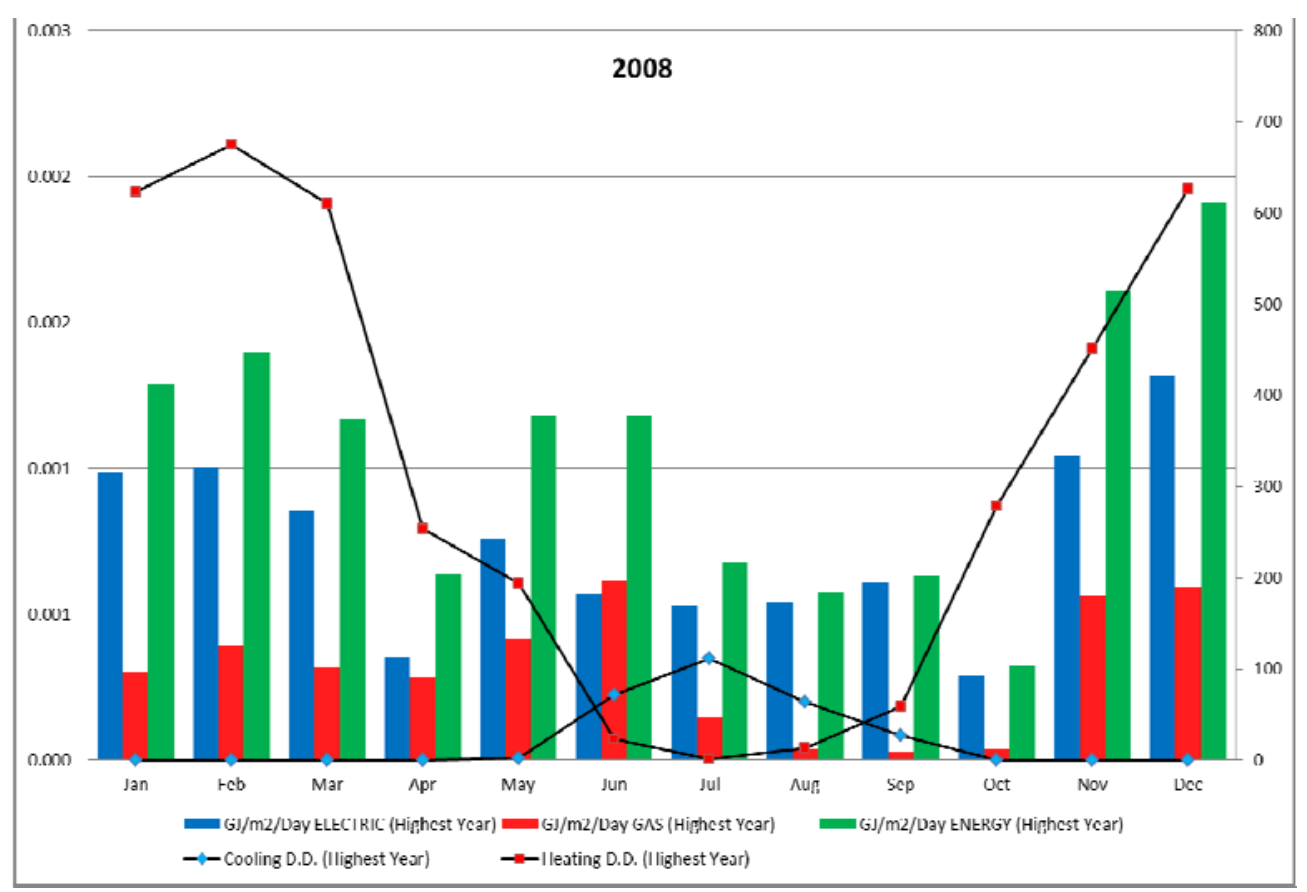

Analysis on how electricity and gas consumption corresponds to heating and cooling periods (for lowest energy consumption year):

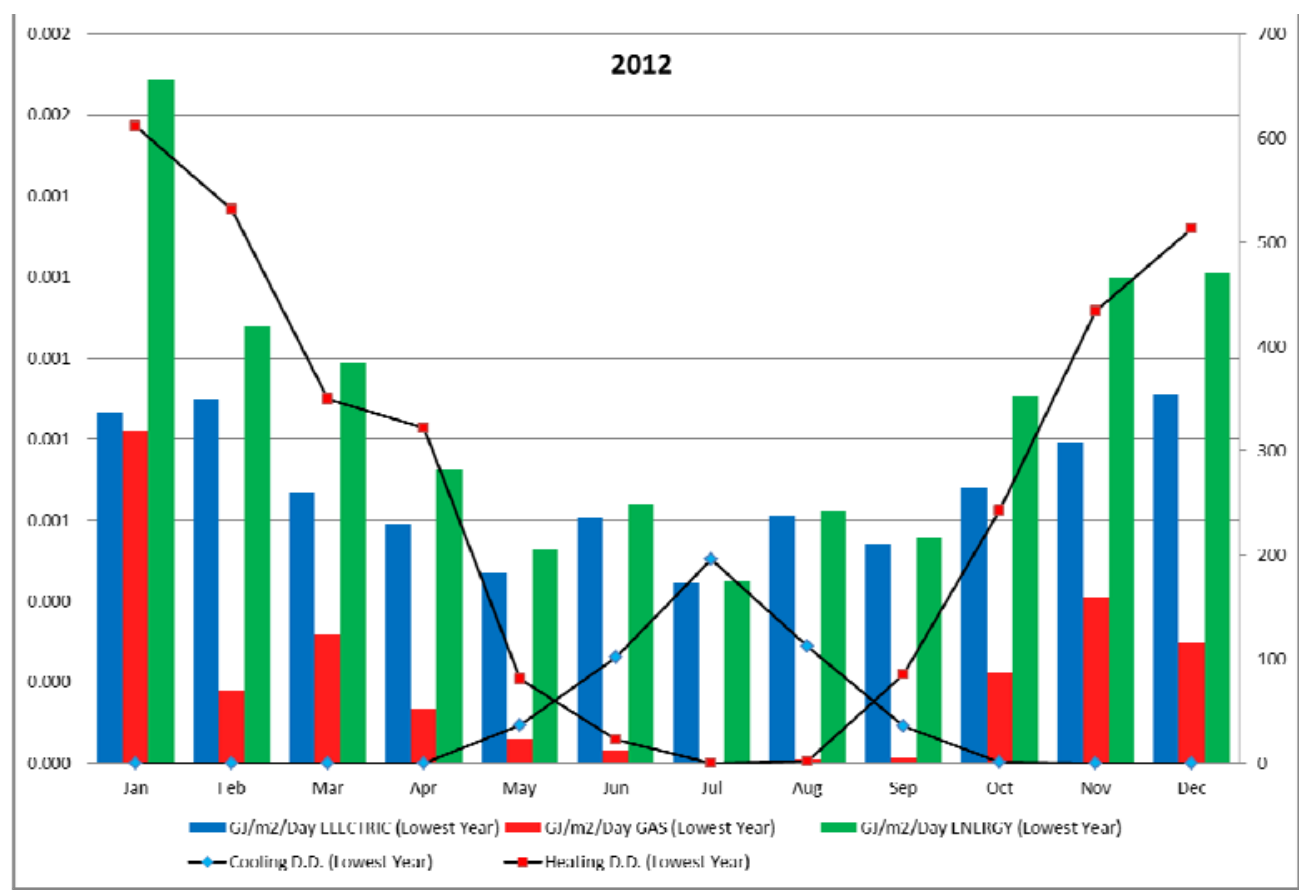


Monthly energy index comparison between highest energy consumption year, lowest, average and benchmark (BOMA) energy intensity:

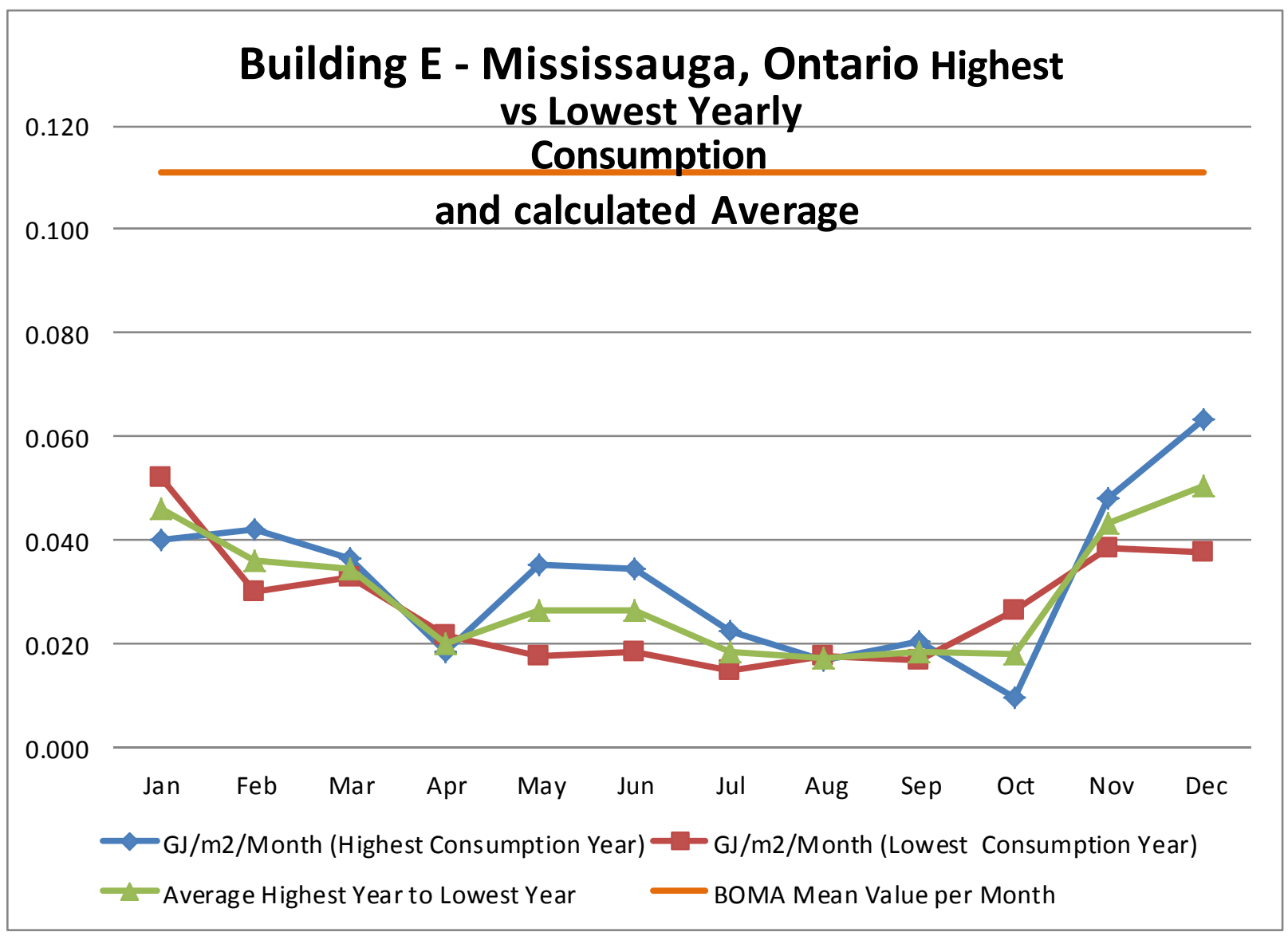


Building \#6 - Utility Bills Analysis

\section{Calculations of Energy Index for Building \#6}

Energy CAP database was utilized to collect energy consumption information for the building. Energy consumption was provided by utility bills for electricity and gas. For Building \#1 utility bills were provided from December 2006 to March 2015. To complete most accurate analysis utility bills for 2007 to 2014 were only analyzed because 2006 and 2015 has incomplete data. By having total floor area for entire building of 2,130 $\mathrm{m}^{2}$, energy index in $\mathrm{GJ} / \mathrm{m}^{2} /$ year was calculated. From calculations it was noticed that yearly data is relatively consistent, therefore all years values were included in calculations.

Utility bills analysis showed following:

\begin{tabular}{|c|c|c|c|c|c|c|c|c|}
\hline \multicolumn{6}{|c|}{ Building F - Scarborough, Ontario } & \multirow[b]{2}{*}{$\mathrm{m}^{3}$-ngas } & \multirow[b]{2}{*}{ Total GJ/yr } & \multirow[b]{2}{*}{$2,130.00$} \\
\hline & & & kWh & & & & & \\
\hline Row Labels & \multicolumn{2}{|c|}{$\begin{array}{c}\text { Sum of Ele Total } \\
\text { Cost / Year }\end{array}$} & $\begin{array}{c}\text { Sum of Ele } \\
\text { Consumption / } \\
\text { Year }\end{array}$ & \multicolumn{2}{|c|}{$\begin{array}{c}\text { Sum of Gas Total } \\
\text { Cost / Year }\end{array}$} & $\begin{array}{c}\text { Sum of Gas } \\
\text { Consumption / } \\
\text { Year }\end{array}$ & Total & $\mathrm{GJ} / \mathrm{m} 2 / \mathrm{yr}$ \\
\hline Year 2006 & $\$$ & $5,287.22$ & $42,840.00$ & $\$$ & $1,974.35$ & $3,846.00$ & & \\
\hline Year 2007 & $\$$ & $31,149.19$ & $240,150.60$ & $\$$ & $17,306.80$ & $33,358.00$ & $2,105.46$ & 0.99 \\
\hline Year 2008 & $\$$ & $33,140.73$ & $238,644.90$ & $\$$ & $20,779.73$ & $40,484.00$ & $2,365.13$ & 1.11 \\
\hline Year 2009 & $\$$ & $24,245.33$ & $193,655.90$ & $\$$ & $13,433.47$ & $25,699.00$ & $1,653.16$ & 0.78 \\
\hline Year 2010 & $\$$ & $28,324.31$ & $228,129.84$ & $\$$ & $13,700.88$ & $25,401.00$ & $1,766.18$ & 0.83 \\
\hline Year 2011 & $\$$ & $34,954.77$ & $276,990.83$ & $\$$ & $10,956.97$ & $21,737.00$ & $1,805.78$ & 0.85 \\
\hline Year 2012 & $\$$ & $34,142.03$ & $242,659.97$ & $\$$ & $6,281.61$ & $19,558.00$ & $1,601.13$ & 0.75 \\
\hline Year 2013 & $\$$ & $38,332.15$ & $249,357.20$ & $\$$ & $6,748.71$ & $22,593.00$ & $1,738.15$ & 0.82 \\
\hline Year 2014 & $\$$ & $37,658.14$ & $230,587.05$ & $\$$ & $7,852.37$ & $23,348.00$ & $1,698.66$ & 0.80 \\
\hline Year 2015 & $\$$ & $13,415.96$ & $88,861.30$ & $\$$ & $3,666.59$ & 9,599.00 & & \\
\hline Average & $\$$ & $32,743.33$ & $237,522.04$ & $\$$ & $12,132.57$ & $26,522.25$ & & 0.86 \\
\hline
\end{tabular}

As it was specified in energy audit, energy consumption of the Building \#6 is relatively low in comparison to similar office buildings in same region; and therefore average energy index which equals to $0.86 \mathrm{GJ} / \mathrm{m}^{2} / \mathrm{yr}$ is also low in comparison to benchmark values of BOMA energy efficient building value of $1.05 \mathrm{GJ} / \mathrm{m}^{2} / \mathrm{yr}$, however value is much lower than average National Resources Canada value of $1.43 \mathrm{GJ} / \mathrm{m} 2 /$ year.

Two charts below show electricity and gas consumption per year. Electricity consumption chart fluctuates throughout the year range without any prominent increase or decrease. But gas consumption chart shows prominent decrease in values, however from utility bills analysis there is no obvious reason why this occurred. 

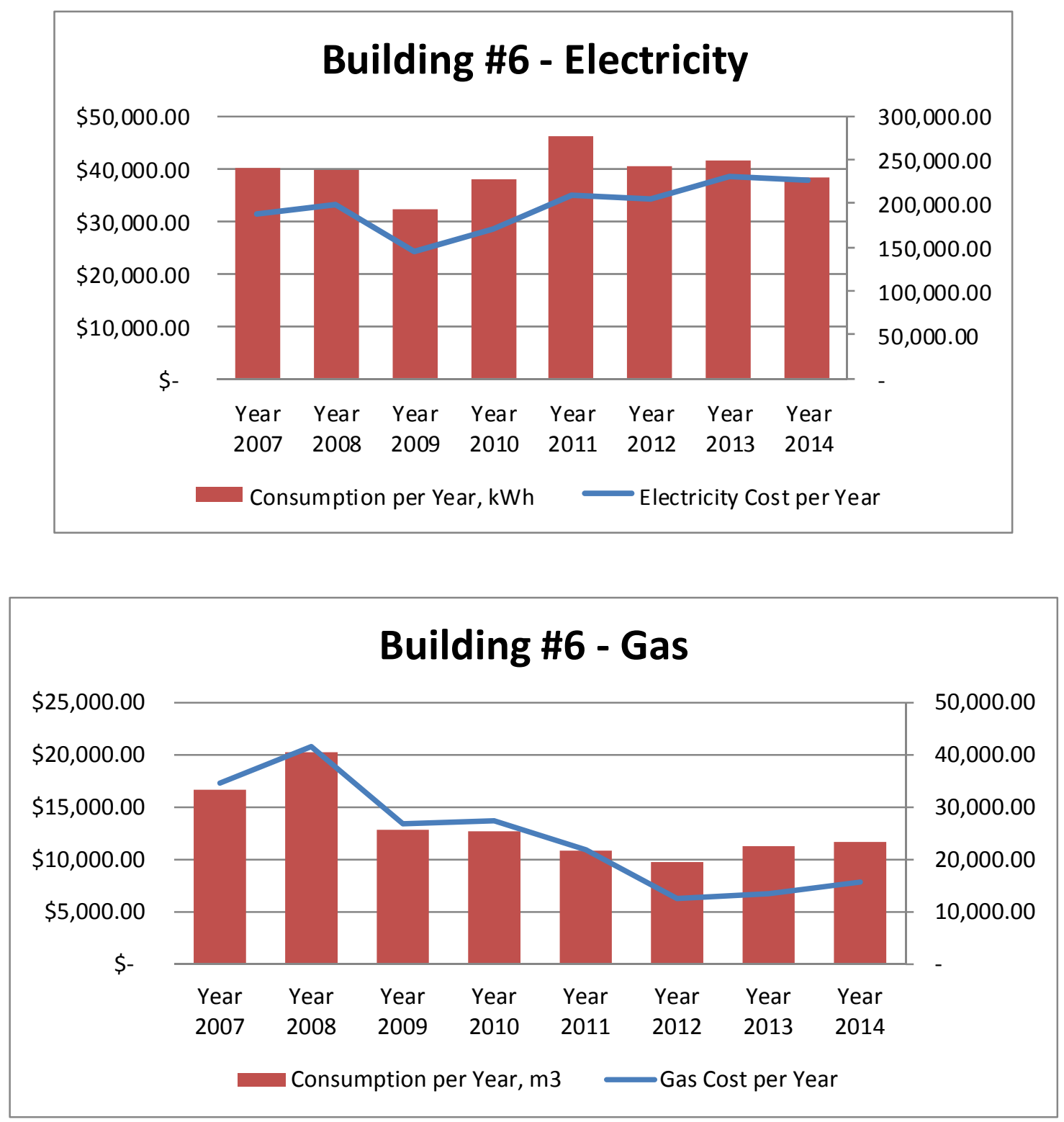

Yearly energy intensity (index) was also plotted to demonstrate increase or decrease over the range of years for which data is available. Chart below shows that energy index value is gradually decreasing and currently around $0.80 \mathrm{GJ} / \mathrm{m}^{2} / \mathrm{yr}$ and much lower than in 2007 of $1.11 \mathrm{GJ} / \mathrm{m}^{2} / \mathrm{yr}$. The lowest energy index was in 2012 and highest in 2008. These two years' data will be used for further calculations and comparisons. 


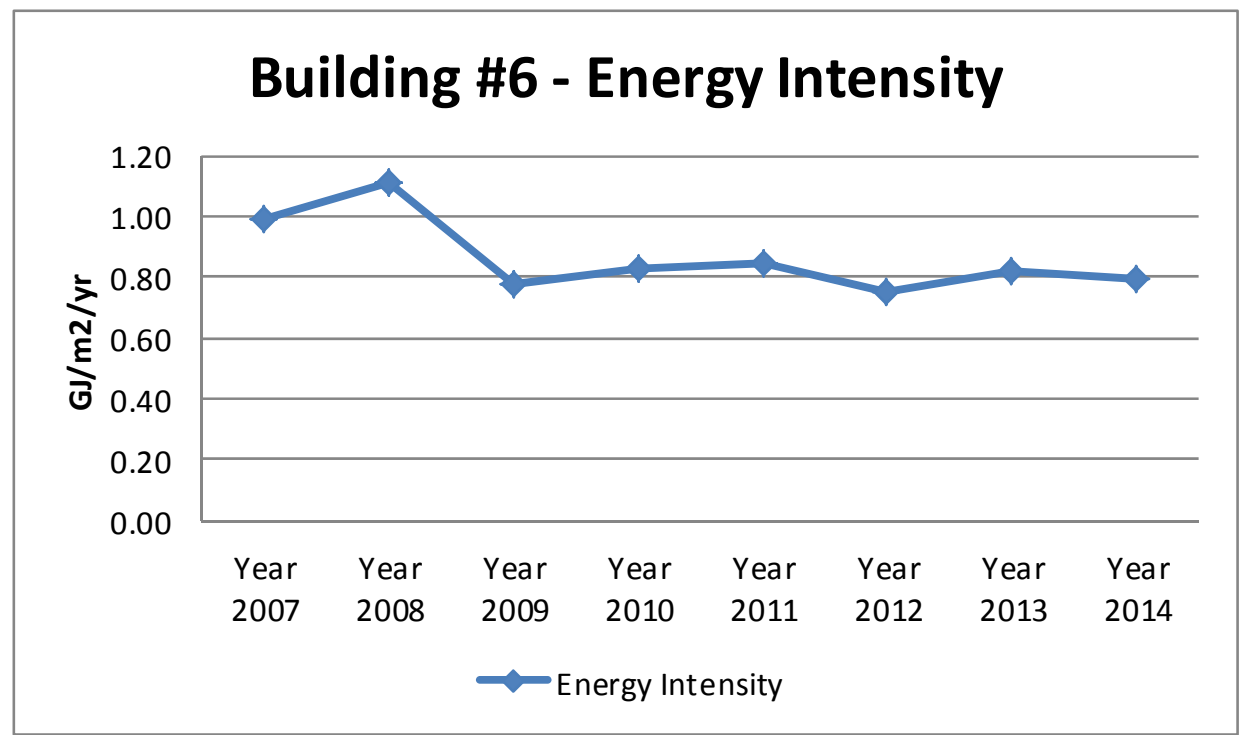

Normalized total energy consumption was calculated for Building \#6. Based on plotted results, shown below in the chart, it can be concluded that energy consumption for 2008 is higher than for 2012. This proves that regardless of weather conditions 2008 has higher energy consumptions than in 2012. Implementing trendline equations, average equation was calculated:

\section{$\gamma=0.2982 x+69.159$}

From above equation normalized average energy index was calculated as $0.93 \mathrm{GJ} / \mathrm{m}^{2} / \mathrm{yr}$, this value is significantly higher than average for 2007 to 2014 years range. As it was discussed previously, to reflect more accurate energy consumption it should be multiplied by $10 \%$, therefore new value is $1.02 \mathrm{GJ} / \mathrm{m}^{2} / \mathrm{yr}$. This value will be used for further case-study buildings comparison. 


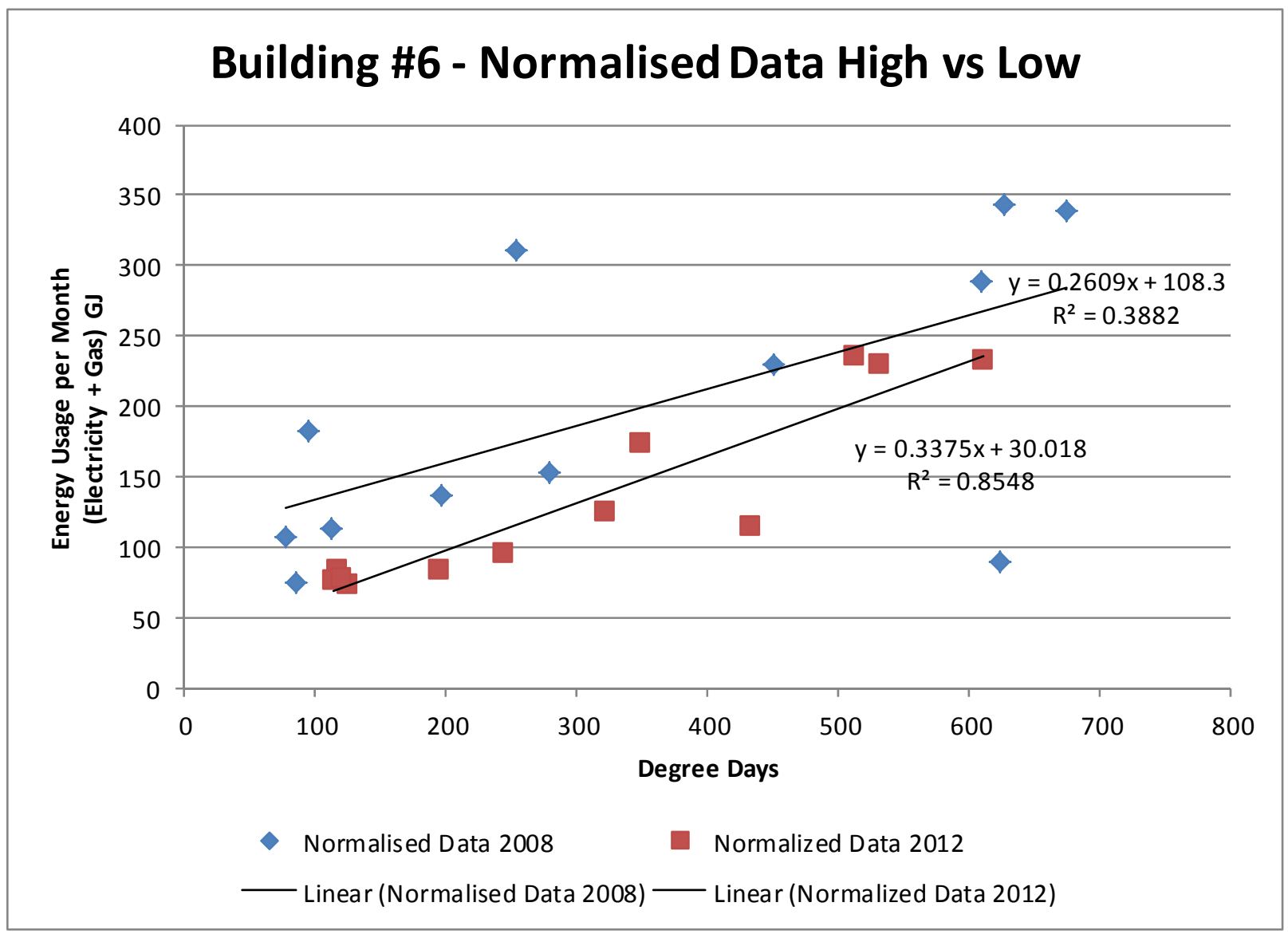


Actual data used for calculations (year with highest energy consumption):

\begin{tabular}{|c|c|c|c|c|c|c|c|c|c|c|c|c|}
\hline ADDRESS: & \multicolumn{4}{|c|}{ Building F - Scarborough, Ontario } & & & & & & & & \\
\hline BUILDING \# & \multicolumn{4}{|c|}{6} & & & & & & & & \\
\hline Year - Highest Energy Consumption: & \multicolumn{4}{|l|}{2008} & & & & & & & & \\
\hline AREA: & \multirow{2}{*}{\multicolumn{3}{|c|}{$\begin{array}{c}2,130 \\
1.11 \\
\end{array}$}} & 1,375 & & & & & & & & \\
\hline USAGE INDEX: & & & & $2,365.13$ & & & & & & & & \\
\hline Month & Jan & Feb & Mar & Apr & May & Jun & Jul & Aug & Sep & Oct & Nov & Dec \\
\hline \multirow{2}{*}{$\begin{array}{l}\text { Electric Billing Date } \\
\text { Electric Billing Days }\end{array}$} & $2008 / 02 / 06$ & $2008 / 03 / 07$ & $2008 / 04 / 07$ & $2008 / 05 / 06$ & $2008 / 06 / 05$ & $2008 / 07 / 04$ & $2008 / 08 / 06$ & $2008 / 09 / 04$ & $2008 / 10 / 06$ & $2008 / 11 / 04$ & $2008 / 12 / 04$ & $2009 / 01 / 06$ \\
\hline & 31 & 30 & 31 & 29 & 30 & 29 & 33 & 29 & 32 & 29 & 30 & 33 \\
\hline \multirow{3}{*}{$\begin{array}{l}\text { Gas Billing Date } \\
\text { Gas Billing Days }\end{array}$} & $2008 / 02 / 06$ & $2008 / 03 / 07$ & $2008 / 04 / 07$ & $2008 / 05 / 06$ & $2008 / 06 / 05$ & $2008 / 07 / 04$ & $2008 / 08 / 06$ & $2008 / 09 / 04$ & 2008/10/06 & $2008 / 11 / 04$ & $2008 / 12 / 04$ & $2009 / 01 / 06$ \\
\hline & 31 & 30 & 31 & 29 & 30 & 29 & 33 & 29 & 32 & 29 & 30 & 33 \\
\hline & & & & & & & & & & & & \\
\hline \multicolumn{13}{|l|}{ COOLING \& HEATING DEGREE DAYS } \\
\hline Cooling D.D. (Highest Year) & 0 & 0 & 0 & 0 & 3 & 72 & 111 & 64 & 27 & 0 & 0 & 0 \\
\hline Daily Clg D.D. Avg. (Highest Year) & 0 & 0 & 0 & 0 & 0 & 2 & 3 & 2 & 1 & 0 & 0 & 0 \\
\hline Normal Cooling D.D. (Highest Year) & & & & & & & & & & & & \\
\hline & & & & & & & & & & & & \\
\hline Heating D.D. (Highest Year) & 624 & 675 & 610 & 254 & 194 & 23 & 1 & 13 & 59 & 279 & 452 & 627 \\
\hline Daily Htg. D.D. Avg. (Highest Year) & 20 & 22 & 20 & 9 & 6 & 1 & 0 & 0 & 2 & 10 & 15 & 19 \\
\hline Normal Heating D.D (Highest Year) & & & & & & & & & & & & \\
\hline & & & & & & & & & & & & \\
\hline ELECTRICAL USAGE \& COST & & & & & & & & & & & & \\
\hline kWh Used & 24,689 & 19,823 & 20,116 & 17,199 & 17,095 & 21,084 & 23,393 & 19,013 & 17,421 & 15,265 & 16,821 & 26,726 \\
\hline Daily kWh Avg. & 796 & 661 & 649 & 593 & 570 & 727 & 709 & 656 & 544 & 526 & 561 & 810 \\
\hline & & & & & & & & & & & & \\
\hline Demand kW/RkVA Used & 40 & 37 & 43 & 43 & 61 & 61 & 61 & 58 & 54 & 43 & 36 & 36 \\
\hline Load Factor (Highest Year) & $84 \%$ & $74 \%$ & $63 \%$ & $57 \%$ & $39 \%$ & $49 \%$ & $48 \%$ & $47 \%$ & $42 \%$ & $51 \%$ & $65 \%$ & $94 \%$ \\
\hline NATURAL GAS USAGE \& COST & & & & & & & & & & & & \\
\hline CCF & & & & & & & & & & & & \\
\hline$m^{\wedge} 3$ Used & 0 & 7,202 & 5,797 & 6,700 & 2,038 & 2,865 & 761 & 1,022 & 306 & 2,617 & 4,530 & 6,646 \\
\hline Daily $\mathrm{m}^{\wedge} 3$ Avg. & 0 & 240 & 187 & 231 & 68 & 99 & 23 & 35 & 10 & 90 & 151 & 201 \\
\hline & & & & & & & & & & & & \\
\hline GREENHOUSE DATA & & & & & & & & & & & & \\
\hline C02 (kgs) (Highest Year) & 16,609 & 64,305 & 54,558 & 58,986 & 25,923 & 34,460 & 21,123 & 20,024 & 13,885 & 28,790 & 43,375 & 65,014 \\
\hline S02 (kgs) (Highest Year) & 179 & 695 & 589 & 637 & 280 & 372 & 228 & 216 & 150 & 311 & 469 & 702 \\
\hline NOx (kgs) (Highest Year) & 79 & 305 & 258 & 279 & 123 & 163 & 100 & 95 & 66 & 136 & 205 & 308 \\
\hline & & & & & & & & & & & & \\
\hline USAGE DATA & & & & & & & & & & & & \\
\hline kWh to GJ & 88.88 & 71.36 & 72.42 & 61.91 & 61.54 & 75.90 & 84.21 & 68.45 & 62.72 & 54.96 & 60.55 & 96.22 \\
\hline GJ/m2/Day ELECTRIC (Highest Year) & 0.001 & 0.001 & 0.001 & 0.001 & 0.001 & 0.001 & 0.001 & 0.001 & 0.001 & 0.001 & 0.001 & 0.001 \\
\hline GJ/m2/Month (Highest Year) & 0.04 & 0.03 & 0.03 & 0.03 & 0.03 & 0.04 & 0.04 & 0.03 & 0.03 & 0.03 & 0.03 & 0.05 \\
\hline m3 to GJ & 0.00 & 267.91 & 215.65 & 249.24 & 75.81 & 106.58 & 28.31 & 38.02 & 11.38 & 97.35 & 168.52 & 247.23 \\
\hline GJ/m2/Day GAS (Highest Year) & 0.000 & 0.004 & 0.003 & 0.004 & 0.001 & 0.002 & 0.000 & 0.001 & 0.000 & 0.002 & 0.003 & 0.004 \\
\hline $\mathrm{GJ} / \mathrm{m} 2 /$ Month & 0.00 & 0.13 & 0.10 & 0.12 & 0.04 & 0.05 & 0.01 & 0.02 & 0.01 & 0.05 & 0.08 & 0.12 \\
\hline $\mathrm{m} 3 / \mathrm{m} 2 /$ Month & 0.00 & 3.38 & 2.72 & 3.15 & 0.96 & 1.35 & 0.36 & 0.48 & 0.14 & 1.23 & 2.13 & 3.12 \\
\hline GJ/m2/Day ENERGY (Highest Year) & 0.001 & 0.005 & 0.004 & 0.005 & 0.002 & 0.003 & 0.002 & 0.002 & 0.001 & 0.002 & 0.004 & 0.005 \\
\hline $\mathrm{GJ} / \mathrm{m} 2 /$ Month (Highest Consumption Year) & 0.042 & 0.159 & 0.135 & 0.146 & 0.064 & 0.086 & 0.053 & 0.050 & 0.035 & 0.072 & 0.108 & 0.161 \\
\hline Energy Usage per Month (Electricity + Gas) & 89 & 339 & 288 & 311 & 137 & 182 & 113 & 106 & 74 & 152 & 229 & 343 \\
\hline Degree Days & 624 & 675 & 610 & 254 & 196 & 94 & 112 & 77 & 86 & 279 & 452 & 627 \\
\hline
\end{tabular}




\section{Actual data used for calculations (year with lowest energy consumption):}

\begin{tabular}{|c|c|c|c|c|c|c|c|c|c|c|c|c|}
\hline ADDRESS: & \multicolumn{4}{|c|}{ Building F - Scarborough, Ontario } & & & & & & & & \\
\hline BUILDING \# & \multicolumn{4}{|c|}{6} & & & & & & & & \\
\hline Year - Lowest Energy Consumption: & \multicolumn{4}{|l|}{2012} & & & & & & & & \\
\hline AREA: & \multicolumn{4}{|l|}{2,130} & & & & & & & & \\
\hline USAGE INDEX: & 0.75 & AVERAGE: & 0.9310 & 0.93396 & & & & & & & & \\
\hline Month & Jan & Feb & Mar & Apr & May & Jun & Jul & Aug & Sep & Oct & Nov & Dec \\
\hline \multirow{2}{*}{$\begin{array}{l}\text { Electric Billing Date } \\
\text { Electric Billing Days }\end{array}$} & $2012 / 01 / 19$ & $2012 / 02 / 17$ & $2012 / 03 / 10$ & $2012 / 04 / 20$ & $2012 / 05 / 18$ & $2012 / 06 / 18$ & $2012 / 07 / 10$ & $2012108 / 20$ & $2012 / 0919$ & 201210 & $201211 / 1$ & $2012 / 12 / 18$ \\
\hline & 31 & 29 & 31 & 32 & 28 & 31 & 31 & 32 & 30 & 29 & 32 & 29 \\
\hline \multirow{2}{*}{$\begin{array}{l}\text { Gas Billing Date } \\
\text { Gas Billing Days }\end{array}$} & $2012 / 01 / 28$ & $2012 / 03 / 01$ & $2012 / 03 / 28$ & $2012 / 05 / 01$ & $2012 / 05 / 31$ & $2012 / 07 / 03$ & $2012 / 07 / 31$ & $2012 / 08 / 31$ & $2012 / 10 / 01$ & $2012 / 10 / 31$ & $2012 / 11 / 29$ & $2012 / 12 / 31$ \\
\hline & 31 & 33 & 27 & 34 & 30 & 33 & 28 & 31 & 31 & 30 & 29 & 32 \\
\hline \multicolumn{13}{|l|}{ COOLING \& HEATING DEGREE DAYS } \\
\hline & & & & & & & & & & & & \\
\hline Cooling D.D. (Lowest Year) & 0 & 0 & 0 & 0 & 37 & 102 & 195 & 112 & 36 & 1 & 0 & 0 \\
\hline \multirow{2}{*}{$\begin{array}{l}\text { Daily Clg D.D. Avg. (Lowest Year) } \\
\text { Normal Cooling D.D. (Lowest Year) }\end{array}$} & 0 & 0 & 0 & 0 & 1 & 3 & 6 & 4 & 1 & 0 & 0 & 0 \\
\hline & & & & & & & & & & & & \\
\hline Heating D.D. (Lowest Year) & 611 & 532 & 349 & 322 & 81 & 23 & 0 & 2 & 85 & 243 & 434 & 513 \\
\hline \multirow{3}{*}{$\begin{array}{l}\text { Daily Htg. D.D. Avg. (Lowest Year) } \\
\text { Normal Heating D.D (Lowest Year) }\end{array}$} & 20 & 16 & 13 & 9 & 3 & 1 & 0 & 0 & 3 & 8 & 15 & 16 \\
\hline & & & & & & & & & & & & \\
\hline & & & & & & & & & & & & \\
\hline \multicolumn{13}{|l|}{ ELECTRICAL USAGE \& COST } \\
\hline kWh Used & 22,934 & 22,949 & 22,877 & 18,211 & 16,228 & 18,384 & 22,334 & 20,616 & 19,199 & 13,128 & 20,756 & 25,046 \\
\hline \multirow{2}{*}{ Daily kWh Avg. } & 740 & 695 & 847 & 536 & 541 & 557 & 798 & 665 & 619 & 438 & 716 & 783 \\
\hline & & & & & & & & & & & & \\
\hline Demand kW/RkVA Used & 45 & 51 & 46 & 52 & 49 & 59 & 69 & 66 & 66 & 52 & 55 & 61 \\
\hline \multirow{2}{*}{ Load Factor (Lowest Year) } & $68 \%$ & $65 \%$ & $66 \%$ & $46 \%$ & $49 \%$ & $42 \%$ & $43 \%$ & $41 \%$ & $41 \%$ & $37 \%$ & $49 \%$ & $59 \%$ \\
\hline & \multirow{2}{*}{\multicolumn{11}{|c|}{ NATURAL GAS USAGE \& COST }} & \\
\hline \multicolumn{12}{|l|}{ CCFF } & \\
\hline $\mathrm{m}^{\wedge} 3$ Used & 4,052 & 3,954 & 2,469 & 1,592 & 679 & 173 & 86 & 69 & 232 & 1,300 & 1,052 & 3,900 \\
\hline \multirow{2}{*}{ Daily $\mathrm{m}^{\wedge} 3$ Avg. } & 131 & 120 & 91 & 47 & 23 & 5 & 3 & 2 & 7 & 43 & 36 & 122 \\
\hline & & & & & & & & & & & & \\
\hline \multicolumn{13}{|l|}{ GREENHOUSE DATA } \\
\hline \multirow{4}{*}{$\begin{array}{l}\text { C02 (kgs) (Lowest Year) } \\
\text { S02 (kgs) (Lowest Year) } \\
\text { N0x (kgs) (Lowest Year) }\end{array}$} & 44,105 & 43,421 & 32,863 & 23,518 & 15,722 & 13,592 & 15,633 & 14,357 & 14,558 & 18,032 & 21,408 & 44,450 \\
\hline & 477 & 469 & 355 & 254 & 170 & 147 & 169 & 155 & 157 & 195 & 231 & 480 \\
\hline & 209 & 206 & 156 & 111 & 74 & 64 & 74 & 68 & 69 & 85 & 101 & 211 \\
\hline & & & & & & & & & & & & \\
\hline USAGE DATA & & & & & & & & & & & & \\
\hline kWh to GJ & 82.56 & 82.61 & 82.36 & 65.56 & 58.42 & 66.18 & 80.40 & 74.22 & 69.12 & 47.26 & 74.72 & 90.17 \\
\hline $\mathrm{GJ} / \mathrm{m} 2 /$ Day ELECTRIC (Lowest Year) & 0.001 & 0.001 & 0.001 & 0.001 & 0.001 & 0.001 & 0.001 & 0.001 & 0.001 & 0.001 & 0.001 & 0.001 \\
\hline GJ/m2/Month (Lowest Year) & 0.04 & 0.04 & 0.04 & 0.03 & 0.03 & 0.03 & 0.04 & 0.03 & 0.03 & 0.02 & 0.04 & 0.04 \\
\hline m3 to GJ & 150.73 & 147.09 & 91.85 & 59.22 & 25.26 & 6.44 & 3.20 & 2.57 & 8.63 & 48.36 & 39.13 & 145.08 \\
\hline GJ/m2/Day GAS (Lowest Year) & 0.002 & 0.002 & 0.002 & 0.001 & 0.000 & 0.000 & 0.000 & 0.000 & 0.000 & 0.001 & 0.001 & 0.002 \\
\hline $\mathrm{GJ} / \mathrm{m} 2 /$ Month & 0.07 & 0.07 & 0.04 & 0.03 & 0.01 & 0.00 & 0.00 & 0.00 & 0.00 & 0.02 & 0.02 & 0.07 \\
\hline $\mathrm{m} 3 / \mathrm{m} 2 /$ Month & 1.90 & 1.86 & 1.16 & 0.75 & 0.32 & 0.08 & 0.04 & 0.03 & 0.11 & 0.61 & 0.49 & 1.83 \\
\hline GJ/m2/Day ENERGY (Lowest Year) & 0.004 & 0.003 & 0.003 & 0.002 & 0.001 & 0.001 & 0.001 & 0.001 & 0.001 & 0.002 & 0.002 & 0.004 \\
\hline $\mathrm{GJ} / \mathrm{m} 2 /$ Month (Lowest Consumption Year) & 0.110 & 0.108 & 0.082 & 0.059 & 0.039 & 0.034 & 0.039 & 0.036 & 0.037 & 0.045 & 0.053 & 0.110 \\
\hline Average Highest Year to Lowest Year & 0.076 & 0.134 & 0.109 & 0.102 & 0.052 & 0.060 & 0.046 & 0.043 & 0.036 & 0.058 & 0.080 & 0.136 \\
\hline BOMA Mean Value per Month & 0.111 & 0.111 & 0.111 & 0.111 & 0.111 & 0.111 & 0.111 & 0.111 & 0.111 & 0.111 & 0.111 & 0.111 \\
\hline Energy Usage per Month (Electricity + Gas) & 233 & 230 & 174 & 125 & 84 & 73 & 84 & 77 & 78 & 96 & 114 & 235 \\
\hline Degree Days & 611 & 532 & 350 & 322 & 117 & 125 & 195 & 114 & 121 & 244 & 434 & 513 \\
\hline Normalized Data (Average Degree Days) & 618 & 582 & 452 & 340 & 125 & 108 & 159 & 106 & 116 & 226 & 456 & 587 \\
\hline Normalized Data (Av Energy Consumption) & 254 & 243 & 204 & 171 & 106 & 102 & 117 & 101 & 104 & 137 & 206 & 245 \\
\hline Normalized Data (Av Energy Index / month) & 0.119 & 0.114 & 0.096 & 0.080 & 0.050 & 0.048 & 0.055 & 0.047 & 0.049 & 0.064 & 0.097 & 0.115 \\
\hline
\end{tabular}


Analysis on how electricity and gas consumption corresponds to heating and cooling periods (for highest energy consumption year):

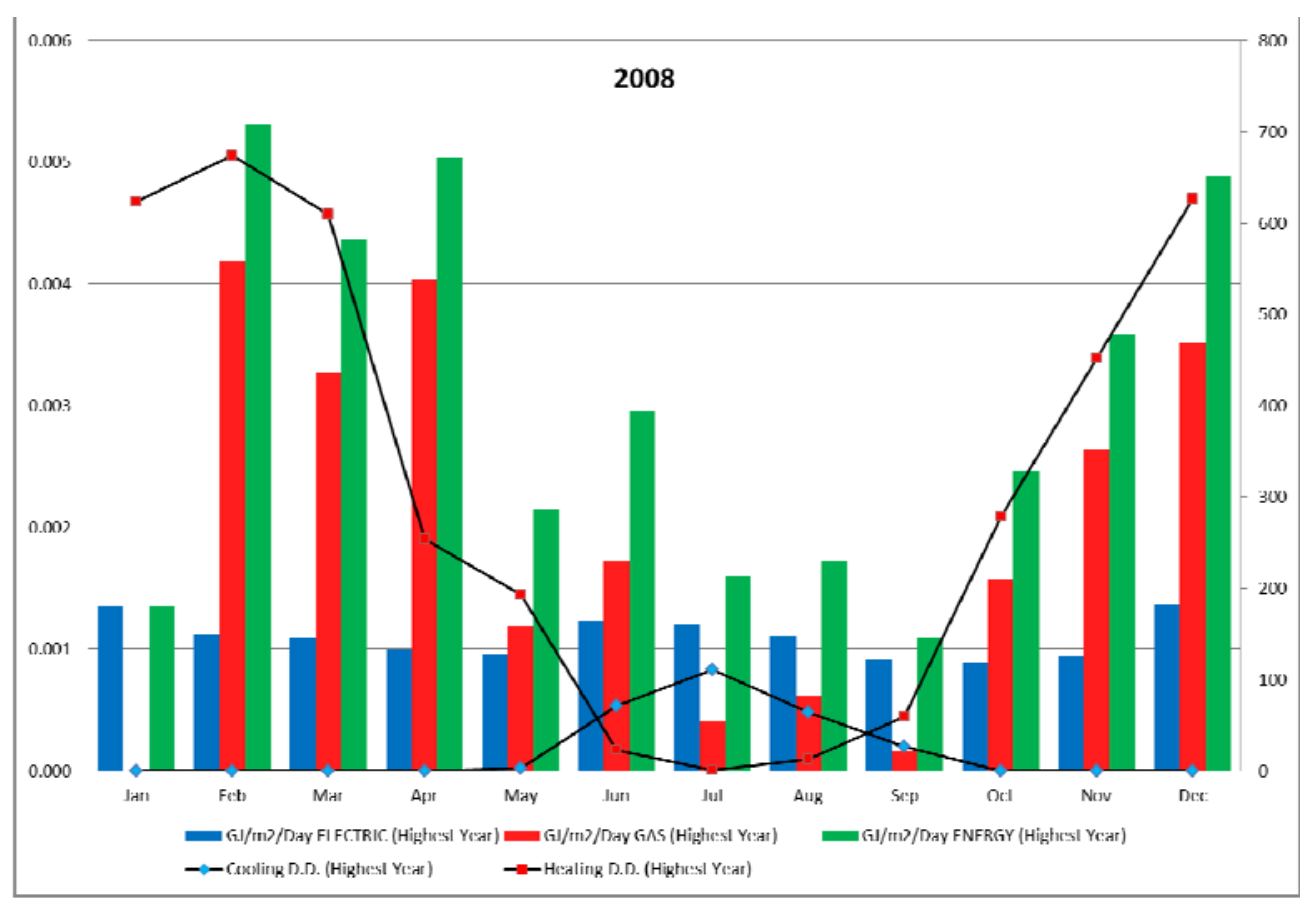

Analysis on how electricity and gas consumption corresponds to heating and cooling periods (for lowest energy consumption year):

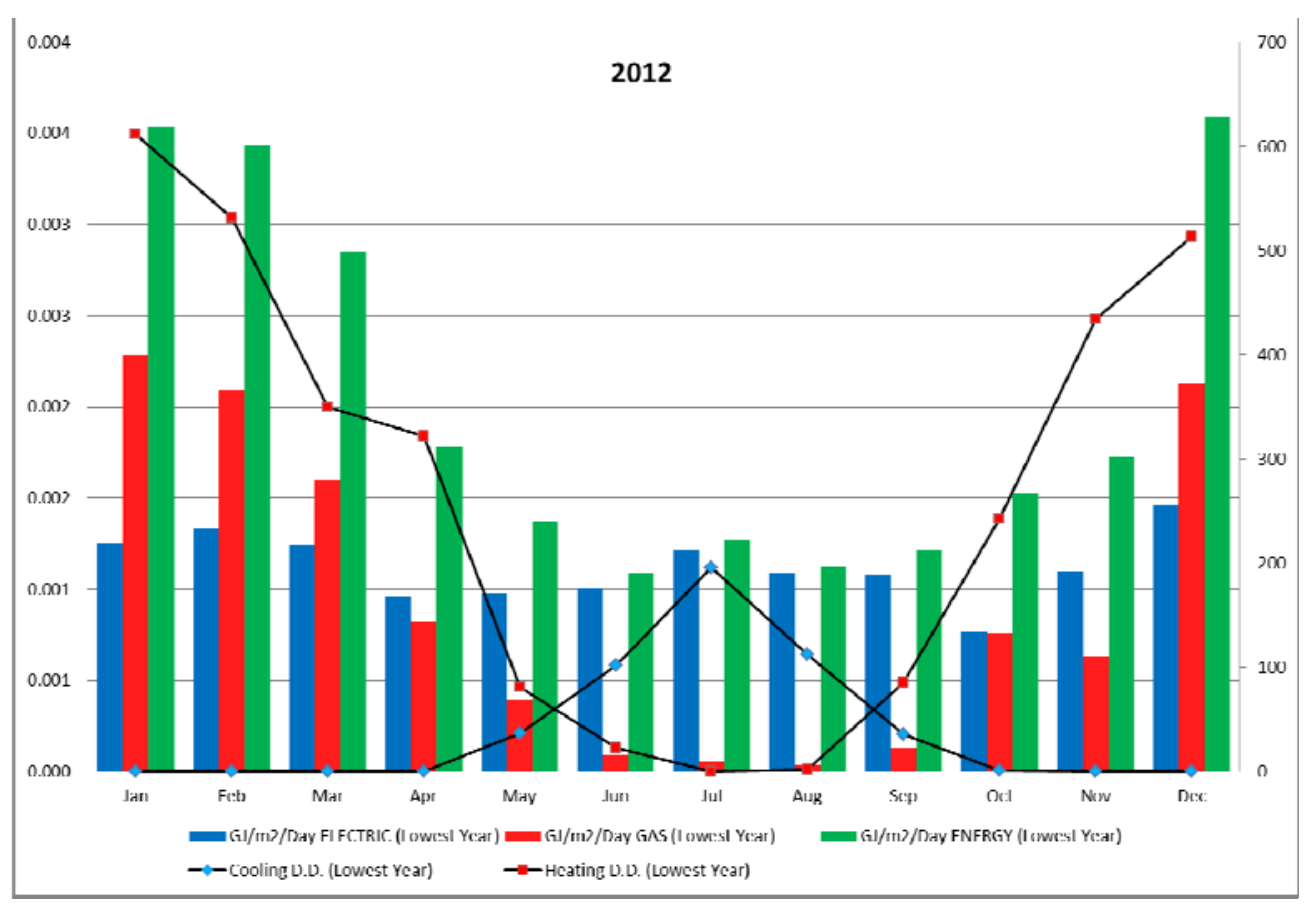


Monthly energy index comparison between highest energy consumption year, lowest, average and benchmark (BOMA) energy intensity:

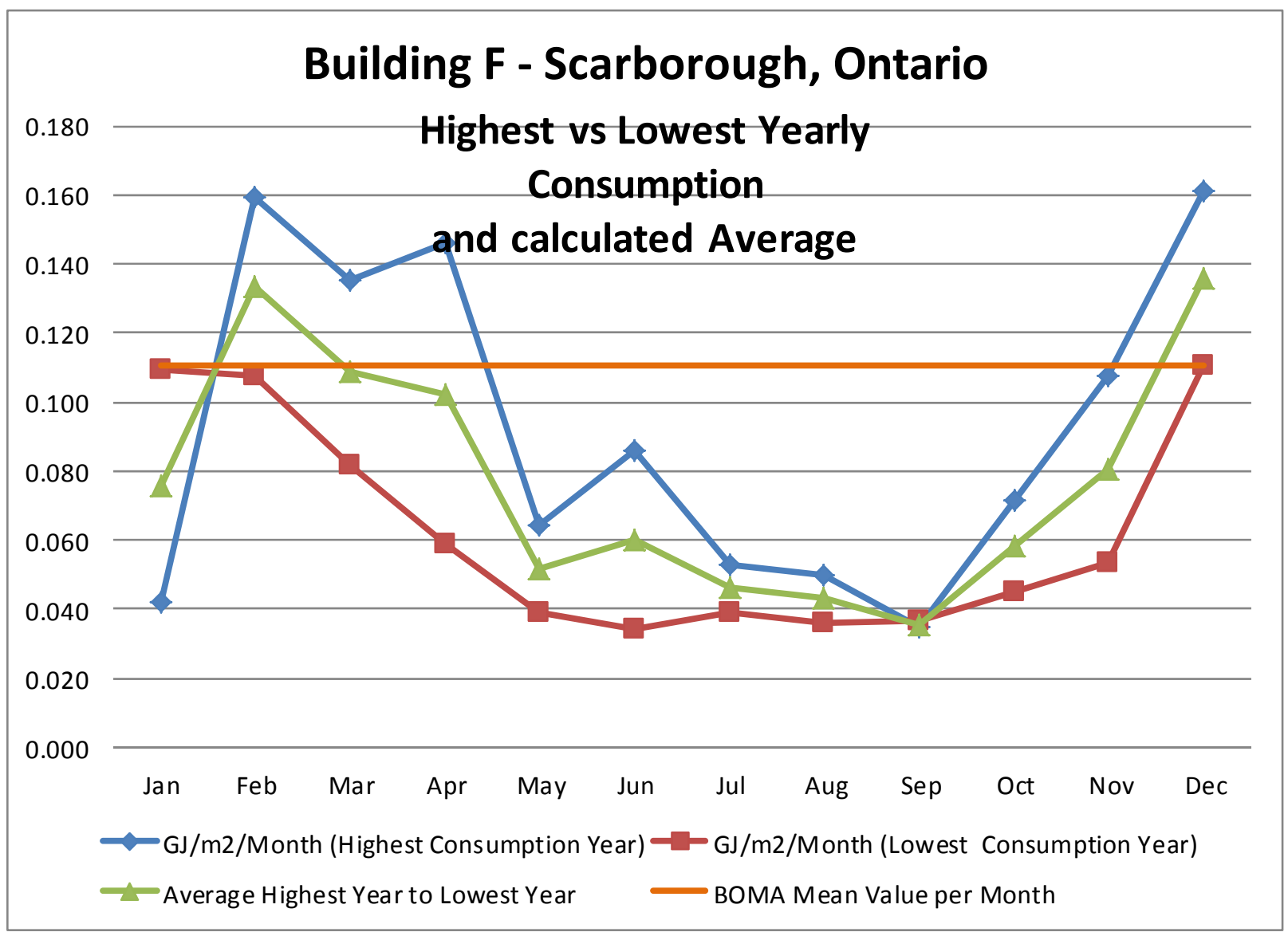


Building \#7 - Utility Bills Analysis

\section{Calculations of Energy Index for Building \#7}

Energy CAP database was utilized to collect energy consumption information for the building. Energy consumption was provided by utility bills for electricity and gas. For Building \#7 utility bills were provided from December 2006 to March 2015. To complete most accurate analysis utility bills for 2007 to 2014 were only analyzed because 2006 and 2015 has incomplete data. By having total floor area for entire building of 8,180 $\mathrm{m}^{2}$, energy index in $\mathrm{GJ} / \mathrm{m}^{2} /$ year was calculated. From calculations it was noticed that utility bills data provided consistent information and therefore all years were included for calculations.

Utility bills analysis showed following:

\begin{tabular}{|c|c|c|c|c|c|c|c|c|}
\hline \multicolumn{9}{|c|}{ Building G - Ottawa, Ontario } \\
\hline \multirow[b]{2}{*}{ Row Labels } & \multirow{2}{*}{\multicolumn{2}{|c|}{$\begin{array}{c}\text { Sum of Ele Total } \\
\text { Cost / Year }\end{array}$}} & \multirow{2}{*}{$\begin{array}{c}\text { kWh } \\
\text { Sum of Ele } \\
\text { Consumption / } \\
\text { Year }\end{array}$} & & & $m^{3}$-ngas & Total GJ/yr & $8,180.00$ \\
\hline & & & & \multicolumn{2}{|c|}{$\begin{array}{c}\text { Sum of Gas Total } \\
\text { Cost / Year }\end{array}$} & $\begin{array}{c}\text { Sum of Gas } \\
\text { Consumption / } \\
\text { Year }\end{array}$ & Total & $\mathrm{GJ} / \mathrm{m} 2 / \mathrm{yr}$ \\
\hline Year 2006 & $\$$ & $77,017.04$ & $718,425.00$ & $\$$ & 468.19 & 842.00 & & \\
\hline Year 2007 & $\$$ & $261,537.40$ & $2,492,279.00$ & $\$$ & $20,995.34$ & $40,955.00$ & $10,495.73$ & 1.28 \\
\hline Year 2008 & $\$$ & $275,706.85$ & $2,620,408.00$ & $\$$ & $18,855.84$ & $36,871.00$ & $10,805.07$ & 1.32 \\
\hline Year 2009 & $\$$ & $275,088.80$ & $2,628,606.71$ & $\$$ & $15,240.91$ & $29,529.00$ & $10,561.46$ & 1.29 \\
\hline Year 2010 & $\$$ & $259,308.67$ & $2,301,725.00$ & $\$$ & $11,312.18$ & $20,917.00$ & $9,064.32$ & 1.11 \\
\hline Year 2011 & $\$$ & $297,341.73$ & $2,339,181.16$ & $\$$ & $14,159.67$ & $25,159.00$ & $9,356.97$ & 1.14 \\
\hline Year 2012 & $\$$ & $283,483.13$ & $2,205,540.61$ & $\$$ & $9,378.44$ & $33,887.00$ & $9,200.54$ & 1.12 \\
\hline Year 2013 & $\$$ & $317,637.06$ & $2,298,816.16$ & $\$$ & $8,844.17$ & $30,965.00$ & $9,427.64$ & 1.15 \\
\hline Year 2014 & $\$$ & $291,286.42$ & $1,980,949.16$ & $\$$ & $12,013.35$ & $37,409.00$ & $8,523.03$ & 1.04 \\
\hline Year 2015 & $\$$ & $107,912.33$ & $719,858.65$ & $\$$ & $10,795.49$ & $29,685.00$ & & \\
\hline Average & $\$$ & $282,673.76$ & $2,358,438.23$ & $\$$ & $13,849.99$ & $31,961.50$ & & 1.18 \\
\hline
\end{tabular}

As it was specified in energy audit, energy consumption of the Building \#7 is high in comparison to similar office buildings in same region; and therefore average energy index which equals to $1.18 \mathrm{GJ} / \mathrm{m}^{2} / \mathrm{yr}$ is also high in comparison to benchmark values of BOMA energy efficient building value of $1.05 \mathrm{GJ} / \mathrm{m}^{2} / \mathrm{yr}$, however value is much lower than average National Resources Canada value of $1.43 \mathrm{GJ} / \mathrm{m} 2 /$ year.

Two charts below show electricity and gas consumption per year. Electricity consumption chart demonstrates decrease in energy usage, with lowest usage in 2014. However gas consumption chart doesn't show values that prominently increasing or decreasing, but more recent years are approaching better efficiency. 

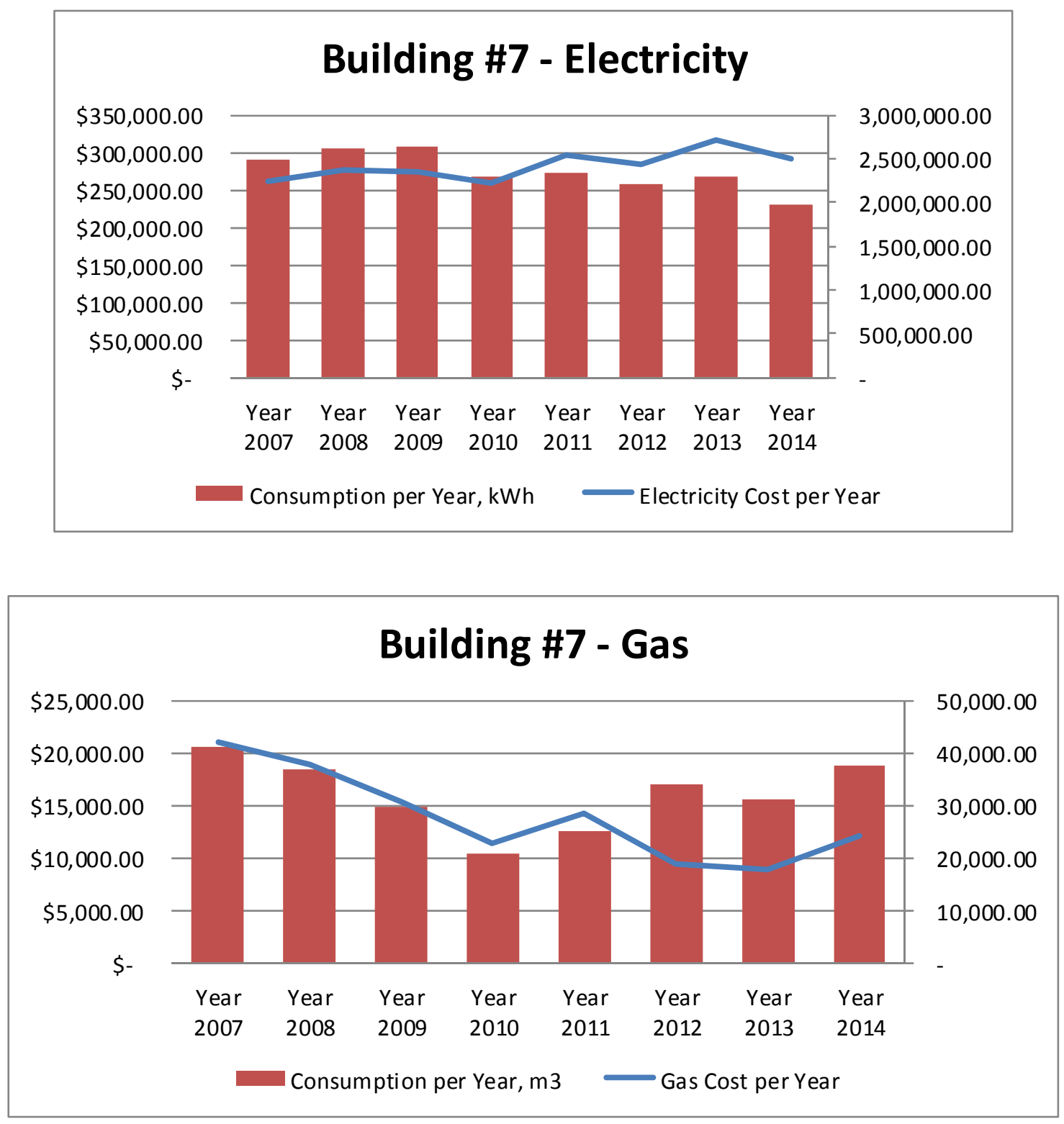

Yearly energy intensity (index) was also plotted to demonstrate increase or decrease over the range of years for which data is available. Chart below shows that energy index value is decreasing and currently has the lowest value of $1.04 \mathrm{GJ} / \mathrm{m}^{2} / \mathrm{yr}$. The lowest energy index was in 2014 , but due to utility bills inconsistency in 2014 for normalization calculation 2010 will be used. The highest energy consumption is in 2008. These two years' data will be used for further calculations and comparisons. 


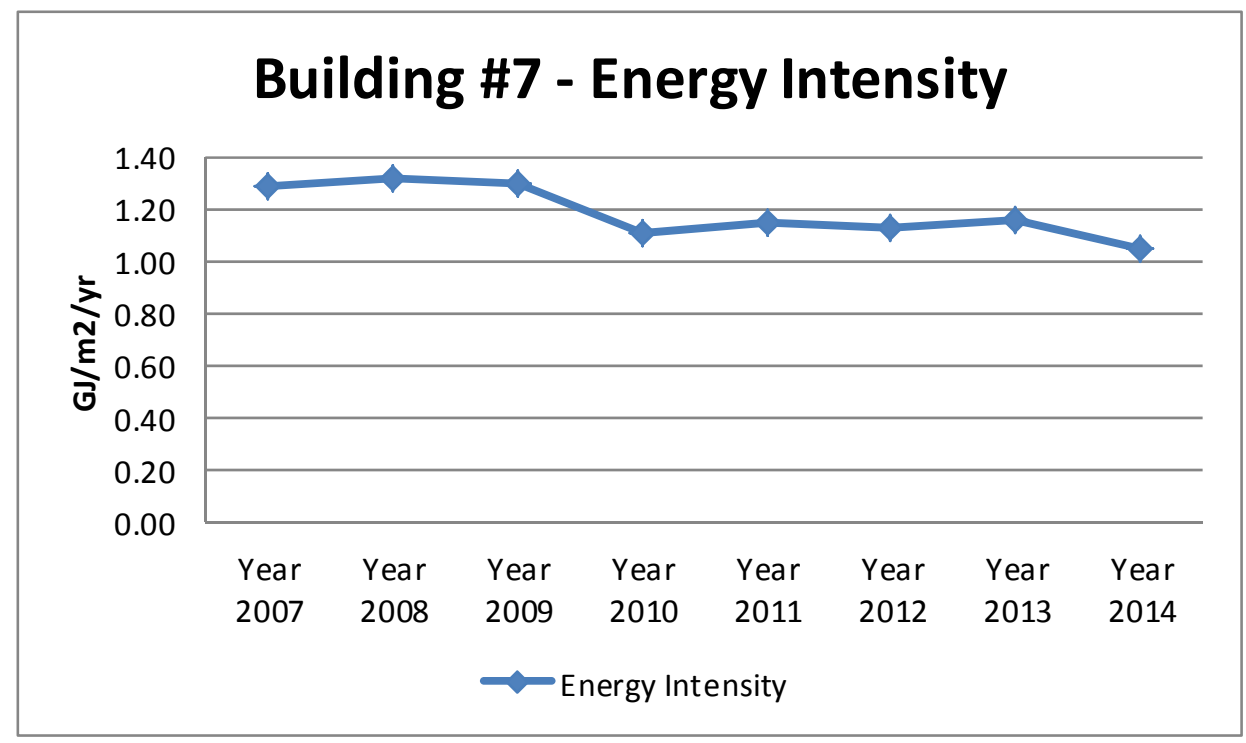

Normalized total energy consumption was calculated for Building \#7. Based on plotted results, shown below in the chart, it can be concluded that energy consumption for 2008 is higher than for 2010. This proves that regardless of weather conditions 2008 has higher energy consumptions than in 2010. Implementing trendline equations, average equation was calculated:

$\gamma=0.7683 x+571.36$

From above equation normalized average energy index was calculated as $1.21 \mathrm{GJ} / \mathrm{m}^{2} / \mathrm{yr}$, this value is higher than average for 2007 to 2014 years range. Calculated value will be used for further case-study buildings comparison. 


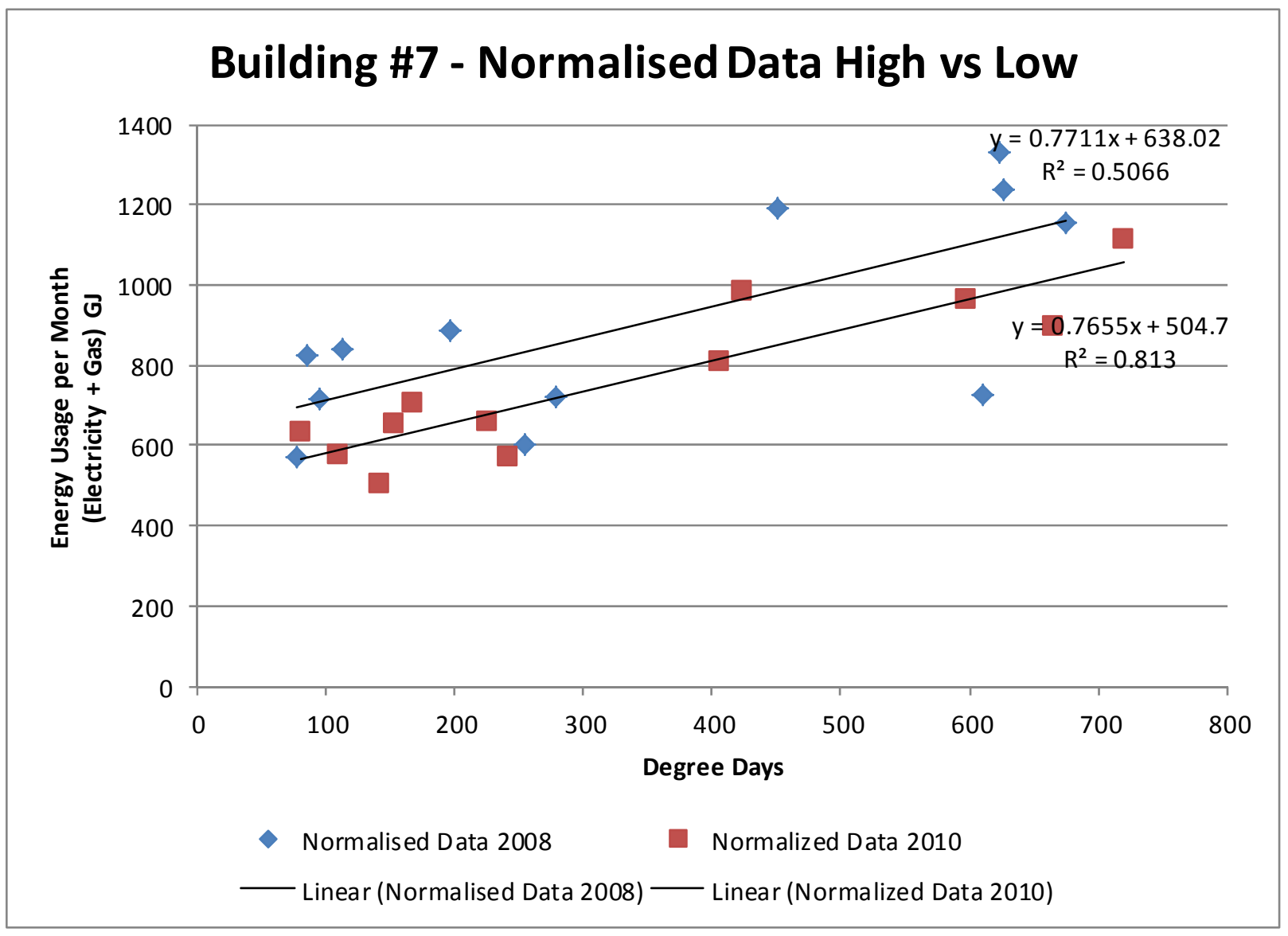


Actual data used for calculations (year with highest energy consumption):

\begin{tabular}{|c|c|c|c|c|c|c|c|c|c|c|c|c|}
\hline ADDRESS: & \multicolumn{4}{|c|}{ Building G - Ottawa, Ontario } & & & & & & & & \\
\hline BUILDING\# & \multicolumn{4}{|c|}{7} & & & & & & & & \\
\hline Year - Highest Energy Consumption: & \multicolumn{4}{|l|}{2008} & & & & & & & & \\
\hline AREA: & \multicolumn{4}{|l|}{8,180} & & & & & & & & \\
\hline USAGE INDEX: & \multicolumn{4}{|l|}{1.32} & & & & & & & & \\
\hline Month & Jan & $\mathrm{Feb}$ & Mar & Apr & May & Jun & Jul & Aug & Sep & Oct & Nov & Dec \\
\hline \multirow{5}{*}{$\begin{array}{l}\text { Electric Billing Date } \\
\text { Electric Billing Days }\end{array}$} & $11 / 02 / 2008$ & $12 / 03 / 2008$ & $11 / 04 / 2008$ & $09 / 05 / 2008$ & $11 / 06 / 2008$ & $14 / 07 / 2008$ & $13 / 08 / 2008$ & 10/09/2008 & $09 / 10 / 2008$ & $12 / 11 / 2008$ & $11 / 12 / 2008$ & $13 / 01 / 2009$ \\
\hline & 31 & 30 & 30 & 28 & 33 & 33 & 30 & 28 & 29 & 34 & 29 & 33 \\
\hline & $29 / 01 / 2008$ & $28 / 02 / 2008$ & $28 / 04 / 2008$ & $25 / 06 / 2008$ & $26 / 06 / 2008$ & $04 / 07 / 2008$ & $06 / 08 / 2008$ & $04 / 09 / 2008$ & $06 / 10 / 2008$ & $28 / 10 / 2008$ & $26 / 11 / 2008$ & $29 / 12 / 2008$ \\
\hline & 31 & 30 & 60 & 58 & 1 & 8 & 33 & 29 & 32 & 22 & 29 & 33 \\
\hline & \multicolumn{12}{|c|}{ COOLING \& HEATING DEGREE DAYS } \\
\hline \multirow{4}{*}{$\begin{array}{l}\text { Cooling D.D. (Highest Year) } \\
\text { Daily Clg D.D. Avg. (Highest Year) } \\
\text { Normal Cooling D.D. (Highest Year) }\end{array}$} & & & & & & & & & & & & \\
\hline & 0 & 0 & 0 & 0 & 3 & 72 & 111 & 64 & 27 & 0 & 0 & 0 \\
\hline & 0 & 0 & 0 & 0 & 0 & 2 & 4 & 2 & 1 & 0 & 0 & 0 \\
\hline & & & & & & & & & & & & \\
\hline & 624 & 675 & 610 & 254 & 194 & 23 & 1 & 13 & 59 & 279 & 452 & 627 \\
\hline \multirow{3}{*}{$\begin{array}{l}\text { Heating D.D. (Highest Year) } \\
\text { Daily Htg. D.D. Avg. (Highest Year) } \\
\text { Normal Heating D.D (Highest Year) }\end{array}$} & 20 & 22 & 10 & 4 & 194 & 3 & 0 & 0 & 2 & 13 & 16 & 19 \\
\hline & & & & & & & & & & & & \\
\hline & & & & & & & & & & & & \\
\hline \multicolumn{13}{|l|}{ ELECTRICAL USAGE \& COST } \\
\hline \multirow{2}{*}{$\begin{array}{l}\text { kWh Used } \\
\text { Daily kWh Avg. }\end{array}$} & 280,330 & 2227,400 & 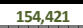 & $\begin{array}{l}167,160 \\
\end{array}$ & 245,625 & 199,560 & 233,218 & 158,880 & 229,177 & 197,760 & 280,517 & 246,360 \\
\hline & 9,043 & 7,580 & 2,574 & 2,882 & 245,625 & 24,945 & 7,067 & 5,479 & 7,162 & 8,989 & 9,673 & 7,465 \\
\hline Demand kW/RkVA Used & 410 & 456 & 180 & 365 & 380 & 412 & 375 & 387 & 375 & 362 & 444 & 419 \\
\hline \multirow{2}{*}{$\begin{array}{l}\text { Demand kW/RkVA Used } \\
\text { Load Factor (Highest Year) }\end{array}$} & $92 \%$ & $69 \%$ & $119 \%$ & $68 \%$ & $82 \%$ & $61 \%$ & $86 \%$ & $61 \%$ & $88 \%$ & $67 \%$ & 944 & $74 \%$ \\
\hline & & & & & & & & & & & & \\
\hline \multicolumn{13}{|l|}{ NATURAL GAS USAGE \& COST } \\
\hline \multicolumn{13}{|l|}{ CCF } \\
\hline $\mathrm{m}^{\wedge} 3$ Used & 8,594 & 9,101 & 4,573 & 42 & 0 & 0 & 0 & 0 & 0 & 250 & 4,943 & 9,368 \\
\hline Daily $\mathrm{m}^{\wedge} 3$ Avg. & 277 & 303 & 76 & 1 & 0 & 0 & 0 & 0 & 0 & 11 & 170 & 284 \\
\hline \multicolumn{13}{|l|}{ GREENHOUSE DATA } \\
\hline \multirow{4}{*}{$\begin{array}{l}\text { C02 (kgs) (Highest Year) } \\
\text { S02 (kgs) (Highest Year) } \\
\text { NOx (kgs) (Highest Year) }\end{array}$} & 249,406 & 217,387 & 136,247 & 112,750 & 165,239 & 134,249 & 156,892 & 106,883 & 154,174 & 134,808 & 223,693 & 232,031 \\
\hline & 2,695 & 2,349 & 1,472 & 1,218 & 1,785 & 1,450 & 1,695 & 1,155 & 1,666 & 1,456 & 2,417 & 2,507 \\
\hline & 1,181 & 1,030 & 645 & 534 & 783 & 636 & 743 & 506 & 730 & 639 & 1,060 & 1,099 \\
\hline \multirow{2}{*}{\multicolumn{13}{|c|}{ USAGE DATA }} \\
\hline & & & & & & & & & & & & \\
\hline \multirow{4}{*}{$\begin{array}{l}\text { kWh to GJ } \\
\text { GJ/m2/Day ELECTRIC (Highest Year) } \\
\text { GJ/m2/Month (Highest Year) }\end{array}$} & 1009.19 & 818.64 & 2555.92 & 601.78 & 884.25 & 718.42 & 839.58 & 571.97 & 825.04 & 711.94 & 1009.86 & 886.90 \\
\hline & 0.004 & 0.003 & 0.002 & 0.003 & 0.003 & 0.003 & 0.003 & 0.002 & 0.003 & 0.003 & 0.004 & 0.003 \\
\hline & 0.12 & 0.10 & 0.07 & 0.07 & 0.11 & 0.09 & 0.10 & 0.07 & 0.10 & 0.09 & 0.12 & 0.11 \\
\hline & 319.70 & 338.56 & 170.12 & 1.56 & 0.00 & 0.00 & 0.00 & 0.00 & 0.00 & 9.30 & 183.88 & 348.49 \\
\hline GJ/m2/Day GAS (Highest Year) & 0.001 & 0.001 & 0.000 & 0.000 & 0.000 & 0.000 & 0.000 & 0.000 & 0.000 & 0.000 & 0.001 & 0.001 \\
\hline $\mathrm{GJ} / \mathrm{m} 2 /$ Month & 0.04 & 0.04 & 0.02 & 0.00 & 0.00 & 0.00 & 0.00 & 0.00 & 0.00 & 0.00 & 0.02 & 0.04 \\
\hline $\mathrm{m} 3 / \mathrm{m} 2 /$ Month & 1.05 & 1.11 & 0.56 & 0.01 & 0.00 & 0.00 & 0.00 & 0.00 & 0.00 & 0.03 & 0.60 & 1.15 \\
\hline GJ/m2/Day ENERGY (Highest Year) & 0.005 & 0.005 & 0.003 & 0.003 & 0.003 & 0.003 & 0.003 & 0.002 & 0.003 & 0.003 & 0.005 & 0.005 \\
\hline $\mathrm{GJ} / \mathrm{m} 2 /$ Month (Highest Consumption Year) & 0.162 & 0.141 & 0.089 & 0.074 & 0.108 & 0.088 & 0.103 & 0.070 & 0.101 & 0.088 & 0.146 & 0.151 \\
\hline Energy Usage per Month (Electricity + Gas) & 1329 & 1157 & 726 & 603 & 884 & 718 & 840 & 572 & 825 & 721 & 1194 & 1235 \\
\hline Degree Days & 624 & 675 & 610 & 254 & 196 & 94 & 112 & 77 & 86 & 279 & 452 & 627 \\
\hline
\end{tabular}




\section{Actual data used for calculations (year with lowest energy consumption):}

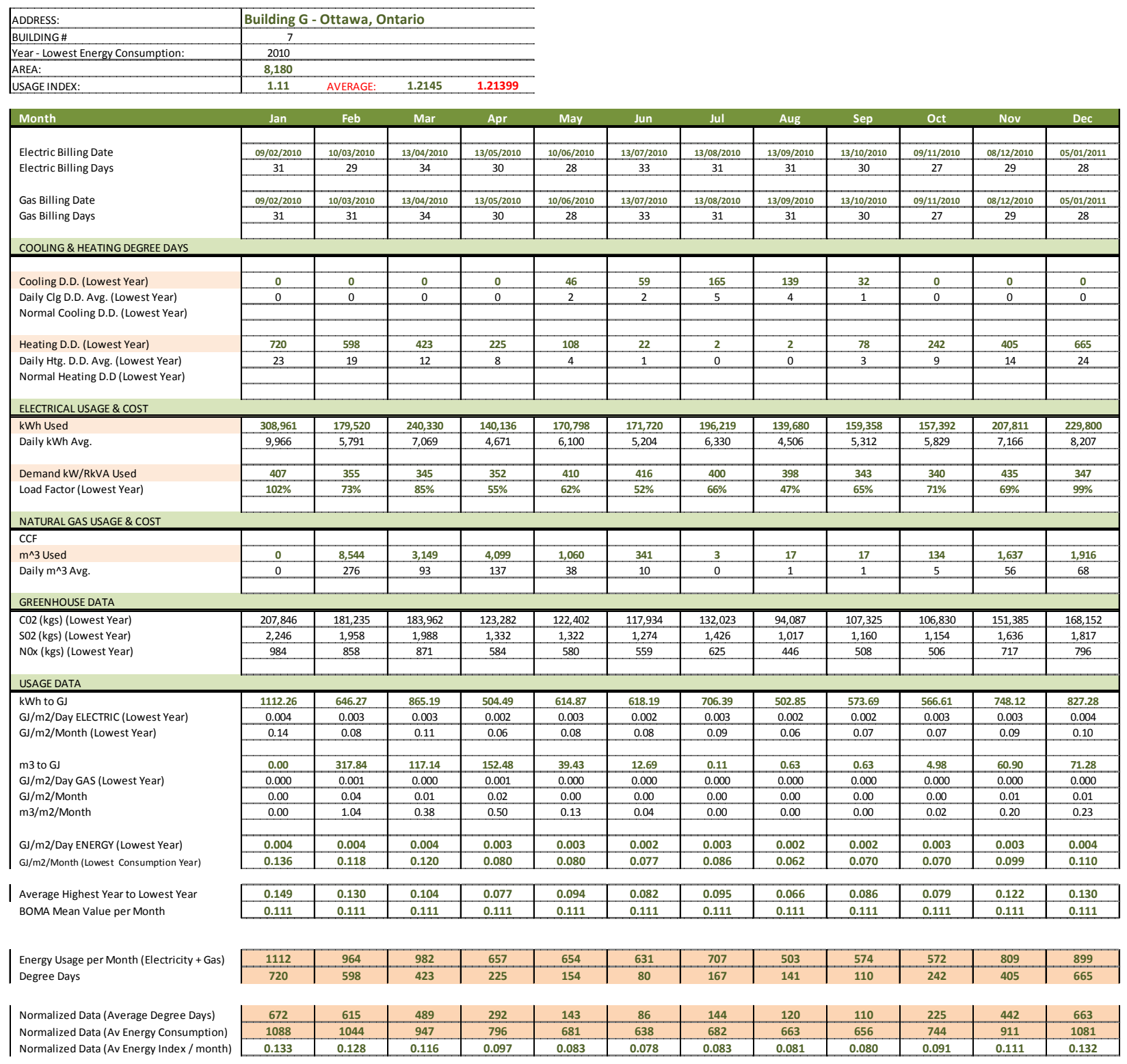


Analysis on how electricity and gas consumption corresponds to heating and cooling periods (for highest energy consumption year):

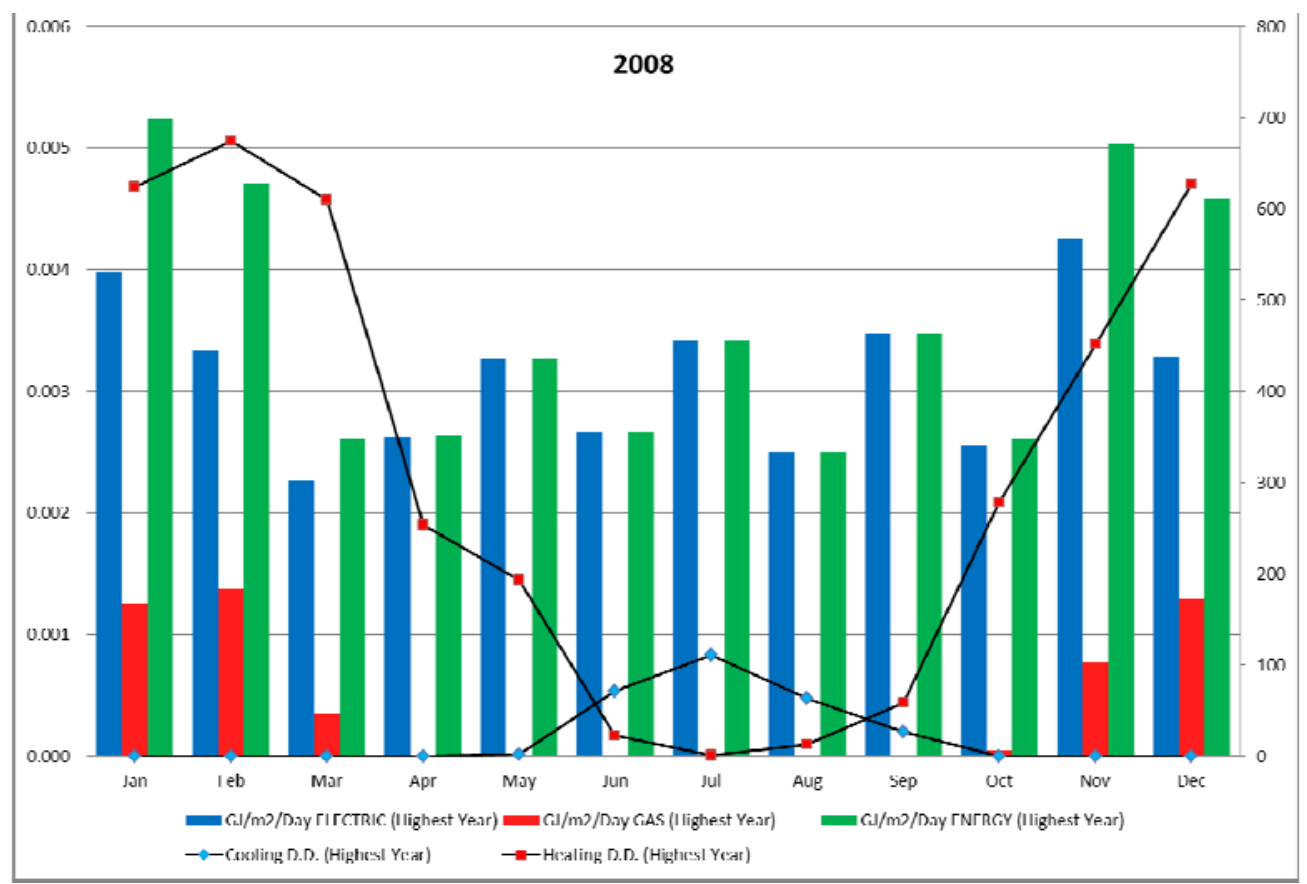

Analysis on how electricity and gas consumption corresponds to heating and cooling periods (for lowest energy consumption year):

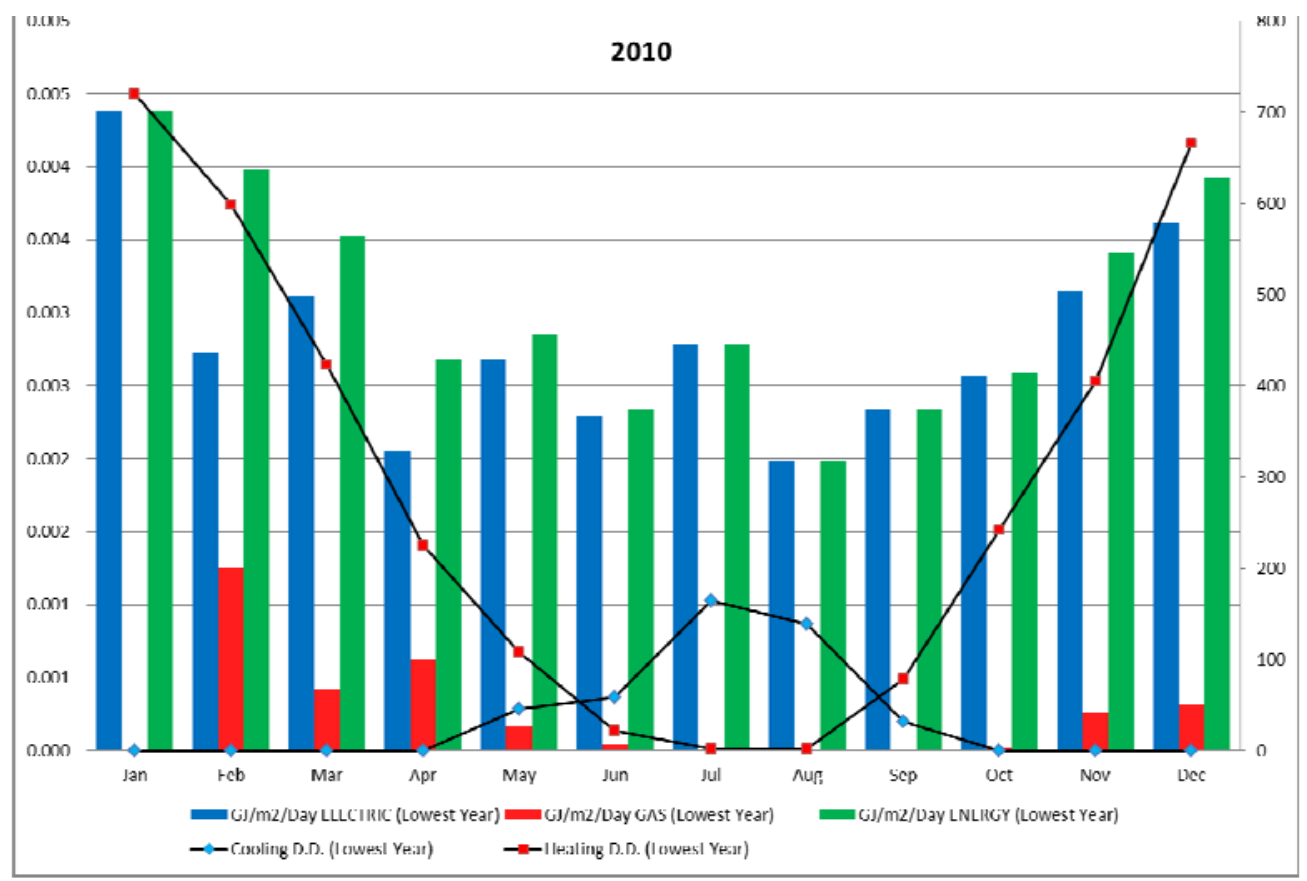


Monthly energy index comparison between highest energy consumption year, lowest, average and benchmark (BOMA) energy intensity:

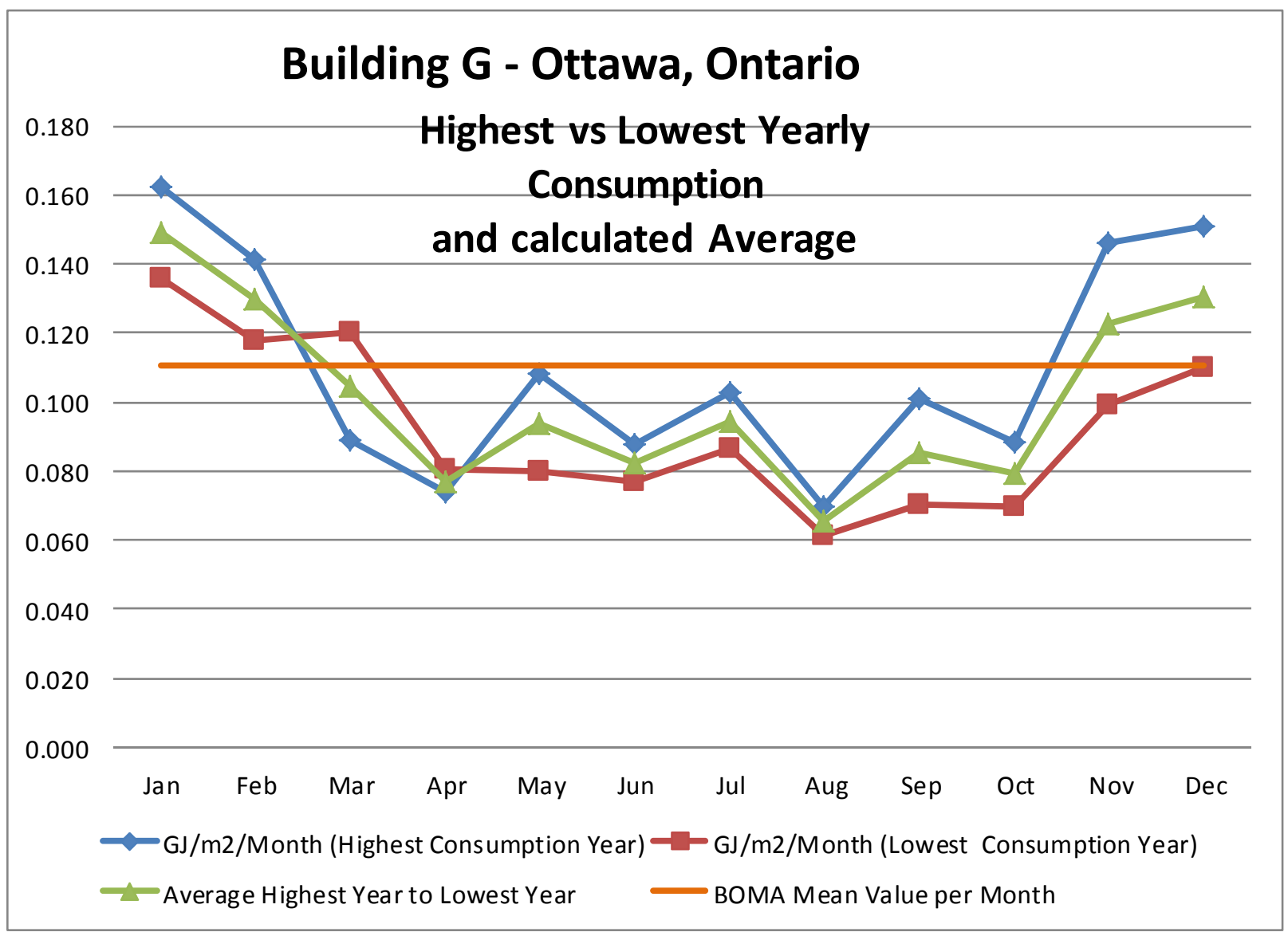


Building \#8 - Utility Bills Analysis

\section{Calculations of Energy Index for Building \#8}

Energy CAP database was utilized to collect energy consumption information for the building. Energy consumption was provided by utility bills for electricity and gas. For Building \#1 utility bills were provided from December 2006 to March 2015. To complete most accurate analysis utility bills for 2007 to 2014 were only analyzed because 2006 and 2015 has incomplete data. By having total floor area for entire building of 5,020 $\mathrm{m}^{2}$, energy index in $\mathrm{GJ} / \mathrm{m}^{2} /$ year was calculated. From calculations it was noticed that 2011 gas consumption show very inconsistent value in comparison to other years, but overall 2011 data wasn't excluded from calculations. After analysing gas utility bills in more details, was concluded that this inconsistency could be due to some of the bills transferred from 2010 to 2011.

Utility bills analysis showed following:

\begin{tabular}{|c|c|c|c|c|c|c|c|c|}
\hline \multicolumn{9}{|c|}{ Building H - Ottawa, Ontario } \\
\hline \multirow[b]{2}{*}{ Row Labels } & \multirow{2}{*}{\multicolumn{2}{|c|}{$\begin{array}{c}\text { Sum of Ele Total } \\
\text { Cost / Year }\end{array}$}} & \multirow{2}{*}{$\begin{array}{c}\text { kWh } \\
\text { Sum of Ele } \\
\begin{array}{c}\text { Consumption / } \\
\text { Year }\end{array}\end{array}$} & & & $m^{3}$-ngas & Total GJ/yr & $5,020.00$ \\
\hline & & & & \multicolumn{2}{|c|}{\begin{tabular}{|c|} 
Sum of Gas Total \\
Cost / Year
\end{tabular}} & \multirow[t]{2}{*}{$\begin{array}{c}\text { Sum of Gas } \\
\text { Consumption / } \\
\text { Year }\end{array}$} & \multirow[t]{2}{*}{ Total } & \multirow[t]{2}{*}{$\mathrm{GJ} / \mathrm{m} 2 / \mathrm{yr}$} \\
\hline Year 2006 & $\$$ & $34,814.04$ & $355,368.00$ & & & & & \\
\hline Year 2007 & $\$$ & $212,376.79$ & $2,073,600.00$ & $\$$ & $62,908.21$ & $127,080.00$ & $12,192.34$ & 2.43 \\
\hline Year 2008 & $\$$ & $226,555.91$ & $2,167,200.00$ & $\$$ & $48,932.17$ & $98,374.00$ & $11,461.43$ & 2.28 \\
\hline Year 2009 & $\$$ & $201,310.10$ & $1,964,088.00$ & $\$$ & $26,371.51$ & $52,369.00$ & $9,018.84$ & 1.80 \\
\hline Year 2010 & $\$$ & $192,938.69$ & $1,808,712.00$ & $\$$ & $39,954.34$ & $81,685.00$ & $9,550.05$ & 1.90 \\
\hline Year 2011 & $\$$ & $202,353.88$ & $1,761,923.81$ & $\$$ & $58,867.11$ & $116,830.00$ & $10,689.00$ & 2.13 \\
\hline Year 2012 & $\$$ & $217,899.83$ & $1,779,480.00$ & $\$$ & $17,781.31$ & $68,518.00$ & $8,955.00$ & 1.78 \\
\hline Year 2013 & $\$$ & $217,769.31$ & $1,664,280.00$ & $\$$ & $14,301.85$ & $54,087.00$ & $8,003.44$ & 1.59 \\
\hline Year 2014 & $\$$ & $198,561.19$ & $1,419,480.00$ & $\$$ & $16,008.26$ & $55,175.00$ & $7,162.64$ & 1.43 \\
\hline Year 2015 & $\$$ & $70,723.43$ & $494,400.00$ & $\$$ & $15,813.63$ & $44,422.00$ & & \\
\hline Average & $\$$ & $208,720.71$ & $1,829,845.48$ & $\$$ & $35,640.60$ & $81,764.75$ & & 1.92 \\
\hline
\end{tabular}

As it was specified in energy audit, energy consumption of the Building \#8 is very high in comparison to similar office buildings in same region; and therefore average energy index which equals to $1.92 \mathrm{GJ} / \mathrm{m}^{2} / \mathrm{yr}$ is also high in comparison to benchmark values of BOMA energy efficient building value of $1.05 \mathrm{GJ} / \mathrm{m}^{2} / \mathrm{yr}$ and then average National Resources Canada value of $1.43 \mathrm{GJ} / \mathrm{m} 2 /$ year..

Two charts below show electricity and gas consumption per year. Electricity consumption chart demonstrates prominent decrease in energy usage, 2013 and 2014 have the lowest energy consumption values. Gas consumption chart shows big jump in 2011 , but at it was discussed earlier this could be due to gas bills. 

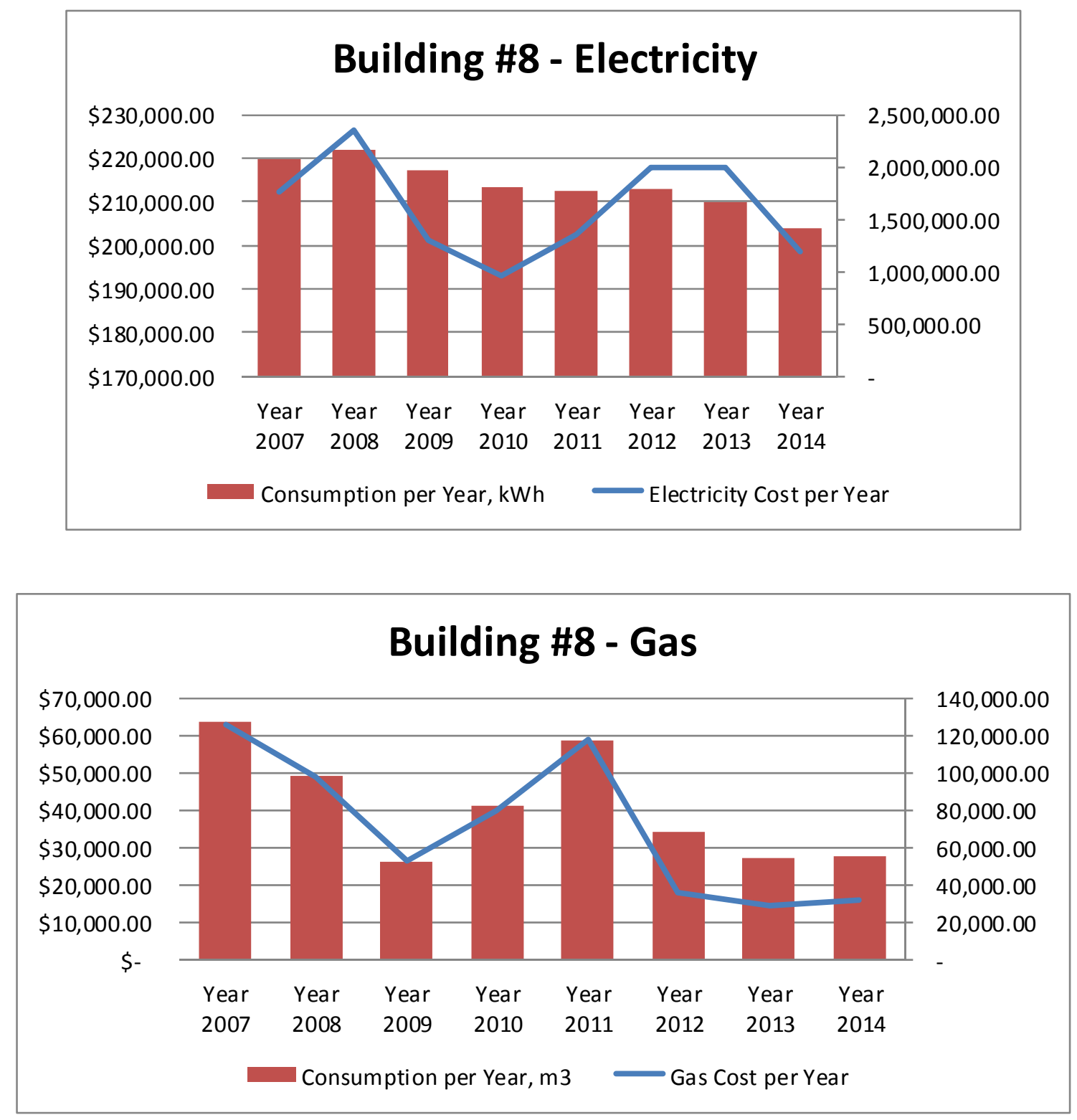

Yearly energy intensity (index) was also plotted to demonstrate increase or decrease over the range of years for which data is available. Chart below shows that energy index value is gradually decreasing, and the lowest energy intensity value is in 2014 and highest in 2007. These two years' data will be used for further calculations and comparisons. 


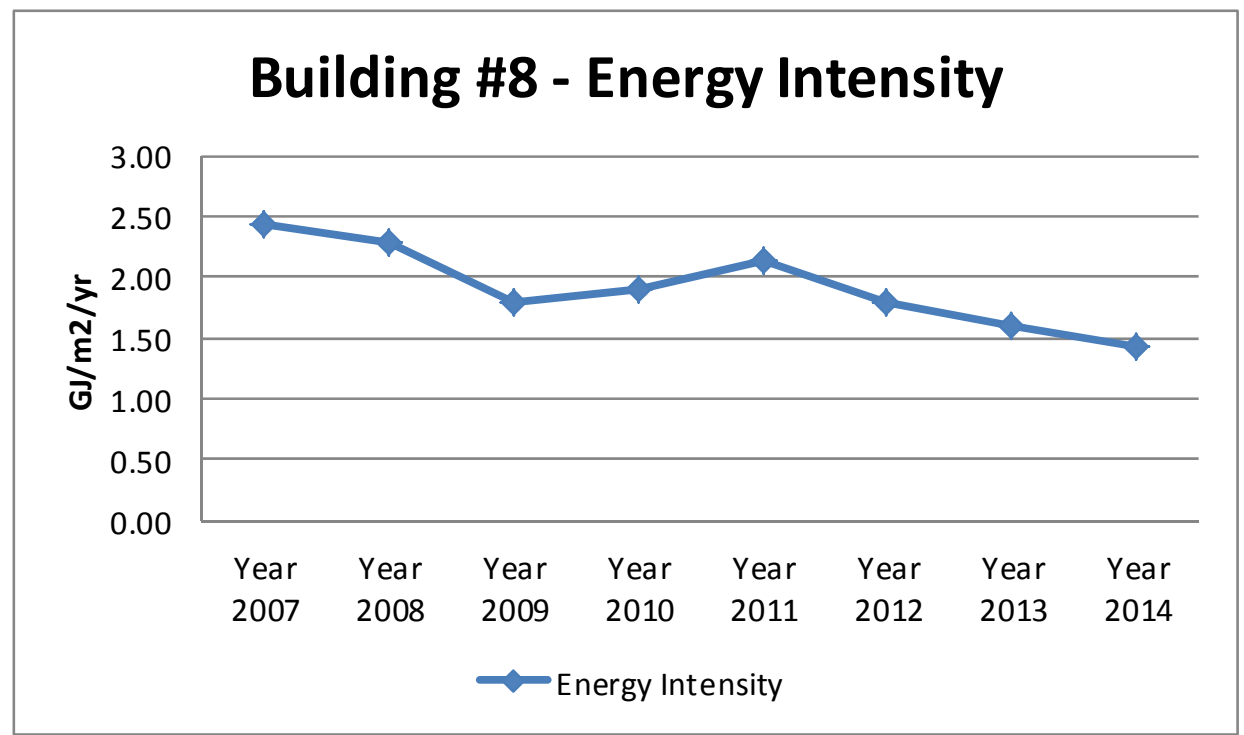

Normalized total energy consumption was calculated for Building \#8. Based on plotted results, shown below in the chart, it can be concluded that energy consumption for 2007 is higher than for 2014. This proves that regardless of weather conditions 2007 has higher energy consumptions than in 2014. Implementing trendline equations, average equation was calculated:

\section{$\gamma=1.4796 x+284.505$}

From above equation normalized average energy index was calculated as $1.93 \mathrm{GJ} / \mathrm{m}^{2} / \mathrm{yr}$, this value is slightly higher than average for 2007 to 2014 years range. Calculated value will be used for further case-study buildings comparison. 


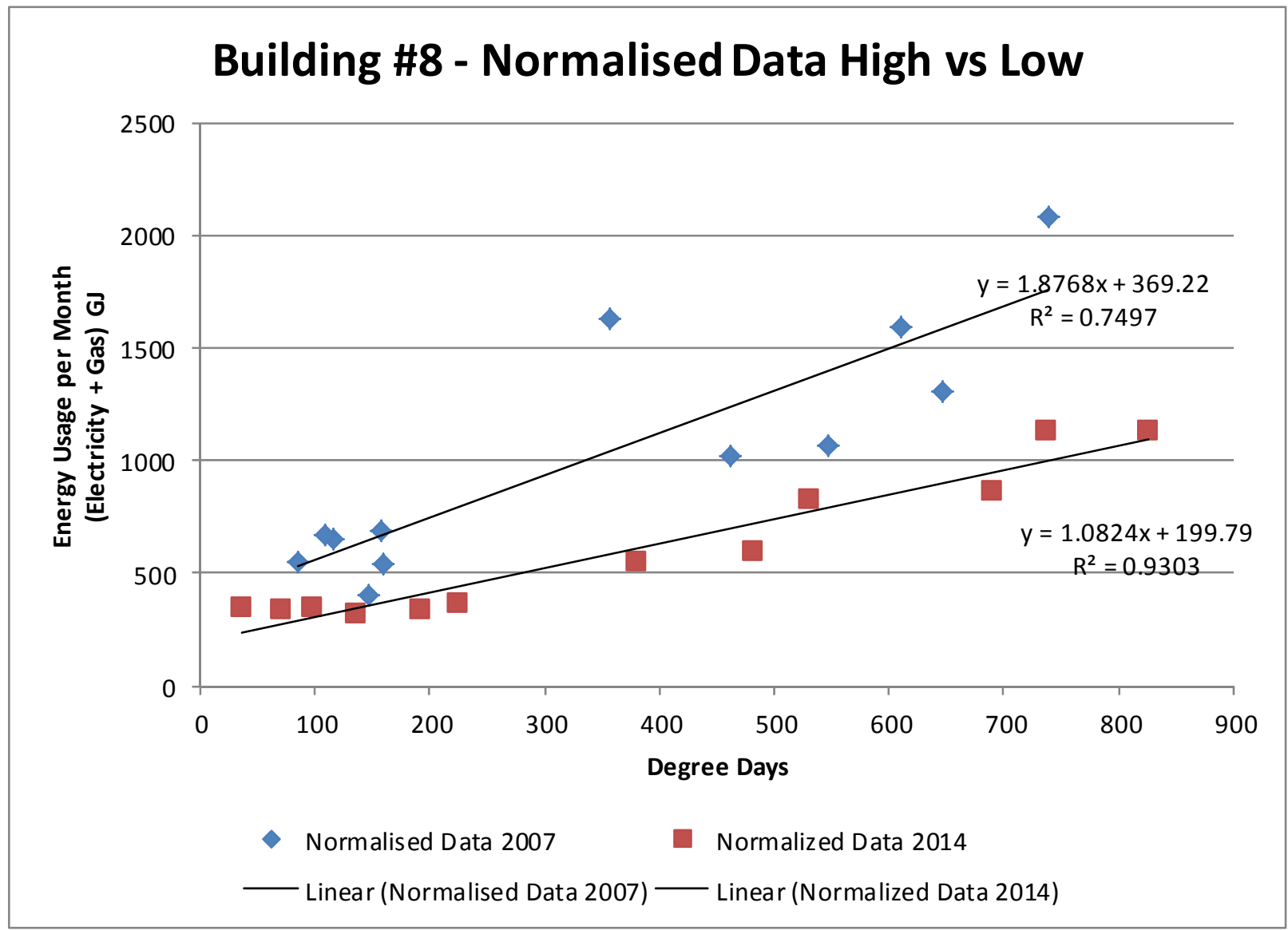


Actual data used for calculations (year with highest energy consumption):

\begin{tabular}{|c|c|c|c|c|c|c|c|c|c|c|c|c|}
\hline ADDRESS: & \multicolumn{4}{|c|}{ Building H - Ottawa, Ontario } & & & & & & & & \\
\hline BUILDING\# & \multicolumn{4}{|c|}{8} & & & & & & & & \\
\hline Year - Highest Energy Consumption: & \multirow{2}{*}{\multicolumn{4}{|c|}{$\begin{array}{c}2007 \\
5,020\end{array}$}} & & & & & & & & \\
\hline AREA: & & & & & & & & & & & & \\
\hline USAGE INDEX: & \multicolumn{4}{|l|}{2.43} & & & & & & & & \\
\hline Month & Jan & Feb & Mar & Apr & May & Jun & Jul & Aug & Sep & Oct & Nov & Dec \\
\hline \multirow{5}{*}{$\begin{array}{l}\text { Electric Billing Date } \\
\text { Electric Billing Days }\end{array}$} & $14 / 02 / 2007$ & $13 / 03 / 2007$ & $13 / 04 / 2007$ & $14 / 05 / 2007$ & $13 / 06 / 2007$ & $13 / 07 / 2007$ & $15 / 08 / 2007$ & $13 / 09 / 2007$ & $12 / 10 / 2007$ & $13 / 11 / 2007$ & $11 / 12 / 2007$ & $11 / 01 / 2008$ \\
\hline & 31 & 27 & 31 & 31 & 30 & 30 & 33 & 29 & 29 & 32 & 28 & 31 \\
\hline & $29 / 01 / 2007$ & $26 / 02 / 2007$ & $27 / 03 / 2007$ & $26 / 04 / 2007$ & 29/05/2007 & $25 / 06 / 2007$ & $27 / 07 / 2007$ & $28 / 08 / 2007$ & $27 / 09 / 2007$ & $25 / 10 / 2007$ & $27 / 11 / 2007$ & $29 / 12 / 2007$ \\
\hline & 31 & 28 & 29 & 30 & 33 & 27 & 32 & 32 & 30 & 28 & 33 & 32 \\
\hline & & & & & & & & & & & & \\
\hline \multicolumn{13}{|l|}{ COOLING \& HEATING DEGREE DAYS } \\
\hline \multirow{4}{*}{$\begin{array}{l}\text { Cooling D.D. (Highest Year) } \\
\text { Daily Clg D.D. Avg. (Highest Year) } \\
\text { Normal Cooling D.D. (Highest Year) }\end{array}$} & 0 & 0 & 0 & 0 & 22 & 99 & 106 & 141 & 48 & 20 & 0 & 0 \\
\hline & 0 & 0 & 0 & 0 & 1 & 3 & 3 & 5 & 2 & 1 & 0 & 0 \\
\hline & & & & & & & & & & & & \\
\hline & 647 & 770 & 547 & 356 & 136 & 17 & 3 & 5 & 37 & 138 & 463 & 611 \\
\hline \multirow{3}{*}{$\begin{array}{l}\text { Heating D.D. (Highest Year) } \\
\text { Daily Htg. D.D. Avg. (Highest Year) } \\
\text { Normal Heating D.D (Highest Year) }\end{array}$} & 21 & 26 & 19 & 12 & 4 & 1 & 0 & 0 & 1 & 5 & 14 & 19 \\
\hline & & & & & & & & & & & & \\
\hline & & & & & & & & & & & & \\
\hline \multicolumn{13}{|l|}{ ELECTRICAL USAGE \& COST } \\
\hline \multirow{3}{*}{$\begin{array}{l}\text { kWh Used } \\
\text { Daily kWh Avg. }\end{array}$} & 222,840 & 170,640 & 188,280 & 141,480 & 135,360 & 150,480 & 185,040 & 112,320 & 153,720 & 186,840 & 196,200 & 230,400 \\
\hline & 7,188 & 6,094 & 6,492 & 4,716 & 4,102 & 5,573 & 5,783 & 3,510 & 5,124 & 6,673 & 5,945 & 7,200 \\
\hline & & & & & & & & & & & & \\
\hline Demand kW/RkVA Used & 354 & 366 & 357 & 0 & 343 & 343 & 323 & 301 & 311 & 323 & 365 & 380 \\
\hline Load Factor (Highest Year) & $85 \%$ & $72 \%$ & $71 \%$ & \#DIV/0! & $55 \%$ & $61 \%$ & $72 \%$ & $54 \%$ & $71 \%$ & $75 \%$ & $80 \%$ & $82 \%$ \\
\hline \multicolumn{13}{|l|}{ NATURAL GAS USAGE \& COST } \\
\hline \multicolumn{13}{|l|}{ CCF } \\
\hline$m^{\wedge} 3$ Used & 13,526 & 39,355 & 10,409 & 29,983 & 1,458 & 3,033 & 0 & 0 & 0 & 398 & 8,397 & 20,521 \\
\hline \multirow{2}{*}{ Daily $\mathrm{m}^{\wedge} 3$ Avg. } & 436 & 1,406 & 359 & 999 & 44 & 112 & 0 & 0 & 0 & 14 & 254 & 641 \\
\hline \multirow{2}{*}{\multicolumn{13}{|c|}{ GREENHOUSE DATA }} \\
\hline & & & & & & & & & & & & \\
\hline \multirow{4}{*}{$\begin{array}{l}\text { CO2 (kgs) (Highest Year) } \\
\text { SO2 (kgs) (Highest Year) } \\
\text { NOx (kgs) (Highest Year) }\end{array}$} & 245,635 & 393,313 & 200,327 & 307,370 & 101,379 & 122,697 & 124,481 & 75,561 & 103,412 & 128,509 & 191,415 & 300,225 \\
\hline & 2,654 & 4,249 & 2,164 & 3,321 & 1,095 & 1,326 & 1,345 & 816 & 1,117 & 1,388 & 2,068 & 3,244 \\
\hline & 1,163 & 1,863 & 949 & 1,456 & 480 & 581 & 590 & 358 & 490 & 609 & 907 & 1,422 \\
\hline & & & & & & & & & & & & \\
\hline \multicolumn{13}{|l|}{ USAGE DATA } \\
\hline \multirow{3}{*}{$\begin{array}{l}\text { kWh to GJ } \\
\text { GJ/m2/Day ELECTRIC (Highest Year) } \\
\text { GJ/m2/Month (Highest Year) }\end{array}$} & 802.22 & 614.30 & 677.81 & 509.33 & 487.30 & 541.73 & 666.14 & 404.35 & 553.39 & 672.62 & 706.32 & 829.44 \\
\hline & 0.005 & 0.005 & 0.004 & 0.003 & 0.003 & 0.004 & 0.004 & 0.003 & 0.004 & 0.004 & 0.005 & 0.005 \\
\hline & 0.16 & 0.12 & 0.14 & 0.10 & 0.10 & 0.11 & 0.13 & 0.08 & 0.11 & 0.13 & 0.14 & 0.17 \\
\hline & 503.17 & 1464.01 & 387.21 & 1115.37 & 54.24 & 112.83 & 0.00 & 0.00 & 0.00 & 14.81 & 312.37 & 763.38 \\
\hline GJ/m2/Day GAS (Highest Year) & 0.003 & 0.010 & 0.003 & 0.007 & 0.000 & 0.001 & 0.000 & 0.000 & 0.000 & 0.000 & 0.002 & 0.005 \\
\hline $\mathrm{GJ} / \mathrm{m} 2 /$ Month & 0.10 & 0.29 & 0.08 & 0.22 & 0.01 & 0.02 & 0.00 & 0.00 & 0.00 & 0.00 & 0.06 & 0.15 \\
\hline $\mathrm{m} 3 / \mathrm{m} 2 /$ Month & 2.69 & 7.84 & 2.07 & 5.97 & 0.29 & 0.60 & 0.00 & 0.00 & 0.00 & 0.08 & 1.67 & 4.09 \\
\hline GJ/m2/Day ENERGY (Highest Year) & 0.008 & 0.015 & 0.007 & 0.011 & 0.004 & 0.004 & 0.004 & 0.003 & 0.004 & 0.004 & 0.007 & 0.010 \\
\hline $\mathrm{GJ} / \mathrm{m} 2 /$ Month (Highest Consumption Year) & 0.260 & 0.414 & 0.212 & 0.324 & 0.108 & 0.130 & 0.133 & 0.081 & 0.110 & 0.137 & 0.203 & 0.317 \\
\hline Energy Usage per Month (Electricity + Gas) & 1305 & 2078 & 1065 & 1625 & 542 & 655 & 666 & 404 & 553 & 687 & 1019 & 1593 \\
\hline Degree Days & 647 & 740 & 547 & 356 & 159 & 116 & 109 & 146 & 84 & 158 & 463 & 611 \\
\hline
\end{tabular}




\section{Actual data used for calculations (year with lowest energy consumption):}

\begin{tabular}{|c|c|c|c|c|c|c|c|c|c|c|c|c|}
\hline ADDRESS: & \multicolumn{4}{|c|}{ Building H - Ottawa, Ontario } & & & & & & & & \\
\hline BUILDING \# & \multicolumn{4}{|c|}{8} & & & & & & & & \\
\hline Year - Lowest Energy Consumption: & \multicolumn{4}{|l|}{2014} & & & & & & & & \\
\hline AREA: & \multicolumn{4}{|l|}{5,020} & & & & & & & & \\
\hline USAGE INDEX: & 1.43 & AVERAGE: & 1.9278 & 1.92910 & & & & & & & & \\
\hline Month & Jan & Feb & Mar & Apr & May & Jun & Jul & Aug & Sep & Oct & Nov & Dec \\
\hline \multirow{4}{*}{$\begin{array}{l}\text { Electric Billing Date } \\
\text { Electric Billing Days }\end{array}$} & $02 / 02 / 2014$ & $04 / 03 / 2014$ & $02 / 04 / 2014$ & $04 / 05 / 2014$ & $03 / 06 / 2014$ & $03 / 07 / 2014$ & $04 / 08 / 2014$ & $04 / 09 / 2014$ & $02 / 10 / 2014$ & $02 / 11 / 2014$ & 30/11/2014 & $28 / 12 / 2014$ \\
\hline & 31 & 30 & 29 & 32 & 30 & 30 & 32 & 31 & 28 & 31 & 28 & 28 \\
\hline & $27 / 01 / 2014$ & $24 / 02 / 2014$ & $26 / 03 / 2014$ & $25 / 04 / 2014$ & $27 / 05 / 2014$ & $24 / 06 / 2014$ & $28 / 07 / 2014$ & $25 / 08 / 2014$ & $25 / 09 / 2014$ & $27 / 10 / 2014$ & $25 / 11 / 2014$ & $24 / 12 / 2014$ \\
\hline & 31 & 28 & 30 & 30 & 32 & 28 & 34 & 28 & 31 & 32 & 29 & 29 \\
\hline \multicolumn{13}{|l|}{ COOLING \& HEATING DEGREE DAYS } \\
\hline & & & & & & & & & & & & \\
\hline \multirow{3}{*}{$\begin{array}{l}\text { Cooling D.D. (Lowest Year) } \\
\text { Daily Clg D.D. Avg. (Lowest Year) } \\
\text { Normal Cooling D.D. (Lowest Year) }\end{array}$} & 0 & 0 & 0 & 23 & 59 & 121 & 94 & 28 & 0 & 0 & 0 & 0 \\
\hline & 0 & 0 & 0 & 1 & 2 & 4 & 3 & 1 & 0 & 0 & 0 & 0 \\
\hline & & & & & & & & & & & & \\
\hline \multirow{4}{*}{$\begin{array}{l}\text { Heating D.D. (Lowest Year) } \\
\text { Daily Htg. D.D. Avg. (Lowest Year) } \\
\text { Normal Heating D.D (Lowest Year) }\end{array}$} & 826 & 737 & 691 & 357 & 132 & 14 & 4 & 9 & 70 & 224 & 482 & 532 \\
\hline & 27 & 26 & 23 & 12 & 4 & 1 & 0 & 0 & 2 & 7 & 17 & 18 \\
\hline & & & & & & & & & & & & \\
\hline & & & & & & & & & & & & \\
\hline \multicolumn{13}{|l|}{ ELECTRICAL USAGE \& COST } \\
\hline kWh Used & 191,160 & 159,840 & 141,480 & 117,360 & 80,640 & 88,200 & 96,120 & 96,120 & 90,000 & 102,240 & 119,520 & 136,800 \\
\hline \multirow[t]{2}{*}{ Daily kWh Avg. } & 6,166 & 5,709 & 4,716 & 3,912 & 2,520 & 3,150 & 2,827 & 3,433 & 2,903 & 3,195 & 4,121 & 4,717 \\
\hline & & & & & & & & & & & & \\
\hline Demand kW/RkVA Used & 356 & 309 & 309 & 276 & 256 & 258 & 252 & 239 & 235 & 247 & 297 & 326 \\
\hline \multirow{2}{*}{ Load Factor (Lowest Year) } & $72 \%$ & $72 \%$ & $66 \%$ & $55 \%$ & $44 \%$ & $47 \%$ & $50 \%$ & $54 \%$ & $57 \%$ & $56 \%$ & $60 \%$ & $62 \%$ \\
\hline & & & & & & & & & & & & \\
\hline \multicolumn{13}{|l|}{ NATURAL GAS USAGE \& COST } \\
\hline \multicolumn{13}{|l|}{ CCF } \\
\hline $\mathrm{m}^{\wedge} 3$ Used & 11,989 & 15,033 & 9,570 & 3,439 & 1,393 & 0 & 51 & 0 & 307 & 3 & 4,465 & 8,925 \\
\hline \multirow[t]{2}{*}{ Daily $m^{\wedge} 3$ Avg. } & 387 & 537 & 319 & 115 & 44 & 0 & 2 & 0 & 10 & 0 & 154 & 308 \\
\hline \multirow{2}{*}{\multicolumn{13}{|c|}{ GREENHOUSE DATA }} \\
\hline & & & & & & & & & & & & \\
\hline "C02 (kgs) (Lowest Year) & 213,446 & 213,919 & 162,905 & 103,289 & 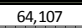 & 59,335 & 65,023 & 64,663 & 62,718 & 68,801 & 112,004 & 155,192 \\
\hline S02 (kgs) (Lowest Year) & 2,306 & 2,311 & 1,760 & 1,116 & 693 & 641 & 703 & 699 & 678 & 743 & 1,210 & 1,677 \\
\hline NOx (kgs) (Lowest Year) & 1,011 & 1,013 & 772 & 489 & 304 & 281 & 308 & 306 & 297 & 326 & 531 & 735 \\
\hline USAGE DATA & & & & & & & & & & & & \\
\hline kWh to GJ & 688.18 & 575.42 & 509.33 & 422.50 & 290.30 & 317.52 & 346.03 & 346.03 & 324.00 & 368.06 & 430.27 & 492.48 \\
\hline $\mathrm{GJ} / \mathrm{m} 2 /$ Day ELECTRIC (Lowest Year) & 0.004 & 0.004 & 0.003 & 0.003 & 0.002 & 0.002 & 0.002 & 0.002 & 0.002 & 0.002 & 0.003 & 0.004 \\
\hline $\mathrm{GJ} / \mathrm{m} 2 /$ Month (Lowest Year) & 0.14 & 0.11 & 0.10 & 0.08 & 0.06 & 0.06 & 0.07 & 0.07 & 0.06 & 0.07 & 0.09 & 0.10 \\
\hline & 445.99 & 559.23 & 356,00 & 127.93 & 5.89 & 800 & 190 & 0.00 & 1147 & 011 & 19610 & 33201 \\
\hline $\begin{array}{l}\mathrm{m} 3 \text { to GJ } \\
\mathrm{GJ} / \mathrm{m} 2 / \text { Day GAS (Lowest Year) }\end{array}$ & $\begin{array}{c}445.99 \\
0.003\end{array}$ & $\begin{array}{c}559.23 \\
0.004\end{array}$ & $\begin{array}{l}356.00 \\
0.002\end{array}$ & $\begin{array}{c}127.93 \\
0.001\end{array}$ & $\begin{array}{l}51.82 \\
0.000\end{array}$ & 0.00 & $\begin{array}{l}1.90 \\
0.000\end{array}$ & $\begin{array}{l}0.00 \\
0.000\end{array}$ & $\frac{11.42}{0.000}$ & $\begin{array}{c}0.11 \\
0.000\end{array}$ & $\frac{166.10}{0.001}$ & $\begin{array}{c}332.01 \\
0.002\end{array}$ \\
\hline $\mathrm{GJ} / \mathrm{m} 2 /$ Month & 0.09 & 0.11 & 0.07 & 0.03 & 0.01 & 0.00 & 0.00 & 0.00 & 0.00 & 0.00 & 0.03 & 0.07 \\
\hline $\mathrm{m} 3 / \mathrm{m} 2 /$ Month & 2.39 & 2.99 & 1.91 & 0.69 & 0.28 & 0.00 & 0.01 & 0.00 & 0.06 & 0.00 & 0.89 & 1.78 \\
\hline GJ/m2/Day ENERGY (Lowest Year) & 0.007 & 0.008 & 0.006 & 0.003 & 0.002 & 0.002 & 0.002 & 0.002 & 0.002 & 0.002 & 0.004 & 0.006 \\
\hline $\mathrm{GJ} / \mathrm{m} 2 /$ Month (Lowest Consumption Year) & 0.226 & 0.226 & 0.172 & 0.110 & 0.068 & 0.063 & 0.069 & 0.069 & 0.067 & 0.073 & 0.119 & 0.164 \\
\hline Average Highest Year to Lowest Year & 0.243 & 0.320 & 0.192 & 0.217 & 0.088 & 0.097 & 0.101 & 0.075 & 0.089 & 0.105 & 0.161 & 0.241 \\
\hline BOMA Mean Value per Month & 0.111 & 0.111 & 0.111 & 0.111 & 0.111 & 0.111 & 0.111 & 0.111 & 0.111 & 0.111 & 0.111 & 0.111 \\
\hline Energy Usage per Month (Electricity + Gas) & 1134 & 1135 & 865 & 550 & 342 & 318 & 348 & 346 & 335 & 368 & 596 & 824 \\
\hline Degree Days & 826 & 737 & 691 & 380 & 191 & 135 & 98 & 37 & 70 & 224 & 482 & 532 \\
\hline Normalized Data (Average Degree Days) & 725 & 684 & 623 & 369 & 162 & 114 & 110 & 68 & 91 & 217 & 480 & 596 \\
\hline Normalized Data (Av Energy Consumption) & 1357 & 1297 & 1206 & 831 & 524 & 452 & 447 & 384 & 419 & 605 & 995 & 1167 \\
\hline Normalized Data (Av Energy Index / month) & 0.270 & 0.258 & 0.240 & 0.166 & 0.104 & 0.090 & 0.089 & 0.077 & 0.083 & 0.121 & 0.198 & 0.232 \\
\hline
\end{tabular}


Analysis on how electricity and gas consumption corresponds to heating and cooling periods (for highest energy consumption year):

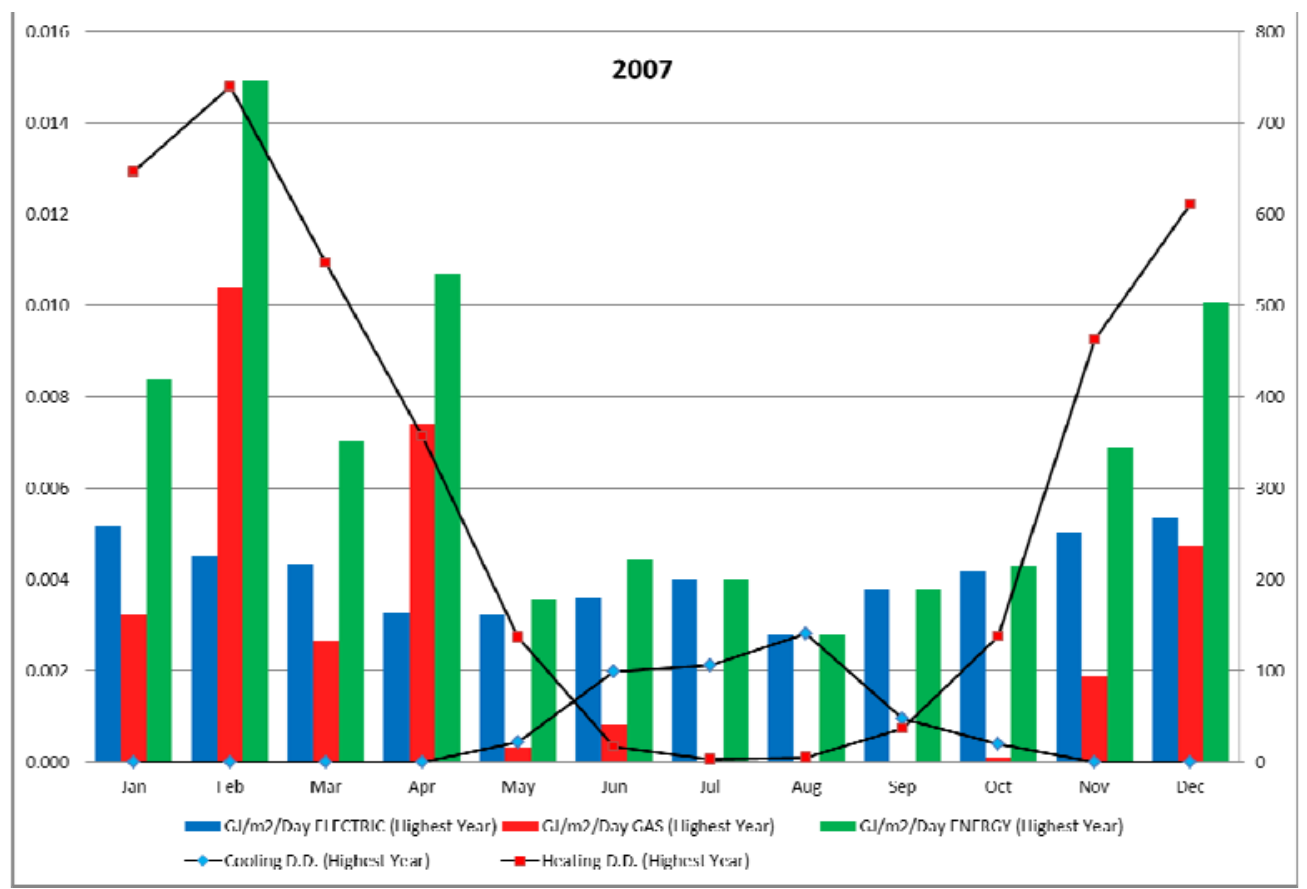

Analysis on how electricity and gas consumption corresponds to heating and cooling periods (for lowest energy consumption year):

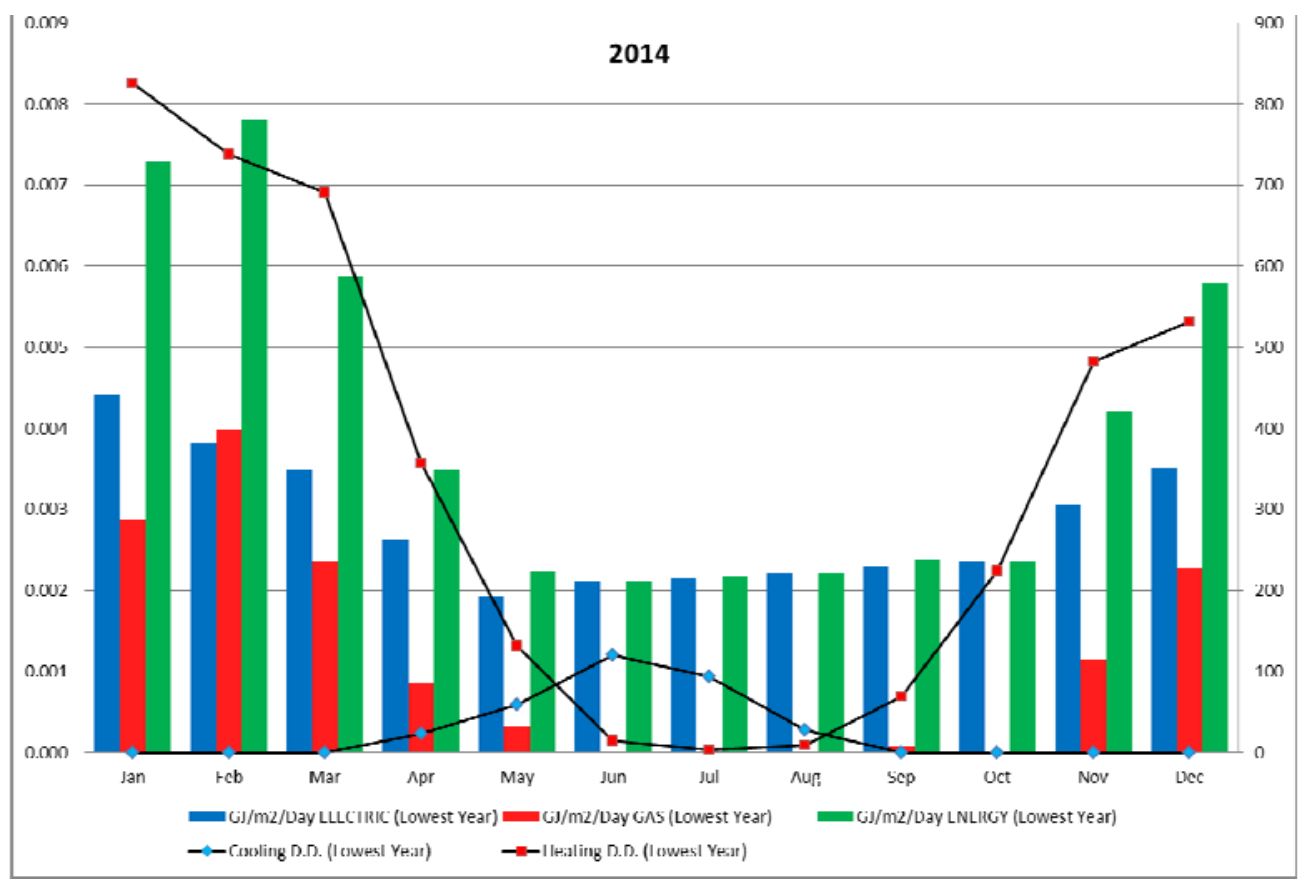


Monthly energy index comparison between highest energy consumption year, lowest, average and benchmark (BOMA) energy intensity:

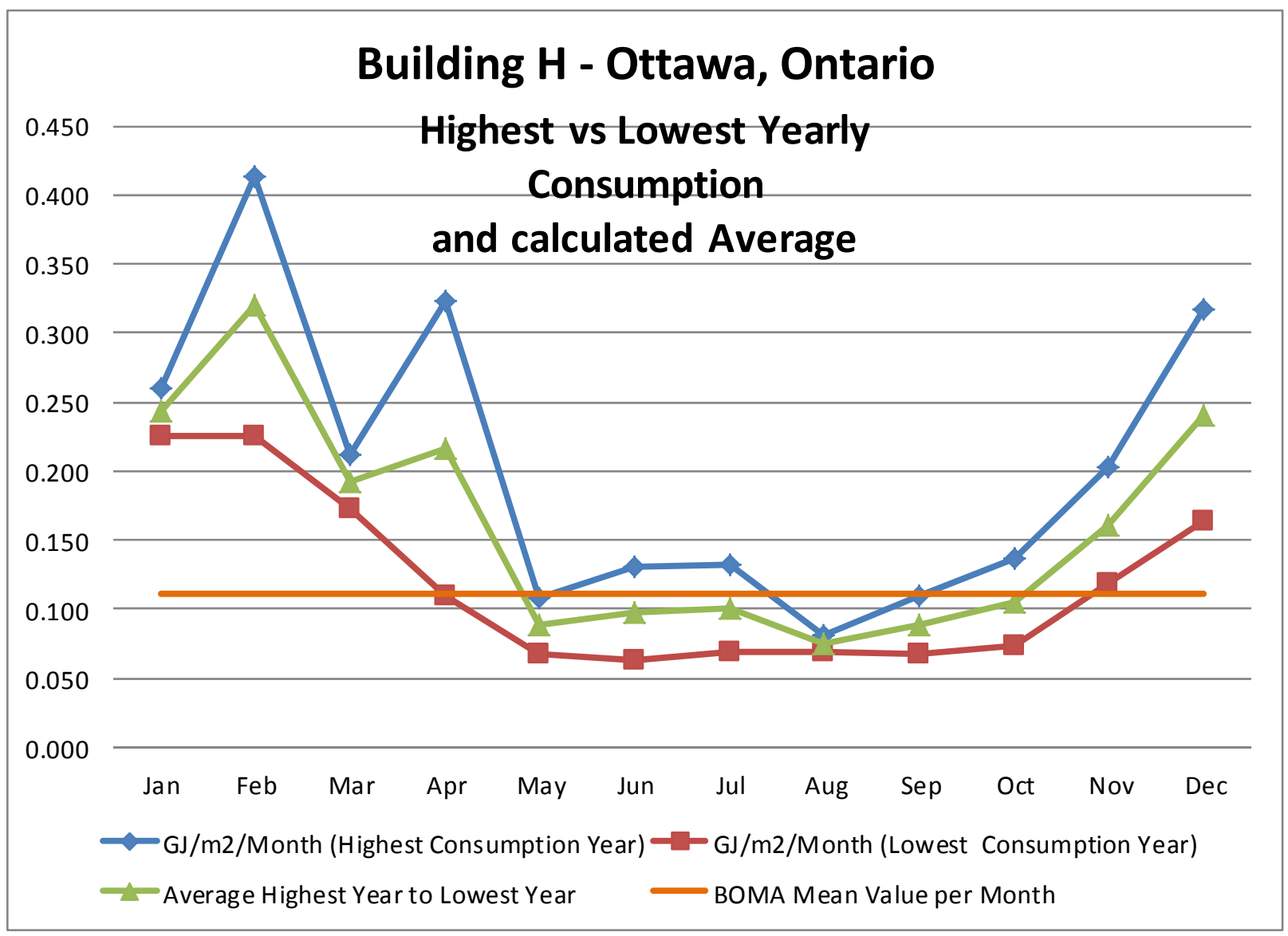


Building \#9 - Utility Bills Analysis

\section{Calculations of Energy Index for Building \#9}

Energy CAP database was utilized to collect energy consumption information for the building. Energy consumption was provided by utility bills for electricity and gas. For Building \#9 utility bills were provided from December 2006 to March 2015. To complete most accurate analysis utility bills for 2007 to 2014 were only analyzed because 2006 and 2015 has incomplete data. By having total floor area for entire building of 4,854 $\mathrm{m}^{2}$, energy index in $\mathrm{GJ} / \mathrm{m}^{2} /$ year was calculated. From calculations it was noticed that energy bills provided very consistent data therefore all years data was included in calculations.

Utility bills analysis showed following:

\section{Building I - Ontario, Tower C}

\begin{tabular}{|c|c|c|c|c|c|c|c|c|}
\hline \multirow[b]{2}{*}{ Row Labels } & \multirow{2}{*}{\multicolumn{2}{|c|}{$\begin{array}{c}\text { Sum of Ele Total } \\
\text { Cost / Year }\end{array}$}} & \multirow{3}{*}{$\begin{array}{c}\text { kWh } \\
\begin{array}{c}\text { Sum of Ele } \\
\text { Consumption / } \\
\text { Year }\end{array} \\
311,000.00 \\
\end{array}$} & \multirow{2}{*}{\multicolumn{2}{|c|}{$\begin{array}{c}\text { Sum of Gas Total } \\
\text { Cost / Year }\end{array}$}} & \multirow{3}{*}{$\begin{array}{c}\mathrm{m}^{3} \text {-ngas } \\
\begin{array}{c}\text { Sum of Gas } \\
\text { Consumption / } \\
\text { Year }\end{array} \\
842.00 \\
\end{array}$} & Total GJ/yr & $4,854.00$ \\
\hline & & & & & & & \multirow[t]{2}{*}{ Total } & \multirow[t]{2}{*}{$\mathrm{GJ} / \mathrm{m} 2 / \mathrm{yr}$} \\
\hline Year 2006 & $\$$ & $31,318.60$ & & $\$$ & 374.09 & & & \\
\hline Year 2007 & $\$$ & $158,746.02$ & $1,426,920.00$ & $\$$ & $2,243.37$ & $4,249.00$ & $5,294.97$ & 1.09 \\
\hline Year 2008 & $\$$ & $181,699.80$ & $1,608,132.76$ & $\$$ & $2,797.49$ & $4,931.00$ & $5,972.71$ & 1.23 \\
\hline Year 2009 & $\$$ & $150,245.56$ & $1,360,798.52$ & $\$$ & $2,358.21$ & $5,048.00$ & $5,086.66$ & 1.05 \\
\hline Year 2010 & $\$$ & $152,691.50$ & $1,323,680.93$ & $\$$ & $2,277.44$ & $4,952.00$ & $4,949.47$ & 1.02 \\
\hline Year 2011 & $\$$ & $165,110.74$ & $1,364,871.04$ & $\$$ & $2,237.54$ & $4,619.00$ & $5,085.36$ & 1.05 \\
\hline Year 2012 & $\$$ & $158,838.82$ & $1,222,999.21$ & $\$$ & $2,161.27$ & $4,656.00$ & $4,576.00$ & 0.94 \\
\hline Year 2013 & $\$$ & $165,048.43$ & $1,184,278.26$ & $\$$ & 2,190.31 & $4,405.00$ & $4,427.27$ & 0.91 \\
\hline Year 2014 & $\$$ & $195,255.26$ & $1,372,687.83$ & $\$$ & $2,418.11$ & $4,116.00$ & $5,094.79$ & 1.05 \\
\hline Year 2015 & $\$$ & $57,634.67$ & $387,763.83$ & $\$$ & 573.35 & 886.00 & & \\
\hline Average & $\$$ & $165,954.52$ & $1,358,046.07$ & $\$$ & $2,335.47$ & $4,622.00$ & & 1.04 \\
\hline
\end{tabular}

As it was specified in energy audit, energy consumption of the Building \#9 is average in comparison to similar office buildings in same region; and therefore average energy index which equals to $1.04 \mathrm{GJ} / \mathrm{m}^{2} / \mathrm{yr}$ is also high in comparison to benchmark values of BOMA energy efficient building value of $1.05 \mathrm{GJ} / \mathrm{m}^{2} / \mathrm{yr}$, however value is much lower than average National Resources Canada value of $1.43 \mathrm{GJ} / \mathrm{m} 2 /$ year.

Two charts below show electricity and gas consumption per year. Electricity consumption chart shows data that fluctuation throughout years range. However on the other side gas consumption chart demonstrates decrease in gas usage. 

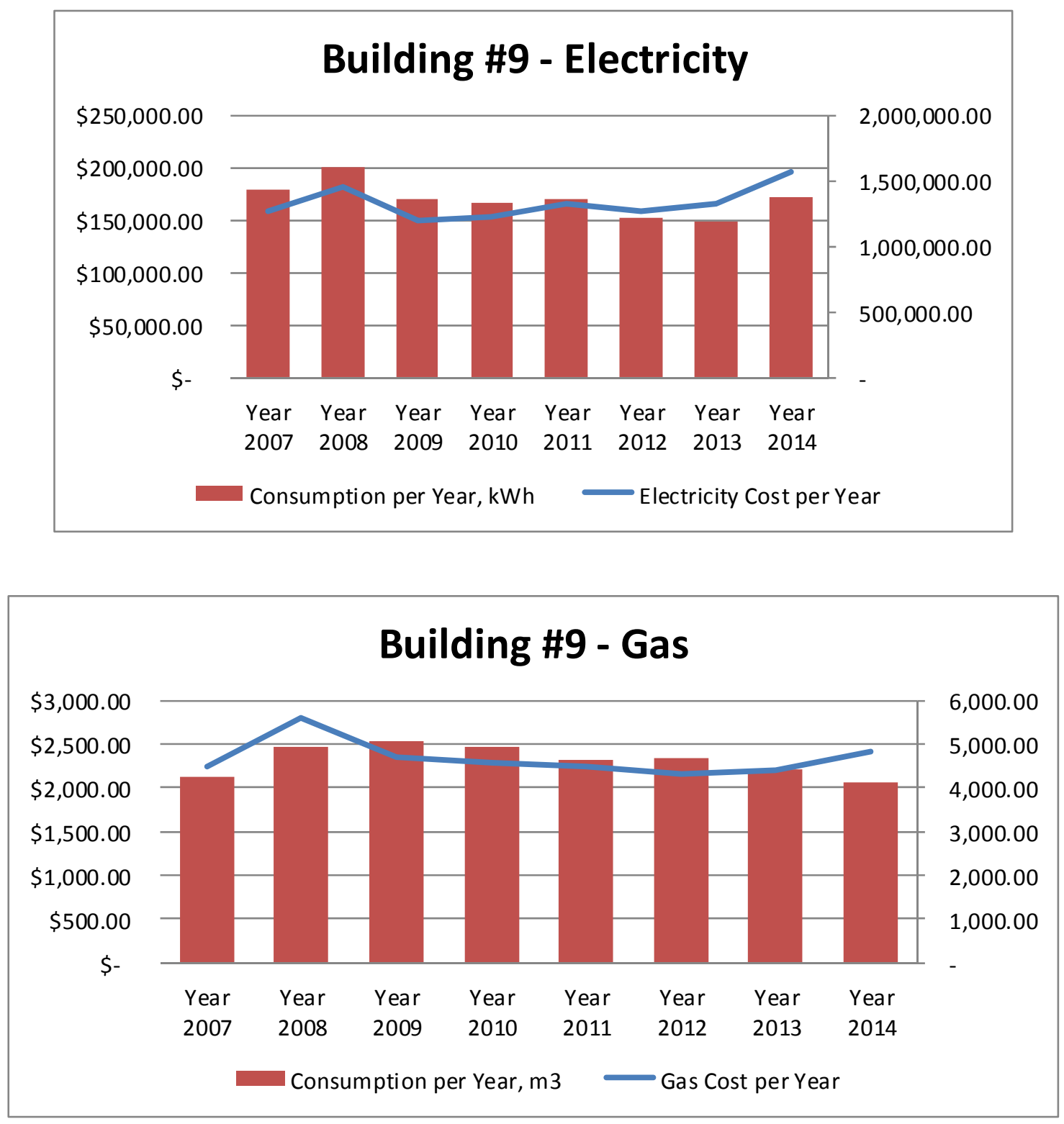

Yearly energy intensity (index) was also plotted to demonstrate increase or decrease over the range of years for which data is available. Chart below shows that energy index value is gradually decreasing. The lowest energy index was in 2013 and highest in 2008. These two years' data will be used for further calculations and comparisons. 


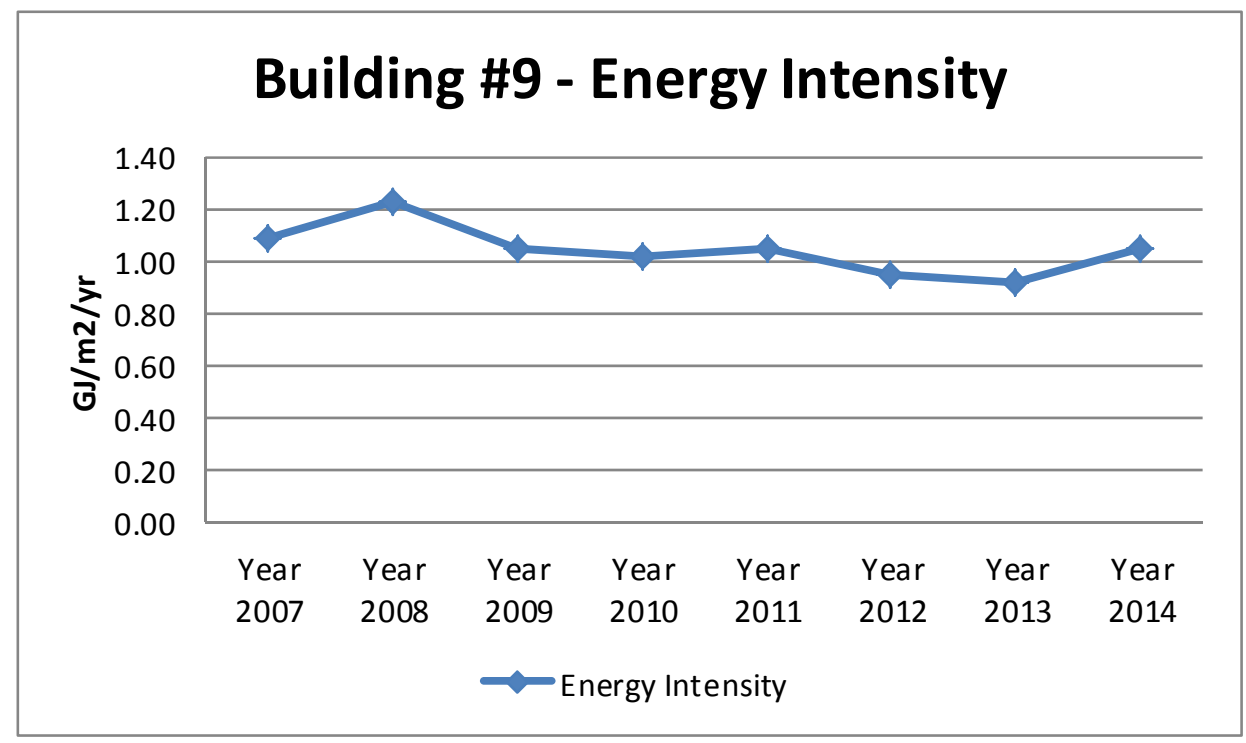

Normalized total energy consumption was calculated for Building \#9. Based on plotted results, shown below in the chart, it can be concluded that energy consumption for 2008 is higher than for 2013. This proves that regardless of weather conditions 2008 has higher energy consumptions than in 2013. Implementing trendline equations, average equation was calculated:

\section{$\gamma=0.4589 x+274.535$}

From above equation normalized average energy index was calculated as $1.07 \mathrm{GJ} / \mathrm{m}^{2} / \mathrm{yr}$, this value is slightly higher than average for 2007 to 2014 years range. Calculated value will be used for further case-study buildings comparison. 


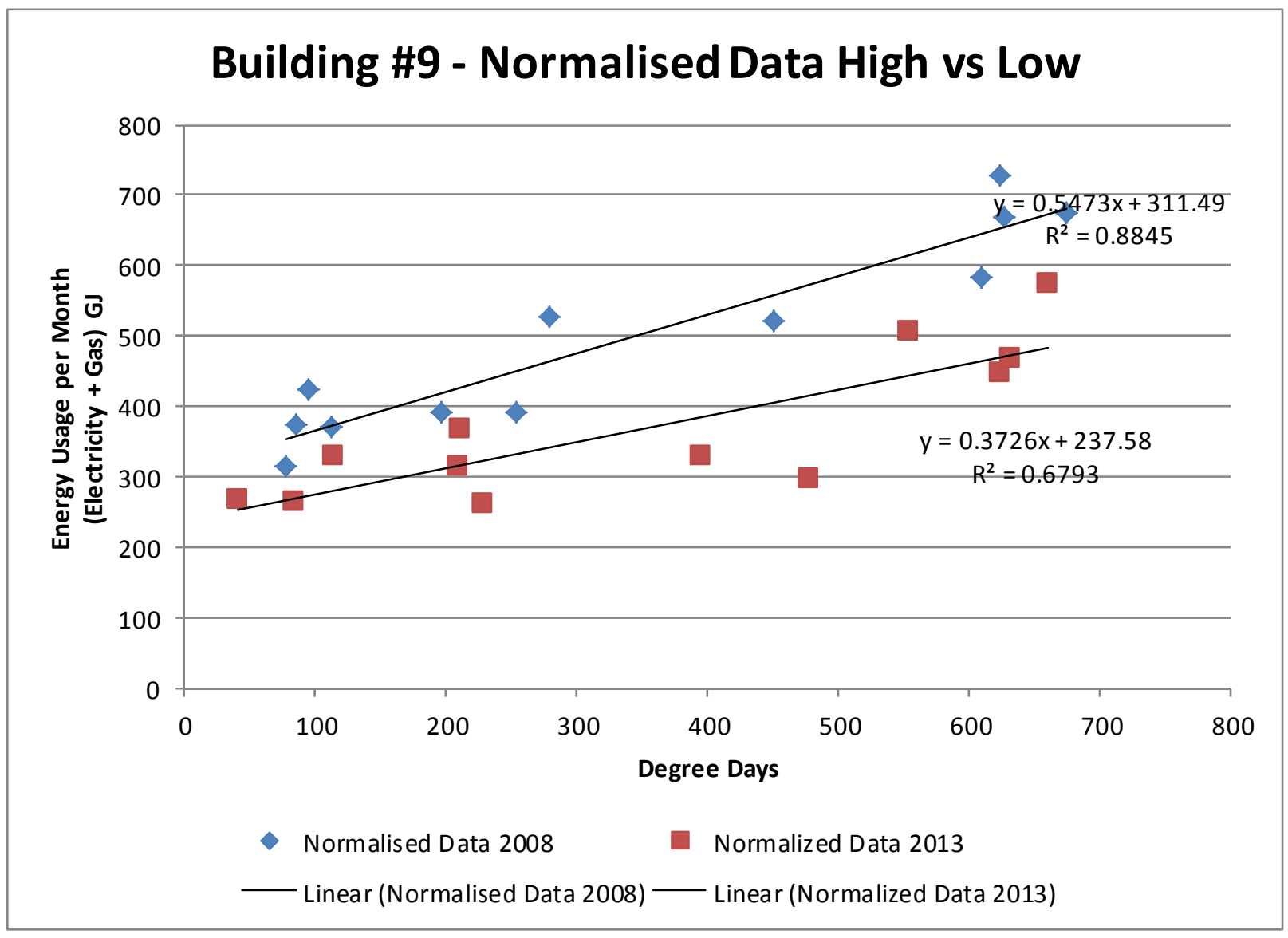


Actual data used for calculations (year with highest energy consumption):

\begin{tabular}{|c|c|c|c|c|c|c|c|c|c|c|c|c|}
\hline ADDRESS: & \multicolumn{4}{|c|}{ Building I - Ottawa, Ontario, Tower C } & & & & & & & & \\
\hline BUILDING\# & \multicolumn{4}{|c|}{9} & & & & & & & & \\
\hline Year - Highest Energy Consumption: & \multicolumn{4}{|l|}{2008} & & & & & & & & \\
\hline AREA: & \multicolumn{4}{|l|}{4,854} & & & & & & & & \\
\hline USAGE INDEX: & \multicolumn{4}{|l|}{1.23} & & & & & & & & \\
\hline Month & Jan & Feb & Mar & Apr & May & Jun & Jul & Aug & Sep & Oct & Nov & Dec \\
\hline \multirow{2}{*}{$\begin{array}{l}\text { Electric Billing Date } \\
\text { Electric Billing Days }\end{array}$} & $12 / 02 / 2008$ & $12 / 03 / 2008$ & $11 / 04 / 2008$ & $12 / 05 / 2008$ & $10 / 06 / 2008$ & $14 / 07 / 2008$ & $12 / 08 / 2008$ & 10/09/2008 & $09 / 10 / 2008$ & $12 / 11 / 2008$ & $10 / 12 / 2008$ & $12 / 01 / 2009$ \\
\hline & 31 & 29 & 30 & 31 & 29 & 34 & 29 & 29 & 29 & 34 & 28 & 33 \\
\hline \multirow{3}{*}{$\begin{array}{l}\text { Gas Billing Date } \\
\text { Gas Billing Days }\end{array}$} & $15 / 02 / 2008$ & $18 / 03 / 2008$ & $16 / 04 / 2008$ & $15 / 05 / 2008$ & $16 / 06 / 2008$ & $16 / 07 / 2008$ & $15 / 08 / 2008$ & $16 / 09 / 2008$ & $15 / 10 / 2008$ & 14/11/2008 & $15 / 12 / 2008$ & $16 / 01 / 2009$ \\
\hline & 31 & 32 & 29 & 29 & 32 & 30 & 30 & 32 & 29 & 30 & 31 & 32 \\
\hline & \multirow{2}{*}{\multicolumn{12}{|c|}{ COOLING \& HEATING DEGREE DAYS }} \\
\hline & & & & & & & & & & & & \\
\hline \multirow{4}{*}{$\begin{array}{l}\text { Cooling D.D. (Highest Year) } \\
\text { Daily Clg D.D. Avg. (Highest Year) } \\
\text { Normal Cooling D.D. (Highest Year) }\end{array}$} & 0 & 0 & 0 & 0 & 3 & 72 & 111 & 64 & 27 & 0 & 0 & 0 \\
\hline & 0 & 0 & 0 & 0 & 0 & 2 & 4 & 2 & 1 & 0 & 0 & 0 \\
\hline & & & & & & & & & & & & \\
\hline & 624 & 675 & 610 & 254 & 194 & 23 & 1 & 13 & 59 & 279 & 452 & 627 \\
\hline \multirow{3}{*}{$\begin{array}{l}\text { Heating D.D. (Highest Year) } \\
\text { Daily Htg. D.D. Avg. (Highest Year) } \\
\text { Normal Heating D.D (Highest Year) }\end{array}$} & 20 & 21 & 21 & 9 & 6 & 1 & 0 & 0 & 2 & 9 & 15 & 20 \\
\hline & & & & & & & & & & & & \\
\hline & & & & & & & & & & & & \\
\hline \multicolumn{13}{|l|}{ ELECTRICAL USAGE \& COST } \\
\hline \multirow{3}{*}{$\begin{array}{l}\text { kWh Used } \\
\text { Daily kWh Avg. }\end{array}$} & 198,314 & 183,475 & 158,389 & 103,775 & 104,357 & 113,675 & 99,592 & 82,775 & 100,276 & 142,803 & 139,759 & 180,941 \\
\hline & 6,397 & 5,734 & 5,462 & 3,578 & 3,261 & 3,789 & 3,320 & 2,587 & 3,458 & 4,760 & 4,508 & 5,654 \\
\hline & 373 & 372 & 340 & 336 & 272 & 260 & 244 & 263 & 255 & 310 & 361 & 360 \\
\hline \multirow{2}{*}{$\begin{array}{l}\text { Demand kW/RkVA Used } \\
\text { Load Factor (Highest Year) }\end{array}$} & $71 \%$ & $71 \%$ & $65 \%$ & $41 \%$ & $55 \%$ & $54 \%$ & $59 \%$ & $45 \%$ & $57 \%$ & $56 \%$ & $58 \%$ & $64 \%$ \\
\hline & & & & & & & & & & & & \\
\hline \multicolumn{13}{|l|}{ NATURAL GAS USAGE \& COST } \\
\hline \multicolumn{13}{|l|}{ CCF } \\
\hline$m^{\wedge} 3$ Used & 384 & 424 & 384 & 468 & 429 & 402 & 352 & 431 & 344 & 380 & 482 & 451 \\
\hline \multirow{2}{*}{ Daily $\mathrm{m}^{\wedge} 3$ Avg. } & 12 & 13 & 13 & 16 & 13 & 13 & 12 & 13 & 12 & 13 & 16 & 14 \\
\hline & & & & & & & & & & & & \\
\hline \multicolumn{13}{|l|}{ GREENHOUSE DATA } \\
\hline \multirow{4}{*}{$\begin{array}{l}\text { CO2 (kgs) (Highest Year) } \\
\text { SO2 (kgs) (Highest Year) } \\
\text { NOx (kgs) (Highest Year) }\end{array}$} & 136,129 & 126,429 & 109,270 & 73,124 & 73,240 & 79,317 & 69,489 & 58,735 & 69,893 & 98,757 & 97,431 & 124,916 \\
\hline & 1,471 & 1,366 & 1,181 & 790 & 791 & 857 & 751 & 635 & 755 & 1,067 & 1,053 & 1,350 \\
\hline & 645 & 599 & 518 & 346 & 347 & 376 & 329 & 278 & 331 & 468 & 461 & 592 \\
\hline & & & & & & & & & & & & \\
\hline USAGE DATA & & & & & & & & & & & & \\
\hline kWh to GJ & 713.93 & 660.51 & 570.20 & 373.59 & 375.69 & 409.23 & 358.53 & 297.99 & 360.99 & 514.09 & 503.13 & 651.39 \\
\hline GJ/m2/Day ELECTRIC (Highest Year) & 0.005 & 0.005 & 0.004 & 0.002 & 0.003 & 0.002 & 0.003 & 0.002 & 0.003 & 0.003 & 0.004 & 0.004 \\
\hline $\mathrm{GJ} / \mathrm{m} 2 /$ Month (Highest Year) & 0.15 & 0.14 & 0.12 & 0.08 & 0.08 & 0.08 & 0.07 & 0.06 & 0.07 & 0.11 & 0.10 & 0.13 \\
\hline m3 to GJ & & & & & & & & & 1280 & & & \\
\hline $\begin{array}{l}\mathrm{m} 3 \text { to GJ } \\
\mathrm{GJ} / \mathrm{m} 2 / \text { Day GAS (Highest Year) }\end{array}$ & $\begin{array}{l}14.28 \\
0.000\end{array}$ & $\begin{array}{l}15.77 \\
0.000\end{array}$ & $\begin{array}{l}14.28 \\
0.000\end{array}$ & $\begin{array}{l}17.41 \\
0.000\end{array}$ & $\begin{array}{l}15.96 \\
0.000\end{array}$ & $\begin{array}{l}14.95 \\
0.000\end{array}$ & $\begin{array}{l}13.09 \\
0.000\end{array}$ & $\begin{array}{l}16.03 \\
0.000\end{array}$ & $\begin{array}{l}12.80 \\
0.000\end{array}$ & $\begin{array}{l}14.14 \\
0.000\end{array}$ & $\begin{array}{l}17.93 \\
0.000\end{array}$ & $\begin{array}{l}16.78 \\
0.000\end{array}$ \\
\hline $\mathrm{GJ} / \mathrm{m} 2 /$ Month & 0.00 & 0.00 & 0.00 & 0.00 & 0.00 & 0.00 & 0.00 & 0.00 & 0.00 & 0.00 & 0.00 & 0.00 \\
\hline $\mathrm{m} 3 / \mathrm{m} 2 /$ Month & 0.08 & 0.09 & 0.08 & 0.10 & 0.09 & 0.08 & 0.07 & 0.09 & 0.07 & 0.08 & 0.10 & 0.09 \\
\hline GJ/m2/Day ENERGY (Highest Year) & 0.005 & 0.005 & 0.004 & 0.003 & 0.003 & 0.003 & 0.003 & 0.002 & 0.003 & 0.003 & 0.004 & 0.004 \\
\hline $\mathrm{GJ} / \mathrm{m} 2 /$ Month (Highest Consumption Year) & 0.150 & 0.139 & 0.120 & 0.081 & 0.081 & 0.087 & 0.077 & 0.065 & 0.077 & 0.109 & 0.107 & 0.138 \\
\hline Energy Usage per Month (Electricity + Gas) & 728 & 676 & 584 & 391 & 392 & 424 & 372 & 314 & 374 & 528 & 521 & 668 \\
\hline Degree Days & 624 & 675 & 610 & 254 & 196 & 94 & 112 & 77 & 86 & 279 & 452 & 627 \\
\hline
\end{tabular}




\section{Actual data used for calculations (year with lowest energy consumption):}

\begin{tabular}{|c|c|c|c|c|c|c|c|c|c|c|c|c|}
\hline ADDRESS: & \multicolumn{4}{|c|}{ Building I - Ottawa, Ontario, Tower C } & & & & & & & & \\
\hline BUILDING \# & \multicolumn{4}{|c|}{9} & & & & & & & & \\
\hline Year - Lowest Energy Consumption: & \multicolumn{4}{|l|}{2013} & & & & & & & & \\
\hline AREA: & \multicolumn{4}{|l|}{4,854} & & & & & & & & \\
\hline USAGE INDEX: & 0.91 & AVERAGE: & 1.0713 & 1.07209 & & & & & & & & \\
\hline Month & Jan & Feb & Mar & Apr & May & Jun & Jul & Aug & Sep & Oct & Nov & Dec \\
\hline \multirow{4}{*}{$\begin{array}{l}\text { Electric Billing Date } \\
\text { Electric Billing Days }\end{array}$} & $12 / 02 / 2013$ & $14 / 03 / 2013$ & $13 / 04 / 2013$ & $14 / 05 / 2013$ & $13 / 06 / 2013$ & $16 / 07 / 2013$ & $15 / 08 / 2013$ & $16 / 09 / 2013$ & $13 / 10 / 2013$ & $14 / 11 / 2013$ & $12 / 12 / 2013$ & $15 / 01 / 2014$ \\
\hline & 31 & 30 & 30 & 31 & 30 & 33 & 30 & 32 & 27 & 32 & 28 & 34 \\
\hline & $12 / 02 / 2013$ & $14 / 03 / 2013$ & $13 / 04 / 2013$ & 14/05/2013 & $13 / 06 / 2013$ & $16 / 07 / 2013$ & 15/08/2013 & $16 / 09 / 2013$ & $13 / 10 / 2013$ & $14 / 11 / 2013$ & $12 / 12 / 2013$ & $15 / 01 / 2014$ \\
\hline & 31 & 30 & 30 & 31 & 30 & 33 & 30 & 32 & 27 & 32 & 28 & 34 \\
\hline \multicolumn{13}{|l|}{ COOLING \& HEATING DEGREE DAYS } \\
\hline Cooling D.D. (Lowest Year) & 0 & 0 & 0 & 37 & 102 & 195 & 112 & 36 & 1 & 0 & 0 & 0 \\
\hline \multirow{2}{*}{$\begin{array}{l}\text { Daily Clg D.D. Avg. (Lowest Year) } \\
\text { Normal Cooling D.D. (Lowest Year) }\end{array}$} & 0 & 0 & 0 & 1 & 3 & 6 & 4 & 1 & 0 & 0 & 0 & 0 \\
\hline & & & & & & & & & & & & \\
\hline Heating D.D. (Lowest Year) & 624 & 632 & 555 & 359 & 109 & 33 & 1 & 4 & 83 & 209 & 478 & 661 \\
\hline \multirow{3}{*}{$\begin{array}{l}\text { Daily Htg. D.D. Avg. (Lowest Year) } \\
\text { Normal Heating D.D (Lowest Year) }\end{array}$} & 20 & 21 & 18 & 12 & 4 & 1 & 0 & 0 & 3 & 7 & 17 & 19 \\
\hline & & & & & & & & & & & & \\
\hline & & & & & & & & & & & & \\
\hline \multicolumn{13}{|l|}{ ELECTRICAL USAGE \& COST } \\
\hline kWh Used & 120,775 & 125,875 & 136,634 & 87,475 & 97,877 & 68,875 & 87,623 & 70,375 & 71,245 & 83,481 & 79,075 & 154,967 \\
\hline Daily kWh Avg. & 3,896 & 4,196 & 4,554 & 2,822 & 3,263 & 2,087 & 2,921 & 2,199 & 2,639 & 2,609 & 2,824 & 4,558 \\
\hline Demand kW/RkVA Used & 282 & 283 & 339 & 258 & 282 & 196 & 278 & 198 & 255 & 257 & 221 & 314 \\
\hline \multirow{2}{*}{$\begin{array}{l}\text { Demand kW/RkVA Used } \\
\text { Load Factor (Lowest Year) }\end{array}$} & $58 \%$ & $62 \%$ & $56 \%$ & $46 \%$ & $48 \%$ & $44 \%$ & $44 \%$ & $46 \%$ & $43 \%$ & $42 \%$ & $53 \%$ & $61 \%$ \\
\hline & & & & & & & & & & & & \\
\hline \multicolumn{13}{|l|}{ CCF } \\
\hline $\mathrm{m}^{\wedge} 3$ Used & 306 & 443 & 382 & 403 & 377 & 384 & 349 & 398 & 242 & 398 & 306 & 417 \\
\hline \multirow{2}{*}{ Daily m^3 Avg. } & 10 & 15 & 13 & 13 & 13 & 12 & 12 & 12 & 9 & 12 & 11 & 12 \\
\hline & & & & & & & & & & & & \\
\hline \multicolumn{13}{|l|}{ GREENHOUSE DATA } \\
\hline \multirow{4}{*}{$\begin{array}{l}\text { C02 (kgs) (Lowest Year) } \\
\text { S02 (kgs) (Lowest Year) } \\
\text { N0x (kgs) (Lowest Year) }\end{array}$} & 83,414 & 87,815 & 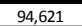 & 61,699 & 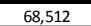 & 499,052 & (61,416 & 50,160 & 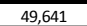 & 58,977 & 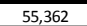 & 107,202 \\
\hline & 901 & 949 & 1,022 & 667 & 740 & 530 & 664 & 542 & 536 & 637 & 598 & 1,158 \\
\hline & 395 & 416 & 448 & 292 & 325 & 232 & 291 & 238 & 235 & 279 & 262 & 508 \\
\hline & & & & & & & & & & & & \\
\hline USAGE DATA & & & & & & & & & & & & \\
\hline kWh to GJ & 434.79 & 4453.15 & 4991.88 & 314.91 & 352.36 & 247.95 & 315.44 & 253.35 & 256.48 & 300.53 & 284.67 & 557.88 \\
\hline $\mathrm{GJ} / \mathrm{m} 2 /$ Day ELECTRIC (Lowest Year) & 0.003 & 0.003 & 0.003 & 0.002 & 0.002 & 0.002 & 0.002 & 0.002 & 0.002 & 0.002 & 0.002 & 0.003 \\
\hline GJ/m2/Month (Lowest Year) & 0.09 & 0.09 & 0.10 & 0.06 & 0.07 & 0.05 & 0.06 & 0.05 & 0.05 & 0.06 & 0.06 & 0.11 \\
\hline m3 to GJ & 11.38 & 16.48 & 14.21 & 14.99 & 14.02 & 14.28 & 12.98 & 14.81 & 9.00 & 14.81 & 11.38 & 15.51 \\
\hline $\mathrm{GJ} / \mathrm{m} 2 /$ Day GAS (Lowest Year) & 0.000 & 0.000 & 0.000 & 0.000 & 0.000 & 0.000 & 0.000 & 0.000 & 0.000 & 0.000 & 0.000 & 0.000 \\
\hline $\mathrm{GJ} / \mathrm{m} 2 /$ Month & 0.00 & 0.00 & 0.00 & 0.00 & 0.00 & 0.00 & 0.00 & 0.00 & 0.00 & 0.00 & 0.00 & 0.00 \\
\hline $\mathrm{m} 3 / \mathrm{m} 2 /$ Month & 0.06 & 0.09 & 0.08 & 0.08 & 0.08 & 0.08 & 0.07 & 0.08 & 0.05 & 0.08 & 0.06 & 0.09 \\
\hline GJ/m2/Day ENERGY (Lowest Year) & 0.003 & 0.003 & 0.003 & 0.002 & 0.003 & 0.002 & 0.002 & 0.002 & 0.002 & 0.002 & 0.002 & 0.003 \\
\hline $\mathrm{GJ} / \mathrm{m} 2 /$ Month (Lowest Consumption Year) & 0.092 & 0.097 & 0.104 & 0.068 & 0.075 & 0.054 & 0.068 & 0.055 & 0.055 & 0.065 & 0.061 & 0.118 \\
\hline Average Highest Year to Lowest Year & 0.121 & 0.118 & 0.112 & 0.074 & 0.078 & 0.071 & 0.072 & 0.060 & 0.066 & 0.087 & 0.084 & 0.128 \\
\hline BOMA Mean Value per Month & 0.111 & 0.111 & 0.111 & 0.111 & 0.111 & 0.111 & 0.111 & 0.111 & 0.111 & 0.111 & 0.111 & 0.111 \\
\hline Energy Usage per Month (Electricity + Ga) & 446 & 470 & 506 & 330 & 366 & 262 & 328 & 268 & 265 & 315 & 296 & 573 \\
\hline Degree Days & 624 & 632 & 555 & 395 & 211 & 228 & 113 & 40 & 84 & 209 & 478 & 661 \\
\hline Normalized Data (Average Degree Days) & 624 & 632 & 555 & 377 & 171 & 160 & 118 & 69 & 98 & 209 & 478 & 661 \\
\hline Normalized Data (Av Energy Consumptio & 562 & 565 & 530 & 448 & 353 & 348 & 329 & 306 & 319 & 371 & 494 & 578 \\
\hline Normalized Data (Av Energy Index / mon & 0.116 & 0.116 & 0.109 & 0.092 & 0.073 & 0.072 & 0.068 & 0.063 & 0.066 & 0.076 & 0.102 & 0.119 \\
\hline
\end{tabular}


Analysis on how electricity and gas consumption corresponds to heating and cooling periods (for highest energy consumption year):

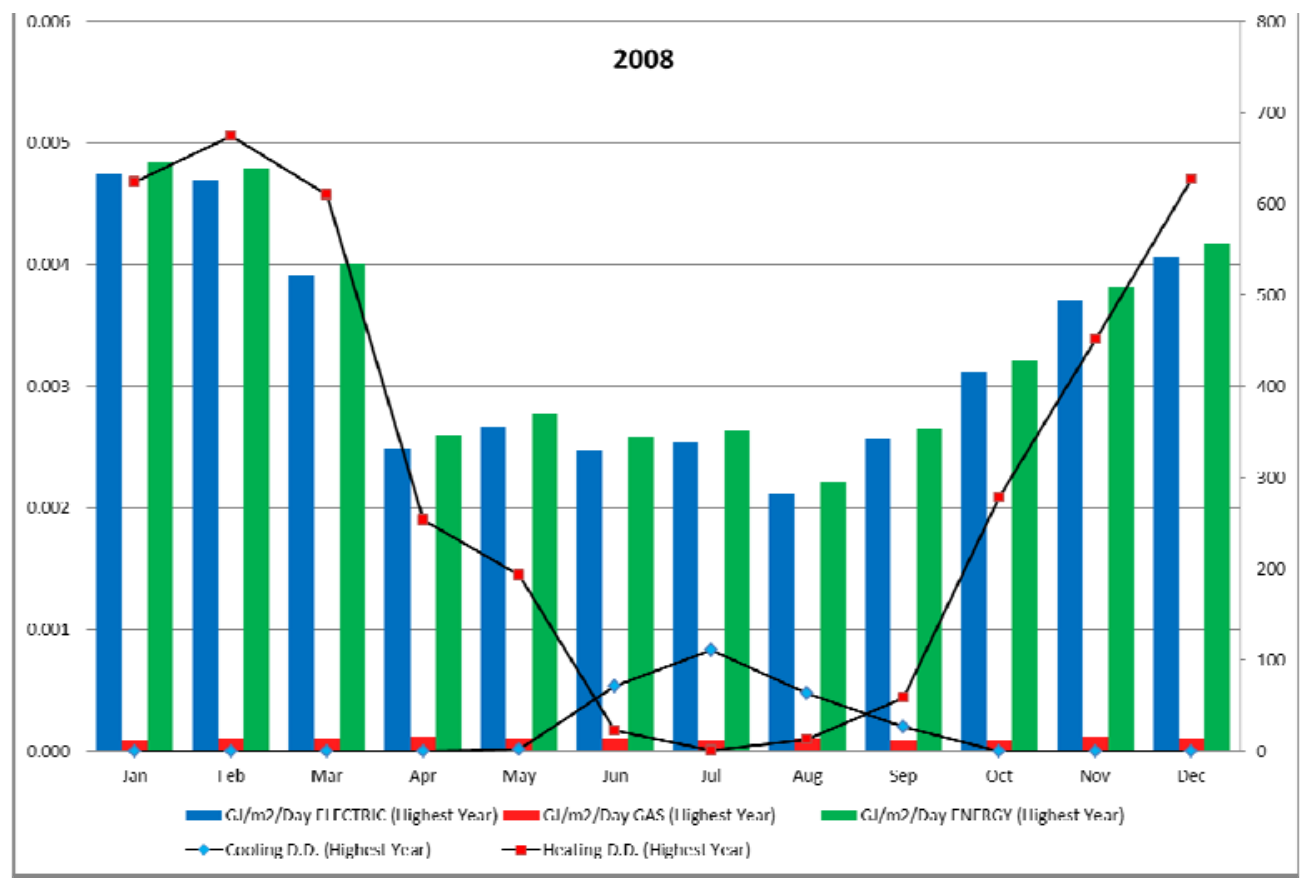

Analysis on how electricity and gas consumption corresponds to heating and cooling periods (for lowest energy consumption year):

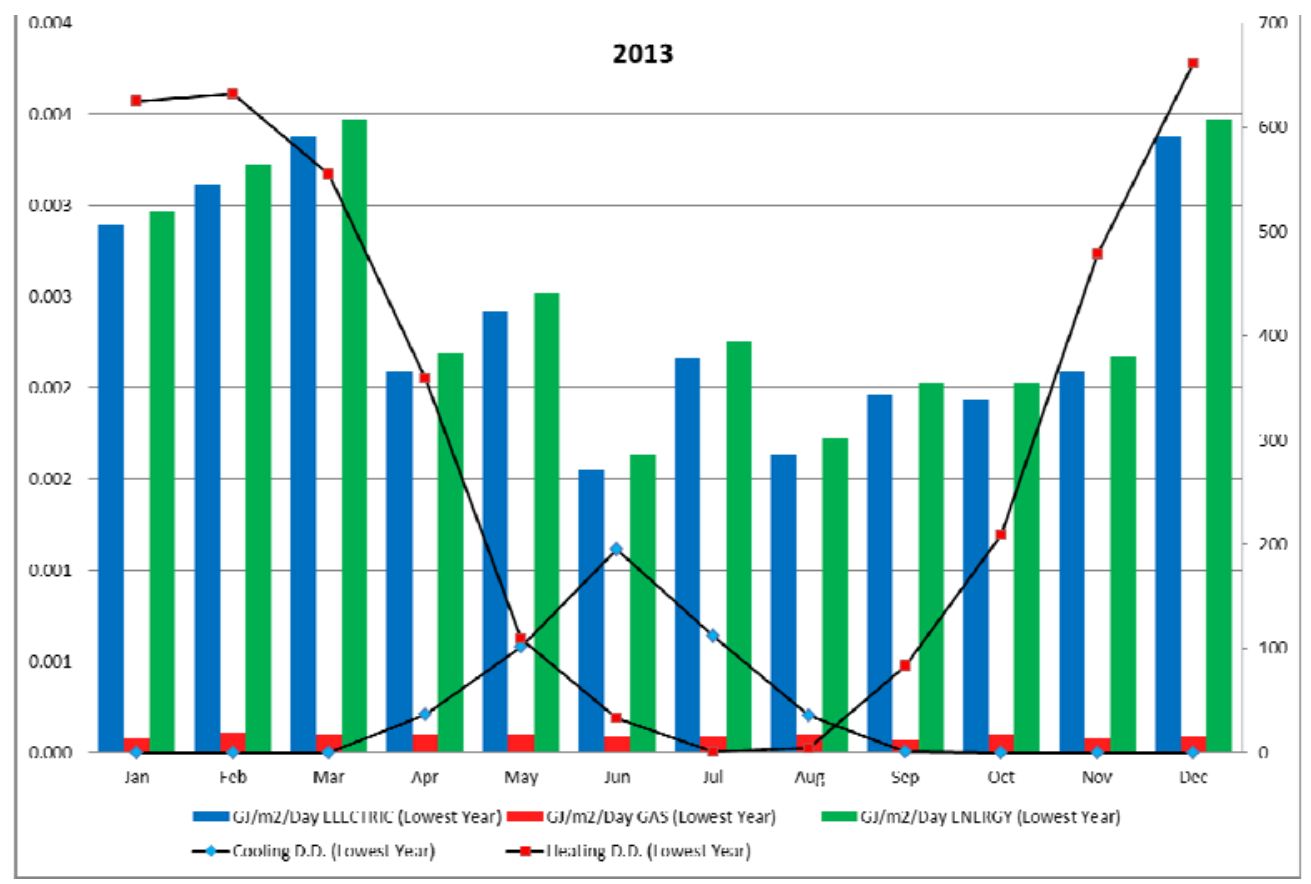


Monthly energy index comparison between highest energy consumption year, lowest, average and benchmark (BOMA) energy intensity:

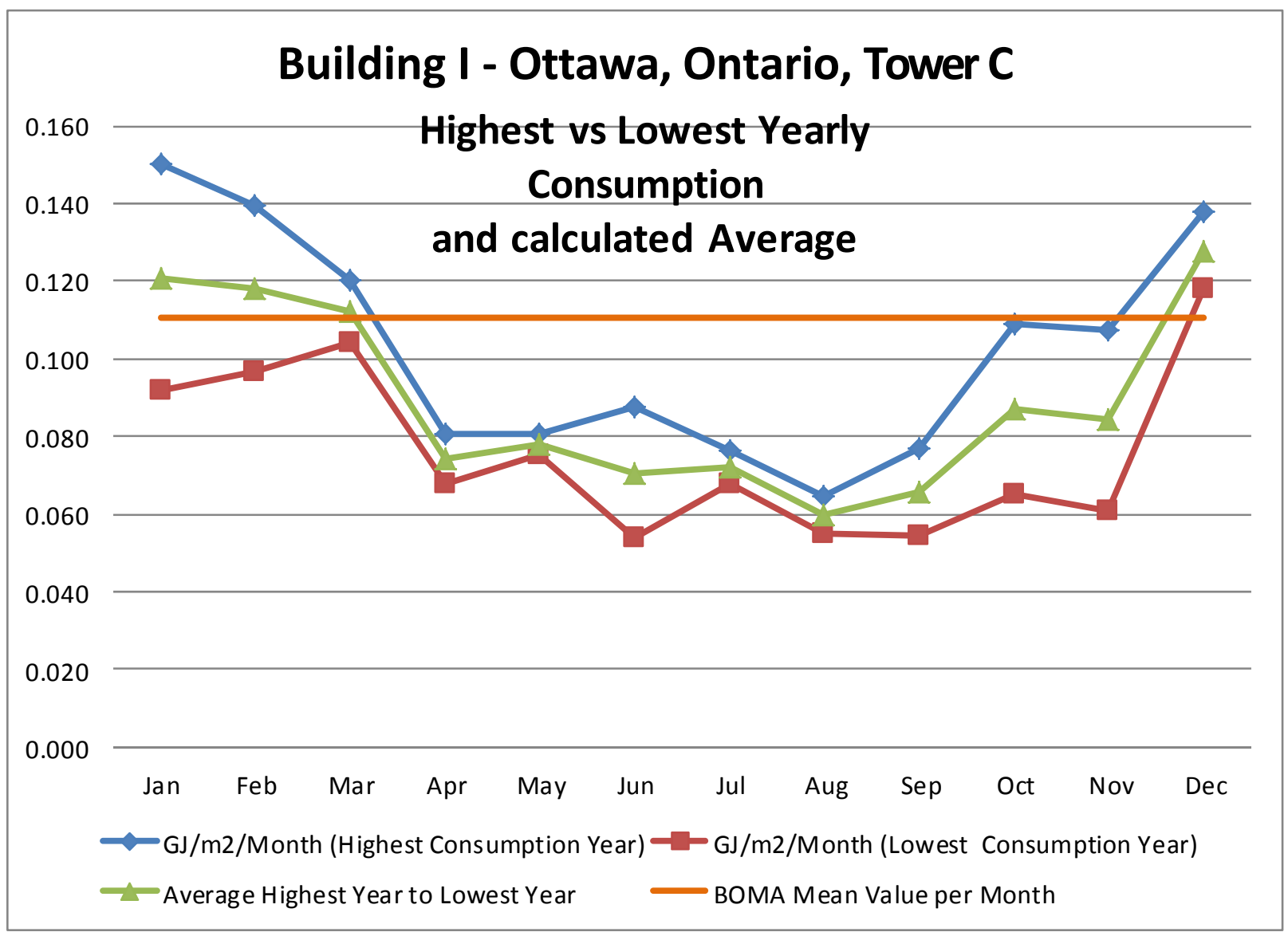


Building \#10 - Utility Bills Analysis

\section{Calculations of Energy Index for Building \#10}

Energy CAP database was utilized to collect energy consumption information for the building. Energy consumption was provided by utility bills for electricity. For Building \#10 utility bills were provided from December 2006 to March 2015. To complete most accurate analysis utility bills for 2007 to 2014 were only analyzed because 2006 and 2015 has incomplete data. By having total floor area for entire building of 8,270 $\mathrm{m}^{2}$, energy index in $\mathrm{GJ} / \mathrm{m}^{2} /$ year was calculated. From calculations it was noticed that electricity consumption is noticeably increasing.

Utility bills analysis showed following:

\begin{tabular}{|c|c|c|c|c|c|c|}
\hline \multicolumn{4}{|c|}{ Building J - Ottawa, Ontario, Tower B } & \multirow[b]{2}{*}{$\mathrm{m}^{3}$-ngas } & \multirow[b]{2}{*}{ Total GJ/yr } & \multirow[b]{2}{*}{$8,270.00$} \\
\hline & & kWh & & & & \\
\hline Row Labels & $\begin{array}{c}\text { Sum of Ele Total } \\
\text { Cost / Year }\end{array}$ & $\begin{array}{c}\text { Sum of Ele } \\
\text { Consumption / } \\
\text { Year }\end{array}$ & $\begin{array}{c}\text { Sum of Gas Total } \\
\text { Cost / Year }\end{array}$ & $\begin{array}{c}\text { Sum of Gas } \\
\text { Consumption / } \\
\text { Year }\end{array}$ & Total & $\mathrm{GJ} / \mathrm{m} 2 / \mathrm{yr}$ \\
\hline Year 2006 & $42,147.20$ & $395,066.52$ & & & & \\
\hline Year 2007 & $257,457.26$ & $2,244,904.38$ & & & $8,081.66$ & 0.98 \\
\hline Year 2008 & $348,922.62$ & $3,446,424.69$ & & & $12,407.13$ & 1.50 \\
\hline Year 2009 & $518,992.42$ & $5,380,956.18$ & & & $19,371.44$ & 2.34 \\
\hline Year 2010 & $666,152.31$ & $6,608,614.99$ & & & $23,791.01$ & 2.88 \\
\hline Year 2011 & $760,441.78$ & $7,158,754.60$ & & & $25,771.52$ & 3.12 \\
\hline Year 2012 & $\$ \quad 867,420.74$ & $7,465,959.75$ & & & $26,877.46$ & 3.25 \\
\hline Year 2013 & $\$ 1,009,936.95$ & $8,117,404.05$ & & & $29,222.65$ & 3.53 \\
\hline Year 2014 & $\$ 1,086,545.67$ & $8,550,109.80$ & & & $30,780.40$ & 3.72 \\
\hline Year 2015 & $\$ \quad 292,627.19$ & $2,223,623.79$ & & & & \\
\hline Average & $689,483.72$ & $6,121,641.06$ & & & & 2.66 \\
\hline
\end{tabular}

As it was specified in energy audit, energy consumption of the Building \#10 is very high in comparison to similar office buildings in same region; and therefore average energy index which equals to $1.13 \mathrm{GJ} / \mathrm{m}^{2} / \mathrm{yr}$ is also high in comparison to benchmark values of BOMA energy efficient building value of $1.05 \mathrm{GJ} / \mathrm{m}^{2} / \mathrm{yr}$, and then average National Resources Canada value of $1.43 \mathrm{GJ} / \mathrm{m} 2 /$ year..

Charts below show electricity consumption per year. Electricity consumption chart demonstrates prominent increase in energy usage. 


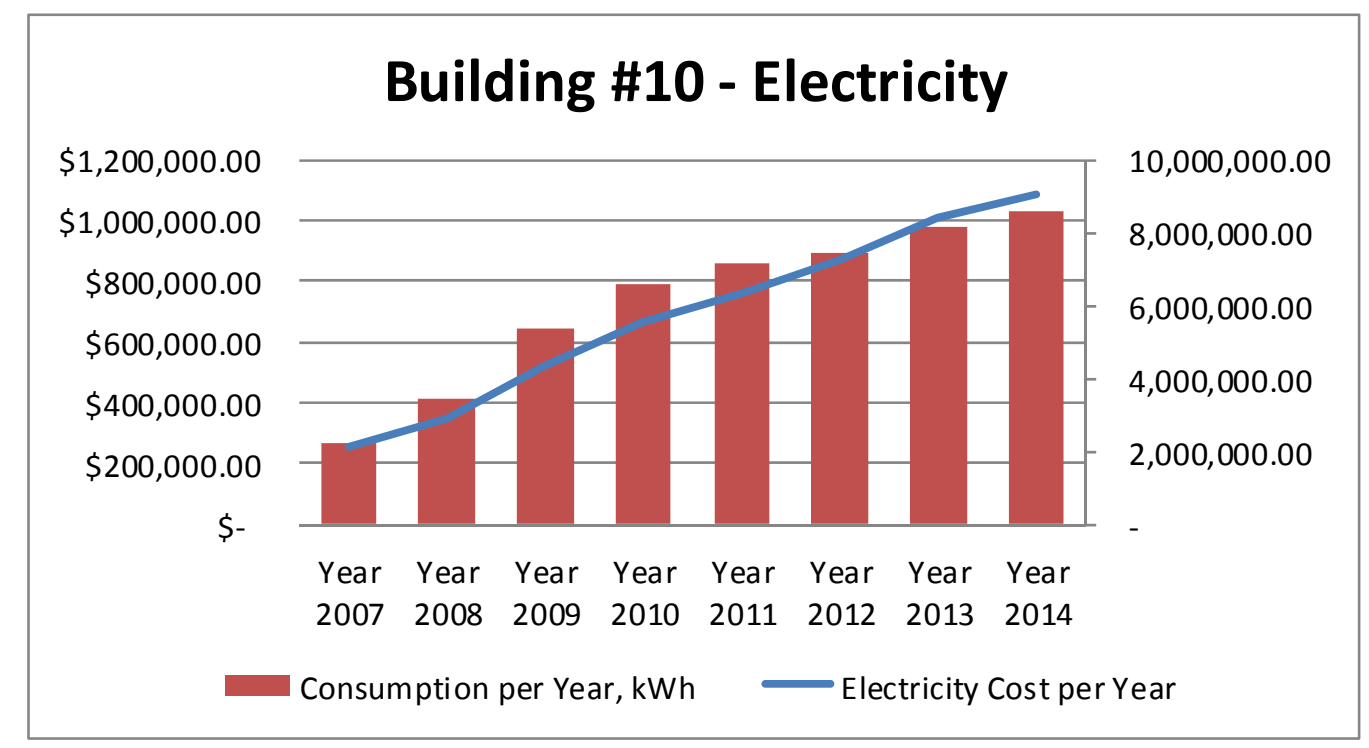

Yearly energy intensity (index) was also plotted to demonstrate increase or decrease over the range of years for which data is available. Chart below shows that energy index value is gradually increasing and currently around $3.72 \mathrm{GJ} / \mathrm{m}^{2} / \mathrm{yr}$; this value is very high. The lowest energy index was in 2007 and highest in 2014 . These two years' data will be used for further calculations and comparisons.

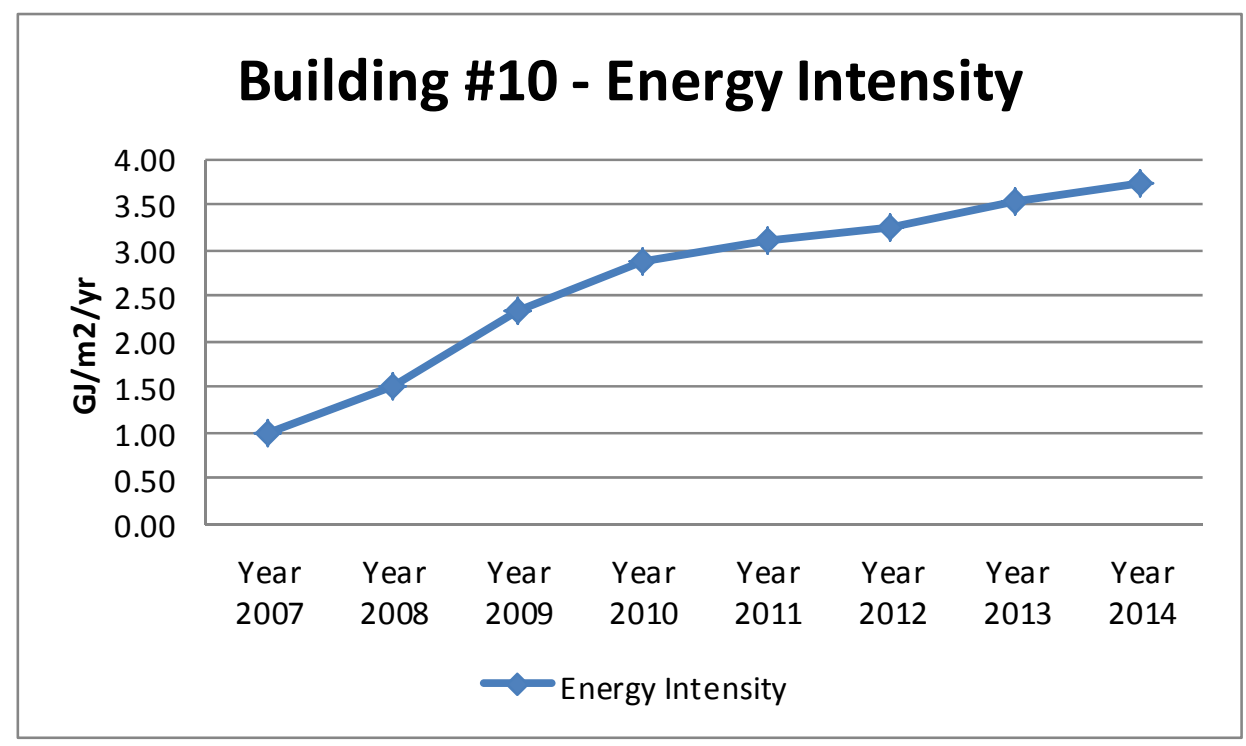

Normalized total energy consumption was calculated for Building \#10. Based on plotted results, shown below in the chart, it can be concluded that energy consumption for 2014 is much higher than for 2007 . This proves that regardless of weather conditions 2014 has higher energy consumptions than in 2007. Implementing trendline equations, average equation was calculated: 
From above equation normalized average energy index was calculated as $2.34 \mathrm{GJ} / \mathrm{m}^{2} / \mathrm{yr}$, this value is slightly lower than average for 2007 to 2014 years range. As it was discussed previously, to demonstrate more accurate energy consumption of the building, current value should be only $75 \%$; therefore new energy intensity index value is $1.76 \mathrm{GJ} / \mathrm{m}^{2} / \mathrm{yr}$. This value will be used for further case-study buildings comparison.

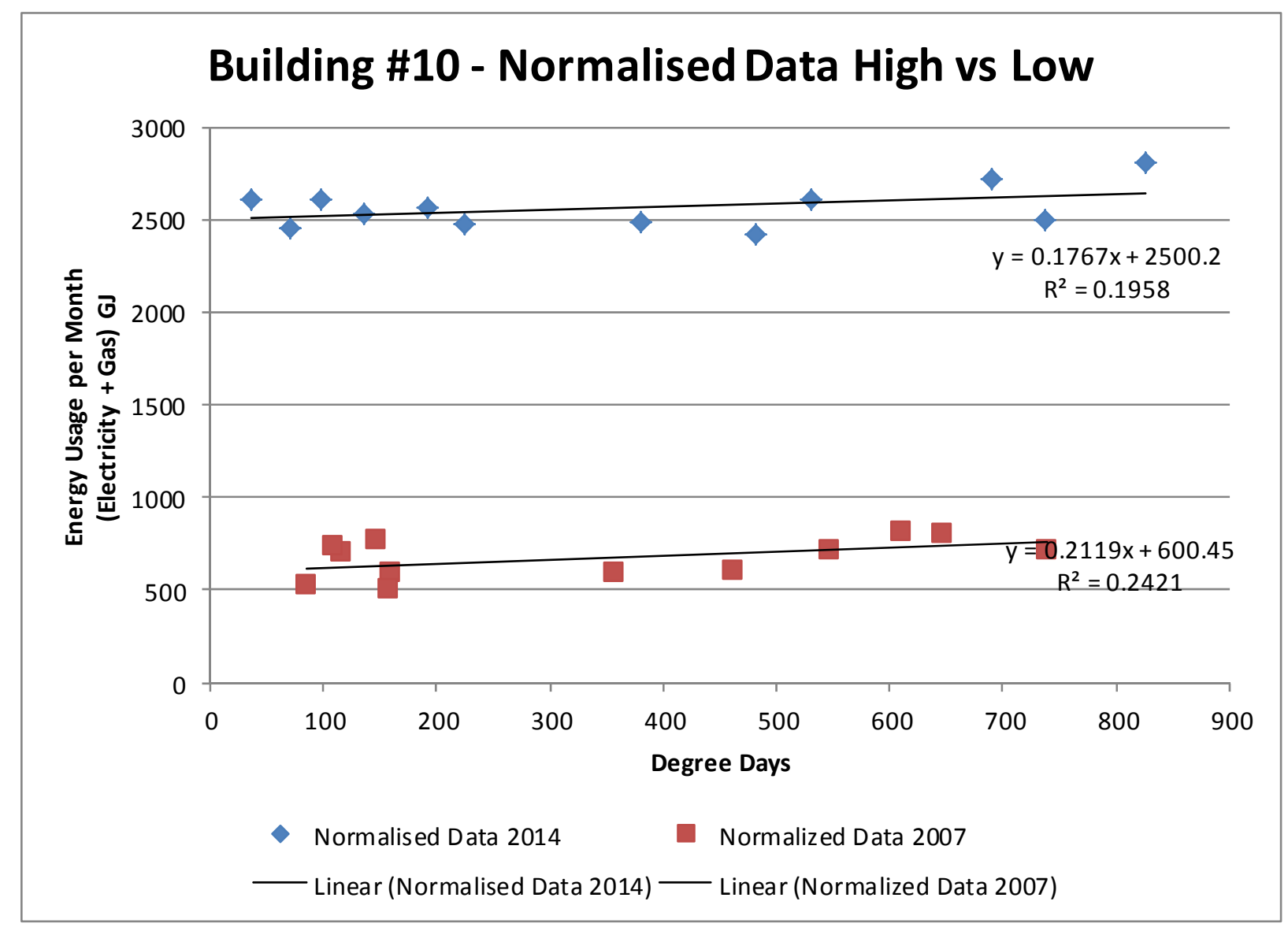


Actual data used for calculations (year with highest energy consumption):

\begin{tabular}{|c|c|c|c|c|c|c|c|c|c|c|c|c|}
\hline ADDRESS: & \multicolumn{4}{|c|}{ Building J - Ottawa, Ontario, Tower B } & & & & & & & & \\
\hline BUILDING\# & \multicolumn{4}{|c|}{10} & & & & & & & & \\
\hline Year - Highest Energy Consumption: & \multicolumn{4}{|l|}{2014} & & & & & & & & \\
\hline AREA: & \multicolumn{4}{|l|}{8,270} & & & & & & & & \\
\hline USAGE INDEX: & \multicolumn{4}{|l|}{3.72} & & & & & & & & \\
\hline Month & Jan & $\mathrm{Feb}$ & Mar & Apr & May & Jun & Jul & Aug & Sep & Oct & Nov & Dec \\
\hline \multirow{4}{*}{$\begin{array}{l}\text { Electric Billing Date } \\
\text { Electric Billing Days }\end{array}$} & $31 / 01 / 2014$ & $28 / 02 / 2014$ & $31 / 03 / 2014$ & $30 / 04 / 2014$ & $31 / 05 / 2014$ & $30 / 06 / 2014$ & $31 / 07 / 2014$ & $31 / 08 / 2014$ & $30 / 09 / 2014$ & $31 / 10 / 2014$ & $30 / 11 / 2014$ & $31 / 12 / 2014$ \\
\hline & 31 & 28 & 31 & 30 & 31 & 30 & 31 & 31 & 30 & 31 & 30 & 31 \\
\hline & $31 / 01 / 2014$ & $28 / 02 / 2014$ & $31 / 03 / 2014$ & $30 / 04 / 2014$ & $31 / 05 / 2014$ & $30 / 06 / 2014$ & $31 / 07 / 2014$ & $31 / 08 / 2014$ & $30 / 09 / 2014$ & $31 / 10 / 2014$ & $30 / 11 / 2014$ & $31 / 12 / 2014$ \\
\hline & 31 & 28 & 31 & 30 & 31 & 30 & 31 & 31 & 30 & 31 & 30 & 31 \\
\hline \multicolumn{13}{|l|}{ COOLING \& HEATING DEGREE DAYS } \\
\hline \multirow{4}{*}{$\begin{array}{l}\text { Cooling D.D. (Highest Year) } \\
\text { Daily Clg D.D. Avg. (Highest Year) } \\
\text { Normal Cooling D.D. (Highest Year) }\end{array}$} & & & & & & & & & & & & 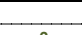 \\
\hline & 0 & 0 & 0 & $\frac{23}{1}$ & $\frac{59}{2}$ & $\begin{array}{c}121 \\
4\end{array}$ & $\begin{array}{c}94 \\
3\end{array}$ & $\begin{array}{c}28 \\
1\end{array}$ & 0 & 0 & 0 & 0 \\
\hline & & & & & & & & & & & & \\
\hline & 826 & 737 & 691 & 357 & 132 & 14 & 4 & 9 & 70 & 224 & 482 & 532 \\
\hline \multirow{3}{*}{$\begin{array}{l}\text { Heating D.D. (Highest Year) } \\
\text { Daily Htg. D.D. Avg. (Highest Year) } \\
\text { Normal Heating D.D (Highest Year) }\end{array}$} & 27 & 26 & 22 & 12 & 4 & 0 & 0 & 0 & 2 & 7 & 16 & 17 \\
\hline & & & & & & & & & & & & \\
\hline \multirow{2}{*}{\multicolumn{13}{|c|}{ ELECTRICAL USAGE \& COST }} \\
\hline & & & & & & & & & & & & \\
\hline \multirow{2}{*}{$\begin{array}{l}\text { kWh Used } \\
\text { Daily kWh Avg. }\end{array}$} & 779,591 & 693,374 & 754,671 & 691,542 & 713,452 & 703,583 & 723,955 & 723,047 & 682,004 & 687,047 & 673,248 & 724,597 \\
\hline & 25,148 & 24,763 & 24,344 & 23,051 & 23,015 & 23,453 & 23,353 & 23,324 & 22,733 & 22,163 & 22,442 & 23,374 \\
\hline \multirow{3}{*}{$\begin{array}{l}\text { Demand kW/RkVA Used } \\
\text { Load Factor (Highest Year) }\end{array}$} & & & & & & & & & & & & \\
\hline & 1,237 & 1,245 & 1,155 & 1,111 & 1,097 & 1,115 & 1,085 & 1,089 & 1,075 & 1,046 & 1,070 & 1,115 \\
\hline & $85 \%$ & $83 \%$ & $88 \%$ & $86 \%$ & $87 \%$ & $88 \%$ & $90 \%$ & $89 \%$ & $88 \%$ & $88 \%$ & $87 \%$ & $87 \%$ \\
\hline \multicolumn{13}{|l|}{ NATURAL GAS USAGE \& COST } \\
\hline \multicolumn{13}{|l|}{ CCFF } \\
\hline $\mathrm{m}^{\wedge} 3$ Used & 0 & 0 & 0 & 0 & 0 & 0 & 0 & 0 & 0 & 0 & 0 & 0 \\
\hline \multirow{2}{*}{ Daily $\mathrm{m}^{\wedge} 3$ Avg. } & 0 & 0 & 0 & 0 & 0 & 0 & 0 & 0 & 0 & 0 & 0 & 0 \\
\hline & & & & & & & & & & & & \\
\hline \multicolumn{13}{|l|}{ GREENHOUSE DATA } \\
\hline \multirow{4}{*}{$\begin{array}{l}\text { C02 (kgs) (Highest Year) } \\
\text { S02 (kgs) (Highest Year) } \\
\text { NOx (kgs) (Highest Year) }\end{array}$} & 524,452 & 466,451 & 507,688 & 465,219 & 479,959 & 473,320 & 487,024 & 486,413 & 458,803 & 462,195 & 452,912 & 487,456 \\
\hline & 5,666 & 5,040 & 5,485 & 5,026 & 5,186 & 5,114 & 5,262 & 5,255 & 4,957 & 4,994 & 4,893 & 5,266 \\
\hline & 2,484 & 2,209 & 2,405 & 2,204 & 2,273 & 2,242 & 2,307 & 2,304 & 2,173 & 2,189 & 2,145 & 2,309 \\
\hline & \multicolumn{12}{|c|}{ USAGE DATA } \\
\hline \multirow{3}{*}{$\begin{array}{l}\text { kWh to GJ } \\
\mathrm{GJ} / \mathrm{m} 2 / \text { Day ELECTRIC (Highest Year) } \\
\mathrm{GJ} / \mathrm{m} 2 / \text { Month (Highest Year) }\end{array}$} & 2806.53 & 2496.14 & 2716.82 & 2489.55 & 2568.43 & 2532.90 & 2606.24 & 2602.97 & 2455.22 & 2473.37 & 2423.69 & 2608.55 \\
\hline & 0.011 & 0.011 & 0.011 & 0.010 & 0.010 & 0.010 & 0.010 & 0.010 & 0.010 & 0.010 & 0.010 & 0.010 \\
\hline & 0.34 & 0.30 & 0.33 & 0.30 & 0.31 & 0.31 & 0.32 & 0.31 & 0.30 & 0.30 & 0.29 & 0.32 \\
\hline $\mathrm{m} 3$ to GJ & 0.00 & 0.00 & 0.00 & 0.00 & 0.00 & 0.00 & 0.00 & 0.00 & 0.00 & 0.00 & 0.00 & 0.00 \\
\hline $\mathrm{GJ} / \mathrm{m} 2 /$ Day GAS (Highest Year) & 0.000 & 0.000 & 0.000 & 0.000 & 0.000 & 0.000 & 0.000 & 0.000 & 0.000 & 0.000 & 0.000 & 0.000 \\
\hline $\mathrm{GJ} / \mathrm{m} 2 /$ Month & 0.00 & 0.00 & 0.00 & 0.00 & 0.00 & 0.00 & 0.00 & 0.00 & 0.00 & 0.00 & 0.00 & 0.00 \\
\hline $\mathrm{m} 3 / \mathrm{m} 2 /$ Month & 0.00 & 0.00 & 0.00 & 0.00 & 0.00 & 0.00 & 0.00 & 0.00 & 0.00 & 0.00 & 0.00 & 0.00 \\
\hline GJ/m2/Day ENERGY (Highest Year) & 0.011 & 0.011 & 0.011 & 0.010 & 0.010 & 0.010 & 0.010 & 0.010 & 0.010 & 0.010 & 0.010 & 0.010 \\
\hline $\mathrm{GJ} / \mathrm{m} 2 /$ Month (Highest Consumption Year) & 0.339 & 0.302 & 0.329 & 0.301 & 0.311 & 0.306 & 0.315 & 0.315 & 0.297 & 0.299 & 0.293 & 0.315 \\
\hline Energy Usage per Month (Electricity + Gas) & 2807 & 2496 & 2717 & 2490 & 2568 & 2533 & 2606 & 2603 & 2455 & 2473 & 2424 & 2609 \\
\hline Degree Days & 826 & 737 & 691 & 380 & 191 & 135 & 98 & 37 & 70 & 224 & 482 & 532 \\
\hline
\end{tabular}




\section{Actual data used for calculations (year with lowest energy consumption):}

\begin{tabular}{|c|c|c|c|c|c|c|c|c|c|c|c|c|}
\hline ADDRESS: & \multicolumn{4}{|c|}{ Building J - Ottawa, Ontario, Tower B } & & & & & & & & \\
\hline BUILDING \# & \multicolumn{4}{|c|}{10} & & & & & & & & \\
\hline Year - Lowest Energy Consumption: & \multicolumn{4}{|l|}{2007} & & & & & & & & \\
\hline AREA: & \multicolumn{4}{|l|}{8,270} & & & & & & & & \\
\hline USAGE INDEX: & 0.98 & AVERAGE: & 2.3496 & 2.34599 & & & & & & & & \\
\hline Month & $\operatorname{Jan}$ & Feb & Mar & Apr & May & Jun & Jul & Aug & Sep & Oct & Nov & Dec \\
\hline \multirow{4}{*}{$\begin{array}{l}\text { Electric Billing Date } \\
\text { Electric Billing Days }\end{array}$} & $31 / 01 / 2007$ & $28 / 02 / 2007$ & $31 / 03 / 2007$ & $30 / 04 / 2007$ & $31 / 05 / 2007$ & $30 / 06 / 2007$ & $31 / 07 / 2007$ & $31 / 08 / 2007$ & $30 / 09 / 2007$ & $31 / 10 / 2007$ & $30 / 11 / 2007$ & $31 / 12 / 2007$ \\
\hline & 31 & 28 & 31 & 30 & 31 & 30 & 31 & 31 & 30 & 31 & 30 & 31 \\
\hline & $31 / 01 / 2007$ & $28 / 02 / 2007$ & $31 / 03 / 2007$ & $30 / 04 / 2007$ & $31 / 05 / 2007$ & $30 / 06 / 2007$ & $31 / 07 / 2007$ & $31 / 08 / 2007$ & $30 / 09 / 2007$ & $31 / 10 / 2007$ & $30 / 11 / 2007$ & $31 / 12 / 2007$ \\
\hline & 31 & 28 & 31 & 30 & 31 & 30 & 31 & 31 & 30 & 31 & 30 & 31 \\
\hline \multicolumn{13}{|l|}{ COOLING \& HEATING DEGREE DAYS } \\
\hline & & & & & & & & & & & & \\
\hline \multirow{3}{*}{$\begin{array}{l}\text { Cooling D.D. (Lowest Year) } \\
\text { Daily Clg D.D. Avg. (Lowest Year) } \\
\text { Normal Cooling D.D. (Lowest Year) }\end{array}$} & 0 & 0 & 0 & 0 & 22 & 99 & 106 & 141 & 48 & 20 & 0 & 0 \\
\hline & 0 & 0 & 0 & 0 & 1 & 3 & 3 & 5 & 2 & 1 & 0 & 0 \\
\hline & & & & & & & & & & & & \\
\hline \multirow{4}{*}{$\begin{array}{l}\text { Heating D.D. (Lowest Year) } \\
\text { Daily Htg. D.D. Avg. (Lowest Year) } \\
\text { Normal Heating D.D (Lowest Year) }\end{array}$} & 647 & 740 & 547 & 356 & 136 & 17 & 3 & 5 & 37 & 138 & 463 & 611 \\
\hline & 21 & 26 & 18 & 12 & 4 & 1 & 0 & 0 & 1 & 4 & 15 & 20 \\
\hline & & & & & & & & & & & & \\
\hline & & & & & & & & & & & & \\
\hline \multicolumn{13}{|l|}{ ELECTRICAL USAGE \& COST } \\
\hline kWh Used & 222,725 & 200,105 & 199,771 & 166,173 & 163,299 & 196,428 & 203,571 & 213,315 & 146,444 & 140,338 & 166,753 & 225,984 \\
\hline \multirow[t]{2}{*}{ Daily kWh Avg. } & 7,185 & 7,147 & 6,444 & 5,539 & 5,268 & 6,548 & 6,567 & 6,881 & 4,881 & 4,527 & 5,558 & 7,290 \\
\hline & & & & & & & & & & & & \\
\hline Demand kW/RkVA Used & 372 & 377 & 395 & 315 & 431 & 400 & 456 & 435 & 335 & 261 & 331 & 392 \\
\hline \multirow{2}{*}{ Load Factor (Lowest Year) } & $80 \%$ & $79 \%$ & $68 \%$ & $73 \%$ & $51 \%$ & $68 \%$ & $60 \%$ & $66 \%$ & $61 \%$ & $72 \%$ & $70 \%$ & $78 \%$ \\
\hline & & & & & & & & & & & & \\
\hline \multicolumn{13}{|l|}{ NATURAL GAS USAGE \& COST } \\
\hline \multicolumn{13}{|l|}{ CCF } \\
\hline $\mathrm{m}^{\wedge} 3$ Used & 0 & 0 & 0 & 0 & 0 & 0 & 0 & 0 & 0 & 0 & 0 & 0 \\
\hline \multirow[t]{2}{*}{ Daily $\mathrm{m}^{\wedge} 3$ Avg. } & 0 & 0 & 0 & 0 & 0 & 0 & 0 & 0 & 0 & 0 & 0 & 0 \\
\hline & & & & & & & & & & & & \\
\hline \multicolumn{13}{|l|}{ GREENHOUSE DATA } \\
\hline "C02 (kgs) (Lowest Year) & 149,833 & 134,616 & 134,391 & 111,789 & 109,856 & 132,142 & 136,948 & 143,503 & 98,517 & 94,409 & 112,179 & 152,025 \\
\hline S02 (kgs) (Lowest Year) & 1,619 & 1,454 & 1,452 & 1,208 & 1,187 & 1,428 & 1,480 & 1,550 & 1,064 & 1,020 & 1,212 & 1,642 \\
\hline NOx (kgs) (Lowest Year) & 710 & 638 & 637 & 529 & 520 & 626 & 649 & 680 & 467 & 447 & 531 & 720 \\
\hline USAGE DATA & & & & & & & & & & & & \\
\hline kWh to GJ & 801.81 & 720.38 & 719.18 & 598.22 & 587.88 & 707.14 & 732.85 & 767.93 & 527.20 & 505.22 & 600.31 & 813.54 \\
\hline $\mathrm{GJ} / \mathrm{m} 2 /$ Day ELECTRIC (Lowest Year) & 0.003 & 0.003 & 0.003 & 0.002 & 0.002 & 0.003 & 0.003 & 0.003 & 0.002 & 0.002 & 0.002 & 0.003 \\
\hline $\mathrm{GJ} / \mathrm{m} 2 /$ Month (Lowest Year) & 0.10 & 0.09 & 0.09 & 0.07 & 0.07 & 0.09 & 0.09 & 0.09 & 0.06 & 0.06 & 0.07 & 0.10 \\
\hline & 0.00 & 0.00 & 0.00 & & & 0.00 & 0.00 & 000 & 0 & O & 0 & 0 \\
\hline $\begin{array}{l}\mathrm{m} 3 \text { to GJ } \\
\mathrm{GJ} / \mathrm{m} 2 / \text { Day GAS (Lowest Year) }\end{array}$ & 0.000 & 0.00 & 0.00 & $\begin{array}{c}0.00 \\
0.000\end{array}$ & $\begin{array}{l}0.00 \\
0.000\end{array}$ & 0.00 & $\begin{array}{c}0.00 \\
0.000\end{array}$ & $\begin{array}{c}0.00 \\
0.000\end{array}$ & 0.00 & $\begin{array}{c}0.00 \\
0.000\end{array}$ & 0.00 & 0.00 \\
\hline $\mathrm{GJ} / \mathrm{m} 2 /$ Month & 0.00 & 0.00 & 0.00 & 0.00 & 0.00 & 0.00 & 0.00 & 0.00 & 0.00 & 0.00 & 0.00 & 0.00 \\
\hline $\mathrm{m} 3 / \mathrm{m} 2 /$ Month & 0.00 & 0.00 & 0.00 & 0.00 & 0.00 & 0.00 & 0.00 & 0.00 & 0.00 & 0.00 & 0.00 & 0.00 \\
\hline GJ/m2/Day ENERGY (Lowest Year) & 0.003 & 0.003 & 0.003 & 0.002 & 0.002 & 0.003 & 0.003 & 0.003 & 0.002 & 0.002 & 0.002 & 0.003 \\
\hline $\mathrm{GJ} / \mathrm{m} 2 /$ Month (Lowest Consumption Year) & 0.097 & 0.087 & 0.087 & 0.072 & 0.071 & 0.086 & 0.089 & 0.093 & 0.064 & 0.061 & 0.073 & 0.098 \\
\hline Average Highest Year to Lowest Year & 0.218 & 0.194 & 0.208 & 0.187 & 0.191 & 0.196 & 0.202 & 0.204 & 0.180 & 0.180 & 0.183 & 0.207 \\
\hline BOMA Mean Value per Month & 0.111 & 0.111 & 0.111 & 0.111 & 0.111 & 0.111 & 0.111 & 0.111 & 0.111 & 0.111 & 0.111 & 0.111 \\
\hline Energy Usage per Month (Electricity + Gas) & 802 & 720 & 719 & 598 & 588 & 707 & 733 & 768 & 527 & 505 & 600 & 814 \\
\hline Degree Days & 647 & 740 & 547 & 356 & 159 & 116 & 109 & 146 & 84 & 158 & 463 & 611 \\
\hline Normalized Data (Average Degree Days) & 636 & 686 & 551 & 358 & 146 & 104 & 116 & 122 & 98 & 183 & 470 & 636 \\
\hline Normalized Data (Av Energy Consumption) & 1674 & 1684 & 1657 & 1620 & 1579 & 1571 & 1573 & 1574 & 1569 & 1586 & 1642 & 1674 \\
\hline Normalized Data (Av Energy Index / month) & 0.202 & 0.204 & 0.200 & 0.196 & 0.191 & 0.190 & 0.190 & 0.190 & 0.190 & 0.192 & 0.199 & 0.202 \\
\hline
\end{tabular}


Analysis on how electricity and gas consumption corresponds to heating and cooling periods (for highest energy consumption year):

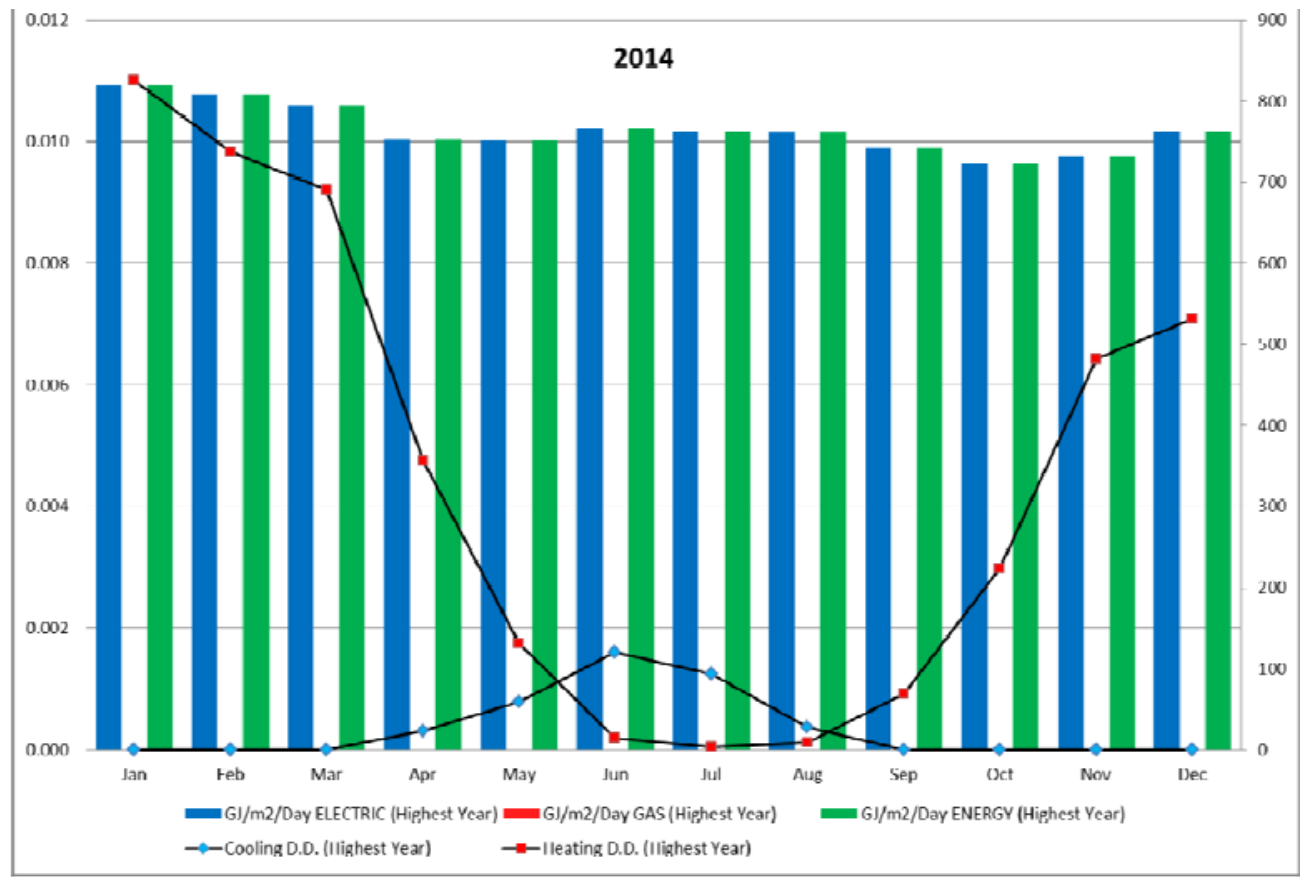

Analysis on how electricity and gas consumption corresponds to heating and cooling periods (for lowest energy consumption year):

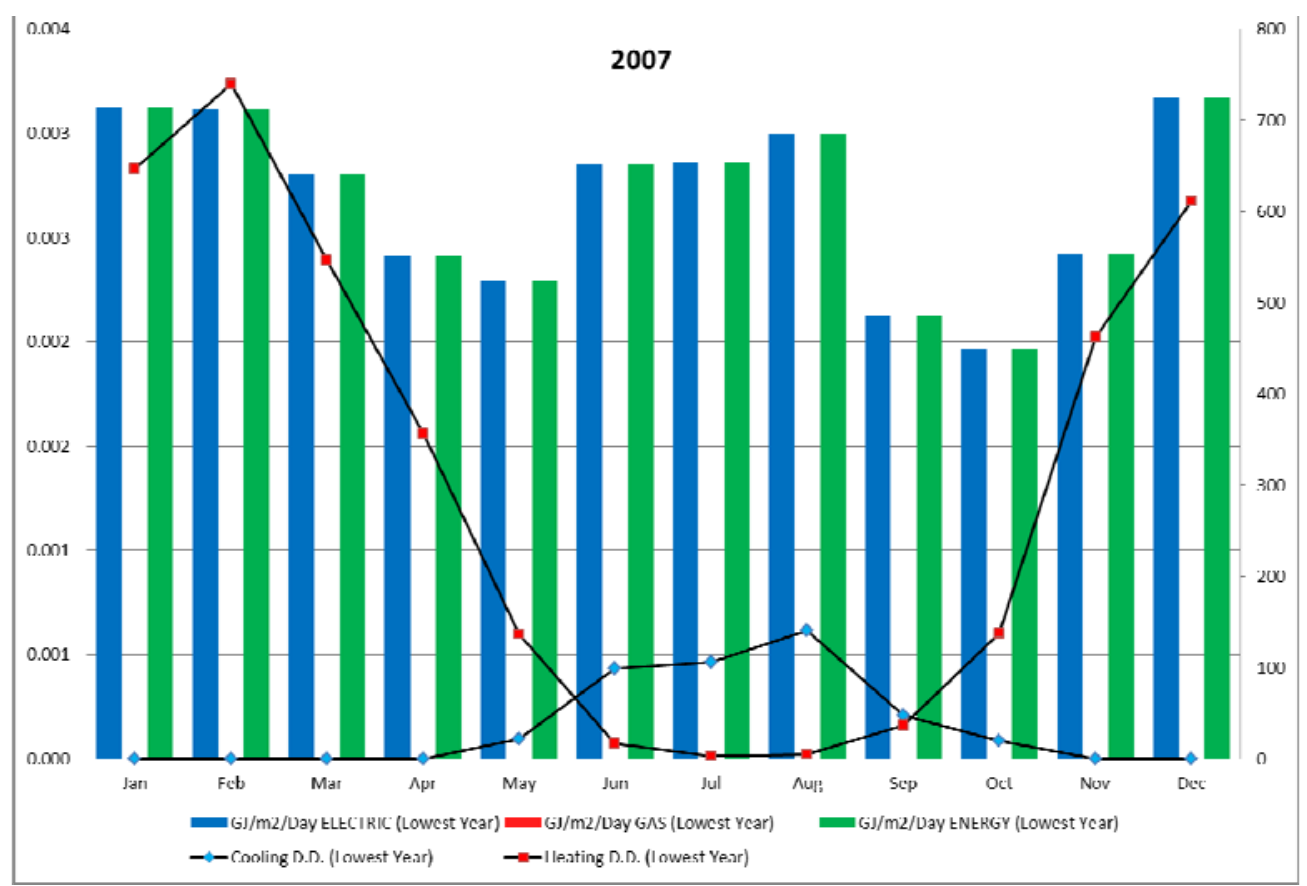


Monthly energy index comparison between highest energy consumption year, lowest, average and benchmark (BOMA) energy intensity:

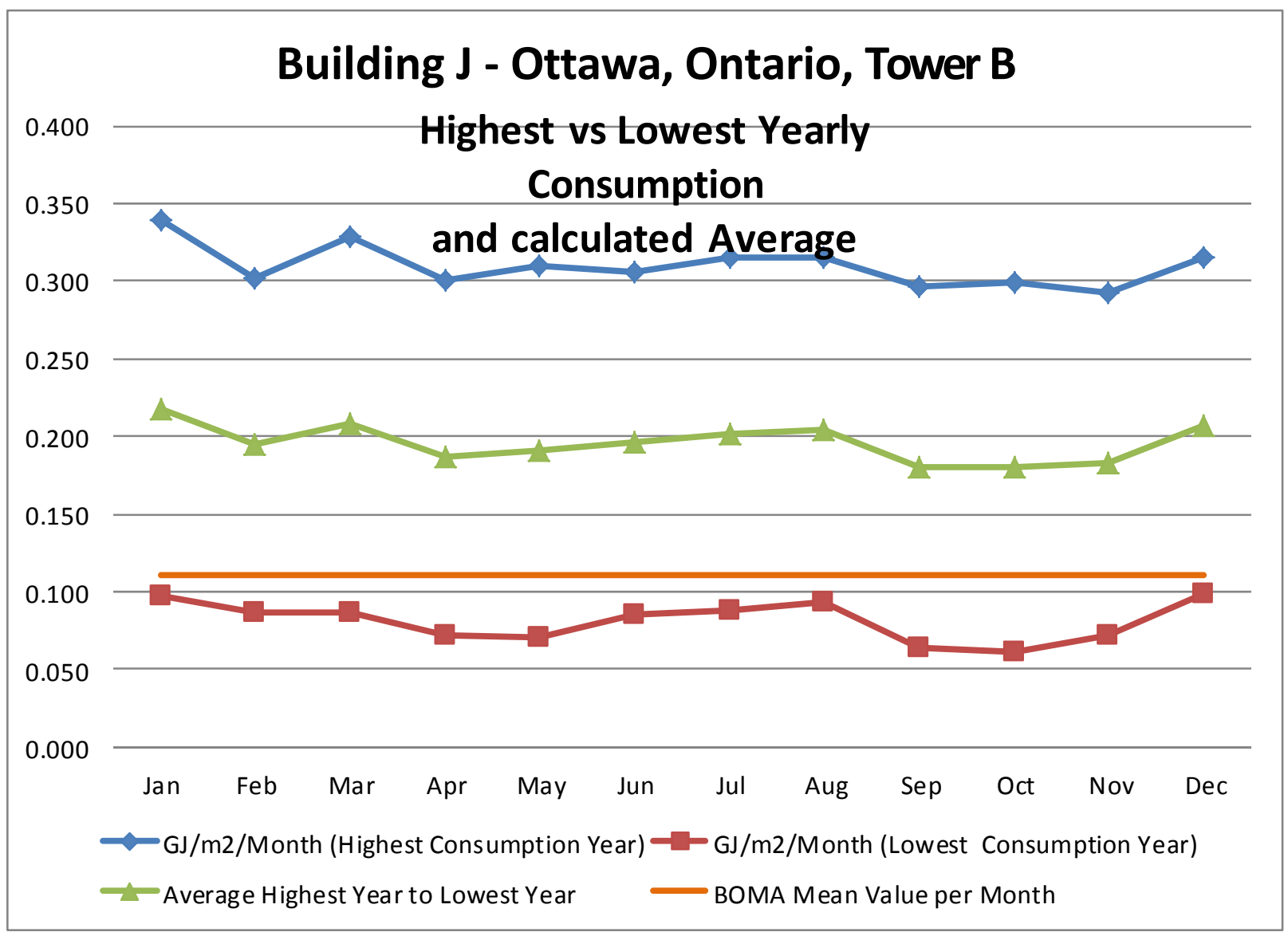


Building \#11 - Utility Bills Analysis

\section{Calculations of Energy Index for Building \#11}

Energy CAP database was utilized to collect energy consumption information for the building. Energy consumption was provided by utility bills for electricity only as gas is not used by this building. For Building \#1 utility bills were provided from December 2006 to March 2015. To complete most accurate analysis utility bills for 2007 to 2014 were only analyzed because 2006 and 2015 has incomplete data. By having total floor area for entire building of $6,162 \mathrm{~m}^{2}$, energy index in $\mathrm{GJ} / \mathrm{m}^{2} /$ year was calculated. From calculations it was noticed that utility bills provide consistent data for all years, therefore all data will be used for calculations.

Utility bills analysis showed following:

\begin{tabular}{|c|c|c|c|c|c|c|c|}
\hline \multicolumn{5}{|c|}{ Building K - Ottawa, Ontario, Tower A } & \multirow[b]{2}{*}{$m^{3}$-ngas } & \multirow[b]{2}{*}{ Total GJ/yr } & \multirow[b]{2}{*}{$6,162.00$} \\
\hline & & & kWh & & & & \\
\hline Row Labels & \multicolumn{2}{|c|}{$\begin{array}{c}\text { Sum of Ele Total } \\
\text { Cost / Year }\end{array}$} & $\begin{array}{c}\text { Sum of Ele } \\
\text { Consumption / } \\
\text { Year }\end{array}$ & $\begin{array}{c}\text { Sum of Gas Total } \\
\text { Cost / Year }\end{array}$ & $\begin{array}{c}\text { Sum of Gas } \\
\text { Consumption / } \\
\text { Year }\end{array}$ & Total & $\mathrm{GJ} / \mathrm{m} 2 / \mathrm{yr}$ \\
\hline Year 2006 & $\$$ & $41,343.23$ & $400,200.00$ & & & & \\
\hline Year 2007 & $\$$ & $206,296.95$ & $1,931,614.00$ & & & $6,953.81$ & 1.13 \\
\hline Year 2008 & $\$$ & $236,996.59$ & $2,151,971.49$ & & & $7,747.10$ & 1.26 \\
\hline Year 2009 & $\$$ & $200,639.58$ & $1,818,159.88$ & & & $6,545.38$ & 1.06 \\
\hline Year 2010 & $\$$ & $213,361.37$ & $1,884,751.63$ & & & $6,785.11$ & 1.10 \\
\hline Year 2011 & $\$$ & $222,630.28$ & $1,865,555.72$ & & & $6,716.00$ & 1.09 \\
\hline Year 2012 & $\$$ & $223,175.74$ & $1,748,425.41$ & & & $6,294.33$ & 1.02 \\
\hline Year 2013 & $\$$ & $213,226.93$ & $1,559,654.90$ & & & $5,614.76$ & 0.91 \\
\hline Year 2014 & $\$$ & $237,831.31$ & $1,662,740.74$ & & & $5,985.87$ & 0.97 \\
\hline Year 2015 & $\$$ & $72,022.73$ & $491,179.84$ & & & & \\
\hline Average & $\$$ & $219,269.84$ & $1,827,859.22$ & & & & 1.07 \\
\hline
\end{tabular}

As it was specified in energy audit, energy consumption of the Building \#11 is average in comparison to similar office buildings in same region; and therefore average energy index which equals to $1.07 \mathrm{GJ} / \mathrm{m}^{2} / \mathrm{yr}$ is also average in comparison to benchmark values of BOMA energy efficient building value of $1.05 \mathrm{GJ} / \mathrm{m}^{2} / \mathrm{yr}$, however value is much lower than average National Resources Canada value of $1.43 \mathrm{GJ} / \mathrm{m} 2 /$ year..

Electricity consumption chart below shows consumption per year; it doesn't demonstrate prominent increase or decrease in consumption, however recent years shows lower values therefore improvement. 


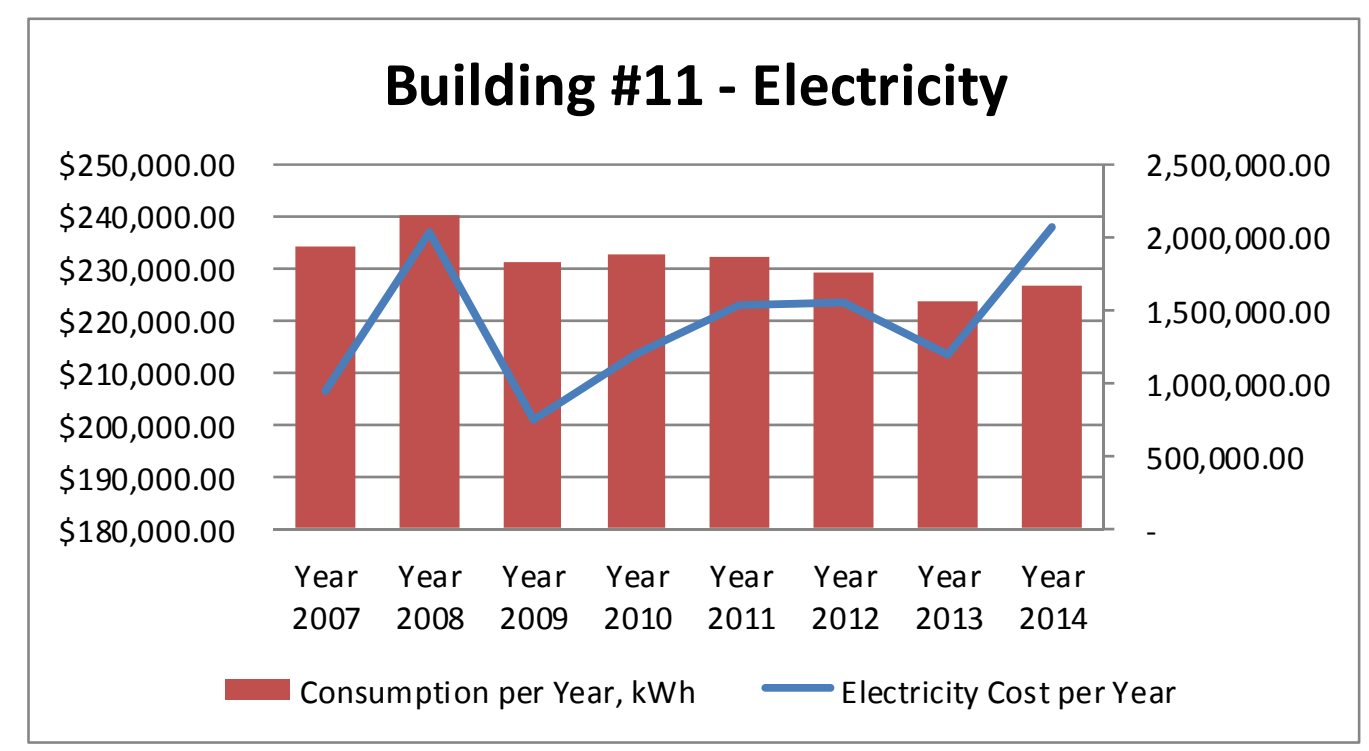

Yearly energy intensity (index) was also plotted to demonstrate increase or decrease over the range of years for which data is available. Chart below shows that energy index value is gradually decreasing and currently around $0.97 \mathrm{GJ} / \mathrm{m}^{2} / \mathrm{yr}$. The lowest energy index was in 2013 and highest in 2008 . These two years' data will be used for further calculations and comparisons.

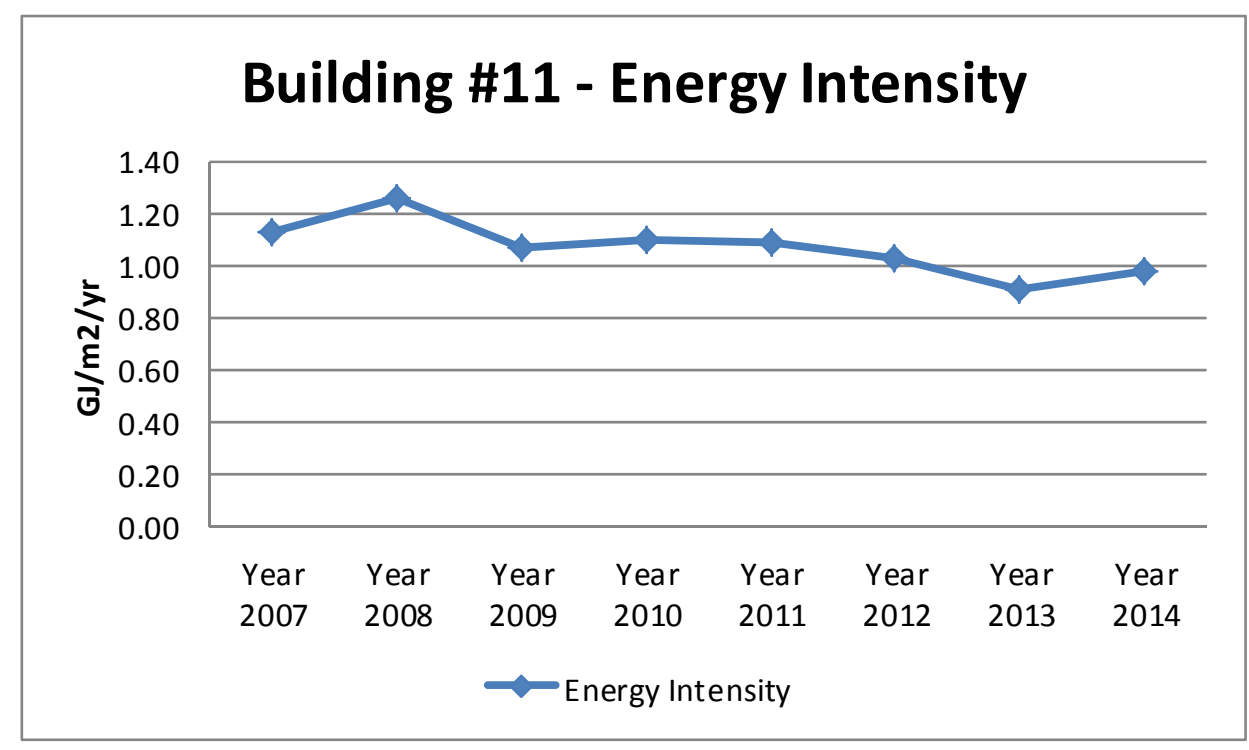

Normalized total energy consumption was calculated for Building \#11. Based on plotted results, shown below in the chart, it can be concluded that energy consumption for 2008 is higher than for 2013. This proves that regardless of weather conditions 2008 has higher energy consumptions than in 2013. Implementing trendline equations, average equation was calculated: 
From above equation normalized average energy index was calculated as $1.1 \mathrm{GJ} / \mathrm{m}^{2} / \mathrm{yr}$, this value is higher than average for 2007 to 2014 years range. Calculated value will be used for further case-study buildings comparison.

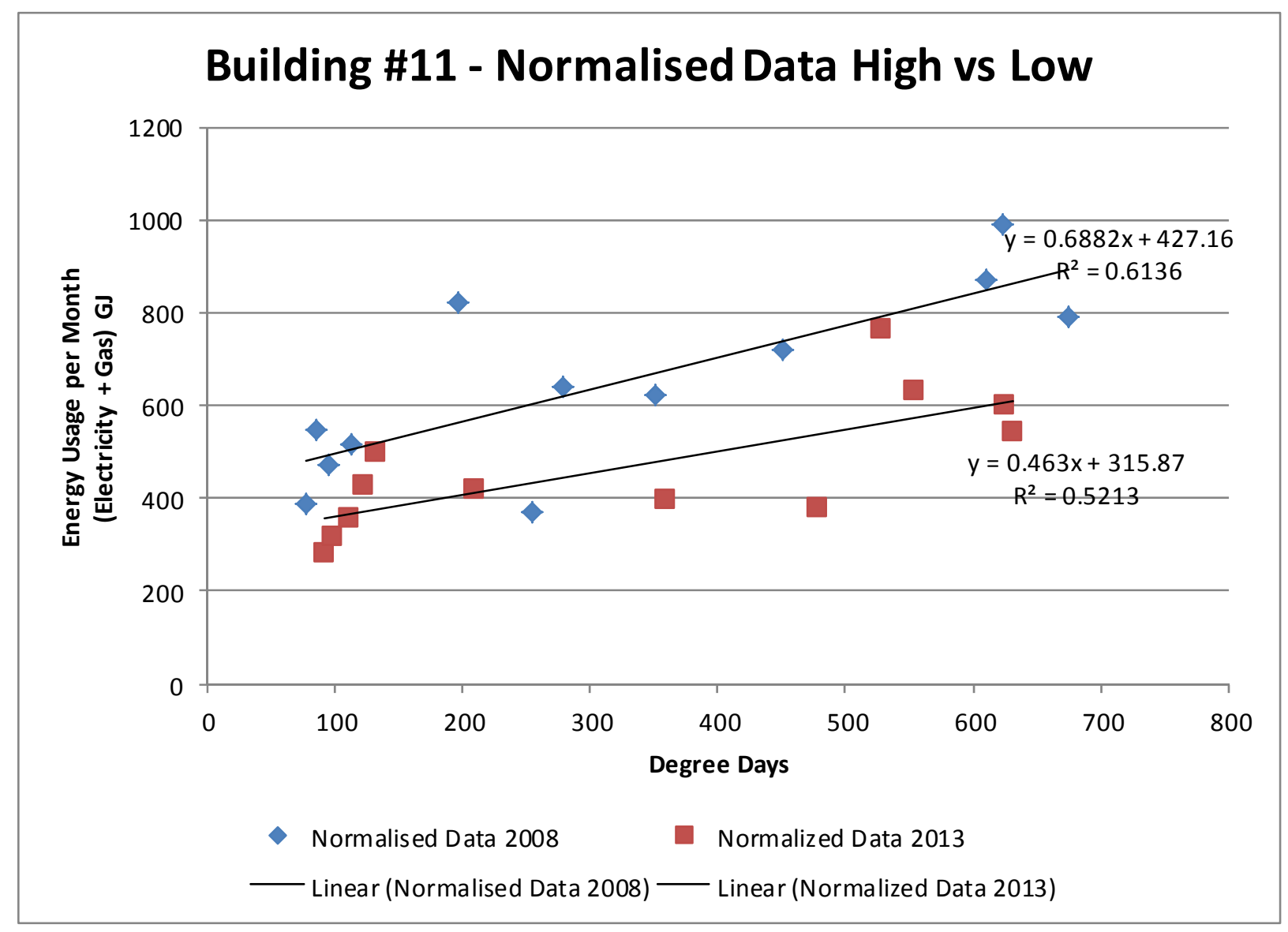


Actual data used for calculations (year with highest energy consumption):

\begin{tabular}{|c|c|c|c|c|c|c|c|c|c|c|c|c|}
\hline ADDRESS: & \multicolumn{4}{|c|}{ Building K - Ottawa, Ontario, Tower A } & & & & & & & & \\
\hline BUILDING\# & \multicolumn{4}{|c|}{11} & & & & & & & & \\
\hline Year - Highest Energy Consumption: & \multicolumn{4}{|l|}{2008} & & & & & & & & \\
\hline AREA: & \multicolumn{4}{|l|}{6,162} & & & & & & & & \\
\hline USAGE INDEX: & \multicolumn{4}{|l|}{1.26} & & & & & & & & \\
\hline Month & Jan & Feb & Mar & Apr & May & Jun & Jul & Aug & Sep & Oct & Nov & Dec \\
\hline \multirow{5}{*}{$\begin{array}{l}\text { Electric Billing Date } \\
\text { Electric Billing Days }\end{array}$} & $12 / 02 / 2008$ & $12 / 03 / 2008$ & $11 / 04 / 2008$ & $12 / 05 / 2008$ & $10 / 06 / 2008$ & $14 / 07 / 2008$ & $12 / 08 / 2008$ & 10/09/2008 & $09 / 10 / 2008$ & $12 / 11 / 2008$ & $12 / 12 / 2008$ & $12 / 01 / 2009$ \\
\hline & 31 & 29 & 30 & 31 & 29 & 34 & 29 & 29 & 29 & 34 & 30 & 31 \\
\hline & $12 / 02 / 2008$ & $12 / 03 / 2008$ & $11 / 04 / 2008$ & $12 / 05 / 2008$ & $10 / 06 / 2008$ & $14 / 07 / 2008$ & $12 / 08 / 2008$ & $10 / 09 / 2008$ & $09 / 10 / 2008$ & $12 / 11 / 2008$ & $12 / 12 / 2008$ & $12 / 01 / 2009$ \\
\hline & 31 & 29 & 30 & 31 & 29 & 34 & 29 & 29 & 29 & 34 & 30 & 31 \\
\hline \multirow{2}{*}{\multicolumn{13}{|c|}{ COOLING \& HEATING DEGREE DAYS }} \\
\hline & & & & & & & & & & & & \\
\hline \multirow{4}{*}{$\begin{array}{l}\text { Cooling D.D. (Highest Year) } \\
\text { Daily Clg D.D. Avg. (Highest Year) } \\
\text { Normal Cooling D.D. (Highest Year) }\end{array}$} & 0 & 0 & 0 & 0 & 3 & 72 & 111 & 64 & 27 & 0 & 0 & 0 \\
\hline & 0 & 0 & 0 & 0 & 0 & 2 & 4 & 2 & 1 & 0 & 0 & 0 \\
\hline & & & & & & & & & & & & \\
\hline & 624 & 675 & 610 & 254 & 194 & 23 & 1 & 13 & 59 & 279 & 452 & 352 \\
\hline \multirow{3}{*}{$\begin{array}{l}\text { Heating D.D. (Highest Year) } \\
\text { Daily Htg. D.D. Avg. (Highest Year) } \\
\text { Normal Heating D.D (Highest Year) }\end{array}$} & 20 & 23 & 20 & 8 & 7 & 1 & 0 & 0 & 2 & 8 & 15 & $\frac{11}{11}$ \\
\hline & & & & & & & & & & & & \\
\hline & & & & & & & & & & & & \\
\hline \multicolumn{13}{|l|}{ ELECTRICAL USAGE \& COST } \\
\hline \multirow{3}{*}{$\begin{array}{l}\text { kWh Used } \\
\text { Daily kWh Avg. }\end{array}$} & 274,953 & 219,826 & 241,264 & 102,826 & 227,732 & 131,626 & 142,877 & 107,626 & 152,045 & 178,066 & 199,922 & 173,206 \\
\hline & 8,869 & 7,580 & 8,042 & 3,317 & 7,853 & 3,871 & 4,927 & 3,711 & 5,243 & 5,237 & 6,664 & 5,587 \\
\hline & 408 & 408 & 41 & 389 & 332 & 314 & 327 & 350 & 357 & 339 & 408 & 386 \\
\hline \multirow[t]{2}{*}{ Load Factor (Highest Year) } & $91 \%$ & $77 \%$ & $821 \%$ & $35 \%$ & $86 \%$ & $51 \%$ & $63 \%$ & $44 \%$ & $61 \%$ & $64 \%$ & $68 \%$ & $60 \%$ \\
\hline & & & & & & & & & & & & \\
\hline \multicolumn{13}{|l|}{ NATURAL GAS USAGE \& COST } \\
\hline \multicolumn{13}{|l|}{ CCF } \\
\hline$m^{\wedge} 3$ Used & 0 & 0 & 0 & 0 & 0 & 0 & 0 & 0 & 0 & 0 & 0 & 0 \\
\hline \multirow{2}{*}{ Daily $\mathrm{m}^{\wedge} 3$ Avg. } & 0 & 0 & 0 & 0 & 0 & 0 & 0 & 0 & 0 & 0 & 0 & 0 \\
\hline & & & & & & & & & & & & \\
\hline \multicolumn{13}{|l|}{ GREENHOUSE DATA } \\
\hline \multirow{4}{*}{$\begin{array}{l}\text { CO2 (kgs) (Highest Year) } \\
\text { SO2 (kgs) (Highest Year) } \\
\text { NOx (kgs) (Highest Year) }\end{array}$} & 184,969 & 147,883 & 162,305 & 69,174 & 153,202 & 88,549 & 96,117 & 72,403 & 102,285 & 119,790 & 134,493 & 116,521 \\
\hline & 1,998 & 1,598 & 1,754 & 747 & 1,655 & 957 & 1,038 & 782 & 1,105 & 1,294 & 1,453 & 1,259 \\
\hline & 876 & 700 & 769 & 328 & 726 & 419 & 455 & 343 & 484 & 567 & 637 & 552 \\
\hline & & & & & & & & & & & & \\
\hline \multicolumn{13}{|l|}{ USAGE DATA } \\
\hline & 989.83 & 791.37 & 868.55 & 370.17 & 819.84 & 473.85 & 514.36 & 387.45 & 547.36 & 641.04 & 719.72 & 623.54 \\
\hline GJ/m2/Day ELECTRIC (Highest Year) & 0.005 & 0.004 & 0.005 & 0.002 & 0.005 & 0.002 & 0.003 & 0.002 & 0.003 & 0.003 & 0.004 & 0.003 \\
\hline $\mathrm{GJ} / \mathrm{m} 2 /$ Month (Highest Year) & 0.16 & 0.13 & 0.14 & 0.06 & 0.13 & 0.08 & 0.08 & 0.06 & 0.09 & 0.10 & 0.12 & 0.10 \\
\hline m3 to GJ & & & & & & & & & 000 & 000 & 0,00 & 800 \\
\hline $\begin{array}{l}\text { m3 to GJ } \\
\text { GJ/m2/Day GAS (Highest Year) }\end{array}$ & 0.000 & 0.000 & 0.000 & 0.00 & 0.00 & $\begin{array}{l}0.00 \\
0.000\end{array}$ & 0.00 & 0.00 & $\begin{array}{l}0.00 \\
0.000\end{array}$ & $\begin{array}{l}0.00 \\
0.000\end{array}$ & 0.000 & 0.00 \\
\hline $\mathrm{GJ} / \mathrm{m} 2 /$ Month & 0.00 & 0.00 & 0.00 & 0.00 & 0.00 & 0.00 & 0.00 & 0.00 & 0.00 & 0.00 & 0.00 & 0.00 \\
\hline $\mathrm{m} 3 / \mathrm{m} 2 /$ Month & 0.00 & 0.00 & 0.00 & 0.00 & 0.00 & 0.00 & 0.00 & 0.00 & 0.00 & 0.00 & 0.00 & 0.00 \\
\hline GJ/m2/Day ENERGY (Highest Year) & 0.005 & 0.004 & 0.005 & 0.002 & 0.005 & 0.002 & 0.003 & 0.002 & 0.003 & 0.003 & 0.004 & 0.003 \\
\hline $\mathrm{GJ} / \mathrm{m} 2 /$ Month (Highest Consumption Year) & 0.161 & 0.128 & 0.141 & 0.060 & 0.133 & 0.077 & 0.083 & 0.063 & 0.089 & 0.104 & 0.117 & 0.101 \\
\hline Energy Usage per Month (Electricity + Gas) & 990 & 791 & 869 & 370 & 820 & 474 & 514 & 387 & 547 & 641 & 720 & 624 \\
\hline Degree Days & 624 & 675 & 610 & 254 & 196 & 94 & 112 & 77 & 86 & 279 & 452 & 352 \\
\hline
\end{tabular}




\section{Actual data used for calculations (year with lowest energy consumption):}

\begin{tabular}{|c|c|c|c|c|c|c|c|c|c|c|c|c|}
\hline ADDRESS: & \multicolumn{4}{|c|}{ Building K - Ottawa, Ontario, Tower A } & & & & & & & & \\
\hline BUILDING\# & \multicolumn{4}{|c|}{11} & & & & & & & & \\
\hline Year - Lowest Energy Consumption: & \multicolumn{4}{|l|}{2013} & & & & & & & & \\
\hline AREA: & \multicolumn{4}{|l|}{6,162} & & & & & & & & \\
\hline \multicolumn{13}{|l|}{ USAGE INDEX: } \\
\hline Month & Jan & Feb & Mar & Apr & May & Jun & Jul & Aug & Sep & Oct & Nov & Dec \\
\hline \multirow{4}{*}{$\begin{array}{l}\text { Electric Billing Date } \\
\text { Electric Billing Days }\end{array}$} & $31 / 01 / 2013$ & $28 / 02 / 2013$ & $03 / 04 / 2013$ & $01 / 05 / 2013$ & $02 / 06 / 2013$ & $03 / 07 / 2013$ & $01 / 08 / 2013$ & $03 / 09 / 2013$ & $01 / 10 / 2013$ & $30 / 10 / 2013$ & $27 / 11 / 2013$ & $29 / 12 / 2013$ \\
\hline & 31 & 28 & 34 & 28 & 32 & 31 & 29 & 33 & 28 & 29 & 28 & 32 \\
\hline & $31 / 01 / 2013$ & $28 / 02 / 2013$ & $03 / 04 / 2013$ & $01 / 05 / 2013$ & $02 / 06 / 2013$ & $03 / 07 / 2013$ & $01 / 08 / 2013$ & $03 / 09 / 2013$ & $01 / 10 / 2013$ & $30 / 10 / 2013$ & $27 / 11 / 2013$ & $29 / 12 / 2013$ \\
\hline & 31 & 28 & 34 & 28 & 32 & 31 & 29 & 33 & 28 & 29 & 28 & 32 \\
\hline \multicolumn{13}{|l|}{ COOLING \& HEATING DEGREE DAYS } \\
\hline & & & & & & & & & & & & \\
\hline Cooling D.D. (Lowest Year) & 0 & 0 & 0 & 0 & 23 & 59 & 121 & 94 & 28 & 0 & 0 & 0 \\
\hline \multirow{3}{*}{$\begin{array}{l}\text { Daily Clg D.D. Avg. (Lowest Year) } \\
\text { Normal Cooling D.D. (Lowest Year) }\end{array}$} & 0 & 0 & 0 & 0 & 1 & 2 & 4 & 3 & 1 & 0 & 0 & 0 \\
\hline & & & & & & & & & & & & \\
\hline & 624 & 632 & 555 & 359 & 109 & 33 & 1 & 4 & 83 & 209 & 478 & 528 \\
\hline \multirow{3}{*}{$\begin{array}{l}\text { Heating D.D. (Lowest Year) } \\
\text { Daily Htg. D.D. Avg. (Lowest Year) } \\
\text { Normal Heating D.D (Lowest Year) }\end{array}$} & 20 & 23 & 16 & 13 & 3 & 1 & 0 & 0 & 3 & 7 & 17 & 16 \\
\hline & & & & & & & & & & & & \\
\hline \multirow{2}{*}{\multicolumn{13}{|c|}{ ELECTRICAL USAGE \& COST }} \\
\hline & & & & & & & & & & & & \\
\hline \multirow[t]{2}{*}{ Daily kWh Avg. } & $\begin{array}{c}166,426 \\
5,369\end{array}$ & $\begin{array}{c}150,226 \\
5,365\end{array}$ & 5,163 & 3,930 & 4,347 & 2,523 & 4,084 & 2,661 & 3,542 & 4,031 & $\begin{array}{c}105,826 \\
3,780\end{array}$ & $\begin{array}{l}21,918 \\
6,622\end{array}$ \\
\hline & & & & & & & & & & & & \\
\hline \multirow{3}{*}{$\begin{array}{l}\text { Demand kW/RkVA Used } \\
\text { Load Factor (Lowest Year) }\end{array}$} & 349 & 333 & 373 & 308 & 343 & 242 & 347 & 245 & 283 & 289 & 301 & 380 \\
\hline & $64 \%$ & $67 \%$ & $58 \%$ & $53 \%$ & $53 \%$ & $43 \%$ & $49 \%$ & $45 \%$ & $52 \%$ & $58 \%$ & $52 \%$ & $73 \%$ \\
\hline & & & & & & & & & & & & \\
\hline \multicolumn{13}{|l|}{ NATURAL GAS USAGE \& COST } \\
\hline \multicolumn{13}{|l|}{ CCF } \\
\hline $\mathrm{m}^{\wedge} 3$ Used & 0 & 0 & 0 & 0 & 0 & 0 & 0 & 0 & 0 & 0 & 0 & 0 \\
\hline \multirow[t]{2}{*}{ Daily $\mathrm{m}^{\wedge} 3$ Avg. } & 0 & 0 & 0 & 0 & 0 & 0 & 0 & 0 & 0 & 0 & 0 & 0 \\
\hline & & & & & & & & & & & & \\
\hline \multicolumn{13}{|l|}{ GREENHOUSE DATA } \\
\hline \multirow{4}{*}{$\begin{array}{l}\text { CO2 (kgs) (Lowest Year) } \\
\text { S02 (kgs) (Lowest Year) } \\
\text { NOx (kgs) (Lowest Year) }\end{array}$} & 1111,960 & \begin{tabular}{l|l}
101,061 \\
\end{tabular} & $\begin{array}{ll}118,098 \\
\end{array}$ & 74,018 & 93,585 & $\overline{52,625}$ & 799,681 & 59,083 & 666,724 & 78,633 & 71,192 & \begin{tabular}{c|}
142,563 \\
\end{tabular} \\
\hline & 1,210 & 1,092 & 1,276 & 800 & 1,011 & 569 & 861 & 638 & 721 & 850 & 769 & 1,540 \\
\hline & 530 & 479 & 559 & 351 & 443 & 249 & 377 & 280 & 316 & 372 & 337 & 675 \\
\hline & & & & & & & & & & & & \\
\hline $\mathrm{kWh}$ to $\mathrm{GJ}$ & 599.13 & 540.81 & 631.98 & 396.09 & 500.81 & 281.61 & 426.40 & 316.17 & 357.07 & 420.79 & 380.97 & 762.90 \\
\hline GJ/m2/Day ELECTRIC (Lowest Year) & 0.003 & 0.003 & 0.003 & 0.002 & 0.003 & 0.001 & 0.002 & 0.002 & 0.002 & 0.002 & 0.002 & 0.004 \\
\hline $\mathrm{GJ} / \mathrm{m} 2 /$ Month (Lowest Year) & 0.10 & 0.09 & 0.10 & 0.06 & 0.08 & 0.05 & 0.07 & 0.05 & 0.06 & 0.07 & 0.06 & 0.12 \\
\hline & & & & & & & & & & & & \\
\hline $\mathrm{m} 3$ to GJ & 0.00 & 0.00 & 0.00 & 0.00 & 0.00 & 0.00 & 0.00 & 0.00 & 0.00 & 0.00 & 0.00 & 0.00 \\
\hline $\mathrm{GJ} / \mathrm{m} 2 /$ Day GAS (Lowest Year) & 0.000 & 0.000 & 0.000 & 0.000 & 0.000 & 0.000 & 0.000 & 0.000 & 0.000 & 0.000 & 0.000 & 0.000 \\
\hline $\mathrm{GJ} / \mathrm{m} 2 /$ Month & 0.00 & 0.00 & 0.00 & 0.00 & 0.00 & 0.00 & 0.00 & 0.00 & 0.00 & 0.00 & 0.00 & 0.00 \\
\hline $\mathrm{m} 3 / \mathrm{m} 2 /$ Month & 0.00 & 0.00 & 0.00 & 0.00 & 0.00 & 0.00 & 0.00 & 0.00 & 0.00 & 0.00 & 0.00 & 0.00 \\
\hline GJ/m2/Day ENERGY (Lowest Year) & 0.003 & 0.003 & 0.003 & 0.002 & 0.003 & 0.001 & 0.002 & 0.002 & 0.002 & 0.002 & 0.002 & 0.004 \\
\hline $\mathrm{GJ} / \mathrm{m} 2 /$ Month (Lowest Consumption Year) & 0.097 & 0.088 & 0.103 & 0.064 & 0.081 & 0.046 & 0.069 & 0.051 & 0.058 & 0.068 & 0.062 & 0.124 \\
\hline Average Highest Year to Lowest Year & 0.129 & 0.108 & 0.122 & 0.062 & 0.107 & 0.061 & 0.076 & 0.057 & 0.073 & 0.086 & 0.089 & 0.112 \\
\hline BOMA Mean Value per Month & 0.111 & 0.111 & 0.111 & 0.111 & 0.111 & 0.111 & 0.111 & 0.111 & 0.111 & 0.111 & 0.111 & 0.111 \\
\hline Energy Usage per Month (Electricity + Gas) & 599 & 541 & 632 & 396 & 501 & 282 & 426 & 316 & 357 & 421 & 381 & 763 \\
\hline Degree Days & 624 & 632 & 555 & 359 & 132 & 92 & 122 & 98 & 111 & 209 & 478 & 528 \\
\hline Normalized Data (Average Degree Days) & 624 & 632 & 555 & 359 & 132 & 92 & 122 & 98 & 111 & 209 & 478 & 594 \\
\hline Normalized Data (Av Energy Consumption) & 731 & 735 & 691 & 578 & 448 & 425 & 442 & 428 & 435 & 492 & 647 & 714 \\
\hline Normalized Data (Av Energy Index / month) & 0.119 & 0.119 & 0.112 & 0.094 & 0.073 & 0.069 & 0.072 & 0.069 & 0.071 & 0.080 & 0.105 & 0.116 \\
\hline
\end{tabular}


Analysis on how electricity and gas consumption corresponds to heating and cooling periods (for highest energy consumption year):

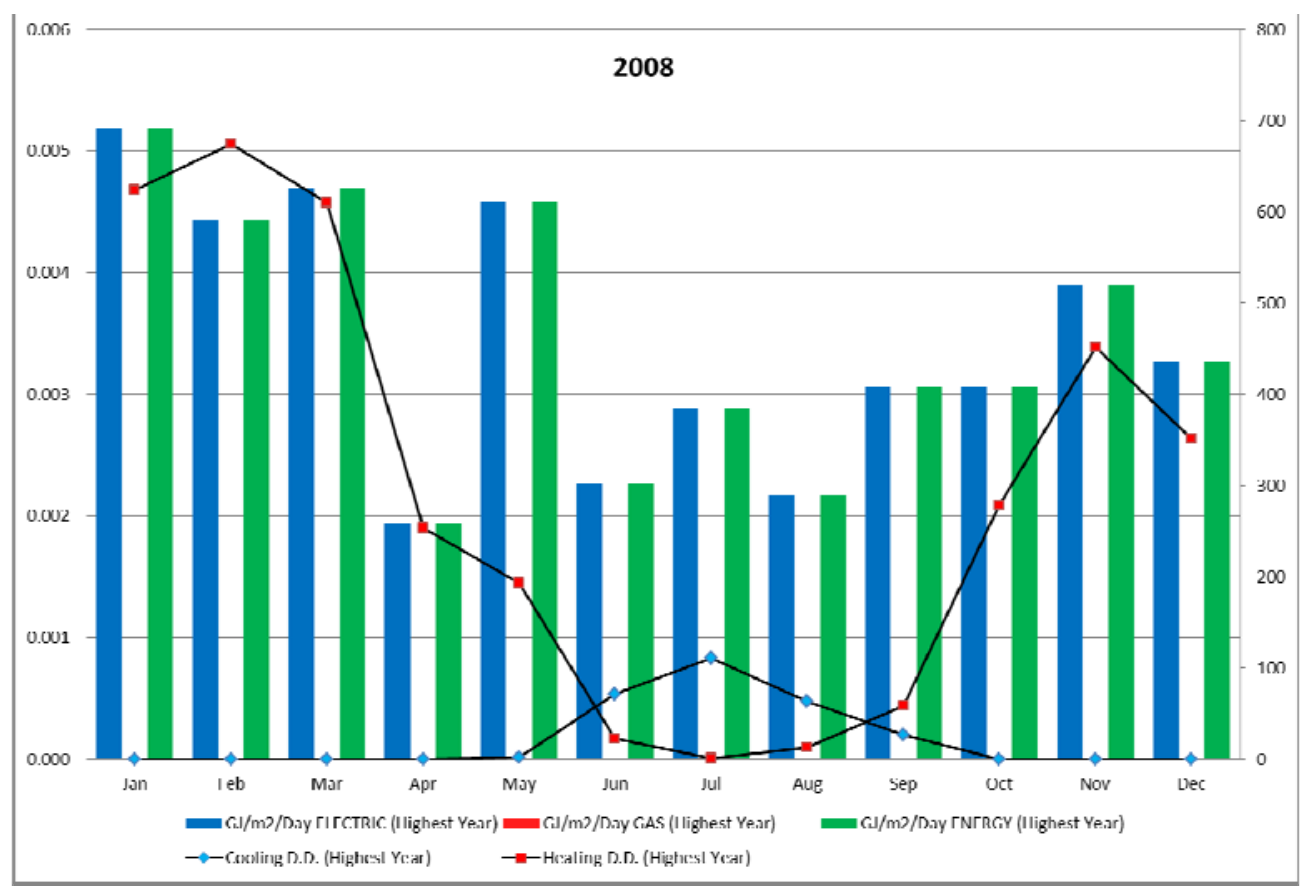

Analysis on how electricity and gas consumption corresponds to heating and cooling periods (for lowest energy consumption year):

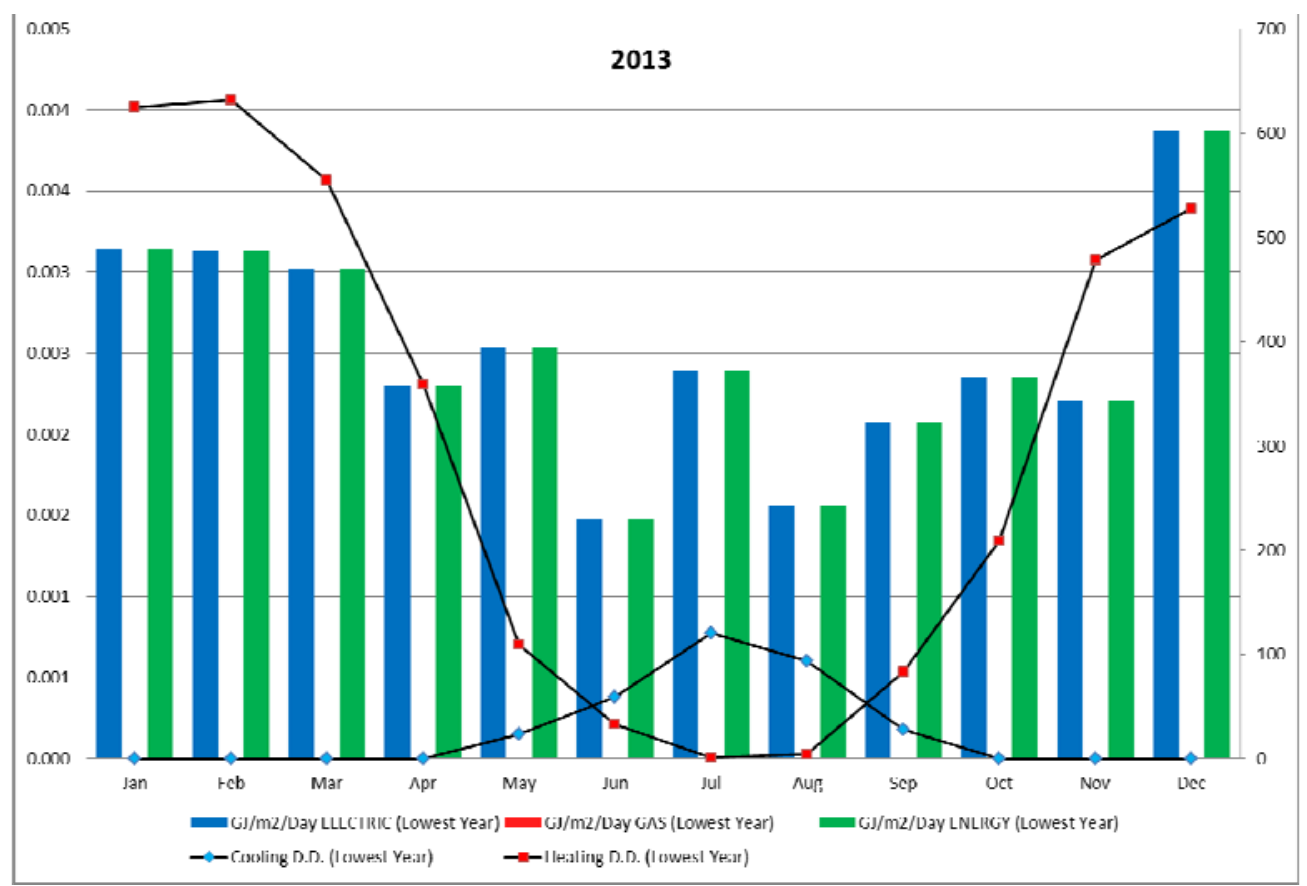


Monthly energy index comparison between highest energy consumption year, lowest, average and benchmark (BOMA) energy intensity:

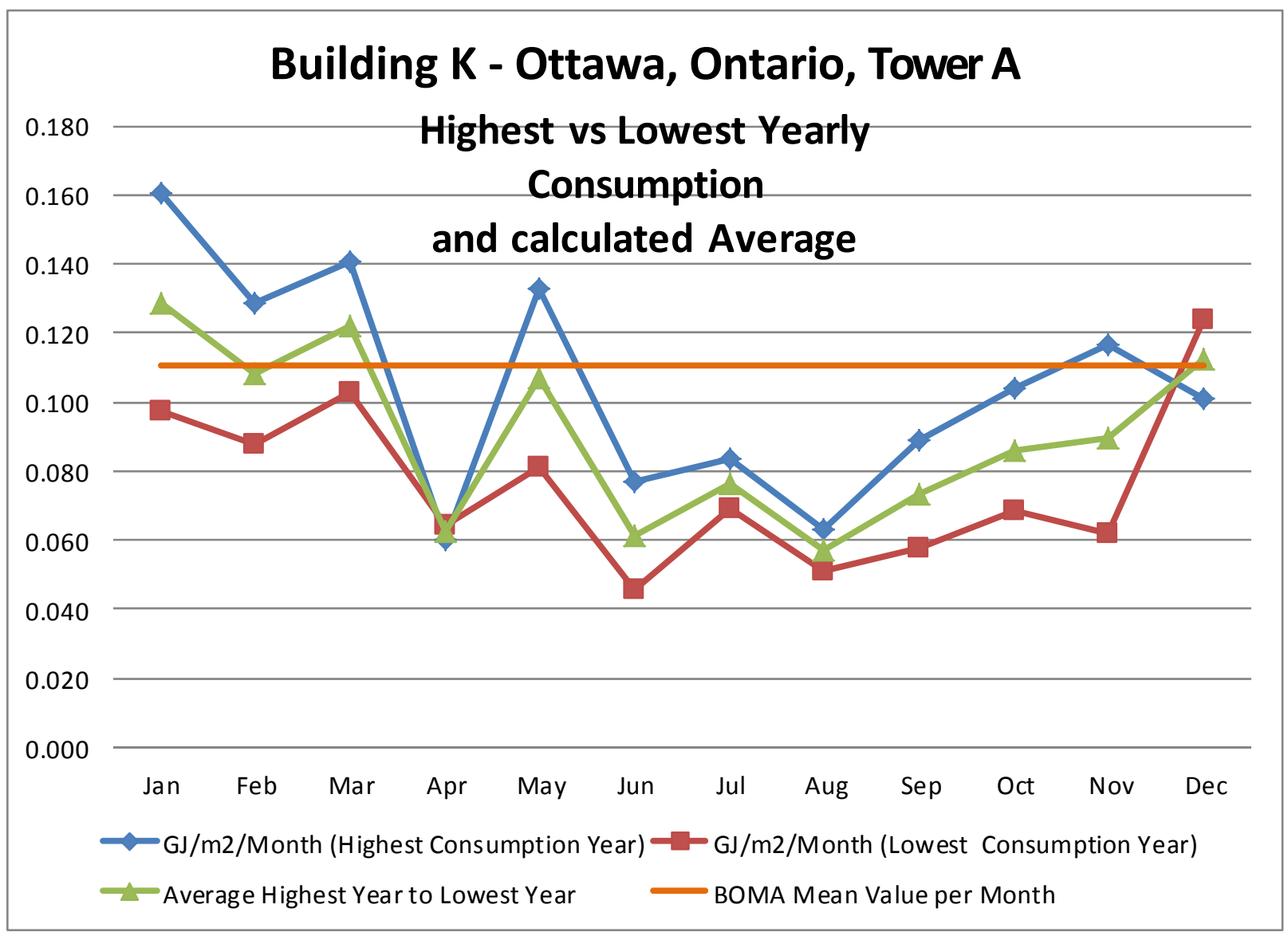


Building \#12 - Utility Bills Analysis

\section{Calculations of Energy Index for Building \#12}

Energy CAP database was utilized to collect energy consumption information for the building. Energy consumption was provided by utility bills for electricity and gas. For Building \#12 utility bills were provided from December 1997 to March 2015. To complete most accurate analysis utility bills for 1998 to 2014 were only analyzed because 1997 and 2015 has incomplete data. By having total floor area for entire building of $3,518 \mathrm{~m}^{2}$, energy index in $\mathrm{GJ} / \mathrm{m}^{2} /$ year was calculated. From calculations it was noticed that 2006 provides not consistent values in comparison with the rest of years, therefore for calculations of average yearly energy index 2006 year was excluded.

Utility bills analysis showed following:

\section{Building L - Montreal, Quebec}

\begin{tabular}{|c|c|c|c|c|c|c|c|c|}
\hline & & & kWh & & & $\mathrm{m}^{3}$-ngas & Total GJ/yr & $3,518.00$ \\
\hline Row Labels & \multicolumn{2}{|c|}{$\begin{array}{c}\text { Sum of Ele Total } \\
\text { Cost / Year }\end{array}$} & $\begin{array}{c}\text { Sum of Ele } \\
\text { Consumption / } \\
\text { Year }\end{array}$ & \multicolumn{2}{|c|}{$\begin{array}{c}\text { Sum of Gas Total } \\
\text { Cost / Year }\end{array}$} & $\begin{array}{c}\text { Sum of Gas } \\
\text { Consumption / } \\
\text { Year }\end{array}$ & Total & $\mathrm{GJ} / \mathrm{m} 2 / \mathrm{yr}$ \\
\hline Year 1995 & $\$$ & $46,473.15$ & $554,160.00$ & & & & & \\
\hline Year 1996 & $\$$ & $56,060.55$ & $710,400.00$ & & & & & \\
\hline Year 1997 & $\$$ & $61,111.64$ & $732,720.00$ & & & & & \\
\hline Year 1998 & $\$$ & $52,212.19$ & $606,000.00$ & $\$$ & $6,655.83$ & $18,059.00$ & $2,853.39$ & 0.81 \\
\hline Year 1999 & $\$$ & $53,234.50$ & $607,680.00$ & $\$$ & $4,222.68$ & $9,920.00$ & $2,556.67$ & 0.73 \\
\hline Year 2000 & $\$$ & $56,552.05$ & $654,000.00$ & $\$$ & $9,641.38$ & $18,495.00$ & $3,042.41$ & 0.86 \\
\hline Year 2001 & $\$$ & $61,806.31$ & $758,160.00$ & $\$$ & $9,798.80$ & $17,112.00$ & $3,365.94$ & 0.96 \\
\hline Year 2002 & $\$$ & $66,099.08$ & $771,360.00$ & $\$$ & $6,687.77$ & $12,296.00$ & $3,234.31$ & 0.92 \\
\hline Year 2003 & $\$$ & $60,045.15$ & $745,440.00$ & $\$$ & $19,456.55$ & $33,708.00$ & $3,937.52$ & 1.12 \\
\hline Year 2004 & $\$$ & $53,977.00$ & $646,560.00$ & $\$$ & $13,964.67$ & $23,521.00$ & $3,202.60$ & 0.91 \\
\hline Year 2005 & $\$$ & $56,554.34$ & $658,320.00$ & $\$$ & $6,914.06$ & $10,084.00$ & $2,745.08$ & 0.78 \\
\hline Year 2006 & $\$$ & $56,086.20$ & $651,360.00$ & $\$$ & $7,696.09$ & $69,246.00$ & $4,920.85$ & 1.40 \\
\hline Year 2007 & $\$$ & $65,142.11$ & $748,320.00$ & $\$$ & $6,967.83$ & $11,391.00$ & $3,117.70$ & 0.89 \\
\hline Year 2008 & $\$$ & $67,890.95$ & $767,760.00$ & $\$$ & $5,373.33$ & $8,004.00$ & $3,061.68$ & 0.87 \\
\hline Year 2009 & $\$$ & $71,817.92$ & $820,800.00$ & $\$$ & $5,314.92$ & $8,245.00$ & $3,261.59$ & 0.93 \\
\hline Year 2010 & $\$$ & $61,971.36$ & $717,600.00$ & $\$$ & $5,079.91$ & $8,234.00$ & $2,889.66$ & 0.82 \\
\hline Year 2011 & $\$$ & $74,183.86$ & $852,240.00$ & $\$$ & $12,102.73$ & $22,108.00$ & $3,890.48$ & 1.11 \\
\hline Year 2012 & $\$$ & $77,733.42$ & $906,240.00$ & $\$$ & $8,703.32$ & $16,058.00$ & $3,859.82$ & 1.10 \\
\hline Year 2013 & $\$$ & $72,736.92$ & $817,440.00$ & $\$$ & $5,750.34$ & $10,018.00$ & $3,315.45$ & 0.94 \\
\hline Year 2014 & $\$$ & $67,502.19$ & $754,560.00$ & $\$$ & $4,695.00$ & $7,356.00$ & 2,990.06 & 0.85 \\
\hline Year 2015 & $\$$ & $26,258.72$ & $299,040.00$ & $\$$ & $2,799.50$ & $4,676.00$ & $1,250.49$ & 0.36 \\
\hline Average & $\$$ & $63,716.21$ & $739,530.00$ & $\$$ & $8,208.07$ & $14,663.06$ & & 0.91 \\
\hline
\end{tabular}


As it was specified in energy audit, energy consumption of the Building \#12 is relatively low in comparison to similar office buildings in same region; and therefore average energy index which equals to $0.91 \mathrm{GJ} / \mathrm{m}^{2} / \mathrm{yr}$ is also high in comparison to benchmark values of BOMA energy efficient building value of $1.05 \mathrm{GJ} / \mathrm{m}^{2} / \mathrm{yr}$, however value is much lower than average National Resources Canada value of $1.43 \mathrm{GJ} / \mathrm{m} 2 /$ year.

Two charts below show electricity and gas consumption per year. Electricity consumption chart demonstrates prominent increase in energy usage. However gas consumption chart shows decrease in usage. As has been mentioned earlier 2006 shows very inconsistent gas consumption, energy bills for this year were analysed in details and showed that in November 2011 gas consumption was 60,347 m3-ngas. Utility bill didn't provide details on why such a high amount of gas consumption occurred; therefore whole 2006 year data was excluded from calculations.
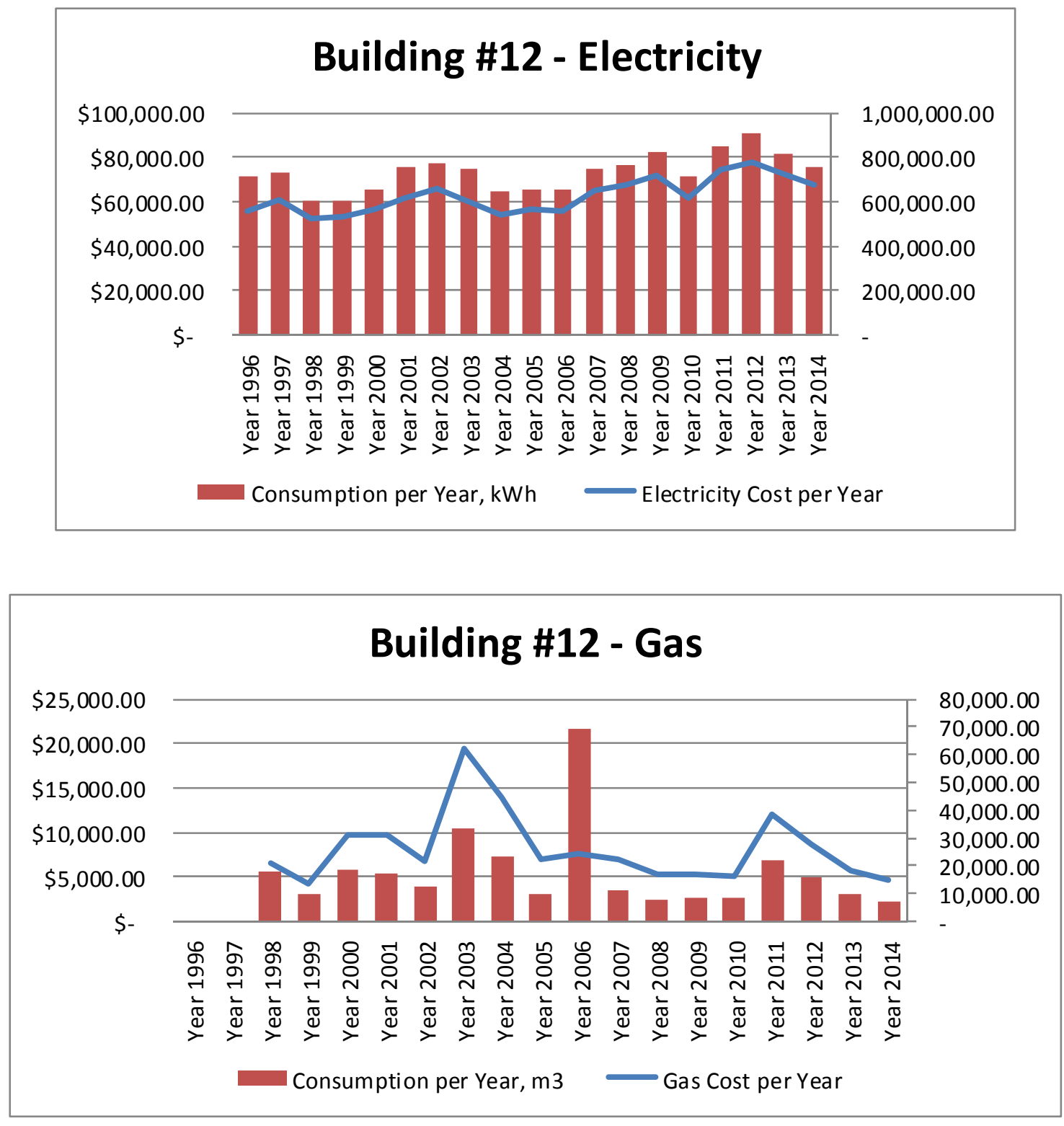
Yearly energy intensity (index) was also plotted to demonstrate increase or decrease over the range of years for which data is available. Chart below shows that energy index value is gradually decreasing excluding high jump in 2006. The lowest energy index was in 1999 and highest in 2003, but 2005 and 2003 were used for further calculations and comparisons, to work with more recent data.

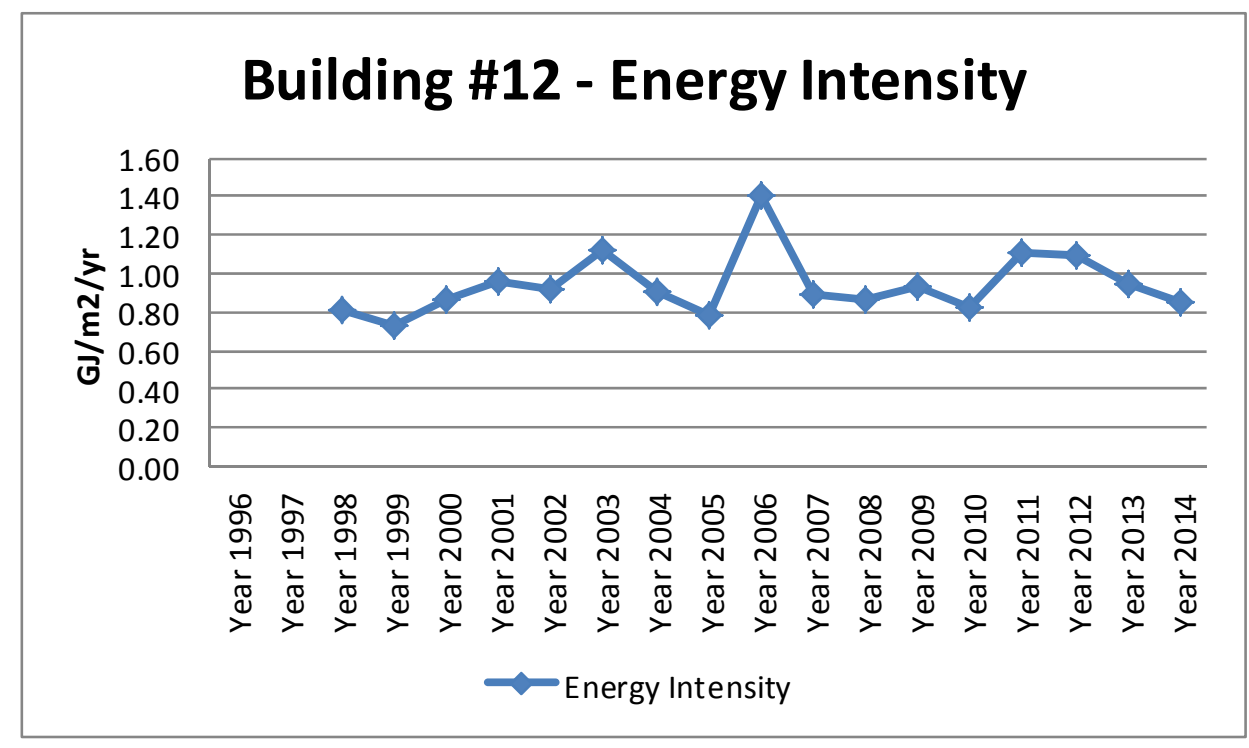

Normalized total energy consumption was calculated for Building \#12. Based on plotted results, shown below in the chart, it can be concluded that energy consumption for 2003 is higher than for 2005 . This proves that regardless of weather conditions 2003 has higher energy consumptions than in 2005. Implementing trendline equations, average equation was calculated:

$\gamma=0.3584 x+150.09$

From above equation normalized average energy index was calculated as $0.94 \mathrm{GJ} / \mathrm{m}^{2} / \mathrm{yr}$, this value is moderately higher than average for 1999 to 2014 years range. Calculated value will be used for further casestudy buildings comparison. 


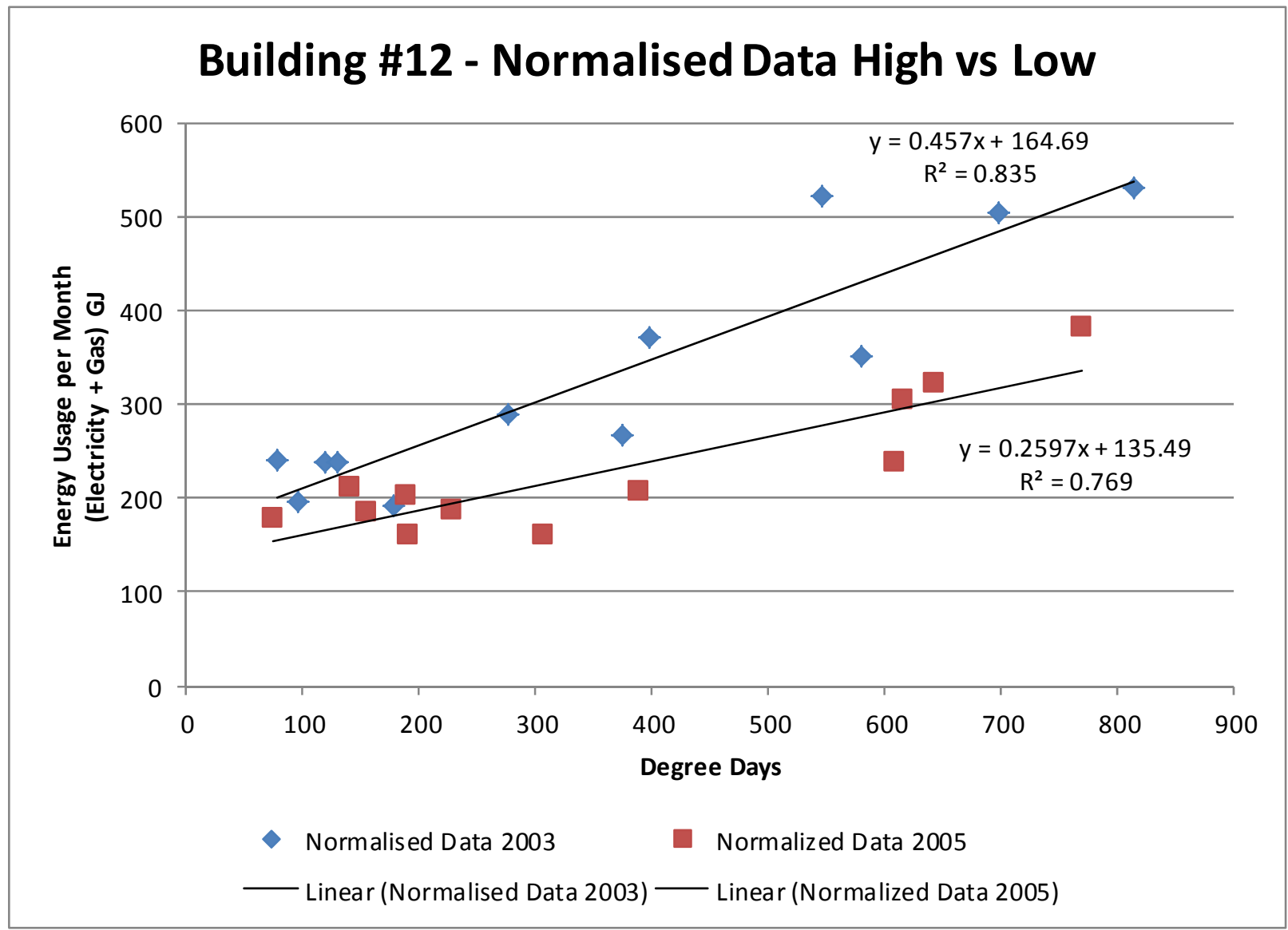


Actual data used for calculations (year with highest energy consumption):

\begin{tabular}{|c|c|c|c|c|c|c|c|c|c|c|c|c|}
\hline ADDRESS: & \multicolumn{4}{|c|}{ Building L - Montreal, Quebec } & & & & & & & & \\
\hline BUILDING\# & \multicolumn{4}{|c|}{12} & & & & & & & & \\
\hline Year - Highest Energy Consumption: & \multicolumn{4}{|l|}{2003} & & & & & & & & \\
\hline AREA: & \multicolumn{4}{|l|}{3,518} & & & & & & & & \\
\hline USAGE INDEX: & \multicolumn{4}{|l|}{1.12} & & & & & & & & \\
\hline Month & Jan & Feb & Mar & Apr & May & Jun & Jul & Aug & Sep & Oct & Nov & Dec \\
\hline \multirow{5}{*}{$\begin{array}{l}\text { Electric Billing Date } \\
\text { Electric Billing Days }\end{array}$} & $31 / 01 / 2003$ & $28 / 02 / 2003$ & $31 / 03 / 2003$ & $30 / 04 / 2003$ & $31 / 05 / 2003$ & $30 / 06 / 2003$ & $31 / 07 / 2003$ & $31 / 08 / 2003$ & $30 / 09 / 2003$ & $31 / 10 / 2003$ & $30 / 11 / 2003$ & $31 / 12 / 2003$ \\
\hline & 31 & 28 & 31 & 30 & 31 & 30 & 31 & 31 & 30 & 31 & 30 & 31 \\
\hline & $14 / 02 / 2003$ & $17 / 03 / 2003$ & $14 / 04 / 2003$ & $16 / 05 / 2003$ & $16 / 06 / 2003$ & $18 / 07 / 2003$ & $16 / 08 / 2003$ & $18 / 09 / 2003$ & $17 / 10 / 2003$ & $15 / 11 / 2003$ & $13 / 12 / 2003$ & $17 / 01 / 2004$ \\
\hline & 31 & 31 & 28 & 32 & 31 & 32 & 29 & 33 & 29 & 29 & 28 & 35 \\
\hline & & & & & & & & & & & & \\
\hline \multicolumn{13}{|l|}{ COOLING \& HEATING DEGREE DAYS } \\
\hline \multirow{4}{*}{$\begin{array}{l}\text { Cooling D.D. (Highest Year) } \\
\text { Daily Clg D.D. Avg. (Highest Year) } \\
\text { Normal Cooling D.D. (Highest Year) }\end{array}$} & 0 & 0 & 0 & 2 & 0 & 53 & 118 & 128 & 24 & 0 & 0 & 0 \\
\hline & 0 & 0 & 0 & 0 & 0 & 2 & 4 & 4 & 1 & 0 & 0 & 0 \\
\hline & & & & & & & & & & & & \\
\hline & 815 & 699 & 581 & 373 & 178 & 43 & 0 & 2 & 55 & 276 & 399 & 546 \\
\hline \multirow{3}{*}{$\begin{array}{l}\text { Heating D.D. (Highest Year) } \\
\text { Daily Htg. D.D. Avg. (Highest Year) } \\
\text { Normal Heating D.D (Highest Year) }\end{array}$} & 26 & 23 & 21 & 12 & 6 & 1 & 0 & 0 & 2 & 10 & 14 & 16 \\
\hline & & & & & & & & & & & & \\
\hline & & & & & & & & & & & & \\
\hline \multicolumn{13}{|l|}{ ELECTRICAL USAGE \& COST } \\
\hline \multirow{3}{*}{$\begin{array}{l}\text { kWh Used } \\
\text { Daily kWh Avg. }\end{array}$} & 84,720 & 70,800 & 67,920 & 60,720 & 52,080 & 54,240 & 66,240 & 66,000 & 61,200 & 52,080 & 50,400 & 59,040 \\
\hline & 2,733 & 2,284 & 2,426 & 1,898 & 1,680 & 1,695 & 2,284 & 2,000 & 2,110 & 1,796 & 1,800 & 1,687 \\
\hline & & & & & & & & & & & & \\
\hline \multirow[b]{2}{*}{ Load Factor (Highest Year) } & 220 & 194 & 162 & 154 & 142 & 167 & 164 & 167 & 158 & 134 & 119 & 135 \\
\hline & $52 \%$ & $54 \%$ & $57 \%$ & $55 \%$ & $49 \%$ & $45 \%$ & $54 \%$ & $53 \%$ & $54 \%$ & $52 \%$ & $59 \%$ & $59 \%$ \\
\hline \multicolumn{13}{|l|}{ NATURAL GAS USAGE \& COST } \\
\hline \multicolumn{13}{|l|}{ CCF } \\
\hline$m^{\wedge} 3$ Used & 6,049 & 6,686 & 2,851 & 1,274 & 115 & 0 & 3 & 8 & 560 & 2,754 & 5,090 & 8,318 \\
\hline \multirow{2}{*}{ Daily $\mathrm{m}^{\wedge} 3$ Avg. } & 195 & 216 & 102 & 40 & 4 & 0 & 0 & 0 & 19 & 95 & 182 & 238 \\
\hline & & & & & & & & & & & & \\
\hline \multicolumn{13}{|l|}{ GREENHOUSE DATA } \\
\hline \multirow{4}{*}{$\begin{array}{l}\text { CO2 (kgs) (Highest Year) } \\
\text { SO2 (kgs) (Highest Year) } \\
\text { NOx (kgs) (Highest Year) }\end{array}$} & 99,803 & 94,947 & 65,868 & 49,864 & 35,850 & 36,489 & 44,583 & 44,457 & 45,134 & 54,526 & 69,928 & 98,585 \\
\hline & 1,078 & 1,026 & 712 & 539 & 387 & 394 & 482 & 480 & 488 & 589 & 756 & 1,065 \\
\hline & 473 & 450 & 312 & 236 & 170 & 173 & 211 & 211 & 214 & 258 & 331 & 467 \\
\hline & & & & & & & & & & & & \\
\hline \multicolumn{13}{|l|}{ USAGE DATA } \\
\hline & 304.99 & 254.88 & 244.51 & 218.59 & 187.49 & 195.26 & 238.46 & 237.60 & 220.32 & 187.49 & 181.44 & 212.54 \\
\hline GJ/m2/Day ELECTRIC (Highest Year) & 0.003 & 0.003 & 0.002 & 0.002 & 0.002 & 0.002 & 0.002 & 0.002 & 0.002 & 0.002 & 0.002 & 0.002 \\
\hline $\mathrm{GJ} / \mathrm{m} 2 /$ Month (Highest Year) & 0.09 & 0.07 & 0.07 & 0.06 & 0.05 & 0.06 & 0.07 & 0.07 & 0.06 & 0.05 & 0.05 & 0.06 \\
\hline m3 to GJ & 225.02 & 248.72 & 106.06 & 47.39 & 4.28 & 0.00 & 0.11 & 0.30 & 20.83 & 102.45 & 189.35 & 309.43 \\
\hline GJ/m2/Day GAS (Highest Year) & 0.002 & 0.002 & 0.001 & 0.000 & 0.000 & 0.000 & 0.000 & 0.000 & 0.000 & 0.001 & 0.002 & 0.003 \\
\hline $\mathrm{GJ} / \mathrm{m} 2 /$ Month & 0.06 & 0.07 & 0.03 & 0.01 & 0.00 & 0.00 & 0.00 & 0.00 & 0.01 & 0.03 & 0.05 & 0.09 \\
\hline $\mathrm{m} 3 / \mathrm{m} 2 /$ Month & 1.72 & 1.90 & 0.81 & 0.36 & 0.03 & 0.00 & 0.00 & 0.00 & 0.16 & 0.78 & 1.45 & 2.36 \\
\hline GJ/m2/Day ENERGY (Highest Year) & 0.005 & 0.005 & 0.003 & 0.002 & 0.002 & 0.002 & 0.002 & 0.002 & 0.002 & 0.003 & 0.004 & 0.004 \\
\hline $\mathrm{GJ} / \mathrm{m} 2 /$ Month (Highest Consumption Year) & 0.151 & 0.143 & 0.100 & 0.076 & 0.055 & 0.056 & 0.068 & 0.068 & 0.069 & 0.082 & 0.105 & 0.148 \\
\hline Energy Usage per Month (Electricity + Gas) & 530 & 504 & 351 & 266 & 192 & 195 & 239 & 238 & 241 & 290 & 371 & 522 \\
\hline Degree Days & 815 & 699 & 581 & 375 & 178 & 96 & 119 & 130 & 79 & 276 & 399 & 546 \\
\hline
\end{tabular}




\section{Actual data used for calculations (year with lowest energy consumption):}

\begin{tabular}{|c|c|c|c|c|c|c|c|c|c|c|c|c|}
\hline ADDRESS: & \multicolumn{4}{|c|}{ Building L - Montreal, Quebec } & & & & & & & & \\
\hline BUILDING \# & \multicolumn{4}{|c|}{12} & & & & & & & & \\
\hline Year - Lowest Energy Consumption: & \multicolumn{4}{|l|}{2005} & & & & & & & & \\
\hline AREA: & \multicolumn{4}{|l|}{3,518} & & & & & & & & \\
\hline USAGE INDEX: & 0.78 & AVERAGE: & 0.9498 & 0.93894 & & & & & & & & \\
\hline Month & Jan & Feb & Mar & Apr & May & Jun & Jul & Aug & Sep & Oct & Nov & Dec \\
\hline \multirow{5}{*}{$\begin{array}{l}\text { Electric Billing Date } \\
\text { Electric Billing Days }\end{array}$} & $31 / 01 / 2005$ & $28 / 02 / 2005$ & $31 / 03 / 2005$ & $30 / 04 / 2005$ & $31 / 05 / 2005$ & $30 / 06 / 2005$ & $31 / 07 / 2005$ & $31 / 08 / 2005$ & $30 / 09 / 2005$ & $31 / 10 / 2005$ & $30 / 11 / 2005$ & $31 / 12 / 2005$ \\
\hline & 31 & 28 & 31 & 30 & 31 & 30 & 31 & 31 & 30 & 31 & 30 & 31 \\
\hline & $14 / 02 / 2005$ & $14 / 03 / 2005$ & $13 / 04 / 2005$ & $13 / 05 / 2005$ & $14 / 06 / 2005$ & $15 / 07 / 2005$ & $15 / 08 / 2005$ & $14 / 09 / 2005$ & $14 / 10 / 2005$ & $15 / 11 / 2005$ & $13 / 12 / 2005$ & $18 / 01 / 2006$ \\
\hline & 31 & 28 & 30 & 30 & 32 & 31 & 31 & 30 & 30 & 32 & 28 & 36 \\
\hline & \multicolumn{12}{|c|}{ COOLING \& HEATING DEGREE DAYS } \\
\hline & & & & & & & & & & & & \\
\hline \multirow{3}{*}{$\begin{array}{l}\text { Cooling D.D. (Lowest Year) } \\
\text { Daily Clg D.D. Avg. (Lowest Year) } \\
\text { Normal Cooling D.D. (Lowest Year) }\end{array}$} & 0 & 0 & 0 & 0 & 1 & 146 & 189 & 141 & 52 & 8 & 0 & 0 \\
\hline & 0 & 0 & 0 & 0 & 0 & 5 & 6 & 5 & 2 & 0 & 0 & 0 \\
\hline & & & & & & & & & & & & \\
\hline \multirow{4}{*}{$\begin{array}{l}\text { Heating D.D. (Lowest Year) } \\
\text { Daily Htg. D.D. Avg. (Lowest Year) } \\
\text { Normal Heating D.D (Lowest Year) }\end{array}$} & 770 & 616 & 609 & 307 & 189 & 9 & 0 & 0 & 23 & 220 & 388 & 643 \\
\hline & 25 & 22 & 20 & 10 & 6 & 0 & 0 & 0 & 1 & 7 & 14 & 18 \\
\hline & & & & & & & & & & & & \\
\hline & & & & & & & & & & & & \\
\hline \multicolumn{13}{|l|}{ ELECTRICAL USAGE \& COST } \\
\hline kWh Used & 81,840 & 61,200 & 57,600 & 44,400 & 44,880 & 51,360 & 56,640 & 59,040 & 49,440 & 44,880 & 44,880 & 62,160 \\
\hline \multirow[t]{2}{*}{ Daily kWh Avg. } & 2,640 & 2,186 & 1,920 & 1,480 & 1,403 & 1,657 & 1,827 & 1,968 & 1,648 & 1,403 & 1,603 & 1,727 \\
\hline & & & & & & & & & & & & \\
\hline \multirow{3}{*}{$\begin{array}{l}\text { Demand kW/RkVA Used } \\
\text { Load Factor (Lowest Year) }\end{array}$} & 185 & 164 & 160 & 129 & 117 & 132 & 137 & 141 & 133 & 136 & 135 & 160 \\
\hline & $60 \%$ & $56 \%$ & $49 \%$ & $48 \%$ & $52 \%$ & $54 \%$ & $55 \%$ & $56 \%$ & $52 \%$ & $44 \%$ & $46 \%$ & $52 \%$ \\
\hline & & & & & & & & & & & & \\
\hline \multicolumn{13}{|l|}{ NATURAL GAS USAGE \& COST } \\
\hline \multicolumn{13}{|l|}{ CCF } \\
\hline $\mathrm{m}^{\wedge} 3$ Used & 2,338 & 2,285 & 854 & 0 & 2 & 0 & 0 & 0 & 0 & 702 & 1,245 & 2,658 \\
\hline \multirow[t]{2}{*}{ Daily $\mathrm{m}^{\wedge} 3$ Avg. } & 75 & 82 & 28 & 0 & 0 & 0 & 0 & 0 & 0 & 22 & 44 & 74 \\
\hline & & & & & & & & & & & & \\
\hline GREENHOUSE DATA & & & & & & & & & & & & \\
\hline "C02 (kgs) (Lowest Year) & 71,602 & 57,342 & 44,793 & 29,869 & 30,206 & 34,551 & 38,103 & 39,718 & 33,260 & 35,160 & 39,003 & 60,628 \\
\hline S02 (kgs) (Lowest Year) & 774 & 620 & 484 & 323 & 326 & 373 & 412 & 429 & 359 & 380 & 421 & 655 \\
\hline NOx (kgs) (Lowest Year) & 339 & 272 & 212 & 141 & 143 & 164 & 180 & 188 & 158 & 167 & 185 & 287 \\
\hline USAGE DATA & & & & & & & & & & & & \\
\hline kWh to GJ & 294.62 & 220.32 & 207.36 & 159.84 & 161.57 & 184.90 & 203.90 & 212.54 & 177.98 & 161.57 & 161.57 & 223.78 \\
\hline $\mathrm{GJ} / \mathrm{m} 2 /$ Day ELECTRIC (Lowest Year) & 0.003 & 0.002 & 0.002 & 0.002 & 0.001 & 0.002 & 0.002 & 0.002 & 0.002 & 0.001 & 0.002 & 0.002 \\
\hline $\mathrm{GJ} / \mathrm{m} 2 /$ Month (Lowest Year) & 0.08 & 0.06 & 0.06 & 0.05 & 0.05 & 0.05 & 0.06 & 0.06 & 0.05 & 0.05 & 0.05 & 0.06 \\
\hline & & & & & & & & & & & & \\
\hline $\mathrm{m} 3$ to GJ & 86.97 & 85.00 & 31.77 & 0.00 & 0.07 & 0.00 & 0.00 & 0.00 & 0.00 & 26.11 & 46.31 & 98.88 \\
\hline $\mathrm{GJ} / \mathrm{m} 2 /$ Day GAS (Lowest Year) & 0.001 & 0.001 & 0.000 & 0.000 & 0.000 & 0.000 & 0.000 & 0.000 & 0.000 & 0.000 & 0.000 & 0.001 \\
\hline $\mathrm{GJ} / \mathrm{m} 2 /$ Month & 0.02 & 0.02 & 0.01 & 0.00 & 0.00 & 0.00 & 0.00 & 0.00 & 0.00 & 0.01 & 0.01 & 0.03 \\
\hline $\mathrm{m} 3 / \mathrm{m} 2 /$ Month & 0.66 & 0.65 & 0.24 & 0.00 & 0.00 & 0.00 & 0.00 & 0.00 & 0.00 & 0.20 & 0.35 & 0.76 \\
\hline GJ/m2/Day ENERGY (Lowest Year) & 0.003 & 0.003 & 0.002 & 0.002 & 0.001 & 0.002 & 0.002 & 0.002 & 0.002 & 0.002 & 0.002 & 0.003 \\
\hline $\mathrm{GJ} / \mathrm{m} 2 /$ Month (Lowest Consumption Year) & 0.108 & 0.087 & 0.068 & 0.045 & 0.046 & 0.053 & 0.058 & 0.060 & 0.051 & 0.053 & 0.059 & 0.092 \\
\hline Average Highest Year to Lowest Year & 0.130 & 0.115 & 0.084 & 0.061 & 0.050 & 0.054 & 0.063 & 0.064 & 0.060 & 0.068 & 0.082 & 0.120 \\
\hline BOMA Mean Value per Month & 0.111 & 0.111 & 0.111 & 0.111 & 0.111 & 0.111 & 0.111 & 0.111 & 0.111 & 0.111 & 0.111 & 0.111 \\
\hline Energy Usage per Month (Electricity + Gas) & 382 & 305 & 239 & 160 & 162 & 185 & 204 & 213 & 178 & 188 & 208 & 323 \\
\hline Degree Days & 770 & 616 & 609 & 307 & 190 & 155 & 189 & 141 & 75 & 228 & 388 & 643 \\
\hline Normalized Data (Average Degree Days) & 697 & 624 & 582 & 333 & 161 & 124 & 155 & 120 & 93 & 218 & 433 & 652 \\
\hline Normalized Data (Av Energy Consumption) & 400 & 374 & 359 & 269 & 208 & 194 & 206 & 193 & 183 & 228 & 305 & 384 \\
\hline Normalized Data (Av Energy Index / month) & 0.114 & 0.106 & 0.102 & 0.077 & 0.059 & 0.055 & 0.058 & 0.055 & 0.052 & 0.065 & 0.087 & 0.109 \\
\hline
\end{tabular}


Analysis on how electricity and gas consumption corresponds to heating and cooling periods (for highest energy consumption year):

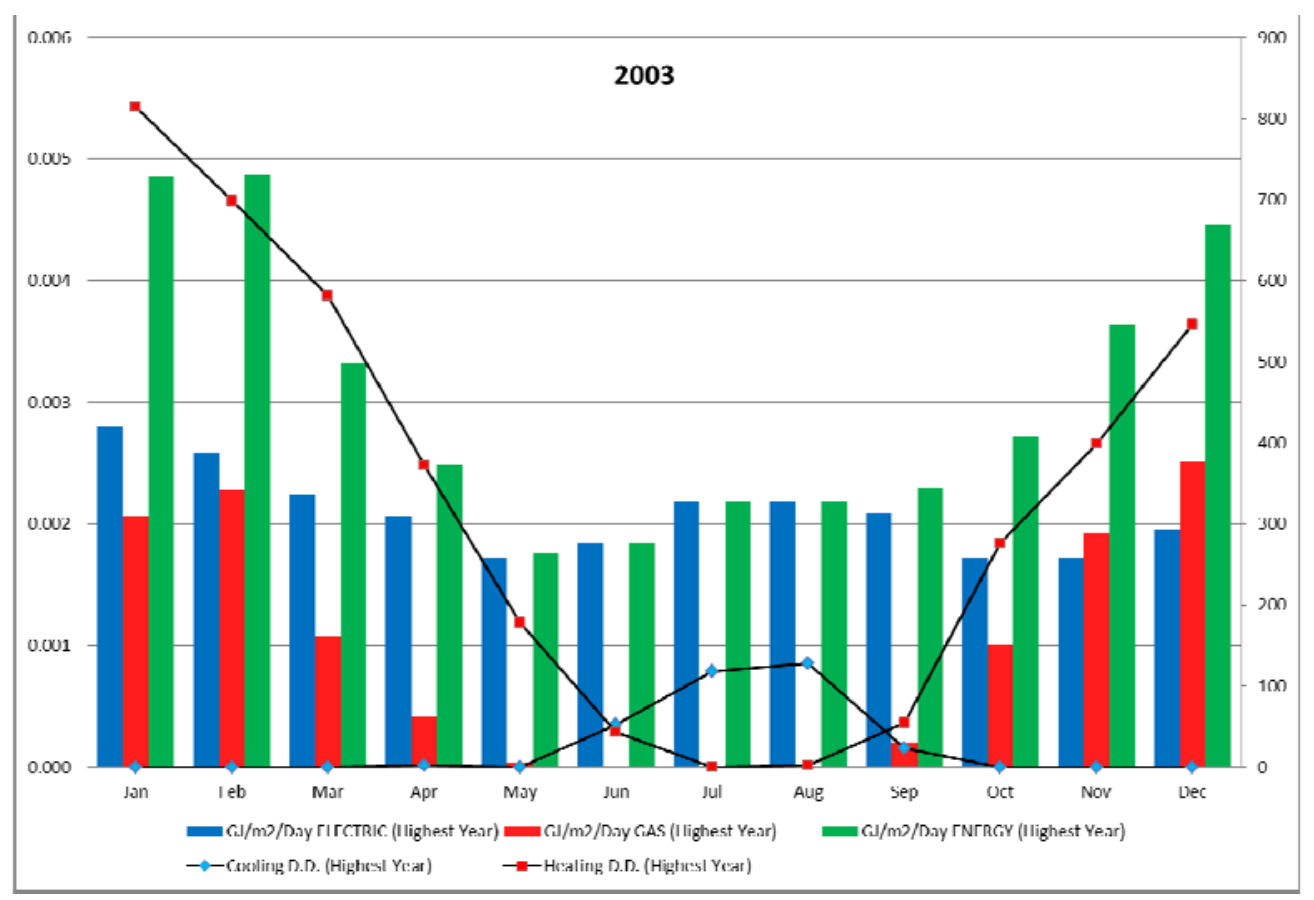

Analysis on how electricity and gas consumption corresponds to heating and cooling periods (for lowest energy consumption year):

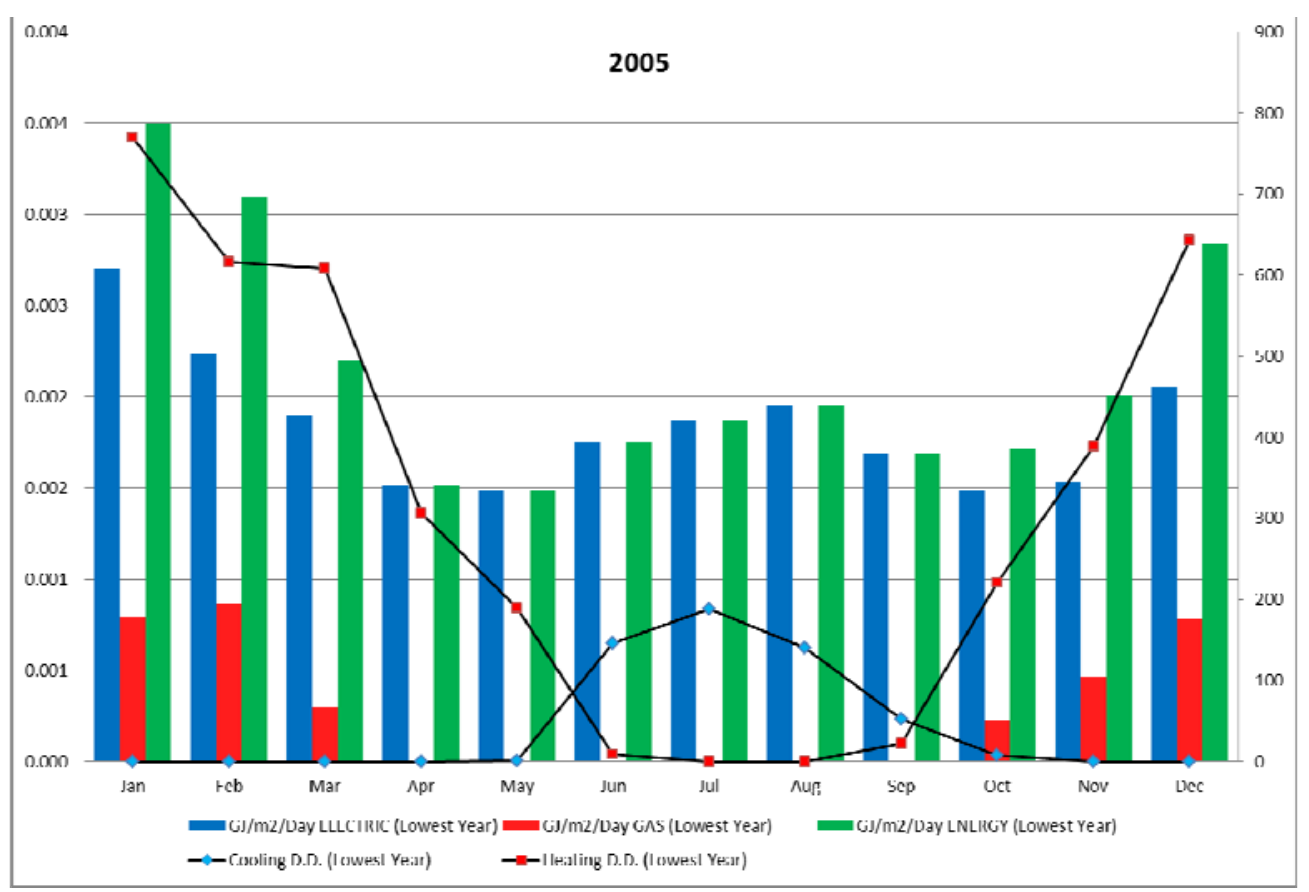


Monthly energy index comparison between highest energy consumption year, lowest, average and benchmark (BOMA) energy intensity:

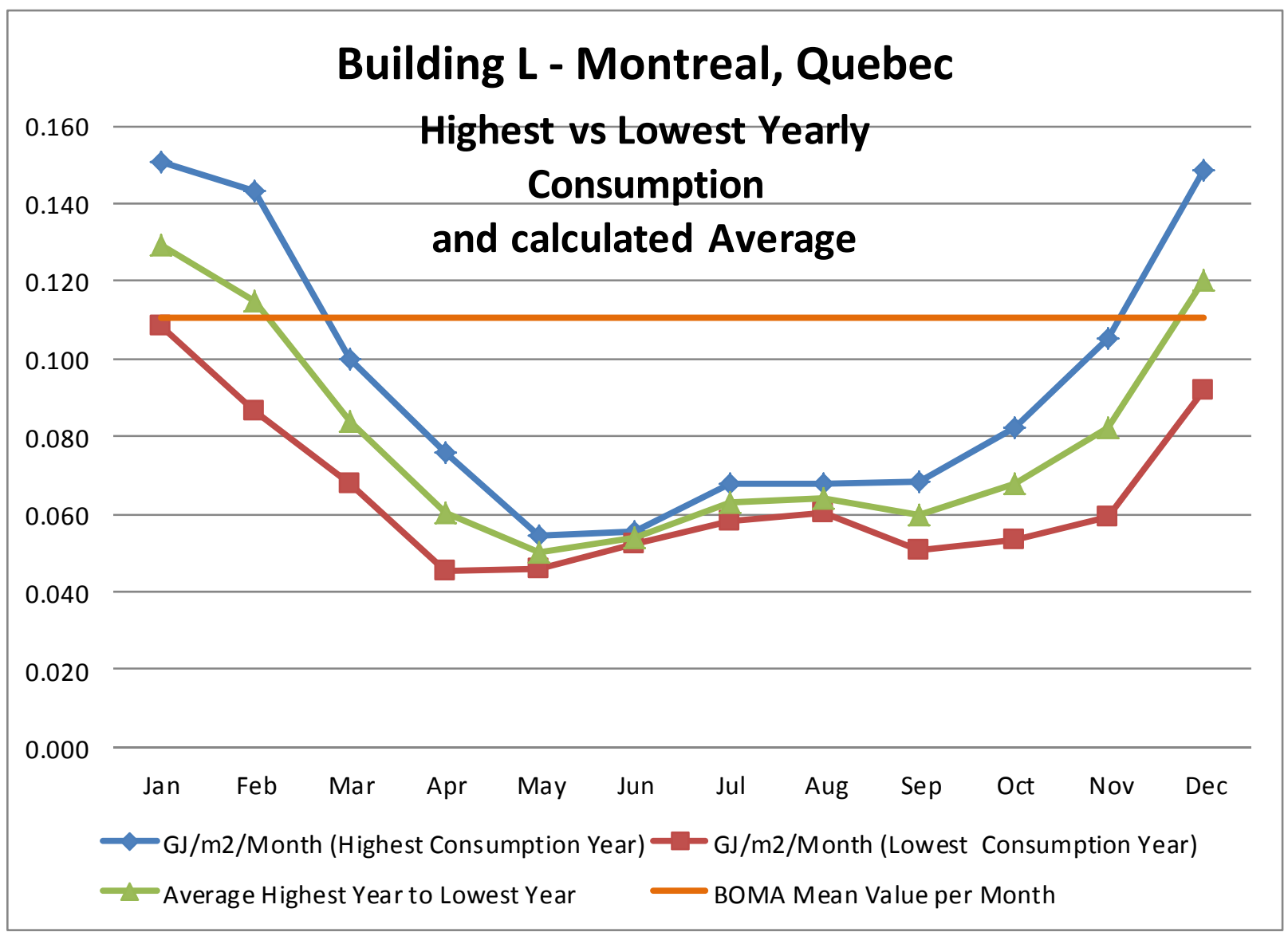


Building \#13 - Utility Bills Analysis

\section{Calculations of Energy Index for Building \#13}

Energy CAP database was utilized to collect energy consumption information for the building. Energy consumption was provided by utility bills for electricity and gas. For Building \#13 electricity utility bills were provided from December 1995 to March 2015; gas utility bills were provided from January 2003 to March 2015. To complete most accurate analysis utility bills for 2003 to 2014 were only. By having total floor area for entire building of $8,022 \mathrm{~m}^{2}$, energy index in $\mathrm{GJ} / \mathrm{m}^{2} /$ year was calculated. From calculations it was noticed that gas utility bills for 2012 provides not consistent values in comparison with the rest of years, and afterwards gas consumption seems much higher than in years prior 2012. By analysing utility bills in more details it was not clear why such inconsistency occurred, therefore for further calculations all years data was included.

Utility bills analysis showed following:

\begin{tabular}{|c|c|c|c|c|c|c|c|c|}
\hline \multicolumn{6}{|c|}{ Building M - Vaudreuil-Dorion, Quebec } & \multirow[b]{2}{*}{$m^{3}$-ngas } & \multirow[b]{2}{*}{ Total GJ/yr } & \multirow[b]{2}{*}{$8,022.00$} \\
\hline & & & kWh & & & & & \\
\hline Row Labels & Sun & $\begin{array}{l}\text { of Ele Total } \\
\text { ost / Year }\end{array}$ & $\begin{array}{c}\text { Sum of Ele } \\
\text { Consumption / } \\
\text { Year }\end{array}$ & Sum & $\begin{array}{l}\text { of Gas Total } \\
\text { st / Year }\end{array}$ & $\begin{array}{c}\text { Sum of Gas } \\
\text { Consumption / } \\
\text { Year }\end{array}$ & Total & $\mathrm{GJ} / \mathrm{m} 2 / \mathrm{yr}$ \\
\hline Year 1995 & $\$$ & $47,828.58$ & $647,940.00$ & & & & & \\
\hline Year 1996 & $\$$ & $71,461.21$ & $953,040.00$ & & & & $3,430.94$ & 0.43 \\
\hline Year 1997 & $\$$ & $105,261.37$ & $1,405,080.00$ & & & & $5,058.29$ & 0.63 \\
\hline Year 1998 & $\$$ & $127,513.05$ & $1,559,400.00$ & & & & $5,613.84$ & 0.70 \\
\hline Year 1999 & $\$$ & $126,240.32$ & $1,551,000.00$ & & & & $5,583.60$ & 0.70 \\
\hline Year 2000 & $\$$ & $120,898.21$ & $1,431,810.00$ & & & & $5,154.52$ & 0.64 \\
\hline Year 2001 & $\$$ & $128,418.77$ & $1,577,150.00$ & & & & $5,677.74$ & 0.71 \\
\hline Year 2002 & $\$$ & $122,699.82$ & $1,493,980.00$ & & & & $5,378.33$ & 0.67 \\
\hline Year 2003 & $\$$ & $146,374.27$ & $1,747,330.00$ & $\$$ & $5,884.62$ & $9,345.00$ & $6,638.02$ & 0.83 \\
\hline Year 2004 & $\$$ & $184,302.66$ & $2,193,660.00$ & $\$$ & $3,988.02$ & $5,737.00$ & $8,110.59$ & 1.01 \\
\hline Year 2005 & $\$$ & $190,976.08$ & $2,219,820.00$ & $\$$ & $4,248.81$ & $6,284.00$ & $8,225.12$ & 1.03 \\
\hline Year 2006 & $\$$ & $178,663.73$ & $1,912,140.00$ & $\$$ & $1,017.33$ & $1,252.00$ & $6,930.28$ & 0.86 \\
\hline Year 2007 & $\$$ & $186,555.40$ & $2,024,430.00$ & $\$$ & 674.29 & 859.00 & $7,319.90$ & 0.91 \\
\hline Year 2008 & $\$$ & $180,115.50$ & $1,915,680.00$ & $\$$ & 427.98 & 450.00 & $6,913.19$ & 0.86 \\
\hline Year 2009 & $\$$ & $185,402.53$ & $1,917,160.00$ & $\$$ & $1,033.12$ & $1,361.00$ & $6,952.41$ & 0.87 \\
\hline Year 2010 & $\$$ & $185,396.49$ & $1,936,200.00$ & $\$$ & $1,227.59$ & $1,621.00$ & $7,030.62$ & 0.88 \\
\hline Year 2011 & $\$$ & $168,687.72$ & $1,735,650.00$ & $\$$ & $7,110.36$ & $11,540.00$ & $6,677.63$ & 0.83 \\
\hline Year 2012 & $\$$ & $169,972.48$ & $1,807,020.00$ & $\$$ & $16,610.37$ & $25,849.00$ & $7,466.85$ & 0.93 \\
\hline Year 2013 & $\$$ & $180,878.36$ & $1,896,000.00$ & $\$$ & $11,106.72$ & $16,511.46$ & $7,439.83$ & 0.93 \\
\hline Year 2014 & $\$$ & $188,104.76$ & $1,919,520.00$ & $\$$ & $12,264.86$ & $17,459.00$ & $7,559.75$ & 0.94 \\
\hline Year 2015 & $\$$ & $66,981.63$ & $706,920.00$ & $\$$ & $6,738.65$ & $10,438.00$ & $2,933.21$ & 0.37 \\
\hline Average & $\$$ & $149,787.57$ & $1,692,200.50$ & $\$$ & $5,466.17$ & $8,189.04$ & & 0.91 \\
\hline
\end{tabular}


As it was specified in energy audit, energy consumption of the Building \#13 is average in comparison to similar office buildings in same region; and therefore average energy index which equals to $0.91 \mathrm{GJ} / \mathrm{m}^{2} / \mathrm{yr}$ is also high in comparison to benchmark values of BOMA energy efficient building value of $1.05 \mathrm{GJ} / \mathrm{m}^{2} / \mathrm{yr}$, however value is much lower than average National Resources Canada value of 1.43GJ/m2/year.

Two charts below show electricity and gas consumption per year. Electricity consumption chart demonstrates prominent increase in energy usage. Gas consumption chart also shows increase in energy use with couple of high gas consumption values in 2004 and 2005.
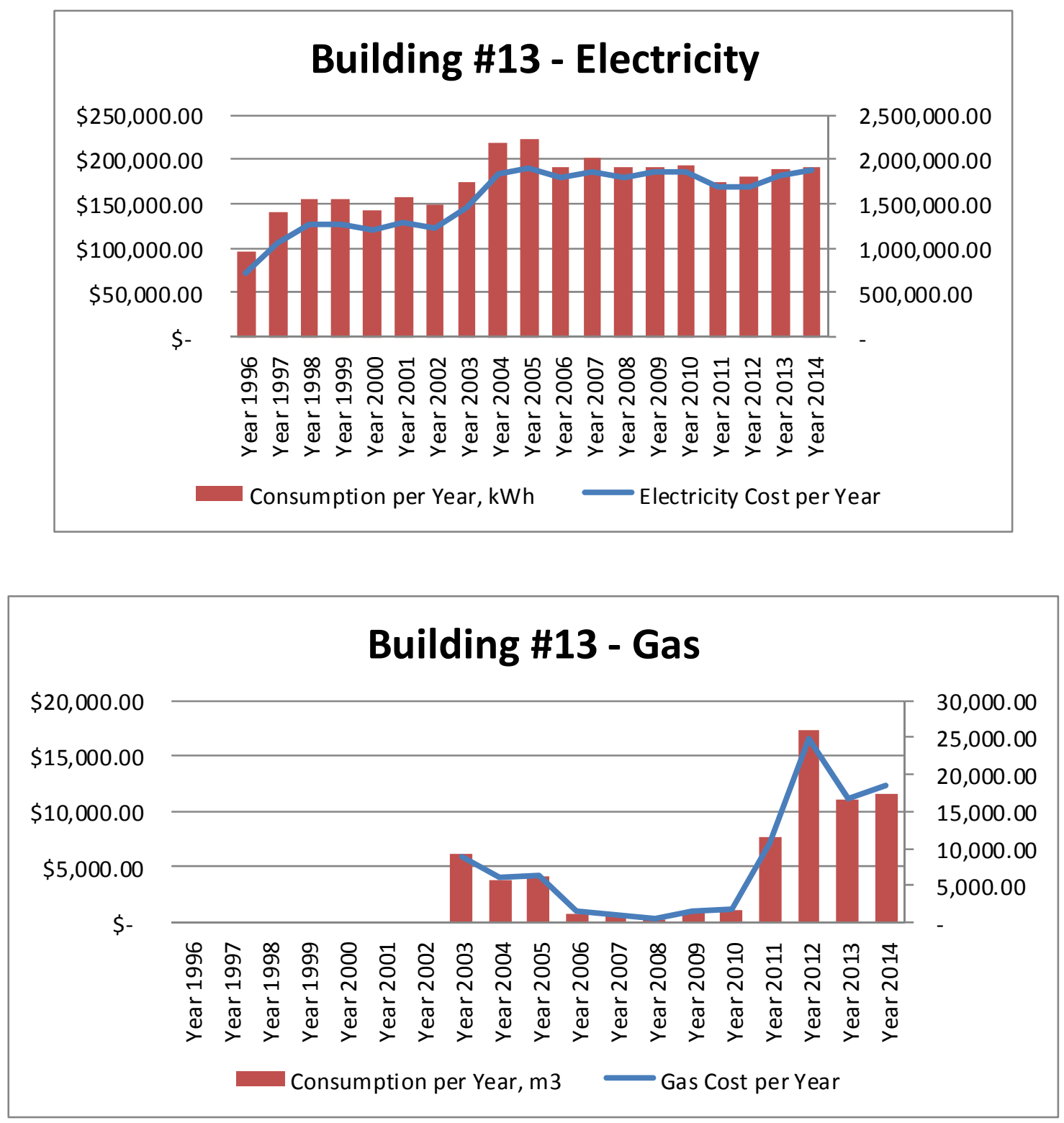

Yearly energy intensity (index) was also plotted to demonstrate increase or decrease over the range of years for which data is available. Chart below shows that energy index value relatively steady starting in 2006. The 
lowest energy index was in 2011 and highest in 2005. These two years' data will be used for further calculations and comparisons.

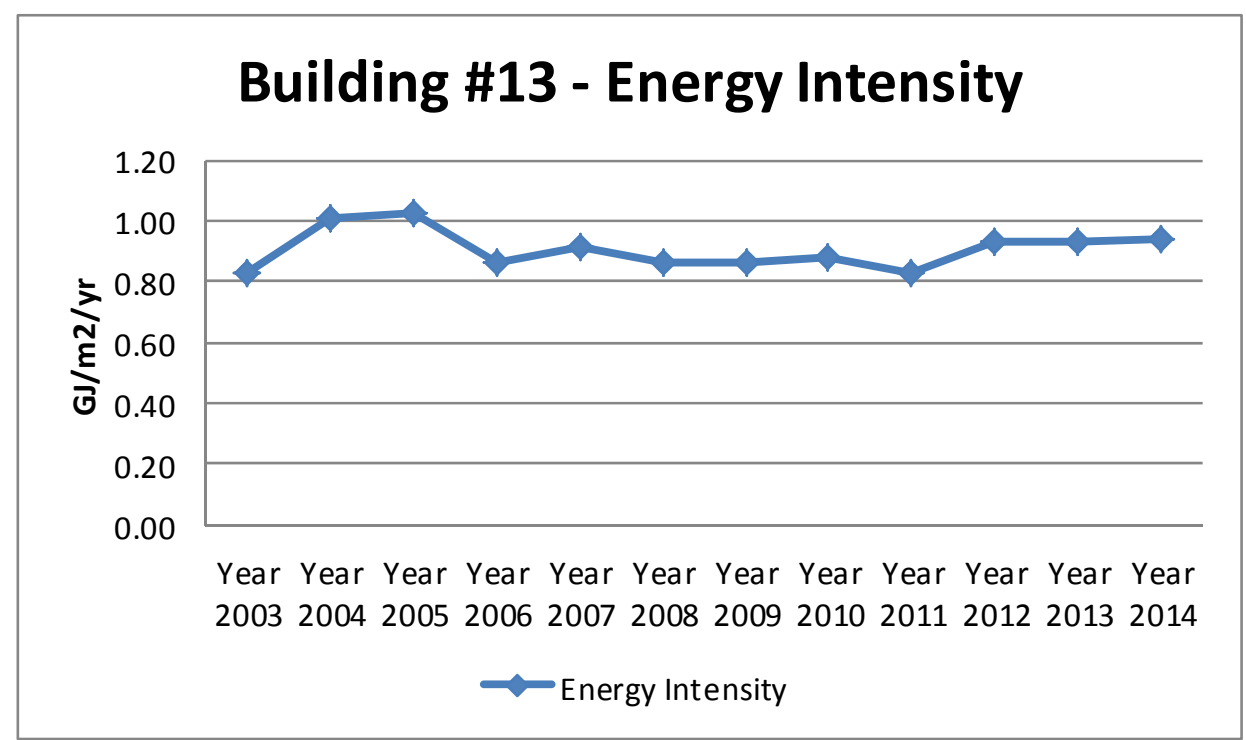

Normalized total energy consumption was calculated for Building \#13. Based on plotted results, shown below in the chart, it can be concluded that energy consumption for 2005 is higher than for 2011 . This proves that regardless of weather conditions 2005 has higher energy consumptions than in 2011. Implementing trendline equations, average equation was calculated:

\section{$\gamma=0.4815 x+4.52,455$}

From above equation normalized average energy index was calculated as $0.92 \mathrm{GJ} / \mathrm{m}^{2} / \mathrm{yr}$, this value is slightly higher than average for 2003 to 2014 years range. Calculated value will be used for further case-study buildings comparison. 


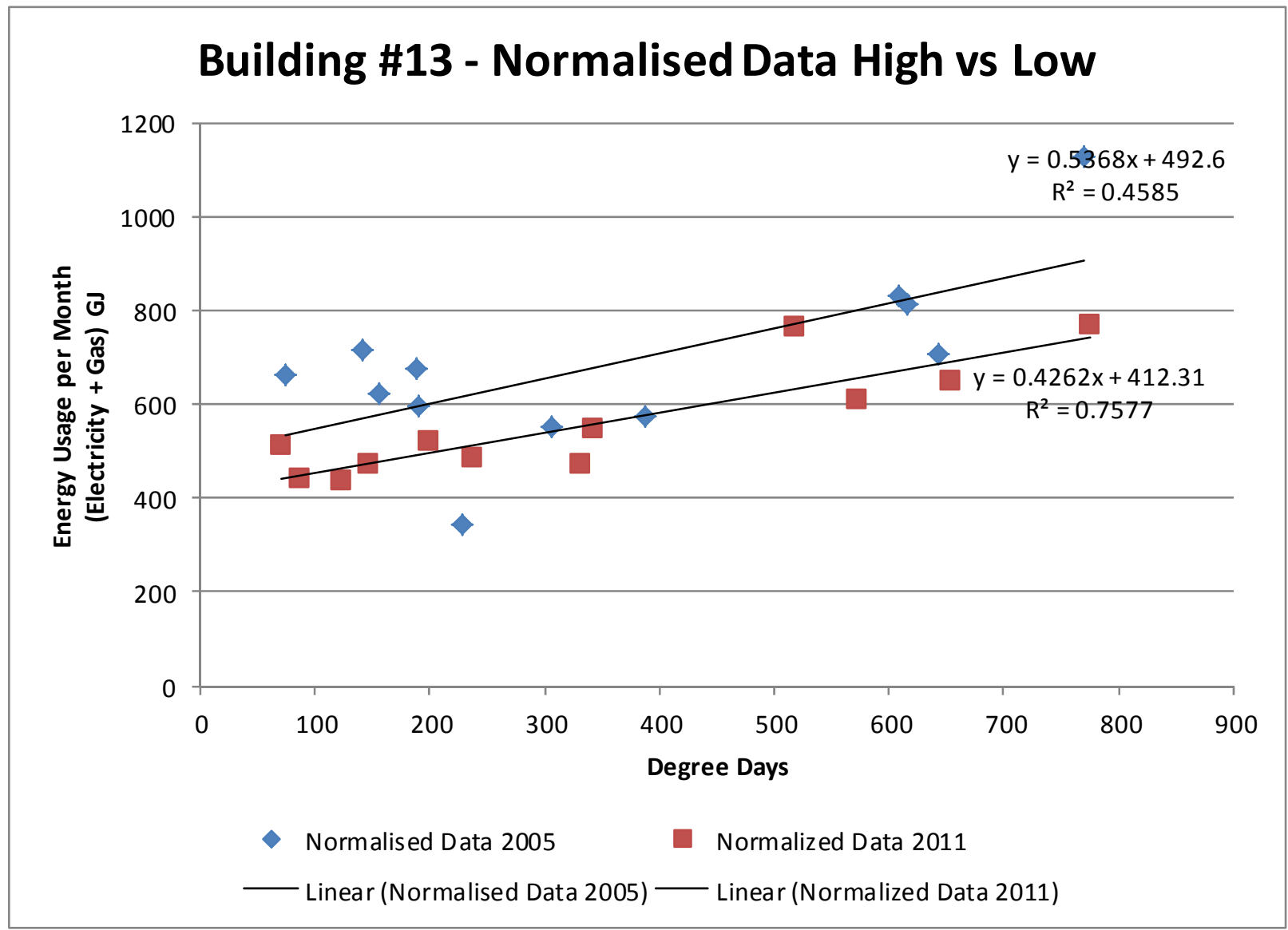


Actual data used for calculations (year with highest energy consumption):

\begin{tabular}{|c|c|c|c|c|c|c|c|c|c|c|c|c|}
\hline ADDRESS: & \multicolumn{4}{|c|}{ Building M - Vaudreuil-Dorion, Quebec } & & & & & & & & \\
\hline BUILDING \# & \multicolumn{4}{|c|}{13} & & & & & & & & \\
\hline Year - Highest Energy Consumption: & \multicolumn{4}{|l|}{2005} & & & & & & & & \\
\hline AREA: & \multicolumn{4}{|l|}{8,022} & & & & & & & & \\
\hline USAGE INDEX: & \multicolumn{4}{|l|}{1.03} & & & & & & & & \\
\hline Month & Jan & $\mathrm{Feb}$ & Mar & Apr & May & Jun & Jul & Aug & Sep & Oct & Nov & Dec \\
\hline \multirow{2}{*}{$\begin{array}{l}\text { Electric Billing Date } \\
\text { Electric Billing Days }\end{array}$} & $31 / 01 / 2005$ & $28 / 02 / 2005$ & $31 / 03 / 2005$ & $30 / 04 / 2005$ & $31 / 05 / 2005$ & $30 / 06 / 2005$ & $31 / 07 / 2005$ & $31 / 08 / 2005$ & $30 / 09 / 2005$ & $31 / 10 / 2005$ & $30 / 11 / 2005$ & $31 / 12 / 2005$ \\
\hline & 31 & 28 & 31 & 30 & 31 & 30 & 31 & 31 & 30 & 31 & 30 & 31 \\
\hline \multirow{3}{*}{$\begin{array}{l}\text { Gas Billing Date } \\
\text { Gas Billing Days }\end{array}$} & $31 / 01 / 2005$ & $28 / 02 / 2005$ & $31 / 03 / 2005$ & $30 / 04 / 2005$ & $31 / 05 / 2005$ & $30 / 06 / 2005$ & $31 / 07 / 2005$ & $31 / 08 / 2005$ & $30 / 09 / 2005$ & $31 / 10 / 2005$ & $30 / 11 / 2005$ & $31 / 12 / 2005$ \\
\hline & 31 & 28 & 31 & 30 & 31 & 30 & 31 & 31 & 30 & 31 & 30 & 31 \\
\hline & & & & & & & & & & & & \\
\hline \multicolumn{13}{|l|}{ COOLING \& HEATING DEGREE DAYS } \\
\hline \multirow{3}{*}{$\begin{array}{l}\text { Cooling D.D. (Highest Year) } \\
\text { Daily Clg D.D. Avg. (Highest Year) } \\
\text { Normal Cooling D.D. (Highest Year) }\end{array}$} & 0 & 0 & 0 & 0 & 1 & 146 & 189 & 141 & 52 & 8 & 0 & 0 \\
\hline & 0 & 0 & 0 & 0 & 0 & 5 & 6 & 5 & 2 & 0 & 0 & 0 \\
\hline & & & & & & & & & & & & \\
\hline \multirow{4}{*}{$\begin{array}{l}\text { Heating D.D. (Highest Year) } \\
\text { Daily Htg. D.D. Avg. (Highest Year) } \\
\text { Normal Heating D.D (Highest Year) }\end{array}$} & 770 & 616 & 609 & 307 & 189 & 9 & 0 & 0 & 23 & 220 & 388 & 643 \\
\hline & 25 & 22 & 20 & 10 & 6 & 0 & 0 & 0 & 1 & 7 & 13 & 21 \\
\hline & & & & & & & & & & & & \\
\hline & & & & & & & & & & & & \\
\hline \multicolumn{13}{|l|}{ ELECTRICAL USAGE \& COST } \\
\hline kWh Used & 254,220 & 223,410 & 230,580 & 153,510 & 165,480 & 173,040 & 187,980 & 198,450 & 183,810 & 95,010 & 158,490 & 195,840 \\
\hline \multirow{2}{*}{ Daily kWh Avg. } & 8,201 & 7,979 & 7,438 & 5,117 & 5,338 & 5,768 & 6,064 & 6,402 & 6,127 & 3,065 & 5,283 & 6,317 \\
\hline & 599 & 605 & 660 & 467 & 476 & 484 & 470 & 490 & 496 & 303 & 516 & 497 \\
\hline \multirow[t]{2}{*}{ Load Factor (Highest Year) } & $57 \%$ & $55 \%$ & $47 \%$ & $46 \%$ & $47 \%$ & $50 \%$ & $54 \%$ & $54 \%$ & $51 \%$ & $42 \%$ & $43 \%$ & $53 \%$ \\
\hline & & & & & & & & & & & & \\
\hline \multicolumn{13}{|l|}{ NATURAL GAS USAGE \& COST } \\
\hline \multicolumn{13}{|l|}{ CCFF } \\
\hline $\mathrm{m}^{\wedge} 3$ Used & 5,691 & 271 & 76 & 0 & 0 & 0 & 0 & 0 & 0 & 64 & 87 & 95 \\
\hline \multirow{2}{*}{ Daily $\mathrm{m}^{\wedge} 3$ Avg. } & 184 & 10 & 2 & 0 & 0 & 0 & 0 & 0 & 0 & 2 & 3 & 3 \\
\hline \multirow{2}{*}{\multicolumn{13}{|c|}{ GREENHOUSE DATA }} \\
\hline & & & & & & & & & & & & \\
\hline \multirow{4}{*}{$\begin{array}{l}\text { C02 (kgs) (Highest Year) } \\
\text { S02 (kgs) (Highest Year) } \\
\text { NOx (kgs) (Highest Year) }\end{array}$} & 211,296 & 152,212 & 155,655 & 103,270 & 111,323 & 116,409 & 126,459 & 133,503 & 123,654 & 64,369 & 107,236 & 132,419 \\
\hline & 2,283 & 1,645 & 1,682 & 1,116 & 1,203 & 1,258 & 1,366 & 1,442 & 1,336 & 695 & 1,159 & 1,431 \\
\hline & 1,001 & 721 & 737 & 489 & 527 & 551 & 599 & 632 & 586 & 305 & 508 & 627 \\
\hline & & & & & & & & & & & & \\
\hline \multicolumn{13}{|l|}{ USAGE DATA } \\
\hline & 915.19 & 804.28 & 830.09 & 552.64 & 595.73 & 622.94 & 676.73 & 714.42 & 661.72 & 342.04 & 570.56 & 705.02 \\
\hline GJ/m2/Day ELECTRIC (Highest Year) & 0.004 & 0.004 & 0.003 & 0.002 & 0.002 & 0.003 & 0.003 & 0.003 & 0.003 & 0.001 & 0.002 & 0.003 \\
\hline GJ/m2/Month (Highest Year) & 0.11 & 0.10 & 0.10 & 0.07 & 0.07 & 0.08 & 0.08 & 0.09 & 0.08 & 0.04 & 0.07 & 0.09 \\
\hline $\mathrm{m} 3$ to GJ & & & & & & & & 000 & 0,00 & & 3.24 & 353 \\
\hline $\begin{array}{l}\mathrm{m} 3 \text { to GJ } \\
\mathrm{GJ} / \mathrm{m} 2 / \text { Day GAS (Highest Year) }\end{array}$ & $\frac{211.71}{0.001}$ & $\begin{array}{l}10.08 \\
0.000\end{array}$ & 2.83 & 0.000 & 0.00 & 0.00 & 0.000 & 0.00 & 0.000 & 2.38 & 0.000 & 0.000 \\
\hline $\mathrm{GJ} / \mathrm{m} 2 /$ Month & 0.03 & 0.00 & 0.00 & 0.00 & 0.00 & 0.00 & 0.00 & 0.00 & 0.00 & 0.00 & 0.00 & 0.00 \\
\hline $\mathrm{m} 3 / \mathrm{m} 2 /$ Month & 0.71 & 0.03 & 0.01 & 0.00 & 0.00 & 0.00 & 0.00 & 0.00 & 0.00 & 0.01 & 0.01 & 0.01 \\
\hline GJ/m2/Day ENERGY (Highest Year) & 0.005 & 0.004 & 0.003 & 0.002 & 0.002 & 0.003 & 0.003 & 0.003 & 0.003 & 0.001 & 0.002 & 0.003 \\
\hline $\mathrm{GJ} / \mathrm{m} 2 /$ Month (Highest Consumption Year) & 0.140 & 0.102 & 0.104 & 0.069 & 0.074 & 0.078 & 0.084 & 0.089 & 0.082 & 0.043 & 0.072 & 0.088 \\
\hline Energy Usage per Month (Electricity + Gas) & 1127 & 814 & 833 & 553 & 596 & 623 & 677 & 714 & 662 & 344 & 574 & 709 \\
\hline Degree Days & 770 & 616 & 609 & 307 & 190 & 155 & 189 & 141 & 75 & 228 & 388 & 643 \\
\hline
\end{tabular}




\section{Actual data used for calculations (year with lowest energy consumption):}

\begin{tabular}{|c|c|c|c|c|c|c|c|c|c|c|c|c|}
\hline ADDRESS: & \multicolumn{4}{|c|}{ Building M - Vaudreuil-Dorion, Quebec } & & & & & & & & \\
\hline BUILDING\# & \multicolumn{4}{|c|}{13} & & & & & & & & \\
\hline Year - Lowest Energy Consumption: & \multicolumn{4}{|l|}{2011} & & & & & & & & \\
\hline AREA: & \multicolumn{4}{|l|}{8,022} & & & & & & & & \\
\hline \multicolumn{13}{|l|}{ USAGE INDEX: } \\
\hline Month & Jan & Feb & Mar & Apr & May & Jun & Jul & Aug & Sep & Oct & Nov & Dec \\
\hline \multirow{2}{*}{$\begin{array}{l}\text { Electric Billing Date } \\
\text { Electric Billing Days }\end{array}$} & $31 / 01 / 2011$ & $28 / 02 / 2011$ & $31 / 03 / 2011$ & $30 / 04 / 2011$ & $31 / 05 / 2011$ & $30 / 06 / 2011$ & $31 / 07 / 2011$ & $31 / 08 / 2011$ & $30 / 09 / 2011$ & $31 / 10 / 2011$ & $30 / 11 / 2011$ & $30 / 12 / 2011$ \\
\hline & 31 & 28 & 31 & 30 & 31 & 30 & 31 & 31 & 30 & 31 & 30 & 30 \\
\hline \multirow{2}{*}{$\begin{array}{l}\text { Gas Billing Date } \\
\text { Gas Billing Days }\end{array}$} & $03 / 02 / 2012$ & $02 / 03 / 2012$ & $04 / 04 / 2012$ & $04 / 05 / 2012$ & $06 / 06 / 2012$ & $05 / 07 / 2012$ & $07 / 08 / 2012$ & $04 / 09 / 2012$ & $04 / 10 / 2012$ & $02 / 11 / 2012$ & $04 / 12 / 2012$ & $04 / 01 / 2013$ \\
\hline & 31 & 28 & 33 & 30 & 33 & 29 & 33 & 28 & 30 & 29 & 32 & 31 \\
\hline \multicolumn{13}{|l|}{ COOLING \& HEATING DEGREE DAYS } \\
\hline & & & & & & & & & & & & \\
\hline Cooling D.D. (Lowest Year) & 0 & 0 & 0 & 0 & 13 & 52 & 199 & 122 & 39 & 2 & 0 & 0 \\
\hline \multirow{3}{*}{$\begin{array}{l}\text { Daily Clg D.D. Avg. (Lowest Year) } \\
\text { Normal Cooling D.D. (Lowest Year) }\end{array}$} & 0 & 0 & 0 & 0 & 0 & 2 & 6 & 4 & 1 & 0 & 0 & 0 \\
\hline & & & & & & & & & & & & \\
\hline & 775 & 654 & 573 & 332 & 134 & 19 & 0 & 0 & 48 & 235 & 342 & 518 \\
\hline \multirow{3}{*}{$\begin{array}{l}\text { Heating D.D. (Lowest Year) } \\
\text { Daily Htg. D.D. Avg. (Lowest Year) } \\
\text { Normal Heating D.D (Lowest Year) }\end{array}$} & 25 & 23 & 17 & 11 & 4 & 1 & 0 & 0 & 2 & 8 & 11 & 17 \\
\hline & & & & & & & & & & & & \\
\hline & \multirow{2}{*}{\multicolumn{12}{|c|}{ ELECTRICAL USAGE \& COST }} \\
\hline $\begin{array}{l}\text { ELECTRICAL USAGE \& COST } \\
\text { kWh Used }\end{array}$ & & & & & & & & & & & & \\
\hline \multirow[t]{2}{*}{ Daily kWh Avg. } & $\begin{array}{c}209,160 \\
6,747\end{array}$ & $\begin{array}{c}171,210 \\
6,329\end{array}$ & 5,062 & 4,326 & 3,967 & 4,915 & 4,370 & 4,344 & 12,040 & 3,959 & 12,000 & 5,024 \\
\hline & & & & & & & & & & & & \\
\hline \multirow{3}{*}{$\begin{array}{l}\text { Demand kW/RkVA Used } \\
\text { Load Factor (Lowest Year) }\end{array}$} & 550 & 485 & 494 & 409 & 370 & 392 & 378 & 383 & 371 & 328 & 329 & 407 \\
\hline & $51 \%$ & $54 \%$ & $45 \%$ & $44 \%$ & $48 \%$ & $51 \%$ & $51 \%$ & $43 \%$ & $46 \%$ & $47 \%$ & $51 \%$ & $53 \%$ \\
\hline & & & & & & & & & & & & \\
\hline \multicolumn{13}{|l|}{ NATURAL GAS USAGE \& COST } \\
\hline \multicolumn{13}{|l|}{ CCF } \\
\hline $\mathrm{m}^{\wedge} 3$ Used & 374 & 303 & 224 & 102 & 0 & 0 & 0 & 0 & 0 & 1,957 & 3,051 & 5,529 \\
\hline \multirow[t]{2}{*}{ Daily $\mathrm{m}^{\wedge} 3$ Avg. } & 12 & 11 & 7 & 3 & 0 & 0 & 0 & 0 & 0 & 67 & 95 & 178 \\
\hline & & & & & & & & & & & & \\
\hline \multicolumn{13}{|l|}{ GREENHOUSE DATA } \\
\hline "C02 (kgs) (Lowest Year) & 14143,354 & \begin{tabular}{c|}
121,358 \\
\end{tabular} & \begin{tabular}{c|}
113,958 \\
\end{tabular} & 88,028 & 88,073 & 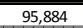 & 977,014 & 81,817 & 82,503 & 91,086 & \begin{tabular}{c|}
102,319 \\
\end{tabular} & 143,893 \\
\hline S02 (kgs) (Lowest Year) & 1,549 & 1,311 & 1,231 & 951 & 952 & 1,036 & 1,048 & 884 & 891 & 984 & 1,105 & 1,555 \\
\hline NOx (kgs) (Lowest Year) & 679 & 575 & 540 & 417 & 417 & 454 & 460 & 388 & 391 & 431 & 485 & 682 \\
\hline USAGE DATA & & & & & & & & & & & & \\
\hline $\mathrm{kWh}$ to GJ & 752.98 & 637.96 & 601.34 & 467.21 & 471.31 & 513.11 & 519.16 & 437.83 & 441.50 & 413.32 & 432.00 & 560.63 \\
\hline $\mathrm{GJ} / \mathrm{m} 2 /$ Day ELECTRIC (Lowest Year) & 0.003 & 0.003 & 0.002 & 0.002 & 0.002 & 0.002 & 0.002 & 0.002 & 0.002 & 0.002 & 0.002 & 0.002 \\
\hline $\mathrm{GJ} / \mathrm{m} 2 /$ Month (Lowest Year) & 0.09 & 0.08 & 0.07 & 0.06 & 0.06 & 0.06 & 0.06 & 0.05 & 0.06 & 0.05 & 0.05 & 0.07 \\
\hline & & & & & & & & & & & & \\
\hline $\mathrm{m} 3$ to GJ & 13.91 & 11.27 & 8.33 & 3.79 & 0.00 & 0.00 & 0.00 & 0.00 & 0.00 & 72.80 & 113.50 & 205.68 \\
\hline $\mathrm{GJ} / \mathrm{m} 2 /$ Day GAS (Lowest Year) & 0.000 & 0.000 & 0.000 & 0.000 & 0.000 & 0.000 & 0.000 & 0.000 & 0.000 & 0.000 & 0.000 & 0.001 \\
\hline $\mathrm{GJ} / \mathrm{m} 2 /$ Month & 0.00 & 0.00 & 0.00 & 0.00 & 0.00 & 0.00 & 0.00 & 0.00 & 0.00 & 0.01 & 0.01 & 0.03 \\
\hline $\mathrm{m} 3 / \mathrm{m} 2 /$ Month & 0.05 & 0.04 & 0.03 & 0.01 & 0.00 & 0.00 & 0.00 & 0.00 & 0.00 & 0.24 & 0.38 & 0.69 \\
\hline GJ/m2/Day ENERGY (Lowest Year) & 0.003 & 0.003 & 0.002 & 0.002 & 0.002 & 0.002 & 0.002 & 0.002 & 0.002 & 0.002 & 0.002 & 0.003 \\
\hline $\mathrm{GJ} / \mathrm{m} 2 /$ Month (Lowest Consumption Year) & 0.096 & 0.081 & 0.076 & 0.059 & 0.059 & 0.064 & 0.065 & 0.055 & 0.055 & 0.061 & 0.068 & 0.096 \\
\hline Average Highest Year to Lowest Year & 0.118 & 0.091 & 0.090 & 0.064 & 0.067 & 0.071 & 0.075 & 0.072 & 0.069 & 0.052 & 0.070 & 0.092 \\
\hline BOMA Mean Value per Month & 0.111 & 0.111 & 0.111 & 0.111 & 0.111 & 0.111 & 0.111 & 0.111 & 0.111 & 0.111 & 0.111 & 0.111 \\
\hline Energy Usage per Month (Electricity + Gas) & 767 & 649 & 610 & 471 & 471 & 513 & 519 & 438 & 442 & 486 & 545 & 766 \\
\hline Degree Days & 775 & 654 & 573 & 332 & 147 & 71 & 199 & 122 & 87 & 238 & 342 & 518 \\
\hline Normalized Data (Average Degree Days) & 700 & 643 & 564 & 345 & 140 & 82 & 160 & 110 & 99 & 223 & 410 & 589 \\
\hline Normalized Data (Av Energy Consumption) & 789 & 762 & 724 & 619 & 520 & 492 & 530 & 506 & 500 & 560 & 650 & 736 \\
\hline Normalized Data (Av Energy Index / month) & 0.098 & 0.095 & 0.090 & 0.077 & 0.065 & 0.061 & 0.066 & 0.063 & 0.062 & 0.070 & 0.081 & 0.092 \\
\hline
\end{tabular}


Analysis on how electricity and gas consumption corresponds to heating and cooling periods (for highest energy consumption year):

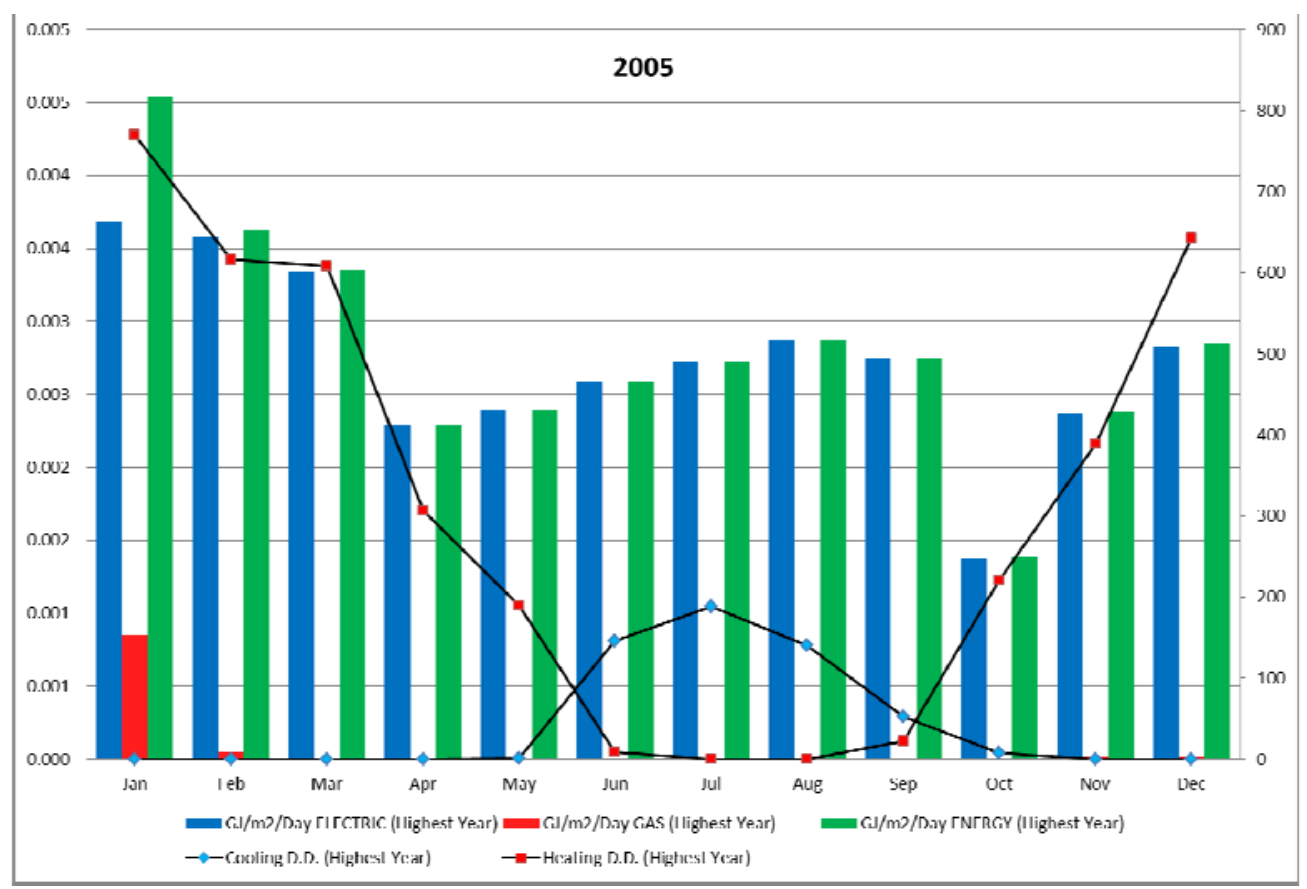

Analysis on how electricity and gas consumption corresponds to heating and cooling periods (for lowest energy consumption year):

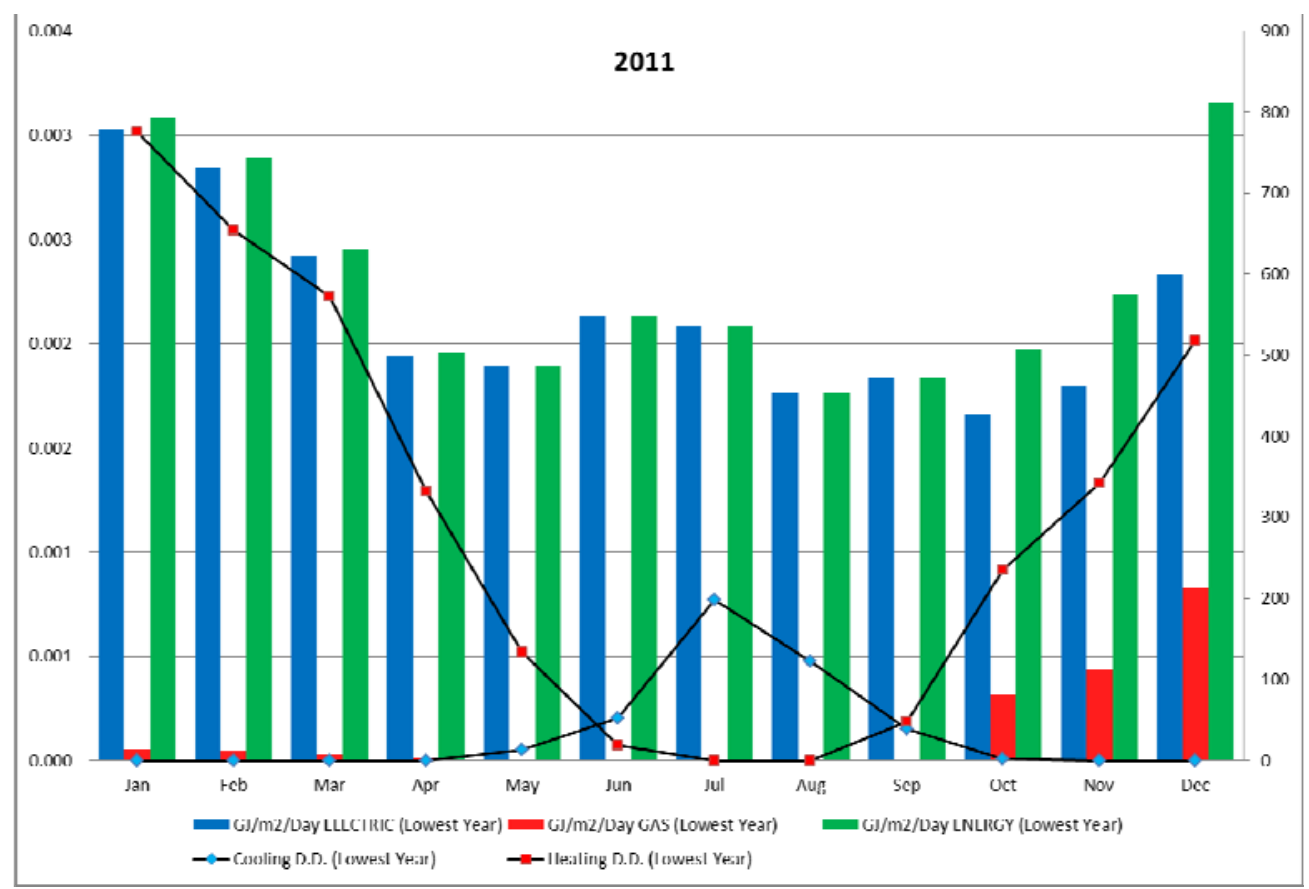


Monthly energy index comparison between highest energy consumption year, lowest, average and benchmark (BOMA) energy intensity:

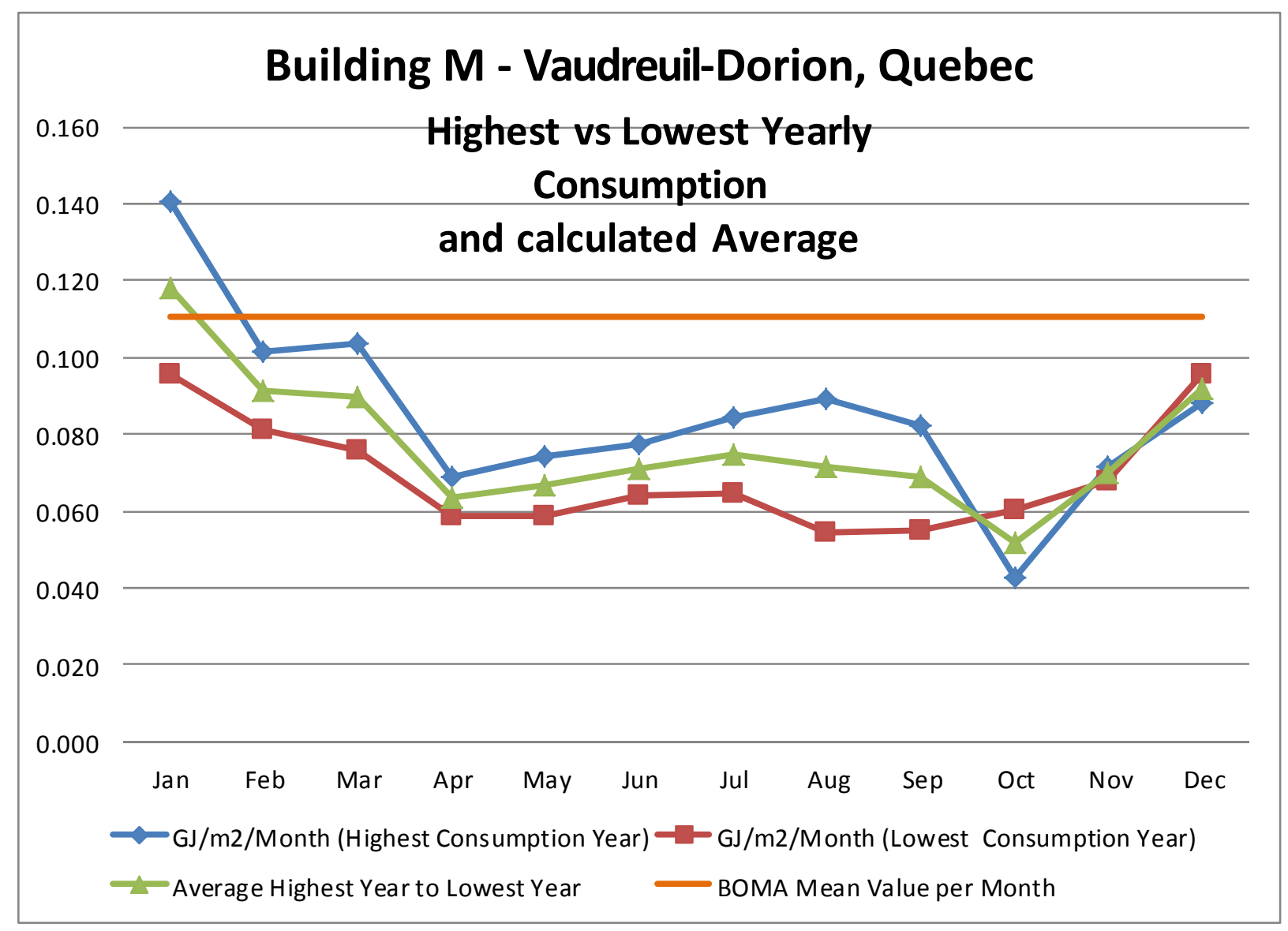


Building \#14 - Utility Bills Analysis

\section{Calculations of Energy Index for Building \#14}

Energy CAP database was utilized to collect energy consumption information for the building. Energy consumption was provided by utility bills for electricity only, as not gas is utilised in this building. For Building \#14 utility bills were provided from December 1999 to March 2015. To complete most accurate analysis utility bills for 2000 to 2014 were only analyzed because 1999 and 2015 has incomplete data. By having total floor area for entire building of $7,943 \mathrm{~m}^{2}$, energy index in $\mathrm{GJ} / \mathrm{m}^{2} /$ year was calculated. From calculations it was noticed that yearly consumption provides consistent data throughout years, therefore all years will be used for calculations.

Utility bills analysis showed following:

\begin{tabular}{|c|c|c|c|c|c|c|c|}
\hline \multicolumn{8}{|c|}{ Building N - Côte-St-Luc, Quebec } \\
\hline & & & kWh & & $m^{3}$-ngas & Total GJ/yr & $7,943.00$ \\
\hline Row Labels & \multicolumn{2}{|c|}{$\begin{array}{c}\text { Sum of Ele Total } \\
\text { Cost / Year }\end{array}$} & $\begin{array}{c}\text { Sum of Ele } \\
\text { Consumption / } \\
\text { Year }\end{array}$ & $\begin{array}{c}\text { Sum of Gas Total } \\
\text { Cost / Year }\end{array}$ & $\begin{array}{c}\text { Sum of Gas } \\
\text { Consumption / } \\
\text { Year }\end{array}$ & Total & $\mathrm{GJ} / \mathrm{m} 2 / \mathrm{yr}$ \\
\hline Year 1999 & $\$$ & $60,046.82$ & $837,600.00$ & & & & \\
\hline Year 2000 & $\$$ & $127,415.11$ & $1,628,400.00$ & & & $5,862.24$ & 0.74 \\
\hline Year 2001 & $\$$ & $198,171.97$ & $2,769,600.00$ & & & $9,970.56$ & 1.26 \\
\hline Year 2002 & $\$$ & $223,651.56$ & $3,081,600.00$ & & & $11,093.76$ & 1.40 \\
\hline Year 2003 & $\$$ & $235,667.15$ & $3,191,600.00$ & & & $11,489.76$ & 1.45 \\
\hline Year 2004 & $\$$ & $239,682.54$ & $3,272,400.00$ & & & $11,780.64$ & 1.48 \\
\hline Year 2005 & $\$$ & $248,677.25$ & $3,472,800.00$ & & & $12,502.08$ & 1.57 \\
\hline Year 2006 & $\$$ & $227,853.30$ & $3,056,400.00$ & & & $11,003.04$ & 1.39 \\
\hline Year 2007 & $\$$ & $240,558.36$ & $3,236,400.00$ & & & $11,651.04$ & 1.47 \\
\hline Year 2008 & $\$$ & $258,831.55$ & $3,417,600.00$ & & & $12,303.36$ & 1.55 \\
\hline Year 2009 & $\$$ & $245,117.35$ & $3,153,600.00$ & & & $11,352.96$ & 1.43 \\
\hline Year 2010 & $\$$ & $247,131.35$ & $3,181,200.00$ & & & $11,452.32$ & 1.44 \\
\hline Year 2011 & $\$$ & $252,991.18$ & $3,201,600.00$ & & & $11,525.76$ & 1.45 \\
\hline Year 2012 & $\$$ & $249,643.25$ & $3,091,200.00$ & & & $11,128.32$ & 1.40 \\
\hline Year 2013 & $\$$ & $258,750.26$ & $3,157,200.00$ & & & $11,365.92$ & 1.43 \\
\hline Year 2014 & $\$$ & $254,123.31$ & $3,001,200.00$ & & & $10,804.32$ & 1.36 \\
\hline Year 2015 & $\$$ & $113,645.04$ & $1,338,600.00$ & & & & \\
\hline Average & $\$$ & $233,884.37$ & $3,060,853.33$ & & & & 1.39 \\
\hline
\end{tabular}

As it was specified in energy audit, energy consumption of the Building \#14 is relatively high in comparison to similar office buildings in same region; and therefore average energy index which equals to $1.39 \mathrm{GJ} / \mathrm{m}^{2} / \mathrm{yr}$ is also high in comparison to benchmark values of BOMA energy efficient building value of $1.05 \mathrm{GJ} / \mathrm{m}^{2} / \mathrm{yr}$, and then average National Resources Canada value of $1.43 \mathrm{GJ} / \mathrm{m} 2 /$ year. 
Charts below show electricity consumption per year. Electricity consumption chart demonstrates increase in energy usage.

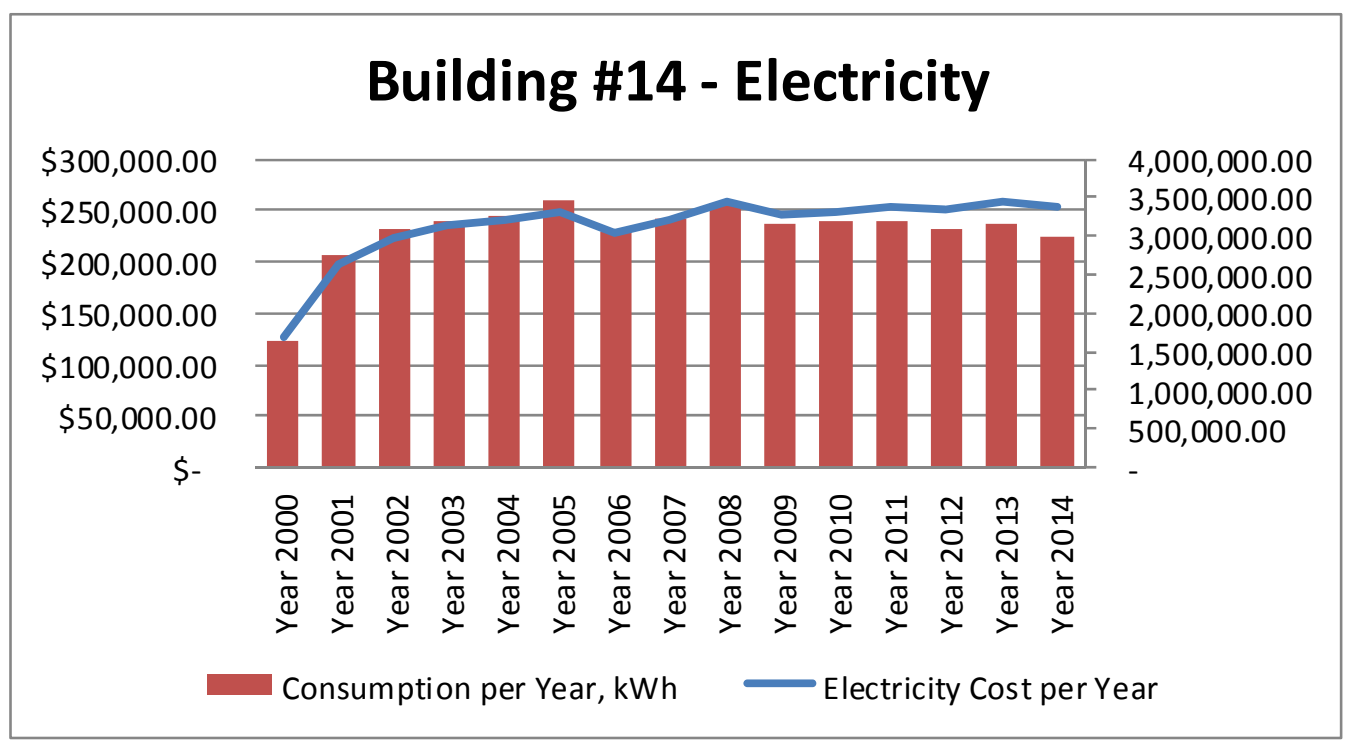

Yearly energy intensity (index) was also plotted to demonstrate increase or decrease over the range of years for which data is available. Chart below shows that energy index value is very steady throughout years. The lowest energy index was in 2000 and highest in 2005, however 2006 and 2005 years will be used for further calculation to reflect more recent years' data. These two years' data will be used for further calculations and comparisons.

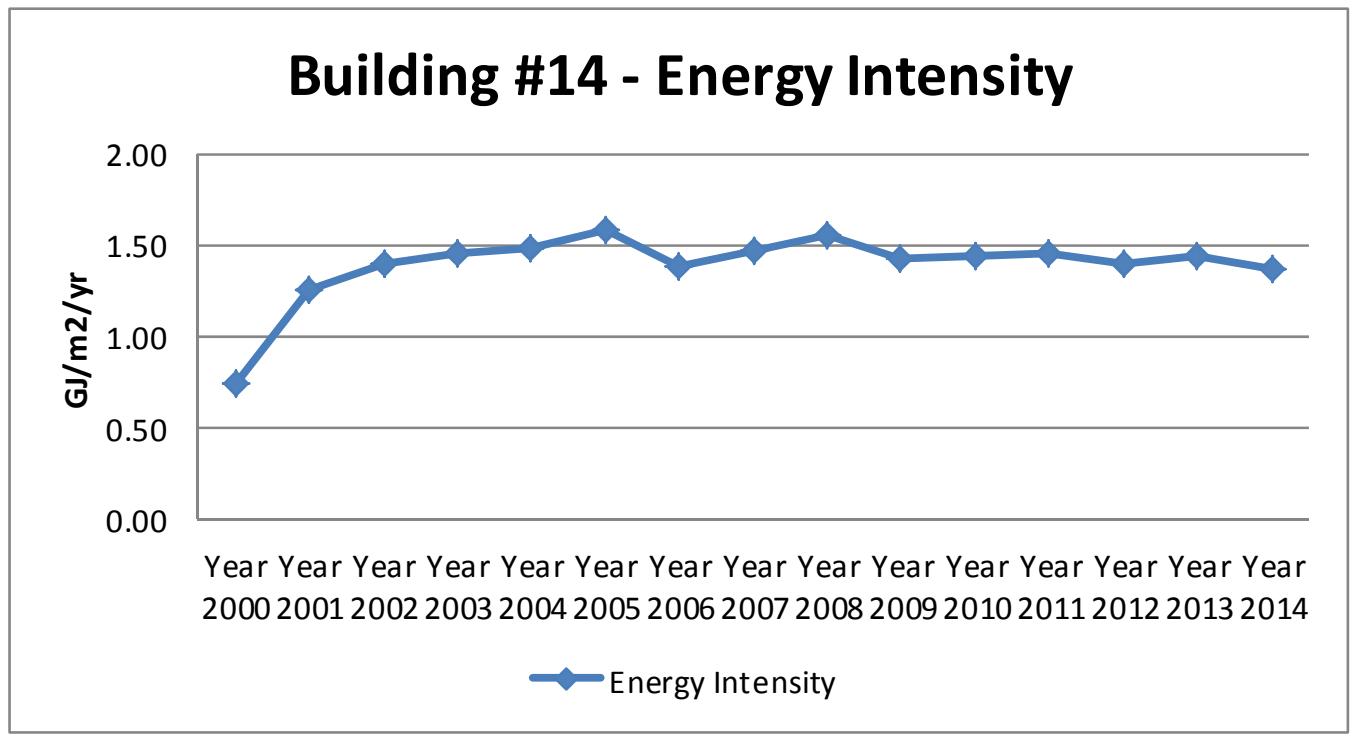

Normalized total energy consumption was calculated for Building \#14. Based on plotted results, shown below in the chart, it can be concluded that energy consumption for 2013 is higher than for 2011. This proves that 
regardless of weather conditions 2013 has higher energy consumptions than in 2011. Implementing trendline equations, average equation was calculated:

\section{$\gamma=0,4114 x+842,115$}

From above equation normalized average energy index was calculated as $1.47 \mathrm{GJ} / \mathrm{m}^{2} / \mathrm{yr}$, this value is higher than average for 2000 to 2014 years range. Calculated value will be used for further case-study buildings comparison.

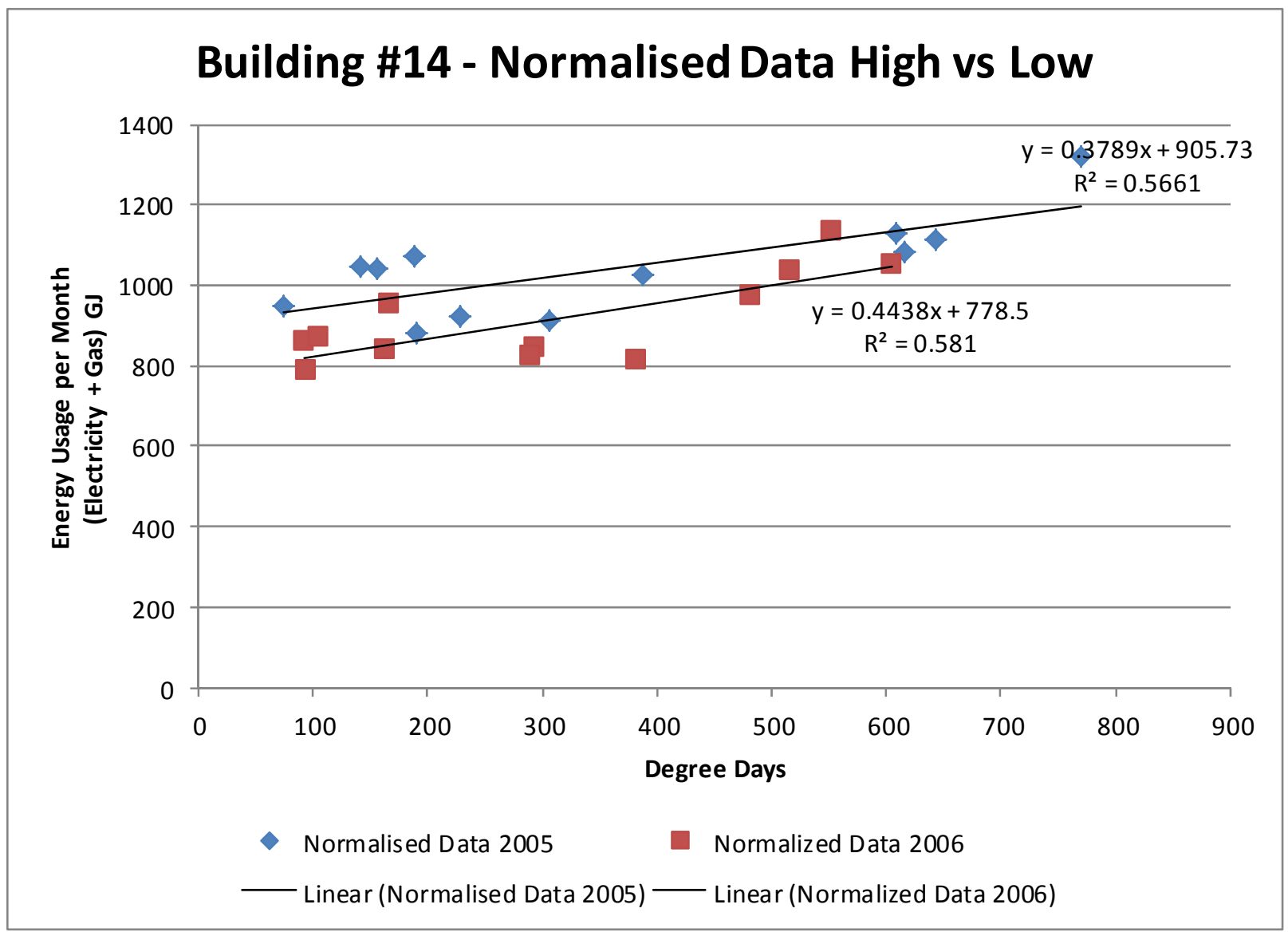


Actual data used for calculations (year with highest energy consumption):

\begin{tabular}{|c|c|c|c|c|c|c|c|c|c|c|c|c|}
\hline ADDRESS: & \multicolumn{4}{|c|}{ Building N - Côte-St-Luc, Quebec } & & & & & & & & \\
\hline BUILDING \# & \multicolumn{4}{|c|}{14} & & & & & & & & \\
\hline Year - Highest Energy Consumption: & \multicolumn{4}{|l|}{2005} & & & & & & & & \\
\hline AREA: & \multicolumn{4}{|l|}{7,943} & & & & & & & & \\
\hline USAGE INDEX: & \multicolumn{4}{|l|}{1.57} & & & & & & & & \\
\hline Month & Jan & $\mathrm{Feb}$ & Mar & Apr & May & Jun & Jul & Aug & Sep & Oct & Nov & Dec \\
\hline \multirow{5}{*}{$\begin{array}{l}\text { Electric Billing Date } \\
\text { Electric Billing Days }\end{array}$} & $31 / 01 / 2005$ & $28 / 02 / 2005$ & $31 / 03 / 2005$ & $30 / 04 / 2005$ & $31 / 05 / 2005$ & 30/06/2005 & $31 / 07 / 2005$ & $31 / 08 / 2005$ & 30/09/2005 & $31 / 10 / 2005$ & $30 / 11 / 2005$ & $31 / 12 / 2005$ \\
\hline & 31 & 28 & 31 & 30 & 31 & 30 & 31 & 31 & 30 & 31 & 30 & 31 \\
\hline & $31 / 01 / 2005$ & $28 / 02 / 2005$ & $31 / 03 / 2005$ & $30 / 04 / 2005$ & $31 / 05 / 2005$ & 30/06/2005 & $31 / 07 / 2005$ & $31 / 08 / 2005$ & $30 / 09 / 2005$ & $31 / 10 / 2005$ & $30 / 11 / 2005$ & $31 / 12 / 2005$ \\
\hline & 31 & 28 & 31 & 30 & 31 & 30 & 31 & 31 & 30 & 31 & 30 & 31 \\
\hline & \multicolumn{12}{|c|}{ COOLING \& HEATING DEGREE DAYS } \\
\hline & & & & & & & & & & & & \\
\hline \multirow{4}{*}{$\begin{array}{l}\text { Cooling D.D. (Highest Year) } \\
\text { Daily Clg D.D. Avg. (Highest Year) } \\
\text { Normal Cooling D.D. (Highest Year) }\end{array}$} & 0 & 0 & 0 & 0 & 1 & 146 & 189 & 141 & 52 & 8 & 0 & 0 \\
\hline & 0 & 0 & 0 & 0 & 0 & 5 & 6 & 5 & 2 & 0 & 0 & 0 \\
\hline & & & & & & & & & & & & \\
\hline & 770 & 616 & 609 & 307 & 189 & 9 & 0 & 0 & 23 & 220 & 388 & 643 \\
\hline \multirow{3}{*}{$\begin{array}{l}\text { Heating D.D. (Highest Year) } \\
\text { Daily Htg. D.D. Avg. (Highest Year) } \\
\text { Normal Heating D.D (Highest Year) }\end{array}$} & 25 & 22 & 20 & 10 & 6 & 0 & 0 & 0 & 1 & 7 & 13 & 21 \\
\hline & & & & & & & & & & & & \\
\hline & & & & & & & & & & & & \\
\hline \multicolumn{13}{|l|}{ ELECTRICAL USAGE \& COST } \\
\hline \multirow{3}{*}{$\begin{array}{l}\text { kWh Used } \\
\text { Daily kWh Avg. }\end{array}$} & 367,200 & 301,200 & 313,200 & 253,200 & 244,800 & 289,200 & 297,600 & 290,400 & 264,000 & 256,800 & 2855,600 & 309,600 \\
\hline & 11,845 & 10,757 & 10,103 & 8,440 & 7,897 & 9,640 & 9,600 & 9,368 & 8,800 & 8,284 & 9,520 & 9,987 \\
\hline & & & & & & & & & & & & \\
\hline Demand kW/RkVA Used & 682 & 614 & 610 & 475 & 452 & 572 & 570 & 508 & 511 & 487 & 574 & 566 \\
\hline \multirow{2}{*}{ Load Factor (Highest Year) } & $72 \%$ & $73 \%$ & $69 \%$ & $74 \%$ & $73 \%$ & $70 \%$ & $70 \%$ & $77 \%$ & $72 \%$ & $71 \%$ & $69 \%$ & $73 \%$ \\
\hline & \multicolumn{12}{|c|}{ NATURAL GAS USAGE \& COST } \\
\hline \multicolumn{13}{|l|}{ CCF } \\
\hline $\mathrm{m}^{\wedge} 3$ Used & 0 & 0 & 0 & 0 & 0 & 0 & 0 & 0 & 0 & 0 & 0 & 0 \\
\hline Daily $\mathrm{m}^{\wedge} 3$ Avg. & 0 & 0 & 0 & 0 & 0 & 0 & 0 & 0 & 0 & 0 & 0 & 0 \\
\hline \multicolumn{13}{|l|}{ GREENHOUSE DATA } \\
\hline \multirow{4}{*}{$\begin{array}{l}\mathrm{CO2} \text { (kgs) (Highest Year) } \\
\text { S02 (kgs) (Highest Year) } \\
\text { N0x (kgs) (Highest Year) }\end{array}$} & 247,025 & 202,625 & 210,698 & 170,335 & 164,684 & 194,553 & 200,204 & 195,360 & 177,600 & 172,756 & 192,131 & 208,276 \\
\hline & 2,669 & 2,189 & 2,276 & 1,840 & 1,779 & 2,102 & 2,163 & 2,111 & 1,919 & 1,866 & 2,076 & 2,250 \\
\hline & 1,170 & 960 & 998 & 807 & 780 & 921 & 948 & 925 & 841 & 818 & 910 & 986 \\
\hline \multirow{2}{*}{\multicolumn{13}{|c|}{ USAGE DATA }} \\
\hline & & & & & & & & & & & & \\
\hline & 1321.92 & 1084.32 & 1127.52 & 911.52 & 881.28 & 1041.12 & 1071.36 & 1045.44 & 950.40 & 924.48 & 1028.16 & 1114.56 \\
\hline GJ/m2/Day ELECTRIC (Highest Year) & 0.005 & 0.005 & 0.005 & 0.004 & 0.004 & 0.004 & 0.004 & 0.004 & 0.004 & 0.004 & 0.004 & 0.005 \\
\hline $\mathrm{GJ} / \mathrm{m} 2 /$ Month (Highest Year) & 0.17 & 0.14 & 0.14 & 0.11 & 0.11 & 0.13 & 0.13 & 0.13 & 0.12 & 0.12 & 0.13 & 0.14 \\
\hline $\mathrm{m} 3$ to GJ & 0.00 & 0.00 & 0.00 & 0.00 & 0.00 & 0.00 & 0.00 & 0.00 & 0.00 & 0.00 & 0.00 & 0.00 \\
\hline GJ/m2/Day GAS (Highest Year) & 0.000 & 0.000 & 0.000 & 0.000 & 0.000 & 0.000 & 0.000 & 0.000 & 0.000 & 0.000 & 0.000 & 0.000 \\
\hline $\mathrm{GJ} / \mathrm{m} 2 /$ Month & 0.00 & 0.00 & 0.00 & 0.00 & 0.00 & 0.00 & 0.00 & 0.00 & 0.00 & 0.00 & 0.00 & 0.00 \\
\hline $\mathrm{m} 3 / \mathrm{m} 2 /$ Month & 0.00 & 0.00 & 0.00 & 0.00 & 0.00 & 0.00 & 0.00 & 0.00 & 0.00 & 0.00 & 0.00 & 0.00 \\
\hline & & & & & & & & & & & & 0005 \\
\hline $\begin{array}{l}\text { GJ/m2/Day ENERGY (Highest Year) } \\
\text { GJ/m2/Month (Highest Consumption Year) }\end{array}$ & $\begin{array}{l}0.005 \\
0.166\end{array}$ & $\begin{array}{l}0.005 \\
0.137\end{array}$ & $\begin{array}{l}0.005 \\
0.142\end{array}$ & $\begin{array}{l}0.004 \\
0.115\end{array}$ & $\begin{array}{l}0.004 \\
0.111\end{array}$ & $\begin{array}{l}0.004 \\
0.131\end{array}$ & $\begin{array}{l}0.004 \\
0.135\end{array}$ & $\begin{array}{l}0.004 \\
0.132\end{array}$ & $\begin{array}{l}0.004 \\
0.120\end{array}$ & $\begin{array}{l}0.004 \\
0.116\end{array}$ & $\begin{array}{l}0.004 \\
0.129\end{array}$ & 0.005 \\
\hline GJ/m2/Month (Highest Consumption Year) & 0.166 & 0.137 & 0.142 & 0.115 & 0.111 & 0.131 & 0.135 & 0.132 & 0.120 & 0.116 & 0.129 & \\
\hline Energy Usage per Month (Electricity + Gas) & 1322 & 1084 & 1128 & 912 & 881 & 1041 & 1071 & 1045 & 950 & 924 & 1028 & 1115 \\
\hline Degree Days & 770 & 616 & 609 & 307 & 190 & 155 & 189 & 141 & 75 & 228 & 388 & 643 \\
\hline
\end{tabular}




\section{Actual data used for calculations (year with lowest energy consumption):}

\begin{tabular}{|c|c|c|c|c|c|c|c|c|c|c|c|c|}
\hline ADDRESS: & \multicolumn{4}{|c|}{ Building N - Côte-St-Luc, Quebec } & & & & & & & & \\
\hline BUILDING \# & \multicolumn{4}{|c|}{14} & & & & & & & & \\
\hline Year - Lowest Energy Consumption: & \multicolumn{4}{|l|}{2006} & & & & & & & & \\
\hline AREA: & \multicolumn{4}{|l|}{7,943} & & & & & & & & \\
\hline USAGE INDEX: & 1.39 & AVERAGE: & 1.4796 & 1.47463 & & & & & & & & \\
\hline Month & Jan & Feb & Mar & Apr & May & Jun & Jul & Aug & Sep & Oct & Nov & Dec \\
\hline \multirow{5}{*}{$\begin{array}{l}\text { Electric Billing Date } \\
\text { Electric Billing Days }\end{array}$} & $31 / 01 / 2006$ & $28 / 02 / 2006$ & $31 / 03 / 2006$ & $30 / 04 / 2006$ & $31 / 05 / 2006$ & $30 / 06 / 2006$ & $31 / 07 / 2006$ & $31 / 08 / 2006$ & $30 / 09 / 2006$ & $31 / 10 / 2006$ & $30 / 11 / 2006$ & $31 / 12 / 2006$ \\
\hline & 31 & 28 & 31 & 30 & 31 & 30 & 31 & 31 & 30 & 31 & 30 & 31 \\
\hline & $31 / 01 / 2006$ & $28 / 02 / 2006$ & $31 / 03 / 2006$ & $30 / 04 / 2006$ & $31 / 05 / 2006$ & $30 / 06 / 2006$ & $31 / 07 / 2006$ & $31 / 08 / 2006$ & $30 / 09 / 2006$ & $31 / 10 / 2006$ & $30 / 11 / 2006$ & $31 / 12 / 2006$ \\
\hline & 31 & 28 & 31 & 30 & 31 & 30 & 31 & 31 & 30 & 31 & 30 & 31 \\
\hline & \multicolumn{12}{|c|}{ COOLING \& HEATING DEGREE DAYS } \\
\hline & & & & & & & & & & & & \\
\hline \multirow{3}{*}{$\begin{array}{l}\text { Cooling D.D. (Lowest Year) } \\
\text { Daily Clg D.D. Avg. (Lowest Year) } \\
\text { Normal Cooling D.D. (Lowest Year) }\end{array}$} & 0 & 0 & 0 & 0 & 26 & 74 & 167 & 102 & 13 & 1 & 0 & 0 \\
\hline & 0 & 0 & 0 & 0 & 1 & 2 & 5 & 3 & 0 & 0 & 0 & 0 \\
\hline & & & & & & & & & & & & \\
\hline \multirow{4}{*}{$\begin{array}{l}\text { Heating D.D. (Lowest Year) } \\
\text { Daily Htg. D.D. Avg. (Lowest Year) } \\
\text { Normal Heating D.D (Lowest Year) }\end{array}$} & 552 & 604 & 517 & 293 & 137 & 20 & 0 & 4 & 81 & 288 & 382 & 483 \\
\hline & 18 & 22 & 17 & 10 & 4 & 1 & 0 & 0 & 3 & 9 & 13 & 16 \\
\hline & & & & & & & & & & & & \\
\hline & & & & & & & & & & & & \\
\hline \multicolumn{13}{|l|}{ ELECTRICAL USAGE \& COST } \\
\hline kWh Used & 315,600 & 291,600 & 288,000 & 235,200 & 232,800 & 238,800 & 265,200 & 242,400 & 219,600 & 229,200 & 226,800 & 271,200 \\
\hline \multirow[t]{2}{*}{ Daily kWh Avg. } & 10,181 & 10,414 & 9,290 & 7,840 & 7,510 & 7,960 & 8,555 & 7,819 & 7,320 & 7,394 & 7,560 & 8,748 \\
\hline & & & & & & & & & & & & \\
\hline Demand kW/RkVA Used & 598 & 616 & 595 & 448 & 498 & 449 & 475 & 464 & 442 & 409 & 416 & 514 \\
\hline \multirow{2}{*}{ Load Factor (Lowest Year) } & $71 \%$ & $70 \%$ & $65 \%$ & $73 \%$ & $63 \%$ & $74 \%$ & $75 \%$ & $70 \%$ & $69 \%$ & $75 \%$ & $76 \%$ & $71 \%$ \\
\hline & & & & & & & & & & & & \\
\hline \multicolumn{13}{|l|}{ NATURAL GAS USAGE \& COST } \\
\hline \multicolumn{13}{|l|}{ CCF } \\
\hline $\mathrm{m}^{\wedge} 3$ Used & 0 & 0 & 0 & 0 & 0 & 0 & 0 & 0 & 0 & 0 & 0 & 0 \\
\hline \multirow[t]{2}{*}{ Daily $\mathrm{m}^{\wedge} 3$ Avg. } & 0 & 0 & 0 & 0 & 0 & 0 & 0 & 0 & 0 & 0 & 0 & 0 \\
\hline & & & & & & & & & & & & \\
\hline \multicolumn{13}{|l|}{ GREENHOUSE DATA } \\
\hline "C02 (kgs) (Lowest Year) & 212,313 & 196,167 & 193,745 & 158,225 & 156,611 & 160,647 & 178,407 & 163,069 & 147,731 & 154,189 & 152,575 & 182,444 \\
\hline S02 (kgs) (Lowest Year) & 2,294 & 2,119 & 2,093 & 1,709 & 1,692 & 1,736 & 1,928 & 1,762 & 1,596 & 1,666 & 1,648 & 1,971 \\
\hline NOx (kgs) (Lowest Year) & 1,006 & 929 & 918 & 749 & 742 & 761 & 845 & 772 & 700 & 730 & 723 & 864 \\
\hline USAGE DATA & & & & & & & & & & & & \\
\hline kWh to GJ & 1136.16 & 1049.76 & 1036.80 & 846.72 & 838.08 & 859.68 & 954.72 & 872.64 & 790.56 & 825.12 & 816.48 & 976.32 \\
\hline $\mathrm{GJ} / \mathrm{m} 2 /$ Day ELECTRIC (Lowest Year) & 0.005 & 0.005 & 0.004 & 0.004 & 0.003 & 0.004 & 0.004 & 0.004 & 0.003 & 0.003 & 0.003 & 0.004 \\
\hline $\mathrm{GJ} / \mathrm{m} 2 /$ Month (Lowest Year) & 0.14 & 0.13 & 0.13 & 0.11 & 0.11 & 0.11 & 0.12 & 0.11 & 0.10 & 0.10 & 0.10 & 0.12 \\
\hline & & & & & & & & & & & & \\
\hline $\begin{array}{l}\mathrm{m} 3 \text { to GJ } \\
\mathrm{GJ} / \mathrm{m} 2 / \text { Day GAS (Lowest Year) }\end{array}$ & $\begin{array}{l}0.00 \\
0.000\end{array}$ & $\begin{array}{c}0.00 \\
0.000\end{array}$ & $\begin{array}{l}0.00 \\
0.000\end{array}$ & $\begin{array}{l}0.00 \\
0.000\end{array}$ & $\begin{array}{l}0.00 \\
0.000\end{array}$ & $\begin{array}{l}0.00 \\
0.000\end{array}$ & $\begin{array}{c}0.00 \\
0.000\end{array}$ & $\begin{array}{c}0.00 \\
0.000\end{array}$ & 0.00 & $\begin{array}{c}0.00 \\
0.000\end{array}$ & $\begin{array}{l}0.00 \\
0.000\end{array}$ & 0.00 \\
\hline $\mathrm{GJ} / \mathrm{m} 2 /$ Month & 0.00 & 0.00 & 0.00 & 0.00 & 0.00 & 0.00 & 0.00 & 0.00 & 0.00 & 0.00 & 0.00 & 0.00 \\
\hline $\mathrm{m} 3 / \mathrm{m} 2 /$ Month & 0.00 & 0.00 & 0.00 & 0.00 & 0.00 & 0.00 & 0.00 & 0.00 & 0.00 & 0.00 & 0.00 & 0.00 \\
\hline GJ/m2/Day ENERGY (Lowest Year) & 0.005 & 0.005 & 0.004 & 0.004 & 0.003 & 0.004 & 0.004 & 0.004 & 0.003 & 0.003 & 0.003 & 0.004 \\
\hline $\mathrm{GJ} / \mathrm{m} 2 /$ Month (Lowest Consumption Year) & 0.143 & 0.132 & 0.131 & 0.107 & 0.106 & 0.108 & 0.120 & 0.110 & 0.100 & 0.104 & 0.103 & 0.123 \\
\hline Average Highest Year to Lowest Year & 0.155 & 0.134 & 0.136 & 0.111 & 0.108 & 0.120 & 0.128 & 0.121 & 0.110 & 0.110 & 0.116 & 0.132 \\
\hline BOMA Mean Value per Month & 0.111 & 0.111 & 0.111 & 0.111 & 0.111 & 0.111 & 0.111 & 0.111 & 0.111 & 0.111 & 0.111 & 0.111 \\
\hline Energy Usage per Month (Electricity + Gas) & 1136 & 1050 & 1037 & 847 & 838 & 860 & 955 & 873 & 791 & 825 & 816 & 976 \\
\hline Degree Days & 552 & 604 & 517 & 293 & 163 & 93 & 167 & 106 & 94 & 289 & 382 & 483 \\
\hline Normalized Data (Average Degree Days) & 588 & 618 & 536 & 326 & 148 & 93 & 145 & 102 & 102 & 249 & 430 & 572 \\
\hline Normalized Data (Av Energy Consumption) & 1084 & 1096 & 1062 & 976 & 903 & 880 & 902 & 884 & 884 & 945 & 1019 & 1077 \\
\hline Normalized Data (Av Energy Index / month) & 0.136 & 0.138 & 0.134 & 0.123 & 0.114 & 0.111 & 0.114 & 0.111 & 0.111 & 0.119 & 0.128 & 0.136 \\
\hline
\end{tabular}


Analysis on how electricity and gas consumption corresponds to heating and cooling periods (for highest energy consumption year):

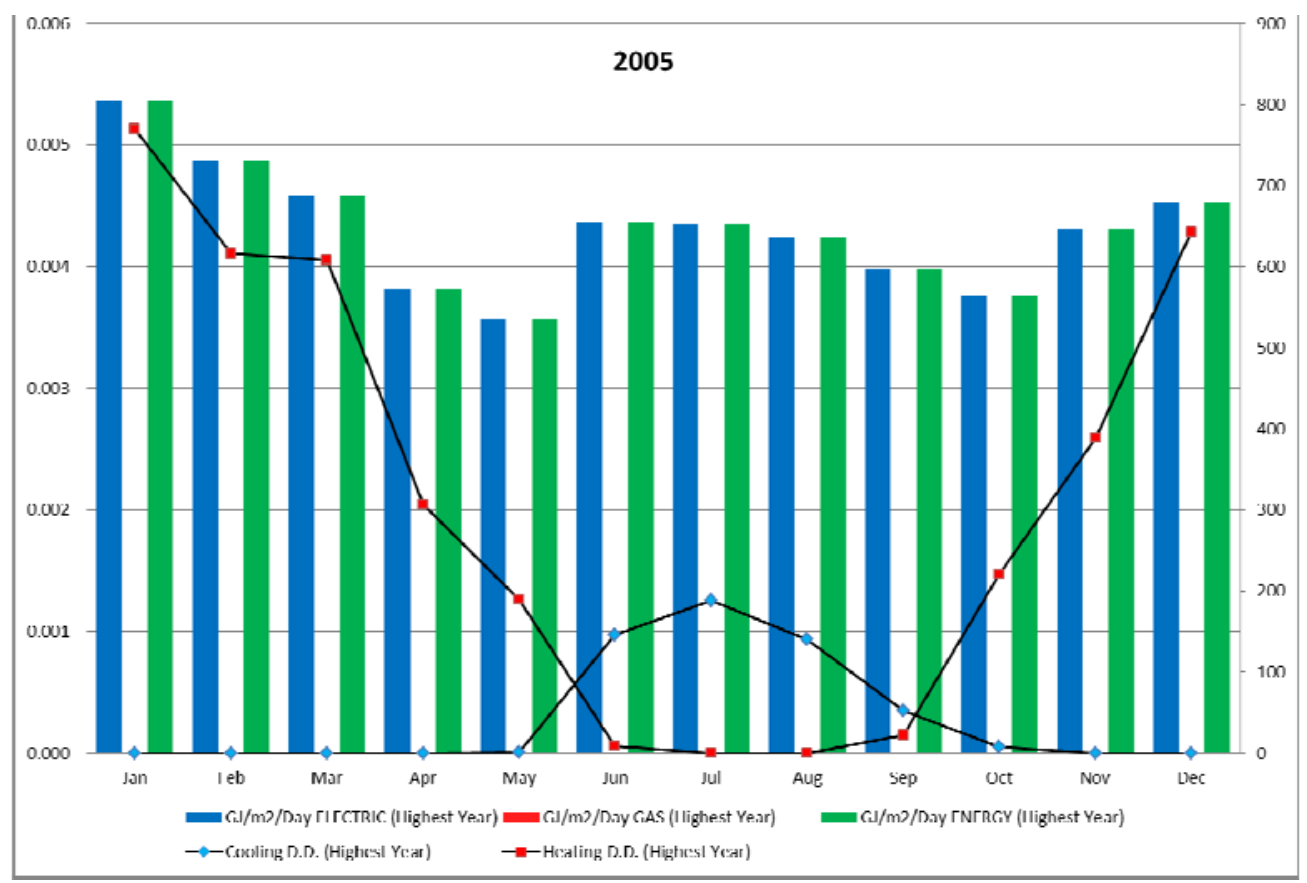

Analysis on how electricity and gas consumption corresponds to heating and cooling periods (for lowest energy consumption year):

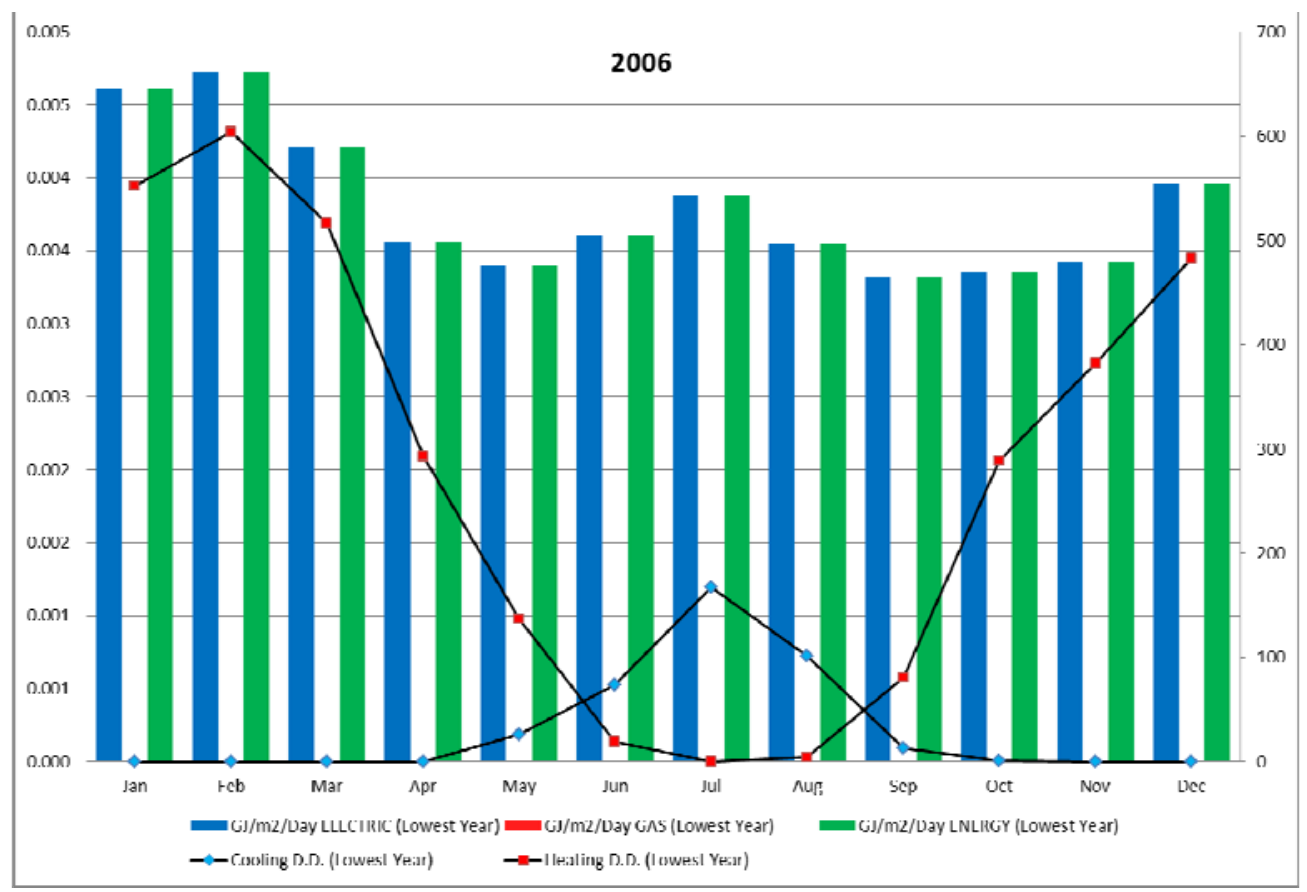


Monthly energy index comparison between highest energy consumption year, lowest, average and benchmark (BOMA) energy intensity:

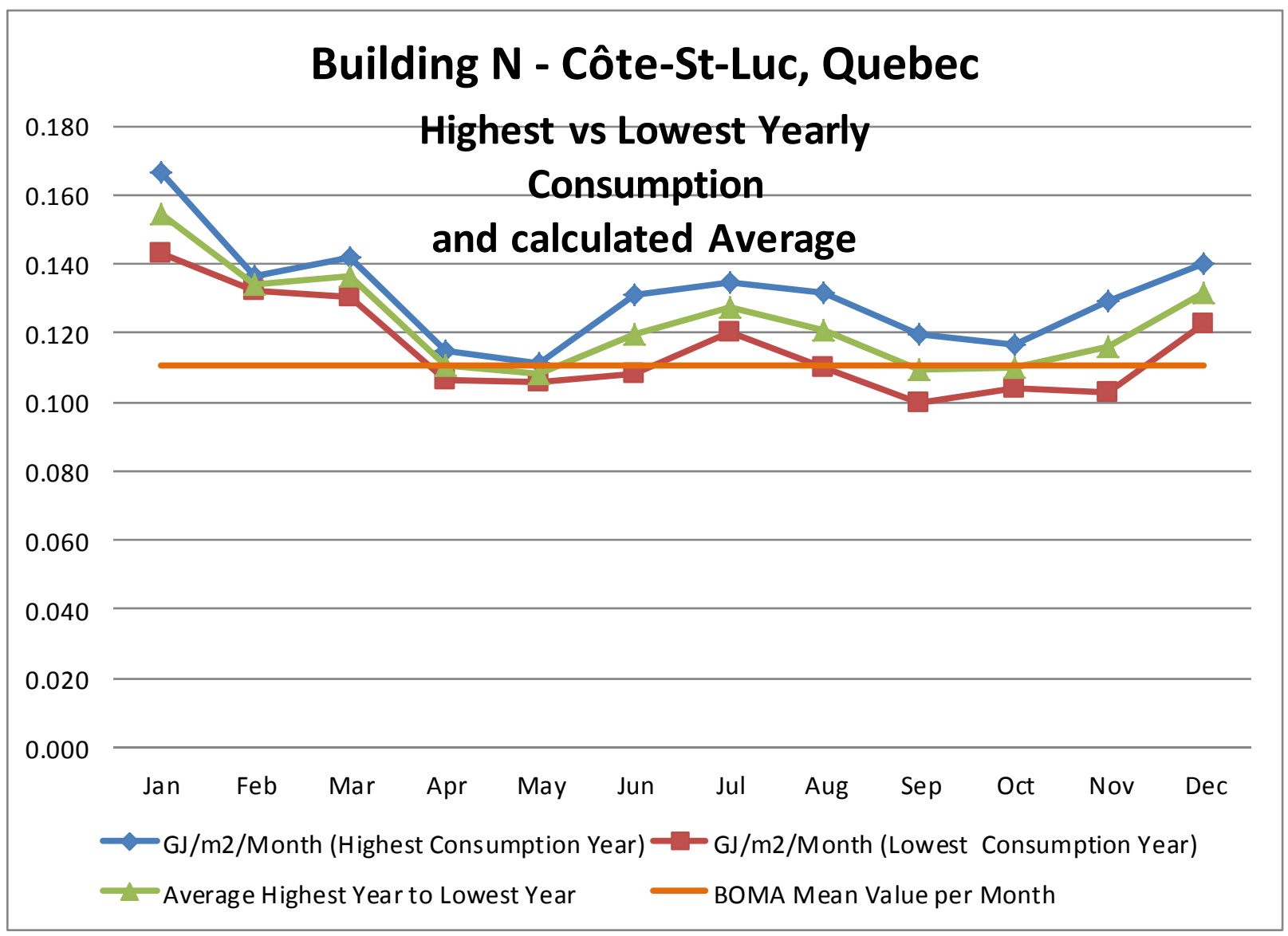


Building \#15 - Utility Bills Analysis

\section{Calculations of Energy Index for Building \#15}

Energy CAP database was utilized to collect energy consumption information for the building. Energy consumption was provided by utility bills for electricity and gas. For Building \#15 utility bills were provided from December 2006 to March 2015. To complete most accurate analysis utility bills for 2007 to 2014 were only analyzed because 2006 and 2015 has incomplete data. By having total floor area for entire building of $5,518 \mathrm{~m}^{2}$, energy index in $\mathrm{GJ} / \mathrm{m}^{2} /$ year was calculated. From calculations it was noticed that electrical utility bills data was consistent throughout years, however gas consumption in 2007 showed lower value in comparison to other years, after analysing utility bills in more details it was concluded that gas bills for 2007 provided incomplete information. Therefore 2007 was excluded from further calculations.

Utility bills analysis showed following:

\begin{tabular}{|c|c|c|c|c|c|c|c|c|}
\hline \multicolumn{4}{|c|}{ Building 0 - Gatineau, Quebec } & & & \multirow[b]{2}{*}{$\mathrm{m}^{3}$-ngas } & \multirow[b]{2}{*}{ Total GJ/yr } & \multirow[b]{2}{*}{$5,518.00$} \\
\hline & & & kWh & & & & & \\
\hline Row Labels & \multicolumn{2}{|c|}{$\begin{array}{c}\text { Sum of Ele Total } \\
\text { Cost / Year }\end{array}$} & $\begin{array}{c}\text { Sum of Ele } \\
\text { Consumption / } \\
\text { Year }\end{array}$ & \multicolumn{2}{|c|}{$\begin{array}{c}\text { Sum of Gas Total } \\
\text { Cost / Year }\end{array}$} & $\begin{array}{c}\text { Sum of Gas } \\
\text { Consumption / } \\
\text { Year }\end{array}$ & Total & $\mathrm{GJ} / \mathrm{m} 2 / \mathrm{yr}$ \\
\hline Year 2006 & $\$$ & $31,318.60$ & $311,000.00$ & $\$$ & 374.09 & 842.00 & & \\
\hline Year 2007 & $\$$ & $164,142.20$ & $2,039,760.00$ & $\$$ & $22,029.21$ & $38,282.00$ & $8,767.23$ & 1.59 \\
\hline Year 2008 & $\$$ & $168,291.14$ & $2,050,800.00$ & $\$$ & $39,369.68$ & $68,116.00$ & $9,916.80$ & 1.80 \\
\hline Year 2009 & $\$$ & $164,229.61$ & $1,953,360.00$ & $\$$ & $28,490.79$ & $56,888.00$ & $9,148.33$ & 1.66 \\
\hline Year 2010 & $\$$ & $160,678.74$ & $1,911,120.00$ & $\$$ & $32,887.37$ & $77,227.00$ & $9,752.88$ & 1.77 \\
\hline Year 2011 & $\$$ & $159,909.60$ & $1,989,600.00$ & $\$$ & $25,887.21$ & $65,179.00$ & $9,587.22$ & 1.74 \\
\hline Year 2012 & $\$$ & $160,769.69$ & $1,895,280.00$ & $\$$ & $19,638.44$ & $50,486.00$ & $8,701.09$ & 1.58 \\
\hline Year 2013 & $\$$ & $160,200.71$ & $1,826,160.00$ & $\$$ & $23,631.94$ & $58,127.00$ & $8,736.50$ & 1.58 \\
\hline Year 2014 & $\$$ & $153,304.00$ & $1,725,600.00$ & $\$$ & $34,948.78$ & $72,948.61$ & $8,925.85$ & 1.62 \\
\hline Year 2015 & $\$$ & $69,009.91$ & $751,320.00$ & $\$$ & $22,851.39$ & $42,916.00$ & & \\
\hline Average & $\$$ & $161,054.78$ & $1,907,417.14$ & $\$$ & $29,264.89$ & $64,138.80$ & & 1.68 \\
\hline
\end{tabular}

As it was specified in energy audit, energy consumption of the Building \#15 is moderately high in comparison to similar office buildings in same region; and therefore average energy index which equals to $1.68 \mathrm{GJ} / \mathrm{m}^{2} / \mathrm{yr}$ is also high in comparison to benchmark values of BOMA energy efficient building value of $1.05 \mathrm{GJ} / \mathrm{m}^{2} / \mathrm{yr}$, and then average National Resources Canada value of $1.43 \mathrm{GJ} / \mathrm{m} 2 /$ year..

Two charts below show electricity and gas consumption per year. Electricity consumption chart demonstrates prominent decrease in energy usage, with 2013 and 2014 having the lowest values. On the other hand gas consumption chart show increase in energy consumption with 2014 much higher than previous years. 

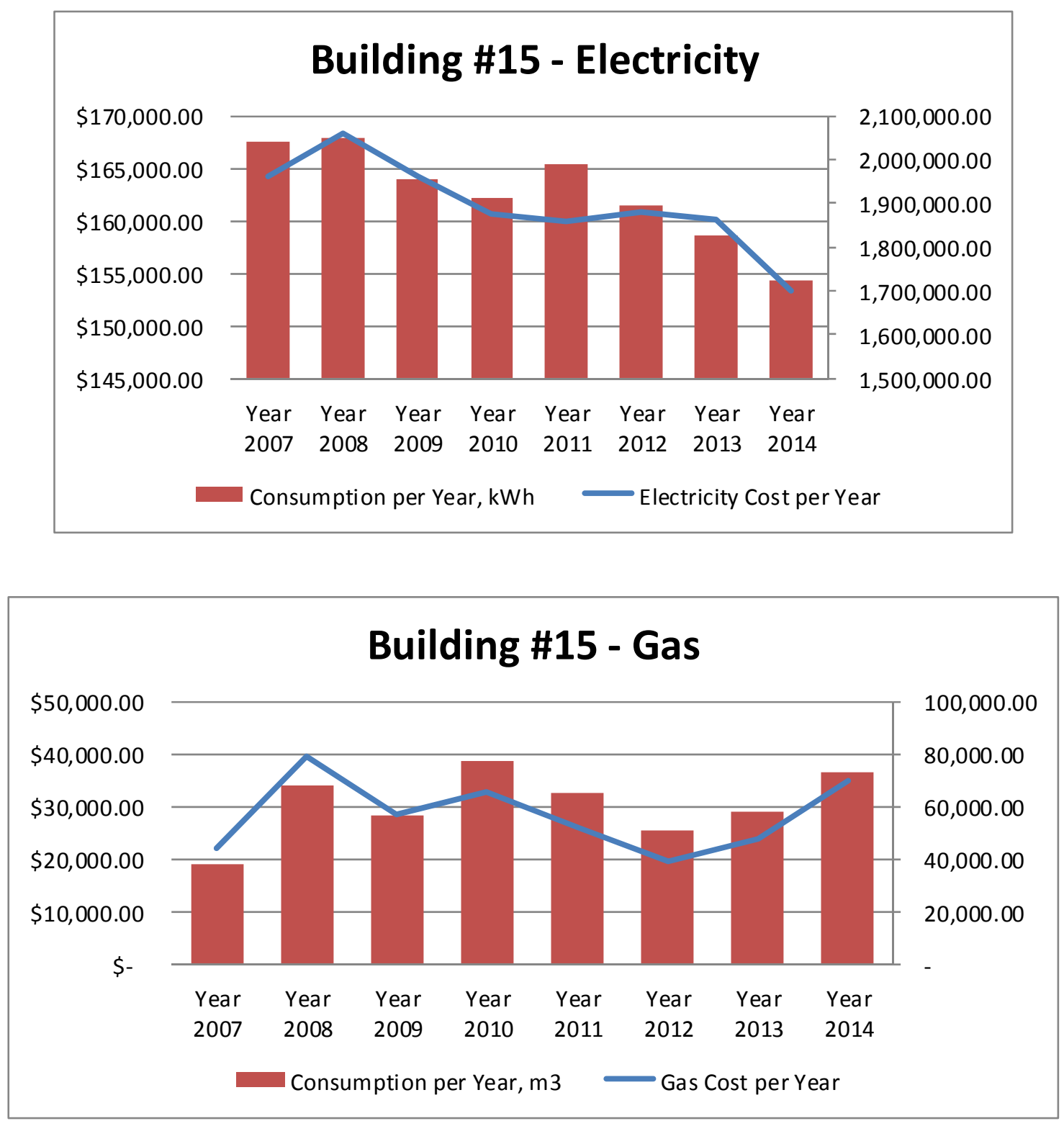

Yearly energy intensity (index) was also plotted to demonstrate increase or decrease over the range of years for which data is available. Chart below shows that energy index value is gradually decreasing with few jumps in 2008 and 2010. The lowest energy index was in 2012 and highest in 2008. These two years' data will be used for further calculations and comparisons. 


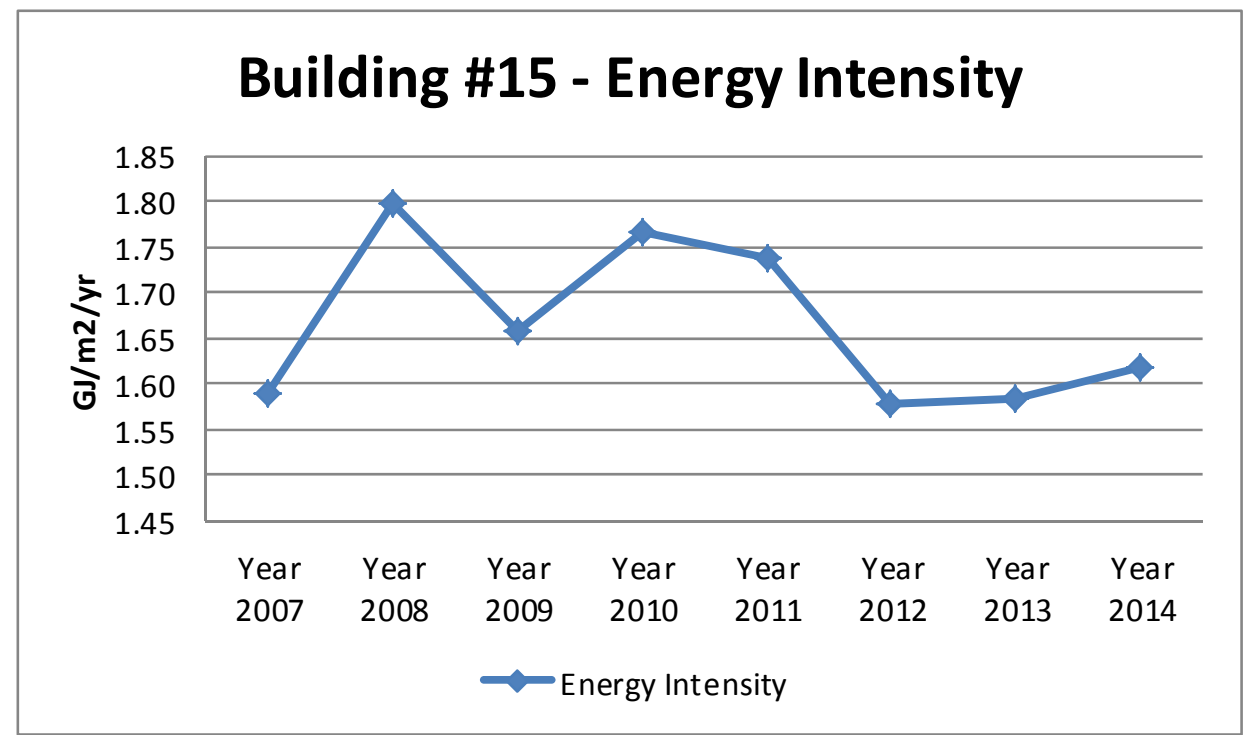

Normalized total energy consumption was calculated for Building \#15. Based on plotted results, shown below in the chart, it can be concluded that energy consumption for 2008 is higher than for 2012. This proves that regardless of weather conditions 2008 has higher energy consumptions than in 2012. Implementing trendline equations, average equation was calculated:

\section{$\gamma=0.6627 x+561.84$}

From above equation normalized average energy index was calculated as $1.69 \mathrm{GJ} / \mathrm{m}^{2} / \mathrm{yr}$, this value is slightly higher than average for 2007 to 2014 years range. Calculated value will be used for further case-study buildings comparison. 


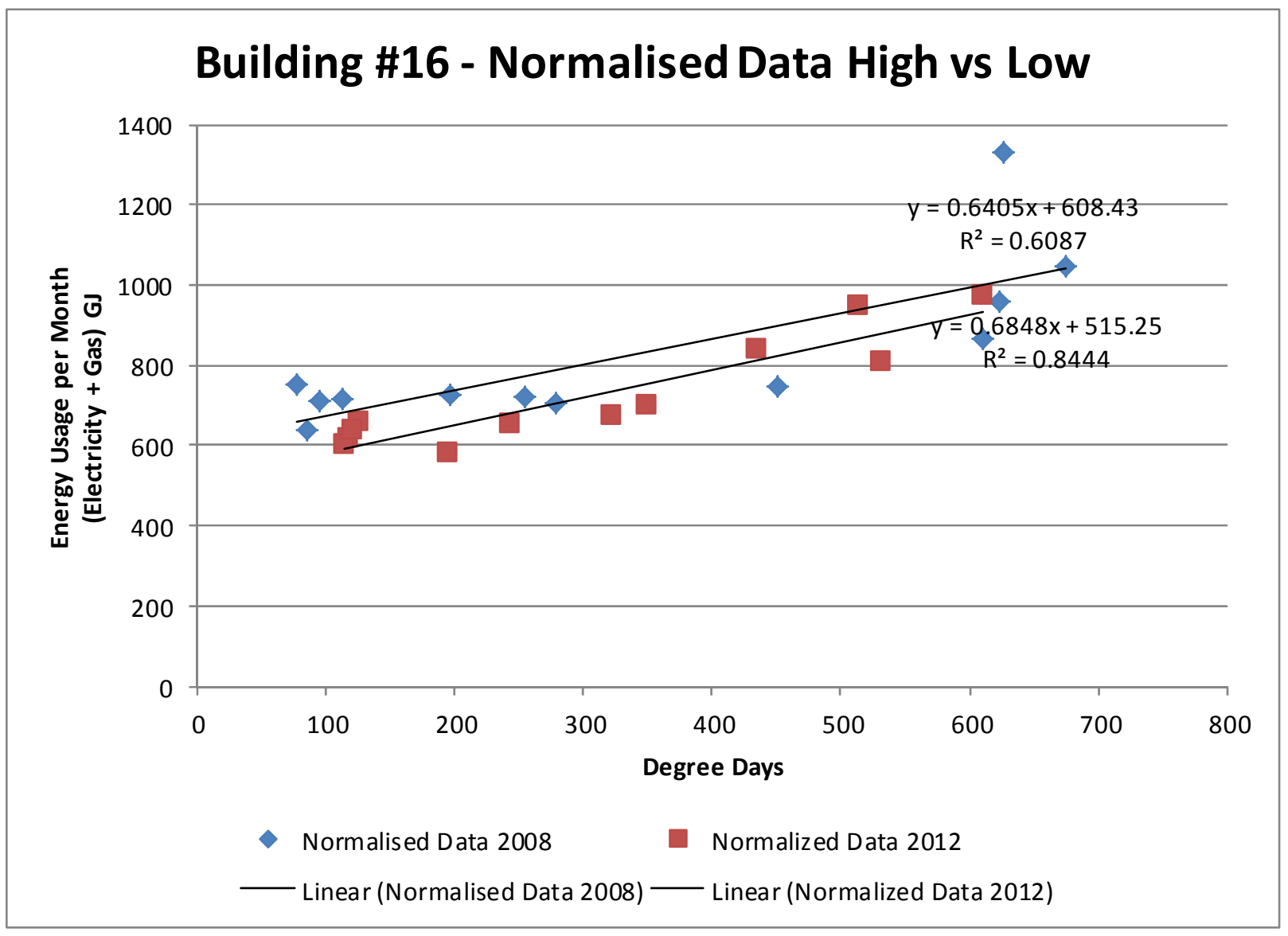


Actual data used for calculations (year with highest energy consumption):

\begin{tabular}{|c|c|c|c|c|c|c|c|c|c|c|c|c|}
\hline ADDRESS: & \multicolumn{4}{|c|}{ Building O - Gatineau, Quebec } & & & & & & & & \\
\hline BUILDING\# & \multicolumn{4}{|c|}{15} & & & & & & & & \\
\hline Year - Highest Energy Consumption: & \multicolumn{4}{|l|}{2008} & & & & & & & & \\
\hline AREA: & \multicolumn{4}{|l|}{5,518} & & & & & & & & \\
\hline USAGE INDEX: & \multicolumn{4}{|l|}{1.80} & & & & & & & & \\
\hline Month & Jan & $\mathrm{Feb}$ & Mar & Apr & May & Jun & Jul & Aug & Sep & Oct & Nov & Dec \\
\hline \multirow{5}{*}{$\begin{array}{l}\text { Electric Billing Date } \\
\text { Electric Billing Days }\end{array}$} & $31 / 01 / 2008$ & $03 / 03 / 2008$ & $01 / 04 / 2008$ & $01 / 05 / 2008$ & $02 / 06 / 2008$ & $03 / 07 / 2008$ & $01 / 08 / 2008$ & $02 / 09 / 2008$ & $02 / 10 / 2008$ & $03 / 11 / 2008$ & $03 / 12 / 2008$ & $06 / 01 / 2009$ \\
\hline & 31 & 32 & 29 & 30 & 32 & 31 & 29 & 32 & 30 & 32 & 30 & 34 \\
\hline & $01 / 02 / 2008$ & $04 / 03 / 2008$ & $02 / 04 / 2008$ & $01 / 05 / 2008$ & $30 / 05 / 2008$ & $02 / 07 / 2008$ & 29/07/2008 & $02 / 09 / 2008$ & $29 / 09 / 2008$ & $31 / 10 / 2008$ & $27 / 11 / 2008$ & $02 / 01 / 2009$ \\
\hline & 31 & 32 & 29 & 29 & 29 & 33 & 27 & 35 & 27 & 32 & 27 & 36 \\
\hline & \multicolumn{12}{|c|}{ COOLING \& HEATING DEGREE DAYS } \\
\hline \multirow{4}{*}{$\begin{array}{l}\text { Cooling D.D. (Highest Year) } \\
\text { Daily Clg D.D. Avg. (Highest Year) } \\
\text { Normal Cooling D.D. (Highest Year) }\end{array}$} & & & & & & & & & & & & \\
\hline & 0 & 0 & 0 & 0 & 3 & 72 & 111 & 64 & 27 & 0 & 0 & 0 \\
\hline & 0 & 0 & 0 & 0 & 0 & 2 & 4 & 2 & 1 & 0 & 0 & 0 \\
\hline & & & & & & & & & & & & \\
\hline \multirow{4}{*}{$\begin{array}{l}\text { Heating D.D. (Highest Year) } \\
\text { Daily Htg. D.D. Avg. (Highest Year) } \\
\text { Normal Heating D.D (Highest Year) }\end{array}$} & 624 & 675 & 610 & 254 & 194 & 23 & 1 & 13 & 59 & 279 & 452 & 627 \\
\hline & 20 & 21 & 21 & 9 & 7 & 1 & 0 & 0 & 2 & 9 & 17 & 17 \\
\hline & & & & & & & & & & & & \\
\hline & & & & & & & & & & & & \\
\hline \multicolumn{13}{|l|}{ ELECTRICAL USAGE \& COST } \\
\hline kWh Used & 205,200 & $\begin{array}{l}182,400 \\
\end{array}$ & $\begin{array}{l}149,760 \\
\end{array}$ & $\begin{array}{l}147,840 \\
\end{array}$ & 1446,400 & 164,880 & $\begin{array}{l}164,160 \\
\end{array}$ & $\begin{array}{l}170,160 \\
\end{array}$ & 150,720 & 153,120 & 170,880 & 245,280 \\
\hline \multirow{2}{*}{ Daily kWh Avg. } & 6,619 & 5,700 & 5,164 & 5,098 & 5,048 & 4,996 & 6,080 & 4,862 & 5,582 & 4,785 & 6,329 & 6,813 \\
\hline & & & & & & & & & & & & \\
\hline Demand kW/RkVA Used & 371 & 348 & 329 & 332 & 305 & 335 & 359 & 342 & 346 & 308 & 339 & 408 \\
\hline \multirow[t]{2}{*}{ Load Factor (Highest Year) } & $74 \%$ & $68 \%$ & $66 \%$ & $62 \%$ & $63 \%$ & $66 \%$ & $66 \%$ & $65 \%$ & $61 \%$ & $65 \%$ & $70 \%$ & $74 \%$ \\
\hline \multirow{2}{*}{\multicolumn{13}{|c|}{ NATURAL GAS USAGE \& COST }} \\
\hline & & & & & & & & & & & & \\
\hline \multicolumn{13}{|l|}{ CCFF } \\
\hline $\mathrm{m}^{\wedge} 3$ Used & 5,960 & 10,448 & 8,724 & 5,075 & 5,353 & 3,204 & 3,302 & 3,742 & 2,604 & 4,115 & 3,550 & 12,039 \\
\hline \multirow{2}{*}{ Daily $\mathrm{m}^{\wedge} 3$ Avg. } & 192 & 327 & 301 & 175 & 185 & 97 & 122 & 107 & 96 & 129 & 131 & 334 \\
\hline & \multicolumn{12}{|c|}{ GREENHOUSE DATA } \\
\hline \multirow{4}{*}{$\begin{array}{l}\text { C02 (kgs) (Highest Year) } \\
\text { S02 (kgs) (Highest Year) } \\
\text { NOx (kgs) (Highest Year) }\end{array}$} & 180,223 & 196,647 & 162,488 & 135,372 & 136,371 & 133,594 & 133,803 & 140,954 & 119,822 & 132,130 & 140,079 & 250,208 \\
\hline & 1,947 & 2,125 & 1,756 & 1,463 & 1,473 & 1,443 & 1,446 & 1,523 & 1,295 & 1,428 & 1,513 & 2,703 \\
\hline & 854 & 931 & 770 & 641 & 646 & 633 & 634 & 668 & 568 & 626 & 663 & 1,185 \\
\hline \multirow{2}{*}{\multicolumn{13}{|c|}{ USAGE DATA }} \\
\hline & & & & & & & & & & & & \\
\hline & 738.72 & 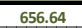 & 539.14 & 532.22 & 527.04 & 593.57 & 590.98 & 612.58 & 542.59 & 551.23 & 615.17 & 883.01 \\
\hline $\mathrm{GJ} / \mathrm{m} 2 /$ Day ELECTRIC (Highest Year) & 0.004 & 0.004 & 0.003 & 0.003 & 0.003 & 0.003 & 0.004 & 0.003 & 0.003 & 0.003 & 0.004 & 0.005 \\
\hline $\mathrm{GJ} / \mathrm{m} 2 /$ Month (Highest Year) & 0.13 & 0.12 & 0.10 & 0.10 & 0.10 & 0.11 & 0.11 & 0.11 & 0.10 & 0.10 & 0.11 & 0.16 \\
\hline m3 to GJ & 221.71 & 388.67 & 324.53 & 188.79 & 199.13 & 119.19 & 122.83 & 139.20 & 96.87 & 153.08 & 132.06 & 447.85 \\
\hline GJ/m2/Day GAS (Highest Year) & 0.001 & 0.002 & 0.002 & 0.001 & 0.001 & 0.001 & 0.001 & 0.001 & 0.001 & 0.001 & 0.001 & 0.002 \\
\hline $\mathrm{GJ} / \mathrm{m} 2 /$ Month & 0.04 & 0.07 & 0.06 & 0.03 & 0.04 & 0.02 & 0.02 & 0.03 & 0.02 & 0.03 & 0.02 & 0.08 \\
\hline $\mathrm{m} 3 / \mathrm{m} 2 /$ Month & 1.08 & 1.89 & 1.58 & 0.92 & 0.97 & 0.58 & 0.60 & 0.68 & 0.47 & 0.75 & 0.64 & 2.18 \\
\hline GJ/m2/Day ENERGY (Highest Year) & 0.006 & 0.006 & 0.005 & 0.004 & 0.004 & 0.004 & 0.005 & 0.004 & 0.004 & 0.004 & 0.005 & 0.007 \\
\hline $\mathrm{GJ} / \mathrm{m} 2 /$ Month (Highest Consumption Year) & 0.174 & 0.189 & 0.157 & 0.131 & 0.132 & 0.129 & 0.129 & 0.136 & 0.116 & 0.128 & 0.135 & 0.241 \\
\hline Energy Usage per Month (Electricity + Gas) & 960 & 1045 & 864 & 721 & 726 & 713 & 714 & 752 & 639 & 704 & 747 & 1331 \\
\hline Degree Days & 624 & 675 & 610 & 254 & 196 & 94 & 112 & 77 & 86 & 279 & 452 & 627 \\
\hline
\end{tabular}




\section{Actual data used for calculations (year with lowest energy consumption):}

\begin{tabular}{|c|c|c|c|c|c|c|c|c|c|c|c|c|}
\hline ADDRESS: & \multicolumn{4}{|c|}{ Building O - Gatineau, Quebec } & & & & & & & & \\
\hline BUILDING\# & \multicolumn{4}{|c|}{15} & & & & & & & & \\
\hline Year - Lowest Energy Consumption: & \multicolumn{4}{|l|}{2012} & & & & & & & & \\
\hline AREA: & \multicolumn{4}{|l|}{5,518} & & & & & & & & \\
\hline USAGE INDEX: & 1.58 & AVERAGE: & 1.6870 & 1.68719 & & & & & & & & \\
\hline Month & Jan & Feb & Mar & Apr & May & Jun & Jul & Aug & Sep & Oct & Nov & Dec \\
\hline \multirow{5}{*}{$\begin{array}{l}\text { Electric Billing Date } \\
\text { Electric Billing Days }\end{array}$} & $01 / 02 / 2012$ & $02 / 03 / 2012$ & $02 / 04 / 2012$ & $01 / 05 / 2012$ & $31 / 05 / 2012$ & $02 / 07 / 2012$ & $29 / 07 / 2012$ & $28 / 08 / 2012$ & $30 / 09 / 2012$ & $30 / 10 / 2012$ & $30 / 11 / 2012$ & $30 / 12 / 2012$ \\
\hline & 31 & 30 & 31 & 29 & 30 & 32 & 27 & 30 & 33 & 30 & 31 & 30 \\
\hline & $31 / 01 / 2012$ & $01 / 03 / 2012$ & 29/03/2012 & $29 / 04 / 2012$ & $31 / 05 / 2012$ & $03 / 07 / 2012$ & $01 / 08 / 2012$ & $30 / 08 / 2012$ & $28 / 09 / 2012$ & $30 / 10 / 2012$ & $29 / 11 / 2012$ & $31 / 12 / 2012$ \\
\hline & 31 & 30 & 28 & 31 & 32 & 33 & 29 & 29 & 29 & 32 & 30 & 32 \\
\hline & \multicolumn{12}{|c|}{ COOLING \& HEATING DEGREE DAYS } \\
\hline & & & & & & & & & & & & \\
\hline \multirow{3}{*}{$\begin{array}{l}\text { Cooling D.D. (Lowest Year) } \\
\text { Daily Clg D.D. Avg. (Lowest Year) } \\
\text { Normal Cooling D.D. (Lowest Year) }\end{array}$} & 0 & 0 & 0 & 0 & 37 & 102 & 195 & 112 & 36 & 1 & 0 & 0 \\
\hline & 0 & 0 & 0 & 0 & 1 & 3 & 7 & 4 & 1 & 0 & 0 & 0 \\
\hline & & & & & & & & & & & & \\
\hline \multirow{4}{*}{$\begin{array}{l}\text { Heating D.D. (Lowest Year) } \\
\text { Daily Htg. D.D. Avg. (Lowest Year) } \\
\text { Normal Heating D.D (Lowest Year) }\end{array}$} & 611 & 532 & 349 & 322 & 81 & 23 & 0 & 2 & 85 & 243 & 434 & 513 \\
\hline & 20 & 18 & 12 & 10 & 3 & 1 & 0 & 0 & 3 & 8 & 14 & 16 \\
\hline & & & & & & & & & & & & \\
\hline & \multirow{2}{*}{\multicolumn{8}{|c|}{ ELECTRICAL USAGE \& COST }} & & & & \\
\hline $\begin{array}{l}\text { ELECTRICAL USAGE \& COST } \\
\text { kWh Used }\end{array}$ & & & & & 138,480 & 153,360 & 139,200 & 141,840 & & & & \\
\hline \multirow{2}{*}{$\begin{array}{l}\text { kWh Used } \\
\text { Daily kWh Avg. }\end{array}$} & $\begin{array}{c}192,000 \\
6,194\end{array}$ & $\begin{array}{c}1 / 9,520 \\
5,984\end{array}$ & $\begin{array}{c}163,920 \\
5,854\end{array}$ & $\begin{array}{c}148,080 \\
4,777\end{array}$ & 4,328 & 4,647 & 4,800 & 4,891 & 14,280 & 4,380 & 5,640 & 5,633 \\
\hline & & & & & & & & & & & & \\
\hline \multirow{3}{*}{$\begin{array}{l}\text { Demand kW/RkVA Used } \\
\text { Load Factor (Lowest Year) }\end{array}$} & 396 & 342 & 351 & 313 & 322 & 359 & 349 & 329 & 328 & 306 & 356 & 349 \\
\hline & $65 \%$ & $73 \%$ & $63 \%$ & $68 \%$ & $60 \%$ & $56 \%$ & $61 \%$ & $60 \%$ & $58 \%$ & $64 \%$ & $64 \%$ & $72 \%$ \\
\hline & & & & & & & & & & & & \\
\hline \multicolumn{13}{|l|}{ NATURAL GAS USAGE \& COST } \\
\hline \multicolumn{13}{|l|}{ CCF } \\
\hline $\mathrm{m}^{\wedge} 3$ Used & 7,588 & 4,442 & 2,962 & 3,811 & 3,190 & 2,817 & 2,221 & 2,413 & 2,769 & 3,957 & 6,218 & 8,098 \\
\hline \multirow[t]{2}{*}{ Daily $\mathrm{m}^{\wedge} 3$ Avg. } & 245 & 148 & 106 & 123 & 100 & 85 & 77 & 83 & 95 & 124 & 207 & 253 \\
\hline \multirow{2}{*}{\multicolumn{13}{|c|}{ GREENHOUSE DATA }} \\
\hline & & & & & & & & & & & & \\
\hline 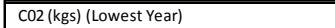 & 182,865 & 152,204 & 131,236 & 126,588 & 115,735 & 123,106 & 109,362 & 112,497 & 120,021 & 122,294 & 157,831 & 178,563 \\
\hline S02 (kgs) (Lowest Year) & 1,976 & 1,644 & 1,418 & 1,368 & 1,250 & 1,330 & 1,182 & 1,215 & 1,297 & 1,321 & 1,705 & 1,929 \\
\hline NOx (kgs) (Lowest Year) & 866 & 721 & 622 & 600 & 548 & 583 & 518 & 533 & 568 & 579 & 748 & 846 \\
\hline USAGE DATA & & & & & & & & & & & & \\
\hline $\mathrm{kWh}$ to GJ & 691.20 & 646.27 & 590.11 & 533.09 & 498.53 & 552.10 & 501.12 & 510.62 & 537.41 & 504.58 & 609.12 & 648.86 \\
\hline $\mathrm{GJ} / \mathrm{m} 2 /$ Day ELECTRIC (Lowest Year) & 0.004 & 0.004 & 0.003 & 0.003 & 0.003 & 0.003 & 0.003 & 0.003 & 0.003 & 0.003 & 0.004 & 0.004 \\
\hline GJ/m2/Month (Lowest Year) & 0.13 & 0.12 & 0.11 & 0.10 & 0.09 & 0.10 & 0.09 & 0.09 & 0.10 & 0.09 & 0.11 & 0.12 \\
\hline & & & & & & & & & & & & \\
\hline $\mathrm{m} 3$ to GJ & 282.27 & 165.24 & 110.19 & 141.77 & 118.67 & 104.79 & 82.62 & 89.76 & 103.01 & 147.20 & 231.31 & 301.25 \\
\hline $\mathrm{GJ} / \mathrm{m} 2 /$ Day GAS (Lowest Year) & 0.002 & 0.001 & 0.001 & 0.001 & 0.001 & 0.001 & 0.001 & 0.001 & 0.001 & 0.001 & 0.001 & 0.002 \\
\hline $\mathrm{GJ} / \mathrm{m} 2 /$ Month & 0.05 & 0.03 & 0.02 & 0.03 & 0.02 & 0.02 & 0.01 & 0.02 & 0.02 & 0.03 & 0.04 & 0.05 \\
\hline $\mathrm{m} 3 / \mathrm{m} 2 /$ Month & 1.38 & 0.81 & 0.54 & 0.69 & 0.58 & 0.51 & 0.40 & 0.44 & 0.50 & 0.72 & 1.13 & 1.47 \\
\hline GJ/m2/Day ENERGY (Lowest Year) & 0.006 & 0.005 & 0.004 & 0.004 & 0.004 & 0.004 & 0.004 & 0.004 & 0.004 & 0.004 & 0.005 & 0.006 \\
\hline $\mathrm{GJ} / \mathrm{m} 2 /$ Month (Lowest Consumption Year) & 0.176 & 0.147 & 0.127 & 0.122 & 0.112 & 0.119 & 0.106 & 0.109 & 0.116 & 0.118 & 0.152 & 0.172 \\
\hline Average Highest Year to Lowest Year & 0.175 & 0.168 & 0.142 & 0.126 & 0.122 & 0.124 & 0.118 & 0.123 & 0.116 & 0.123 & 0.144 & 0.207 \\
\hline BOMA Mean Value per Month & 0.111 & 0.111 & 0.111 & 0.111 & 0.111 & 0.111 & 0.111 & 0.111 & 0.111 & 0.111 & 0.111 & 0.111 \\
\hline Energy Usage per Month (Electricity + Gas) & 973 & 812 & 700 & 675 & 617 & 657 & 584 & 600 & 640 & 652 & 840 & 950 \\
\hline Degree Days & 611 & 532 & 350 & 322 & 117 & 125 & 195 & 114 & 121 & 244 & 434 & 513 \\
\hline Normalized Data (Average Degree Days) & 618 & 582 & 452 & 340 & 125 & 108 & 159 & 106 & 116 & 226 & 456 & 587 \\
\hline Normalized Data (Av Energy Consumption) & 971 & 947 & 861 & 787 & 645 & 634 & 667 & 632 & 639 & 712 & 864 & 951 \\
\hline Normalized Data (Av Energy Index / month) & 0.176 & 0.172 & 0.156 & 0.143 & 0.117 & 0.115 & 0.121 & 0.115 & 0.116 & 0.129 & 0.157 & 0.172 \\
\hline
\end{tabular}


Analysis on how electricity and gas consumption corresponds to heating and cooling periods (for highest energy consumption year):

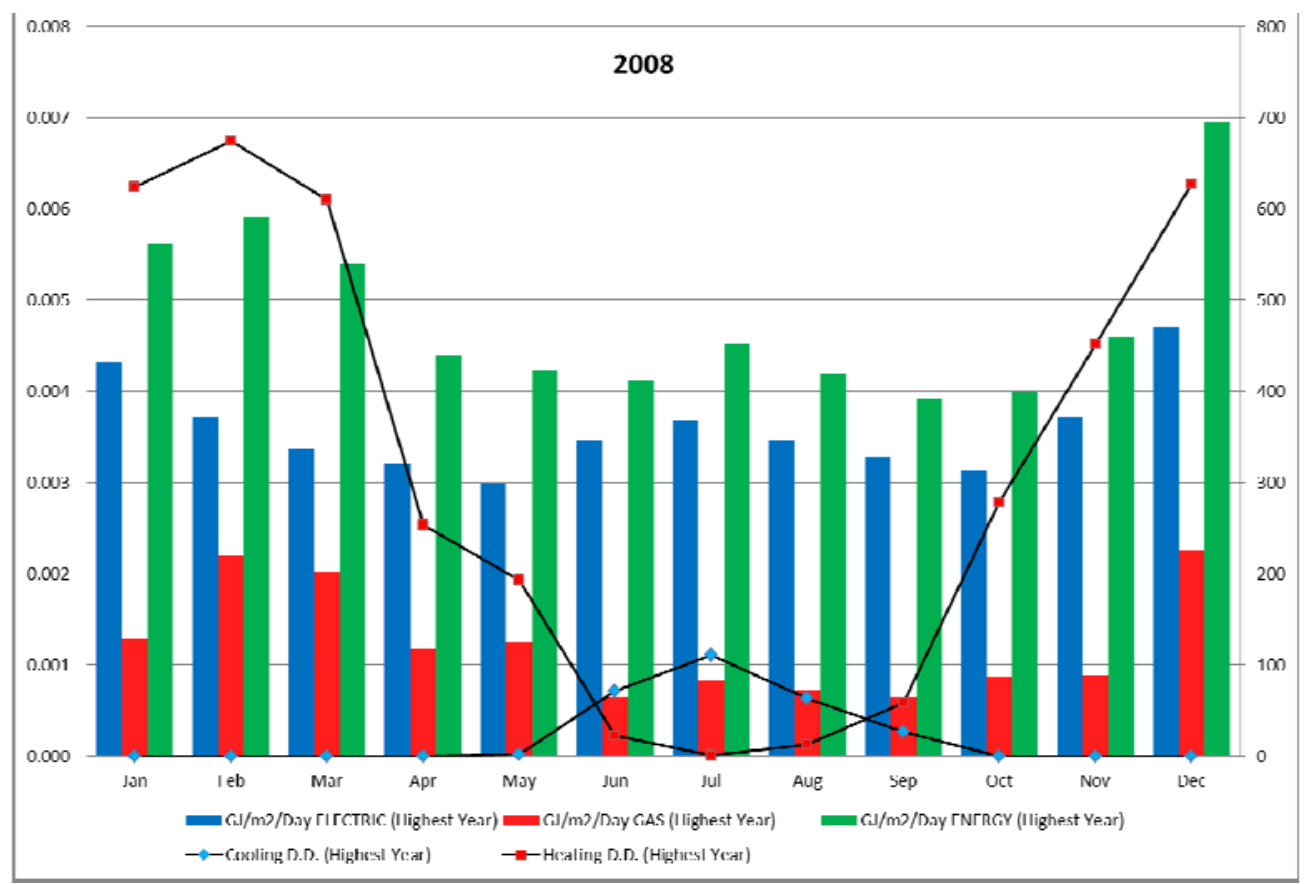

Analysis on how electricity and gas consumption corresponds to heating and cooling periods (for lowest energy consumption year):

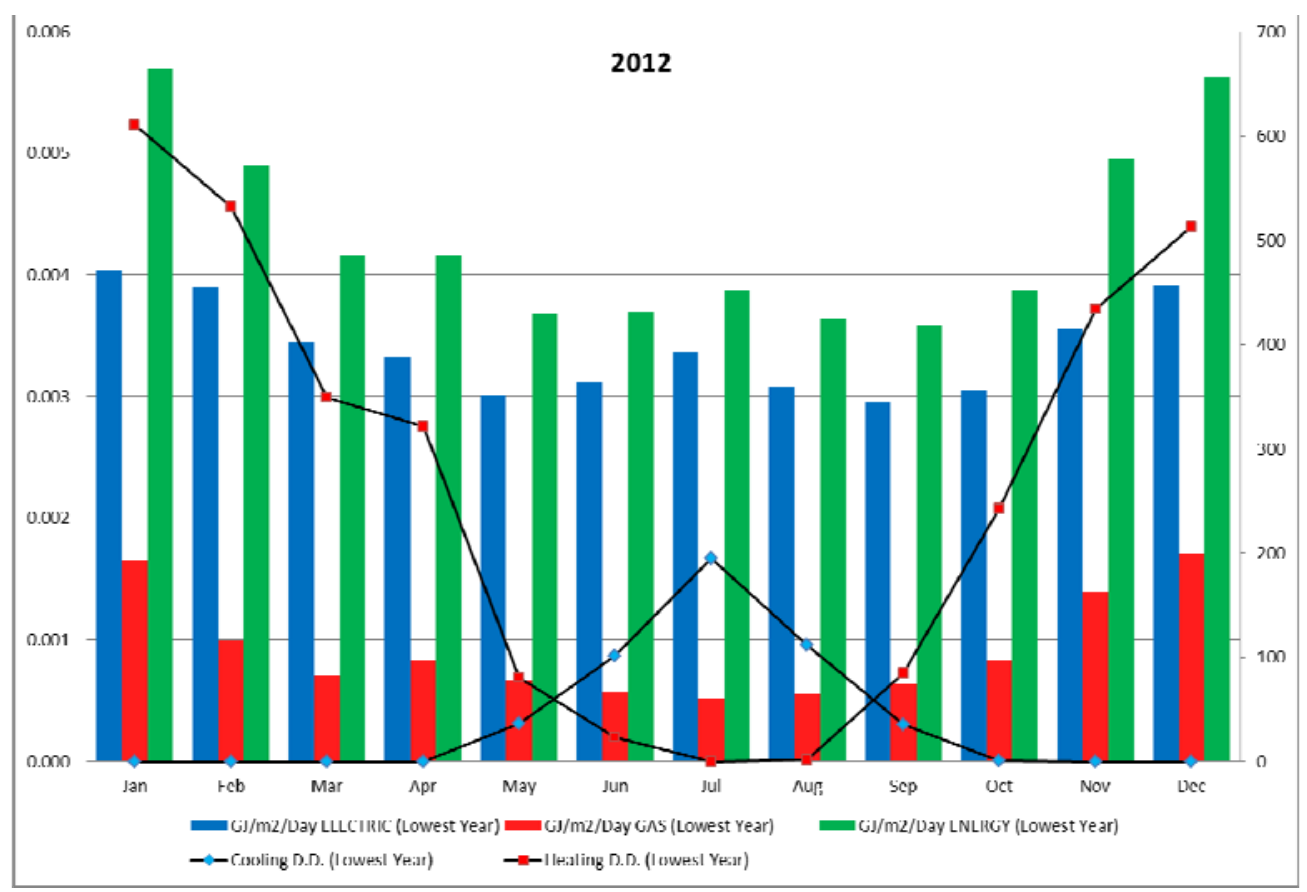


Monthly energy index comparison between highest energy consumption year, lowest, average and benchmark (BOMA) energy intensity:

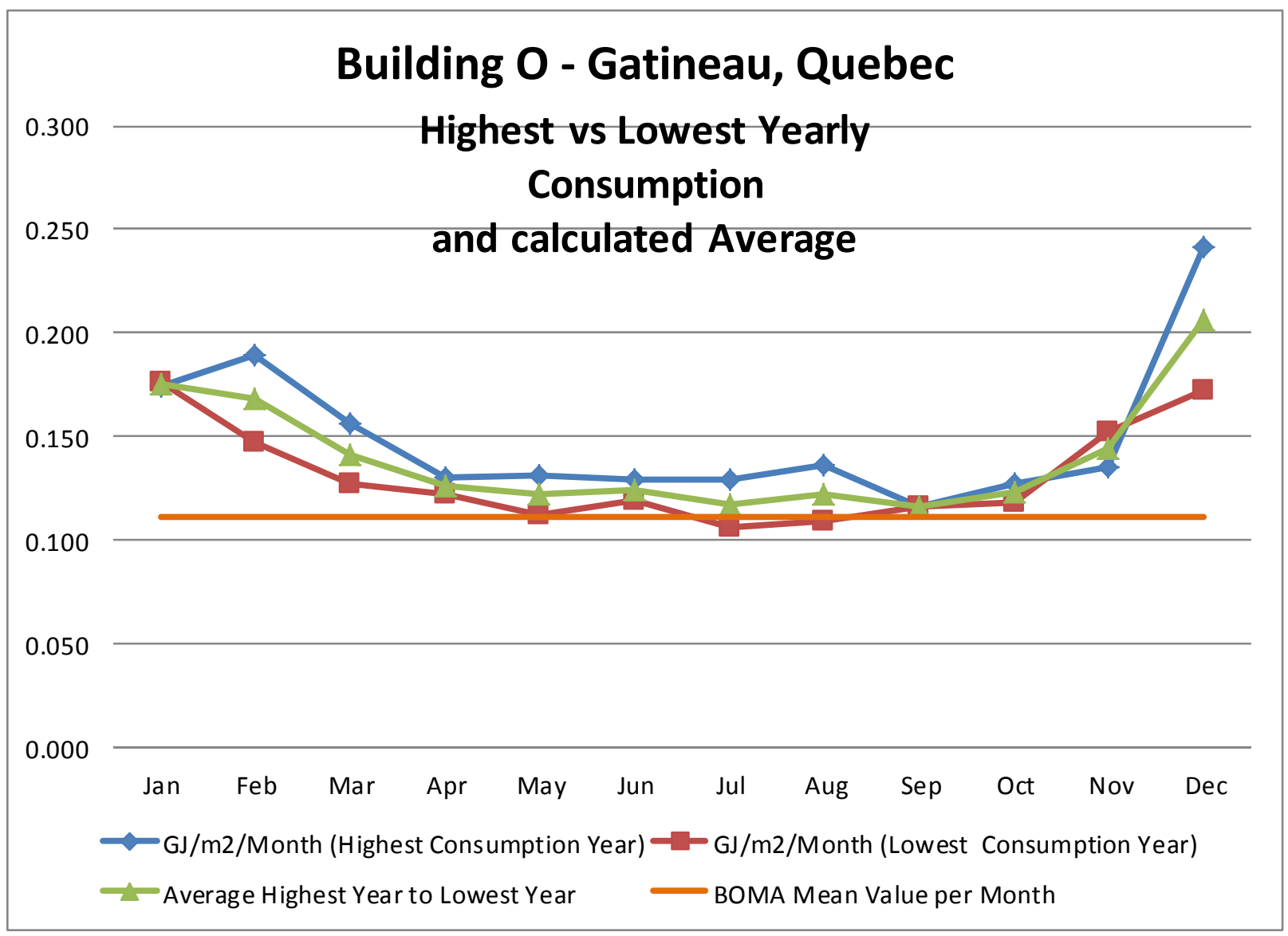


Appendix 2

Appendix B 
Window to Wall Ratio Calculations

“Assumption” 10-20\% stands for mullions percentage assumption. WWR for each case-study building was calculated based on architectural drawings (for buildings \#1, \#2, \#3 and \#4). For those building where drawings weren't available, vise visit was conducted or assumptions were made from building pictures available online (Google Earth).

Building \#1

\begin{tabular}{|c|c|c|c|c|c|c|c|c|c|}
\hline \multicolumn{5}{|c|}{ Building A - Toronto, Ontario } & \multirow[t]{2}{*}{ assamption } & \multirow[t]{2}{*}{$10 \%$} & & & \\
\hline $43.76 \%$ & 25,424 & & & & & & & & \\
\hline South & sf & Units & sf & $\mathrm{m} 2$ & East & sf & Units & sf & $\mathrm{m} 2$ \\
\hline \multicolumn{5}{|l|}{ Glazed Area } & \multicolumn{5}{|l|}{ Glazed Area } \\
\hline Spandrell Glass & $1,025.00$ & 9 & $9,225.00$ & 857.03 & Spandrell Glass & $1,024.00$ & 9 & $9,216.00$ & 856.19 \\
\hline Spandrell Glass & 186.00 & 1 & 186.00 & 17.28 & Spandrell Glass & 764.00 & 2 & $1,528.00$ & 141.96 \\
\hline Spandrell Glass & 155.00 & 2 & 310.00 & 28.80 & Spandrell Glass & $1,151.00$ & 1 & $1,151.00$ & 106.93 \\
\hline Spandrell Glass & 79.00 & 2 & 158.00 & 14.68 & Spandrell Glass & 595.00 & 1 & 595.00 & 55.28 \\
\hline Spandrell Glass & 49.00 & 1 & 49.00 & 4.55 & Spandrell Glass & 82.00 & 1 & 82.00 & 7.62 \\
\hline Spandrell Glass & 769.00 & 2 & $1,538.00$ & 142.88 & Spandrell Glass & 47.00 & 1 & 47.00 & 4.37 \\
\hline Spandrell Glass & 143.00 & 1 & 143.00 & 13.29 & Spandrell Glass & 143.00 & 1 & 143.00 & 13.29 \\
\hline Spandrell Glass & $1,532.00$ & 1 & $1,532.00$ & 142.33 & Spandrell Glass & 159.00 & 1 & 159.00 & 14.77 \\
\hline Spandrell Glass & 234.00 & 1 & 234.00 & 21.74 & Spandrell Glass & 149.00 & 1 & 149.00 & 13.84 \\
\hline Spandrell Glass & 12.00 & 48 & 576.00 & 53.51 & Spandrell Glass & 78.00 & 1 & 78.00 & 7.25 \\
\hline \multirow[t]{2}{*}{ Clear Glass } & 699.00 & 1 & 699.00 & 64.94 & Spandrell Glass & & 1 & 0.00 & 0.00 \\
\hline & & & & $1,224.93$ & & & & & $1,099.34$ \\
\hline \multicolumn{5}{|c|}{ Mullions and Framing } & \multicolumn{5}{|c|}{ Mullions and Framing } \\
\hline \multicolumn{3}{|c|}{ assumption value } & $14,650.00$ & 136.10 & \multicolumn{3}{|c|}{ assumption value } & $13,148.00$ & 122.15 \\
\hline \multicolumn{5}{|l|}{ Wall Area } & \multicolumn{5}{|l|}{ Wall Area } \\
\hline & $30,475.00$ & 1 & $30,475.00$ & $2,831.22$ & & $28,501.00$ & 1 & $28,501.00$ & $2,647.83$ \\
\hline & & & \begin{tabular}{|l|}
0.00 \\
\end{tabular} & 0.00 & & & & 0.00 & 0.00 \\
\hline & & & & $2,831.22$ & & & & & $2,647.83$ \\
\hline \multicolumn{5}{|l|}{ WWR } & \multicolumn{5}{|l|}{ WWR } \\
\hline & & & & $43.26 \%$ & & & & & $41.52 \%$ \\
\hline & & & & & & & & & \\
\hline & & & & & & & & & \\
\hline assamption & $10 \%$ & & & & assamption & $10 \%$ & & & \\
\hline & & & & & & & & & \\
\hline North & sf & Units & sf & $\mathrm{m} 2$ & West & sf & Units & sf & $\mathrm{m} 2$ \\
\hline \multicolumn{5}{|l|}{ Glazed Area } & \multicolumn{5}{|l|}{ Glazed Area } \\
\hline Spandrell Glass & 81.00 & 1 & 81.00 & 7.53 & Spandrell Glass & $1,025.00$ & 9 & $9,225.00$ & 857.03 \\
\hline Spandrell Glass & 53.00 & 1 & 53.00 & 4.92 & Spandrell Glass & 891.00 & 1 & 891.00 & 82.78 \\
\hline Spandrell Glass & 240.00 & 1 & 240.00 & 22.30 & Spandrell Glass & 857.00 & 2 & $1,714.00$ & 159.24 \\
\hline Spandrell Glass & 587.00 & 1 & 587.00 & 54.53 & Spandrell Glass & $1,173.00$ & 1 & $1,173.00$ & 108.98 \\
\hline Spandrell Glass & $1,025.00$ & 9 & $9,225.00$ & 857.03 & Spandrell Glass & 600.00 & 1 & 600.00 & 55.74 \\
\hline Spandrell Glass & 793.00 & 2 & $1,586.00$ & 147.34 & Spandrell Glass & 12.00 & 52 & 624.00 & 57.97 \\
\hline Spandrell Glass & 749.00 & 1 & 749.00 & 69.58 & Spandrell Glass & & & 0.00 & 0.00 \\
\hline Spandrell Glass & $1,496.00$ & 1 & $1,496.00$ & 138.98 & Spandrell Glass & & & 0.00 & 0.00 \\
\hline Spandrell Glass & 12.00 & 52 & 624.00 & 57.97 & Spandrell Glass & & & 0.00 & 0.00 \\
\hline Spandrell Glass & & & 0.00 & 0.00 & Spandrell Glass & & & 0.00 & 0.00 \\
\hline \multirow[t]{2}{*}{ Spandrell Glass } & & & 0.00 & 0.00 & Spandrell Glass & & & 0.00 & 0.00 \\
\hline & & & & $1,224.17$ & & & & & $1,189.56$ \\
\hline \multicolumn{5}{|c|}{ Mullions and Framing } & \multicolumn{5}{|c|}{ Mullions and Framing } \\
\hline & umption va & & $14,641.00$ & 136.02 & & umption va & & $14,227.00$ & 132.17 \\
\hline Wall Area & & & & & Wall Area & & & & \\
\hline & $29,303.00$ & 1 & $29,303.00$ & $2,722.34$ & & $28,271.00$ & 1 & $28,271.00$ & $2,626.46$ \\
\hline & & & 0.00 & 0.00 & & & & 0.00 & 0.00 \\
\hline & & & & $2,722.34$ & & & & & $2,626.46$ \\
\hline WWR & & & & & WWR & & & & \\
\hline & & & & $44.97 \%$ & & & & & $45.29 \%$ \\
\hline
\end{tabular}




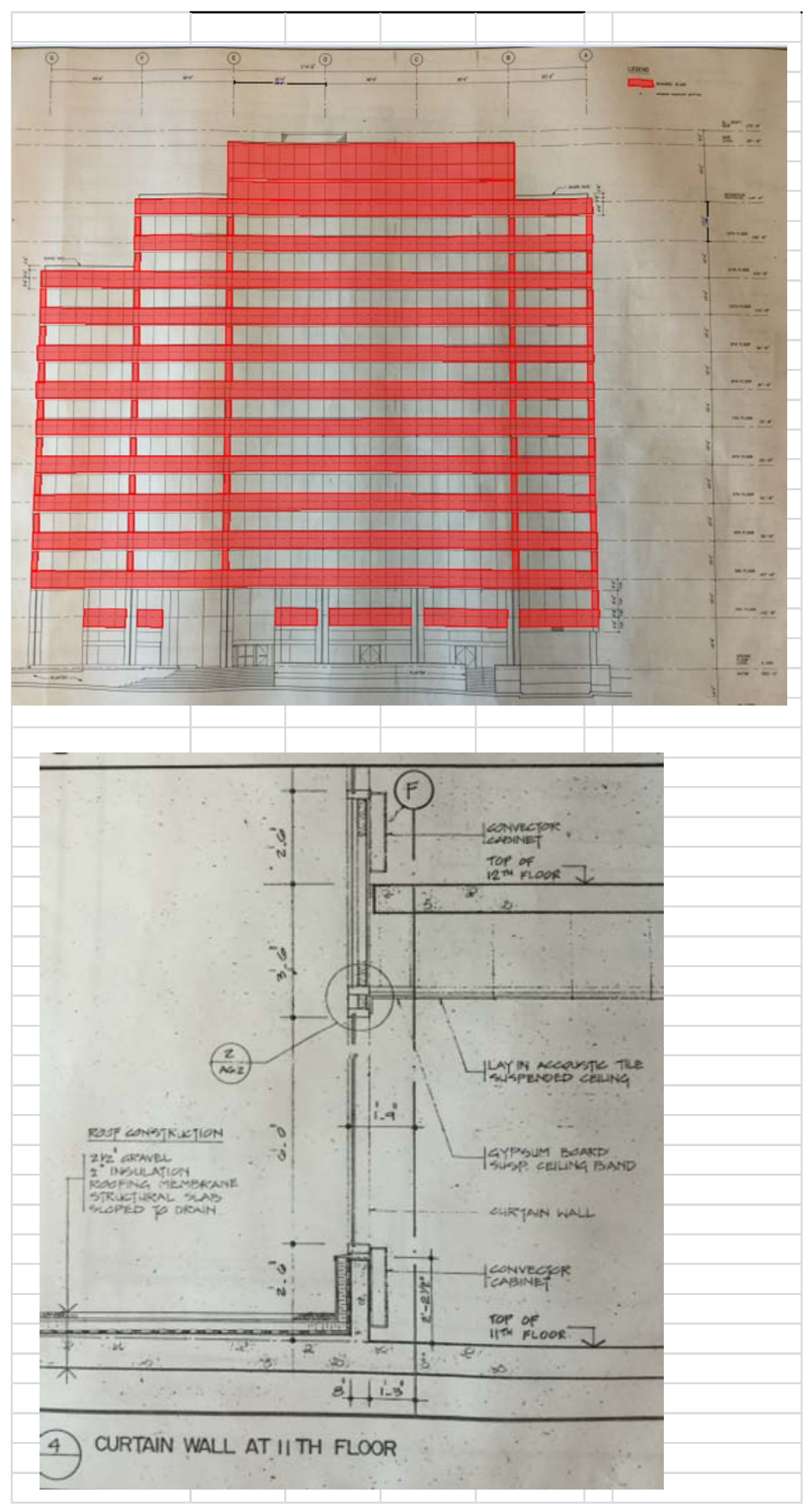




\section{Building \#2}

\begin{tabular}{|c|c|c|c|c|c|c|c|}
\hline \multicolumn{3}{|l|}{ Building B - Mississauga, Ontario } & $20 \%$ & assamption & $20 \%$ & & \\
\hline \multicolumn{3}{|l|}{$27.24 \%$} & & & & & \\
\hline South & $\mathrm{m} 2$ & Units & $\mathrm{m} 2$ & East & $\mathrm{m} 2$ & Units & $\mathrm{m} 2$ \\
\hline \multicolumn{4}{|l|}{ Glazed Area } & \multicolumn{4}{|l|}{ Glazed Area } \\
\hline $\begin{array}{l}\text { Sealed Double Dlazing in Thermally Brocken } \\
\text { Aluminum Frames }\end{array}$ & 1.13 & 21 & 23.73 & $\begin{array}{l}\text { Sealed Double Dlazing in Thermally Brocken } \\
\text { Aluminum Frames }\end{array}$ & 1.13 & 121 & 136.73 \\
\hline \multirow[t]{11}{*}{$\begin{array}{l}\text { Sealed Double Dlazing in Thermally Brocken } \\
\text { Curtain Wall }\end{array}$} & 5.88 & 38 & 223.55 & $\begin{array}{l}\text { Sealed Double Dlazing in Thermally Brocken } \\
\text { Curtain Wall }\end{array}$ & 10.54 & 4 & 42.16 \\
\hline & 111.30 & 1 & 111.30 & & 8.00 & 1 & 8.00 \\
\hline & 4.20 & 2 & 8.40 & & 8.60 & 1 & 8.60 \\
\hline & 6.30 & 2 & 12.60 & & 5.88 & 11 & 64.71 \\
\hline & 6.00 & 2 & 12.00 & & 13.50 & 1 & 13.50 \\
\hline & 5.90 & 5 & 29.50 & & 9.40 & 1 & 9.40 \\
\hline & 14.50 & 1 & 14.50 & & 19.10 & 1 & 19.10 \\
\hline & 2.30 & 5 & 11.50 & & 9.00 & 1 & 9.00 \\
\hline & & & 0.00 & & 9.50 & 1 & 9.50 \\
\hline & & & 0.00 & & & & 0.00 \\
\hline & & & 357.67 & & & & 256.56 \\
\hline \multicolumn{4}{|l|}{ Mullions and Framing } & \multicolumn{4}{|l|}{ Mullions and Framing } \\
\hline \multicolumn{3}{|c|}{ assumption value } & 89.42 & \multicolumn{3}{|c|}{ assumption value } & 64.14 \\
\hline \multicolumn{4}{|l|}{ Wall Area } & \multicolumn{4}{|l|}{ Wall Area } \\
\hline & $1,030.00$ & 1 & $1,030.00$ & & $1,294.00$ & 1 & $1,294.00$ \\
\hline & & & 0.00 & & & & 0.00 \\
\hline & & & $1,030.00$ & & & & $1,294.00$ \\
\hline \multicolumn{4}{|l|}{ WWR } & \multicolumn{4}{|l|}{ WWR } \\
\hline & & & $34.72 \%$ & & & & $19.83 \%$ \\
\hline & & & & & & & \\
\hline & & & & & & & \\
\hline assamption & $20 \%$ & & & assamption & $20 \%$ & & \\
\hline North & $\mathrm{m} 2$ & Units & $\mathrm{m} 2$ & West & $\mathrm{m} 2$ & Units & $\mathrm{m} 2$ \\
\hline \multicolumn{4}{|l|}{ Glazed Area } & \multicolumn{4}{|l|}{ Glazed Area } \\
\hline $\begin{array}{l}\text { Sealed Double Dlazing in Thermally Brocken } \\
\text { Aluminum Frames }\end{array}$ & 1.30 & 108 & 140.40 & $\begin{array}{l}\text { Sealed Double Dlazing in Thermally Brocken } \\
\text { Aluminum Frames }\end{array}$ & 1.30 & 25 & 32.50 \\
\hline \multirow[t]{11}{*}{$\begin{array}{l}\text { Sealed Double Dlazing in Thermally Brocken } \\
\text { Curtain Wall }\end{array}$} & 44.00 & 1 & 44.00 & $\begin{array}{l}\text { Sealed Double Dlazing in Thermally Brocken } \\
\text { Curtain Wall }\end{array}$ & 9.50 & 8 & 76.00 \\
\hline & 5.60 & 9 & 50.40 & & 5.20 & 1 & 5.20 \\
\hline & 6.50 & 1 & 6.50 & & 5.70 & 4 & 22.80 \\
\hline & 16.60 & 1 & 16.60 & & 5.60 & 5 & 28.00 \\
\hline & 5.80 & 1 & 5.80 & & 9.30 & 1 & 9.30 \\
\hline & & & 0.00 & & 6.10 & 1 & 6.10 \\
\hline & & & 0.00 & & 5.60 & 38 & 212.80 \\
\hline & & & 0.00 & & 2.50 & 5 & 12.50 \\
\hline & & & 0.00 & & 122.00 & 1 & 122.00 \\
\hline & & & 0.00 & & & & 0.00 \\
\hline & & & 210.96 & & & & 421.76 \\
\hline \multicolumn{4}{|l|}{ Mullions and Framing } & \multicolumn{4}{|l|}{ Mullions and Framing } \\
\hline \multirow{2}{*}{\multicolumn{4}{|c|}{ assumption value }} & \multicolumn{3}{|c|}{ assumption value } & 105.44 \\
\hline & & & & Wall Area & & & \\
\hline & $1,030.00$ & 1 & $1,030.00$ & & $1,243.00$ & 1 & $1,243.00$ \\
\hline & & & 0.00 & & & & 0.00 \\
\hline & & & $1,030.00$ & & & & $1,243.00$ \\
\hline WWR & & & & WWR & & & \\
\hline & & & $20.48 \%$ & & & & $33.93 \%$ \\
\hline & & & & & & & \\
\hline
\end{tabular}




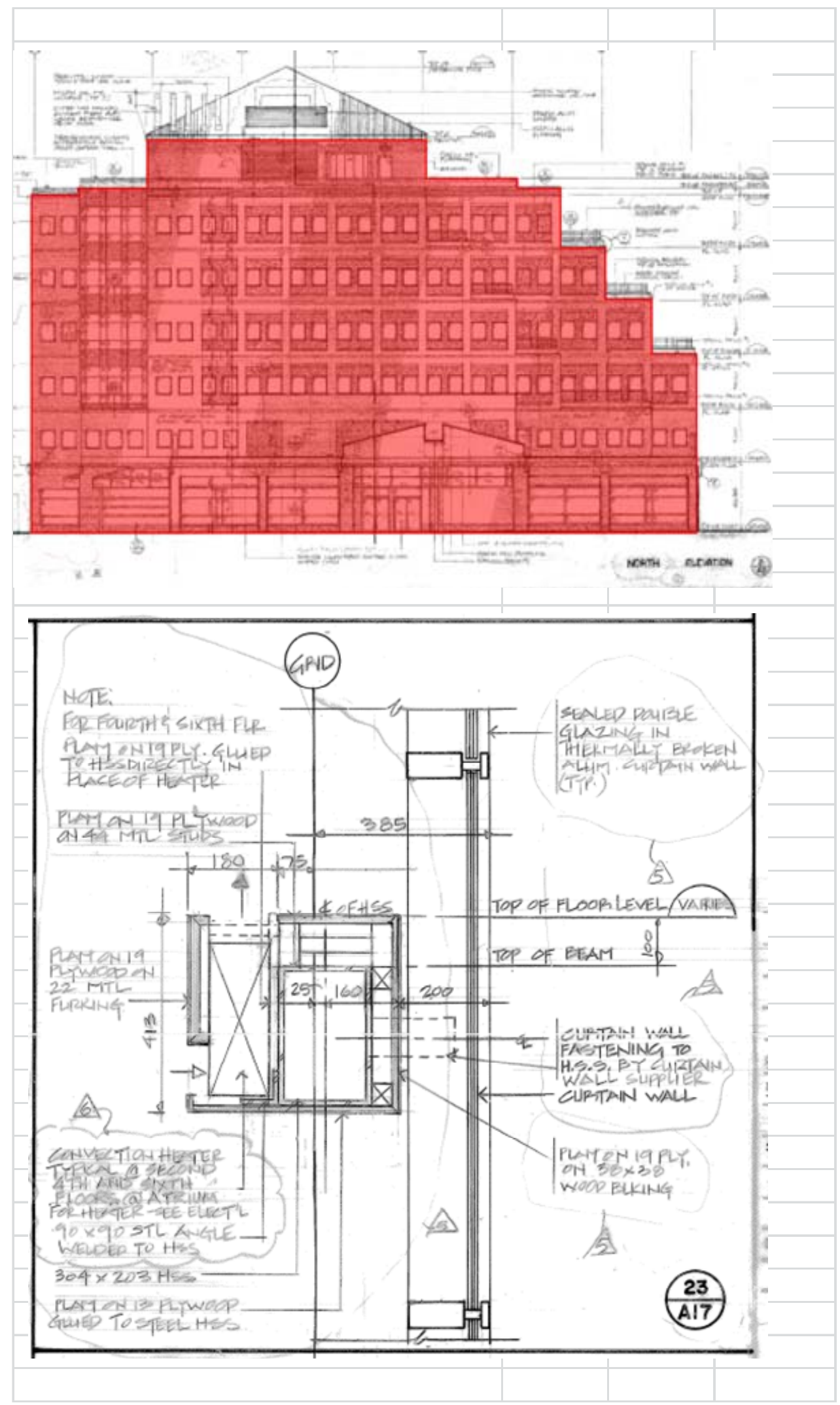




\section{Building \#3}

\begin{tabular}{|c|c|c|c|c|c|c|c|c|c|}
\hline \multicolumn{4}{|l|}{ Building C - Toronto, Ontario } & $20 \%$ & assamption & $20 \%$ & & & \\
\hline \multicolumn{10}{|l|}{$38.89 \%$} \\
\hline South & sf & Units & sf & $\mathrm{m} 2$ & East & sf & Units & sf & $\mathrm{m} 2$ \\
\hline \multicolumn{5}{|l|}{ Glazed Area } & \multicolumn{5}{|l|}{ Glazed Area } \\
\hline Precast Panels with Tinted Glass & 540.00 & 7 & $3,780.00$ & 351.17 & Precast Panels with Tinted Glass & 810.00 & 7 & $5,670.00$ & 526.76 \\
\hline \multirow[t]{11}{*}{ Clear Plate Glass } & 963.00 & 1 & 963.00 & 89.47 & Clear Plate Glass & $1,490.00$ & 1 & $1,490.00$ & 138.43 \\
\hline & & & 0.00 & 0.00 & & & 1 & 0.00 & 0.00 \\
\hline & & & 0.00 & 0.00 & & & 1 & 0.00 & 0.00 \\
\hline & & & 0.00 & 0.00 & & & 1 & 0.00 & 0.00 \\
\hline & & & 0.00 & 0.00 & & & 1 & 0.00 & 0.00 \\
\hline & & & 0.00 & 0.00 & & & 1 & 0.00 & 0.00 \\
\hline & & & 0.00 & 0.00 & & & 1 & 0.00 & 0.00 \\
\hline & & & 0.00 & 0.00 & & & 1 & 0.00 & 0.00 \\
\hline & & & 0.00 & 0.00 & & & 1 & 0.00 & 0.00 \\
\hline & & & 0.00 & 0.00 & & & 1 & 0.00 & 0.00 \\
\hline & & & & 352.51 & & & & & 532.15 \\
\hline \multicolumn{5}{|l|}{ Mullions and Framing } & \multicolumn{5}{|l|}{ Mullions and Framing } \\
\hline \multicolumn{3}{|c|}{ "assumption value } & $4,743.00$ & 88.13 & \multicolumn{3}{|c|}{ assumption value } & $7,160.00$ & 133.04 \\
\hline \multicolumn{5}{|l|}{ Wall Area } & \multicolumn{5}{|l|}{ Wall Area } \\
\hline & $10,217.00$ & 1 & $10,217.00$ & 949.19 & & $14,700.00$ & 1 & $14,700.00$ & $1,365.67$ \\
\hline & & & 0.00 & 0.00 & & & & 0.00 & 0.00 \\
\hline & & & & 949.19 & & & & & $1,365.67$ \\
\hline \multicolumn{5}{|l|}{ WWR } & \multicolumn{5}{|l|}{ WWR } \\
\hline & & & & $37.14 \%$ & & & & & $38.97 \%$ \\
\hline & & & & & & & & & \\
\hline assamption & $20 \%$ & & & & assamption & $20 \%$ & & & \\
\hline North & sf & Units & sf & $\mathrm{m} 2$ & West & sf & Units & sf & $\mathrm{m} 2$ \\
\hline \multicolumn{5}{|l|}{ Glazed Area } & \multicolumn{5}{|l|}{ Glazed Area } \\
\hline Precast Panels with Tinted Glass & 540.00 & 7 & $3,780.00$ & 351.17 & Precast Panels with Tinted Glass & 856.00 & 7 & $5,992.00$ & 556.67 \\
\hline \multirow[t]{11}{*}{ Clear Plate Glass } & 915.00 & 1 & 915.00 & 85.01 & Clear Plate Glass & $1,291.00$ & 1 & $1,291.00$ & 119.94 \\
\hline & & & 0.00 & 0.00 & & & & 0.00 & 0.00 \\
\hline & & & 0.00 & 0.00 & & & & 0.00 & 0.00 \\
\hline & & & 0.00 & 0.00 & & & & 0.00 & 0.00 \\
\hline & & & 0.00 & 0.00 & & & & 0.00 & 0.00 \\
\hline & & & 0.00 & 0.00 & & & & 0.00 & 0.00 \\
\hline & & & 0.00 & 0.00 & & & & 0.00 & 0.00 \\
\hline & & & 0.00 & 0.00 & & & & 0.00 & 0.00 \\
\hline & & & 0.00 & 0.00 & & & & 0.00 & 0.00 \\
\hline & & & 0.00 & 0.00 & & & & 0.00 & 0.00 \\
\hline & & & & 348.94 & & & & & 541.29 \\
\hline \multicolumn{5}{|l|}{ Mullions and Framing } & \multicolumn{5}{|l|}{ Mullions and Framing } \\
\hline \multicolumn{3}{|c|}{ assumption value } & $4,695.00$ & 87.24 & \multicolumn{3}{|c|}{ assumption value } & $7,283.00$ & 135.32 \\
\hline Wall Area & & & & & Wall Area & & & & \\
\hline & $9,416.00$ & 1 & $9,416.00$ & 874.77 & & 14,731.00 & 1 & $14,731.00$ & $1,368.55$ \\
\hline & & & 0.00 & 0.00 & & & & 0.00 & \begin{tabular}{|l|}
0.00 \\
\end{tabular} \\
\hline & & & & 874.77 & & & & & $1,368.55$ \\
\hline WWR & & & & & WWR & & & & \\
\hline & & & & $39.89 \%$ & & & & & $39.55 \%$ \\
\hline
\end{tabular}




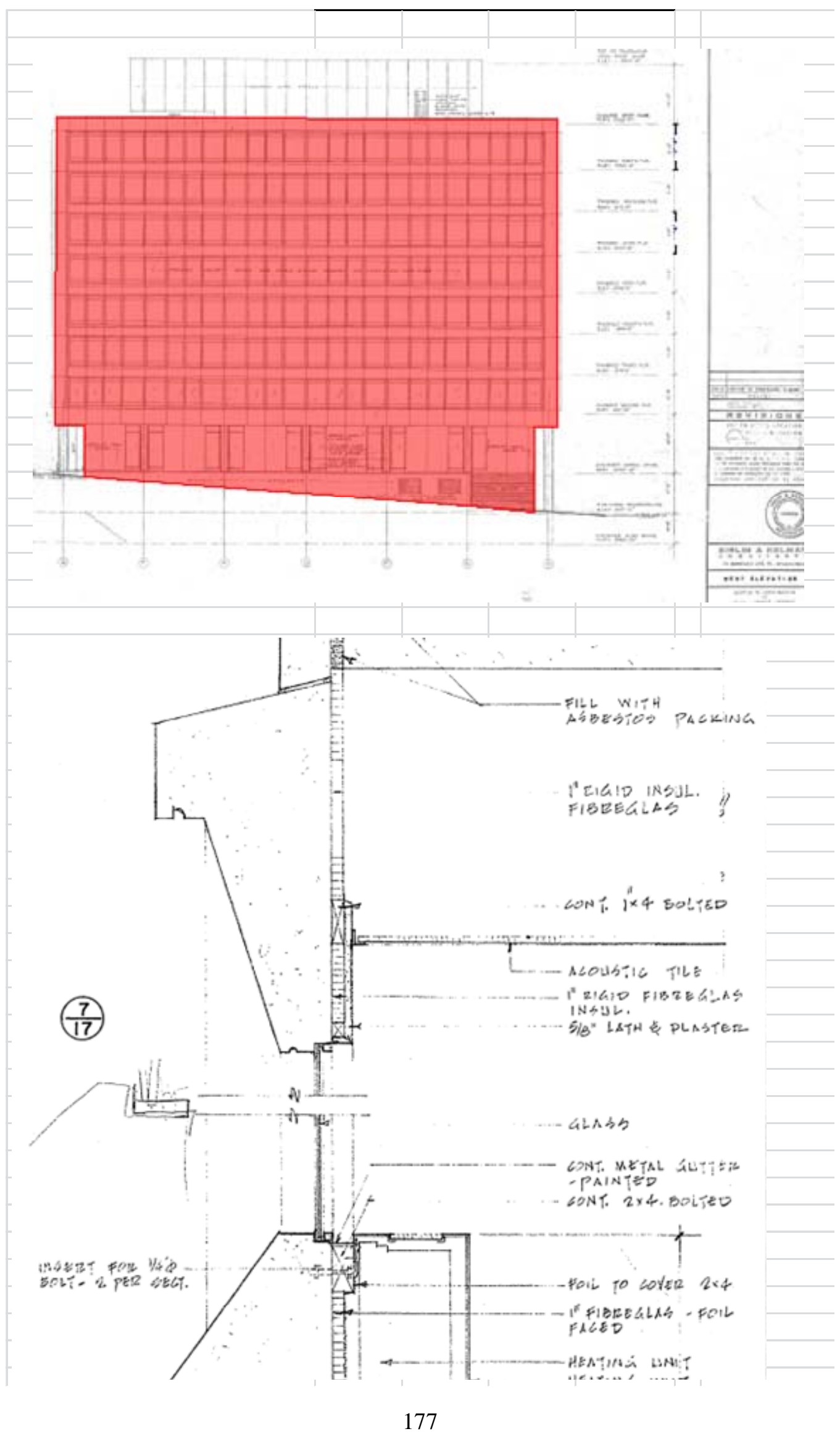




\section{Building \#4}

\begin{tabular}{|c|c|c|c|c|c|c|c|c|c|}
\hline \multicolumn{4}{|l|}{ Building D - Mississauga, Ontario } & $10 \%$ & assamption & $10 \%$ & & & \\
\hline \multicolumn{4}{|l|}{$42.05 \%$} & & & & & & \\
\hline South & sf & Units & sf & $\mathrm{m} 2$ & East & sf & Units & sf & $\mathrm{m} 2$ \\
\hline \multicolumn{5}{|l|}{ Glazed Area } & \multicolumn{5}{|c|}{ Glazed Area } \\
\hline Hermetically Sealed Double Glazing Curtain Wa & $1,034.00$ & 6 & $6,204.00$ & 576.37 & Hermetically Sealed Double Glazing Curtain WA & $1,035.00$ & 6 & $6,210.00$ & 576.93 \\
\hline Hermetically Sealed Double Glazing Curtain Wa & 878.00 & 3 & $2,634.00$ & 244.71 & Hermetically Sealed Double Glazing Curtain WE & 919.00 & 3 & $2,757.00$ & 256.13 \\
\hline Penthouse Curtain Wall & 795.00 & 1 & 795.00 & 73.86 & Penthouse Curtain Wall & 775.00 & 1 & 775.00 & 72.00 \\
\hline \multirow[t]{9}{*}{ Curtain wall with clear glass } & $1,396.00$ & 1 & $1,396.00$ & 129.69 & Curtain wall with clear glass & $1,351.00$ & 1 & $1,351.00$ & 125.51 \\
\hline & & & 0.00 & 0.00 & & & & 0.00 & 0.00 \\
\hline & & & 0.00 & 0.00 & & & & 0.00 & 0.00 \\
\hline & & & 0.00 & 0.00 & & & & 0.00 & 0.00 \\
\hline & & & 0.00 & 0.00 & & & & 0.00 & 0.00 \\
\hline & & & 0.00 & 0.00 & & & & 0.00 & 0.00 \\
\hline & & & 0.00 & 0.00 & & & & 0.00 & 0.00 \\
\hline & & & 0.00 & 0.00 & & & & 0.00 & 0.00 \\
\hline & & & & 922.16 & & & & & 927.52 \\
\hline \multicolumn{5}{|l|}{ Mullions and Framing } & \multicolumn{5}{|l|}{ Mullions and Framing } \\
\hline & & & $11,029.00$ & 102.46 & & & & $11,093.00$ & 103.06 \\
\hline \multicolumn{5}{|l|}{ Wall Area } & \multicolumn{5}{|l|}{ Wall Area } \\
\hline & $23,239.00$ & 1 & $23,239.00$ & $2,158.97$ & & $23,247.00$ & 1 & $23,247.00$ & $2,159.72$ \\
\hline & & & 0.00 & 0.00 & & & & 0.00 & 0.00 \\
\hline & & & & $2,158.97$ & & & & & $2,159.72$ \\
\hline \multicolumn{5}{|l|}{ WWR } & \multicolumn{5}{|l|}{ WWR } \\
\hline & & & & $42.71 \%$ & & & & & $42.95 \%$ \\
\hline & & & & & & & & & \\
\hline assamption & $10 \%$ & & & & assamption & $10 \%$ & & & \\
\hline North & sf & Units & sf & $\mathrm{m} 2$ & West & sf & Units & sf & $\mathrm{m} 2$ \\
\hline \multicolumn{5}{|c|}{ Glazed Area } & \multicolumn{5}{|l|}{ Glazed Area } \\
\hline "Hermetically Sealed Double Glazing Curtain Wa & $1,035.00$ & 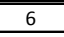 & $6,210.00$ & 576.93 & " Hermetically Sealed Double Glazing Curtain WA & $1,035.00$ & 6 & 6,210.00 & 576.93 \\
\hline Hermetically Sealed Double Glazing Curtain Wa & 884.00 & 3 & $2,652.00$ & 246.38 & Hermetically Sealed Double Glazing Curtain W- & 867.00 & 3 & $2,601.00$ & 241.64 \\
\hline Penthouse Curtain Wall & 841.00 & 1 & 841.00 & 78.13 & Penthouse Curtain Wall & 842.00 & 1 & 842.00 & 78.22 \\
\hline \multirow[t]{9}{*}{ Curtain wall with clear glass } & $1,100.00$ & 1 & $1,100.00$ & 102.19 & Curtain wall with clear glass & 900.00 & 1 & 900.00 & 83.61 \\
\hline & & & 0.00 & 0.00 & & & & 0.00 & 0.00 \\
\hline & & & 0.00 & 0.00 & & & & 0.00 & 0.00 \\
\hline & & & 0.00 & 0.00 & & & & 0.00 & 0.00 \\
\hline & & & 0.00 & 0.00 & & & & 0.00 & 0.00 \\
\hline & & & 0.00 & 0.00 & & & & 0.00 & 0.00 \\
\hline & & & 0.00 & 0.00 & & & & 0.00 & 0.00 \\
\hline & & & 0.00 & 0.00 & & & & 0.00 & 0.00 \\
\hline & & & & 903.27 & & & & & 882.36 \\
\hline \multicolumn{5}{|l|}{ Mullions and Framing } & \multicolumn{5}{|l|}{ Mullions and Framing } \\
\hline & & & $10,803.00$ & 100.36 & & & & $10,553.00$ & 98.04 \\
\hline \multicolumn{5}{|l|}{ Wall Area } & \multicolumn{5}{|l|}{ Wall Area } \\
\hline & $23,337.00$ & 1 & $23,337.00$ & $2,168.08$ & & $23,226.00$ & 1 & $23,226.00$ & $2,157.77$ \\
\hline & & & 0.00 & 0.00 & & & & 0.00 & 0.00 \\
\hline & & & & $2,168.08$ & & & & & $2,157.77$ \\
\hline \multicolumn{5}{|l|}{ WWR } & \multicolumn{5}{|l|}{ WWR } \\
\hline & & & & $41.66 \%$ & & & & & $40.89 \%$ \\
\hline
\end{tabular}




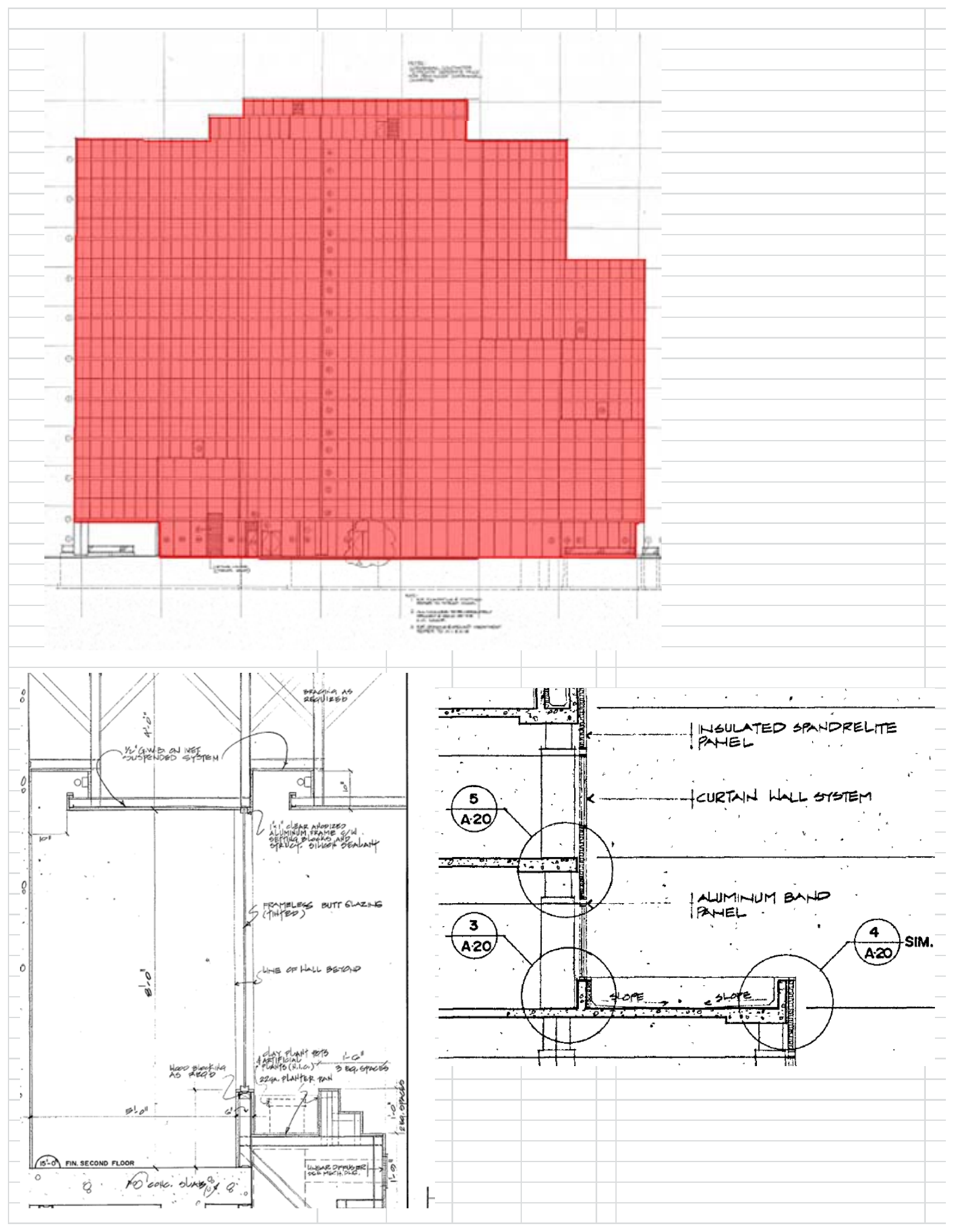




\section{Building \#5}

Assumed WWR $=40 \%$ (based on the site visit)

Building \#6 (based on the site visit)

\begin{tabular}{|c|c|c|c|c|c|c|c|c|c|}
\hline \multicolumn{4}{|c|}{ Building E - Scarborough, Ontario } & $10 \%$ & Mullions assamption & $10 \%$ & & & \\
\hline \multicolumn{10}{|c|}{\begin{tabular}{|l|l|}
$39.82 \%$ & \\
\end{tabular}} \\
\hline South & $\mathrm{m}$ & $\mathrm{m}$ & Units & $\mathrm{m} 2$ & East & $\mathrm{m}$ & $\mathrm{m}$ & Units & $\mathrm{m} 2$ \\
\hline \multicolumn{5}{|l|}{ Glazed Area } & \multicolumn{5}{|l|}{ Glazed Area } \\
\hline Glass Strip & 61.00 & 1.50 & 1 & 91.50 & Glass Strip & 18.00 & 1.50 & 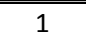 & 27.00 \\
\hline \multirow[t]{5}{*}{ Glass first floor } & 5.60 & 3.20 & 10 & 179.20 & Glass first floor & 4.75 & 3.20 & 1 & 15.20 \\
\hline & & & & 0.00 & Glass first floor & 9.00 & 3.20 & 1 & 28.80 \\
\hline & & & & 0.00 & & & & & 0.00 \\
\hline & & & & 0.00 & & & & & 0.00 \\
\hline & & & & 243.63 & & & & & 63.90 \\
\hline \multicolumn{5}{|c|}{ Mullions and Framing } & \multicolumn{5}{|l|}{ Mullions and Framing } \\
\hline & & & & 27.07 & & & & & 7.10 \\
\hline \multicolumn{5}{|l|}{ Wall Area } & \multicolumn{5}{|l|}{ Wall Area } \\
\hline & 61.00 & 8.70 & 1 & 530.70 & & 18.00 & 8.70 & 1 & 156.60 \\
\hline & & & & 0.00 & & & & & 0.00 \\
\hline & & & & 530.70 & & & & & 156.60 \\
\hline \multicolumn{5}{|l|}{ WWR } & \multicolumn{5}{|l|}{ WWR } \\
\hline & & & & 45.91\% & & & & & $40.80 \%$ \\
\hline & & & & & & & & & \\
\hline assamption & $10 \%$ & & & & assamption & $10 \%$ & & & \\
\hline & & & & & & & & & \\
\hline North & $\mathrm{m}$ & $\mathrm{m}$ & Units & $\mathrm{m} 2$ & West & $\mathrm{m}$ & $\mathrm{m}$ & Units & $\mathrm{m} 2$ \\
\hline \multicolumn{5}{|l|}{ Glazed Area } & \multicolumn{5}{|l|}{ Glazed Area } \\
\hline Glass Strip & 61.00 & 1.50 & 1 & 91.50 & Glass Strip & 8.00 & 1.50 & 1 & 12.00 \\
\hline \multirow[t]{5}{*}{ Glass first floor } & 3.20 & 5.60 & 10 & 179.20 & Glass Strip & 0.50 & 1.28 & 1 & 0.64 \\
\hline & & & & 0.00 & Glass first floor & 7.50 & 4.50 & 1 & 33.75 \\
\hline & & & & 0.00 & & & & & 0.00 \\
\hline & & & & 0.00 & & & & & 0.00 \\
\hline & & & & 243.63 & & & & & 41.75 \\
\hline \multicolumn{5}{|c|}{ Mullions and Framing } & \multicolumn{5}{|l|}{ Mullions and Framing } \\
\hline & & & & 27.07 & & & & & 4.64 \\
\hline \multicolumn{5}{|l|}{ Wall Area } & \multicolumn{5}{|l|}{ Wall Area } \\
\hline & 61.00 & 8.70 & 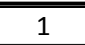 & 530.70 & & 18.00 & 8.70 & 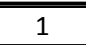 & 156.60 \\
\hline & & & & 0.00 & & & & & 0.00 \\
\hline & & & & 530.70 & & & & & 156.60 \\
\hline \multicolumn{5}{|l|}{ WWR } & \multicolumn{5}{|l|}{ WWR } \\
\hline & & & & 45.91\% & & & & & $26.66 \%$ \\
\hline
\end{tabular}

Building \#7

Assumed WWR $=32 \%$ (based on Google Earth images) 


\section{Building \#8}

\begin{tabular}{|c|c|c|c|c|c|c|c|c|c|}
\hline \multicolumn{4}{|c|}{ Building H - Ottawa, Ontario } & \multirow[t]{2}{*}{$10 \%$} & \multirow[t]{2}{*}{ assamption } & \multicolumn{2}{|l|}{$10 \%$} & \multirow[b]{3}{*}{ Units } & \multirow[b]{3}{*}{$\mathrm{m} 2$} \\
\hline $43.03 \%$ & 5,020 & & & & & & & & \\
\hline South & $\mathrm{m}$ & $\mathrm{m}$ & Units & $\mathrm{m} 2$ & South/East & $\mathrm{m}$ & $\mathrm{m}$ & & \\
\hline \multicolumn{5}{|l|}{ Glazed Area } & \multicolumn{5}{|l|}{ Glazed Area } \\
\hline Curtain Wall & 22.00 & 1.80 & 3 & 118.80 & Curtain Wall & 16.00 & 1.80 & 3 & 86.40 \\
\hline Curtain Wall & 8.70 & 1.80 & 1 & 15.66 & Curtain Wall & & & & 0.00 \\
\hline Glassed Area & 5.20 & 2.80 & 3 & 43.68 & Glassed Area & 3.70 & 2.00 & 4 & 29.60 \\
\hline \multirow[t]{2}{*}{ Glassed Area } & & & & 0.00 & Glassed Area & 6.00 & 4.60 & 1 & 27.60 \\
\hline & & & & 160.33 & & & & & 129.24 \\
\hline \multicolumn{5}{|c|}{ Mullions and Framing } & \multicolumn{5}{|c|}{ Mullions and Framing } \\
\hline & & & & 17.81 & & & & & 14.36 \\
\hline \multicolumn{5}{|l|}{ Wall Area } & \multicolumn{5}{|l|}{ Wall Area } \\
\hline & 20.60 & 15.00 & 1 & 309.00 & & 20.00 & 16.00 & 1 & 320.00 \\
\hline & 9.00 & 3.80 & 1 & 34.20 & & & & & 0.00 \\
\hline & & & & 343.20 & & & & & 320.00 \\
\hline \multicolumn{5}{|l|}{ WWR } & WWR & & & & \\
\hline & & & & $46.72 \%$ & & & & & $40.39 \%$ \\
\hline & & & & & & & & & \\
\hline assamption & $10 \%$ & & & & assamption & $10 \%$ & & & \\
\hline & & & & & & & & & \\
\hline East & $\mathrm{m}$ & $\mathrm{m}$ & Units & $\mathrm{m} 2$ & North & $\mathrm{m}$ & $\mathrm{m}$ & Units & $\mathrm{m} 2$ \\
\hline Glazed Area & & & & & Glazed Area & & & & \\
\hline Curtain Wall & 47.00 & 1.80 & 1 & 84.60 & & & & & 0.00 \\
\hline Curtain Wall & 21.00 & 1.80 & 2 & 75.60 & & & & & 0.00 \\
\hline Curtain Wall & 8.48 & 1.80 & 1 & 15.26 & & & & & 0.00 \\
\hline Glassed Area & 3.00 & 5.50 & 3 & 49.50 & & & & & 0.00 \\
\hline Glassed Area & 3.00 & 3.00 & 2 & 18.00 & & & & & 0.00 \\
\hline Glassed Area & 3.00 & 15.50 & 1 & 46.50 & & & & & 0.00 \\
\hline & & & & 260.52 & & & & & 0.00 \\
\hline Mullions and $\mathrm{Fr}$ & & & & & Mullions and $\mathrm{Fr}$ & & & & \\
\hline & & & & 28.95 & & & & & 0.00 \\
\hline Wall Area & & & & & Wall Area & & & & \\
\hline & 477.00 & 8.00 & 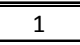 & 376.00 & & & & 1 & 0.00 \\
\hline & 21.00 & 7.00 & 1 & 147.00 & & & & & 0.00 \\
\hline & 8.00 & 4.00 & 1 & 32.00 & & & & & 0.00 \\
\hline & & & & 555.00 & WWR & & & & \\
\hline WWR & & & & & assumed & & & & $42.00 \%$ \\
\hline & & & & 46.94\% & & & & & \\
\hline & & & & & & & & & \\
\hline assamption & $10 \%$ & & & & & & & & \\
\hline & & & & & & & & & \\
\hline West & $\mathrm{m}$ & $\mathrm{m}$ & Units & $\mathrm{m} 2$ & & & & & \\
\hline Glazed Area & & & & & & & & & \\
\hline Curtain Wall & 477.00 & 1.80 & 1 & 84.60 & & & & & \\
\hline Curtain Wall & 21.00 & 1.80 & 2 & 75.60 & & & & & \\
\hline Curtain Wall & 8.48 & 1.80 & 1 & 15.26 & & & & & \\
\hline Glassed Area & 3.00 & 4.00 & 3 & 36.00 & & & & & \\
\hline Glassed Area & 3.00 & 3.00 & 2 & 18.00 & & & & & \\
\hline Glassed Area & 3.00 & 8.00 & 1 & 24.00 & & & & & \\
\hline & & & & 0.00 & & & & & \\
\hline & & & & 228.12 & & & & & \\
\hline Mullions and $\mathrm{Fr}$ & & & & & & & & & \\
\hline & & & & 25.35 & & & & & \\
\hline Wall Area & & & & & & & & & \\
\hline & 47.00 & 8.00 & 1 & 376.00 & & & & & \\
\hline & 21.00 & 7.00 & 1 & 147.00 & & & & & \\
\hline & 8.00 & 4.00 & 1 & 32.00 & & & & & \\
\hline & & & & 555.00 & & & & & \\
\hline WWR & & & & & & & & & \\
\hline & & & & $41.10 \%$ & & & & & \\
\hline
\end{tabular}


Building \#9

Assumed WWR $=42 \%$ (based on Google Earth images)

Building \#10

Assumed WWR $=42 \%$ (based on Google Earth images)

Building \#11

Assumed WWR $=42 \%$ (based on Google Earth images)

Building \#12

Assumed WWR $=19 \%$ (based on Google Earth images) 
Building \#13

\begin{tabular}{|c|c|c|c|c|c|c|c|c|c|}
\hline \multicolumn{4}{|c|}{ Building M - Montreal, Quebec } & $10 \%$ & assamption & $10 \%$ & & & \\
\hline \multicolumn{10}{|c|}{\begin{tabular}{|l|l|l|}
$18.61 \%$ & & \\
\end{tabular}} \\
\hline South & $\mathrm{m}$ & $\mathrm{m}$ & Units & $\mathrm{m} 2$ & East & $\mathrm{m}$ & $\mathrm{m}$ & Units & $\mathrm{m} 2$ \\
\hline \multicolumn{5}{|l|}{ Glazed Area } & \multicolumn{5}{|l|}{ Glazed Area } \\
\hline \multirow[t]{4}{*}{ Punched Window } & 2.44 & 1.30 & 12 & 38.06 & Punched Windows & 1.10 & 2.30 & 18 & 45.54 \\
\hline & & & & 0.00 & & 1.10 & 1.30 & 6 & 8.58 \\
\hline & & & & 0.00 & & & & & 0.00 \\
\hline & & & & 34.26 & & & & & 48.71 \\
\hline \multicolumn{5}{|l|}{ Mullions and Framing } & \multicolumn{5}{|l|}{ Mullions and Framing } \\
\hline & & & & 3.81 & & & & & 5.41 \\
\hline \multicolumn{5}{|l|}{ Wall Area } & \multicolumn{5}{|l|}{ Wall Area } \\
\hline & 22.00 & 26.00 & 1 & 572.00 & & 21.30 & 7.00 & 1 & 149.10 \\
\hline & 12.00 & 4.60 & 1 & 55.20 & & 14.00 & 9.00 & 1 & 126.00 \\
\hline & 16.50 & 26.00 & 1 & 429.00 & & 7.00 & 14.00 & 1 & 98.00 \\
\hline & 10.00 & 7.00 & 1 & $1,056.20$ & & & & & 373.10 \\
\hline \multicolumn{5}{|l|}{ WWR } & \multicolumn{5}{|l|}{ WWR } \\
\hline & & & & $3.24 \%$ & & & & & $13.05 \%$ \\
\hline & & & & & & & & & \\
\hline assamption & $10 \%$ & & & & assamption & $10 \%$ & & & \\
\hline North & $\mathrm{m}$ & $\mathrm{m}$ & Units & $\mathrm{m} 2$ & West & $\mathrm{m}$ & $\mathrm{m}$ & Units & $\mathrm{m} 2$ \\
\hline \multicolumn{5}{|l|}{ Glazed Area } & \multicolumn{5}{|l|}{ Glazed Area } \\
\hline \multirow[t]{3}{*}{ Punched Window } & 1.50 & 2.44 & 18 & 65.88 & Punched Windows & 1.50 & 2.44 & 10 & 36.60 \\
\hline & 1.50 & 4.00 & 18 & 108.00 & & 1.50 & 4.00 & 10 & 60.00 \\
\hline & & & & 156.49 & & & & & 86.94 \\
\hline \multicolumn{5}{|l|}{ Mullions and Framing } & \multicolumn{5}{|l|}{ Mullions and Framing } \\
\hline & & & & 17.39 & & & & & 9.66 \\
\hline \multicolumn{5}{|l|}{ Wall Area } & \multicolumn{5}{|l|}{ Wall Area } \\
\hline & 29.00 & 23.00 & 1 & 667.00 & & 25.00 & 18.00 & 1 & 450.00 \\
\hline & & & & 0.00 & & & & & 0.00 \\
\hline & & & & 667.00 & & & & & 450.00 \\
\hline \multicolumn{5}{|l|}{ WWR } & \multicolumn{5}{|l|}{ WWR } \\
\hline & & & & $23.46 \%$ & & & & & $19.32 \%$ \\
\hline
\end{tabular}

Building \#14

Assumed WWR = 23\% (based on Google Earth images) 
Building \#15

\begin{tabular}{|c|c|c|c|c|c|c|c|c|c|}
\hline \multicolumn{4}{|c|}{ Building 0 - Côte-St-Luc, Quebec } & $10 \%$ & assamption & $10 \%$ & & & \\
\hline \multicolumn{10}{|c|}{\begin{tabular}{|l|l|l|}
$23.00 \%$ & & \\
\end{tabular}} \\
\hline South & $\mathrm{m}$ & $\mathrm{m}$ & Units & $\mathrm{m} 2$ & East & $\mathrm{m}$ & $\mathrm{m}$ & Units & $\mathrm{m} 2$ \\
\hline \multicolumn{5}{|l|}{ Glazed Area } & \multicolumn{5}{|l|}{ Glazed Area } \\
\hline \multirow{4}{*}{ Punched Window } & 1.20 & 2.40 & 80 & 230.40 & Punched Windows & 1.20 & 2.40 & 40 & 115.20 \\
\hline & 1.20 & 2.40 & 16 & 46.08 & & 1.20 & 2.40 & 5 & 14.40 \\
\hline & 4.30 & 3.00 & 2 & 25.80 & & & & & 0.00 \\
\hline & & & & 272.05 & & & & & 116.64 \\
\hline \multicolumn{5}{|l|}{ Mullions and Framing } & \multicolumn{5}{|l|}{ Mullions and Framing } \\
\hline & & & & 30.23 & & & & & 12.96 \\
\hline \multicolumn{5}{|l|}{ Wall Area } & \multicolumn{5}{|l|}{ Wall Area } \\
\hline & 41.00 & 18.00 & 1 & 738.00 & & 25.00 & 18.00 & 1 & 450.00 \\
\hline & 22.00 & 18.00 & 1 & 396.00 & & 3.00 & 18.00 & 1 & 54.00 \\
\hline & & & & $1,134.00$ & & & & & 504.00 \\
\hline \multicolumn{5}{|l|}{ WWR } & \multicolumn{5}{|l|}{ WWR } \\
\hline & & & & $23.99 \%$ & & & & & $23.14 \%$ \\
\hline & & & & & & & & & \\
\hline assamption & $10 \%$ & & & & assamption & $10 \%$ & & & \\
\hline North & $\mathrm{m}$ & $\mathrm{m}$ & Units & $\mathrm{m} 2$ & West & $\mathrm{m}$ & $\mathrm{m}$ & Units & $\mathrm{m} 2$ \\
\hline \multicolumn{5}{|l|}{ Glazed Area } & \multicolumn{5}{|l|}{ Glazed Area } \\
\hline \multirow[t]{3}{*}{ Punched Window } & 1.20 & 2.40 & 70 & 201.60 & Punched Windows & 1.20 & 2.40 & 40 & 115.20 \\
\hline & 1.20 & 2.40 & 30 & 86.40 & & 1.20 & 2.40 & 5 & 14.40 \\
\hline & & & & 259.20 & & & & & 116.64 \\
\hline \multicolumn{5}{|c|}{ Mullions and Framing } & \multicolumn{5}{|l|}{ Mullions and Framing } \\
\hline & & & & 28.80 & & & & & 12.96 \\
\hline \multicolumn{5}{|l|}{ Wall Area } & \multicolumn{5}{|l|}{ Wall Area } \\
\hline & 41.00 & 18.00 & 1 & 738.00 & & 25.00 & 18.00 & 1 & 450.00 \\
\hline & 22.00 & 18.00 & 1 & 396.00 & & 3.00 & 18.00 & 1 & 54.00 \\
\hline & & & & $1,134.00$ & & & & & 504.00 \\
\hline \multicolumn{5}{|l|}{ WWR } & \multicolumn{5}{|l|}{ WWR } \\
\hline & & & & $22.86 \%$ & & & & & $23.14 \%$ \\
\hline
\end{tabular}


Appendix 3

Appendix $\mathrm{C}$ 
Calculations only performed for case-study buildings \#1, \#2 and \#3 because architectural drawings were only available for these buildings.

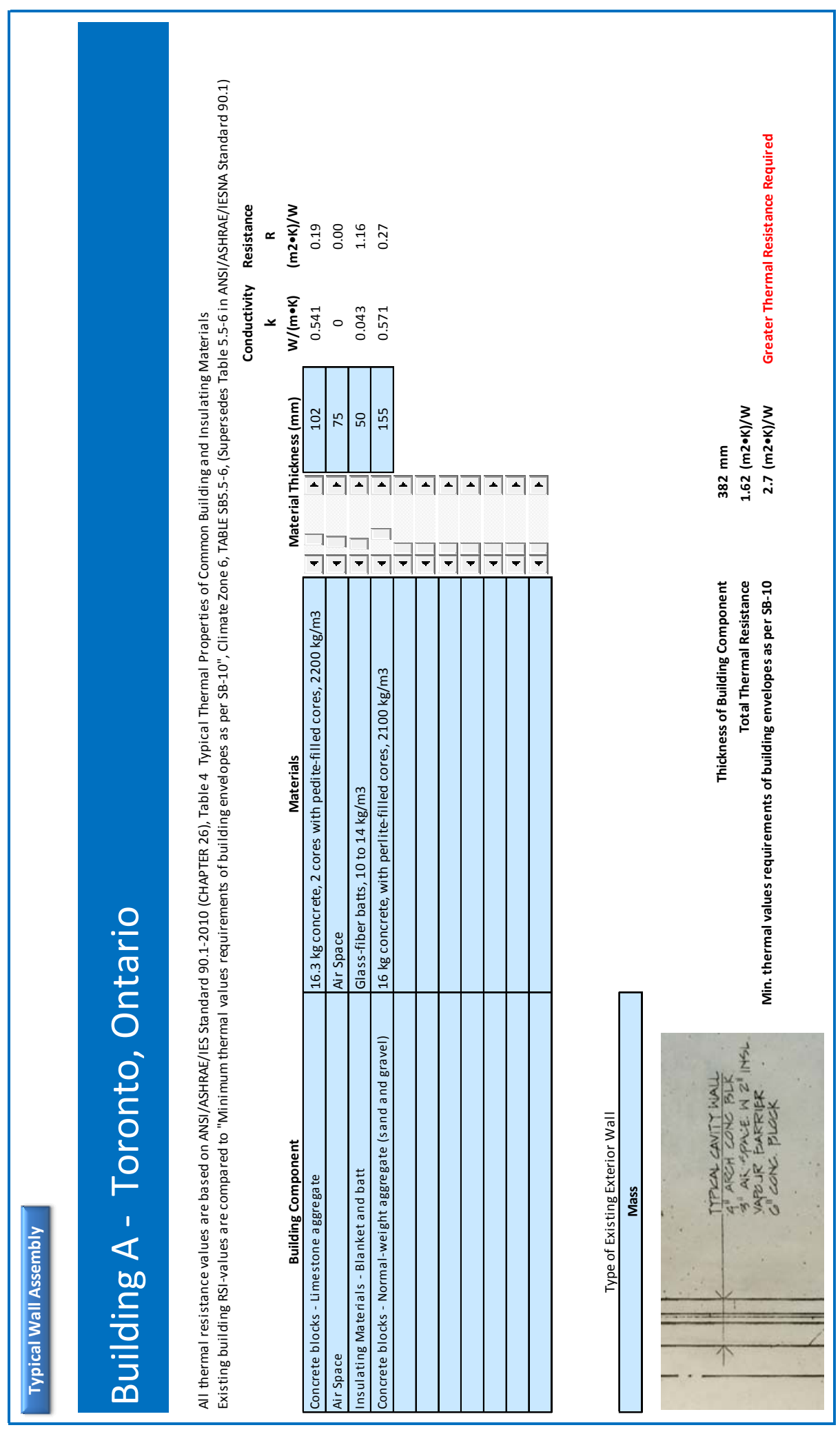




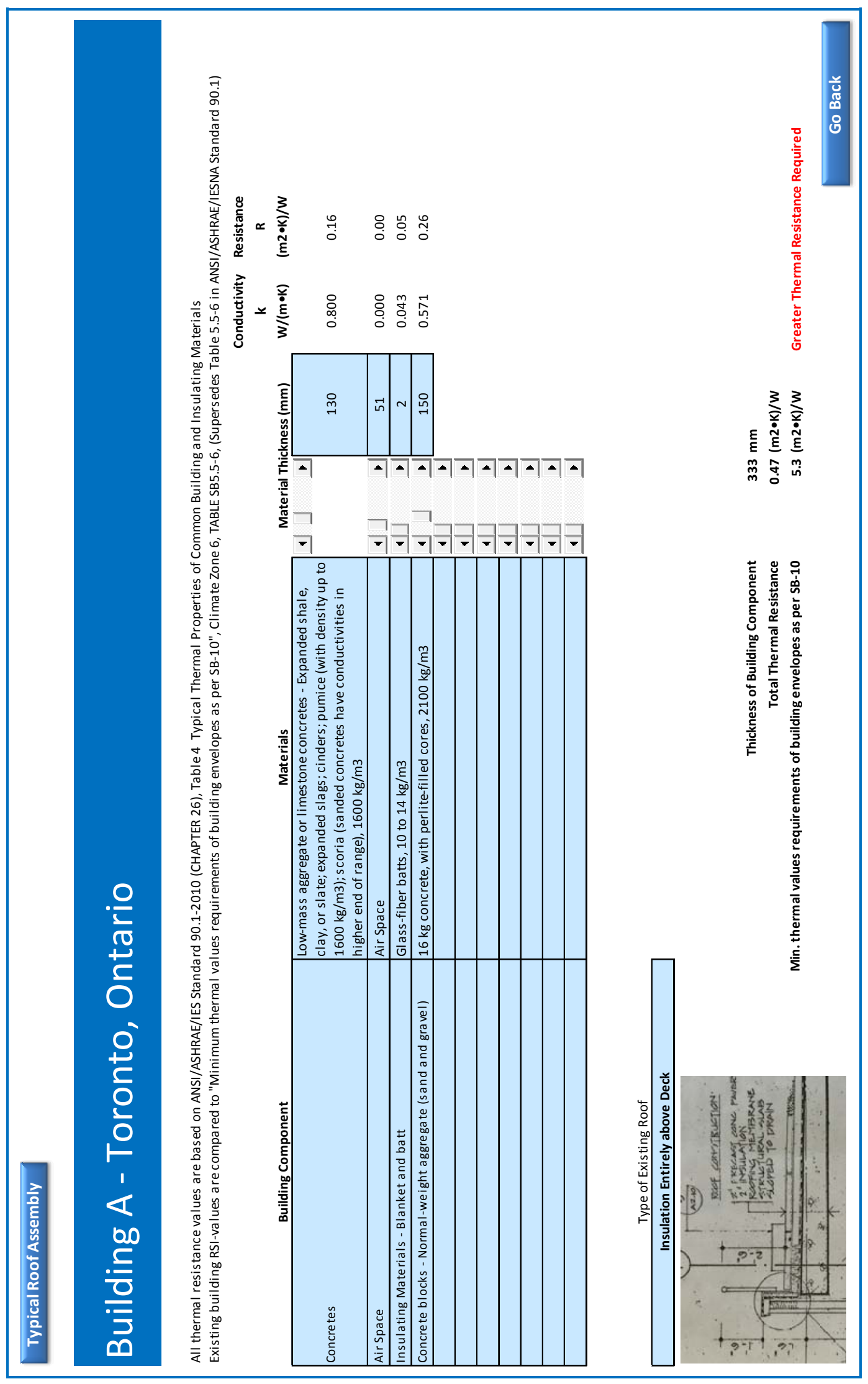




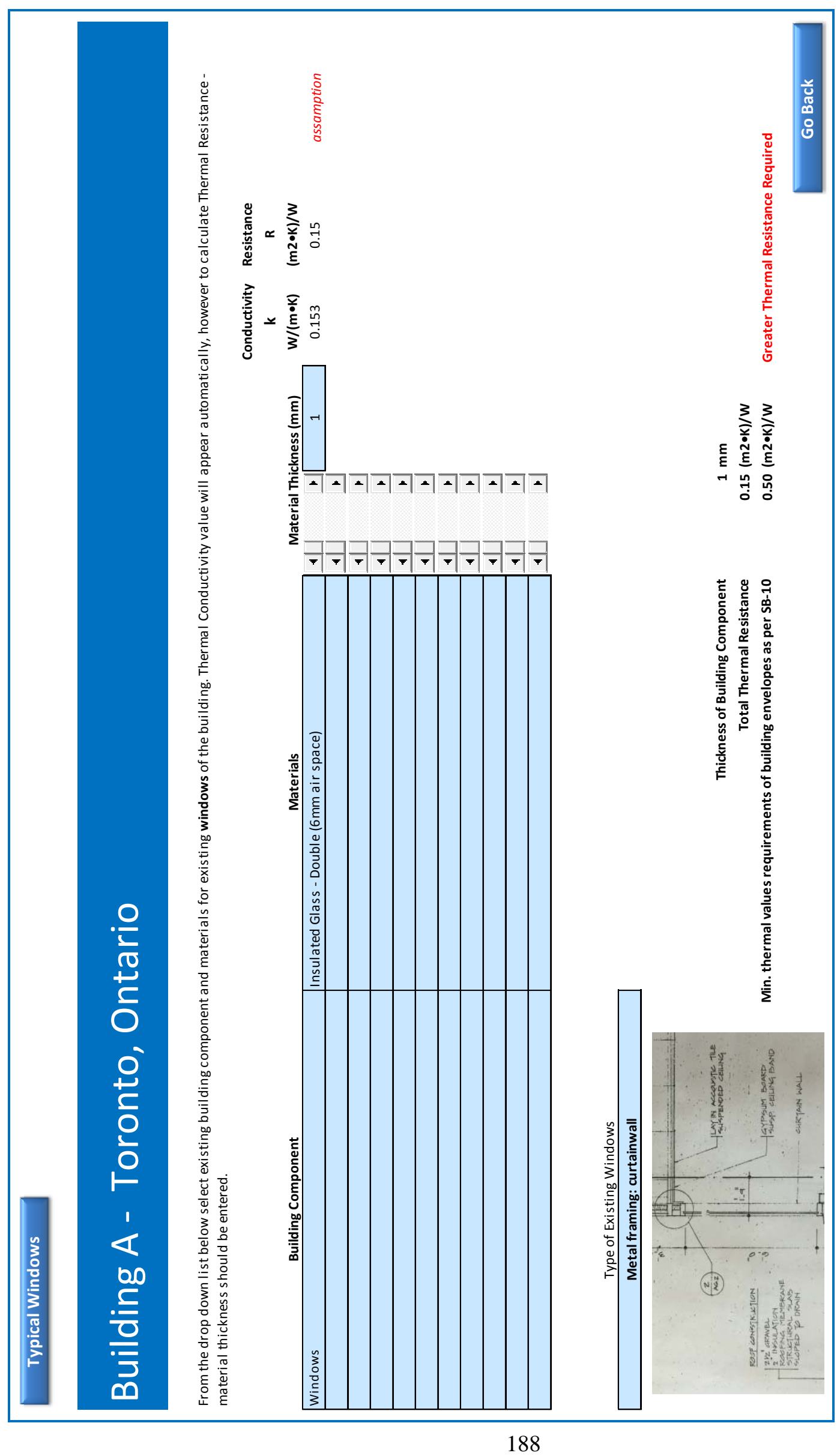




\section{Building A - Toronto, Ontario}

Select building envelope component "button" to enter materials information; all entered materials will be summarised below (cells are locked and can not be modified). If type of material is not provided in the drop down list, than "Other" should be selected, R-value will be entered manually.

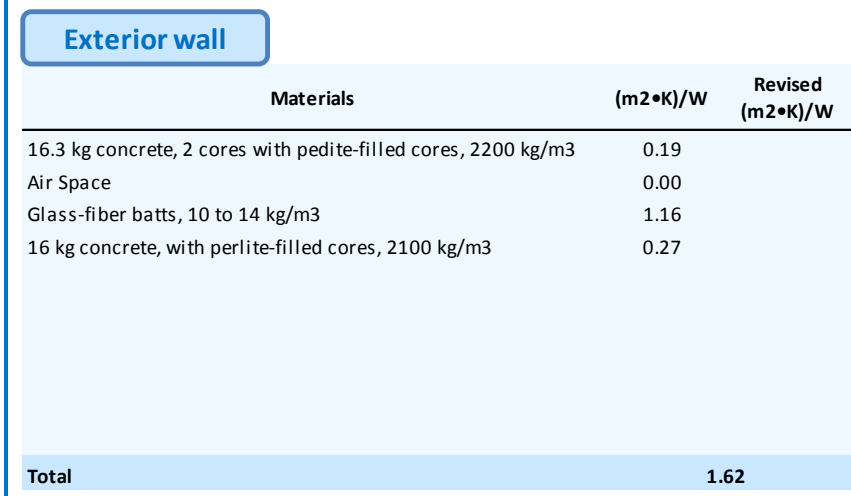

Greater Thermal Resistance Required

\section{Roof}

\begin{tabular}{lll}
\multicolumn{1}{c}{ Materials } & $\begin{array}{c}\text { Typical } \\
\text { Value }\end{array}$ & (m2•K)/W \\
\hline Low-mass aggregate or limestone concretes - Expanded shale, cl & 0.16 & \\
Air Space & 0.00 \\
Glass-fiber batts, 10 to $14 \mathrm{~kg} / \mathrm{m} 3$ & 0.05 \\
$16 \mathrm{~kg}$ concrete, with perlite-filled cores, $2100 \mathrm{~kg} / \mathrm{m} 3$ & 0.26 \\
& \\
& \\
& & \\
& & \\
Total & $\mathbf{0 . 4 7}$
\end{tabular}

Greater Thermal Resistance Required

\begin{tabular}{|c|c|c|c|}
\hline \multicolumn{4}{|c|}{ Overall Thermal Transmittance } \\
\hline Total Area & 10827.85 & m2 & $100 \%$ \\
\hline Wall Area & 6089.85 & m2 & $56 \%$ \\
\hline Windows Area & 4738.00 & $\mathrm{~m} 2$ & $44 \%$ \\
\hline
\end{tabular}

\section{Effective thermal resistance}

\begin{tabular}{|c|c|c|c|}
\hline Ao & 10827.85 & $\mathrm{~m} 2$ & \\
\hline $\mathrm{R}$ wall & 1.62 & $\mathrm{~W} /(\mathrm{m} 2 \cdot \mathrm{K})$ & 0.153 \\
\hline A wall & 6089.85 & $\mathrm{~m} 2$ & \\
\hline$R$ window & 0.15 & $\mathrm{~W} /(\mathrm{m} 2 \bullet \mathrm{K})$ & \\
\hline A window & 4738.00 & $\mathrm{~m} 2$ & \\
\hline
\end{tabular}




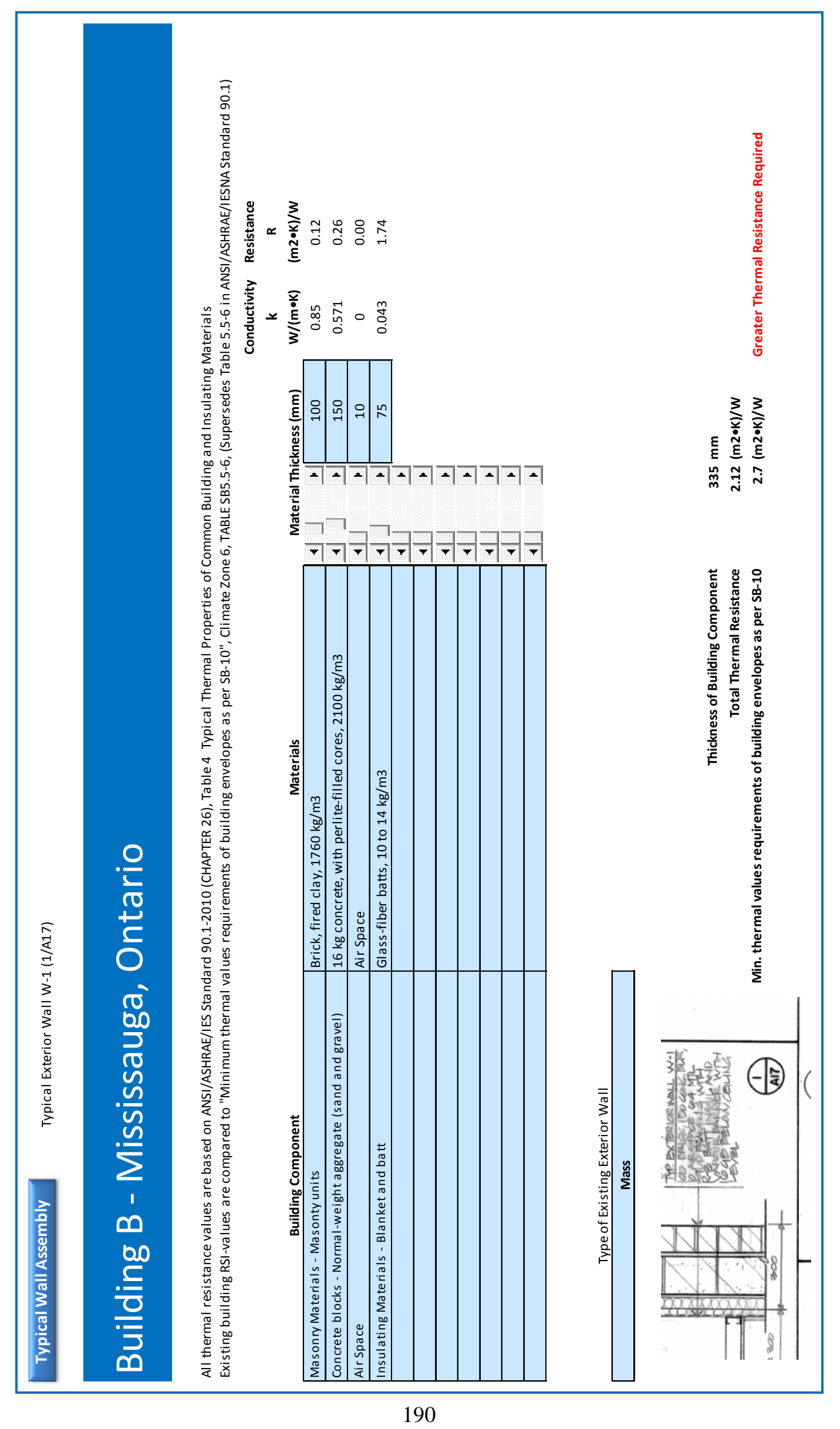




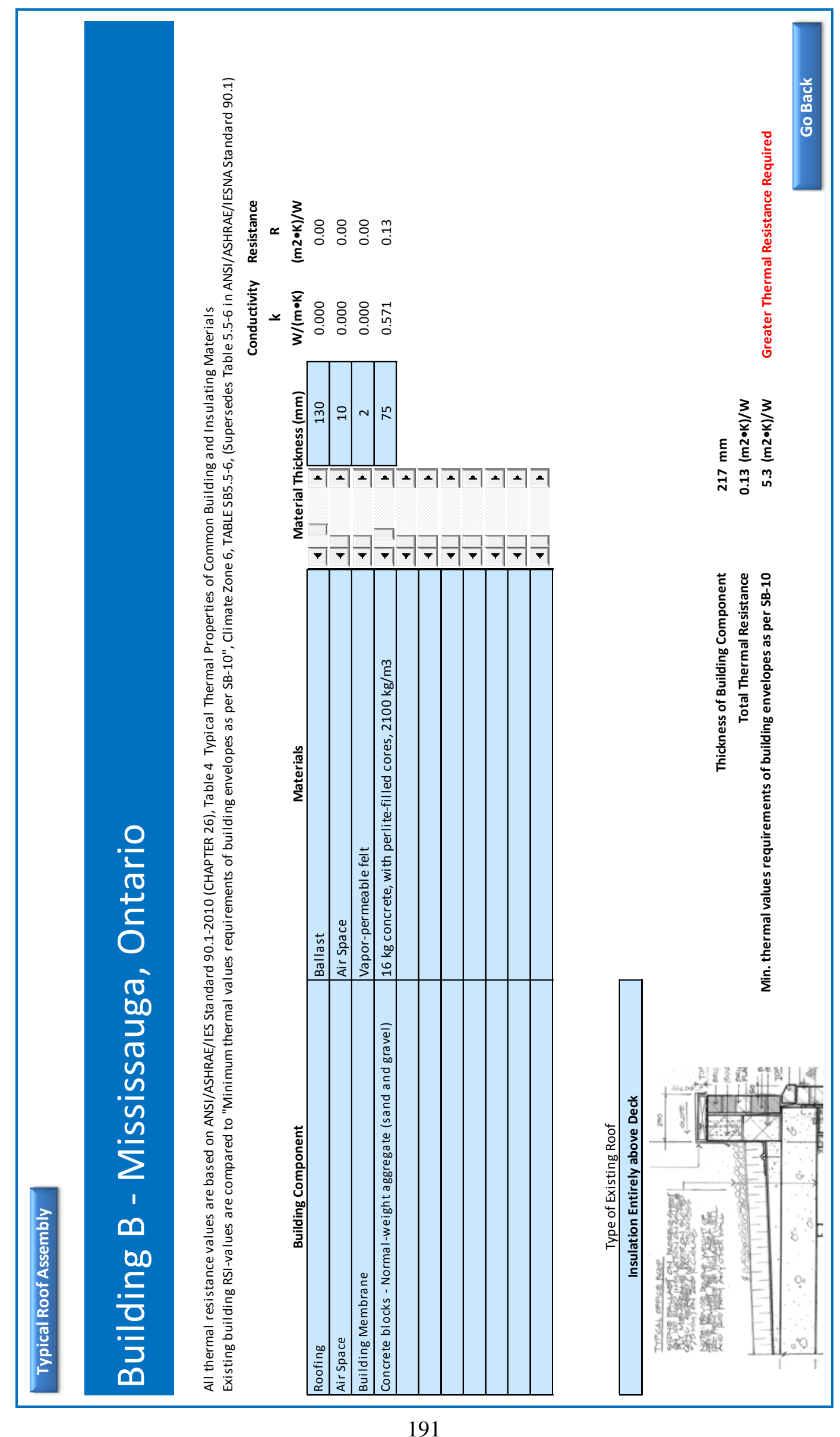




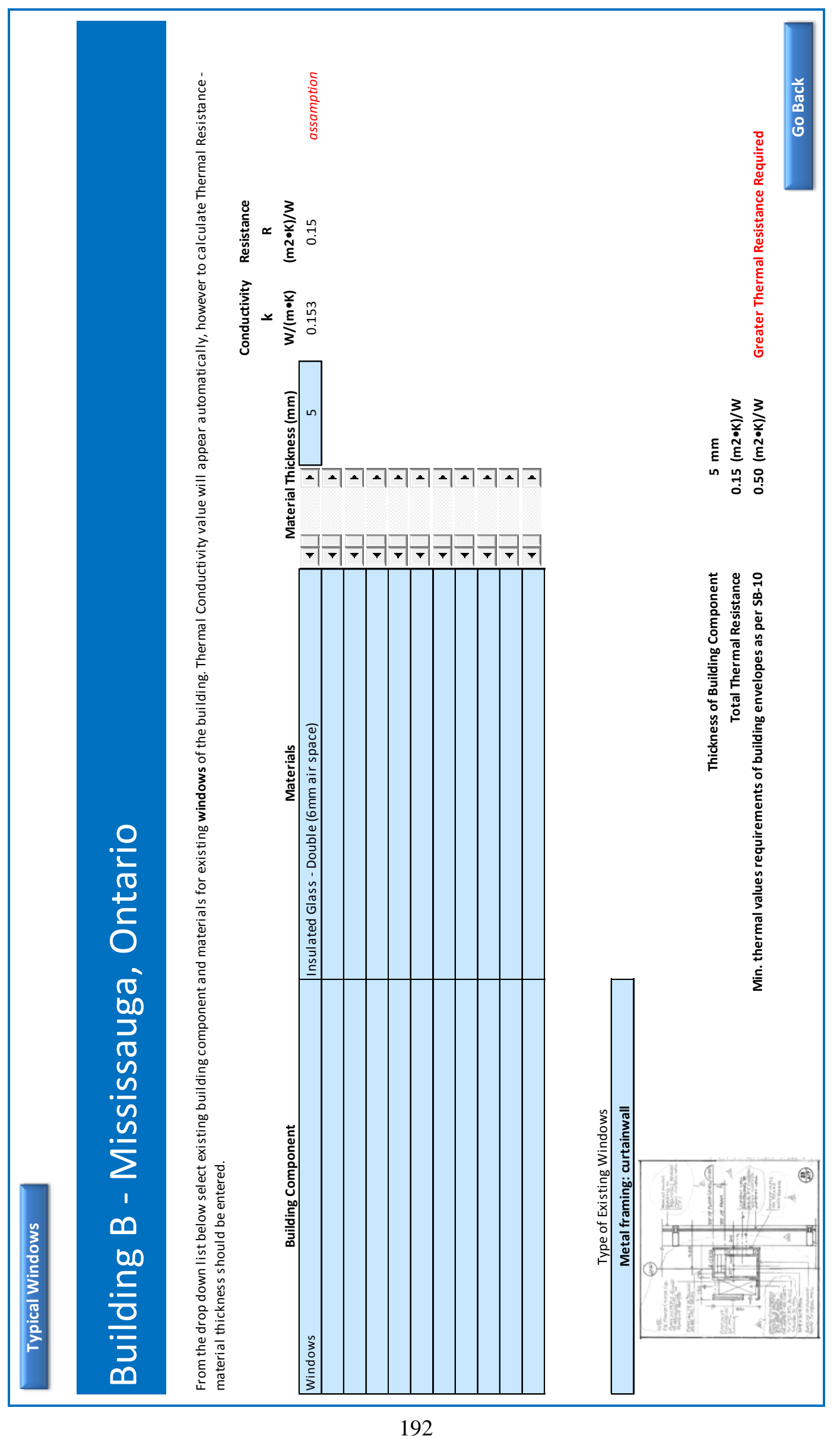




\section{Building B - Mississauga, Ontario}

Select building envelope component "button" to enter materials information; all entered materials will be summarised below (cells are locked and can not be modified). If type of material is not provided in the drop down list, than "Other" should be selected, R-value will be entered manually.

\begin{tabular}{|c|c|c|c|c|c|c|c|}
\hline Exterior wall & \multirow[b]{2}{*}{ Materials } & \multirow[b]{2}{*}{$(\mathrm{m} 2 \cdot \mathrm{k}) / \mathrm{w}$} & \multirow[b]{2}{*}{$\begin{array}{c}\text { Revised } \\
(\mathrm{m} 2 \bullet \mathrm{k}) / \mathrm{W}\end{array}$} & \multicolumn{4}{|c|}{ Overall Thermal Transmittance } \\
\hline & & & & \multirow{2}{*}{$\begin{array}{l}\text { Total Area } \\
\text { Wall Area }\end{array}$} & \multirow{2}{*}{$\begin{array}{c}4597 \\
\quad 3350.05\end{array}$} & \multirow{2}{*}{$\begin{array}{l}\mathrm{m} 2 \\
\mathrm{~m} 2\end{array}$} & $100 \%$ \\
\hline \multicolumn{2}{|c|}{ Brick, fired clay, $1760 \mathrm{~kg} / \mathrm{m} 3$} & 0.12 & & & & & $73 \%$ \\
\hline \multicolumn{2}{|c|}{ Air Space } & 0.00 & & Windows Area & 1246.95 & $\mathrm{~m}^{2}$ & $27 \%$ \\
\hline \multicolumn{2}{|c|}{ Glass-fiber batts, 10 to $14 \mathrm{~kg} / \mathrm{m} 3$} & 1.74 & & omicoustre & 1270.00 & & \\
\hline \multicolumn{2}{|l|}{ Total } & \multicolumn{2}{|c|}{2.12} & & & & \\
\hline \multicolumn{8}{|c|}{ Greater Thermal Resistance Required } \\
\hline \multirow[t]{2}{*}{ Roof } & & & & \multicolumn{4}{|c|}{ Effective thermal resistance } \\
\hline & Materials & $\begin{array}{c}\text { Typical } \\
\text { Value }\end{array}$ & $(\mathrm{m} 2 \bullet \mathrm{K}) / \mathrm{W}$ & \multicolumn{4}{|c|}{$R o=3 R i A i / A 0=(R 1 A 1+R 2 A 2+\ldots+R n A n) / A o$} \\
\hline \multirow{6}{*}{$\begin{array}{l}\text { Ballast } \\
\text { Air Space } \\
\text { Vapor-permeable felt } \\
16 \text { kg concrete, with pe }\end{array}$} & 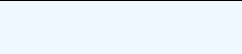 & 0.00 & & Ao & 4597 & \multicolumn{2}{|l|}{ m2 } \\
\hline & & 0.00 & & & & & \\
\hline & e-filled cores, $2100 \mathrm{~kg} / \mathrm{m} 3$ & \multicolumn{2}{|l|}{$\begin{array}{l}0.00 \\
0.13\end{array}$} & $\mathrm{R}$ wall & 2.12 & $\mathrm{w} /(\mathrm{m} \mathbf{2} \cdot \mathrm{k})$ & 0.153 \\
\hline & & & & A wall & 3350.05 & $\mathrm{~m} 2$ & \\
\hline & & & & $\mathrm{R}$ window & 0.15 & $\mathrm{~W} /(\mathrm{m} 2 \bullet \mathrm{K})$ & \\
\hline & & & & A window & 1246.95 & $\mathrm{~m} 2$ & \\
\hline \multicolumn{2}{|l|}{ Total } & \multicolumn{2}{|c|}{0.13} & & & \multirow{2}{*}{\multicolumn{2}{|c|}{$W /(m 2 \bullet K)$}} \\
\hline \multicolumn{2}{|c|}{ Greater Thermal Resistance Required } & & & & 1.590 & & \\
\hline \multicolumn{8}{|l|}{ Windows } \\
\hline & Materials & $\begin{array}{c}\text { Typical } \\
\text { Value }\end{array}$ & $(\mathrm{m} 2 \bullet \mathrm{K}) / \mathrm{W}$ & & & & \\
\hline \multicolumn{2}{|c|}{ Insulated Glass - Double (6mm air space) } & 0.15 & & & & & \\
\hline \multicolumn{2}{|l|}{ Total } & \multicolumn{2}{|c|}{0.153} & & & & \\
\hline \multicolumn{4}{|c|}{ Greater Thermal Resistance Required } & & & & \\
\hline
\end{tabular}




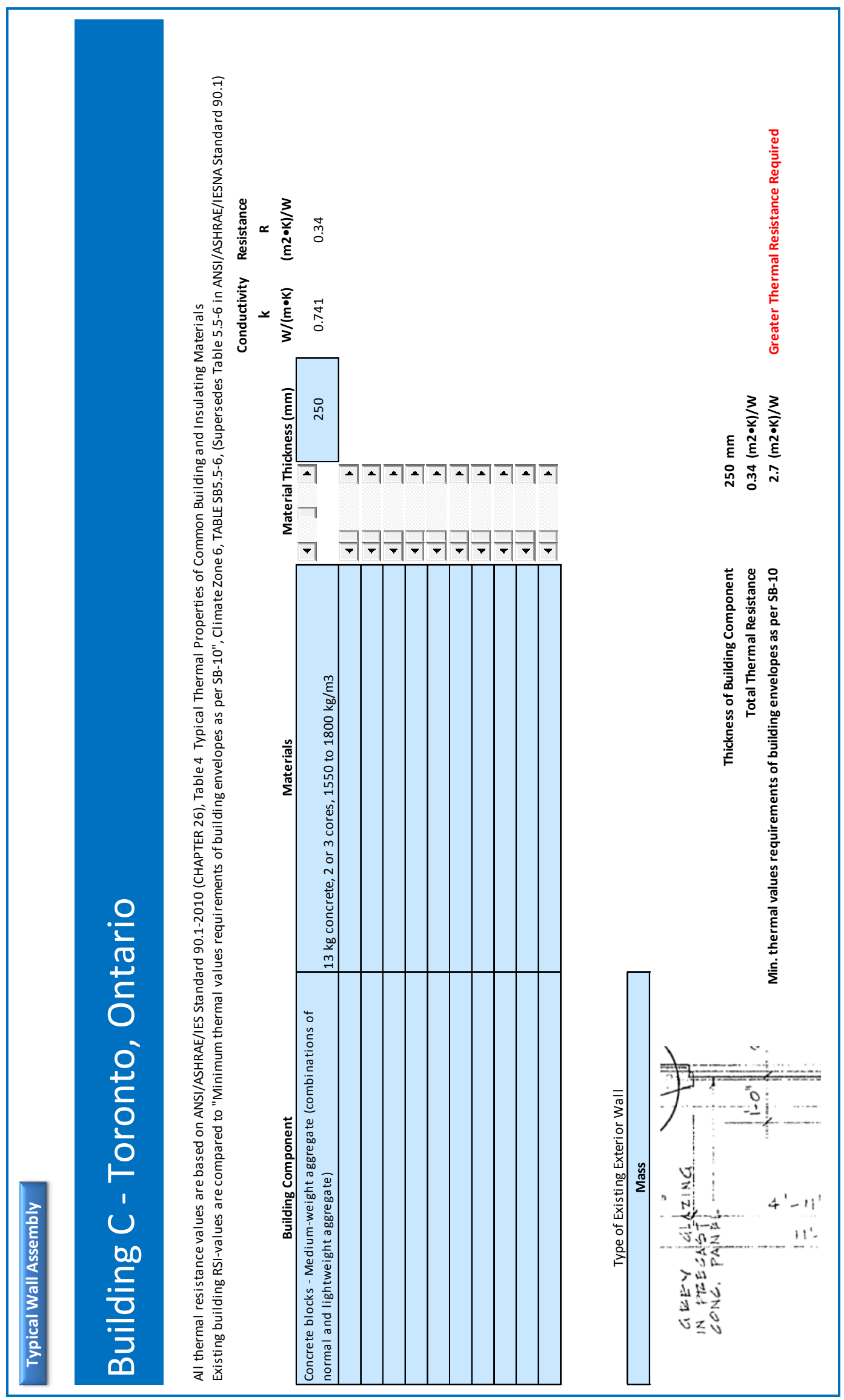




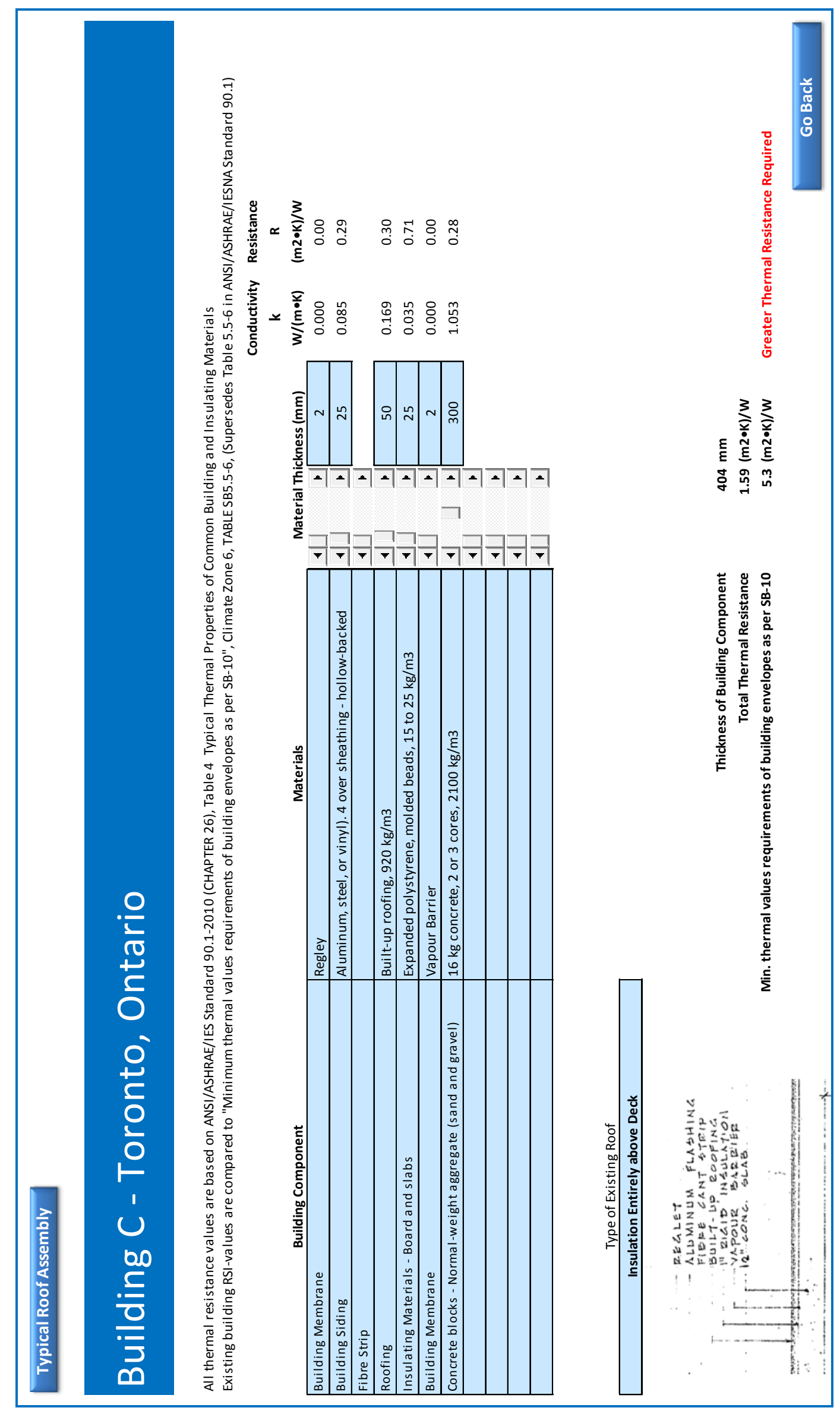




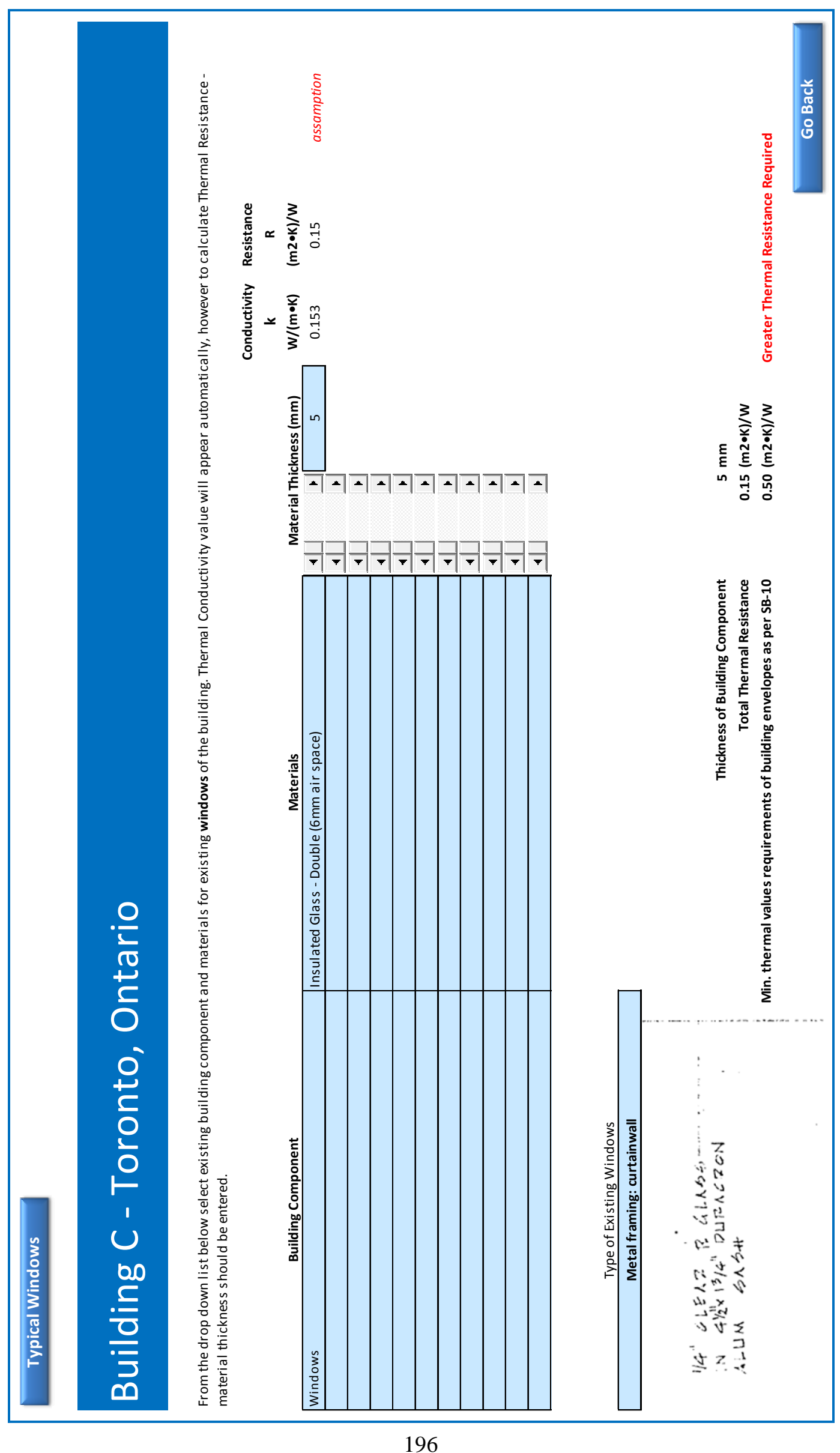




\section{Building C - Toronto, Ontario}

Select building envelope component "button" to enter materials information; all entered materials will be summarised below (cells are locked and can not be modified). If type of material is not provided in the drop down list, than "Other" should be selected, R-value will be entered manually.

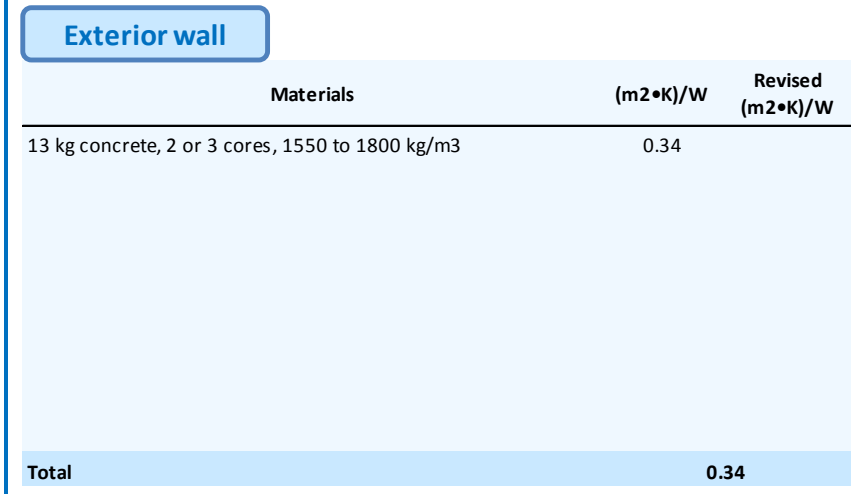

Greater Thermal Resistance Required

\begin{tabular}{|c|c|c|}
\hline \multicolumn{3}{|l|}{ Roof } \\
\hline Materials & $\begin{array}{c}\text { Typical } \\
\text { Value }\end{array}$ & $(\mathrm{m} 2 \bullet \mathrm{K}) / \mathrm{W}$ \\
\hline Regley & 0.00 & \\
\hline Aluminum, steel, or vinyl). 4 over sheathing - hollow-backed & 0.29 & \\
\hline Built-up roofing, $920 \mathrm{~kg} / \mathrm{m} 3$ & 0.30 & \\
\hline Expanded polys tyrene, molded beads, 15 to $25 \mathrm{~kg} / \mathrm{m} 3$ & 0.71 & \\
\hline Vapour Barrier & 0.00 & \\
\hline $16 \mathrm{~kg}$ concrete, 2 or 3 cores, $2100 \mathrm{~kg} / \mathrm{m} 3$ & 0.28 & \\
\hline Total & & 59 \\
\hline
\end{tabular}

Greater Thermal Resistance Required

\begin{tabular}{|c|c|c|c|}
\hline \multicolumn{4}{|c|}{ Overall Thermal Transmittance } \\
\hline Total Area & 4558.18 & m2 & $100 \%$ \\
\hline Wall Area & 2783.29 & m2 & $61 \%$ \\
\hline Windows Area & 1774.89 & $\mathrm{~m} 2$ & $39 \%$ \\
\hline
\end{tabular}

\section{Effective thermal resistance}

\begin{tabular}{|c|c|c|c|}
\hline Ao & 4558.18 & $\mathrm{~m} 2$ & \\
\hline R wall & 0.34 & $W /(m 2 \bullet K)$ & 0.153 \\
\hline A wall & 2783.29 & $\mathrm{~m} 2$ & \\
\hline$R$ window & 0.15 & $w /(m 2 \bullet K)$ & \\
\hline A window & 1774.89 & $\mathrm{~m} 2$ & \\
\hline
\end{tabular}

$0.266 W /(m 2 \bullet K)$ 
Appendix 4

Appendix D 
Energy Balance percentages calculations examples:

Relative Impact of Architectural Features on Heating Loads (Canada Mortgage and Housing Corporation (CMHC), 2014):

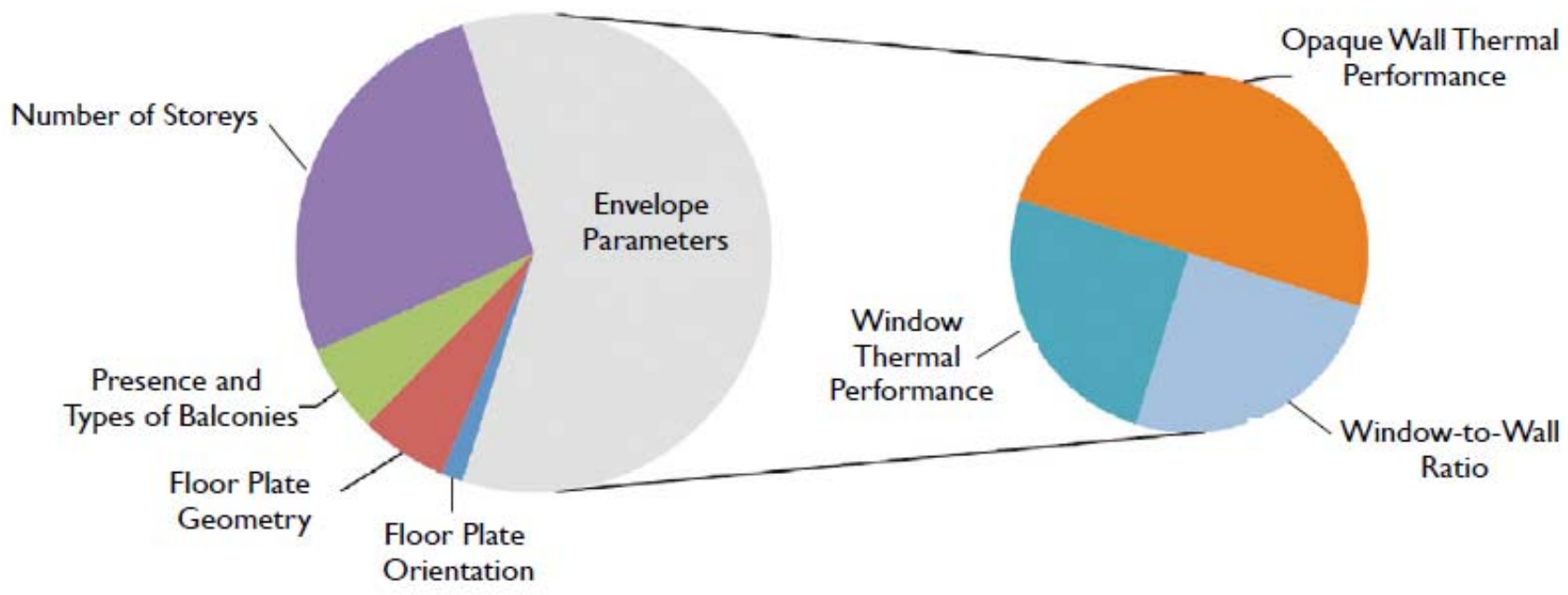

Relative Impact of Architectural Features on Cooling Loads (Canada Mortgage and Housing Corporation (CMHC), 2014):

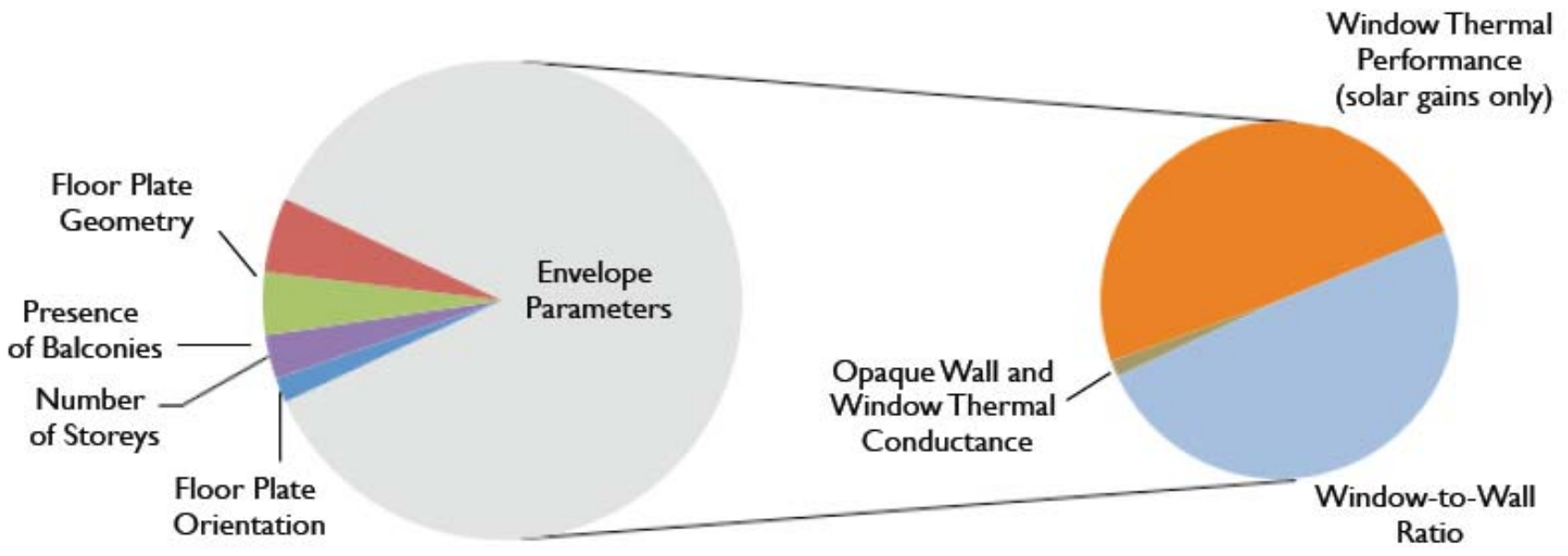

Figures above were retrieved from Canada Mortgage and Housing Corporation report completed in November 2014. This report summarizes a research of impact of architectural form on the potential energy performance of multi-unit residential buildings. Research explains that thermal characteristics of wall and window areas of the building envelope, as well as proportion of window area to wall area can have a significant impact on the annual 
heating and cooling loads of building. Percentages in the figure above were calculated by using computerized hourly building energy consumption modelling to assess the impact of these parameters on heating and cooling loads. Simulations were conducted in Toronto, Ontario, and investigated five different building shapes (floor plate geometries), three wall thermal resistance values, six window performance levels, three window to wall ratios, three balcony configurations, three different number of stories (low-rise 3 storey, mid-rise 5 storey, and high-rise 10 storey), and in four orientations. Facilities comparison was also made on number of suites and occupants. Research results showed that floor plate geometry and building orientation were typically found to have a minor impact on heating loads, however slightly bigger on cooling loads. On the other hand, wall insulation, WWR and window U-value had much greater impacts on heating and cooling loads than other factors. 

Appendix 5

Appendix E 
Energy loads (electricity and gas) distributions for cooling, heating and lighting.

\section{Cooling Loads Distribution (Electricity) in GJ Based on Architectural Features Indicators}

\begin{tabular}{|c|c|c|c|c|c|c|c|c|}
\hline \multicolumn{3}{|c|}{ Heating Loads Percentage Distribution } & \multirow{2}{*}{$\begin{array}{l}5 \% \\
\text { GJ }\end{array}$} & \multirow[t]{2}{*}{$5 \%$} & \multirow[t]{2}{*}{$35 \%$} & \multirow[t]{2}{*}{$35 \%$} & \multirow[t]{2}{*}{$5 \%$} & \multirow[t]{2}{*}{$15 \%$} \\
\hline & & & & & & & & \\
\hline & Address & \begin{tabular}{|c|}
$\begin{array}{c}\text { Cooling Loads } \\
\text { Electricity } \\
\text { Balance }\end{array}$ \\
\end{tabular} & $\begin{array}{c}\text { Number of } \\
\text { Stories }\end{array}$ & $\begin{array}{c}\text { Building } \\
\text { Orientation }\end{array}$ & $\begin{array}{l}\text { Window to } \\
\text { Wall ratio }\end{array}$ & \begin{tabular}{|c|} 
Window \\
Thermal \\
Performance \\
\end{tabular} & $\begin{array}{l}\text { Opaque Wall } \\
\text { Thermal } \\
\text { Performance }\end{array}$ & Other \\
\hline 1 & Building A - Toronto, Ontario & \begin{tabular}{|l|}
$8 \%$ \\
\end{tabular} & $37,495.4$ & $37,495.4$ & $262,467.8$ & $262,467.8$ & $37,495.4$ & $112,486.2$ \\
\hline 2 & Building B - Mississauga, Ontario & $8 \%$ & $14,852.9$ & $14,852.9$ & $103,970.3$ & $103,970.3$ & $14,852.9$ & $44,558.7$ \\
\hline 3 & Building C - Toronto, Ontario & $8 \%$ & $13,386.9$ & $13,386.9$ & $93,708.1$ & $93,708.1$ & $13,386.9$ & $40,160.6$ \\
\hline 4 & Building D - Mississauga, Ontario & $8 \%$ & $23,953.6$ & $23,953.6$ & $167,675.4$ & $167,675.4$ & $23,953.6$ & $71,860.9$ \\
\hline 5 & Building E - Mississauga, Ontario & $8 \%$ & $3,178.5$ & $3,178.5$ & $22,249.4$ & $22,249.4$ & $3,178.5$ & $9,535.4$ \\
\hline 6 & Building F - Scarborough, Ontario & $8 \%$ & $1,662.7$ & $1,662.7$ & $11,638.6$ & $11,638.6$ & $1,662.7$ & $4,988.0$ \\
\hline 7 & Building G - Ottawa, Ontario & $8 \%$ & $16,509.1$ & $16,509.1$ & $115,563.5$ & $115,563.5$ & $16,509.1$ & $49,527.2$ \\
\hline 8 & Building H - Ottawa, Ontario & $8 \%$ & $12,808.9$ & $12,808.9$ & $89,662.4$ & $89,662.4$ & $12,808.9$ & $38,426.8$ \\
\hline 9 & Building I - Ottawa, Ontario, Tower C & $8 \%$ & $9,506.3$ & $9,506.3$ & $66,544.3$ & $66,544.3$ & $9,506.3$ & $28,519.0$ \\
\hline 10 & Building J - Ottawa, Ontario, Tower B & $8 \%$ & $42,851.5$ & $42,851.5$ & $299,960.4$ & $299,960.4$ & $42,851.5$ & $128,554.5$ \\
\hline 11 & Building K - Ottawa, Ontario, Tower A & $8 \%$ & $12,795.0$ & $12,795.0$ & $89,565.1$ & $89,565.1$ & $12,795.0$ & $38,385.0$ \\
\hline 12 & Building L - Montreal, Quebec & $8 \%$ & $5,176.7$ & $5,176.7$ & $36,237.0$ & $36,237.0$ & $5,176.7$ & $15,530.1$ \\
\hline 13 & Building M - Vaudreuil-Dorion, Quebec & $8 \%$ & $11,845.4$ & $11,845.4$ & $82,917.8$ & $82,917.8$ & $11,845.4$ & $35,536.2$ \\
\hline 14 & Building N - Côte-St-Luc, Quebec & $8 \%$ & $21,426.0$ & $21,426.0$ & $149,981.8$ & $149,981.8$ & $21,426.0$ & $64,277.9$ \\
\hline 15 & Building O - Gatineau, Quebec & $8 \%$ & $13,351.9$ & $13,351.9$ & $93,463.4$ & $93,463.4$ & $13,351.9$ & $40,055.8$ \\
\hline
\end{tabular}

\section{Cooling Loads Distribution (Electricity) in GJ $/ \mathrm{m}^{2} /$ year Based on Architectural Features Indicators}

\begin{tabular}{|c|c|c|c|c|c|c|c|c|}
\hline \multicolumn{3}{|c|}{ Heating Loads Percentage Distribution } & \multirow{2}{*}{$\begin{array}{c}5 \% \\
\text { GJ/m2/year }\end{array}$} & \multirow[t]{2}{*}{$5 \%$} & \multirow[t]{2}{*}{$35 \%$} & \multirow[t]{2}{*}{$35 \%$} & \multirow[t]{2}{*}{$5 \%$} & \multirow[t]{2}{*}{$15 \%$} \\
\hline & & & & & & & & \\
\hline & Address & \begin{tabular}{|c|}
$\begin{array}{c}\text { Cooling Loads } \\
\text { Electricity } \\
\text { Balance }\end{array}$ \\
\end{tabular} & $\begin{array}{l}\text { Number of } \\
\text { Stories }\end{array}$ & $\begin{array}{l}\text { Building } \\
\text { Orientation }\end{array}$ & $\begin{array}{l}\text { Window to } \\
\text { Wall ratio }\end{array}$ & $\begin{array}{c}\text { Window } \\
\text { Thermal } \\
\text { Performance }\end{array}$ & $\begin{array}{l}\text { Opaque Wall } \\
\text { Thermal } \\
\text { Performance }\end{array}$ & Other \\
\hline 1 & Building A - Toronto, Ontario & \begin{tabular}{|l|}
$8 \%$ \\
\end{tabular} & 0.003 & 0.003 & 0.021 & 0.021 & 0.003 & 0.009 \\
\hline 2 & Building B - Mississauga, Ontario & $8 \%$ & 0.004 & 0.004 & 0.026 & 0.026 & 0.004 & 0.011 \\
\hline 3 & Building C - Toronto, Ontario & $8 \%$ & 0.003 & 0.003 & 0.021 & 0.021 & 0.003 & 0.009 \\
\hline 4 & Building D - Mississauga, Ontario & $8 \%$ & 0.003 & 0.003 & 0.022 & 0.022 & 0.003 & 0.009 \\
\hline 5 & Building E - Mississauga, Ontario & $8 \%$ & 0.001 & 0.001 & 0.007 & 0.007 & 0.001 & 0.003 \\
\hline 6 & Building F - Scarborough, Ontario & $8 \%$ & 0.002 & 0.002 & 0.011 & 0.011 & 0.002 & 0.005 \\
\hline 7 & Building G - Ottawa, Ontario & $8 \%$ & 0.004 & 0.004 & 0.029 & 0.029 & 0.004 & 0.012 \\
\hline 8 & Building H - Ottawa, Ontario & $8 \%$ & 0.005 & 0.005 & 0.037 & 0.037 & 0.005 & 0.016 \\
\hline 9 & Building I - Ottawa, Ontario, Tower C & $8 \%$ & 0.004 & 0.004 & 0.028 & 0.028 & 0.004 & 0.012 \\
\hline 10 & Building J - Ottawa, Ontario, Tower B & $8 \%$ & 0.011 & 0.011 & 0.075 & 0.075 & 0.011 & 0.032 \\
\hline 11 & Building K - Ottawa, Ontario, Tower A & $8 \%$ & 0.004 & 0.004 & 0.030 & 0.030 & 0.004 & 0.013 \\
\hline 12 & Building L - Montreal, Quebec & $8 \%$ & 0.003 & 0.003 & 0.021 & 0.021 & 0.003 & 0.009 \\
\hline 13 & Building M - Vaudreuil-Dorion, Quebec & $8 \%$ & 0.003 & 0.003 & 0.021 & 0.021 & 0.003 & 0.009 \\
\hline 14 & Building N - Côte-St-Luc, Quebec & $8 \%$ & 0.006 & 0.006 & 0.039 & 0.039 & 0.006 & 0.017 \\
\hline 15 & Building O- Gatineau, Quebec & $8 \%$ & 0.005 & 0.005 & 0.035 & 0.035 & 0.005 & 0.015 \\
\hline
\end{tabular}


Gas consumption for heating loads calculations are shown in the tables below.

Heating Loads (Gas) Distribution in GJ Based on Architectural Features Indicators

\begin{tabular}{|c|c|c|c|c|c|c|c|c|}
\hline & Loads Percentage Distribution & & $25 \%$ & $10 \%$ & $15 \%$ & $15 \%$ & $30 \%$ & $5 \%$ \\
\hline & & & & & GJ & & & \\
\hline & Address & $\begin{array}{c}\text { Heating Loads } \\
\text { GAS Balance }\end{array}$ & $\begin{array}{l}\text { Number of } \\
\text { Stories }\end{array}$ & $\begin{array}{l}\text { Building } \\
\text { Orientation }\end{array}$ & $\begin{array}{l}\text { Window to } \\
\text { Wall ratio }\end{array}$ & $\begin{array}{c}\text { Window } \\
\text { Thermal } \\
\text { Performance }\end{array}$ & $\begin{array}{l}\text { Opaque Wall } \\
\text { Thermal } \\
\text { Performance }\end{array}$ & Other \\
\hline 1 & Building A - Toronto, Ontario & $100 \%$ & $64,142.6$ & $25,657.0$ & $38,485.5$ & $38,485.5$ & $76,971.1$ & $12,828.5$ \\
\hline 2 & Building B - Mississauga, Ontario & $100 \%$ & $20,704.3$ & $8,281.7$ & $12,422.6$ & $12,422.6$ & $24,845.2$ & $4,140.9$ \\
\hline 3 & Building C - Toronto, Ontario & $100 \%$ & $39,590.7$ & $15,836.3$ & $23,754.4$ & $23,754.4$ & $47,508.8$ & $7,918.1$ \\
\hline 4 & Building D - Mississauga, Ontario & $100 \%$ & $14,639.0$ & $5,855.6$ & $8,783.4$ & $8,783.4$ & $17,566.8$ & $2,927.8$ \\
\hline 5 & Building E - Mississauga, Ontario & $100 \%$ & $4,498.8$ & $1,799.5$ & $2,699.3$ & $2,699.3$ & $5,398.5$ & 899.8 \\
\hline 6 & Building F - Scarborough, Ontario & $100 \%$ & $6,630.6$ & $2,652.2$ & $3,978.3$ & $3,978.3$ & $7,956.7$ & $1,326.1$ \\
\hline 7 & Building G - Ottawa, Ontario & $100 \%$ & $7,990.4$ & $3,196.2$ & $4,794.2$ & $4,794.2$ & $9,588.5$ & $1,598.1$ \\
\hline 8 & Building H - Ottawa, Ontario & $100 \%$ & $20,441.2$ & $8,176.5$ & $12,264.7$ & $12,264.7$ & $24,529.4$ & $4,088.2$ \\
\hline 9 & Building I - Ottawa, Ontario, Tower C & $100 \%$ & $1,155.5$ & 462.2 & 693.3 & 693.3 & $1,386.6$ & 231.1 \\
\hline 10 & Building J - Ottawa, Ontario, Tower B & $100 \%$ & & & & & & \\
\hline 11 & Building K - Ottawa, Ontario, Tower A & $100 \%$ & & & & & & \\
\hline 12 & Building L - Montreal, Quebec & $100 \%$ & $3,665.8$ & $1,466.3$ & $2,199.5$ & $2,199.5$ & $4,398.9$ & 733.2 \\
\hline 13 & Building M - Vaudreuil-Dorion, Quebec & $100 \%$ & $2,047.3$ & 818.9 & $1,228.4$ & $1,228.4$ & $2,456.7$ & 409.5 \\
\hline 14 & Building N - Côte-St-Luc, Quebec & $100 \%$ & & & & & & \\
\hline 15 & Building O - Gatineau, Quebec & $100 \%$ & $16,034.7$ & $6,413.9$ & $9,620.8$ & $9,620.8$ & $19,241.6$ & $3,206.9$ \\
\hline
\end{tabular}

Heating Loads (Gas) Distribution in GJ/m²/year Based on Architectural Features Indicators

\begin{tabular}{|c|c|c|c|c|c|c|c|c|}
\hline \multirow{2}{*}{\multicolumn{2}{|c|}{ Loads Percentage Distribution }} & & $25 \%$ & $10 \%$ & $15 \%$ & $15 \%$ & $30 \%$ & $5 \%$ \\
\hline & & \multicolumn{7}{|c|}{ GJ/m2/year } \\
\hline & Address & $\begin{array}{c}\text { Heating Loads } \\
\text { Gas Balance }\end{array}$ & $\begin{array}{l}\text { Number of } \\
\text { Stories }\end{array}$ & $\begin{array}{c}\text { Building } \\
\text { Orientation }\end{array}$ & $\begin{array}{l}\text { Window to } \\
\text { Wall ratio }\end{array}$ & $\begin{array}{c}\text { Window } \\
\text { Thermal } \\
\text { Performance } \\
\end{array}$ & $\begin{array}{c}\text { Opaque Wall } \\
\text { Thermal } \\
\text { Performance }\end{array}$ & Other \\
\hline 1 & Building A - Toronto, Ontario & $100 \%$ & 0.018 & 0.007 & 0.011 & 0.011 & 0.022 & 0.004 \\
\hline 2 & Building B - Mississauga, Ontario & $100 \%$ & 0.018 & 0.007 & 0.011 & 0.011 & 0.022 & 0.004 \\
\hline 3 & Building C - Toronto, Ontario & $100 \%$ & 0.031 & 0.012 & 0.019 & 0.019 & 0.037 & 0.006 \\
\hline 4 & Building D - Mississauga, Ontario & $100 \%$ & 0.007 & 0.003 & 0.004 & 0.004 & 0.008 & 0.001 \\
\hline 5 & Building E - Mississauga, Ontario & $100 \%$ & 0.005 & 0.002 & 0.003 & 0.003 & 0.006 & 0.001 \\
\hline 6 & Building F - Scarborough, Ontario & $100 \%$ & 0.022 & 0.009 & 0.013 & 0.013 & 0.027 & 0.004 \\
\hline 7 & Building G - Ottawa, Ontario & $100 \%$ & 0.007 & 0.003 & 0.004 & 0.004 & 0.008 & 0.001 \\
\hline 8 & Building H - Ottawa, Ontario & $100 \%$ & 0.029 & 0.012 & 0.018 & 0.018 & 0.035 & 0.006 \\
\hline 9 & Building I - Ottawa, Ontario, Tower C & $100 \%$ & 0.002 & 0.001 & 0.001 & 0.001 & 0.002 & 0.000 \\
\hline 10 & Building J - Ottawa, Ontario, Tower B & $100 \%$ & & & & & & \\
\hline 11 & Building K - Ottawa, Ontario, Tower A & $100 \%$ & & & & & & \\
\hline 12 & Building L - Montreal, Quebec & $100 \%$ & 0.008 & 0.003 & 0.005 & 0.005 & 0.009 & 0.002 \\
\hline 13 & Building M - Vaudreuil-Dorion, Quebec & $100 \%$ & 0.002 & 0.001 & 0.001 & 0.001 & 0.002 & 0.000 \\
\hline 14 & Building N - Côte-St-Luc, Quebec & $100 \%$ & & & & & & \\
\hline 15 & Building O - Gatineau, Quebec & $100 \%$ & 0.021 & 0.008 & 0.013 & 0.013 & 0.025 & 0.004 \\
\hline
\end{tabular}


Lighting Loads Distribution (Electricity) in $\mathrm{GJ} / \mathrm{m}^{2} /$ year Based on Architectural Features Indicators

\begin{tabular}{|c|c|c|c|c|c|}
\hline & \multicolumn{2}{|c|}{ Lighting Loads Percentage Distribution } & \multirow{2}{*}{$\begin{array}{c}40 \% \\
\text { GJ }\end{array}$} & & \multirow{2}{*}{$\begin{array}{c}40 \% \\
\text { GJ/m2/year }\end{array}$} \\
\hline & & & & & \\
\hline & Address & $\begin{array}{c}\text { Lighting Loads } \\
\text { Electricity } \\
\text { Balance }\end{array}$ & $\begin{array}{l}\text { Window to } \\
\text { Wall ratio }\end{array}$ & $\begin{array}{c}\text { Lighting Loads } \\
\text { Electricity } \\
\text { Balance }\end{array}$ & $\begin{array}{l}\text { Window to } \\
\text { Wall ratio }\end{array}$ \\
\hline 1 & Building A - Toronto, Ontario & $33 \%$ & $707,056.2$ & $33 \%$ & 0.100 \\
\hline 2 & Building B - Mississauga, Ontario & $33 \%$ & $280,083.3$ & $33 \%$ & 0.123 \\
\hline 3 & Building C - Toronto, Ontario & $33 \%$ & $252,438.1$ & $33 \%$ & 0.098 \\
\hline 4 & Building D - Mississauga, Ontario & $33 \%$ & $451,697.0$ & $33 \%$ & 0.103 \\
\hline 5 & Building E - Mississauga, Ontario & $33 \%$ & $59,937.1$ & $33 \%$ & 0.034 \\
\hline 6 & Building F - Scarborough, Ontario & $33 \%$ & $31,352.9$ & $33 \%$ & 0.053 \\
\hline 7 & Building G - Ottawa, Ontario & $33 \%$ & $311,313.8$ & $33 \%$ & 0.137 \\
\hline 8 & Building H - Ottawa, Ontario & $33 \%$ & $241,539.6$ & $33 \%$ & 0.173 \\
\hline 9 & Building I - Ottawa, Ontario, Tower C & $33 \%$ & $179,262.1$ & $33 \%$ & 0.133 \\
\hline 10 & Building J - Ottawa, Ontario, Tower B & $33 \%$ & $808,056.6$ & $33 \%$ & 0.352 \\
\hline 11 & Building K - Ottawa, Ontario, Tower A & $33 \%$ & $241,277.4$ & $33 \%$ & 0.141 \\
\hline 12 & Building L - Montreal, Quebec & $33 \%$ & $97,618.0$ & $33 \%$ & 0.100 \\
\hline 13 & Building M - Vaudreuil-Dorion, Quebec & $33 \%$ & $223,370.5$ & $33 \%$ & 0.100 \\
\hline 14 & Building N - Côte-St-Luc, Quebec & $33 \%$ & $404,032.6$ & $33 \%$ & 0.183 \\
\hline 15 & Building O - Gatineau, Quebec & $33 \%$ & $251,779.1$ & $33 \%$ & 0.164 \\
\hline
\end{tabular}




\section{Bibliography}


ASHRAE Handbook Fundamentals. (2012). American Society of Heating, Refrigerating, and Air-Conditioning Engineers.

ASHRAE Standard 90.1. (2010). Energy Standard for Buildings Except Low-Rise Residential Buildings.

Azar, E. (2014). A Comprehensive Framework to Assess, Model, and Enhance the Human Role in Conserving Energy in Commercial Buildings. Wisconsin: The University of Wisconsin - Madison, ProQuest, UMI Dissertations Publishing.

BOMA. (2014). BOMA BESt Energy and Environment Report. Retrieved from http://www.bomabest.com/newspublications/publications/.

Boubekri, M., Hull, R., \& Boyer, L. (1991). Impact of windows size and sunlight penetration on office workers' mood and satisfaction: A novel way of ssessing sunlight. Environment and Behavior 23.4, 474-493.

Canada Mortgage and Housing Corporation (CMHC). (2014). Impact of Architectural Form and Features on the Energy Performance of High Performance MURBs, Task 1, 2 and 3. Ottawa.

Carmody, J. (2004). Window Systems for High-performance Buildings. London: 1st ed. New York : Norton.

CMHC, Robertson. (2014). Daylighting Guide for Buildings. Retrieved April 8, 2015, from www.cmhcschl.gc.ca: http://www.cmhc-schl.gc.ca/en/inpr/bude/himu/coedar/upload/Daylighting-Guide-forBuildings.pdf

Dogrusoy, I., \& Tureyen, M. (2007). A field study on determination of preferences for windows in office environments. Building and Environment 42.10, 3660-3668.

Ferdous, T. (2012). Determining the Effect of Building Geometry on Energy Use Patterns of Office Developments. Toronto, Ontario: Major Research Project presented to Ryerson University.

Government of Canada. (2013). Canada's National Model Construction Codes and Guides, Adaptation Guidelines for the National Energy Code of Canada for Buildings 2011. Retrieved from http://www.nationalcodes.nrc.gc.ca.

Graz Energy Agency Ltd \& Berlin Energy Agency Ltd. (2008). Comprehensive Refurbishment of Buildings with Energy Performance Contracting, Final Manual Nr.1, Version_071220.

Harvey, L. D. (2013). Recent Advances in Sustainable Buildings: Review of the Energy and Cost Performance of the State-of-the-Art Best Practices from Around the World. Annual Review of Environment and Resources, Vol. 38: 281-309. 
Harwani, B. K. (2004). Design Optimization with Daylighting. Calgary: University of Calgary, ProQuest, UMI Dissertations Publishing.

Ko, D.-H. (2009). Fenestration Guideline for Energy and Daylight Efficiency: Evaluation and Prediction of Performance in Office Buildings. Chicago: Illinois Institute of Technology, ProQuest, UMI Dissertations Publishing.

Krarti, M. (2010). Energy Audit of Building Systems: An Engineering Approach, Second Edition. Boca Raton, FL: CRC Press.

Liddle, B. (2012). OECD Energy Intensity: Measures, Trends, and Convergence. Energy Efficiency (5), 583597.

Ludlow, A. M. (1976). The functions of windows in buildings. Lighting and Research Technology 8, 57-68.

Motuziene, V., \& Juodis, E. S. (2010). Simulation Based Complex Energy Assessment of Office Building Fenestration. Journal or Civil Engineering and Management. 16(3), 345-351.

National Resources Canada. (2008). Commercial \& Institutional Consumption of Energy Survey Summary Report.

Natural Resources Canada Handbook. (2014). Energy Use Data Handbook. Retrieved March 31, 2015, from Natural Resources Canada, Office of Energy Efficiency: http://oee.nrcan.gc.ca

OEE. (2002). Commercial and Institutional Building Energy Use Survey (CIBEUS) 2000. Ottawa: Office of Energy Efficiency, Natural Resources Canada.

OEE. (2003). Consumption of Energy Survey (CES). Ottawa: Office of Energy Efficiency, Natural Resources Canada.

OEE. (2004). Commercial and Institutional Consumption of Energy Survey (CICES). Ottawa: Office of Energy Efficiency, Natural Resources Canada.

OEE. (2005). Commercial and Institutional Consumption of Energy Survey, Summary Report - June 2007.

Ottawa: Natural Resources Canada, Office of Energy Efficiency.

OEE. (2011). Commercial \& Institutional Consumption of Energy Survey, Summary Report 2008. Ottawa: Natural Resources Canada, Office of Energy Efficiency. 
OEE. (2013). Survey of Commercial and Insitutional Energy Use: Buildings 2009, Summary Report. Ottawa: Natural Resources Canada, Office of Energy Efficiency.

Public works and Government Services Canada. (2002). Daylighting Guide for Canadian Commercial Buildings.

PWC. (2002). Daylighting Guide for Canadian Commercial Buildings. Public Works and Government Services Canada. Retrieved April 2015, from eere.energy.gov: http://apps1.eere.energy.gov/buildings/publications/pdfs/commercial_initiative/hvac_volume2_final_re port.pdf

Ross, B. M. (2009). Design with Energy in Mind: Toward a Low-load and High-satisfaction Civic Architecture in the Great Lakes Basin. Master of Architecture thesis, University of Waterloo.

Ryan, M. (2012). A Comparison Study of Irish and American Building Energy Polices Using. West Lafayette, Indiana: ProQuest, UMI Dissertations Publishing.

SB-10. (2011). Supplementary Standard SB-10, Energy Efficiency Supplement. Toronto: Ministry of Municipal Affairs and Housing.

The Conference Board of Canada. (2013). How Canada Performs: A Report Card on Canada, Energy Intensity. Retrieved March 16, 2015, from http://www.conferenceboard.ca.

Tzempelikos, A. (2005). A Methodology for Integrated Daylighting and Thermal Analysis of Buildings. Concordia: Concordia University (Canada), ProQuest, UMI Dissertations Publishing. 


\section{Glossary}

Low-emissivity (low-e) A coatings applied to window glass to reduce heat loss from the inside without reducing solar gain from outside. 11

Solar Heat Gain Coefficient (SHGC) Solar heat gain through the total window system relative to the incident solar radiation. 10,13

Visible Transmittance (VT) The fraction of visible light that having entered a layer of absorbing material reaches into the space. 10

Window-to-Wall Ratio (WWR) The ratio of the wall fenestration area to the gross exterior wall area. $\mathrm{v}$, vi, xi, $1,3,8-15,34,36,37,43-45,48-51,54-57$ 